University of Louisville

ThinkIR: The University of Louisville's Institutional Repository

Electronic Theses and Dissertations

$5-2015$

\title{
William Faulkner and alcoholism : distilling facts and fictions.
}

Quintin Thomas Chipley 1956-

University of Louisville

Follow this and additional works at: https://ir.library.louisville.edu/etd

Part of the Literature in English, North America Commons

\section{Recommended Citation}

Chipley, Quintin Thomas 1956-, "William Faulkner and alcoholism : distilling facts and fictions." (2015).

Electronic Theses and Dissertations. Paper 2106.

https://doi.org/10.18297/etd/2106

This Doctoral Dissertation is brought to you for free and open access by ThinkIR: The University of Louisville's Institutional Repository. It has been accepted for inclusion in Electronic Theses and Dissertations by an authorized administrator of ThinkIR: The University of Louisville's Institutional Repository. This title appears here courtesy of the author, who has retained all other copyrights. For more information, please contact thinkir@louisville.edu. 


\title{
WILLIAM FAULKNER AND ALCOHOLISM: DISTILLING FACTS AND FICTIONS
}

\author{
By \\ Quintin Thomas Chipley \\ B.A., William Marsh Rice University, 1978 \\ M.Div., Southeastern Baptist Theological Seminary, 1984 \\ M.A., University of Louisville, 1992 \\ M.D., University of Louisville, 2000
}

\begin{abstract}
A Dissertation
Submitted to the Faculty of the

College of Arts and Sciences of the University of Louisville

In Partial Fulfilment of the Requirements

For the Degree of
\end{abstract}

Doctor of Philosophy

In Humanities

Department of Humanities

University of Louisville

Louisville, Kentucky

May 2015 
Copyright 2015 by Quintin Thomas Chipley

All rights reserved 

WILLIAM FAULKNER AND ALCOHOLISM:

DISTILLING FACTS AND FICTIONS

\author{
By \\ Quintin Thomas Chipley \\ B.A., William Marsh Rice University, 1978 \\ M.Div., Southeastern Baptist Theological Seminary, 1984 \\ M.A., University of Louisville, 1992 \\ M.D., University of Louisville, 2000 \\ A Dissertation Approved on
}

April 15, 2015

by the following Dissertation Committee:

Annette Allen, Ph.D.

Paul Griner, M.A.

Paul Salmon, Ph.D.

Christopher Stewart, M.D. 
To David Minter, Robert L. Patten and, in memoriam, Charles Garside, Jr.:

Three giants from my "One Matchless Time.” 


\section{ACKNOWLEDGMENTS}

For support and love, through this project and during long years before, I first acknowledge Leo Schwendau, my life partner. He knows me better than I often wish to be known, and he is more patient with me than I am with myself. If you ever choose to read these meanderings, Leo, please know how much I love you.

For the inspiration to pursue the doctoral program, and for specific guidance in this project, I credit Professor Annette Allen. Our first conversation about Absalom, Absalom! confirmed my decision to enroll. For her love of the Modernists which has remained unswayed and convincing, for her seminar on "Creativity and Madness" which spawned the central notions of this project, and for her encouragement to pursue the topic when I had become myopic in my immersion, I am grateful.

Each of the other committee members, too, has contributed both valued time and content to this project. Professor Paul Griner taught me, a bad poet, the principles of good fiction in a stellar course in creative writing. The trope, "a character faces a problem, undertakes action to address it, and arrives at a win, lose, or draw," is his entirely; as well as the notion, "the easiest act a writer can accomplish is to confuse the reader." Professor Christopher Stewart as Director of the Additction Psychiatry Fellowship at the University of Louisville School of Medicine lends the clinical expertise to the supervision. He extends here the mentoring he has provided since my brief foray in the psychiatry residency where we has an upper level resident in the years before I decided I enjoyed 
more the practice of psychology. Professor Paul Salmon serves as the external reader for this project, extending an interest he first showed in me when I was a graduate student in clinical psychology. His reading assignment from 1987 included the essay by B.F. Skinner that posits the alienation of workers from the products of their labor, a point in this project.

For the foundation that has allowed me so many opportunities, I am forever grateful to the faculty of Rice University. I admit nostalgia, but I fiercely defend this retrospection. In those years, 1974-1978, every course in which I was enrolled was taught not just by tenure-track faculty members, but by fully tenured faculty members. Outside the classroom, these women and men sat at table with me in one of the richest experiences of the Academy, a place as pleasant as Plato's grove. Professor David Minter appeared in my life first not as a Faulknerian, but as the Master of Baker College, our residential community at Rice. He stays in my thoughts in his retirement. Professor Robert L. Patten was as much an energetic Baker College Associate as he was the eminent Victorian literature scholar; a professor who was kind enough to tell me that the Baker College Cabinet minutes I wrote weekly embodied both good and lively prose, and that my term paper in his Dickens class was abysmally bad beyond salvation. In authentic education there is no substitute for such truth in guidance. He remains constantly in my heart, and I am humbled to call him a friend.

Finally, I honor Professor Charles Garside, Jr., bene decessit, scholar of Reformation and Renassiance studies. Every lecture for every class was prepared with twelve hours of his life. There is not a day that passes when I do not remember him fondly. He ever remains my mentor magnum cum amore even in his absence. 


\section{ABSTRACT \\ WILLIAM FAULKNER AND ALCOHOLISM: DISTILLING FACTS AND FICTIONS

\author{
Quintin Thomas Chipley
}

April 15, 2015

Opinions about alcoholism as a construct, and opinions about William Faulkner's alcoholism as a fact, have varied. By considering carefully the role alcohol plays in human society, and by looking at these matters of concern through several different lens models, we can explain both why Faulkner was attracted abnormally to alcohol and why others around Faulkner have responded ambivalently to him, to his drinking and to his fiction. Faulkner's alcoholism was rumored and denied during his life (1897-1962), evaded and contested after his death, and consistently affirmed after 1980. Attention to David Minter and Joseph Blotner, biographers, reveals much about the shifted opinion. Evolutionary psychology establishes origins of alcoholism, and medical science of heredity, genetics, and neurophysiology describes the problem. Theoreticians such as Wayne Booth, Harold Bloom, Frederic Jameson and Slavoj Žižek provide tools to explain why we vary in our narratives about our favored writers, their personal problems, and the quality of their works. Narrative and rhetorical choices such as telling vs. showing, framing, and word-choice determine focus in biographies. Likewise, Faulkner's use of doubled-characters both conceals and reveals his own alcoholism in his fictions. The project argues for practice of simultaneity in the application of multiple perspectives. Links connect survival advantages, intoxication, divergent thinking, and 
heightened creativity, as well as chronic alcoholism, anhedonia, and impaired creativity. The project explains why Faulkner, early in his career, received a creative spark from drinking, was able to sustain this creative flame for a few years even as other bad consequences emerged, and then found his creativity extinguished in alcohol. His rise to fame, however, began exactly at the time that his creativity was waning; a fact that is not so much ironic as it is determined by a drive for others to cling to a creative leader beyond the height of his or her powers. Readers are ardently prone to persist in their attachments to favored writers who no longer function well, paralleling alcoholics who are ardently prone to drink after alcohol no longer benefits them. Both tendencies are coded in our genes. 


\section{TABLE OF CONTENTS}

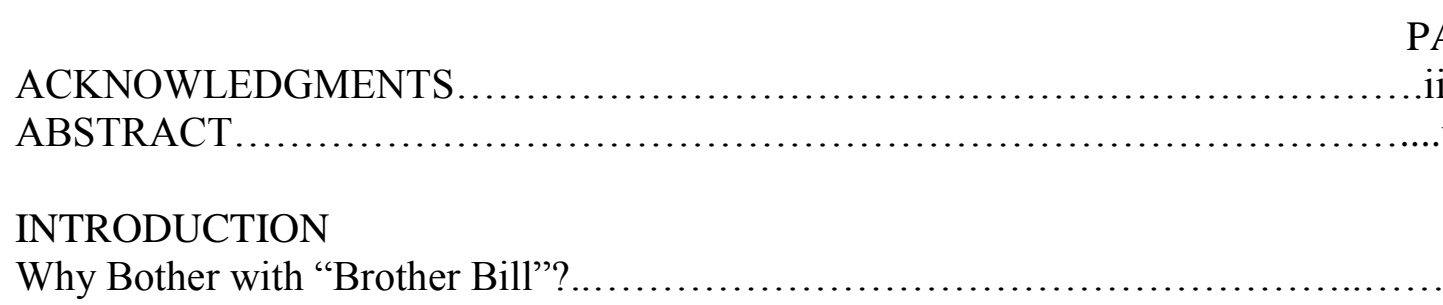

PAGE

ii

V

Chapter One

Taking a Drink, Taken by Drink, and Taking the Cure......................... 25

Chapter Two

Drink in the Ink of Writers: Credential, Crutch, or Crisis?.

Chapter Three

Fermenting the Mash:

Strong Opinions on Strong Minds, Strong Drink and Strong Imagination

Chapter Four

Of Double Vision and a Double Life:

Alcohol and Character-Doubling in Faulkner's Fiction...

Chapter Five

'The Lion in the Garden,' the Elephant in the Room, and 'In Time, That Made a Monkey of Us All'"...............................255

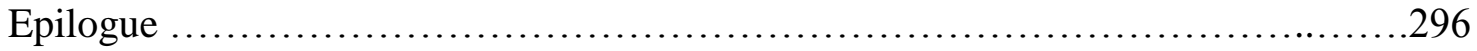

REFERENCES.......................................................... 302

APPENDIX

Blotner Distilled............................................................ 314

CURRICULUM VITAE ............................................... 423 


\section{INTRODUCTION \\ WHY BOTHER WITH “BROTHER BILL”?}

William Faulkner (dubbed "Brother Bill" by most of his family) once quipped, "Civilization began with distillation," an aphorism that leans on the poetic consonance and humor of the words more than on anthropological facts. This project in great measure reverses the order of the rhyme, not so much to assert the obvious and prosaic truth that distillation actually began with civilization, but to emphasize that fermentation preceded both. As it turns out, an aspect of pure science (ethanol as derived from simple carbohydrates) mixes with zoology (primates and how they find ethanol) which mixes with social science (how humans concentrate on both carbohydrates and ethanol, and how they concentrate both) which mixes with the humanities (in this case, writers and how they get drunk). Not only does the project reverse the rhyme, it promises to reverse the mix.

This notion of applying a distilling process to some mixture in order to separate the contents and to recover origins would seem straightforward enough, and it lends itself to the metaphor (again, with a nod to humor) in the title of this project, "William Faulkner and Alcoholism: Distilling Facts and Fictions." But that which is obvious is not always easy. A riff on Sigmund Freud comes to mind, for this project addresses "Distillation and Its Dis-contents" as much as Civilization and Its Discontents. Another physician, Robert Silkworth, M.D. -- the non-alcoholic staff doctor at the Charles B. Townes hospital in New York who became the first medical voice to endorse Alcoholics 
Anonymous -- described alcoholics famously: "They are irritable, restless and

discontented unless they can experience again the ease and comfort which comes at once by taking a few drinks - drinks that they see others taking with impunity. [emphasis added]." Finding contentment in the problems of contents is not so simple, and short cut "solutions" that offer "ease and comfort" for a while may turn on us after they have stopped turning us on. This project hopes to offer a "solution" to the crossed interaction of four variables that are thoroughly mixed in a "solution."

I play on the double entendre inherent in the word "solution" with a purpose. In one turn, finding a "solution" is the result of resolving components from a mixture. In the next turn, making a "solution" is the result of dissolving components into a mixture. The title states the four variables: 1) William Faulkner, 2) Alcoholism, 3) Facts and 4) Fictions. They are mixed in simple and complex orders of interaction. I play on the word "play" in the course of this "work" to highlight the fact that "facts" and "factors" are hard to isolate. Were this project a pure exercise in the sciences, whether, natural or social, each variable would require measurement, and the hypotheses probably would best be subjected to statistical tools involving arcane names like MANOVA, eigenvalues and eigenvectors. There is no way to "play" that game thoroughly in this mixed arena of art and science, however. Here-and-there, some important insights from such empirical methods will appear, but some characteristics are not amenable to such processes. The resistance to measurement may be due either to their intrinsic natures or due to Time's unremitting, eroding, corroding and consuming process, or to the reality that what method fits one venue may rupture another. Gavin Stevens, for example, in Requiem For a Nun speaks what is probably the single, most-often repeated Faulkner quotation, "The 
past is never dead. It is not even past." In his avuncular, patrician role in Requiem, Stevens can use such an insight to good purpose as he leads Temple Drake to investigate her own truth; but were Stevens functioning as the Yoknapatawpha County attorney before a judge, his Senecan wisdom would probably not sway the court's opinion regarding rules of evidence. That particular work, Requiem, also serves as a good objectlesson concerning the intrinsic "immeasurability" of certain variables. That book is a perfectly dreadful work, whether approached as a stage-play or as an experimental novel. I can describe why I find it, as a whole, such a failure (and I will do so in Chapter Four, along with discussion of several failed works from the 1950's) but I find impossible the task of quantifying what qualities make one of Faulkner's works better than another. When working with a mix of methods, the limits of each demands respect. Uniform empiricism, when it marches across borders to enforce some Anschluss on the humanities, brings a crushing imperialism. Likewise, a blind and obstinate refusal to acknowledge that aspects of the humanities are, indeed, illuminated by empiricism's normative methods, reduces truth to tiny fiefdoms ruled fiercely by personal opinion.

I offer this project as an alternative; a way of spawning conversation and collaboration. I offered above a small riff on the odd way that "solution" takes on opposite meaning "by turns." I play now on "taking turns" on the word "play" itself as well, and I consciously steal it from one of Faulkner's best novels, Absalom, Absalom! Quentin Compson and his Harvard roommate, Shreve McCannon, take turns in a winter night (perhaps a "winter of our discontent") to work out what happened, what it meant, and what it means. One story could not do it, and Faulkner lets four iterations of the tale tangle and untangle, weave and unravel. Only by "taking turns" can the "turns the story 
takes" be worked out; and even then, not perfectly. There is never a full harmonization and we are not absurd to note that four similar, but non-harmonized, version of a Big Story has considerable precedence in the Four Gospels. This "prequel" of a novel highlights the "fact" that Quentin's struggle with the "fictions" from his region saves him during that winter night of hard work with its turn-taking and play. The shivering Mississippi boy from the sultry South cannot get at "it" without the Canadian who is apparently so impervious to the cold that he invites, bare chested, the freeze into the room, but the cold-blooded Canadian, on his own, cannot comprehend the Southern boy's experience without listening to him tell the heat of the passion. Yet listening is not enough. This is serious work that requires "turns" and "play." Shreve chimes in with his famous demand, "Let me play a while," and he narrates his own Tale of the South and the Sutpens. As long as "turns" and "play" are allowed, life for that one day gains meaning. By the time Quentin gets to The Sound and the Fury a few months later (as measured in Faulkner's narrative time) but five years earlier (as measured in Faulkner's published time) the Mississippi boy is no longer talking to anyone but himself, and that monologue does not go well for him. He drowns himself. "Drowning in drink" and drowning in "the drink" are a serious play on words, and it is no accident that one of Quentin's most severely failed conversations had been with his alcoholic father who could only talk and would never listen, and who takes his "turn" nightly down the hallway to the bottle in the sideboard.

This project's conversation will not be simple. Any approach to the complexity of the four variables offered in the title will require more than simple chemistry, for the basic problem with simple distillation appears even on the laboratory bench. Bunsen 
burners and spiral glass tubes have their limits. Any high-school student worthy of registration for the AP Chemistry Exam can explain, by recourse to Raoult's Law, the reasons why the physical separation of ethanol from water faces an upper limit in an azeotrope that persists with $95 \%$ ethanol by volume. At that ratio, subtle, non-covalent forces cause the heterogeneous molecules in the liquid state to associate at the same ratio as is found for their peer components floating as a gas. When there is no distinction, there is no distillation. No matter how hard the student concentrates on boiling and cooling pure grain alcohol, the solution will keep the same concentrations.

Sceptics and scoffers both might well extend the azeotrope metaphor to this resurrected question of the relationship of William Faulkner and alcoholism. Most would simply say, "Your apparent point that Faulkner was alcoholic has enough proof (pun intended). Moreover, it is overcooked. Please move on.” A minority opposition, furthermore, could well claim, "You can never achieve $100 \%$ purity in an answer by the same methods, and the conclusion that he was alcoholic is not certain." Both voices would perhaps be persuasive if the project were, indeed, only one more attempt to demonstrate that William Faulkner did not drink normally. I admit upfront that a part of this project will both revisit and reaffirm his aberrant drinking, but that part really only adds a few relevant stories to the catalog of events provided by the major biographer, Joseph Blotner, in the massive 1974, two-volume work. Blotner gives us more than sufficient evidence in anecdotes for us to get "the big picture," even if Blotner himself finesses - even at times obfuscates -- a blunt interpretation of Faulkner's problem.

Blotner's hesitancy to label Faulkner consistently as alcoholic, in fact, serves as natural laboratory to examine the complex manner in which normal-drinkers and non- 
drinkers respond to their fellows who demonstrate an aberrant relationship with alcohol. When the old chestnut of a problem, "Was Faulkner an alcoholic?" is addressed by a rather free-wheeling conversation that invokes several seemingly disparate theories, the resulting voices have something to say that transcends the alcohol-addicted writers themselves. The conversation will illuminate why the consumers of art behave the way they do toward the producers of art, whatever relationship the artist might or might not have with alcohol. This project will offer a tentative understanding of why the very large majority of the human species' members (myself included) energetically seek to consume artistic products that a gifted minority of our species produce from states of inspiration. A complex, and sometimes contentious, relationship of Spirit, spirits and inspiration emerges here. The problem of the readers' relationships with the inspired writers themselves is as interesting to me as is the problem of that writer's relationship to her or his sources of inspiration, whether they be endogenous, exogenous, or both.

The structure of this complex, and perhaps presumptuous, project, hopes to introduce four different voices via four chapters and then to let them "listen" to each other in a fifth (pun intended) and final chapter.

The first voice - and I admit it to be the cantus firmus -- simply reviews the literature on alcoholism to present the dominant models for interpreting it and some competing models offered to correct it. In Chapter One, "Taking a Drink, Taken by Drink, and Taking the Cure," the emphasis falls almost exclusively on the simple substance of ethanol and the few other agents (barbiturates and benzodiazepines) that closely mimic ethanol's effects on the brain. This voice undergirds the entire project because, if there is no such "thing" as alcoholism, any discussion regarding "Faulkner 
and Alcoholism" is rendered either completely absurd or absurdly short. This first chapter will look at 1) evolutionary models via primate comparisons, 2) medical models via inferential genetics and neuroscience, 3) psychological explanations, 4) morality models and 4) social-construct models. That last category includes attempts a) to attribute the alcohol problems observed among writers to special risks created by residence in North America (especially in Southern U.S. culture), b) to assert that a Modernist mandate (concurrent with Prohibition) required writers to flaunt humanity's social conventions as much as to taunt an unyielding and brutal Existence that appeared, by all their accounts, frankly unconcerned with humans, c) to a socially constructed, gender-role that tied heavy drinking to masculinity and symmetrically divorced femininity from the same habit, and d) to socio-economic and racial-class stratification that allow power brokers to assign different labels to same conditions found among people who differ only by social rank. This chapter will introduce the various and often conflicting programs that have arisen as purported correctives to the drink problem.

The second voice, in Chapter Two, "Drink in the Ink of Our Writers: Credential, Crutch, or Crisis?" will address the literature that has investigated problem-drinking among writers and will examine the ways different reviewers try to explain why American writers have been more prone to the problem than their British and European writers. Of interest here is, of course, the way that Faulkner is included in some of these catalogs of writers. Of even greater interest, however, is the way in which Faulkner is omitted from a few of the most trenchant and creative surveys of drunken authors. Thomas Gilmore identifies his important book, Equivocal Spirits, as the first one of its kind to consider the relationships of alcoholism and writers as intrinsic to literature and 
not simply accidents of biography. His book is also one that does not look specifically at Faulkner, but his hypothesis that a shift in philosophy and aesthetic from Modernist to Post-modernist decades brought a shift from the glorification of alcoholic escapades (e.g., F. Scott and Zelda Fitzgerald) to a loss of enchantment with alcohol as both Muse and amusing, and a concomitant rise in the romanticizing of other drugs among the postmodernists and their fans. In short, the excusing of excess drinking was on its way "out" (although actual rates of drinking persist) while a lenient attitude toward "smoke and snort" was rising. This same section's review also highlights the way in which some of Faulkner's defenders have strained mightily to deny his problem, to create meaning for his problem, or to interpret his problem psycho-dynamically and existentially so as to avoid any reductionist "disease" model.

The third voice in Chapter 3, "Fermenting the Mash: Strong Opinions on Strong Minds, Strong Drink and Strong Imagination," addresses the interactions of creativity, mental illness, and intoxicants. This chapter will look at the interaction of three dyads, and it is utterly dependent on the David Nettles' twenty-first century work on creativity and mental illness, which results will be coupled theoretically to the evolutionary biology of alcohol-use as reviewed in Chapter One. The exploration will examine three variables taken two-at-a-time: first, the classic dyad of "Mental Illness and Creativity;" next the dyad, "Substance Use and Creativity," and last, "Substance Use and Mental Illness." The fourth voice from Chapter Four, "Of Double Vision and a Double Life: Alcohol and Character-Doubling in Faulkner's Fiction," looks first at the ways in which Faulkner creatively (and sometimes quite successfully) wrote aspects of his aberrant drinking into his fiction and, second, the ways in which his aberrant drinking, in the long run, blunted 
his gifts. The chapter reviews the varied ways that Faulkner presents drinkers and abstainers in his fiction, and will focus heavily on Faulkner's use of the literary device of character doubling both as a craft in fiction and as his own psychological defense.

Focused readings of two characters in one book, Pylon, and broad interpretations of two close relative characters, Gowan Stevens and Gavin Stevens, figures in many of his novels and stories, constitute most of the investigation. The section also proposes that Faulkner's bottle enhanced his creative genius initially and impeded it eventually. Recourse to the natural history of alcoholism explains why, in general, his best works clump early in his career and his worst works clump late in life.

In Chapter Five, “'The Lion in the Garden,' the Elephant in the Room and 'In Time, That Made a Monkey of Us All', "I apply the first four chapters as an experiment in criticism. This harmonizing and summarizing chapter looks at the way Faulkner's family, editors, publishers, critics, biographers, and U.S. State Department handlers have all responded to Faulkner's alcohol problem. Joseph Blotner and his massive, twovolume, William Faulkner: A Biography (1974) will figure most heavily in the discussion. Blotner's words receive such attention for two reasons. First, with the exception of the brief overview given by Millgate in 1963, Blotner's biography undergirds every subsequent attempt to interpret Faulkner's work with any significant reference to Faulkner's life. Second, Blotner's craft as a biographer actually borrows techniques in fiction for telling stories. When his craft is analyzed, when his personal and social attachments to Faulkner are considered, and when the quarter-century timespan of Blotner's engagement with Faulkner and the biography (the early 1950's through 1975) is considered, this example supports strongly Gilmore's thesis that a 
Modernist trait to embrace the alcoholic writer was transitioning to a rejection of their behaviors, rendering "equivocal" opinions on the role of "spirits." Malcom Cowley, Michael Millgate, Cleanth Brooks, who figure in Faulkner's life before Blotner also are considered, as are the Faulkner biographers and interpreters Minter, Grey, Oates, and Parini, Karl and Weinstein who follow Blotner. Robert Goodwin and Tom Dardis, already reviewed in the second section, are revisited in this section because several of the later Faulkner scholars were forced to acknowledge the works of the physician researcher, Donald Goodwin, and the recovering-alcoholic writer, Tom Dardis. This chapter attempts to orchestrate monkeys, genes, geniuses, drunks, and all their handlers. This summary chapter contends that readers will entertain (and that they have entertained, in the case of Faulkner) some rather contorted explanatory arrangements when confronted with alcohol's effects on the artist's industry as long as the artist's product continues to satisfy the readers' appetites. These appetites are not simply primitive in origin; they are primate in origin. Humans may arguably be "more" than their primate cousins (and the developed verbal skills that undergird human civilization in general -- and human poetics in particular -- point to some aspect of a qualitative difference) but we humans are not anything "less" than our evolutionarily related primate cousins. What drives them will drive us, though what inspires us may not inspire them. This simply means 1) that our art has origins in primate behavior, 2) that our art can have genuine and intrinsic meaning for us as humans despite its primate origins, and 3) that our human art has no meaning for other primates because our human attribution of meaning is a very sophisticated adumbration - perhaps better called an inspired 
transcendence - of evolutionarily adaptive traits that enhance our survival probabilities within our peculiar human context.

A brief Epilogue places the entire approach within the context of some recent critical theory, and, finally, to assist this project's readers, an Appendix to the project attempts to provide every narrative instance from Joseph Blotner's 1974 biography where Faulkner or the Faulkner-family are shown affected by alcohol.

The preview of Chapter Five, with the consciously selected words "producer" and "consumer," as well as the preview to Chapter One where the word "thing" was denoted in quotation marks, suggests that the project, to some degree, has some minimal engagement with Critical Theory. I admit my diffidence. Critical Theory has necessarily complicated everything, and I actually accept that the complication is necessary. I also suggest that Critical Theory has not really solved anything, and I am now pleased and relieved to find that one Theory's best thinkers, Bruno Latour (2003) has carefully reconsidered --- and has as thoughtfully declined to repent of -- his part in unleashing highly amplified critiques that questioned modernity's assumptions about "naturalized facts" of science. I set apart this word "thing" in quotation marks to indicate upfront that it is not as simply or naïvely employed here as might be imagined, and Latour brilliantly reviews the opposition of "thing" and "object" in his essay. I am compelled by his choice to turn Critical Theory onto itself as a corrective to the absurdity of a wholesale academic industry intent on stating that, 1) because all facts are constructed and 2) that any fact can be deconstructed, then 3) no fact is worthy of trust. This conclusion serves neither construction nor deconstruction; it becomes destructive to understanding real functions. My house, for example, was constructed around 1921, it can be deconstructed at any 
time, but as it is, it is warmer, drier and cozier in a Kentucky winter when compared to a shack constructed of appliance cartons and wedged under an interstate overpass. The functional Kentucky house may, however, be far inferior to the function of an animalskin yurt were I to live in Mongolia. Our experience of situational relativity does not mean that the constellation of the relationships fails, "in fact," to create reliable meaning in the immediate circumstances,

The most compelling aspect of Latour's call for reason is that he issues it in the context of "matters of concern." Here the words "thing" and "object" find a nexus point. Latour notes that the etymology of all instances of the word "thing" (e.g. res in Latin and "vyech" in Russian) hearkens back to the named congregations of people who assembled themselves to talk about matters of concern; for instance, Icelandic's word, Alting. In such places of conversation, the "matter of concern" is "thrown out" for discussion, forming the "object" or the "Gegenstand." Real things take on real meaning in the context of real people making objects that have meaning because of matters of concern. As Latour notes, this vision does not require a neomodernism reversion to old ways of "kicking the stone" with Samuel Johnson, but it can allow for what Latour prefers to label "non-modernism."

Latour was prompted to his revised positon vis-à-vis science critique because he saw that his and others' work that had questioned the Moderns' assumption of a canon of "naturalized facts" had been warped in two different ways against "matters of concern." The two most important experiences he was forced to face were the simultaneous emergence of the "conspiracy theorists," with his example of those in his village who denied any real agency to the hijackers and the planes that felled the Twin Towers (or 
even denied that planes hit the towers), and the orchestrated campaigns by those who do not like the threats to the status quo created by a science they actually acknowledge to be true. The example of this latter distortion comes from political opponents of the science confirming human agency in global warming. These critics consciously construct counter-campaigns (actions Latour calls "artificially maintained controversies") that capitalize on the reality that science, by definition, can never present one hundred percent certainties. What began in the nineteenth century with important thinkers who questioned foreclosed conclusions, the theorists whom Paul Ricoeur dubbed "Masters of Suspicion," had split in the twenty-first century into patterns of either 1) an unsophisticated and solipsistic denial or 2) a patently orchestrated deceit. Latour finds that both travesties derive from uses of theory that have been divorced from "matters of concern." Latour's corrective insight has particular importance for Chapter One of this project where the varied models of alcoholism - medical, psychological, and moral - are reviewed, including some argument that no "thing" called addiction really exists, and if it does, medical science has nothing of importance to say about it.

In these regards, an unavoidable, but mercifully brief, discourse of Critical Theory will require some indulgence. I have introduced the problems of poetics with these rather prosaic (and, perhaps, artistically offensive) economic nouns "consumer" and "producer" to emphasize economics. These are terms of the "household law" (oikovouia) by which we trade our units of nurture because such objects are "things," or matters of concern. Despite some excesses, I have learned to appreciate from Theory, especially the "bad boy" of current popular critical theory circuits, Slavoj Žižek, that nothing is too sacred 
and nothing too profane for Theory to raid, whether it be a work of Karl Barth or a Woody Allen film.

So I turn to Mel Brooks and Silent Movie (1976). With a "turn" that Brooks was turning on himself, the film presents the parody of the famous Metro-Goldwyn-Meyer "roaring lion" seal and motto “ARS GRATIA ARTIS," or “Art for Art's Sake.” His film features at its end a seal with the "Big Picture Studios" ribbon-banner motto, "ARS EST PECUNIA" or "Art Is Money." Marxist theory seeks to explore this capital relationship, and one scholar of such bent in particular, Lawrence Schwartz, has provided a brilliant account of the way the U.S, publishing industry, movie industry and State Department's Information Services program coordinated to increase significantly Faulkner's reputation after World War II.

Behind Marxism, Capitalism, or Socialism looms the question of what we humans seek when we seek "matters of concern," whether they be money, art, or food. I find that evolutionary biology and psychology contribute well in an attempt to answer that question when they are allowed a "turn" at play. The fact that our experience of "nurture" includes the humanities with its "diet" of spiritual and intellectual food does not obviate its roots in a primate drive to maximize access to the biochemical nutrients. Therein we humans share our common nature with monkeys and chimps. That we end up, however, creating something of a human experience that transcends the primate experience is certainly a sustainable argument; but it is an argument better explained by David Dennett's thesis of the "science of large numbers" in his book, Darwin's Dangerous Idea: Evolution and the Meanings of Life, than by recourse to various 
explanations of a categorical Homo sapiens privilege that accesses "sky hooks," whether those devices be secular humanism's hubris or some religion's Deus ex machina.

Several points of evolutionary theory deserve review. First, it asserts that our most adaptable characteristics are never single-mined: they spawn varied behaviors within the individual and the species under varied conditions. Furthermore, evolutionary theory explains that genes really are "concerned" about themselves and not particularly about the specific organisms that carries their copies. In Richard Dawkins' words, they are "selfish." A gene has its copies scattered about the species, concentrated more strongly with closer genetic lineage. The gene itself does not really care if it replicates out of Brother Bill or Brother John or Cousin Mary. It would "prefer" a trifecta win, but it can win on any single horse at the finish line. It is therefore important to remember that Darwin's book was about the Origin of the Species, and not the Rise of Gifted Individual. A species" arrival and survival has some "conversation" with individuals, but the group as a whole will do what it can to benefit from the behavior of any one individual. Chapter One will look more closely at the way that, in a primate troop, the minority's propensity to find ethanol (the fermentation product of the nutrient carbohydrates), will alert the majority of the troop to the availability of the carbohydrate, a substance which is a "matter of concern" Drunk-monkeys are sentinels who direct attention to rich resources. Alcohol is "tagged" to a nutrient in a social group and, in certain situations, the ethanol functions as a "matter of concern" in its own right and with a positive valence because it promotes the probability of reproduction for the whole troop. In other situations, ethanol can function as a "matter of concern" in its own right and with a negative valence because it decreases the probability of reproduction for the whole truth. 
Ethanol is an equivocal spirit, as Thomas Gilmore will show specifically regarding our favored writers.

Situations across different types of primates (with humans being one type) and across different economic and historical settings of humans (with Southern Modernist fiction writers being one type), make a difference as to how salient alcohol is for survival or demise. By now, readers who know Faulkner's work well also know that he had a problem with alcohol, though they may differ in their interpretations of 1) what, in general, an alcohol problem is in itself, 2) what factors created and sustained Faulkner's alcohol problem in particular, or 3) how salient alcohol was for his creative process. Those same readers may be surprised, however, to learn that the existence of alcoholism as a problem was ever even doubted, whether in general (say, in the population of the seventeenth and early-eighteenth century American Colonies) or in particular (regarding William Faulkner). When reviewing our retrospective evaluations of Faulkner, the shift from denial to acceptance of the problem provides an interesting case-study for the way we reevaluate a creative giant's behaviors as his or her creative product changes. There is a little bit of Hans Christian Andersen's famous fable of The Emperor's New Clothes at work. The paradigm shift from denial to recognition requires a voice from below (a person not beholden to the king) to counter the abject denial from the voices above (those who have something to gain or lose from a king's favor). The child in the story does not speak derisively; only truthfully. It is the chagrinned adults who, in a spectacular display of over-compensation in response to their own prior folly, are the ones who laugh contemptuously. 
In Faulkner's case, a famous instance (or infamous, if we take his mother Maud's perspective) came with the 1953 Life magazine article in which the reporter, Robert Coughlan, goes out of his way to declare Faulkner, “"not an alcoholic but perhaps more accurately an alcoholic refugee, self-pursued" ("The Private World of William Faulkner," Life, 35, Sept. 28, 1953, 118-36; quoted in Blotner, 1467). Whether this convoluted statement was a cagey ploy to communicate that Faulkner was, indeed, alcoholic, without bluntly stating it as fact and, thereby, to evade libel charges, or if it was the journalist's clumsy betrayal of his own self-deception, such a statement is simply not germane to an article about a normal drinker. It is also of note that the Life magazine coverage of Faulkner and his cups appeared almost 30 years after a first interview in a regional magazine when the young writer, early in his career, is shown brewing beer in his kitchen. Something more than coincidence is at work.

The Life article "denying" an alcohol problem appeared in the 1953, just a few years after Faulkner was awarded the Nobel Prize in Literature. Everyone was reading Faulkner; and at rates exponentially larger than his sales rates twenty years before, they were buying both his reissued works and the later works, several of which were, frankly, hardly readable. The first interview, with its highlight of beer-brewing, appeared when his considerable acclaim among a few writers and few literary intellectuals was high, but when his market-share was negligible. Average readers had not much bought his books before the 1950's.

The problem these days is simply convincing any twenty-first century readers -outside of college-course assignments (and even there this task is a battle) -- to read even the best of Faulkner's works. Postmodern fiction has shifted agendas for creative writers, 
and the concomitant rise of Continental Theories has cracked the crystal globe of impenetrability that the Vanderbilt school of New Criticism had attempted to blow around the Modernists. This privileged isolation of author-from-work was particularly at play for the modernists from the South, and a New Critic like Cleanth Brooks could build a well-marketed brand of scholarship on Faulkner and his ilk. The amplified voice, "Pay no attention to the man behind the curtain" had become the meme of the New Critics, and it did not take long for some little dog to pull aside the drape to reveal the machinations of a desperately lost trickster frantically manipulating a grand illusion. Alcoholism may have been one of the problems, but greater credibility problems were found in attempts to reconcile the Southern drawl in the great Modernist Truth narratives with the embarrassingly slow Southern crawl out of legalized racism. If the Modernist can be depicted as the outlaw Everyman shaking a drunken fist at an indifferent Universe, deaf to human complaints and void of meaning beyond such gestures, the Postmodernist can be seen as an ideologue convinced that human injustice can be addressed by raising arms against those who manipulate political and economic power. Each creed requires considerable belief, but they are each different faiths. Faith in Faulkner's vision fell out of favor sometime in the mid 1980's. Whether it will be revived remains to be seen, and the loss resonates in the nostalgic tone of Jay Parini's title, One Matchless Time: A Life of William Faulkner (2004).

While I love to talk about his works and his life, Faulkner hated to talk about either. I assert that at some level he knew that, should he lower the façades, he would relinquish his ability to cope with both. Faulkner took the sanctity of his trade one step further than the stage magicians who protect their secrets. The prestidigitator cloaks 
secrets so that the audience remains spell-bound, but the performer holds no selfdeception. Oracles of fiction, however, have to protect themselves at some level from their own self-knowledge. If they know too much, they cannot convince themselves to believe in the worlds they craft, and that failure to hold themselves steady in a trance would, in turn, keep readers from becoming entranced by the fictive worlds. Good fiction is an altered perception of the world that, when shared, allows construction of an alternate world and, thereby, alters our relationship with this world. The way a writer first chances upon the "altered perception" of the world can vary, and a substance such as alcohol can play a role.

Faulkner's texts are also textiles (those words are related, of course), for his fictions are both a curtain and a screen. From behind his curtain he projects to the silvered-side of the fabric a life that correlates with just enough outline and shape to lend credence, yet distorting enough details to reveal some new Truth (and the capital $\mathrm{T}$ is important). His project was his Truth about himself and any attempt to self-interpret that Truth introduced him to the uncomfortable process of accounting for both the correlations and the distortions. When Faulkner was finally lured into the classrooms of Ole Miss and the University of Virginia, as well as into other interview situations on his U.S. State Department tours of the 1950's, he learned to develop certain stock-in-trade remarks regarding what he was "up to" in his work. The answers are rarely very illuminating and hardly ever very satisfying. At times they appear to be well-constructed prevarications, as distinct from explanatory fictions. Although he was an ardent consumer of fiction and poetry, and a producer of both, he did not confuse those tasks with analysis. He shopped the bookshelves like a chef shops the early morning market, not as the anatomist haunts 
the morgues. It is one thing to know how to buy from the butcher a perfect bird and then quarter it with skill so as to prepare it with relish. A chef, however, is not an anatomist. Frankly, no one really wants to consider the anatomist in the kitchen. That scenario is too much like dinner with Hannibal Lector. Literary Theory is really quite antithetical to the fiction it examines precisely because fiction hopes to tell some human truth by means of human deception while Theory aims to deconstruct fiction's deceptions in an effort to uncover human facts. Stephen King wrote Misery about a reader with too many demands on a novelist's work, and no author wants to end up in a salon with Annie Wilkes' approach to the creative process.

Despite Latour's insistence that certain "matter of concern" are knowable, he is never naïve regarding our current ambivalence or about the historical ambivalence we can learn from etymology. He notes, for example, that our words "fact" and "fairy," two "things" we do not normally confuse, have descended from the same root. This observation leads to the similar consternation encountered with the words of "facts" and "fictions," the other components of the project title. The etymology of "facts" and "fictions" is precisely the etymology of "facts" and fairy." The word "facts" comes from facere and our notion of "fictions" comes from fingere, but both Latin words branched from a common Indo-European trunk that combined the notions of "making." Here, as with Shreve in Absalom, Absalom!, I intrude with "Let me play a while."

In English, a little amplification of the word "facts" will lead us into "factions," a fate scholars encounter in the fractious world of finding truth, while our word "fictions" will not distill down to much of anything monosyllabic. It will divert into "fictive," as an adjective, but it will give us fits if we try to make it give us "ficts." (In fact, there is a 
dead use of "fit" or "fyte" which referred to a "section of a poem or ballad," but the etymological precursor is not established by evidence, so any attempt to tie it as a fact to fingere might be mere fiction.) The Latin fingere survives in English not only in "fiction," but also in "feign." This devious word, fingere, makes a career out of evasion, I have smuggled into this discussion the word "evidence," presumed to function as some tool or wedge that helps us separate "facts" from "fictions." Evidence derives from "ex-videre" or from "from seeing," suggesting that sight reigns supreme for epistemology. Our courts have long loved eye-witness testimonies; that is, until psychologists like Nobel laureate Kahneman came along to show how unreliable the eyewitness reports are when compared to physical evidence. Eyewitnesses are not deceitful, mind you; but they are self-deceived by quirks of the brain that will make (facere) a processed, stored, and retrievable cognition we like to call memory, but which has definitive aspects of fingere tainting it. With regard to Faulkner, the confusion of eyewitness reports about his drinking episodes and the visual evidence (plain film x-rays, for example, of old vertebral fractures earned by a drunken tumble down the full flight of stairs at Rowan Oak) will merge, conflict, and concur at various points. Reading the accounts becomes an exercise in detection.

This bête noir of psychology and philosophy -- vetting evidence to determine truths by sorting facts from fictions -- has been tamed to become the favorite neutered pet of Theory, whereby all notions of Truth and Grand Narratives are reduced to constructed "truth" (with a little "t") and petit recits to demonstrate the constructed nature of our epistemes. In fact, Theory likes to deconstruct our epistemes; to take the legs off them so they cannot wander from its range of vision. Theory suspects that errant 
epistemes will adopt old bad habits of espousing intrinsic authority, and in their role as the deconstructionists of the Grand Narrative, they have installed themselves as the Grand Inquisitors over all the prophets of fiction lest any of those upstart oracles essay again to offer readers anything grand.

This mission, of course, is all well and good until some Master of Theory is suddenly faced with the reality of a horrible case of methicillin resistant staphylococcus aureus. Here, suddenly, abstract notions of recit, whether grand or petit, meets the concrete world of the doctor's prescription (also recit), and the concerns are no longer academic. The "true" difference between the actions of the antibiotic linozalid and sulfa drugs becomes pertinent. When interjected into the conversation, therefore, the concept of "disease" and "cure" makes a difference in our willingness to "have the strength to force the moment to its crisis," for the "crisis" was, in early English usage, the point in a disease course where either the return to health or a decline to demise occurred. Ready access to a clinic suddenly becomes much more relevant than ready access to a copy of Michel Foucault's discourse on The Birth of the Clinic: An Archaeology of Medical Perception.

It would appear, then, that we can trump any esoteric discussion with a physical diagnosis of disease, and this leads us back the matter of concern regarding Faulkner and alcoholism. But that power is really only an appearance. Access to this privileged realm of diagnostic entity is as likely to open new questions of privilege. Some problems earn an ICD-10 code while some problems are "kicked to the curb" as mere disturbances of human of existence, and some people with exactly the same problems but of differing 
cadres of social class are also treated as differentially. After all, "All animals are equal, but some animals are more equal than others."

Even if all-comers with equal symptoms (perhaps, for example, symptoms of aberrant drinking) were met with equitable diagnosis and treatment, however, the power of the diagnosis and treatment would not fully satisfy the questions that good fiction (or poesis, for the terms are essentially equivalent) raises about the human condition. As Michael Hoffman, poet and translator, notes, "A doctor on horseback with a gold chain and sensitive hands is not enough to solve the problems of existence ("The Woman who Quit")." So it seems that though we can allow medicine to have a voice in this process, that voice does not have the final word. The problem of meaning remains even when the problem of suffering is reduced to pathogens and mutations. Or even when expressed as genetic predispositions shared with primate cousins.

By this slight meandering among terms of Theory, I hope to provide a little more than some obligatory academic demonstration of "Yes, I have read that material, Now let me talk about what I love." This, however, this is precisely the problem to which Latour points to in his corrective essay:

We explain the objects we don't approve of by treating them as fetishes; we account for behaviors we don't like by discipline whose makeup we don't examine; and we concentrate our passionate interest on only those things that are for us worthwhile matters of concern. But of course such a cavalier attitude with such contradictory repertoires is not possible for those of us, in science studies, who have to deal with states of affairs that fit neither in the list of plausible fetishes -- because everyone, including us, does believe very strongly in the -- nor in the list of undisputable facts because we are witnessing their birth, their slow construction, their fascinating emergence as matters of concern. 241-242

As little as I enjoy Theory for Theory's sake, I do appreciate that Theory has raised immensely important questions about "What we are up to when we are up to art." I also 
contend that as much as Theory enjoys the horse it rides, Theory has to admit that it really has no answers that satisfy us any better than Hoffman's horseback doctor -precisely because the doctor is Theory personified.

Faulkner, himself, was an ardent horseman, even if not particularly skilled and elegant in the saddle according to his fox-hunting friends. He confronted horses more than he mastered them, and, at times, he confronted them specifically because he knew he was confronting his own fear of their power. He was thrown badly on multiple occasions. The events of Faulkner's last fifteen years make it appear that horses and bottles were, for a time, running neck-and-neck to see which might kill him first. Without knowing the outcome, it would be hard to know on which one to put your money. Some of his best fiction recounts thrilling (often hilarious) tales of trading horses: wild horses, un-mountable horses, rigged horses, and homicidal horses. One of his worst works, A Fable, has as its only compelling narrative the tall-tale of a broken horse which was redeemed for success by love, skill and patience.

Faulkner could not stay off horses or away from horses for long, and in the end, he too, while "on horseback," fails to solve fully the problem of human existence. But maybe if the doctor with "sensitive hands and a gold chain" rides by the side of the poet, novelist and raconteur, William Faulkner, whose creative hands often held a gold nib pen and a golden toddy, some assuaging words to address the problems of our existence might emerge from the conversation; if each takes time to listen, and if each offers a turn at some play. 


\section{CHAPTER ONE}

TAKING A DRINK, TAKEN BY DRINK, AND TAKING THE CURE

As Faulkner continued drinking and stopped eating, his friends' concern increased.

"Bill," said Hempstead, "how can you keep this up?"

Faulkner looked at him unalarmed. "Dave," he said, "there's a lot of nourishment in an acre of corn." Blotner, Faulkner (2 Vols.) 927-8

Although Faulkner's daughter, as she reported to Joseph Blotner, could tell when her father was building up for one of his liquor binges, she was powerless to head them off:

Sometimes Jill could see one coming when, a few days before the onset, he would begin to recite "The Phoenix and the Turtle" or that other harbinger, "When daisies pied and violets blue." She pleaded with him to hold on, to resist. "Think of me," she appealed. But it was already too late, and he answered her with a phrase she never forgot. "Nobody remembers Shakespeare's children," he said. (Blotner Faulkner 2 Vols., 1204.)

Faulkner spat that verbal venom in 1947 , more than a quarter-century after James

Feibelman in 1921 observed a then-unknown poet at a bohemian artists' party in New

Orleans abruptly toss a bit of hubris into the talk:

He was "a little man with a well-shaped head, a small moustache and a slightly receding chin." He had a bottle of whiskey, "which he held near his head and tipped into his mouth from time to time." Watching this process, Feibleman "had the impression more of nursing than of drinking." Finally the conversation turned to Shakespeare and to Hamlet. It was only then that the little man in the corner spoke.

"I could write a play like Hamlet if I wanted to," he said, and then lapsed back into silence. (Blotner Faulkner 2 Vols., 330)

This "little man" was Faulkner, the aspiring poet who had begun early in his days in

Oxford, Mississippi to chase the long shadow which "The Poet" had cast from Stratford- 
on Avon. His fitful starts as an undergraduate had yielded little of a transcript -- and no degree -- but Faulkner had absorbed almost verbatim the Shakespeare course he took at the University of Mississippi. He continued to read Shakespeare all his life, and although he always stretched his imagination -- and listeners' credulity -- when he cataloged his literary influences (he purported, for example, to read through Moby Dick once a year), his claim to a full and constant conversation with Shakespeare appears to be authentic. A portable "complete-works" went with him in all his travels.

Harold Bloom could hardly ask for a better example to illustrate The Anxiety of Influence, the essay that brilliantly traces how every poet both worships and resents the predecessor, and that Shakespeare is, sui generis, the parent of them all. Faulkner's struggle with the Master was usually taciturn or surreptitious, but the evidence of the agon is strewn throughout his works, ranging from The Sound and the Fury title itself through the references littering Go Down, Moses where names like Warwick, Sophonsiba, and George Wilkins find unlikely mention in Yoknapatawpha. And Faulkner, of course, did write his own "Hamlet." His title, The Hamlet, the first and best book in the Snopes trilogy, is a blatant usurpation of the "Danish play" title much more than it is a common term for some piss-ant cross-roads community in Mississippi. The noun has as little place in the region's dialect as tea and crumpets would find in the Snopes' diner. After a few drinks, however, Faulkner's quiet competition with the Bard would erupt in the intoxicated recitations of the Shakespeare poems that prefaced an obliterating binge. Brother Bill seems always to have kept the bottle and the Bard near each other in his head and on his desk. 
William Faulkner's competitive obsession with William Shakespeare parallels our general Atlantic culture's high-estimation of the Bard, and it is not surprising that one of our foundational cultural tropes about alcohol comes from the senior Will:

$\begin{array}{ll}\text { Porter: } & \text { Faith sir, we were carousing till the second } \\ & \text { cock: and drink, sir, is a great provoker of three things. } \\ \text { Macduff : } & \text { What three things does drink especially provoke? } \\ \text { Porter: } & \text { Marry, sir, nose-painting, sleep, and urine. } \\ & \text { Lechery, sir, it provokes, and unprovokes; it provokes the desire, } \\ \text { but it takes away the performance. Therefore, much drink may be } \\ \text { said to be an equivocator with lechery: it makes him, and it mars } \\ \text { him; it sets him on, and it } \\ \text { takes him off; it persuades him, and disheartens him; makes him } \\ \text { stand to, and not stand to; in conclusion, equivocates } \\ \text { him in a sleep, and, giving him the lie, leaves him. }\end{array}$
(Macbeth II, 3.)

This dialog from Macbeth provides us with a case-study of the kind of influence one great authority exerts on all who follow, for that comic scene -- in a tragic setting -- still punctuates discussions about alcohol. Its ubiquity reminds us that Shakespeare's speech shapes our interpretations of individual experiences in ways that convince us to equate his depictions with universal experience. Whereas Faulkner's aphorism, "Civilization began with distillation," can easily be taken as a potent jest with a twist of bitter-lemon, Harold Bloom seriously advances his view of a different origin of civilization. In Shakespeare: The Invention of the Human, Bloom argues, in so many words, that "In the beginning was the word of the Bard." We might contest Bloom's apotheosis of Shakespeare, but the reality is that Bard and the bottle are closely linked in the Western canon and not just in Faulkner's life. A close look at the way the scene from Macbeth functions reveals two common tactics our culture uses to address alcohol and its effects on "the human." 
First, the Porter makes several good jokes on drink as an equivocator, ranging from his high-end wit on the give-and-take of alcohol's effects on sex and sleep, to lowroad hilarity about micturition. Second, this scene provides the tragedy's only light moment, one that would seem better matched by John Belushi's antics in Animal House than to its place among the murders, ghosts and guilt of "the Scottish play." This use of Comedy's relief in the midst of a dramatic Tragedy points up a second, powerful trope. In parallel to the depiction of drink as an "equivocator," the clowning drunk is cast in roles played under both theatrical masks - under smiles and frowns -- and the clown is allowed to espouse equivocal myths about alcohol's universal effects. Just as Melancholy Jacques' monologue on Seven Stages of Man in As You Like It offers us a universalizing rubric for interpreting Time's life-span effect on "The Human," the Porter offers a universal rubric about alcohol's "last night's" effects on "lechery." In that synecdoche of that singular noun, individual and group differences dissolve, leaving a space for Shakespeare to build a spectacularly crafted -- and very crafty -- fiction regarding "the human" experience when any person is "under the influence."

Fiction or not, I have no problem admitting that in the case of a house fire, I will grab my copy of The Riverside Shakespeare and leave the Diagnostic and Statistical Manual of Mental Disorders to burn with the shelf. But Shakespeare's universalizing fiction, as fascinating and compelling as it remains for me, is not an exhaustive description. When viewed with more breadth and depth, we will find that that alcohol is not simply an equivocator for "the human." The chemical acts equivocally in varied contexts for various humans, causing some of us to look upon others (and ourselves) with 
bewilderment when the experiences exceed the received canon of universality. No single description of humanity "under the influence" will capture all complexities.

Even Omar Khayyam's triad, "a loaf of bread, a jug of wine, and thou," -a poetic line that seamlessly links nutrition, drink, and romance in a picture of universal bliss -will crack when it is stretched across the experiences of some aberrant drinkers and their courted companions. Who could ever imagine from that poem a situation in which the line's second element - a jug of wine - could trump both the lover's bread and lover's bed? Yet for some drinkers, the jug comes to eclipse both loaf and love, and the epigraph to this chapter recounts precisely such a darkening in Faulkner's life. The vignette comes from accounts of Faulkner's mid-1930's Hollywood years as a screen writer. In it Joseph Blotner, in his two-volume Faulkner: A Biography (1974), relates the 1935 Hollywood conversation between William Faulkner and Dave Hempstead.

Hempstead was a friend and a colleague in the screen-writer pool, and he somehow found himself the designated spokesperson for a broader circle of friends.

I will return to the content of the vignette -- the clash of nutrition, drink, and relationships -- after a brief look at the way Blotner's thirty seven words in the epigraph, with those words punctuated as dialog, work as a narrative. This small side-step serves, early in this project, to demonstrate what will be pursued in earnest in Chapter Five. Our stories about storytellers who drink are spawned in complexity and are only reconciled (if ever) over time as our relationships with the drinker change. That is, our gaze on the designated drinker generates narratives. In those few lines, Blotner creates an omniscient narrator able to see both Faulkner and his friends; a narrator we presume to be trustworthy. The narrator sets up the problem: interpersonal relationships are in quandary 
of "concern." A shill character (Hempstead) is set up and sent out to confront the hero. His sincere and powerful challenge is issued to the hero, and the hero replies with skill and words to blunt the challenge. This one narrative gives two outcomes. Hempstead has a problem, pursues action, and arrives at a "loss." The hero faces a problem, pursues action, and arrives at a "win." On the one hand, this type of micro-narrative is the stuff of the New Testament gospels where rigid authorities confront the renegade rabbi, only to be "schooled" thoroughly into shamed defeat. On the other hand, Blotner's narrator (and I am not yet ready to equate the biographer with the narrator) lets Faulkner's "bullshit" answer stand unchallenged. In fact, were Blotner to extend the narrative so as to reveal the problems in Faulkner's answer (something I will, in fact do shortly), Blotner would "kill" the narrative, because he knows that we readers want Faulkner to win this round in order for us to stay interested in the rest of The Story that will be composed from the accretion of these kinds of stories. There is a bit of Scheherazade at work in any biographer who has to take a story through 1800 pages, though her narrator's trope of "and morning came and she fell silent" does not play well to a modern audience. Blotner requires a different device to maintain the reader's interest. As readers, we can be simultaneously delighted by Faulkner's reply and not the least bit convinced of its truth.

The vignette in the epigraph also illustrates the practical problems that a biographer faces when wrangling sources. The circle of friends that Hempstead "represents" during those years most likely included Faulkner's actual lover, Meta Carpenter. She was a Mississippian who had, by chance, landed in the same studio as script supervisor, and it is from her 1976 report that we get the one clear story of Faulkner in full delirium tremens. She had found him on the floor next to his bed, 
hallucinating WWI German air attacks (Blotner, Faulkner Single Volume, 369). Blotner was not able to include her story in his 1974 work. In his 1984 revision, he states "Meta Carpenter Wilde, who had declined to be interviewed when I was doing research for Faulkner, wrote with Orin Borstein, A Loving Gentleman, and has kindly permitted me to quote from it (Faulkner Single Volume, x)." The phrasing hints that Faulkner knew prior to 1974 exactly who the players were in the circle of friends around the mid 1930's, but that was he was not permitted to name all names.

Regardless of the extent of Hempstead's deputation or Blotner's exact scope of knowledge, the vignette illustrates the problem drink can bring to the table -- and to fellowship at table -- when drink lures the drinker away from the table for days and weeks at a time, and it shows that Khayyam's picnic-in-the-park can devolve into a nightmare for the lover. The vignette also illustrates Faulkner's "solution" to patch the fracture created by facts. He adopts the "clown" role in this evasive response. Though Hempstead raises Faulkner's drinking as the "matter of concern," how can a friend possibly parry Faulkner's witty riposte? At least in this response to his friend Dave, unlike in the sharp jab he made at Jill, Faulkner fences with a buttoned foil.

I know I promised a quick return to the "meat of the matter;" that is, to the relationship of alcohol and nutrition. But one more side-trip will add still another layer of meaning to the larger quest for understanding the ways we experience meaning in the course of eating and drinking in fellowship. I have mixed Khayyam's wine and Faulkner's corn whisky in a faux pas that parallels the old adage of "never mix the grape and the grain." This "slip" is more than sleight-of-hand, because the intersection of the grape and the grain, whether fermented or unfermented, appears as an almost ubiquitous 
junction of the Sacred and the Profane. The Holy is always lurking when Bacchus and Ceres are nearby, and a good drunk can always defend drinking by such reference. Therefore, if the mask of the clown fails to obfuscate the "matter of concern" via laughter, a quick costume-change into the robes of an inspired priest who holds the bread and the wine can sometimes do the trick. These gifts, the bread and wine, are the very elements of the Real Presence in Calvin's communion, the ringing bell at the Holy Mass, the ritual questions at a Passover seder and the drama on Greek threshing-floor where Euripides' tragedy (literally, a "goat ode") treads the boards to explore the Bacchae and the claim, "Dionysus' powers are manifold; he gave to men the vine to cure their sorrows." These rituals have long mixed the grape and the grain to please the people and to appease the gods. Heavy drinkers who are also recalcitrant drunks have choices, then. They can dismiss their friends' and family's "matters of concern" with defenses imported on the high roads traced from Geneva, Rome, Jerusalem and Athens; or like the Porter in Scotland, they can take their critics down the low-road of raucous humor. Should both buffoonery and sanctity fail to scotch the meddlesome queries, Faulkner illustrates a last resort in his retaliatory response to Jill: scorch the questioner, even if that choice means "going nuclear" on the nuclear family.

Evasion, not fact, was the point of Faulkner's response to Hempstead, though it is telling that, thirty years earlier, Feibelman had observed Faulkner's relationship to the bottle to be "more of nursing than of drinking." These shadows of metaphor - nutrition, nurture and nursing -- are the favored ground for psychodynamic explorations. But setting Freud and orality aside, the pedestrian reality is that ethanol is not a nutrient and it is famous for its "empty calories." The "acre of corn" - when fermented as a beer - 
might feed the body equivocally (hence the true, but overstated, bumper-sticker wisdom that "Beer is food"), but after it is distilled to liquor, it does not offer even a hint of nutrition, setting up the dichotomy that Hogarth has presented in 1751 in his etching, Beer Street and Gin Alley. To give the grape its due, the transitions from the vine, to the vintner, and to the brandy-making monk, show the same declension from nutrition. Although the ancillary benefits of moderate use of both the fermented and distilled beverages are well attested, and though ethanol might very well "fire the imagination" to a degree that allows the drinker to devise new ways to obtain nourishment, ethanol itself will not a fuel a cellular process. It does not enter into the pathways on any one of the three metabolic options: the anaerobic oxidation of glucose, the aerobic oxidation of the glucose metabolite, pyruvate, or the beta-oxidation of lipids. Furthermore, ethanol does not bring any nitrogen-rich amino acids to table, so it does not help the cells build proteins.

A bit of truth, however, survives in Faulkner's reply to Hempstead. Faulkner was no biochemist, but he was a "high-priest" of fiction, and he offers Hempstead words of "de-institution" in a joke that functions as a ruse rather than a rubric; words that unsubstantiate Hempstead's "matter of concern" by transubstantiating Hempstead's words into an "object" of a joke. Faulkner, even as he deflects attention from his plight with his evasive move, invokes a truth that transcends the distortion of the facts. Ethanol and carbohydrates - though not the same -- are indeed linked, both in the interface of zoology with botany and within human agricultural societies. Faulkner's quip may use humor as a psychological defense that works well to leave even the science-savvy 
listeners diverted by laughter, but the sotted writer unwittingly veers into the origin of primates' use, abuse, and avoidance of ethanol.

Grace Paley tells a lovely and hilarious tale of eccentric people, their pursuit of science, and their human foibles in her story, "In Time, Which Made a Monkey of Us All." Though alcohol does not play a role in that romp, the best way to consider humanity, alcohol, and writers, is to take our cue from her riff on Charles Darwin. More than Bloom's Shakespeare: The Invention of the Human, therefore, we will need to consider Darwin's On the Origin of Species.

Though humans did not "descend from monkeys," all primates descend from a common ancestor, and tippling humans wind up, at times, looking more like their tumbling monkey-cousins than they would like to admit. Vice versa, monkeys begin to behave more like stumbling humans than they otherwise would when they come into close contact with human agricultural economies. We can look to monkeys to find ourselves. Like monkeys, we, as a species (though not uniformly as individuals), will seek both fermented and unfermented carbohydrates. As will be made clear below, alcohol is a marker for locating nearby sugar, a simple carbohydrate. Sugar is a highlyvalued biochemical nutrient, and predictable access to nutrients -- both for individuals in a species and for the species that comprises them -- increases probabilities for reproduction and survival. When primates increase repertoires of behavior that increase control over nutrition, the adumbrated behaviors which create the greater probability for nutrient-access become, at some level, "attached" to the behaviors associated with approaching -- or avoiding -- ethanol. This attachment may occur by learning within the individual's lifespan (a change registered in neuronal changes within the individual) or by 
polymorphic genetic selections that span many lives (changes registered in alleles of the DNA within a species that are not uniform to all members) or by the impress of environmental contingencies that guide the expression of genetic material within individuals (changes that are only recently being clarified by the rapid rise of epigenetic science).

Just as alcohol is proximate to nutrition, creativity becomes proxy for both, and alcohol can become either an avenue or an impediment in the pursuit of the other two. For example, just as some humans will forgo food to pursue alcohol, some artists will forgo food in pursuit of creative work. The fuller reality is that this tendency is an exercise in mathematical permutations, where we find three variables - nutrition, intoxication, and creativity -- each taken two at a time, with order being important. Order matters because the operations take place in linear time, imposing order irreversibly. There are six possible results. Not each possibility, however, holds the same probability, because each variable carries a certain "weight" and the weight is not uniform for all members of a species. Human primates present themselves as the most complex and fickle of all primates in this triad relationship of food, alcohol, and art. They have devised highly sophisticated behaviors that yield considerable control over methods to extraction of all three target variables from our environments' contingencies, and each of the target variables has many varieties of choices (i.e. many kinds of food, many kinds of drink, and many kinds of creative behavior). Since the three variables of the basic permutation are subject to differently weighted constants, a resultant for one person (or cadre of similar persons) may end up as nearly deponent (i.e. - having no power; fallen out of use) while for another individual (or cadre of individuals) it may have high value. 
Behaviors that appear irrational at one level of observation (perhaps, for example, drinking alcohol rather than eating) may be found to have a reasonable explanation at another level of observation (increased creativity secondary to alcohol consumption might earn high social status and thereby allow the drinker more access to eating). In a complex society, this leads to the conundrum that both observations can be simultaneously true even when antithetical. This is particularly true when the proxy variables such as "creativity" and "social status" gain such heavily weighting coefficients that they eclipse the foundational survival-benefit of the variables from which they first derive "meaning." Before we can parse such complex organizations, however, we need to start somewhere simpler.

The green vervet monkey colonies on St. Kits in the Caribbean provide a natural laboratory for studying primates, alcohol and sugar. Abstracted from Africa to the New World and the island's sugarcane monoculture during the Middle Passage trade, the monkeys are now surrounded by a year-round tourist industry that leaves the unattended alcoholic cocktails and sugar-sweetened sodas at the beach-resorts easy targets for theft. In the days before tourism, the ripening and rotting sugarcane in the fields gave them a year-round access to both considerable ethanol and a surfeit of sucrose. These monkeys have it "made in the shade," and the vervets' actions in such an environment show what happens when a primate species is exposed to constant supplies of both unfermented and fermented carbohydrates. Regarding ethanol, the vervet monkeys divide themselves quite neatly into categories of the Abstainers, the Partakers (moderate-to-abusive drinkers), and the Taken-by (i.e. - addicted alcohol drinkers), yielding percentages that parallel closely what is observed among humans, though the dividing line between 
alcohol abusers and alcohol dependents remains hotly contested. For the St. Kits vervets, about $17 \%$ meet the Diagnostic and Statistical Manual IV - TR criteria for alcohol dependence, about $32 \%$ for alcohol abuse, and the remainder either very moderate samplers of ethanol or complete abstainers. Prospective, controlled studies of vervet subjects which have been taken from the wild, placed in caged settings, and then provided access to carefully measured quantities of ethanol and sucrose have confirmed the natural laboratory observations on percentage divisions (Ervin et al. 1990).

Humans measure out similarly. As a comparison for drinkers in the United States, the top $10 \%$ drink over one-half of all alcohol consumed, or the equivalents of ten drinks per day. That number is "of drinkers," not of the "whole population" from who the $30 \%$ abstainers are excluded from the calculation (Saha et al.). As another way of depicting the profoundly skewed distribution of alcohol consumption Christopher Ingraham has provided his article Washington Post article with a bar graph where the Xaxis divides the population into ten deciles and where the $\mathrm{Y}$-axis registers the average number of drinks per week. The graphic representation of the human data shows that the consumption curve rises exponentially from flat zero drinks per week for the bottom three deciles, and very slightly climbs from 0.02 drinks to 2.17 drinks per week for the next four deciles (we have now covered $70 \%$ of the population) and then zooms up as follows: 6.5 drinks per week at the eighth decile, to 15.28 drinks per week at the ninth decile, and 73.85 drinks per week at the tenth decile (Ingraham). If we reach down from the tenth decile and dip into the ninth decile of the population to pick up the other $7 \%$ of heavy drinking humans needed to match the reports of $17 \%$ of drunk monkeys, the humans who drink four to ten drinks a day are now seen to consume more than three- 
fourths of all alcohol. This curve is not simply some "slippery slope." It is not even as mild as a ski jump. This graph looks like an Austrian luge course.

Studies in the neurophysiology and neuroanatomy of vervets and humans reveal another striking similarity between the two species. Subjects who show extremely pronounced attraction to alcohol share abnormalities in dopamine, a neurotransmitter crucial to pleasure-reward pathways that link midbrain regions to the frontal cortex. The neurochemical dice in this brain-game of probability are differentially loaded within both populations (Mash et al. 1996; Goldstein and Volkow, 2011). This group difference within Homo sapiens goes far in explaining why learning the "habits" of addiction (whether for alcohol or other substances) is intrinsically easy for certain subjects and why "unlearning" those habits for those same subjects seems nearly impossible by recourse only to the clinical application of psychology's principles, whether those principles be derived from psychodynamic theory, behavioral theory, or cognitive-behavioral theory. Alcoholic vervets would, presumably, also show similar recalcitrance if some aspect of their lives tried to nudge them into sobriety, but there is no indication that concerned vervets are motivated to arrange "interventions" on their drunken peers.

Vervets and humans, in fact, differ distinctly in the long-term social-tolerance the bulk of each species shows for the small minority of persistent drunkards. Vervet troops not only install their emerging drunks as leaders; they also keep them in leadership positions for life. They do not depose them in the manner humans eventually will "fire" their drunks (BBC Worldwide).

I offer the observation that we humans follow a three-stage pattern regarding our aberrant drinkers. First, we value them highly. The example of "frat-boy" antics that 
earn the drinker high-status on campus easily come to mind. It is a type of idol-worship which often matures into admiration for the "man who can hold his liquor," and it even has extended to an admiration of assertive women professionals who "can drink the men under the table" as socialized gender inequalities have lessened. Second, we begin to move to a stage that mixes emotions of concern with emotions of exasperation, a situation that engenders emotional ambivalence and leads to an expression of tolerance, but not endorsement, for the aberrant drinker. The cognitive parallel to our mixed emotions entails mixed thoughts: "this must be my fault," "they are really misunderstood," "They can stop if they want to; they just are not trying," "it's not so bad all the time," and so forth. The behavioral mix that accompanies this mixed-up second stage sends mixed signals: direct confrontations, directs pleas, and direct ultimatums are emitted, while, at the same time, excuses to others are voiced, strategies to limit the drinker's access to alcohol are launched and liquor stockpiles are poured down the drain. In that stage we often retain in leadership the aberrant drinkers who can successfully "rein it in" or demonstrate abstinence when their drinking has interfered sufficiently with our lives, or we may retain them even as heavy drinkers as long as we continue to garner from our aberrant relationship with the drinker some secondary gain that is not yet fully eclipsed by the drinker's aberrant relationship with alcohol. Third, and finally, we often dismiss the non-reformed drunks from leadership at some point in their alcoholic careers. Here, though, we will consider restoring them to "Admiration" status if they, too, demonstrate a new approach to leadership; one that has no aberrant drinking. This shift within the third phase even presents a conundrum. The "reformed" alcoholic who is "restored" to status may end up with a higher status when compared to the naturally 
abstinent members because his or her narrative has demonstrated all the traits of a good story: a character with a character flaw, faces problems, engages actions, and arrives at the end of the tale with a "win." Everybody loves a winner, and no character can rightfully "win" without that agon. This is the story of the Prodigal Son; which is also the narrative of the Obedient Son who does not get a party; nor his name in the title.

I now turn to evolutionary theory's insight concerning adaptive advantage to explain both the similarities and the differences which vervets and humans exhibit in regard to leaders who are aberrant drinkers. I find two orthogonally related (i.e. "at right angles," the way the $\mathrm{X}$ and $\mathrm{Y}$ axis in a Cartesian coordinate plane are related) dimensions. Each dimension is blocked into three divisions. The vertical dimension shows the three levels of drinking behavior (the abstinent, the partaking, and the takenby). The horizontal dimension shows the three attitudes or positions others take in response to aberrant drinkers (admiring, tolerating, and rejecting). Cross-multiplication of the two dimensions will create a complex $3 \times 3$ matrix of possible combinations at any sampled time. Changes in the contingencies of the environment across time can alter a value in any matrix cell (See Table1).

\section{PRIMATE RELATIONSHIPS}

To Drinkers

Admiring Tolerating Rejecting

$\begin{array}{ccccc} & \text { Abstinent } & 1 \text { or } 0 & 1 \text { or } 0 & 1 \text { or } 0 \\ \text { To Drink } & \text { Partaking } & 1 \text { or } 0 & 1 \text { or } 0 & 1 \text { or } 0 \\ & \text { Taken-by } & 1 \text { or } 0 & 1 \text { or } 0 & 1 \text { or } 0\end{array}$

Table 1 
The matrix-cell values are dictated by the contingencies in the environment, and contingent probability of acquiring nutrition for those who are Abstinent and Partaking will shape their behavior choices (i.e. Admiring, Tolerating or Rejecting) regarding those members who are in the Taken-by set. If the contingencies for nutrition-access never significantly change, matrix-cell values that have been selected by the long-game of evolution will persist. In fact, even when contingencies toward nutrition do shift across a generation or two, the strong impress of genetically-preserved, evolutionarily-prejudiced behavior repertoires which have been encoded in a species' genetic polymorphisms over thousands of generations can hinder what would seem to be a rationally-determined need to relearn relationship behavior, whether that problematic relationship be "with the drink" or "with the drunk." Not surprisingly, the contingencies within human social environments are considerably more complex than contingencies within vervet social environments, regardless of where the monkeys found. That is, whether they are 1) in their original habitat in Africa or 2) in the novel free-range habitat in St. Kits or 3) in well-controlled experimental habitats created by human researchers.

In their original African habitats -- areas that had not significantly been altered by human agriculture and industry - vervet monkeys would only find fermenting fruit once a year for a few days only; perhaps twice a year in certain double-fruiting zones. These ethanol-enriched fruits are usually found on the ground. There they were easy-pickings for any primates which have learned to come down from trees. The distinction between exclusively tree-dwelling primates such as orangutans and the ambi-environmental (tree and ground) primates such as the ancestors of vervets and humans appears to be crucial, for a recent study shows that a particular alcohol dehydrogenase enzyme that is common 
and in large concentration in the ambi-environment primates is entirely lacking in orangutans. The behavioral observation that correlates with the biochemical finding is that orangutans do not desire ethanol when it is available, and they do not tolerate its effects when ingested. (Zolfagharifard.) These natural laboratories offer insight both into the differences between primate species (orangutans and vervets, for example) and within species (alcoholic humans and moderate drinking humans, for example.) The exclusive tree-dwellers do have some variants of alcohol dehydrogenase, but those variants are not as efficient as the type that marks we who have come down from trees. The orangutans have, as in the Goldilocks fairy tale, a "just right" enzyme complement to deal with the trace amounts of ethanol that show up in ripe fruit that is still hanging from the limbs, and their ancestors either experienced no shift in environmental contingencies to "shove" them out of the trees in search of food, or, if they had reached the ground, some other contingency change "lured" them back exclusively into the trees in the manner that land mammals returned to the sea to become cetaceans. The direction of the mechanism is not important as long as the process of evolutionary selection has ample time to adjust the species' biochemistry to fit the environment. If you are a tree-dwelling primate who depends on constant, exquisite coordination of your own limbs to move from tree-limb to tree-limb, it is presumably good that your biochemistry and the surrounding botanical food supply coordinate with each the other so that you do not get drunk and fall out of your trees. The risk-versus-benefit of intoxication is quite different for exclusive tree dwellers than for those who can accommodate the contingences of ground-level existence. The process of evolution has had time to refine the tree-dwelling primates and tree-ground dwelling monkeys in ways that maximize benefits and minimize dangers of 
drunken behaviors. Human civilization has not had the advantage of evolutionary time to get to a point of "just right." We seem sentenced to a concocted mix of slurred denials, failed breathalyzer tests, DUIs and court-mandated treatment.

A corollary to the Goldilocks notion of "just right" drives a basic dictum of toxicology: any substance, in sufficient quantity, is toxic. This truth includes required substances (water and oxygen, as examples) and ancillary, equivocal substances. Ethanol is of the latter sort. All liquid suspensions of carbohydrates will have some minor oxidation product as ethanol. If our bodies were equipped with a sufficiently high quantity of the few basic enzymes (especially the variants of alcohol dehydrogenase and aldehyde dehydrogenase) already found in our gut-linings and livers, as well as the amplification of some other sophisticated mechanisms called peroxisomes and cytochrome P450's, achieving intoxication even after taking high alcohol concentrations would be impossible because the alcohol would be quickly rendered into water and carbon dioxide minutes before any ethanol molecules ever has a chance to tease our brain cells. Such efficiency would even rob the Porter of his joke about excess urine because there would be no significant effect on the back side of the pituitary gland, the brain area which stores the vasopressin hormone that superintends how much water is allowed to leave the blood stream for the bladder. In such a hypothetical situation, the kidney filtration rate engendered by a tumbler of rum would be about the same as for a glass of water.

Nature, however, does not like to spend expensive amino acids needlessly, and enzymes are proteins crafted from those nitrogen-rich gems. If we imagine the longgame of evolution as a twenty-four hour day, the equivalent behaviors of holding "tail- 
gate parties on game-day" have only emerged in the last few seconds before midnight. From the perspective of evolution, agricultural civilization instantaneously changed the contingencies for humans' relationship to alcohol. This abrupt change in behaviors that extract carbohydrates from growing plants is not quite as dramatic as the way we have burned up in only 200 years the fossil fuels which had stored millions of years of solar energy, but the two trends are in nearby exponential ball parks. Before the time this spectacular display of human inventiveness, ingenuity, and creativity in agriculture changed the rules, a modicum of detoxifying enzymes did well-enough to handle the constant, trace amounts of ethanol found in fruit and wet grains, and the body was even somewhat forgiving of the short periods when that easily saturated enzyme system was subjected to the small bursts of excess ingestion allowed by seasonal fermentation.

Where we now stand (or stagger), however, ethanol and its metabolites are not gentle chemicals in cases of constant exposure, though some bodies have greater tolerances than others. These differences are attributable both to intrinsic causes and to acquired causes. Ethanol itself has both toxic effects (tissue-damage potential, severe disturbance of electrolyte balances, and the potential for suppression of central nervous system respiratory controls) and intoxicating effects (the enhancement of certain brain functions including heightened mood and pleasure). These effects overlap to some degree.

As a rule, alcohol's extremely acute toxic effects of that can result in sudden death require a rapid consumption of highly concentrated ethanol by a subject whose body is naïve to alcohol. Examples, unfortunately, crop up in undergraduate Freshman Week parties. The alcohol-naïve young adult with a blood alcohol level (BAL) of .42 
can easily end up in the morgue while the chronically alcohol-experienced peer with a BAL of .42 can be astoundingly articulate, ambulatory and complaining to the Emergency Department intake worker that this latest binge has failed to bring a sufficient "buzz." The advancement to this latter extreme requires both large-dose exposures over extended time and some foundational (i.e. - pre-exposure) differences in neurochemistry and somatic physiology. The acute intoxication effects are observed at relatively low levels of consumption and also with low concentration doses. Here again, the greater effect of intoxication is also seen among the naïve drinkers when compared to veteran drinkers. The chronic, toxic effects of ethanol ingestion are quite different from the acute, toxic effects, with some subjects more easily affected by hepatocyte (liver cell) damage, secondary to lipid peroxidation, and with some subjects more easily suffering neuronal damage that manifests as dementia. Behavioral changes secondary to intoxication can also present dangers for the intoxicated subject and the probability of dangers varies greatly with the environment. Subjects who become so intent on alcohol consumption that they neglect to eat foods with thiamine can inadvertently create neurological damage if they eat a meal rich in carbohydrates. Subjects who consume other psychoactive substances in tandem with alcohol can potentiate fatal reactions. Cocaine and alcohol, for example, conspire to make a metabolite that acts like the parent cocaine molecule but which stays in the body several days longer. Alcohol in the presence of opiates or barbiturates can suppress the respiratory centers of the brain, causing death. With less potential, the same problem has occurred when alcohol is paired with benzodiazepines - medications such as Xanax and Valium. 
Despite the real dangers presented in that bleak and clinical review, most humans who have a taste for ethanol (though some do not care for it at all) can imbibe the chemical with impunity and with sufficient auto-regulation of both rate and quantity so as to enjoy the gift and to avoid the disaster. They are not entirely immune from problems, but if problems begin to emerge, they have some meaningful chance to correct behavior. Some drinkers do not have such control, either for moderating episodes or for a sustained abstinence based simply on solo efforts to weave a safety net from affect, cognitions and behavior. The explanation as to why some would be bereft of control is quite simple if considered from the vantage point of millions of years: why would the process of evolution universally bestow all of the "expensive" biochemical equipment for internal damage-control into a species when the control was always "presumed" to reside in the climate, seasons, and botany of the environment? Such action makes no more sense than would be the building of screen doors in Antarctica or coal furnaces in Tahiti.

A tantalizing question remains, however: what was the adaptive advantage bestowed on the few individuals who, even in the environments with heightened external restrictions on an alcohol supply, would go for it double-fisted? An answer is proposed further along in this discussion, but arriving at it requires a bit more meandering through the maze of some amazing physiology.

The basic biochemistry that has sufficed for most primates throughout time is fairly well known, and some attempts to intervene at this molecular level to correct aberrant drinking have been offered. After ingestion, ethanol is detoxified in a four-stage process before it is safely dismissed as water and carbon dioxide. Each detoxification depends on its own category of enzyme, and each category of enzymes can have subtly 
different variants that demonstrate different affinities for the substrate molecules and different efficiencies in action. Similarly, variances in neuronal receptors and the intricacies of the neurotransmitter management systems make for differences in how ethanol is subjectively experienced. Alcohol dehydrogenase starts the cascade, turning the alcohol into an aldehyde. This product, by processing through aldehyde dehydrogenase, must then be turned into acetate, and if some problem holds up this stage, the mammal becomes very ill. Some human populations, especially from Asia, are deficient in the aldehyde dehydrogenase needed for that step in the detoxification. A build-up of aldehyde prompts severe nausea, vomiting, and skin flush. A common antibiotic, Flagyl (metronidazole), will interfere with the enzyme to cause some of those symptoms, prompting the pharmacist to label the pill bottle with the warning that the patient should not drink alcohol.

Another medication, Antabuse (disulfiram), blocks that enzyme even more forcefully. The latter drug has been used in aversion therapy for alcohol dependence where it serves as an operant-conditioning "punisher" after alcohol consumption. Logic suggests that the aberrant drinker will take disulfiram daily and will then refuse alcohol because of a learned aversion to the dysphoric consequences. An observed learningparadigm does emerge; but usually not the one intended. In most cases, the patient learns to avoid the Antabuse. In some cases an alcoholic will drink alcohol even in the presence of Antabuse, knowing full well the misery that will ensue. Such a result shows that, for some humans, excess alcohol consumption is not amenable to simple behavioral treatment (i.e. - the application of punishers) even if the drinking behavior of drinking is amenable to behavioral explanations (the presentation of reinforcement). As it turns out, 
the same humans are also resistant to sole interventions that are proposed by cognitive behavioral theories or by psychoanalytic theory (including the derivative ego psychologies) even though those theoretical models may actually contribute to understanding of the cognitive schemes or the developmental trauma that are concurrent with the problem. In short, it is easier to generate reasonable descriptions of the problem from several different theoretical perspectives than it is to remedy the problem primarily out of any of those perspectives.

All brains are not the same. Besides possible dysphoria, ethanol also spawns a mix of euphoric and sedating effects, and that mix is a not a universal experience, despite the Porter's speech in Macbeth. Genetic differences, for example, dictate a difference in sensitivity to inhalation anesthesia in order to "put the patient under," with redheads requiring more than others (Liem et al). Operating room nurses had long reported their anecdotal observations of this phenomenon, and that controlled, prospective study has corroborated their hunch. Whether the genetic variant underlying this phenomenon is directly "caused" by a difference in melanin production, or if it is "correlated" to the difference is not known. What is known is that redheads are not light-weights in the surgery suite. This finding makes it possible that the anecdotal reputation for Irish excess in drink may not be a mere myth; it may be as valid as the Emerald Isle population's increased probability of neural tube defects, such as seen in spina bifida (Fisk-Green $e t$ al., passim).

For the majority of people who drink some alcohol (not to be confused with the minority of people who drink most all of the alcohol), the sedating effect of ethanol is felt strongly and quickly. Those drinkers will decide to stop drinking early in an episode, or 
drink very slowly in the episode, or pass out quickly in the episode. These drinkers who sedate well are, frankly, the most "normal" when norms are measured by math. They are the much-more frequently encountered subjects, and they earn the reputation of being "light weights" and who are described as "can't hold their liquor." The heavy drinkers who keep on walking and talking despite heavy intake are really the abnormal drinkers, although when they finally do succumb to the sedation, they are very deeply sedated. They are also prone to amnestic episodes (blackouts) of the ambulatory period prior to sleep: other people have to tell them what they did last night. Similarly, drinkers report highly-varied experiences regarding the dysphoric effects from ethanol such as ataxia, nausea, and vomiting (acutely) or dehydration headaches (post-acutely) and chronic gastric changes (chronically); and they interpret differently the psychological dysphoria from loss of social position (jobs, careers, marriages, etc.). In cases where the drinker is sensitive to dysphoric effects, the recourse to psychology, especially behaviorism and cognitive behavioral theory, has efficacy for both explaining the problem and for correcting the behavior. For other drinkers, however, the pleasure-reward pathways involving the neurotransmitter dopamine can be of such power that pleasure-seeking will override avoidance of dysphoria, especially when sedation fails to put the drinker to sleep.

The balance between the somatic experiences of euphoria and dysphoria has a counterpart in the balance of risks-versus-benefits as dictated by the external environment. When environmental contingencies directed some primates to take up partial ground-dwelling and left others only in the trees, the risk-versus-benefit of intoxication changed. It should be noted here that the orangutan's predecessors may have 
been on the ground with the same ancestor of humans and vervets, and that subsequent contingencies in one geographic region may have taken them back into trees exclusively, a shift analogous of cetacean predecessors, land mammals, which returned exclusively to water. The important ingredient for such radical adaptation is that there be sufficient time for the genetics that drive the physiology to change in accord with the habitat's contingencies. Regardless of the order of those events, under certain conditions being drunk might be for the individual less of an "occupational" hazard and perhaps even an "occupational" asset, while simultaneously offering a "net gain" for the rest of the species. Under other conditions the same behavior may be a detriment to both individual and species, or it may be good for the individual and bad for the species, or bad for the individual and good for the species. Evolution will always "ring the changes" on chance.

For vervets, the first situation ("win-win") seems to apply. The vervets that strongly ingest alcohol in preference to simple unfermented sweet drinks exhibit ataxic gaits and excess vocalizations, behaviors that are easily observed by all others and which become "signals" that are easily associated by social-learning mechanisms to indicate that the drunk-monkey has located, by proximity, a food supply. In so many words, even the Abstainers will say (if monkeys could talk), "Follow that crazy guy. He hangs around where carbohydrates are hanging around."

This notion of signal-association extends Robert Dudley's evolutionary theory of "ripened fruit" to explain human alcohol consumption, a theory he bases on historical ecology. Douglas Levey opposes Dudley's “ripened fruit" interpretation and suggests that humans accommodated to alcohol because of "food preservation by alcohol," a phenomenon that would increase available calories. Although Levey recognizes the 
proximate relationship of alcohol and nutrition, the obvious problem with his theory is that vervet monkeys do not preserve food. Primates were getting pickled long before they learned to pickle. Dudley wins this round (against Levey, at least) because his argument explains temporal primacy and also allows for generalizability across related species, both of which are necessary, though not sufficient, components to build an argument for causality. The triad, "motive, means, and opportunity," holds sway in detective fiction and scientific reasoning, even if the terms are slightly altered. I am convinced that Dudley's "ripened fruit" hypothesis has answered all three, but confirming work using controlled experimental conditions can probably never be made, if for no other reason than scientists do not have the ability to replicate the time spans required to track evolutionary change.

Dudley's reasoning allows a hypothesis that explains how humans are like vervets regarding alcohol consumption. Now, however, we are faced with answering the question of why humans differ from vervets regarding response to alcohol consumers. Given that growing-seasons limited the opportunity for intoxication to only a few days a year, even stumbling-drunk monkeys could not become "chronic alcoholics," so it is pretty easy to understand that there was also a time in human social development when the exact situation obtained: there was not enough alcohol available to let any human develop a full-blown case of alcoholism. The question of how to respond to a chronic drunk was not even a conceivable question to ask. It would be like a community asking itself how it should handle a member who levitates in the air for ten minutes with each leap. Earth gravity does not allow it. 
In settings where vervet monkeys can take advantage of humans who concentrate, store and ferment carbohydrates, the drunk-prone monkeys, however, will become "prone drunk" monkeys; or perhaps supine, as noted from the videos of vervets in St. Kits (BBC Worldwide video). A minority group of those monkeys become and remain chronic alcoholics, yet the alcohol-abstinent and normal-drinking vervet monkeys treat these drunks in one single and consistent way: they continue to value them as leaders. If we refer back to the matrix Table 1 and choose numbers, it is clear that vervets keep the values in Column 1 (Admiring) at " 1 " all the way down, and columns 2 and 3 have only "0." Those last two columns are moot for monkeys, and they are essentially "erased" from the table. The table becomes a simple column of "Admired by all." The monkey allegiance to admiration persists, presumably, because even when the sentinel-behavior function of the alcohol-obsessed monkey is rendered pointless by a hugely ample and constant carbohydrate supply in the environment, the drunken behavior of the alcoholobsessed monkey does not significantly compromise other survival-benefit contingencies in the environment. The vervet social structure does not require complex, fine-tuned and consistent interactions such as showing up to work on Monday mornings, driving automobiles, cooperatively superintending child-rearing tasks over fifteen year spans, or meeting a publisher's deadline. Nor do some monkeys pay for other monkeys' hospitalizations for illnesses secondary to alcohol disorders.

All the vervets ever "needed" from the leaders in a pre-agricultural environment was for the sentinel behaviors of intoxication to emerge a few days at a time. They also only "needed" them for a few years because other sentinels would certainly be born into the troop to take up the task. Beyond the emission of the signal, the length of the leaders' 
drunken binge is irrelevant as long as the leaders' drunken binge never excessively complicates the lives of the others. The majority members do not care if the drunken leaders have livers that grow fatty or cirrhotic as long as the leaders stay out of the way of nutrition-access and allow the followers a reasonable shot at desirable mates. From the perspective of a vervet majority in St. Kits, the drunken minority are not free-loading off the majority because the drunks are not trying to compete for the unfermented sugar which is ample supply regardless of the drunks' activities, nor do the drunks demand that the majority divert energy (always measured in terms of calories) to the care and maintenance of the drunks. It is like watching the British population's continued loyalty to the royal family, an institution which became relatively irrelevant to the creation of the enormous wealth of Empire as the nation transitioned from mercantilism to full blown capitalism. The conditions in France in the late eighteenth century and Russia in the early twentieth century were not so similar to those in Britain, and the royal leaders in those two continental nations not only failed to escape a benign reduction in estimation to become simply "vestigial" or "deponent," they attracted violent opprobrium and attack. The British had already had their spate of regicide under Cromwell, and they then accommodated themselves again to a benign indulgence of a mostly-pointless royal privilege with Charles II. Some small British irritation with the Royal family barely managed in the twentieth century to exceed the level of ridicule, such as with the Canadian wags who changed "God Save the Queen" to "God Shave the Queen," and altered lyrics to rhyme, "Send her to Halifax! Make her pay income tax!” Ruling individuals might die easily from blade or bullet, but ruling institutions die hard despite any rational analysis of all the evidence. 
Although some humans actually do get a bit altruistically concerned about the livers - and therefore the lives -- of their drunk friends and relatives, the greater reality is that humans do not put up well with the drunk's behavior when the behavior diminishes payoff on the deals previously made with the drunk, or when the behavior interferes with the non-drunk majority's ability to seek payoff from other relationship ventures. Though we use our drunks indefinitely when they benefit us, and tolerate them for considerable periods while they pester us and muddle up our other interests, the discernment process for determining risks and benefits is a tug-of-war. Indecisiveness as to when to stick with them, when to cut-loose from them, or when to trust them once more, creates many options for all three columns of Table 1. This array would be complex enough if we were only coldly rational in our calculations; i.e. only working off our considerably large cerebral cortices. But we are still primates, and evolution has loaded our limbic systems with the same attachment that governs vervet monkeys in Column 1. Humans are certainly more than monkeys, but we are not less than monkeys. Looking again at Table 1, we humans can have either 0 or 1 in any of the cells in any of the columns at any time, depending on the complexities of our rational economics and on the intensity of our own primal, primate bonding.

It is not surprising, then, that the writers who review the history of alcoholism by whatever name it might be discussed (i.e. chronic drunkenness, inebriety, dipsomania, etc.) have placed the origins of public acknowledgement of alcohol as a "matter of concern" around the end of the eighteenth century and the beginning of the nineteenth century. Prior to that time conversations about drunkenness might emerge in certain constrained settings of religion, but it was, at most, a subtype of gula, or gluttony, in the 
Western cannon of the Seven Deadly Sins. Dante finds no specific drunks in the Third Circle of Hell, for example. Rumblings from England and John Wesley in the eighteenth century had begun to draw attention to drunkenness as a problem, but the religious discussions in the United States only abruptly changed in the course of the nineteenth century. A particularly telling point emerges in the case of bourbon. Whether or not the story that it was first distilled by a Baptist minister, Elijah Craig, is apocryphal or historical, that man of the cloth was certainly a man of the mash, and he opened a distillery in Bourbon County, Kentucky in 1789. Social opinion of the time found nothing contradictory in his two roles of preacher and distiller. Within fifty years, however, abstinence from all alcoholic drink became a marker of Baptists' practice, grape juice replaced wine in communion, and contorted interpretations and translations sought to bowdlerize the Bible when the Greek word for wine was found near Jesus' lips. Perceptions, replete with this new deception that oivos when in proximity to Jesus, John the Baptist, the disciples, or the apostles, could not have meant fermented beverage. Perceptions changed radically in a very short time-span and distortions emerged.

The change in perceptions paralleled a change in consumption. William White summarizes the numbers:

Between 1790 and 1830, America fundamentally altered its pattern of alcohol consumption. In 1792, there were 2,579 distilleries in the U.S., and annual per-capita alcohol consumption was 2 1/2 gallons. In 1810, there were 14,191 U.S. distilleries, and annual per-capita alcohol consumption had risen to more than 4 1/2 gallons. By1830, annual per-capita consumption had risen to 7.1 gallons of pure alcohol per person. Problems of public drunkenness and disorder, and the impact of drunkenness on family life, intensified in the midst of this collective spree.

The growth in America's alcohol-related problems stemmed, in part, from changes in availability and taste for particular types of alcoholic beverages. Most important was the shift in consumption from beer and wine to distilled spirits. The 
drink of choice was whiskey, and Americans were consuming it in unprecedented quantities. It was potent, cheap, and highly portable. (5)

John Crowley's number for 1830 is slightly discrepant to White's, but Crowley was writing in 1994 before White's book appeared in in its first edition in 1998 and long before the 2014 second edition which stands as the single, most-thorough review of the literature to-date. Crowley leans heavily on Rorabaugh's 1979 work, one of several studies of alcohol in society that applied cliometrics heavily in historiography. Of interest, however, is that Crowley notes consumption quantities with a comparison, "[A] staggering peak in 1830 of four gallons per capita (more than double the current level.)" Whether the figure for 1830 was four gallons or 7.1 gallons -- and I side with White's more recent source research and with the higher number -- the amazing aspect is that the "current level" of the early 1990's level as cited by Crowley would have been "only" around two gallons per capita. Although increased ease of access to large quantities of alcohol, and increased strength of dose per drink, is arguable a very strong variable in the rise of chronic, intoxicated states and frequency of acute intoxications, there must be other variables at work to explain the change in perception of a problem.

White lists other changes in variables that were concurrent in the early 1800's:

A new type of drinker and a new drinking institution emerged in the 19th century. New immigrants, industrialization, and the movement into the Western frontier had all served to create a class of American men who organized work life and leisure time around drinking. These men were virtually alone, unencumbered by duty to family or enduring community ties. America's changing drinking rituals were also reflected in the evolution from the tavern to the saloon. The tavern had been the center of village life, but the saloon-associated with violence, crime, vice, and political corruption-now emerged as a threat to community life. (6)

The key words, which are easily recognized as the catchwords, are "industrialization" and "leisure time." These concepts are the markers for an invading, advanced capitalism that 
was displacing older values ("duty to family or enduring community ties") with the new values of duties to employer and an infatuation with mechanization, whether that be the impress of Eli Terry's 1816 mass-produced box-clock made parts stamped out by steam power, the steam powered river boats that took the clocks to market, or the steam locomotives that would soon distribute the clocks across the continent. The contingencies of the human environment were rapidly changing; so much so that an average consumption of 2.5 gallons per capita in 1792 was not widely perceived as a problem whereas an average consumption of 2.3 gallons in 2009 is recognized as quite a problem (LaVallee and Yi). What Americans did in their leisure time increasingly became a "matter of concern" to an industrialized society as a whole as the intricacies of industrial capitalism made the coordination of interests increasingly important and mechanistic. After all, industrialized capitalism created leisure-time, so it had the "right" to supervise its own product. In fact, what people did with the very measurement of "time" became importantly shaped by the mechanization, power, and speed that river boats and railroads brought to bear on the contingencies of the environment. After Bessemer in 1851 patented a process for making dependable, strong, and cheap steel, dependable, strong, and cheap labor has to follow. It is not an accident that preferred metaphors for problematic people and relationships have to do with "a complete train wreck," "jumping the tracks" and "totally derailed." Steel rails standardized our time zones, and the derivative standards for maximizing profit ("you can set your clock by him") and minimizing loss (avoiding train wrecks, both literal and figurative) began to exercise influence everywhere. With clock-watching came bottle-watching, whether it be with a distinct lack of humor while still at work, or with the addition to the day of a 
"Happy Hour" after leaving work and before going home, implying that both the eight hours spent at work were more than likely sad and the impending four hours looming at home would not be much better. No wonder, then, that we have the drinker's joke, "It is five o'clock somewhere in the world."

An increasingly mechanized view of the exterior world that human bodies inhabited was actually somewhat preceded by an increasingly mechanized view of those bodies themselves. William Harvey's 1628 publication in Frankfurt of De Motu Cordis had already fundamentally changed the way medicine conceptualized the body by the clear description of the heart as a time regulated pump that conserved blood in circulation. Prior to that discovery, the presumption was that blood was expended on a daily basis in varied ways to create the "humors," and the heart was thought to be a place of hot combustion of blood. Suddenly two concepts that had ruled medicine since Galen were deposed. Although it would take decades for the conversion to have full effect, Harvey's work would not so much sever the notion of character traits (sanguine, phlegmatic, etc.) from the mechanics of the body as it would refine understanding and posit a linear causality (temporal arrangements in time) of symptoms secondary to a pathology of the mechanism. This shifts the explanation away from Galen's theory of difference of place (spleen, liver, etc.). Thomas Willis's 1664 work that showed the circulation of blood in the brain provided the logical bridge to the notion that if the heart pumps circulating blood, the brain might be an analogous "pump" for thoughts and behavior. The logical conclusion was that a disturbance in the body's mechanisms that related to place-and-time in the mechanism would be the explanation of disease, and that restoration of the well-working of the body must precede a correction of the disturbance. 
Increasingly, behavior could be explained by a flawed medical mechanism rather than by a flawed character. By the late eighteenth century the two sides of the Atlantic each spawned a disease model of alcoholism with the work of Thomas Trotter in England and Benjamin Rush in the United States (White 2-4).

As William White notes, alcoholism had been begun to be understood as a medical problem in the late eighteenth and early nineteenth centuries, then saw a return to moral fault or character failure model in the beginning of the twentieth century. In the United States, Benjamin Rush was the earliest physician to pioneer the notion that the problem is better addressed as an illness rather than as a vice. White has reviewed succinctly the many names applied to the varied phenomena characterized by excess alcohol consumption. The common term "drunkard" was applied to the person affected throughout the nineteenth century. One of the early (and surprisingly successful) movements, The Washingtonians, felt no chagrin in labelling themselves as such. A general term of "inebriety" in the nineteenth century was used to designate intoxication by any element, and specific agents would designate the source; in this case, "alcohol inebriety." The now popular term "alcoholism" was first advanced by a Swedish physician, Huss, in 1849. It took root in the vernacular lexicons in the first decades of the twentieth century at a time when non-professionals and entrepreneurs had a strong hand and interest in the problems (e.g. Richard Peabody and Charles Towns), but it gained professional cache with its adoption in 1908 by Karl Abraham, a psychoanalyst. The term thrived in both the lay and professional through the 1930's and was much bolstered in the laity by the publication of Alcoholics Anonymous in 1939 as well as by the proliferation of A.A. members. White notes, however, that by the 1940's the professional 
fields began to resist the term alcoholism (White 40). Faulkner's preferred term was "dipsomania," when writing about his characters in his fiction and that episodic, binge variant of the problem was particularly descriptive of his own pattern even when he denied it in himself.

The nineteenth century disease model, however, denied heredity as the origin of the disease. At that time the statistical predictability of even the simplest inherited traits was not understood. Gregor Mendel's wrinkled-pea results had not been published and the molecules of heredity as untwisted by Watson and Crick were unknown. Even Freud was Lamarckian rather than Darwinian in his science. "Heredity" was associated with "character," and since the disease model hoped to move away from explanations based on morality and bad character, the dominant nineteenth century disease-model eschewed heredity. As Joseph Blotner opines concerning the influences of the disease model on William Falkner's paternal grandmother, "Sallie Murry Falkner may have read Dr. Leslie E. Keeley's major work, The Non-Heredity of Inebriety, published in 1896, which held that drinking was a disease rather than a vice."

Current twenty-first century adherents to a disease-model are immensely puzzled by that quotation because the model now definitively couples the disease to heredity. This shift has occurred because the notion of pathology has broadened. The diseasemodel in the nineteenth century was one that might be termed "adventitious" or "infectious;" one where some agent is presumed to enter and disturb the organism. The microbial model had gained ground with Pasteur because he was able synthetically to relate the existence of bacteria and a rational application their presence to what was a major advancement in the ancient "humoral" model, creating the field that has become 
immunology. Just as one could inoculate against infection, some proponents of the ninetenth century disease model, therefore, proposed agents that would "inoculate" against alcohol. Dr. Keely made a small fortune with a patent remedy involving "double chloride of gold," and William Faulkner's grandfather and father both contributed their share of dollars to the business of his quack-cures when they were carted to the Keely Institute fifteen miles out of Memphis, Tennessee. (Blotner Faulkner, 2 Vols., 98-99)

The patent-medicine interventions were not the only nineteenth century efforts. Special long-term residences known as inebriate asylums (to be distinguished from insane asylums) were created, especially in the wake of the Washingtonian movement, the first mutual aid self-help approach to sobriety. These approaches emphasized "moral suasion" as the way to counter inebriate disease. But as Americans became increasingly impatient with the many failures of drunks to get sober, the Temperance Movement (which, as the name would suggest, began as advocacy for moderate drinking) turned to an agenda of blanket abstinence, a movement that culminated in 1919 with both Eighteenth Amendment as Prohibition and the Volstead Act as the means of enforcement. As White notes, "By the early $20^{\text {th }}$ century, optimism about personal reformation had faded and left in in its wake a more pessimistic view of the problems that the reform movements had promised to eliminate. Americans came to view addiction less in terms of disease and more in terms of defects in character and morality (41)." This period, of course, was about the time William Faulkner arrived in this world to leave his mark in it; and for the world to leave its marks in him. It would take another half century to recover a cogent medical model for alcoholism with the American Medical Association's determination in 1956 that it is a disease. E.M. Jellinek's 1960 book - though not 
without its faults - secured a solid place for the model with the title, The Disease Concept of Alcoholism. Now in the twenty-first century, the American Society of Addiction Medicine (ASAM) bluntly states in the opening sentence of the short definition, "Addiction is a primary, chronic disease of brain reward, motivation, memory and related circuitry," alcohol being one of many substances that can create addiction.

Throughout the nineteenth century the disease model was challenged at times, complemented at other times, on both sides of the Atlantic by an increasing confidence in will-power, dedication, honesty, efficiency, and progress; all concepts folded into a moral-competency model of humans and their behaviors. The inebriate asylums tended to allow a mix of the medical model and moral suasion. Not all proponents of a moralcompetency model of the human condition, however, felt that the competencies were evenly distributed across races, genders, and class. Gender differences in foundational character traits were emphasized, and social performance of gender role was expected to conform. Alcohol consumption increasingly became confined to men, a shift from the mid-eighteenth century patterns when women drank like men, as described by Rorabaugh and cited by Crowley. Hogarth's famous Beer Street and Gin Alley print appeared in 1751 in England and it highlighted the traditional value that good English ale promoted health and society while gin destroyed both. Although the women gin drinkers are depicted pejoratively, the women who are beer drinkers are wholesome. Similarly, the middle class of both genders are healthy and hale on ale, but the poor Gin Alley reprobates are, literally, poor. The picture of middle class health was the picture of acceptable drinking for women in colonial America where both gin and poverty were of less significance compared to London of the same year. After independence, and after 
Americans began their attachment to whiskey, stratification by gender emerged.

Likewise, stratification by class, began to emerge in the United States.

The masculinized and homosocial environment of the saloon solidified the emerging perception that whiskey was for strong men and bad women, especially as the saloon became one roof for the bottle and the bawd. Crowley has reviewed well the differential impact that views of masculinity and femininity had on the role alcohol played in the lives of male U.S. writers, but Faulkner is only mentioned in passing as one in a catalog of heavy drinking writers. In an unpublished dissertation, Conor Picken investigates the particular way Southern writers have wrestled with the masculine attachment to drunkenness in connection with a Southern region's attachment to drunkenness, and with each of those concerns manifesting a type of self-definition that renders the language of recovery as a metaphor for change for the region. He pays particular attention to Faulkner in these matters. Susan Zieger provides another insightful examination of the interaction of social attribution and gender regarding various addictions as depicted in British and U.S. literature. These studies shed important light on the way the social constructs of alcohol's acceptance, rejection, and tolerance are at least partially interactive with the social constructs of gender, class and region. Though a full review of the complexities falls outside the constraints of this project, the works by Crowley, Zieger and Pickens are much to be commended in this regard.

When we come to "the Falkners" (the father's and grandfather's spelling of the name) and "the Faulkners" (the spelling that came to dominate after William Faulkner's choice restored the $u$ to the name), the construct of gender and the sanctioned genderperformance roles shaped perceptions of drinking. The rule for white, Mississippi society 
of the late nineteenth and early twentieth century was that good women did not drink, real men were expected to drink, but gentlemen did not bring their drink into the presence of women, and women did not meddle in the men's segregated opportunities to drink. In the Falkner/ Faulkner case, these rules of division, however, were not well obeyed. Although homosocial male drinking was to be confined by men to their hunting and fishing camps, Maud Falkner (William's mother) would intrude herself at the "The Camp" specifically to keep an eye on her husband, Murry, and his aberrant drinking. Her action in those years was about as disconcerting as a woman entering a men's locker room and they embarrassed William Faulkner.

In an ironic twist of fate for Maud, she then had to deal at close quarters with a woman who did drink: William's wife, Estelle. The town's grudging tolerance of Estelle's drinking behavior probably had much to do with her high social status. She was, despite her divorce, of a prominent family and the daughter of Judge Oldham. Estelle's problem with alcohol again points up the complexities of the written and unwritten rules about drinking. She, unlike her husband, eventually found a way to sobriety, and her path to recovery in that mode began in the $1955 \mathrm{~s}$ in the program of Alcoholics Anonymous (Oates 288).

Donald Goodwin plays a double-role in the literature that explores the intersection of alcohol use, the medical science of heredity, and the risks for those of literary genius. Prior to exploring the microcosm of U.S. alcoholic authors in his book Alcoholism and the Writer (1988), a book that devotes much attention to Faulkner, Goodwin had examined a naturally occurring human "laboratory" for clues about alcoholism found in Denmark's superbly-kept health records. From these he constructed a retrospective study 
known as the Danish adoption study and he published the results in four major articles in The Archives of General Psychiatry from 1973 through 1977. His research, in tandem with that of others, appears in his book Is Alcoholism Hereditary? (1976, 234). His answer to the question on the title is yes, and the answer is compelling. Although he does not discount the claim that nurture can modulate the major effect created by nature, the evidence clearly indicates heritability of the trait. This evidence contradicts the medical understanding that had influenced Joseph Blotner as he researched his biography of William Faulkner:

All of Murry Falkner's sons drank, and to excess. Of the four of them, only Jack finally became an abstainer. Excessive drinking can often be a familial condition. It is not transmitted biologically; it is "passed on in the same way that money is inherited, not in the way that, say, eye colour is." In this case the means of transmission was only a technical matter. The inheritance was conveyed. (Faulkner 2 Vols..718; Quotation from Neil Kessel and Henry Walton, Alcoholism (Baltimore, 1965.)

Blotner's medical source, the Kessel and Walton textbook, was simply wrong. The inheritance pattern might not be as simply described as in the case of eye-color, but the mechanisms of both are essentially the same and vary only by degree of complexity, not the common source which is DNA. George Vaillant's forty-year longitudinal prospective study of two cohorts of men also finds that the strongest predictor variable accounting for the reclassification of certain subjects who "progressed" by age 60 from Class IV heavy drinkers to Class V Heavy Drinkers was "especially family history." As he summarizes, "Put differently, the 'loss of control' inherent in the clinical concept of alcohol abuse bore as strong a relationship to hereditary factors as it did to reported quantity and/or frequency." (Vaillant, 129.) The American Society for Addiction Medicine (ASAM) states "Genetic factors account for about half of the likelihood that an individual will develop addiction. Environmental factors interact with the person's biology and affect 
the extent to which genetic factors exert their influence [Emphasis in original]." The reality is that Blotner did not have the advantage of Goodwin's 1970's articles, much less the results of Vaillant's revised reports or ASAM's condensed understandings, at the time the Faulkner biography was being researched. Faulkner and his family certainly had no such benefit during their lives. Even Edward Khantzian, a preeminent psychiatrist who judiciously applies ego psychology to addiction treatment and who parses the preferences for substance in the pursuit of self-regulation, acknowledges that genetic factors (among others) “may either protect against or heighten a person's vulnerability to substance use disorders (46).”

The fact that Faulkner met all needed criteria to be classified as alcoholic (or, better stated, as alcohol dependent) is now patently obvious. Goodwin refers to the screening devise of four questions known as the CAGE as a useful tool for detecting alcoholism. A straight reading of Faulkner's life shows that, if he were to have been honest, he would have had to have answered "yes" to each of the four CAGE questions: 1) he had tried to $\underline{\mathrm{Cut}}$ back on drinking without success, 2) he became $\underline{\text { Angry }}$ when confronted about his drinking, 3) he expressed Guilt about his drinking and 4) he used Eye-opener drinks to get his day going. A score of 2/4 warrants a thorough evaluation; a score of 3/4 indicates an extremely high probability of alcoholism, and a score of 4/4 indicates a probable need for detoxification and a definite need for treatment. We know he had episodes of delirium tremens, he had seizures related to his use and cessation of alcohol, he had hiccups lasting more than 48 hours (another symptom of alcohol abuse), he had at least one gastrointestinal hemorrhage that nearly killed him in 1940, and he had the onset of blackout episodes, the amnestic periods when the drunk person is still 
conscious. He also had paradoxical episodes of perfectly accurate memory when full-on drunk, and he had post-acute withdrawal anxiety (a condition he called feeling his “doom" coming on).

Faulkner, indeed, had multiple inpatient admissions for detoxification in every region of the country where his writing took him. Paraldehyde was a common agent to replace the ethanol in detoxification, and Seconal (a barbiturate) was also used extensively. Even though other problems, including orthopedic injuries and arthritis, sometimes prompted physicians to write him prescriptions for opiate pain relievers, Faulkner showed a particular aversion to even minimal use of opiates. The prejudice against "dopes" (as opiate users were known) was particularly strong in the mid-twentieth century, a prejudice that even showed up early in the discussions and literature given out by Alcoholics Anonymous. Although Faulkner did not share A.A.'s view of his probable problem with alcohol, he would have been mortified to hear that he was, in all probability, polypharmacy-drug dependent the entire last fifteen years of life; perhaps the last twenty-five years. He probably had already met the criteria for Alcohol Dependent by age nineteen. The South's social convention of heavy drinking for its men and the medical source of his barbiturates, however, conspired to cloak a reality. Without a dependable record of his Seconal dosing (most of which were his own ad hoc use of the medication as a sleep aid) it is hard to determine how much his liver had increased the enzymes that get rid of barbiturates (i.e. - auto-induction of his liver CYP 450 enzymes). If such happens, the patient can have levels of barbiturate in the blood stream insufficient to prevent seizures. 
One hospital intervention that went beyond the level of detoxification involved Faulkner's receiving six electroconvulsive treatments (presumed bilateral, given the practice standards in the 1950's) for severe depression. The number of ECT treatments would have been greater if the patient had not balked at the cost. A better diagnosis than “depression” by current standards would be Substance Induced Mood Disorder, Depressed Type, and the best therapy would be to see if the mood disorder can clear after sufficient absence of intoxicants. That corrective is not to say that some positive intervention for depression might not be warranted, though antidepressant medication choices were limited at the time, but had current standard-of-practice been in place, they should have clearly informed the patient that the most probable cause of the problem was what he was putting in his mouth; not what was going on inside the head.

On another occasion, Faulkner was under the care of a psychiatrist, Dr. Wortis, who tried to find a psychodynamic origin (lack of maternal love, in this case) for his patient's problems. Although psychodynamic therapies (as well as cognitive-behavioral methods not known in Faulkner's life) can be a useful adjunct to other carefully controlled medication-supplemented and abstinence-based treatments, they do not work well alone, primarily because they leave the patient "alone;" i.e. - with no group of similar patients. As Ludwig has noted, whether solutions are found in A.A. twelve step programs or other programs that offer both a communal and transcendent-element for recovery, those two variables - community and a focus outside of the self - seem to be essential for long-term sobriety for the addicted person. In Faulkner's case, the attraction to psychoanalysis died when the bill arrived:

"Stay away from Wortis," he advised Joan. "I thought I had warned you. His bill was four hundred and fifty dollars. I asked how come, he said he charges 50 
dollars a visit, made me 9 visits. I remember only 3, two of which I called at his office by his request, not mine. He is a psychiatrist; in my experience, psychiatrists will do anything. Stay with Melchionna, who is a simple doctor. He gave me a complete physical overhaul, charged $\$ 85$ against Wortis's $\$ 450$, out of which I got one bottle of seconal capsules." (quoted by Blotner Faulkner 2 Vols., 1454-5)

The sad aspect of this letter is that Faulkner's denial was oddly in synchrony with the physicians who were handing him Seconal and little else. It raises the issue of how would Faulkner have fared in the present climate or atmosphere.

From the perspective of societal freedom to declare his disease openly and to seek treatment, Faulkner might have better odds for recovery in a milieu consistent with today's options of diagnosis and treatment. After all, the average person now is much more likely to know of The Betty Ford Clinic than of Townes Hospital. When the name of a Presidential First Lady not only lends advantage to an institution but also legitimacy to the condition, attitudes have changed. Alcoholics are now certainly "out of the closet" even if they are still most frequently "anonymous" and even if arguments over the best means of treatment persist.

Regardless of prevailing standards-of practice both then and now, aspects of Faulkner's personality suggest that he may have been a person who was "constitutionally incapable of being honest with" himself, thus rendering his chances "less than average," if the folks who claim benefit from A.A. can be trusted (Alcoholics Anonymous, 58). He showed early in his life a peculiar capacity not simply to generate fictional worlds on paper, but to create fictional personae which he acted out in daily life. These examples include his adoption of a fake, but surprisingly convincing, British accent when in Canada in WWI, his confabulation of a British birthplace for his registration in aeronautic 
training, his altering of the military uniform to ape an officer upon his return to Mississippi, and his tall-tale reports of combat service and plane crashes which have neither corroborating records nor eye-witness reports. Another phase soon after the end of WWI saw him adopt a type of "Bohemian poet drag," complete with tattered clothes and a brushy beard. His was abusively drinking during these young adult years but this drive to dissimulate seems to have exceeded effects caused by alcohol consumption. His actions and presentation do not seem to have risen to the level of frank delusions (i.e. schemata endorsed as incontrovertible truth without consensual validation from observers) but to be better described as "fantasy realms." The old joke that "neurotics only build castles in the air, while psychotics live in them" does not quite capture his condition. For Faulkner, it appears that he knew perfectly well that he had built the castles, but that he also saw nothing at all abnormal in taking extended vacations in them without changing his permanent address.

Even given that caveat of suspicion, I find no citation in any of the biographical works that suggest that Faulkner ever had the advantage of hearing from another recovering alcoholic any story that might have resonated with him. Estelle's recovery in A.A. after 1955 does not count because, if anything, a recovering spouse is probably the worst person possible to carry any message of experience, strength and hope. Conor Picken provides a good review of Faulkner's rather bitter mention and dismissal of the "Sobriety Movement" in Requiem for a Nun. The concurrence of Estelle's move to sobriety in AA in 1955 was approximately concomitant with her husband's revelation to her that he was conducting a sexual affair with Jean Stein, a woman forty years his junior, and just after the end of his other well-known affair with Joan Williams, his protégé and 
collaborator on that odd chimera play/ novel that became Requiem. Although reports show that he was confronted by colleagues, family members, physicians, and publishers about his drinking, but there is no indication that he actually heard another objective person's parallel story of dependence that offered an alternate ending. And there is no indication that he ever really expressed a desire for a change beyond, of course, the understandable desire to have the drinking stop causing him problems in life. He used alcohol to solve his inner insecurities. When Lauren Bacall asked, "Bill, why do you drink?" he answered, "When I have one martini," he said, "I feel bigger, wiser, taller. When I have a second, I feel superlative. When I have more, there's no holding me" (Blotner Faulkner 2 vols., 1487). On one 1953 day in Paris he had twenty-three martinis (Dardis, Thirsty 86). After that kind of dosing he should have been feeling taller and bigger than the Eifel Tower and wiser than the Académie française.

Some of the speculative opinions just expressed touch on the stated principles articulated by Alcoholics Anonymous. This movement has earned both its champions and its detractors, but the reality was in the years between 1939 (the year the first edition of what A.A. now casually calls the BigBook) and Faulkner's death in 1963, there were no other options than the ones he had tried (as reviewed above) and this 12 Step approach that he did not try.

A.A. recognized from its inception than their program was not for everybody and would only offer relief to the person who fully identified with the founding members' plights and who was willing to "go to any lengths" to obtain recovery. A.A. also further articulated from the outset that certain heavy drinkers, despite the pathology of their problem, could get better either by finding moderation in drink or abstinence on their 
own, and the foundational text even encourages the person in doubt to test his own resources to stop or moderate. Once a person did find, however, that he or she was a drinker who either could not stop drinking or who always drank to excess once a drinking episode began, and who identified with them and their stories, A.A. did suggest that they knew of no other remedy than what they offered as a daily method of living, a program which offered a reprieve, though never a cure.

The later 1920's and early 1930's were productive for both Faulkner and A.A.. Faulkner was having some of his best years of writing, and A.A.'s co-founders, Bill Wilson in New York and Bob Smith in Akron, Ohio, were independently suffering their worst years of drinking. The A.A. experience arose as a peculiar amalgam of many different models of human experience after coincidence and social connections brought the two together in Akron in 1935. Wilson was the dominant personality and interpreter of the program, but his first draft of the BigBook was subjected to what is reported to have been as a rather heated and brutal process of revision by the first one-hundred members who were his fellow recovering alcoholics. Wilson did go on to become, however, the leading voice of the approach, and he frequently and openly acknowledged that the first A.A. members had consciously adopted an eclectic approach to recovery. Wilson states in a 1944 address to psychiatrists:

At the very outset we would like to make it ever so clear that A.A. is a synthetic concept - a synthetic gadget, as it were, drawing upon the resources of medicine, psychiatry, religion, and our own experiences of drinking and recovery. You will search in vain for a new fundamental. We have merely streamlined old and proven principles of psychiatry and religion into such forms that the alcoholic will accept them. And then we have created a society of his own kind where he can enthusiastically put these very principles to work on himself and other suffers. (Three Talks, 24) 
This mélange does not fit well in any camp, but it is obvious that despite the varied terms that had been tossed about across two centuries, A.A. sought a synergy -- more than a truce -- between the warring camps of morality and medicine. It avoided, wherever possible, the allowance of one model or term to trump all others. Some critics were not so ready to trust A.A. entirely in this regard; and sometimes the doubts are raised with good reason. Yet, as Ben Adams documents in his 1999 essay, Bill Wilson handled criticism quite non-defensively, even acknowledging that one critic's points were well placed regarding the way some A.A. groups had conducted themselves (Adams 38). A.A. was, at least in those years, more flexible than its detractors. Adams offers one very telling citation from Bill Wilson,

"We have never called alcoholism a disease because, technically speaking, it is not a disease entity. For example, there is no such thing as heart disease. Instead there are many separate heart ailments, or combinations of them. It is something like that with alcoholism. Therefore we did not wish to get in wrong with the medical profession by pronouncing alcoholism a disease entity. Therefore we always called it an illness, or a malady -- a far safer term for us to use." (Wilson quoted by Adams 39)

At first blush, this seems like a retraction of the earlier quotes statements that cite principles of medicine. In fact, Wilson's parsing of terms represents exactly the position of mid-twentieth century medicine which took pains to reserve the word disease for a clearly identified physical pathology of certain etiology. In that milieu, the terms disease, illness and malady would all fall within the purview of medicine. A favored way to finesse pathologies that obviously caused suffering but could not be pinned down to simple etiologies was the word "syndrome." The distinctions really no longer hold much sway. 
Ben Adams' essay is intended as a counterpoint to the powerful challenge that the philosopher of ideas, Herbert Fingarette, had raised in Heavy Drinking: The Myth of Alcoholism As a Disease (1988). It is an argument against both the medical model of alcoholism and the A.A. 12 Step recovery. But as Adams notes, Fingarette was moving the understanding of alcoholism back into moralism:

Fingarette cannot, in all fairness, be accused of merely attacking without offering any suggestions of his own on how to help alcoholics and heavy drinkers recover. However, what he suggests to replace treatment related to the disease concept turns out to be a return to what is fundamentally a moral approach to heavy drinking. (Adams 41)

The A.A. synthesis was under attack, and the battle had been joined. Fingarette gained a mentee and co-critic in the expressed dissatisfaction with the medical model of alcoholism and the A.A. program of recovery in Stanton Peele, a lawyer cum psychologist. Peele launched his objections in the book Love and Addiction (1975) and continued his attack in other articles and books, most notably, Diseasing of America (1989).

Both Fingarette's and Peele's critiques might have found more traction had not a major development in non-invasive imaging of the brain (functional magnetic resonance imaging, or functional MRI, and positron emission tomography, or PET scan) arrived as a research tool in the 1990's, presaging and equipping the ten year period launched as the "Decade of the Brain." With solid government funding and these powerful tools, researchers could watch the brain work in real-time. The evidence began pouring in: brain difference correlated as predicted with drug-using and alcohol-using behaviors. All data, of course requires interpretation, and good science requires replication of even good experiments, but Stanton Peele's response to the research derived from such methods, 
especially the work by Nora Volkow at the National Institute on Drug Abuse, particularly odd. Rather than ramping up his own hypothesis by matching her results with similar studies and similar methods that might counter her conclusions, he resorts to the lawyer's rhetorical tactics. First, he issues a type of "cease and desist" letter. Second, he repeats his preferred opinions at louder volumes rather than offering stronger evidence for his views. He calls for Volkow to stop what she is doing because the neurophysiological model she investigates has not produced applicable treatments and complains:

They distract us above all from the major truth revealed by addiction epidemiology: Most people overcome alcoholism and drug addiction on their own. Finally, belief in the disease theory-to the extent that it persuades you of your powerlessness to control your substance use- has been shown to increase relapse and diminish the prospects for recovery. (Peele, "Why We Need.")

The multiple problems with this type of response will be discussed below in the context of what happens when Critical Theory goes awry. Suffice it to say, for the moment, that a scholar's reply to unfavorable data with "stop doing what you are doing and do what I want you to do instead" is, at best, perplexing.

Beside the temporal parallel of Faulkner's great period and A.A. origins, another less pleasant parallel of characteristics and character is evident. Both Faulkner and early A.A. were born into a racist and sexist world that presumed white privilege and male leadership. Rosie the Riveter, the WWII icon, was not yet a propaganda campaign which would bode the transition of women into men's jobs, and President Truman had not yet desegregated the armed forces, an act which initiated the painfully slow process of addressing legalized racism. In 1939, any transcendence, in any arena, of the color bar would have been the extraordinary exception rather than the expected rule. It is not surprising that Faulkner's writing and A.A.'s early composition reflected those dual facts 
of unfairness. Although the very first sentence in the first edition of Alcoholics Anonymous states, "We, of Alcoholics Anonymous, are more than one hundred men and women who have recovered from a seemingly hopeless state of mind and body," and though there were indeed alcoholic women who certainly were part of the group, the pages that follow are dominated by the stories of men and by masculine pronouns. It is pretty obvious that most of the women were the wives (presumed to be non-drunks) who suffered under the husbands' outrageous behaviors and who were learning a mode of recovery of their own. What eventually became AlAnon in 1951 (a movement that was predominantly attractive to women) was still blended in early Alcoholics Anonymous within family groups. That they were somewhat "addicted" to their alcoholic spouses is not surprising given the primate's evolutionary draw towards Admiring the drunk: they too were predisposed to a problem. As for race, the only clear presence of black in the BigBook of 1939 is in the ink; there is no specific address to the question of racial participation, but subsequent history of the program notes that when African Americans did enter A.A., the meetings were segregated, not by program dictates but by the force of the dominant social conventions (Kurz, 148-149).

Conor Picken addresses these problems well and notes, "Alcoholism—at least the treatment for it — re-instantiated traditional power hierarchies that privileged disease and recovery: drunkenness is a white man's affliction and is treatable after he reasserts himself as a societal leader." I would only quibble with the temporal order in the statement. I would suggest that "he" reasserts himself as a societal leader after he is treatable. Like the gospel story of lepers who have been healed, they are then to go and present themselves to the priests. These deposed drunk men had been the leading 
monkeys of their day, but they had lost their status. After demonstrating recovery and after presenting themselves to the "authorities" of medicine and religion, they were restored to leadership. The Foreword to the Second Edition of the BigBook of A.A. gives a litany of such redeeming authorities: William Silkworth, M.D. at the Townes Hospital, Fulton Oursler, a journalist, Harry Emerson Fosdick, a preeminent Protestant pastor, and John D. Rockefeller, a captain of industry. These men were not alcoholics, but they were the powerful white men who were shepherding a group of previously-deposed white men back into leadership. A cadre of leaders can only be restored to leadership if they have previously possessed, then subsequently lost, leadership status.

As women become allowed as leaders, and as their alcoholic leaders are deposed, they too garner the privilege of a restoration to leadership via recovery. It is no accident that a leading treatment facility is named after a Presidential First Lady alcoholic, Betty Ford, and it is probably more than coincidence that Estelle Faulkner sought sobriety in A.A. at the very time that her status as wife to the Nobel Laureate was being threatened by her husband's flagrant affairs and his reluctant consideration of divorce. Quoting a letter William Faulkner had written in 1952 to Joan Williams, Joel Williamson (1993) writes, "Estelle, on her side, felt that 'Estelle Faulkner without Bill \& Jill would be a total nonentity' (286)." The same pattern can be expected for all traditionally oppressed groups as they achieve leadership status but then find that alcoholism threatens ability to hold that status. The fact that other groups never had status in the first place in no way means that they never had alcoholics. It only means that those alcoholics never even first earned a gaze of opprobrium, much less a review for restoration. They were never perceived as important enough to monitor. 
The more common complaint currently brought against A.A. is that it is a religion by another name. Bill Wilson was pretty frank about the fact that the founders were equal-opportunity thieves when it came to a good idea. The first fellowships of Alcoholics Anonymous were, indeed, birthed out of the Oxford Groups, a very energetic, trans-denominational Christian movement intent of restoring the world to moral order through some particular practices of piety. It has changed its name twice, first to The Moral Rearmament Movement and now to Initiatives of Change. The recovering drunks did not last more than a few years among the Oxford Groupers, and though AA acknowledges that certain concepts survived the split, the focus and organizational structure of the two groups could hardly have been more different. Wilson describes it, "[t]he forces of anarchy, democracy and dictatorship play impressive roles in the structure and containment of our Society (Three Talks 42)." But the question of religion still lingers. Bill Wilson defends the assertion with the suggestion:

Alcoholics Anonymous is not a religious organization; there is no dogma. The one theological proposition is a "Power greater than one's self." Even this concept is forced on no one. The newcomer merely immerses himself in our society and tries the program as best as he can.[...] The dying can become remarkably open minded. Of course we speak little of conversion nowadays because so many people dread being God-bitten. But conversion as broadly described by [William] James, does seem to be our basic process; all other devices are but foundation. 41

This might be dubbed double-speak, or it might be Modernist thought. One aspect of AA which seems often neglected is that it was born into two worlds: a world still somewhat positivist and traditionalist in philosophy, but also a world rife with skepticism about those very aspects of itself. This comparison may be heresy for all camps, but there exists something of resonance across Bill Wilson's suspicious openness to a spirituality 
and the poetry of William Carlos Williams (a physician, by the way) in "Asphodel, That Greeny Flower":

It is difficult

to get the news from poems

yet men die miserably every day

for lack

of what is found there.

Rainer Maria Rilke's sonnet also invokes a call to change:

Archaïscher Torso Apollos

Wir kannten nicht sein unerhörtes Haupt, darin die Augenäpfel reiften. Aber sein Torso glüht noch wie ein Kandelaber, in dem sein Schauen, nur zurückgeschraubt,

sich hält und glänzt. Sonst könnte nicht der Bug der Brust dich blenden, und im leisen Drehen der Lenden könnte nicht ein Lächeln gehen $\mathrm{zu}$ jener Mitte, die die Zeugung trug.

Sonst stünde dieser Stein entstellt und kurz unter der Schultern durchsichtigem Sturz und flimmerte nicht so wie Raubtierfelle

und bräche nicht aus allen seinen Rändern aus wie ein Stern: denn da ist keine Stelle, die dich nicht sieht. Du mußt dein Leben ändern.

As translated by C.F.MacIntyre:

Torso of an Archaic Apollo

Never will we know his fabulous head where the eyes' apples slowly ripened. Yet his torso glows: a candelabrum set before his gaze which is pushed back and hid, restrained and shining. Else the curving breast could not thus blind you, nor through the soft turn 
of the loins could this smile easily have passed into the bright groins where the genitals burned.

Else stood this stone a fragment and defaced, with lucent body from the shoulders falling, too short, not gleaming like a lion's fell;

nor would this star have shaken the shackles off, bursting with light, until there is no place that does not see you. You must change your life.

Modernists have always believed in a higher power of inspiration, but they were certainly folks who were wary of once again being "God-bitten," to borrow Bill Wilson's term. Being inspired, or god-nudged, however, is an entirely different experience. But whether the inspiring force comes in fourteen lines or in Twelve Steps, the ending is the same: "Du mußt dein Leben ändern."

I find no indication that William Faulkner knew Rilke. Nor that he took any interest in A.A. We do know that his wife, Estelle Oldham Faulkner, did find help in A.A. for her own alcoholism (Oates 288).

The argument made to this point presumes that the "hard sciences" and their medical applications, due to some intrinsic trustworthiness embedded in their methods, have an important place in the conversations about alcoholism. It should be equally clear that the argument also listens to the social sciences as trustworthy means of explanation. And if the passion driving the project - a love for the humanities and a high estimation of insights garnered from poetry, fiction, biography - is not obvious, then the argument has failed miserably. This conscious accounting of these methods becomes the opportune time to address what Critical Theory brings to the table.

One of the best of critical theorists, Bruno Latour, applies his foundational critique specifically to science. He can hold his own in conversations with his colleagues 
from the radical and skeptical schools of Continental Critical Theory or the U.S. representatives such as Jameson, Fish and Rory because he is their peer. He has long shared their discontent with what has too often been the Modern Atlantic culture's naïve and supercilious trust in hard-fact empiricism, whether the certainties be advanced in historiography, literary criticism, or the sciences. Ever since Antoine Laurent Lavoisier proved that, counter to intuition, the rust conserved from a piece of iron weighs more than the iron itself had weighed, and after his intellectual collaborator, Pierre-Simon Laplace, responded to the Emperor Napoleon's question as to why he failed to mention of God in a scientific treatise with "je n'avais pas besoin de cette hypothèse-là ("I had no need for that hypothesis"), science has often carried itself with some swagger. Whether Laplace found no need for God per se as the hypothesis, or merely for God's intervention in natural processes is a matter of debate; and it is a moot point. Success in the visible world of iron, rust, hot air balloon flights, steam engines, railroads, and telegraphs allowed empiricism tacitly to say, NOLI ME TANGERE. "Do not touch me."

For an emerging cadre of Continental intellectuals -- especially among the French who looked with dismay at a world double-dealt the disasters of WWI and WWII who knew full-well that both debacles directly resulted from actions driven by empiricism in the service of Imperialism -- sacrosanct Certainty might as well have had taped a 'KICK ME" placard on its back. Indeed they kicked. Under the scrutiny of Critical Theory, they showed the world of facts to be a mélange of constructs. Then, just as quickly, the constructs themselves were deconstructed. These therorists proved that our certainty, like iron, rusts into dust; but now in the powder there is less to weigh than at the start. The names Deleuze, Derrida, and Foucault, dominated critical theory, and others joined them. 
As Latour in 2003 admits, he was among such thinkers who felt that many of the presumptions of science needed a thorough interrogation, and he signals that his problem really is not with those mentors and colleagues.

What has disturbed Latour has been the realization that not all those who have adopted Critical Theory methods really share the goal of placing intellectual life on a stronger, more durable and more humane foundation. From his perspective, the avant garde of the Critics had correctly recognized that an un-questioning "worship" of science had, at times, resulted in unethical, or ethically questionable, applications (examples being the military-industrial complex, an arrogant medical establishment, and the ruin of the natural environment) or had canonized facile explanations. The Theorists had genuinely sought a corrective approach. With their ever-broadening view, the structures that promoted art and literature were brought under the lens of criticism. If Paul Ricouer could dub the methods espoused by the later nineteenth century figures Marx, Nietsche and Freud as "the Hermenutics of Suspicion," then this cadre of Critical Theorists could be dubbed "the Harbingers of Cynicism." These strong left-wing thinkers held the anarchist belief that exposing the received epistemes as constructs would advance the disassembly of all structures, and thereby clear the ground for humanity to generate a new and just manner of living even while their vision still oddly retained faith both in a proletariat and in an eventual "withering away of the State."

As Latour points out in his 2003 essay, however, no one really considered at the time the critical apparatus was being perfected -- the one in which radical Theory essentially proclaimed the dis-use of Science -- that their own tools would be turned against them in two ways. First, naïve populations deluded into conspiracy theories 
would invoke their methods. Second, wily power-brokers who actually understand the "mene mene tekel upharsin" which the very visible finger of Science has written on the wall regarding Climate Change, have co-opted Critical Theory to divert the naïve population from believing in the impending disaster. Latour cites a New York Times editorial "Environmental Word Games," from March 15. 2003, p. A16:

"Most scientists believe that [global] warming is caused largely by manmade pollutants that require strict regulation. Mr. Luntz [a Republican strategist] seems to acknowledge as much when he says that "the scientific debate is closing against us." His advice, however, is to emphasize that the evidence is not complete. "Should the public come to believe that the scientific issues are settled," he writes, "their views about global warming will change accordingly. Therefore, you need to continue to make the lack of scientific certainty a primary issue." (Quoted in Latour 226)

It is into this double breach - the assertion that nothing is knowable and the claim that known-things can be denied -- that Latour has advanced his call for a turn to "matters of concern." He finds that this concept serves better than Early Modern "matters of fact" and that it counters actions both by the naively ignorant, who careen into conspiracy theories, and the willfully evil, who conspire to keep the naïve folks stupid. He anchors "thing" in the human organization of conversation from which the word "thing" is philologically derived. It always refers back to the conference of community voices discussing "maters of interest."

By now the reader can reasonably ask, "What does this excursion into rusted iron and French intellectuals have to do with alcoholism?" Radical suspicion, beginning with Ricouer's three masters and threading through the epistemological crisis that has led to Latour's call for a new method, has radically questioned any conclusions drawn from historiography, from philosophy, from the sciences, from medicine, and from religion. But there is a difference between a scholarship which purposefully sets out to rattle the 
cherished epistemes when those systems have become stodgy and sham epistemes of the naïve and of the manipulators of the naïve.

Although I am not convinced that Herbert Finagrette's attempt to shake up the dominant forces of alcoholism's medical model and A.A. recovery succeeds, his contribution to the argument at least seems sincerely intent on respecting the method of the conversation. I find that his argument fails in the wake of subsequent research comes after his complaint in several waves. Nora Volkow's corpus of imaging studies regarding group differences in neurophysiology is one flank of attack. Project MATCH, where an A.A.- facilitated treatment protocol using the first three steps equaled (perhaps slightly exceeded) Motivational Enhancement Therapy and Cognitive Behavioral Therapy except for subjects with high anger, addresses the question of treatment from another flank. Yet Finagrette's attempt to challenge, from a philosophical perspective, the earlier acceptance granted the disease model addiction that differs from mere abuse, at least seems consistent with the Academy's long-standing standards of debate.

In contrast, Stanton Peele's title "Why We Need To Stop Nora Volkow From Taking over the World" sounds like riff on a Quentin Tarantino' film such as Kill Bill. A little investigation into his attack suggests an extremely serious problem, for Peele shares too much similarity with the political strategist who sand-bags the rising tide of global warming science. Peele's research on the benefits of moderate drinking is beholden to unrestricted grants from The Distilled Spirits Council of the United States, Inc. (DISCUS) and The Wine Institute. In the resultant article, Peele tells the world exactly what A.A. told the world in 1939: moderate drinkers can drink normally and have a good time at it; even benefiting from it. This news is older than Bacchus and it has never been 
in question. The problem real addiction medicine faces is the best way to help the extreme problem-drinkers. Reference to the to the Ingraham graph shows the very nasty reality that the alcohol beverage industry sells well over $50 \%$ of its products to less than $10 \%$ of drinkers. It is not hard to see what would happen to that industry if only moderate drinkers drank: the cost-per-bottle would double initially. Since moderate drinkers can respond to contingencies in the environment in accord with basic principles of learning and behavior change, even that level of moderate drinking would then decrease in response to increased price, causing either a price hike for the moderate consumer or a revenue-reduction for the industry. The pricing per drink would eventually find a new homeostasis, but the alcohol beverage industry currently depends on the uncontrolled (and uncontrollable) drinking of the top decile of population as the market price stabilizer. Peele's study, then, serves industry as the smoke-and-mirrors distraction from what the business-model's intrusion into science hopes to accomplish. Nearly all of such industries' "good turns," when turned over for close examination, turn out to be filling the pockets of the industries themselves. There is little reason to pretend otherwise.

Were even that serious problem with Peele's publication set aside, another fault is patently obvious. The article abstract clearly states, "It is as yet impossible to determine to what extent moderate alcohol consumption causes positive psychological outcomes and to what extent it is part of a complex pattern of mutually reinforcing variables (221).” This admission comes from the same person who wants to shut down Nora Volkow's research because her pure science has not immediately translated into clinical treatments. 
Evidently he finds immediate practical application more important for others than for himself.

The virulently anti-A.A. (and even more rigorously anonymous) website, www.orange-papers.org is more in line with the conspiracy theroies Latour's bemusedly encounters. Latour, for example, was simply flummoxed by his naïve French village neighbors who, after the Twin Towers on September 11, 2001 collapsed, immediately resorted to the conspiracy theory that blamed the Israel's Mossad, though the villagers had exercised no prudent pause and had no evidence. The Orange Papers' attack on A.A. is of similar ilk. Though addressing the rant far exceeds the scope of this project, any attempt to untangling it would really be impossible for exactly the same reasons that a conspiracy theory cannot be quelled: an attempt to do so aligns you with the enemy and further proves the conspiracy. The best you can hope is that the entranced person will become bored.

In summary, alcoholism (regardless of nomenclature) did not exist as an entity until the late eighteenth and early nineteenth century. But this word "entity" presumes that the answer to the philosophical query, "If a tree falls in the forest and no one is there to listen, does it make any noise?" should clearly be answered as "No." It is more accurate to state that the aberrant drinker did not exist as a recognized phenomenon until that time period. The "problem" of alcoholism only becomes a problem when a person who is prone to drink very large quantities of alcohol confronts an opinion that the person is interfering with other people's lives. Vervet monkeys do not read the DSM-IV TR and they do not diagnose their heavy drinkers as drunks. They actually like their heavy drinkers as leaders. 
Whether or not the heavy drinker, whether monkey or human, likes what is happening to himself or herself is another issue entirely. That self-evaluation may depend somewhat on a subjective understanding of how others perceive the drinking individual, and it may also depend on the individual's own self-imposed sense of self. This type of critical analysis could easily move us toward Jacques Lacan's lectures and chalk-board diagrams of S and barred-S, and his discussions of "gaze." This project will refer to Lacan's theory of gaze as it explains the way we create our stories about drunk story-tellers, and makes for interesting discourse on the text and context of alcohol consumption. I emphasize, however, that probably makes not a bit of difference (or even différance, to use Derrida's neologism) for a person who is dying of excess alcohol consumption. It may change the way we talk about them, however.

The reality is that people were dying of excess alcohol consumption long before ever being "Othered" as alcoholic, and the rate of destruction did correlate to the ease of supply access. Others have died of alcoholism even after being "Othered" as an alcoholic, but having never been "Selfed" as an alcoholic. If any tension still exists between what medicine does and what A.A. offers, it is here precisely. A.A. is blunt, "We do not like to pronounce any individual as alcoholic, but you can quickly diagnose yourself (31)." Medicine, however, will label, and does label, a person as Alcohol Dependent (or perhaps in accord with the new DSM V, as having a Substance Use Disorder, Severe) and that label, as applied by The Other, carries weight in courts of law and salons of reputation.

Faulkner seems never to have diagnosed himself as an alcoholic. His medical records, however, at Gartley-Ramsay Hospital, a private psychiatric facility in Memphis, 
bluntly stated, “'An acute and chronic alcoholic.' (Hickman 175)." His last trip to a facility was to Wright's Sanitarium in Byhalia, Mississippi, and the admission was due to a binge on alcohol. He left in a hearse the next morning, with the death certificate citing "coronary occlusion (Blotner, Faulkner 2 Vols., 1836)." 


\section{CHAPTER TWO \\ DRINK IN THE INK OF WRITERS: CREDENTIAL, CRUTCH OR CRISIS?}

I usually write at night. I always keep my whiskey within reach.

- William Faulkner (from Coindreau, quoted by Dardis, Thirsty, p. 26)

This chapter is unavoidable, and I can only hope to render the needed reviews in a manner that navigates well between the Scylla of boredom and the Charybdis of pedantry. Progress toward the more interesting questions and answers entertained in the final three chapters of the project, however, depend on a dual foundation offered here; a foundation in some first principles of science and a foundational literature review.

I preemptively summarize here what is detailed below: every review of American writers finds both that the prevalence of alcoholics among them is far greater than the prevalence of alcoholics within the general American population and that the prevalence among American writers is greater than among writers in Britain and Europe. To assist our thinking toward an explanation of this observed fact, I must review, in advance of the literature review, the manner in which differential concentrations of any energy (as measured in physics) or substance (as measured in the basic sciences) or behavioral characteristic (as measured in the social sciences) can actually first come to exist and then be maintained in existence. This excursion visits the Laws of Thermodynamics, of which the classic expression of the Second Law states, "All systems tend toward maximum entropy and minimum enthalpy." The corollary to this dictum implies that anywhere less entropy (i.e. - more order) and more enthalpy (more heat) is observed, some work has necessarily preceded those conditions. If those conditions are observed to stay in 
maintenance, that observation implies that work is continuing to impinge on that system. Should this dull review threaten readers with immanent sleep, I heartily recommend they avail themselves now to the hilariously sung rendition of the First and Second Laws of Thermodynamics as performed by the mid-twentieth century British musical comedy team, Michael Flanders and Donald Swann. They give us the lyrics, “Heat won't pass from a cooler to a hotter (x2); you can try it if you like, but you far better naughter (x2); 'cause the cold in the cooler will get hotter as a rule-r (x2), because the hotter body's heat will pass to the cooler (x2) (Flanders and Swann)."

After that primer in some first-principles of the universe, the chapter lists, summarizes and classifies several key catalogs of writers who drink and the purported meaning of such drinking. The reviews in which William Faulkner receives strong attention will be of special interest. This "review of the reviews" reveals a major thesis of the project: the varied conclusions that reviewers offer about the way alcohol affects creative writers depends very much on the reviewers' prior relationships with alcohol and/ or alcoholics. These reviewers are analyzed in accord with concepts presented in Table 1, found in Chapter One, and the analysis points to another matrix relationship, opinions about the interaction of alcohol and creativity, found in Table 2 in Chapter Three. I hold that any writer who writes about drinkers has some extra-authorial experience which shapes the authored narratives he or she writes, whether those texts be fiction or non-fiction. This applies to biography's investigation of lives as well as to fiction's interpretation of life. As William Booth in The Rhetoric of Fiction has demonstrated so well, no manipulation of narrative craft -- even within the fiction genres that allow some considerable escape from the pedestrian constrictions of mundane rules - 
ever allows author to efface themselves completely from the narration. An intersection of life-experience with a creative gift accounts for convincing products. Had Faulkner, for example, not heeded advice from his mentor, Sherwood Anderson, to write "what you know," he would not have discovered Yoknapatawpha as the "postage stamp" of fictive landscape that actually allowed him to create much more than he had ever known from the mundane arena of Lafayette County, Mississippi (Faulkner, Essays,.8; Meriwether \& Millgate, Eds., Lion, 255).

In the Introduction of this project, I cited a basic principle regarding the creation of an azeotrope in miscible solutions, the mix that cannot become any less of a mix by the simple act of thermal distillation. I applied that mundane reality as a metaphor regarding the difficulties we face when we try to distill facts from fictions. I now need to raid the laboratory once more to borrow some other metaphors from the basic sciences, comparisons that will help the social sciences explain how unequal distributions of any behavioral characteristics arise and survive among human groups.

The action of osmosis reveals that, should we divide a container with a membrane that is completely permeable to both a solute (let us choose ethanol) and the solvent (let us choose water), both the concentration of the solute and volume will equilibrate across that permeable membrane, no matter how you add solute and solvent to one or both sides of the divided vessel. If we substitute, however, a selectively permeable membrane for the fully permeable membrane - let us say, put in a device that allows water molecules to pass, but which blocks ethanol molecules -- the system will still do all it can to equilibrate the concentration of ethanol on each side, but that it will achieve that goal by unequally distributing the volumes. The volume on each side will only remain the same 
if we add equal quantities at the same concentration and at equal rates to each side. If we start with one liter of $20 \%$ ethanol in water on Side 1 and with one liter of a $40 \%$ ethanol in water on Side 2 and wait just a bit, Side 1 will change in two ways: the volume will decrease and the concentration will increase, while Side 2 will change inversely: the volume will increase and the concentration will decrease. Basic physical chemistry tells us that Nature tries to its best to equilibrate both volume and concentration, but if a system is semi-restricted, the system will equilibrate concentration. The semi-permeable membrane actually is a type of tool known as a filter, and it works on the intrinsic energies within two different entities. One of these is the intrinsic energy stored passively in the membrane structures as order, and this order allows the tool to sort, at a minimum, two different things that are distinguished by shape, size, or electrical charge. The second entity, the solution (the combination of the solvent and the solvent) has a randomly distributed, randomly acting transfer of thermal energy-- or enthalpy -- that manifests as independent motions of particles. As they jiggle about and bump into each other to transfer energy, they eventually knock the well-matched particles to the other side of the filter, while retaining the poorly-matched particles on the original side. The latent energy of the system will let the well-matched particles be bounced back-and-forth across the membrane for as long as the system has passive and intrinsic thermal energy.

Of course, if you go to the liquor cabinet and find a bottle of 80-proof bourbon standing next to a bottle of 120-proof bourbon, and if no one disturbs this arrangement, the concentrations of ethanol in each bottle and the volumes of liquid in each bottle will remain the same as long as the glass bottles remain intact and the sealed caps hold well. The impermeable barriers of two glass walls and two good caps essentially have rendered 
them into two independent systems. Despite our insistence in scientific method (which, please understand, I still hold to be valid) that posits a difference between dependent and independent variables or events, we rarely encounter in nature absolutely independent systems. This is especially true for human social systems. We may have filters, and some of those filters may be extremely effective and extremely resilient, but we really find few absolute barriers. This distinction between the words "barrier" and "boundary" will be useful.

Anytime, therefore, we encounter a system, whether in the natural sciences or the social sciences, where we can measure a difference in a concentration of some entity across some distinguishing -- but (at least) semipermeable -- boundary, we have to look for yet another metaphor from the laboratory to explain why the Flanders and Swann lyric about thermodynamics is not being obeyed, because in a closed system, "Heat can't pass from a cooler to a hotter." There has to be a third element at work.

This third element is the pump. It is a device which, at some level, requires energy to maintain a concentration gradient across a boundary. The better-insulated a boundary is, the less energy will be required to maintain the gradient, as we discover when we have lower heating bills in the winter for homes that are built to reduce heatloss. But even the best house requires some sort of energy input, because we rarely ever find a naturally occurring system that is fully "leak proof." Bench chemists try to construct some ideal systems in order to carry out what are called "adiabatic" reactions, but natural systems are somehow and somewhere almost always "open" to external influences. Biochemistry has well described many kinds of pumps that allow our cells to build and maintain concentration gradients across cell membranes, systems that must 
maintain gradients in the face of real world influence from outside forces. This is the conundrum of biological life: if there is no induced gradient, there is no Life, but there is no Life if the induced gradient is not equalized in an orderly fashion. There must be an orderly alternation between stabilized and destabilized conditions within one system. Many a third-year medical student is made the butt of an attending physician's joke when upbraided for writing in a chart, "vital signs stable," for even a corpse has stable vital signs.

A pump requires not only extrinsic energy, but it must also have at least one degree of structural complexity greater that the membrane with which it is negotiating. The semipermeable membrane works on the intrinsic intermolecular forces latent among molecules and can differentiate volume, but not concentration. In order to account for a system in which there is both differentiated volume and concentration, there must be a pump that 1) is more complex than the membrane itself and that 2) has access, whether directly or indirectly, to some energy source that is extrinsic to both the pump and the membrane. The membrane can help the pump, but the membrane alone cannot achieve vitality. It is a necessary, but not a sufficient, condition. Similarly, the pump cannot long succeed if the membrane fails. The pump, even though more powerful than a membrane, and even though necessary to achieve the required gradient for life, does not rise to level of "sufficiency."

American writers are a subset of all Americans, and we will observe in the reviews below that there is a concentration-gradient of alcoholics in that total system, with a greater percentage of alcoholics on the writers' side of the boundary when compared to the rest of the population. Yet we do not observe their total volume of 
writers to be expanding. Some active force has to pump them to that level of concentration and keep them at that level while also not swelling the ranks. If the "pump" is found to function at a slow-changing, genetic level, we should not expect to see much of a change in only a few generations. If the "pump" is at a social-construct level that, perhaps, alters somewhat readily in the face of generational changes, then we might see a difference. Fashion and fad are good examples of rapid change. Changes in preferences for professions are another, though slightly less volatile, example of easily observed change, usually as altered technologies intervene. For example, there is no longer much call for bookbinders, moveable-type setters, or typewriter repair technicians outside of a specialty niche market.

Attention to these concepts of active-energy systems and their concentrating (or dissipating) effects will be useful as we approach the reviews of drinking and writing among American authors. We are ready to listen with an open mind and a critical ear to the people who have found drinking writers fascinating.

John Crowley prefaces his 1994 review of the American Modernist writers' relationships with alcohol with an overview of the American Realist writer, W.D. Howells and the way he wrote alcoholism into his fiction. He develops the thesis that Howells interpreted drinking characters in terms of both the medical model and the moral model of alcohol addiction. The drinking author, however, who supplies Crowley with the topic of his title, The White Logic: Alcoholism and Gender in American Modern Fiction, is Jack London, not Howells. The metaphorical phrase, "the White Logic," comes from the first-person narrator's lips in London's roman a clef titled John Barleycorn: An Alcoholic Memoir. I begin with Crowley, not because his book is 
chronologically first (in fact, his publication date comes near the end of the time-line in these reviews), but because he provides such a good introduction to London's work, which truly is a "first."

London's book is a conundrum. He wrote the piece as propaganda to promote the temperance movement's goal to win Prohibition. Although the narrator is explicit about his early and long outrageous excesses with the bottle -- habits that began in early adolescence -- London never lets the narrator admit that he is, or ever was, a true alcoholic. As Crowley documents, London follows the view that true "dipsomania," the pure and unalterable addiction to alcohol, was so rare as to only occur once in ten thousand; London finds instead that the narrator's exploits were really just a roguerelationship with the bottle, and that the relationship could be broken by sufficient will power. By parallel argument, London is insisting that the U.S. body-politic could stamp out the scourge of liquor via Prohibition just as the narrator stamps out his own scourge. Crowley quotes the narrator's victory-vow: “Never again would I invoke the White Logic,' which 'now lies decently buried alongside the Long Sickness' (Crowley, White Logic, 20)." Crowley then shifts focus immediately to the author, London:

The 'White Logic' and the 'Long Sickness' were soon disinterred, however, when he picked up the bottle again. Within three years London was dead - under ambiguous circumstances, including a possible overdose of prescription morphine. Although the question of suicide has been debated by his biographers, exactly what happened will never be known. Drinking, in any case, had undoubtedly hastened London's bodily and mental deterioration; and although he had developed multiple addictions by the end of his life, alcohol had always been his primary drug. (20-21)

London's fiction gives the reader a character who faces a dilemma and then, through dramatic actions, arrives at a "win." Crowley then gives the reader a brief biography, presenting a writer, London, who follows the narrator's trajectory to an interim and 
unstable "win," and then he extends the narrative with the writer's subsequent encounter with the problem, now arriving at a "loss." As a vehicle of persuasion, the brakes fail on this roman a clef when it tries to stop, and it hurtles the author off a cliff. Crowley's narrative takes us to the place where the fiction-writer and the fiction's narrator meet each other in disaster. Discussion of such of such interplay of the biographers' narratives with the fiction-writers' narratives - both their autobiographical tales and their creative fiction tales -- will come to bear on conclusions in Chapter Five.

Crowley considers London's John Barleycorn to be a transition from American naturalism into American Modernism, with "[...] its heroic narrator, who attains thorough his duel with meaninglessness a dark triumph of the will (White Logic, 34)." It is in this chapter on Modernism that Crowley cites the work of sociologist Robin Room, whom he quotes as finding “'a clear association of problematic drunkenness not only with American writers, but with a particular generational cohort that came of age in 1909-1921.' (White Logic, 35)." Room targets WWI as the decisive factor for that cohort. Crowley looks further, however, at drinking writers who came of age during Prohibition. When he finds the same percentage of problem drinkers in the next cohort as in Room's, he argues that more than just the cultural trauma of the "war to end all wars" was at work since the problem persists at the same rate after the war ends. He asserts, "The attitudes of the Lost Generation, those children of the century who believed that they had come too soon into a world too old, were formed as much by growing up in the heyday of Prohibition as by living through the Great War. (White Logic, 35-37)." The male drinking writers Crowley examines after Howells and London are Ernest Hemingway, F. Scott Fitzgerald, John O'Hara, and Malcom Lowry (the last with some 
necessary mention of Daniel Jackson by dint of The Lost Weekend, a novel which Lowry resented as having overshadowed his own novel, Under the Volcano). Djuna Barnes is the drinking female writer reviewed.

Faulkner's birth in 1897 places his disconsolate arrival almost exactly between Room's five birth-years, 1893 to1897, and Crowley's clump of thirteen years, 1898 to 1912. In The White Logic, however, Crowley does not examine Faulkner's case explicitly. One of Faulkner's most famous phrases, however, echoes in the quotation that Crowley selects to end the chapter:

In communion with the White Logic, these writers fashioned a literature steeped in what Donald Newlove calls "the authentic rhetoric of the true drunk, its shadows and ironies, universal overcast, the last red dingdong of doom breaking ecstatically over a dying landscape." (White Logic, 42)

Not only does the metaphor "communion" -- that context for excess that essays to turn any Lost Weekend into a Passion Week complete with a Last Supper - arise, but Faulkner's Nobel banquet speech (“the last ding dong of doom”) haunts Crowley's book like Banquo's ghost haunting Macbeth's banquet table (Faulkner, Essays, p. 20).

Whether that ghost can be satisfied by explanations of alcohol-excess based on a doubleold-fashioned modernist recoil from the wounds of the Great War (i.e. "Culture Kills") and Prohibition (i.e. "Culture Constricts") is another matter entirely.

Besides Donald Newlove's work, Crowley acknowledges the other "pioneering studies" that preceded his work, and he mentions his debt to the books by Thomas B, Gilmore, Donald W. Goodwin and Tom Dardis. Crowley contrasts his model against those writers, however.

[...] I do not share completely their authors' confidence in the 'disease concept" that has shaped thinking about "alcoholism" for over five decades. I am concerned here with the historical formation of this and earlier concepts of 
habitual drunkenness and their bearing on the social construction of gender roles. In this sense, The White Logic is akin to projects in "cultural studies" of the sort that have become so fashionable in English departments. But it is also a work of traditional criticism and literary history in its attention to what I have called the drunk narrative: a mode of fiction that expresses the conjunction of modernism and alcoholism in the pervasive ideology of despair. (White Logic, x.)

Crowley's project, then proposes that the "drunk narrative" is somehow the literary cocktail that results when we mix despair, modernism and alcoholism.

I have argued in Chapter One that the movement which became Alcoholics Anonymous is of this same Modernist mix as Cowley's "drunk narrative," and that the distinctly Modernist element which emerges in A.A. is the dual autonomies for the individual both to diagnose self and to choose for self a Higher Power consonant only with the self's own understanding. Both Modernist projects, Crowley's drunk narrative and A.A.'s BigBook offer aspects of what Susan Zieger (2008) dubs “temperance fiction," works which she notes, "[...] characteristically adhered to a narrative formula that traced the writer's descent from bourgeois promise to destitution, followed by either recovery and moral transformation or abjection and death (37)." Obviously, a vignette in the first person is most easily narrated if it ends in "recovery and moral transformation," but it is conceivable that it might end in abjection (i.e. - accounts of a persisting condition of isolation, despair, sullenness, etc.), which is somewhat akin to a narrative that ends in a "draw." But a writer who is synonymous with an autobiographical narrator cannot realistically end the narrative post mortem. A fiction writer might craft such a "loss" ending as told by a voice that speaks despite the grave, if not so much from the grave. Addie Bundren's narrated sections in As I Lay Dying comes to mind as an example, though her horrible childhood and her despicable husband, Anse, and not 
alcoholism, were her issues of despair. But short of some questionable transcript from an Edwardian séance, this option is not tenable for the auto-narration of real lives.

\section{Susan Zieger, Inventing the Addict: Drugs, Race and Sexuality in Nineteenth-} Century British and American Literature (2008), shares with Crowley a strong interest in the interaction of constructions of gender, disease, and alcoholism, but she also includes the constructions of race in her study. Two other differences are also clear. First, Crowley deals much more with drinking writers' lives than with drinking writers' fictions. Zieger is almost uninterested in the biographical material as compared to the themes of the fictions and the social history milieu from which the fictions emerge. Second, rather than offering a focus on drunk narratives as Crowley prefers, Zieger chooses to explore what she calls the "drug autobiography." She contrasts her succinct outline of temperance narratives, cited above, with the observation, "[the] drug autobiography self-consciously flaunts its more elite, literary origins, deriving authority from the drugged self's experiences that is not primarily didactic or regulatory but scholarly and aestheticized (37)." Zieger demonstrates that these narratives extoll "[...] the transcendent wonder of intoxication, the mobility and self-expansion that feels like freedom " and she finds that "[...] their fantasies of esoteric exploration derived from broader cultural ideals of imperial power and knowledge." Drawing a parallel between imperialism (the British fantasy that became their obsession) and Manifest Destiny (the American "drug" of choice) she "[...] explains two crossings: how intoxication becomes addiction, and how the drug autobiography begins as a British form of imperial mastery before shifting to a U.S. continental one (19-20)." The metaphorical application of intoxication and addiction to national movements is fascinating, and it is easy to 
understand Conor Picken's extension of recovery-from-alcoholism as the metaphor-ofchoice for Southern writers who struggle with the South's battle with itself in the region's "recovery" from racism.

I apply Zieger's work to this project, however, more literally. Her focus on "drug autobiography" allows a different way to tell a story in which a character faces a dilemma and then undergoes trials in order to arrive at "a win, a loss, or a draw." In a drug autobiography, a "win" is quite conceivably the attainment of some new power of vision or insight into reality, whether that reality be found "at large" or "in the self." Rimbaud's "Drunken Boat" comes to mind as literary success fueled by exogenous chemicals. Similarly, a loss might be the faded vision that cannot be retained or returned. For example, we will never know all that which inhabited Kubla Khan's Xanadu, a "loss" for Coleridge when his inspiring intoxication left him too soon. Understanding these two types of narratives, the "drunk narrative" and the "drug autobiography," will help in understanding what Faulkner does with the exploits of drunk characters in his fiction, material to be considered in Chapter Four. Given Faulkner's strong creative powers, it is not surprising that he never lets either genre rest easy on its reputation. Under his pen, stories rarely tell us exactly what might be predicted. But they do reflect this challenge to be free to tell the same story two different ways so that two different outcomes are observed, even if the "two" experiences are most likely derived from the life experience of one writer. As Chapter Four details concerning alcohol and writing, Faulkner was most certainly a participant-observer, just as Jack London was a participant-observer in his book. 
But what of Zieger's place as an observer? Zieger is clear by her own statement, and she should be presumed as trustworthy. She knows that some critics cry "foul" when a user (whether happy-and-active or happy-and-recovered) writes about addiction, and she refers clearly to David Lenson's "polemic" (n. 65 250) and Jacques Derrida's reflections (n.66 250) when she writes

Finally, just as this book is not a conventional history, it is also not written from "that forbidden focus, the user's point of view." ${ }^{65}$ Indeed, one of this book's tasks is to illuminate the historical underpinnings of present ideological investments in both the prohibitive concept of drugs, in which addiction is a ubiquitous, looming bogeyman, and the permissive resistance or transcendence, in which addiction does not exist or does not matter. ${ }^{66}(17)$

She presents herself as a non-addicted (though not necessarily an abstinent) observer, and it is fairly easy to see why her focus falls on the metaphorical extensions of intoxication and addiction, both in the fictions and in the social-economic history of the imperialisms, rather than on their concrete effect on the individual bodies and minds of those writers who explored intoxication and tripped into addiction.

Crowley does not overtly tip his hand regarding participant-observer status, and a possible answer comes only after a bit of sleuthing. In 1999 Cowley published another book related to writing and alcohol, a compendium of "drunk narratives," The Drunkard's Progress: Narratives of Addiction, Despair and Recovery (1999). He dedicates the book, "For the Out to Lunch Bunch of Skaneateles, New York." That town is a suburb of Syracuse where Crowley was then professor of English at Syracuse University. Perhaps there may be more than one group of people in that suburb who call themselves by that particular name, but one such group is certainly an A.A. discussion group that meets on Mondays at 12 noon ("Monday Meetings"). The meeting is designated as "closed" and that term means "For alcoholics only." 
Approximately halfway between Cowley's 1994 exploration of alcoholism and Jack London's 1913 disavowal of non-alcoholism, Upton Sinclair published The Cup of Fury (1956), a little review remarkable for his many creative friends (mostly writers, but including actors and others) who had been beset by alcohol. Upton Sinclair intended his book as a warning that no one should drink at all. The catalog of drunks includes his literary “double," Sinclair Lewis, a writer with whom Upton Sinclair was confused all through their lives; at times even when being introduced to speak before learned audiences. The two could not have been more different in demeanor and habit. Sinclair Lewis was outrageously alcoholic, and Upton Sinclair was abstinent. In deference to the tendency to confuse them, I always use their first and last names. Upton Sinclair's catalog did not include William Faulkner, however. A speculative reason is that Faulkner was still alive, for a glance at the contents shows that Upton Sinclair only mentioned living authors with a reputation for drink if they were recovering from drink. If they were not in recovery, he did not cover the living. As for his own motivation to review drinking writers, early in his book, Upton Sinclair states:

I will write as one has had but three or four sips of liquor in his life; as one who was early warned away from alcohol. It was my fate to be raised in a virtual sea of liquor. First it was my father. Then no fewer than three of my uncles proud Southern gentlemen, one of them a naval hero. Then one friend after another, colleagues and writers, many of them famous and all of them destroying themselves. (13)

For the purposes of this project, Upton Sinclair's view of drinking writers is of interest because of his advocacy of disease model and his endorsement of A.A. His disease model, however, was understandably bound to mid-twentieth century medical science, and he far exceeds A.A. in his crusading against all use of beverage alcohol. 
Upton Sinclair turns to Leon A. Greenberg of Yale for his medical model, one that espoused the topographical, "top-down" notion that alcohol consumption successively suppresses the brain from the higher cortical areas, to the midbrain regions, and, finally, to the brainstem functions. Greenberg also espoused a single-action theory of alcohol, stating that it was only a sedative. Implicit in the model is the notion of universal effect, though with none of the humor and none of the poetry of Shakespeare's Porter in Macbeth. Upton Sinclair quotes him:

Contrary to old and popular belief, alcohol does not stimulate the nervous system. The illusion of stimulation results from the removal of inhibitions and restraints. The effects may be compared to a releasing of the brakes, not a stepping on the accelerator. Even with a few drinks, digital dexterity is reduced; auditory and visual discrimination fall away; tactile perception is lowered; the speed of motor responses drops. Despite these measurable losses, the drinker often asserts that his reaction, perception and discrimination are better. (152)

This view implies that the results will be the same for all drinkers, for the medical community showed little understanding of group differences regarding either affective responses or predisposition to addiction. The various types of alcoholics as they had been described by William Silkworth, M.D. in 1939, were still essentially unrecognized by his colleagues fifteen years later, this point of difference gains importance regarding the effects of alcohol on creativity as discussed in Chapter Three. Upton Sinclair extrapolates immediately from Greenberg "[t]his is the false effect, then, which has led so many writers to believe that their work is more fluent and inspired after a round of drinks (152)." His opinion about the risk-versus-benefit of alcohol is clear: "I cast my vote against social drinking. I will not keep a dog in my house that bites one out of every five or nine people who stoop to pet it. Nor will I sanction alcohol because it dooms or harms just one of every five, nine or sixteen who drink it." Oddly enough, this view is not one 
for which he would be able to find support from A.A., a movement he much admired and extolled. He ends his book stating:

For those who are alcoholics - the AA is perhaps the finest answer. For those who have not yet had their first drink - the wisdom and courage to say "No" is the answer.

For those who have seen the misery and understood the devastation caused by drink - a continuing fight is the answer. (185)

Is Upton Sinclair a non-participant-observer or not? His agenda is entirely different from Zieger's stance, and she would probably classify him, in her terms, as on the extreme of those who find the "boogeyman of addiction everywhere." I would suggest that the best answer comes by using in the tripartite division of attitudes, "Admiring, Tolerating, and Rejecting" coupled with the three possible behaviors, "Abstinent, Partaking, and TakenBy.” Upton Sinclair is the Abstinent x Rejecting block. As for Susan Zieger I simply cannot find enough evidence to place her and her work. If we trust her self-report, however, we can rule out Taken-by, even if not distinguish between Abstinent and Partaking. Whether a Partaker or an Abstainer, she falls in the Tolerating category. Comparison of these varied reviews begins to illustrate that the $3 \times 3$ matrix is more useful than a simple linear model and even more useful that a 2x2 matrix of participant/ non-participant x observer/ non-observer. Returning to Crowley, he is a Taken-by (though sober) who is Tolerating. At the top of the list, Jack London is a Taken-by who is Rejecting.

Slightly more than thirty years after Upton Sinclair's Cup of Fury made its 1956 debut, a spate of three important titles left the presses for the shelves in very short succession. Thomas Gilmore brought out Equivocal Spirits: Alcoholism and Drinking in Twentieth-Century Literature in1987, Donald Goodwin released Alcohol and Writers in 
1988, and Tom Dardis published The Thirsty Muse: Alcohol and the American Writer in 1989. This tight skein of similar yarns about alcoholic yarns and the drunks who spin them requires a bit of untangling.

Gilmore cites Goodwin's work on alcoholic writers, but Gilmore's depends on two of Goodwin's journal articles that predated his book (Gilmore 208). Gilmore, however, cites neither Goodwin's earlier articles nor the earlier book that investigated heredity and alcoholism. Goodwin, in his book, cites Gilmore, referring both to Gilmore's book, Equivocal Spirits, and to Gilmore's scholarly journal articles that had prepared the material for the book (Goodwin Alcohol, 210). Neither Gilmore nor Goodwin seems to have any knowledge that Dardis was simultaneously working in their field of interest. These lacunae are from lack of advantage rather than lazy attention: Dardis' contribution appears, like Athena from Zeus' head, both full-grown and armorclad, in his book in 1989, after Gilmore and Goodwin had published. Dardis had not written articles that would have been available to them. Dardis acknowledges in his book Goodwin's two different research foci (heredity and alcoholism, and writers and alcoholism), but his knowledge of Goodwin's approach to "writers" is really only in regard to the one writer, Fitzgerald, via Goodwin's 1970 JAMA article. It appears that in 1989, Dardis did not know Goodwin's 1988 book, a lack most probably attributable to the lag-time incumbent in the process of turning a manuscript into a published item. It appears, however, that Dardis subsequently read Goodwin's book after his own was published, and in a 1994 article, he differs strongly with Goodwin's conclusion that Faulkner was able to demonstrate some control over his drinking behaviors ("Oh, Those 
Awful Pressures”). Dardis cites Gilmore's book, though not Gilmore's earlier articles (Dardis, Thirsty p. 270 and 273, respectively).

Thomas Gilmore presents his thesis, that the fiction which drunk writers create tells us much about their drinking, as a corrective to the earlier biographical works about drinking writers. He does not fault them, however, for indulging some alleged "biographical fallacy" (an interpretative sin in the eyes of the New Criticism): "Their deficiency lies rather in their apparent failure to realize that without his work the drinking or alcoholic writer is of no more intrinsic interest than a skid-row derelict or a drunken truck driver, and that for this reason his work should have primary focus [...] (3)." He goes on to clarify, "More accurately, I am trying to show how two separate subjects, the writer's drinking and the work in which he writes about drinking, can shed light on each other. (3)" Gilmore sides with Newlove in voicing skepticism regarding opinions, such as found in Goodwin, that writers are at particular risk, and he quotes Newlove, “" [...] there are as many drunken sanitation workers, brain surgeons, priests and car thieves as there are drunken writers, printers, actors and ad men' (4)." A gracious reading of the quotation can excuse both Newlove and Gilmore for the presumed error of confusing "as many" with the mathematically accurate phrase "as prevalent," but even with such allowance, the assertion does not withstand measurements such as made by Arnold Ludwig and published in The Price of Greatness (1995), and the significance of this differences will become evident as the relationship of creativity and mental illness is considered in conjunction with intoxication, as promised in Chapter Three. Not only are writers at greater risk, the type of writing practiced (fiction, poetry, or biography) varies the risk. 
Gilmore, however, takes Newlove to task for using a faulty method that indulges a "biographical generalizing" about authors themselves but which "slights or ignores their actual work (5)." Gilmore is parsing several complexities, and he does so gently. One other generalization that he resists is the notion that it takes an alcoholic writer to create a convincing alcoholic character, and he provides as a strong case for a counterexample, Saul Bellow's “[...] The Victim, one of the major studies of the indeterminate character of alcoholism [...] (17).” Bellow was in no way an alcoholic and Gilmore's caveat is crucial. Were first-hand experience required for every author to write every character, we would have to issue bench warrants for the arrest of every novelist who convincingly creates psychopath rapists and murderers. Gilmore eloquently explains, "To have worked with the assumption that only writers who are certifiably alcoholic can write perceptively about alcoholism would have belittled the power of observation and imagination (17)."

A critical question still remains, however. Why is it that some writers experience sufficient "power of observation and imagination" for constructing a psychopath murderer without using a drug, and why others of equivalent skill find it useful (or even necessary) to spark those powers with a drug in order to create the character who is a psychopath murderer? Faulkner's character, Popeye, in Sanctuary, a quintessential psychopathic murderer and the infamous corn-cob rapist, comes to mind. For all of his misdeeds, and though Judith Wittenberg in Faulkner: The Transfiguration of Biography (1979), justifiably draws parallels between Faulkner and Popeye in regard to physiognomy and physiology as will be discussed in Chapter Four, no one suggests that Faulkner was a murderer. I will argue strongly, however, that Faulkner had a good deal 
in common with Gowan Stevens, the drunk who put Temple Drake in harm's way in the same novel, and that his choice to incorporate some autobiography into his fiction represents both the psychological processes of creativity and the psychological defenses employed to mediate internal tension with the self.

Gilmore does not examine Faulkner or Faulkner's works. His essays look at the writers Lowry, Waugh, O’Neill, Cheever, Allbee, Fitzgerald, Berryman, as well as comic scenes written by Kingsley Amis and George Orwell. The book was constructed from research previously published as journal articles, and the selection of those particular writers may simply be attributable to Gilmore's professional focus in academics, one where Faulkner was not of primary interest, for he states "[...] my primary criterion of choice has been my keen interest in the works considered here" and that he consciously selected "one extended treatment of each modern literary genre, novels, plays, short stories, and poems (16-17).” The Latin aphorism obtains here: de gustibus non est disputandum. For whatever reason, Gilmore does not turn his skill and eye to Faulkner. It is also obvious from Gilmore's list that testosterone is as strong a force as alcohol: there are no women writers in his mix.

Gilmore appends an opinion in the "Epilogue" of his book: drinking and drugging among writers are Modernist phenomena that will wane. He sets up the argument If two of the leading characteristics of modernism are a radical dissatisfaction with commonplace reality and a consequent attempt to undermine conventional reality by greatly altering traditional states of consciousness, the fundamental challenges to and ruptures of these states offered by heavy drinking may seem desirable from a modernist viewpoint. [...] One could argue that, just as early modernism is marked by a willingness to alter consciousness or perception by the use of opium, late modernism is marked by a similar willingness to use alcohol. (170)

Gilmore arrives at a rather interesting conclusion. 
Although some artists will doubtless always wish to experiment with the heavy use of alcohol or drugs, in my view such experimentation will increasingly come to be regarded as an exercise in futility. For one thing, writers like Malcolm Lowry and John Berryman have probably demonstrated all that drinking can do to enlarge the writer's repertoire of experiences and perceptions; further attempts of this sort would probably only sound like a mediocre imitation, a harsh phrase nevertheless accurately characterizes the relationship of, for Kerouac's Big Sur to Under the Volcano. For another, there are signs of an increasing reluctance among modern writers like Carver, Dickey, and Berryman to see a martyrdom to alcohol as somehow warranted by the resulting work of art. (175)

Essentially, he is suggesting that social learning will warn-off the would-be creative writer from the lure of intoxication, because that practice results only in genres that have become aesthetically passé, or that artists will, by social learning, make an accurate riskversus-benefit assessment of the destruction the artist endures compared to the creation the artist makes. It will be interesting to see if genre mutation will trump gene stability. I personally doubt that it will.

Gilmore presents A.A. in a very positive light and hints at more than a casual acquaintance with the organization, in that he must not say "too much," a reticence that a keeps the tradition of never breaking anonymity at the level of press. He states in the opening sentences of his Introduction:

Probably some readers will sense how profoundly personal this book is: the experiential suffering and knowledge in which it is grounded at its deepest levels are the kinds that, as Kirby Allbee puts it in Saul Bellow's novel The Victim, can only be gained "the hard way, the way you pay for with years of your life." To say more would be to too much, except to add my heartfelt gratitude for being among the few who have been able to pass beyond their suffering and use it as one means to secure and enlarge their knowledge. (3, emphasis added)

A bit further he offers, "[...] the usual result of alcoholic drinking, as AA has discovered, is the escalation of fear rather than the courageous confrontation or use of it [... (13)."

Yet at the end of the Epilogue, after contrasting James Boswell's drunkenness against Samuel Johnson's abstemiousness (a stance Johnson adopted in response to his 
wife's alcoholism), Gilmore makes the odd statement, "No important thinker before the advent of Alcoholics Anonymous subjected the attractions of drinking to such skeptical and damaging attention as did Johnson (175)." Others have obviously offered attention in exactly that criticizing manner, and A.A. has never criticized attraction to drink per se. A.A. is quite clear that it has no quarrel with drinking for people who are not alcoholic. In fact, the only condition among normal drinkers on which that A.A. ever comments pejoratively is anger, an emotion which the members have dubbed as a certain poison for themselves and the "dubious luxury of normal men (66)." Though it is certainly true that A.A. has brought attention to the problem the problem-drinker has with alcohol, it is equally clear that A.A. has no interest in addressing or criticizing the way that normal drinkers drink alcohol, or the way that some people simply leave it alone because they do not like it. A.A. simply carries the message that those who find themselves in their fellowship, and who admit to being real alcoholics, will never find a place among normal drinkers or the normally abstinent.

What becomes clear, then, is that Samuel Johnson -- in ways similar to Upton Sinclair -- is a non-participant observer of the "Abstainer x Rejecting" cell, and that Thomas Gilmore is a participant-observer of the "Taken-by" x "Tolerating" cell; though his toleration is tinged with skepticism and he leans toward the Rejecting category.

Donald Goodwin, the psychiatrist who generated the research that establishes a hereditary predisposition for alcoholism as cited above in Chapter One, contributes to this narrowed discussion with his book, Alcohol and the Writer. For Goodwin, this dual focus of his work - the investigation in Danish adoption records for the hereditary causes and combing through famous authors' biographies for their drinking habits-- makes 
perfect sense: each inquiry is sparked by his fascination with group differences. That is to say, Goodwin is not seduced by Shakespeare's Porter. He doubts alcohol's universal effects and he adopts a hermeneutic of suspicion. The first sentences of the "Introduction" state, "This book has a hypothesis. The hypothesis is that well-known writers in America during the first half of the twentieth century were extraordinarily susceptible to the disease called alcoholism (Alcohol, 1)." This psychiatrist is clear that he accepts a disease model. The emphasis on groups differences regarding predispositions to the disease is even more clearly stated in, "Notes on an Epidemic," where Goodwin summarizes across all of his studies relating to alcoholism:

Alcoholism is distributed unequally among groups. More men than women are alcoholic, more Irishmen than Jews, more bartenders than bishops. The group, however, with perhaps a higher rate of alcoholism than any other consist of famous American Writers. (Alcohol, 172)

Neither bartenders nor American writers share familial lineages the way that Jews and the Irish do, so Goodwin faces the task of inferring a mediating variable that accounts for the expression of group-differences among occupations. Although he does not explicate their particular situation, bartenders - who can both self-select into their situation and are then allowed easy access to ample quantities of alcohol -- represent the very opposite condition of that found among Saudi Arabian subjects, who cannot self-select their nationality and have virtually no conditions of easy access to alcohol. It is clear that Goodwin, although accepting (even having proven) the genetic propensity to alcoholism, knows that it is a necessary, but not a sufficient condition, for disease expression.

So what, then, does he infer about American writers, especially those of the first half of the twentieth century? Goodwin wrestles the variables individually. He sets and answers a series of italicized questions in the book Alcohol and the Writer. For the 
question, "Did the epidemic mainly involve American writers?” he concludes, “...the epidemic, until proven otherwise, remains a largely American phenomenon (Alcohol, 173-175)." For the questions, "Did the epidemic chiefly occur in the first half of the twentieth century? What is happening in the second half?" he admits that there is little hard data (Alcohol, 175). He does note that if there were changes, it is not because alcohol, as a legal drug, was used in less frequency of quantity within the entire population (not just among writers). The data only show, for the whole population, that use of other recreational drugs rose in the second half of the century, but not that alcoholuse declined. After asking, "So, to the question 'Are writers drinking less?' he opines the answer "probably." To the question, "Is the drinking writer the celebrity he once was?" the answer is categorically "no" (Alcohol,175-177, emphases in original)." To the question, "Did the epidemic also involve creative people in the other arts?" his opinion is "[p]robably, to some extent (Alcohol, 177)." For the question, "Did the epidemic mainly involve well-known writers?" he concludes, "[i]t is impossible to know whether obscure writers are as frequently alcoholic as well-known writers, for the obvious reason that well-known writers are well-known and obscure writers are obscure (Alcohol, 178 179)." For the question "Did the epidemic involve specifically alcohol, or were other drugs also abused ?," he finds that though other drugs, especially barbiturates and other sedatives, were evident, "For most alcoholic writers in the twentieth century's first half, alcohol was the 'drug of choice' and he adds, "[w]hether this is changing in the second half is not really known (Alcohol, $179-80) . "$

Those are questions of correlation. Next Goodwin addresses causality and acknowledges bluntly, "[...] the problem may be unstudiable (Alcohol, 181)." He does 
not let, however, that possibility stop his inquiry, and he states, "[s]till, curiosity is not satisfied by saying many writers drank, and isn't that interesting (Alcohol, 182)." He explores some hypotheses. First, "The hours are good (Alcohol, 182)." This sets the opinion that the unstructured, solitary nature of writing creates opportunity for unsupervised drinking, a condition which leads to excess drinking that would not otherwise have occurred. Goodwin finds, however, the reverse explanation is actually the better one: people self-select into professions that cater to a characteristic. In this case, the characteristic is a desire to drink. Bartenders become bartenders because it allows them to drink, and postal carriers become postal carriers because, on the whole, they have little interest in drinking and no need to avoid a profession which, by its demands, militates against excess drinking. He states, "People choose jobs and jobs choose people (Alcohol, 183)." Synergy, more than something insidious about the act of writing per se, is at work. People get drunk on alcohol, not ink. For the hypotheses of "It is expected," he voices considerable agreement (Alcohol, 181). He notes, "In the twentieth century society came to expect drunkenness in its famous writers," and he concludes tersely, "[t]he moral is this: societies, like individuals, get the sort of drunken comportment they allow (Alcohol, 185)." For the hypothesis, "Writers need inspiration," he parses the answers he had heard: "There are three opinions about whether alcohol provides inspiration for writers. One holds that it never does, another that it sometimes does, and a third that it is essential (Alcohol, 186 - 187)." Goodwin entertains the second of the inspiration hypotheses:

Drinking produces a kind of chemical trance, an "altered state of consciousness" in the current jargon. If alcohol does help writers write, this may be why. "Genius," William James said, "is little more that the faculty of 
perceiving in an unhabitual way." Nongeniuses, intoxicated, see the world in an unhabitual way. (Alcohol, 187)

Goodwin's states that in addition to inspiration, alcohol may help the writer in two other ways: "It may help in starting and help in stopping (Alcohol, 189)." The first effect has to do with quelling the critical inner-voice that would inhibit initial expression, and he quotes Tolstoy. The second effect may be to sedate the racing thoughts of some writers who are either prone to rapid, manic cognition (he cites Truman Capote), or the obsessive-compulsive type, exemplified by James Thurber (Alcohol, 189). Goodwin also entertains slightly the reports that some writers actually felt they needed to feel poorly to write, citing T.S. Eliot, Turgenev, and Freud (Alcohol, 190).

Goodwin's major assertion in his work, however, depends on an insight from historian Gilman Ostrander, whom he quotes, "'Alcoholism is basically a disease of individualism" and that writing "' $[\ldots]$ is a profession which allows the individual to be tremendously convivial all by himself .... Writing and drinking are two forms of companionship' (Alcohol, 191)." Goodwin riffs on this notion, suggesting three ways this theory "explains much (Alcohol, 193)." First, that "[w]riting and alcohol both produce trancelike states." Second, that "[c] reative writing requires a rich fantasy life; loners have rich fantasy lives -- the ultimate loner is the schizophrenic who lives in a prison of fantasy. Alcohol produces fantasy (Alcohol, 193)." Third, that "[p]eople with so-called multiple personalities are said to be loners regardless of the personality they assume. The writers in this book can all be said to have multiple personalities: they were chameleons, always changing, particularly when drunk (Alcohol, 193).” After punctuating his discussion with citations from the lives of famous writers, he notes: 
Their storytelling gifts as children, their tortured sensitivity, their inability to mature completely, the incongruities in their personalities - all may reflect an inability to feel at home with people. With Thomas Wolfe and the rest, it wasn't just that they could not return home again; they didn't know where home was if they looked. (193)

Goodwin speculates further that this "loner theory" nests nicely with "rugged American individualism," thereby answering the question of "Why America (Alcohol, 193-194)?" He also considers the possibility that many famous American creative writers cut their quills first in the rough-and tumble, heavy drinking arena of newspaper journalism (Alcohol, 204). This suggestion, however, undercuts his previously argued point that certain professions allow more than spawn aberrant drinking.

This final section of Goodwin's book is simultaneously fascinating and frustrating. It reads like a hodge-podge of richly provocative ideas, but the ideas are tangled fragments and are presented in a way that is oddly out of character for someone of Goodwin's stature. He has proven himself otherwise to be such a thorough master of method on medical science, a skill which his careful sifting of data regarding heredity and alcoholism had demonstrated. The problem is not simply, as Goodwin acknowledges, "[m] uch of the above is based on impressions and anecdotes (Alcohol, 197)." It is the way he has interpreted those impressions and anecdotes.

He has already admitted, at the section that seeks to determine causes, "[...] the problem may be unstudiable. There will always be theoretically minded people who will cram the writer-drinker phenomenon into a favorite theory, but the connection seems to resist the scientific method (Alcohol, 181)." The task of operationalizing the variables in accord with appropriate sampling and measurement of subjects would be immense, of course; and, indeed, it is quite likely impossible. The problem with Goodwin's musings, 
however, is not simply that they are impressions and anecdotes and that the larger task is perhaps unapproachable. The problem is, rather, that several of Goodwin's important interpretations, as well as the limited hard data available and presented, are not carefully arranged and vetted by the foundational principles of scientific method using simple thought experiments.

For example, Goodwin posits certain attributes that can construct a testable argument. 1) If alcoholics are loners (following Ostrander, whom Goodwin quotes) and “"[t]his solitary outlook prevents them from gaining emotional release through associations with other people, but they find they can get this emotional release by drinking' (Alcohol, 191)," and 2) if alcohol spawns trance-like states that allow the alcoholic to create fictive relationships and a fictive, controllable access to self-discovery not available in real-world encounters, and 3) if writing is the avenue to such fictive encounters, then all alcoholics should be found to exhibit the behavior of creative writing, regardless of the particular skill any individual drunk might be able to muster up for the task. This result, however, is not observed. Although a great percentage of writers are indeed observed to be alcoholic, a great percentage of alcoholics are not observed to be writers; not even obscure, untalented writers.

The reason Goodwin's argument fails is that it has become mired in what is known as a fundamental error in inferential statistics. It assumes that the probability of event A, given event B, is the same as the probability of event B, given event A. This problem in statistical inference is the offspring of the fallacies exposed by philosophical logic as it demonstrates the outcome of flawed syllogisms when categories of "all" and "some" are confounded. These thought exercises fuel the wicked delight of the high 
school student who learns to "prove" (by false inference) that "Socrates is a dog." We are back to our problem of the Porter in Macbeth and universals, and Goodwin has lapsed into it. He has done a good job of demonstrating that a disproportionate number of writers are alcoholic simply by measuring the behaviors that appear in the biographies, but his theory of causality suddenly swerves toward a proof that a disproportionate number of alcoholics should be writers. He does not draw that conclusion himself in the book, but it is sitting there quietly, awaiting enunciation and this repudiation.

Goodwin also contradicts his own presentation of hard evidence when he makes another error. His observation, quoted above and offered again for clarity, is "[c]reative writing requires a rich fantasy life. Loners have rich fantasy lives - the ultimate loner is the schizophrenic who lives in a prison of fantasy. Alcohol produces fantasy observations (Alcohol, 193)." This condition should lead logically to the conclusion that people with schizophrenia, even more than alcoholics, should be frequently observed to be creative writers. Goodwin, however, cites Nancy Andreasen's longitudinal research on thirty writers, research that shows no schizophrenia but which does show $30 \%$ of them to be alcoholic. The zero-percent for schizophrenia is less than the $2 \%$ for the population at large while the $30 \%$ for alcoholism is at least twice (perhaps thrice) the rate for the general population. His knowledge of Andreasen's data should have given pause to his articulation to his particular formulation of the "loner" hypothesis.

To his credit, Goodwin did understand that Andreasen's data provided a fundamentally important discovery: creative writing correlates more strongly with the biological family members' expressions of creativity (whether in writing or other activities such as art or dance) and with biological family members' mental illnesses. 
This linkage and Goodwin's initial musings about the fact that both manic-depressive disease and alcoholism each have a strong genetic basis will become very important in the discussions in Chapter Three of this project. Goodwin, however, shows another interpretative error even when he comments on Andreasen's research. He states, “[ ...] this study had drawbacks, the main one being the small number of subjects (thirty)" and "[t]he sample was, alas, exceedingly small, although the difference between the writers and controls reached statistical significance (Alcohol, 197,199)." If there is a problem with Andreasen's subject sample, it has nothing to do with sufficient size in the sample. There may be a legitimate question as to whether or not the sample is representative of the target population of all writers, but increasing sample size does not answer that question. I, for one, cannot definitively say that writers from the Iowa Writers Workshop represent well the population of all creative writers in America. I can say, however, that if a researcher is able to find such strong statistical significances with a small number of subjects, then the discovered effect (in this case, expression of alcoholism) within the sample reveals, in fact, a very strong effect and the researcher does not need a larger sample. Increased sample sizes only increase the statistical power of the study, not the force of the effect being studied. Graduate students fail exams in statistics every semester over this difference. An analogy would be that our ability to detect the weak radio waves from stellar sources requires a radio telescope the size of the volcanic crater in Puerto Rico, whereas the ability to detect my local classical music station's strong radio signal only requires a small coil made of a few copper wire windings. Andreasen detected a strong effect using a study that actually had very little power, and this result speaks in loud volume with little effort. 
Goodwin's musings have shaken a few more important variables into view, but they are not well enough arranged in his book to allow for convincing conclusions. His writing about the alcoholic writers themselves, however, is lively and it is consonant with the biographical facts. His book mentions many writers (he offer at one point a list of forty-eight names of famous writers who were also famous for being at least sometime drunks, a list he generated himself in only a half-hour's meditation), but he focuses on Poe, Fitzgerald, Hemingway, Steinbeck, Faulkner, O’Neill, and Lowry in his descriptive chapters $($ Alcohol, 4). Although he does not delve deeply into the way Faulkner depicts drinking in his fiction, he does note that, in the masculine culture of Faulkner's family, "[d]rinking and violence were all mixed together, as they were in Faulkner's stories (Alcohol, 118)." Goodwin is well acquainted with the then-published sources of Faulkner's life, including Blotner's 1974 two-volume work and the 1984 reissue, a work that Goodwin recognizes as having been "much revised (Alcohol, 122)." Further discussion of Blotner's revision - and not simply his concision of the two volumes into one - will be germane to the discussions in Chapter Five of this project. Goodwin also knows Judith Wittenberg's seminal study Faulkner: The Transfiguration of Biography, a work that ties the author's life to the author's work. Not surprisingly, Goodwin focuses on the evidence for Faulkner's predisposition to "drink in the genes," but he is as perplexed as most observers regarding the very peculiar form of "dipsomania" that seemed to allow Faulkner some degree of control over when-and-how to conduct his flights into oblivion (Alcohol, 115). He concludes, however, "If William Faulkner was not alcoholic, then the concept of alcoholism should be abandoned once and for all (Alcohol, 120).” 
Is Goodwin a participant-observer? Regarding alcohol, he notes that he was a drinker when it was fun to break the rules in his Methodist college during undergraduate years, but that he simply (and naturally) slacked off when he was a young adult in New York: "I discovered the three-martini lunch, but something was missing: the drinks were legal. (Alcohol, ix).”

Concerning writers, however, Goodwin would qualify as "taken by" if we were to be talking about addiction to the English language. His father owned the small town newspaper, he majored in English as an undergraduate, he was accepted into English studies at Columbia University, New York, where he had courses under Lionel Trilling and W.S. Auden, and he became a successful newspaper columnist before he turned to medical school at age 29 (Alcohol, ix; frontispiece).

This shift was no mean feat in those years when medical schools rarely accepted applications from anyone over the age of twenty-six. After the turn to psychiatric medicine, Goodwin notes of his research focus: "I wanted to do research and needed something to study. I chose alcohol. There were sound reasons for doing so but one reason, I suspect, was Uncle Ralph and his six-pack (Alcohol, ix).” The opening paragraph, written in the terse, staccato, journalistic prose that dominates his entire book, sets the stage of Goodwin's life with clarity:

I discovered books and alcohol at about the same age: seven. A boy's adventure book was lent to me by a- neighbor, and I was hooked. Alcohol I owe to Uncle Ralph. He brought back his fiancée, Alice, to our home in Kansas to be married. He also brought a six-pack of beer. It was the first time alcohol had been permitted in the house. My father even refused beer advertising in his small-town newspaper. Ralph was a former football star, my boyhood hero. Alice was beautiful. Sports, girls, and the six-pack all became identified in my mind. They still are. (Alcohol, ix) 
The vignette sets up a rich mix of primate attractions, human admirations, and the creative adumbrations of both affinities. When analyzed, Goodwin emerges as a Partaker who holds a Tolerant view of leaders who drink. Concerning Faulkner in particular, he notes:

In truth, Faulkner's brain may have been "stunned" by alcohol but alcohol may have fueled his genius and given this shy, introspective man the confidence he needed to write. This of course remains speculative, but for reasons discussed in chapter nine, one cannot dismiss entirely the possibility that alcohol is a source of inspiration for some writers. (Alcohol, 117)

The final impression is that Goodwin's gaze leans toward his admiration of the genius that the genie in the bottle might bestow on the one who courts it. Yet Goodwin is quite aware of the havoc the uncorked power threatens to wreak.

In a move from the genie to the muse, we come to Tom Dardis, The Thirsty Muse: Alcohol and the American Writer (1989). He addresses four major topics in his Introduction before he proceeds in four long chapters to examine, one chapter for each, four major American writers: William Faulkner, F. Scott Fitzgerald, Ernest Hemingway, and Eugene O’Neill.

In the first of the four topics of the Introduction, Dardis (similar to Goodwin) catalogs many more famous drinking American writers than he will actually analyze, and then he offers a similar list of famous American painters who were heavy drinkers. This sets the stage for the hypothesis he hopes to test (and one he eventually will claim to disprove):

Since the painters, and other artists as well, have had their own share of the problem, it seems reasonable to ask if some link exists between alcoholism and creativity. Over the many years, many of our best artists have accepted such a connection. In fact, several have claimed they had little choice but to drink, and heavily at that, if they were to perform at their creative peak. (Thirsty, 3. Emphasis in original) 
Dardis, in retrograde, cites first, Hart Crane, and then Horace as poets who defended intoxication as a required credential. The conundrum of the "American problem" vexes Dardis, and he notes his conversation with English writer Anthony Powell, whom he quotes, “'Good British writers are apt to be by no means total abstainers, but I should have thought you were right in supposing the matter to be less disastrous' (Thirsty,5)." This conversation across the Atlantic has its counterpart in Goodwin's citation of Alastair Cooke, an observer who dismissed (incorrectly, as it turns out) the notion that different professions have differing rates of alcoholism, but who remained puzzled by the undeniable reality of the excess problem among American writers of the first half of the twentieth century (Goodwin, Alcohol, 1). Dardis asserts strongly and early that progressive alcoholism diminished the American writers' creativity:

Many of them became alcoholic, a malady that had much, if not all, to do with the erosion of their talents at ages that were characteristically far younger than those of their European counterparts. Nevertheless, many American writers were convinced that they had benefited richly from their early pact with alcohol and remained assured that had been a necessary ingredient in the brief yet golden period of their youth spite the fact that the muse of alcohol became increasingly deaf to the pleas of these writers as they aged. (Thirsty, 5)

He states, by assertion rather than by measurement, that the European writers kept their creativity charged far longer than the Americans, and proposes "[w]e've had many brilliant beginnings in American writers but far fewer sustained careers (Thirsty, 5)," then moves rather quickly to the conclusion "[it] is clear that alcoholism has played an immense part in this sad and premature loss of creativity (Thirsty p. 6).” Almost in passing, Dardis also notes that women American writers were less affected by alcoholism, a fact he defers in most part to a "social norms" explanation that finds that women were allowed full access to drinking in the mid-twentieth century. 
In the remainder of his Introduction, Dardis lays out the complaint, "[t]here has been a curious unwillingness on the part of the critical community to deal openly with alcoholic writers (Thirsty,.6).” He cites Christopher Sykes's denial that Evelyn Waugh “...could have been alcoholic despite all the evidence he presents to the contrary (Thirsty, 6);" he takes issue that "Blotner views the prolonged binges as experiences that Faulkner chose of his own accord, something willed (Thirsty,7, emphasis in original);" and he takes umbrage at the James R. Mellow statement, which he quotes, “"the best approach would be not to let the Fitzgeralds get away with anything' (Thirsty, 9)." Dardis is quite consciously looking at the way people have been looking at drunk writers; he has stepped into a pragmatic analysis of Lacanian gaze with its bewildering generation of reflected reflections. For Dardis, the mirrors in this funhouse are not funny in the way they distort the images. He chides:

Mellow believes that Fitzgerald's excessive drinking was a clear sign of immorality rather than an indication of his alcoholism. It is fair to say that Mellow and the other Fitzgerald biographers have failed to grasp the implications of a disease that destroys talent as surely as it does health. (Thirsty, 9)

Not surprisingly, this complaint and these examples segue into an extensive presentation and positive defense of the disease-concept of alcoholism. For Dardis, this defense also requires his very severe dismissal of the notion that alcoholics are intrinsically more neurotic than the general population prior to the damage that the drinking itself confers in the course of its three stages - early, middle and final. The first stage offers a friendly relationship between drinkers and drink, and in it the drinkers show both an extreme tolerance for alcohol while garnering very pleasant effects; they can hold their liquor and they like holding it. The second stage introduces a crisis of where the graphed lines of tolerance v. reward cross, leaving drinkers struggling to chase the effect in the face of 
decreasing tolerance. The last stage leaves the drinker in collapse. Dardis develops his defense of the disease model from E.M. Jellinick's 1960 work and George Valliant's first, unrevised 1983 book The Natural History of Alcoholism (1983) (Valliant revisited it in 1995), a work that reports on a longitudinal study of two significantly large cohorts of men followed from their late teen years through adulthood (Thirsty, 14-15). Finally, Dardis caps his Introduction with a very thorough review of Donald Goodwin's amassed evidence for the heritability of alcoholism, a conclusion he heartily endorses while still holding out that environmental factors must be present to trip the switch which genetics have installed. Here he notes, "[t]here are few alcoholics in Saudia Arabia. As indicated earlier, the trigger for the writers in this book was the myth that 'good writers are drinking writers' (Thirsty, 17)."

Dardis errs in method as he presents his argument. The quotation just provided is a good example with which to begin. Dardis is exactly correct about the low rate of alcoholism among Saudis. But note carefully that Dardis has not told us anything about the rate of creative writers among Saudis (i.e. - how many Saudi's per thousand engage in creative writing) nor has he told us about the rate of alcoholic writers among Saudi creative writers (a number which may be so small due to infrequency; an event as difficult to detect as is the elusive monopole for experimental physicists). We do not know from this juxtaposition of "Saudis" against these "four American writers of interest" if there may be among Saudi creative writers a similarly high rate of alcoholism, nor do we know if Saudi creative writers have some similar (or even some different) myth regarding behavior that inspires good writing. What is implied (and what is true) is that the legal penalties against any drinking alcohol for any person in Saudi Arabia are so 
harsh that the drinking of alcohol is almost non-existent, and even harder to detect should any cases occur. The implication from Dardis' statement is that the base-rate of alcoholism in a general population at large correlates with the rate in the subset who are creative writers, an assumption which actually makes perfect sense if we have no contravening data. Yet Dardis has already shown that the base-rate of alcoholism among American writers is extraordinarily higher than base-rate of alcoholism observed in the general population. The inductive power of his argument fails because Dardis has argued first, from missing or confused variables and, second, despite contradicting evidence that he has already affirmed.

This second part of the quotation, "the myth that "good writers are drinking writers"," also reveals a leap in logic. Dardis had carefully shown earlier that the threestage nature of the disease of alcoholism has, as the first stage, a "friendly relationship" of drinker to drink. He had also posited (and I believe, validly) that the late-middle to final stage progression clips creativity and shortens the creative lifespan of a writer. What he has never shown, however, is that drink does not enable a writer to become a good writer in the first stage. He has only shown that good writers who drink too much become bad writers. This difference is crucial, because there lingers the strong possibility that, at least for some people, a "friendly relationship" with drink at the outset of the relationship also enables them to become good writers in that first stage. The question about the quality of craft as alcoholism progresses is an entirely different question; though of course, it is a very important question. But answering it (as Dardis probably does succeed in doing) does not answer the other question: can alcohol possibly help some good writers write better, or help some people who would not otherwise be 
writers, write well? As mentioned in the discussion above, Goodwin has already answered that question affirmatively, and Goodwin offers Faulkner as a prime case example.

Dardis' early error arises when he tries to explain why the U.S.A., with the high rate of drinking writers as compared to Britain and Europe, is "a nation apart (Thirsty, 4). The error is again related to a confusion of general population rates of alcoholism with the creative writer subset rates of alcoholism.

From the earliest days of the Republic, Americans have displayed so avid a thirst for alcoholic beverages that it astonished such visitors as Tocqueville and Dickens. In the nineteenth century, America was often jokingly referred to as the "Alcoholic Republic," and its best writers, from Poe onward, have acquired a well-deserved reputation for the amount of liquor they consume. (Thirsty, 4)

Dardis starts with the general population, and gives two anecdotal reports made by august visitors from across the Atlantic. These reports may have been very accurate in their day, as noted in Chapter One. Those visitors were touring America after the whiskey revolution had altered American alcohol habits. In Dickens' case, his visit comes after his chance to see some effects of some reforms in England that had been addressing the gin problem already depicted by Hogarth in 1751. For De Toqueville's France, there really had been no comparable distribution of inexpensive distilled beverage. I am rephrasing, of course, a two-variable theory that posits the intersection of access-theory (can people get their hands on alcohol?) and social-opprobrium theory (do other people slap their hands when they do put their hands on alcohol?). This two-variable theory is reasonable, and it is actually supported both by the Saudi case and by the thirteen years of Prohibition in the U.S.A. when measurable data shows a reduction of alcohol-related physical diseases, such as cirrhosis, esophageal varices, etc. The risks of a public 
beheading in the Saudi case or a friendly visit from Al Capone in the Chicago scenario are other matters entirely regarding mortality statistics. There may be yet more variables at play in the European American immigration and colonization experience that, perhaps, also explain a genetic pre-disposition to alcoholism for the drinking members of the general population (the upper two deciles), as well as the ease at which about one third of the U.S. population simply does not like to drink and another twenty percent are so moderate in consumption as to be nearly unmeasurable. A hypothesis will be offered in Chapter Three.

Dardis' argument from Dickens and de Toqueville, however, obscures that fact that those two men made observations about the American public at large and not about American writers in particular. Unless a new variable can be identified that distinguishes a subset from its parent population, basic inferential statistics tell us that the best predictor for a phenomenon for both the set and subset should be the same and it should be the statistical mean as the measure of central tendency. There should be no difference between the means. What everyone now has agreed upon, however, is the mean measurement for alcoholism for those American writers is staggeringly higher than the mean measurement for all Americans. Therefore, if Dickens is astounded that more Americans, on average, are drunks compared to all the English, it would not be a surprise if he were then to find that more American writers are drunks compared to all English writers. That would be the "expected value" of the observation. What no one, to date, has established with much rigor, however, is why the mean among American writers is not the American population mean. There are two questions, then. First, what force "distils" drunks (creates a higher concentration) into the American general population 
compared to their parent populations from Europe (if we believe Dickens and de Toqueville)? Second, what force distils drunks within the subset of American writers when compared to the parent population of U.S. citizens (if we believe just about every account so far encountered)? It is easy enough to see, by the transitive property of algebra, that the distillation of drunks among American writers will be greater than the distillation of drunks among British/ European writers if the two prior hypotheses are affirmed, and therefore the percentage of American drunk writers will be greater than the percentage of British/ European drunk writers.

The problem with Dardis' hypothesis, however, is that the effect of his proposed "myth," even if we grant the myth some functional ability to shape behavior, should drive an equilibration of alcoholism percentages when the parent population, "Americans," is compared to the subset, "American writers." If there is a powerful myth that "the good writer is the drinking writer" then such a myth implies that the act of drinking creates good writing, and, therefore, that people who drink will become good writers. Rather than driving writers to drink, this understanding of the force vector should actually drive drinkers to become writers. The expected effect would be that drinking Americans should swell the ranks of the writing profession (i.e. expand the volume), but not that they become more "distilled" (i.e. concentrated) within that population.

Prepared with the basic description of what is required to create differentially concentrated systems as presented at the beginning of this chapter, we can apply it to Dardis's convictions and assertions. Dardis has actually constructed with his "myth" a model of a semipermeable membrane whereby osmotic pressures should cause 
equilibration of concentrations and swell the volume of writers with non-alcoholics. I hope to reveal this claim in step-by-step process that involves some intricacies.

Let us assume with Dardis that writers on one side of social membrane suddenly believe the myth that "a good writer drinks heavily." They obey the myth, and their amplified drinking increases the concentration of alcoholic writers who are in their compartment. But, Dardis also holds that drinking destroys good writing. Therefore, the concentration of truly good writers (not merely alcohol-deluded "good writers" who may never have been any good at the craft, but those who were formerly talented and are now spoiled) should decrease because the poor, misguided talented writers have poisoned their skill sets. This result should lead to an influx of "aspiring" writers into the chamber. If there is some allowance for the now "spoiled writers, whether ever good or always bad," to be washed out, the "aspiring" writers will perhaps keep the volume at near the same level, but the concentration of "alcoholic writers" will fall. If the "alcohol impaired writers" are not washed out, then the total volume has to increase. Whichever is the case, the model does not account for homeostasis of both volume and concentration.

Perhaps Dardis is correct that alcohol consumption is antithetical to good writing, and perhaps we simply lack a sufficient time-span to see an influx of enough nondrinking writers to dilute the "writers' chamber" sufficiently for the concentration of alcoholics to fall, but even that allowance still demands an answer to a question that Dardis has not sufficiently provided: how did the drinking writers ever get so concentrated in the first place, even if the concentration might be now declining. That is to ask, what force "pumped" them into the profession, or what force "pumped" the myth that "good writers drink heavily" into the "writers' chamber," and what force accounts 
for the fact that there are, and have been, some really good writers who, despite assertions to the contrary, really wrote well even while drinking heavily?

I suggest that Dardis cannot be allowed to invoke his same hypothesis of the "myth" to explain the origins of "good writers drink heavily" because the "myth" itself presupposes some learned-experiences (perhaps the term "mis-learned experiences" would be better suited to Dardis' view) based on the non-drinking writers' attention to the good reputations of heavy-drinking writers. By formal logic, an explanation of cause cannot resort to a declaration of axiom. Even if we were to concede 1) that this powerful -- but deceiving - myth seduces many naïve non-drinking American writers so as to convert within the subset of American writers and to become drunk American writers and, thereby, increase the concentration of drunk writers, and 2) that this false, but formerly powerful, "pump" has worn itself out and is no longer maintaining the concentration at the formerly high percentage, Dardis' explanation fails to construct a pump with enough component parts to explain how the original five-of-seven Nobel prize drunks, or even Andreasen's 30\% alcoholics in her Iowa Writers Workshop study, first came to be in the writers' chamber. Is this a mere role-of-the dice in a probability game that seeds the pool of writers with excellent talent and blatant alcoholism, and that their example of "good writing" then causes other rising writers to mimic their drinking in efforts to become good writers? He cannot say.

This silence raises the interesting question: have alcoholics "swollen" the ranks of writers in America (and that is different from asking if they are more prevalent within the cadre of writers than they are outside the cadre of writers). I have no data regarding the percentage of the general American population who call themselves writers; nor any data 
comparing percentage of American writers to other national populations (Britain and Europe seem of special interest). It is not a moot point for discussion of alcoholism and writing in general, but it is not the main point of the project. The works considered here have not considered the question of whether or not Americans, in general, are more or less likely than the British and Europeans, in general, to be creative writers, whether well-known or obscure; talented or pitiable.

Dardis' hypothesis only accounts for origins in the way the Edenic Myth accounts for The Fall. Alcohol, the fermented fruit, is for Dardis, the forbidden fruit. If the writer takes of it, the writer's talent dies, and he or she will fall from the grace of inspiration and be banished from the Garden of Writing. He is working with a universalizing myth

Dardis' model lacks a third variable that would build a pump. Not only does Dardis' proposal lack the third element, Dardis denies the existence of the one possible third variable that would explain a concentrating (rather than a swelling) effect. He denies that alcohol actually correlates at some level --at least for some writers -- with an increase in writing performance. As shown above, he finds that claim to be false. If, however, it were true even for some writers, the phenomenon of observational learning could, in fact, support Dardis' "myth" theory. But that ability to mimic observed behaviors depends upon the ability to observe that the behaviors are reinforced by some pay-off. If the contingencies of the environment never reward the behavior emitted by the observed subject, and even if the observed individual who is fruitless in outcome still finds himself or herself pathologically locked in perseverative behavior such as constant, disastrous drinking, the other non-drinking primates who gaze on the behavior will not 
mimic it unless they become convinced by an alternate reinforcement source to emit the observed behavior.

A quick return to Goodwin's proposal of a "loner" hypothesis shows logically (even if not empirically) the power of a third variable. For Goodwin 1) "loner" personalities prefer alcohol drinking, 2) rugged American individualism increases the base-rate of "loner" personalities, and 3) writing is a profession that fits "loners." Once they are transferred across the membrane from the general population and into the writer subset, the alcoholic writers have a secondary gain in staying on that side even if their writing is not particularly well-known or well-received: the profession itself lets them be alone. Whether or not Goodwin's theory is empirically valid remains open because Goodwin does not offer any psychometric data to support the assertions of personality style. At least at the level of logical analysis, however, the argument has some face validity when considered as a thought-experiment, though I am still not convinced of Goodwin's "loner theory" due to lack of data. I will defer to Chapter Three an argument for a pump that links creativity, leader selection, and alcohol intoxication to the immigrant experience of Americans. "Charting new territory" is a phrase that is used both mundanely for actual migrations and metaphorically for creative writing, and "intoxicating vision" plays a role in both.

Unlike Goodwin, Dardis not only lacks the third variable, but he reduces his argument down to the basic conundrum, "alcoholic writers drink alcoholically because they are alcoholics." Tautology is not really a fault by dint of being a tautology -- every classic argument has to start from an axiom, and axioms are posited, not proven. Dardis' use is a problem, however, because it does not explain the greater percentage of 
alcoholics among writers compared to the general population, and that was a central objective of the book. Dardis' argument is similar to William Silkworth's observation in "The Doctor's Opinion" of A.A. that men and women drink because they like the effect, but Silkworth's axiomatic observation is allowable because it starts with the general population of "all alcoholics" and does not attempt to answer the riddles of uneven distribution among subsets of the general population.

Once this fault is apparent, Dardis becomes an easy target for any whose gaze still rests on the drunk-writer as an individual rather than drunk-writers as a group. Philip Weinstein tilts at this windmill once more in regard to Faulkner's alcoholism:

That "diagnosis" would make Faulkner's chemical dependency essentially the same as anyone else's: alcohol calls the shots, not the profile of the alcoholic. It omits the intricate algebra of the troubled man's encounters with the world. ${ }^{1}$ In what follows I argue that alcohol provides a revealing window into Faulkner's psychological and social makeup. (171)

This section requires Weinstein to acknowledge Dardis' work in a footnote:

1. Tom Dardis [...] devotes some seventy pages to arguing otherwise. [....] Dardis maintains that neither moralizing nor psychologizing is pertinent. "Most alcoholics do not drink because they're emotionally ill to begin with. They drink because they're alcoholics" (13). Dardis provides information about Faulkner's history but offers no explanatory framework for making sense of it other than chemically. (n. 1, 240)

Weinstein does not show any knowledge of Goodwin whose work on alcohol and writers, though nuanced differently than Dardis' review, comes to the same conclusion regarding attempts to let psychoanalytic theory declare the solution to the "intricate algebra" of alcoholism: it simply does not work. It is odd that a writer like Weinstein, who chooses the chapter subtitle, "Rough Spas: Faulkner and Alcoholism," and who essays a psychological interpretation of an author, has not attended to Goodwin. Goodwin is the only noted reviewer of drunk writers, including a drunk Faulkner, who is both a trained 
psychiatrist and a renowned researcher in the hereditary nature of alcoholism. His publications are easily available. As I demonstrate in Chapter Four, psychological theories, such as the notion of defense mechanisms, are, in fact, successfully used to describe how alcoholics enact their disease, but that is a different application of such theory compared to attempts to explain why they acquire their disease.

Dardis can be classified as a "participant-observer" on two counts. Like Goodwin, he was an undergraduate English major (New York University), and like Goodwin, he attended graduate school at Columbia. Unlike Goodwin, he earned both M.A. and a Ph.D. in English there, rather than taking a turn to medicine (Pace 2001 passim). He was both a biographer and an alcoholic, though in recovery by the time he wrote The Thirsty Muse. An obituary appearing soon after his death in 2001 notes that Dardis was "[a] recovering alcoholic who had stayed sober for more than 30 years." The article does not specify what approach he took both to attain and to maintain sobriety ("Tom Dardis, 78" passim). He obviously fits the category of "Taken-by." As to the dimensions of my matrix, he is complex. In regard to the alcoholic, he is Tolerant, and consequently intolerant of interpreters who deny the problem of the disease or misattribute the problem as mere lack of will power or an excess of immoral character.

In regard to alcoholism, i.e. the disease as a scourge for the individual, he is Rejecting, but in a manner that leads to an oversimplification. Some of the matters discussed in Chapter One regarding Alcoholics Anonymous become very pertinent and require some expanded discussion regardless of whether Dardis was or was not conversant with A.A. as his mode of recovery. I would offer, however, that certain hints, such as his use of the word "malady" - a favorite term found in the A.A. literature - as 
well as his strong argument for absolute lack of control of drinking, another prime A.A. tenant, strongly suggest he was a member.

From this perspective, his singular focus on alcoholism as a disease sharpens his pen well. Dardis is a good example of the old adage "you can't bullshit a bullshitter." He has little patience with interpretations of alcoholic behaviors that gloss them either as excusable or as admirable, though he certainly accepts them as symptoms of disease. In another way, however, he has taken a tact that diminishes a foundational insight and directive A.A. offers its adherents. The first one-hundred members of A.A. are quite clear to their readers, "Our liquor was but a symptom. So we had to get down to causes and conditions (p. 64)." Liquor is neither the cause nor the condition. A.A. presents alcohol as their failed solution to address the underlying problems. Causes and conditions always precede symptoms, and even if the A.A. approach parses those precedents in terms of "character flaws" and "our mistakes" - terms more consonant with what has been termed "moral psychology" rather than "psychoanalysis" and with more reference to William James and Carl Jung than to Sigmund Freud or Alfred Adler -- that recovery movement was wrestling with "the Self" as the root of the problem (62).

Bill Wilson made clear in his approaches to the medical and psychiatric societies that he addressed, that he considered a good one-half of the recovering A.A. members to exhibit neurosis, and he does not attribute those conditions only to the effects left by years of drinking. They were neurotic before the first drink, but the origin of the neurosis may be even more biochemically foundational than psychodynamic explanations allow. Wilson also was clear that A.A. welcomed the insights psychiatry and biochemistry each brings to the problem. He was equally clear that, in the experience of the people who 
created A.A., psychological solutions alone would never suffice to correct the problem for them. He states clearly, "It should be noted here that some of the recovery methods employed outside A.A. are quite in contradiction to A.A. principles and practice. Nevertheless, we of A.A. ought to applaud the fact that certain of these efforts are meeting with increasing success (Three Talks, 21)." For those, however, who are in A.A., even if a psychological diagnosis may be pertinent, a psychological solution that touts self-sufficiency alone is insufficient, and he interprets to the health-field professionals one articulation of their solution: “This is what most A.A.'s are trying to say when they talk about a spiritual experience. They mean a certain quality of personal change which, in their belief, could not have occurred without the help and presence of the creative Spirit of the universe (Three Talks, 29).”

I defend this return to discussions of alcoholism models because such conceptions affect not only the gaze people cast at alcoholics, but also the gaze that people cast at the bottle. Dardis simply does not trust the bottle at any level. If he did know the A.A. dictum (and he probably did), "Remember that we deal with alcohol - cunning, baffling, and powerful (p. 58)!" he is not paying much attention to the subtleties of the baffling and powerful attributes. This is where I find too much resonance in his myth with the Edenic serpent, the most "cunning" creature of the garden. He is obsessed with the cunning part. Dardis really finds it impossible to consider that a baffling aspect of alcohol, even among alcoholics, is that the chemical might very well prompt authentic creativity for a period of time in some people before the physiology of the alcoholic turns to crisis and then to collapse. He reads Faulkner's creative life, then, primarily as one in which Faulkner's intrinsic creative gift of genius surpasses the effects of alcohol in the 
first stage of an amiable relationship to drink, and not as a life in which the alcohol itself either created, or at least amplified, the genius itself. Dardis always tends to see the cunning aspect of alcohol in rather simple terms. The chemical only tricks the writer into believing that alcohol has helped; not that alcohol truly helps the alcoholic writer for a period of time and then later fails to help. Despite the metaphor, alcohol never turns on the drinker. The alcoholic's body (and the brain is part of the body) turns on the alcohol, lending a deafened ear to the former muse. Yet those in A.A. are advised, "We are careful never to show intolerance or hatred of drinking as an institution (103).” This presumably means also the institution of drinking among writers.

After Dardis' book appeared in 1989, Crowley emerged with his contribution in 1994, but we then must wait a biological to find young reviewers gazing at our old drunks. The as-of-yet unpublished dissertation (2013) by Conor Picken has been mentioned already. As noted, Picken turns to the trope of the drinking Southern genius to find some redemption of an individual's recovery from addiction (or the failure to recover) as a metaphor for the region itself in its struggle to recover from a collapsed addiction to power structures built on white, male privilege and dominance, a problem comparable to the third-stage of alcoholism. His review addresses Faulkner's biography and writings well, and he shows a thorough knowledge of the literature that has been reviewed above. Picken examines the way writers write alcoholism into their characters and narratives, and even the way Faulkner writes "sobriety" into Requiem for a Nun. These aspects of his work will assist well in Chapter Four of this project. Picken moves from William Faulkner to Robert Penn Warren and then to Cormac McCarthy, bridging that ever-mentioned mid-century divide by the continuity of their three august traditions 
of writing. He then takes his reader into the emerging "Grit Lit" rebellion in Southern writing as led by Harry Crews, Larry Brown and Nelson Jordan. Theirs is a movement determined to burn down every last magnolia and plantation, and one which finds little hope in recovery, whether considered concretely in regard to addiction in the South or metaphorically in regard to the any significant social recovery from racism and poverty. Picken appears to be neither Taken-by nor Abstinent, and he is more than Tolerating. "Long suffering" better catches his character.

In another book where reality and metaphor vie with each other for dominance, The Trip to Echo Spring (2013), Olivia Laing presents a travelogue which is a dialogue of her life in concert with the lives of famous American alcoholic writers. The book is literally a train-of-thought: her memoir of her train-trip across the U.S.A. to visit the prime places associated with John Cheever, F. Scott Fitzgerald, Tennessee Williams, Ernest Hemingway, Raymond Carver, and John Berryman. Truman Capote and Hart Crane also each gets a mention in passing. The book is a lovely read, but hers is a thoroughly personal journey: she is out to make sense of her own life, not necessarily the lives of those she reads. She notes, "As to the origin of my interest, I might as well admit I grew up in an alcoholic family myself. Between the ages of eight and eleven, I lived in a house under the rule of alcohol, and the effects have stayed with me ever since (Trip, 12)." Her narrative reveals hers enjoying wine on the trip, so she is not an abstainer. Laing is English, and her mother, also a writer and English, is the designated alcoholic, but her attraction to the Americans came in her encounter with Tennessee Williams' play, Cat on a Hot Tin Roof, where she found her experience of dealing with an alcoholic's behavior, Brick on a crutch, taking his short trip to Echo Springs (his name for the liquor 
cabinet) by limping across its page and stage (Trip, 12). She explains her book in terms of her itinerary:

Each of these locations had served as a way station or staging post in which the successive phases of alcohol addiction had been acted out. By travelling through them in sequence, I thought it might be possible to build a kind of topographical map of alcoholism, tracing its contours from the pleasure of intoxication through to its grueling realities of the drying-out process. And as I worked across the country, passing back and forth between books and lives, I hoped I might come closer to understanding what alcohol addiction means, or at least, to finding out what those who struggled with and were sometimes destroyed by it thought alcohol had meant for them. (Trip, 14)

Women, except for the reference to her mother, are absent. She addresses this lack in a lengthy 2014 article where she abandons both the confines of U.S. geography and the limits of testosterone. To answer the question, "are their women alcoholic writers," she lists Jean Rhys, Jean Stafford, Marguerite Duras, Patricia Highsmith, Elizabeth Bishop, Jane Bowles, Anne Sexton, Carson McCullers, Dorothy Parker and Shirley Jackson. She notes, accurately, that the best evidence indicates that alcoholism is about twice as likely for men than women in general ("Every Hour," passim). As to whether they drink for different reason than men, she tends toward the answer that socially-imposed shame of betraying an expected gender role plays strongly in their drive to the bottle, and that the turn to the bottle is itself a violation of the same expectations. This reciprocation compounds the shame. Although the article is descriptive and informative, the format is simply too short to contribute much to the conversation about the relationship of "ink and drink" for writers. Perhaps Laing will take the opportunity of the interest and expand that small survey into a well-needed book.

But what of Laing's view of Faulkner? She does not even mention him. Her chapter title, "Going South," raises the hope of a side-trip to Rowan Oak, and the map of 
her itinerary (Trip, xi) shows the railroad line she traveled from New Orleans to Chicago, grazing Oxford, Mississippi. The limits of American rail transit may be to blame for her choice to leave Faulkner out, but Laing had indulged air travel to get to Hemingway's Key West, so she was not rigid in choosing transportation modes. It is puzzling, and perhaps she simply had never been "Taken-by" the drunk genius who wrote about Jason Richmond Compson's nightly visits to the sideboard. Whatever the reason, there is no trip to Yoknapatawpha. 


\section{CHAPTER THREE FERMENTING THE MASH: STRONG OPINIONS ON STRONG MINDS, STRONG DRINK AND STRONG IMAGINATION}

Bourbon is birthed from a rank, opaque mash that little resembles -- and poorly promises - the amber clarity that fills glass bottles from charred aging oak barrels. The sources of creative genius that allow someone like William Faulkner to summon a Yoknapatawpha into existence are of similar, muddled origin. It is no surprise that David Nettle, a leading researcher in the components of creativity, turns to the Bard for a litany of the mix:

The lunatic, the lover, and the poet Are of imagination all compact.

....

And as imagination bodies forth

The form of things unknown, the poet's pen

Turns them to shapes, and gives to airy nothing A local habitation and a name. Such tricks have strong imagination.

Nettle's work, including his book Strong Imagination: Madness, Creativity and Human Nature, will be considered in detail below, and he quotes these lines, along with a few ellipsed, from A Midsummer Night's Dream. Theseus' words serves as the inspiration for Nettle's thesis:

What Shakespeare has posited, then, is a psychological trait, dubbed strong imagination. He has also made three claims about it. First, it is and inherent aspect of human nature; second, it is especially highly developed in madness and in creativity; third, it is somehow associated with the business of love, or at least, sexual attraction. (Strong, 3) 
I add to the list a fourth component - intoxication -- to ferment in the mix. It plays a role in describing an arc that spans Faulkner's life from cradle to grave; from the origins of a creative drive he first exercised stunningly and in obscurity, to a brilliance recognized belatedly in awards like the Nobel, and finally, to an ability so diminished that even in the immediate glow of the prizes, magazine editors turned down stories from the Nobel laureate. Even while fame failed to keep pace with his talent, Faulkner's gift failed to keep pace with his drinking. But there was a short span in the middle when magic happened.

Coming to clear conclusions about how endowed talent, mental health cum mental illness, and intoxication mix together in artists either to make a masterpiece or to mess up a project will not be easy. Juggling the three variables 1) creative endowment, 2) mental illness, and 3) substance use/abuse is somewhat like juggling three balls: at least one is always up in the air. Examples of such dexterity are not currently clear in the literature, with the possible exceptions of Nancy Andreasen's longitudinal study published in 1987 and Arnold Ludwig's 1995 book, The Price of Greatness, and even there the concurrent variables are actually cataloged rather than explained in relationship. When explanatory connections are attempted, the variables are generally approached as pairs, with creativity and mental illness in the first coupling, creativity and substance use/abuse in the second pairing, and mental illness and substance use/abuse as a third dyad. Discussion of a relationship across all three, therefore, will require a bit of a round-robin approach.

A foundational question about a basic dyad serves as a preface to all three dyads just listed: what is the relationship of creativity and the arts? Mihaly Cszikzentmihalyi has been concerned throughout his professional career with exactly this relationship. His 
1965 University of Chicago Ph.D. dissertation is titled, "Artistic problems and their solutions: An exploration of creativity and the arts." Three decades later, he published, Creativity: Flow and the Psychology of Discovery and Invention (1996). Reading across those years of findings reveals that his concept of "flow" is his answer to the nexus of creativity and artistic production: the experience of flow allows the latter, and the latter allows the experience of flow. This proposal appears a bit circular, and Cszikzentmihalyi is both honest enough to admit that an unavoidable circularity is implicit in the arguments, and he is clear enough to point out that the very reason for the circularity is that the complex systems depend on a constant integration of the differentiated components. Although he does not draw the comparison himself, it is simple enough to refer to The Calculus for the parallel: differentials and integrals are each the inverse of the other and constantly refer to the reflection. Although Creativity, his 1996 book, is to be commended for the way it focuses information theory on the categories of skills, domain and mastery and then applies such analysis to the redacted self-reports solicited from hundreds of eminently famous artists and inventors concerning their subjective experience of flow, I find that Czikszentmilhalyi's earlier work addresses the underlying components of the creative writers' experiences more effectively. His academic articles on flow precede but are well presented in his book, Flow: The Psychology of Optimal Experience (1990). In the preface he states, "This book summarizes, for a general audience, decades of research on the positive aspects of human experience - joy, creativity, the process of total involvement with life I call flow (Flow, xi)."

Within human experience, he clarifies a crucial distinction between pleasure and enjoyment. First, consider his understanding of pleasure: Pleasure is a feeling of contentment that one achieves whenever information in consciousness says that expectations set by biological programs or by social conditioning have been met. 
The taste of food when we are hungry is pleasant because it reduces a physiological imbalance. Resting in the evening while passively absorbing information from the media, with alcohol or drugs to dull the mind overexcited by the demands of work, is pleasantly relaxing. (Flow, 45)

Next, for enjoyment, he notes:

Enjoyable events occur when a person has not only met some prior expectation of satisfied a need or a desire but also gone beyond what he or she has been programmed to do and achieved something unexpected, perhaps something even unimagined before.

Enjoyment is characterized by this forward movement: by a sense of novelty, of accomplishment. (Flow, 47 )

His crucial concept of novelty within enjoyment will appear again as Nettle traces the roots that nourish strong imagination.

Cszikzentmihalyi's implicit assumption of universality regarding where the boundary lies between pleasure and enjoyment also deserves special mention. He introduces in the book, Flow, several key concepts that are expanded in Creativity, one being that the achievement of enjoyment requires mastery of a domain by expert skills, but he seems to assume that the opportunity to transform a pleasure-driven life into an enjoyment-enticed life is pretty much the same option for all. He is not saying that anyone can become a Picasso, or that a medium of paint-on-canvas (or any other medium for that matter) is the superior way to experience flow. He does hold, however, that flow is a possibility for nearly anyone in any line of work. He overtly states, "[...] it would be a mistake to assume that only art and leisure can provide optimal experiences. In a healthy culture, productive work and the necessary routines of everyday life are also satisfying (Flow, 51).” Cszikzentmihalyi's assumptions of such equal opportunity reveal a problem after making a close examination of his statements on both pleasure and enjoyment. 
Reviewing first pleasure and the individual's response to alcohol and drugs as quoted above, Cszikzentmihalyi assumes three things. First, he only considers that the substance dulls the brain rather than sharpens it. What of the possibility that the actual use (i.e. - ingesting the substance) leads to a heightened brain function that is still within the domain of pleasure? Second, he ignores the possibility (closely related to the notion of pleasure in excitation) that a person who uses alcohol might not actually transform the foundational pleasure of ingestion into novelties of acquiring alcohol, sharing it with others and comparing the experiences in ways that it actually becomes a type of enjoyment. Members of Alcoholics Anonymous, in the paradox of their program, have long noted both aspects of alcohol: "For normal folks, drinking means conviviality, companionship and colorful imagination," and A.A. has no argument against such conviviality for normal drinkers (151). As for their selves, they have, however, recognized the dark side of each aspect of "the game of using" and they have distinguished between the cognitions directed toward the pleasure response of the substance and those directed toward the enjoyment of the institution of drinking. They call the first craving ("They cannot start drinking without developing the phenomenon of craving (xxx).") and the second, obsession ("The idea that somehow, someday, he will control and enjoy his drinking is the obsession of every abnormal drinker (30)"). Third, Cszikzentmihalyi implies that one individual's response to a chemical is fairly similar to another individual's response, and therefore, that each individual really has the ability to "decide" to forgo a chemically induced pleasure and to choose non-substance related actions that will afford novelty with its concomitant enjoyment. 
This brings us back to his second concept, enjoyment. Without pushing far enough into his paradigm to see the implications, Cszikzentmihalyi describes a situation is which enjoyment itself can go awry:

Almost any enjoyable activity can become addictive, in the sense that instead of being a conscious choice, it becomes a necessity that interferes with other activities. Surgeons, for instance, describe operations as being addictive, "like taking heroin."

When a person becomes so dependent on the ability to control an enjoyable activity that he cannot pay attention to anything else, then he loses the ultimate control: the freedom to determine the content of consciousness. Thus enjoyable activities that produce flow have a potential negative aspect: while they are capable of improving the quality of existence by creating order in the mind, they can become addictive, at which point the self becomes captive of a certain kind of order, and then unwilling to cope with the ambiguities of life. (Flow, 62)

He has actually posited in this 1990 book a view that is increasingly accepted (though not without continued argument) among health professionals. They hold that behavioral process disorders are similar enough to substance-use disorders that they deserve similar diagnostic recognition, and that they are more than variants of obsessive-compulsive disorders. One such process problem, pathological gambling, has now "made the leap" from one category to the other in the Diagnostic and Statistical Manual V. The emerging trend in nosology seems to accept that though there are two kinds of addiction, one to substance and one to process, both are, indeed, addictions.

With his foresight in diagnosis, however, Cszikzentmihalyi has also unwittingly painted himself into a corner regarding options for intervention. He implies that the remedy for pleasure addiction is for the person to choose, instead, engagement in acts that generate enjoyment. But where does the addict turn when even acts of enjoyment become addictive? To other acts of enjoyment? Does this turn then bode simply a sequence of "enjoyment addictions" until death intervenes? If so, why bother? He does 
not push his program to this explicit extent, but it is hard to see hard to see how we avoid singing with Peggy Lee, "Is that all there is? If that's all there is my, friend, then let's keep dancing. Let's break out the booze, and have a ball, if that's all there is." In both astrophysics and phenomenological psychology, the event horizon looms as the last line before a black hole swallows all light.

Despite this critique, I still find Cszikzentmihalyi's insights in Flow the more useful for this project when compared to those in his later book, Creativity. In Flow, he reports on people who are both inside and outside the creative and artistic fields. That is to say, this earlier focus on the experience of "flow" sets up a way of looking at group differences as he divides the population into artists (writers, painters, sculptors, and so forth) and non-artists (mountain climbers, factory workers, rural Italian goat herders, for example) who report the experience of "flow."

Such a division also implies two other divisions. First, it implies that some people do not experience flow easily. Second, it implies that even those folk who do experience flow easily at certain times have other periods when flow is absent. To some extent, he assumes that most of the population is in-and-out of flow at different times. The one category of people he reports to be universally cut-off from flow are people with schizophrenia. He finds that their disease reduces ability to judge the salience (or personal value) of any one experience when compared to another, and that this deficit, therefore, reduces their ability to focus consciousness on goal-directed behaviors which would increase the possibility of pleasure. He is touching on a foundational inability to experience pleasure, or anhedonia. This factor of anhedonia takes on increased importance in David Nettles' 2006 research that followed his book, Strong Imagination. 
The condition of being in-and-out of the flow experience can be parsed by philosophy as well as by psychology. An old joke goes: An otter sticks his head in a pond and asks a fish, "What's it like to live always under water?" The puzzled fish responds, "What's water?" The punchline highlights the reality that when some phenomenon is everpresent, it seems almost impossible to detect its presence without some experience of its absence. It is conceivable that I might know that I am happy, but it is not readily conceivable that I would know that I am happy because of the element in which I am always immersed. I must experience some prior alienation from some element in order to appreciate the experience of being reconnected to that element. Interpretations of origins of alienation are as old as Genesis (disobedient fruit-tree tenders), as modern as Marx (workers despoiled of their means of production), and as recent as B.F. Skinner (workers detached from the fruit of their labor). I am certainly not going to solve this quandary of alienation in this project but I am going to consider its implications. This struggle to bridge alienation, however, drives every creative narrative, though perhaps not every creative act. The distinction between those two categories will be considered below.

Cszikzentmihalyi begins his argument with a summary of the way our old narratives used to work, and he offers that review as way of prefacing the problem of human experience:

Before describing how the optimal flow experience can be attained, it is necessary to review briefly some of the obstacles to fulfillment implicit in the human condition. In the old stories, before living happily ever after the hero had to confront fiery dragons and wicked warlocks in the course of a quest. This metaphor applies to the exploration of the psyche as well. (Flow, 7) 
I highlight here the axiomatic character of his statement that asserts the obstacles are "implicit in the human condition." By the fiat of an axiom, has side-stepped the origins of alienation in his own myth. He then continues:

I shall argue that the primary reason it is so difficult to achieve happiness centers on the fact that, contrary to the myths mankind has developed to reassure itself, the universe was not created to answer our needs. Frustration is deeply woven into the fabric of life. And whenever some of our needs are temporarily met, we immediately start wishing for more. This chronic dissatisfaction is the second obstacle that stands in the way of contentment. Flow, p. 7.

He states, "the universe was not created to answer our needs" but he offers no statement as to what needs the universe was created to answer, nor as to what active Creator is cloaked by the passive voice. Declaring that "[f]rustration is deeply woven into the fabric of life," tells us no more than the Norse myth's claim that the serpent Níðhöggr gnaws the roots of the ash tree Yggdrasill. The difference is that Norse version is more enjoyable; at least it is more pleasurable. I can visualize both a snake and tree. Cszikzentmihalyi only lets me see a piece of cloth somehow needled by an abstract noun called "frustration." Other than flat prose, his assertion is not a philosophical problem as long as we accept the axiomatic principle on faith. Cszikzentmihalyi then posits what I call the "Oliver Twist explanation" of desire and insatiability. There is a, "Please, Sir, I want some more" request after every modicum of gruel, with the bumbling universe responding as ineptly (not necessarily malevolently) as did the Beadle Bumble.

I have no illusions that chasing down the last quark in the chain of biochemical reactions which the brain and greater body make will ever explain the conundrum of consumption and satiety, but the chain may reveal group differences that the universalizing myths obscure. A myth very different from the Norse, but similarly axiomatic, is a Creation story that says humans were created with the needs of the 
universe in mind and that the original relationship of humans to their universe was harmonious before they themselves frustrated the design. Another myth holds that humans all lived with each other in pre-feudal harmony until some few of them began hogging all the means of production. Another myth finds that the infant raged when the mother's teat was withdrawn and the breast tucked away. Another myth sees workers' direct reinforcement from products replaced by abstract conventions called money. Again, belief in any one or the other of the stories is a belief, but the fact that Cszikzentmihalyi is a psychologist should not keep us from recognizing that he, too, is making a myth. It may be that his myth accords better with our experience in life than some of the others, but a closer correlation does not change the genre.

This observation becomes important when we consider what Cszikzentmihalyi discovers to be discontented humans' failed responses in dealing with an indifferent universe:

To deal with these obstacles, every culture develops with time protective devices - religions, philosophies, arts, and comforts -- that help shield us from chaos. They help us believe that we are in control of what is happening and give reasons for being satisfied with our lot. But these shields are effective only for a while; after a few centuries, sometimes after only a few decades, a religion or belief wears out and no longer provides the spiritual sustenance it once did. (Flow, 7-8)

Here we can intuit what he does not make extremely explicit about the relationship of creativity and the arts: It is another opiate of the people. These are all "medications" that wear off, or lose their efficacy after treatment-resistance increases.

Culture and art fails somewhat gently in the Cszikzentmihalyi myth as long as some remnant of a "faith in faith" keeps people bound to each other. But when that connection erodes, the situation gets worse. 
When people try to achieve happiness on their own, without the support of a faith, they usually seek to maximize pleasures that are either biologically programmed in their genes or are out as attractive by the society in which they live. Wealth, power. and sex become the chief goal that give direction to their strivings. But the quality of life cannot be improved this way. Only direct control of experience, the ability to derive moment-by-moment enjoyment from everything we do, can overcome the obstacles to fulfillment. (Flow, 8)

Note the paradigm that is emerging: what has worked for a while (cultural products) to quell discontentment eventually fails to work. Next, sub-cultural (i.e. - species-related) competition ensues. Here Cszikzentmihalyi does not even say that it works a bit and then fails; he just says it cannot improve the situation. Then he unveils the solution: a new way of direct control.

To overcome the anxieties and depressions of contemporary life, individuals must become independent of the social environment to the degree that they no longer respond exclusively in terms of its rewards and punishments. To achieve such autonomy, a person has to learn to provide rewards to herself. She has to develop the ability to find enjoyment and purpose regardless of external circumstance. Flow, p. 16

With one small (but crucial) change, this program could be A.A. Cszikzentmihalyi talks about "frustration" and striving where Silkworth speaks in terms of irritability and restlessness, but they both talk of discontentment and seeking relief. The crucial difference is in his emphasis on direct control of experience. Here A.A. parts company. The members find, "Lack of power, that was our dilemma. We had to find a power by which we could live, and it had to be a Power greater than ourselves. Obviously (45)" and "The first requirement is that we be convinced that any life run on self-will can hardly be a success (60)." I will not argue one against the other in this context, but the distinction is still important to clarify.

Of course, Cszikzentmihalyi is not out to sober-up drunks specifically, and he even denies that he is out to describe a self-help method of recovery from the humanity's 
implicit alienation from the universe. He hopes only to describe what he has seen happen for a small number of people: the ability to keep a focused interest in the moment simply on the moment and the opportunities of the problems that unfold around them. Two crucial, and very creative idea, are presented at the end of his book, Flow.

First, he locates the origin of life in systems that cheat chaos. He leans into a chemist for his model: "The Nobel-prize winning chemist Ilya Prigogine calls physical systems that harness energy which otherwise would be dispersed and lost in random motion 'dissipative structures.' (Flow, 201).” The example he cites is plant life on earth harnessing solar energy. This is the universe's creative response to its own profligacy. Sunlight that would otherwise simply be overruled by the laws of thermodynamics explored in Chapter Two, with the dictum that all systems tend toward maximum entropy and minimum enthalpy, is actually captured, stored and concentrated. His observation at this ecological level should remind us of the discussion in the previous chapter that introduced the notion of pumps to work against gradients at the cellular level, and which relates to the concentration of alcoholics among writers.

Second, he essentially argues that meaning is made, not found. His program for making meaning entails four steps, not twelve. He calls them cultivating purpose, forging resolve, recovering harmony, and unifying life themes (Flow, Chapter 10, passim). He recognizes this as a requirement for himself that some people are not burdened with, because for them meaning is "found." The example he offers is the calm constantly exhibited by Saudi Muslim professionals despite stressful tasks, and their reference to the basic, Insha'Allah, "as Allah wills." Cszikzentmihalyi admires their result but cannot align with their method: "Such implicit faith used to be widespread in 
our culture as well, but it is not easy to find it now. Many of us have had to discover a goal that gave meaning to life on our own, without the help of a traditional faith (Flow, 215)." Though this quest has some resonance, it has a greater difference when compared to the A.A. approach:

To us the Realm of the Spirit is broad, roomy, all inclusive; never exclusive or forbidding to those who earnestly week. It is open, we believe, to all men.

When, therefore, we speak to you of God, we mean your own conception of God. This applies, too, to other spiritual expressions which you find in this book. (46-47)

The resonance is in the similar degree of individuality involved. The difference is that Cszikzentmihalyi says it "is not easy" to find, but that "it" is replaceable by a construction of meaning. A.A. says that it is easy to find and entirely irreplaceable (as quoted above, "we had to find," not we sought to make), though no one can ever tell any member what she or he should find. Each approach is fraught with its own paradox.

I am taking Cszikzentmihalyi and A.A. to this logical conclusion of an inevitable collision regarding this rather ineffable experience of meaning. It carries consequences for the function of creativity in the experience of flow, in the experience of intoxication, in the experience of mental illness, and in the experience of recovery. A brief turn to a living poet, Luke Davies, seems to sum up the entire Cszikzentmihalyi program in five lines:

And if every step taken is a step well-lived but a foot towards death, every pilgrimage a circle, every flight-path the tracing of a sphere: I will give myself over and over. I have migrated through Carpathians of sorrow to myself heaped happy in the corner there.

This poem is about personal meaning in a hard-won personal happiness, but there is a subtle clue that it is the poetry itself that is the important power at work in making that 
meaning. That is to say, the poem is not just a medium of report; it is not simply a narrative about "character/challenge/struggle/win." Poetry is the medium of the transformation itself. The hint for that interpretation comes in the last word of the first line where "foot" is placed in parallel to "step." When a poet mentions "foot," there is more in the conversation about the anatomy of a poem (the iamb) than about the anatomy of a lower extremity. Every foot of the poem is itself an attempt to respond to alienation and pain through a creative art and a creative act.

Another poem, this one by Raymond Carver (though this prose poem is far from representing his best poetry), openly narrates his recovery from alcoholism:

Gravy

No other word will do. For that's what it was. Gravy.

Gravy these past ten years.

Alive, sober, working, loving and .

being loved by a good woman. Eleven years

ago he was told he had six months to live

at the rate he was going. And he was gong

nowhere but down. So he changed his ways

somehow. He quit drinking! And the rest?

After that it was all gravy, every minute

of it, up to and including when he was told about, well, some things that were breaking down and

building up inside his head. "Don't weep for me,"

he said to his friends. "I'm a lucky man.

I've had ten years longer than I or anyone

expected. Pure gravy. And don't forget it."

Armed with examples like these two, I take issue with Cszikzentmihalyi when he says of art and its kindred belief systems, "[t]hey help us believe that we are in control of what is happening and give reasons for being satisfied with our lot." I disagree primarily because I read his analysis as an underestimation of the actual, enduring power expressed by some acts of poesis. The difference is between the notion of "they help us believe" and the 
stronger idea of they help us be. These poems, one from someone who in no-way indicates an issue with alcohol, and the other from one who admits that problem and a solution, are not arrogant declarations of "I have arrived" or some assertion of an absolute control, but neither are they the veneers of delusion, either for the poet or the reader. These poems are the firm declarations of the very experience of flow that Cszikzentmihalyi advocates. Though we may each be called to "make it new," the older affirmations brought others have not necessarily "wear out." They endure, and because of them, we more than endure.

This argument with Cszikzentmihalyi may seem to be a quibble over a minor difference, and to be as fair to him as is possible to his presentation, I will let him speak in his own words as he encourages readers to address the arts:

The strategy consists in extracting from the order achieved by past generations' patterns that will help avoid disorder in one's own mind. There is much knowledge - or well-ordered information - accumulated in culture, ready for this use. Great music, architecture, art, poetry, drama, dance, philosophy, and religion are there for anyone to see as examples of how harmony can be imposed on chaos. Yet so many people ignore them, expecting to create meaning in their lives by their own devices. Flow. p. 235.

The tenor of his advice, however, still strikes my ear as advocating a type of tourism rather than a call to encounter the "matters of concern" that those artifacts persist in embodying. And something about his assessment of "the shields of culture" still sounds like a polite relegation of those creative acts to the realm of psychological denial; a view that, in the end, sees only The End as real. Perhaps the opposite is true, that in the end, only The Beginning is real; that by it, a creative genesis, by whatever, means continues to inspire. 
This defense of authentic, rather than apparent, meaning within creative works does not erase, however, the vexing problems we create in our narratives as a result of our own complexities. In particular, we face the problem that, should everything in a particular existence actually achieve harmony, any interesting narrative grinds to a halt. Roger Forseth, an editor of the journal, Dionysos: The Literature and Intoxication Triquarterly, and a contributor to Lilienfeld's edited collection, The Languages of Addiction, confesses exactly his fall into such a situation:

The alcoholic mechanism of "denial" has as many incarnations as Poseidon: it is the fifth master trope that Kenneth Burke forgot to mention. And as I discovered to my dismay, it appears in the most unexpected places. I recently published an article in which I declared that Sams in a Dry Season was emotionally complete at the point where Jason Sams admits his alcoholism and joins Alcoholics Anonymous. I added, "The final section of the novel, an account of this developing fellowship, is instructive but aesthetically unnecessary; we know where Jason's headed." Upon reading the essay, Ivan Gold wrote me, "I disagree somewhat with your thoughts about where my book should have ended, but understand why the Paradiso would seem (and be) less gripping than the Inferno." His comment set me to thinking: I haven't had a drink in twenty years, but it would seem some part of me would still prefer to dwell in chaos than in heaven. One more time, blindsided by booze! (Forseth 11)

Gold's reference to Dante's Divine Comedy is right on target. The Parsdiso is beautiful.

But it is, well... boring. A friend once described to me her impression of Paradiso, "Well, there is light. A lot of light." After reading the Inferno, however, every reader remembers tortured souls with their eyes wired shut, blasted trees that bleed and talk, and demons who fall out among themselves as they fall headlong into boiling pitch. The Inferno is the kind of story that makes us say with Oliver, "Please sir, I want more." But to make it through Paradiso, the reader, for whatever the reason, has to arrive at it already holding a vested interest in heaven, crystal spheres, and angels who form up like daisy petals. It may confirm that interest, but it will not create it. Rather than an 
experience of flow, my reading of the Paradiso generated a twinge of guilt: I felt like an eight year old in a church pew, yawning in the presence of God and too many soothing IIV-V chords in $4 / 4$ time flowing from the organ.

These experiences create ambiguity for the concept of creativity itself. If "flow" were ubiquitous across the whole population from birth to death, and if we were never rippled with discontent, our very category of "creativity" would collapse. Either every act and breath would be so supremely creativity that everyone would get a Nobel prize, or creativity would vanish and there would be nothing to reward. The dark side of creativity, then, is comparison and competition, just like the dark side of the Nobel prize is dynamite and munitions. Even the etymology of competition, reveals our ambivalence. It is either "struggling together" or "vying against," with its core found in peto, "I ask, I strive."

Perhaps somehow we would "grow" constantly and experience growth sans discontent, thereby to find creativity itself constantly expanding, such that acts simply create without reference to self and therefore without comparison to acts by others of similar ilk, an act that adds only to what is already plenary in the totally-other Other. If you think that this line of thought has rocketed us into some sort of fourth dimension, you are exactly right. This vision of creativity becomes adoration, which would be the perfect remedy if we could make the pesky word, peto, vanish. That would be exactly the case of the Paradiso, though even there Dante must spike it with just enough chiding remarks from the guide directed at his alter-ego narrator so that the plot will plod to the Imperium. Unfortunately, when it comes to creativity, "to adore" too often rhymes with "to be a bore." 
Two foundational narrative archetypes, one from Hebrew tradition and one from Greek tradition, push us further into the complex relationship of creation and adoration, of narrative and creativity, of narrative and creative leaders, or simply of narrative and leaders.

When creative types find drives to adore, and some Judge inspires him or her to create the best (note the competition) mode of adoration of the One who is truly Creator, this act can get explosive, with or without Nobel's dynamite or prizes. This mix of competition, creativity, and adoration leads to one of the first tales of fratricide: the trope of Cain and Abel. For whatever reason in that story, herding-animals trumps growinggrain in the eyes of the Ultimate Critic. We are back at simple tragedy. Is it not remarkable that tragedy is born anywhere goat-herders and grain-growers meet up to thresh out their differences? "To the Jews first, and then the Greeks," to steal a phrase from St. Paul.

The grain-grower Cain makes a killing (pun intended) in the marketplace of the world, receives the mark of his flawed character, and then faces obstacles that he will somehow meet with a win, a loss, or a draw. Abel, who has adored God well, but who ends up only with an honorable mention, gets no further shot at a narrative. An act of pure adoration, if it succeeds, seems to kill a good story, as that good story shows us. But it would not be enjoyable without Cain.

If we take the liberty of substituting the concept "leadership" for the notion "creativity," we will move from the Jews to the Greeks and arrive at a complex tragedy of double-fratricide, the tale that became Sophocles' Antigone. The initial competition for leadership is between Eteocles and Polynices. Their names mean, respectively, "the 
truly glorious one" and "manifold strife," and the implicit conflict of Adoration and Competition shows up in the proper nouns. Unlike Cain, who lives to tell a tale another day, neither guy in this story gets to get up. In fact, they do not even get to walk onto stage. They are dead before the curtain rises. Their narrative depends on others who direct a gaze at their dead bodies. After sister Ismene refuses to participate in this deadly game, the narrative is driven by the agon between Antigone and Creon. If we think we hear some rich poetry happening among those two names and that one noun, just imagine what an amphitheater full of Greeks would have heard.

In a very ironic way, the words Shakespeare puts on Brutus' lips in Julius Caesar, "I come bury Caesar, not to praise him," also fit Antigone in two ways: her brother Polynieces was a ruler by dint of being a prince, but she really has no desire to praise him in that regard. She is not telling the world he was "right" and worthy of adoration. She is only telling the world that she intends to act rightly by him and to let his story on earth end in the earth. As our saying goes, she wants to give it a rest! Simultaneously, she refuses to praise Creon (whose name means "Prince") and her act threatens to bury his authority. In turn, Creon, by refusing to bury Polyneices, actually keeps the rebellious nephew prince's name alive among the living, so that Creon inadvertently contributes to Polyneices' praise. Whether he knows it or not, Creon is riffing on Brutus' line in three different ways. Concerning Polyneices, the line morphs into I come not to bury the ruler but to praise him. For Eteocles, it becomes I come to bury the ruler and not to praise him, because burial removes "the praise worthy one" from the human realm where praise is possible. Concerning Creon himself, the line becomes I come to bury the ruler and to praise him, for his conflict with Antigone ultimately buries his reputation as a leader but 
his words constantly try to puff up his own power. In the ultimate irony, Creon entombs the living Antigone who then hangs herself. Everything, literally, is "up in the air." Her entombment is not burial because it reverses life and death; suicide is not escape; clemency is not effective; Haemon's attempt at patricide fails. Nothing works, but this story will not die. Yet nothing about it even hints at what Cszikzentmihalyi would call an experience of flow except our perverse response (enjoyment) in reading it or watching it enacted.

Resolving the interpretations of Antigone would be as daunting as explaining the origin of alienation, but I will suggest that readers of such courage and inclination traipse through the Antigone tropes of Hegel, Nietzsche, Freud, Lacan, Butler, and Žižek. Resolving our responses to Antigone, however, is a bit easier. Or at least understanding my own response is easy: I take pleasure as a voyeur, and I then must find enjoyment in the creative work I have to do to escape the guilt of the pleasure. This "reading" of the act of reading demonstrates flow at work from a reader-response perspective.

For this project, the point of pointing at the old stories of Cain and Abel and Antigone and Creon is simply this: secondary narratives generated out of a gaze on others' primary narratives become exponentially more complex than the original sources. The story of Cain and Abel, while powerful, is still rather simple; so simple that it can even be turned into sermon. You can’t preach on Antigone, however. We can rewrite it, and we can write about it, but that narrative will neither be buried by "threes points and a poem" nor will it be transfigured to ascend to heaven. Antigone as a story will not be ruled any more easily than Antigone the character would be ruled. Our attempts to turn creativity to bear on this vexation (for no one is "happy" about this lingering tale) is 
exactly an attempt to rule our discomforts and to achieve a state of satisfaction or happiness with this totality of life. Obviously, we are back to the experience of flow. Creativity may not transfigure the struggle of humans and their chthonic gods into some Olympian bliss, but the "struggling together" and the "vying against" seems to allow some access to joy, at least in its embedded verbal form "enjoyment."

It is also obvious that the Greek name Creon (prince, or ruler) and the Latin word creare (to make, from which we get the English word "creativity") share a common etymological parent. Our prior substitution of "leadership" for "creativity" is now revealed to be no substitution at all. It's the "same song; different verse." If Janis Joplin was right to sing, "freedom's just another name for nothing left to lose," then Creativity is just another name for another way to rule. And as the band "Tears for Fears" sang in the mid 1980's, "Everybody wants to rule the world."

Or at least his or her own small postage-stamp part of it, as Faulkner described his Yoknapatawpha.

No, I have not forgotten about Brother Bill and his primary story of struggle in the world. Nor have I forgotten about the biographers, critics, editors, and journalists who cast their gazes on him to generate an exceedingly complex array of secondary narratives. The primary narrative he displayed in himself by his actions figures in this chapter as we regarding how alcohol affected his creativity. The narratives he created for his characters as he cast his gaze on them will be the subject of Chapter Four. The narratives others have crafted about him will be addressed in Chapter Five. Against this background discussion of "creativity and the arts," we can now play the round-robin tournament with 
the other three dyads: creativity and mental illness, creativity and substance use/abuse in , and mental illness and substance use/abuse.

In the back ground of all these works lies a very clean, though small, fifteen year longitudinal study by Nancy Andreasen (published in 1987) in which she followed 30 writers admitted to the prestigious Iowa Writers Workshop. Donald Goodwin gives as good a summary of her work as I could write, so I will turn to his words:

Here is what she found. Compared to a control group of non- writers, matched for age, sex, education, and intelligence, the writers were

a. more often depressed (37 percent) .

b. more often manic (43 percent)

c. more often alcoholic ( 30 percent).

In all, twenty-four of the thirty writers had experienced depression or mania, or both-and two committed suicide during the fifteen-year study. (One wonders if John Berryman was one of the suicides; he was at Iowa during that period.) Moreover, these were not impressions of mental illness; these were diagnoses based on accepted medical criteria. As noted, this is the first scientific study that ever showed a link between creativity and mental illness. No schizophrenia, by the way, was found in the group. Before the study, most authorities would probably have predicted that schizophrenia was more related to creativity than were depression and mania, but not so in this study. Andreasen found something else interesting. Compared to control subjects, the creative writers had a high percentage of manic depressive relatives and a high percentage of creative relatives.

In any case, Andreasen concludes from her study that the families of writers were "riddled with both creativity and mental illness, while in the families of the control subjects, much of the illness and creativity seemed to be randomly scattered." (Alcohol, 198-9)

All of these results show that all forms of mental illness and substance use disorders are higher among writers than among control groups. Goodwin continues about Andeasen's work:

Whereas 30 percent of the creative writers were alcoholic, only 7 percent of their relatives were alcoholic. This was surprising. Alcoholism generally runs in families. Not always, however. "Non familial" alcoholics exist and they often have other psychiatric illnesses than alcoholism, one being manic-depressive disease. Is it possible the link between creativity and alcoholism is genetic (a 
"hereditary taint," as Lombroso said), but the genes connecting the two are actually the genes for manic-depressive illness and not the genes for alcoholism? $[\ldots]$ This is a tantalizing possibility, consistent with many of the anecdotal accounts in this chapter ("I was having fifty perceptions a minute to every one else's five," wrote Truman Capote, and a less well-known writer said that his mind moved at a "fearful pace ... the brain is over - charged, running at full tilt." This is precisely the way manics describe their thinking). Alcohol, 199

Recent research has identified at least one gene variant that accounts for a three-fold higher rate for those affected compare to the non-carriers in bipolar illness, alcoholism and schizophrenia (O'Brienna et al. 2014). Goodwin's hunch and that research are well on the way to confirming the relationships.

Following Andreasen, Kay Redfield Jamison appears as an anchoring scholar who brought the question of creativity and mental illness to the attention of both the academic press and the popular reader. She knows Andreasen's work well. Jamison, however, does not specifically address alcoholism, however. In Touched With Fire (1993) she reviews the measurements of four different variables.

First, she confirms that the base rate for mood disorders for creative writers versus the population at large is enormously higher; as much as nine times, using her own research and Arnold Ludwig's journal reports, both of which concord with Andreasen (88).

Second, while the rate of mood disorder (bipolar, major depression and cyclothymia) for both poets and fiction writers is much higher than in the general population, a comparison of poets to fiction writers shows that poets have twice the rate of bipolar disorder. The amount of time poets spend in some kind of depression, however, is much greater than their fiction writing peers (88). 
Although Jamison does not go into much analysis of this contrast, it is easy to explain, and I will attempt to do so before picking up again the thread of Jamison's research. This difference is due to the summation of all the ways that a poet could be depressed: major depression plus bipolar (depressed episode) plus depressed mood of a cyclothymia. One characteristic of bipolar illness is that the depressed episodes are more likely to be detected for two reasons. First, those states generate the most subjective discomfort for the patient so they are more likely to seek help during them, and those depressed states are prone to last much longer than the manic states. In fact, bipolar patients most often first diagnosed as simply depressed because no evidence or reports of mania are brought to the interview. Only after following the patient for a while, or after triggering a manic phase by administering an antidepressant medication, is the diagnosis refined to reflect bipolar illness. Unfortunately, poets show twice the rate of suicide compared to their peers; presumably because they are more likely to end up by one of the three disease vehicles to become depressed, and a depressed state is a major predictor of suicidality.

A third major contribution form Jamison is her meticulous correlation composers' and writers' creative output against their dominant mood states when tracked across time. These data are compelling and they far exceed anecdote: the periods of hypomania and mania show huge spikes in creative output, and the periods of depressed mood coincide with creative nadirs. The interpretation is easy: euphoria correlates positively with creativity, and depression correlates negatively with creativity. These variables will come to play under slightly different vocabulary with David Nettles' 2006 research. 
As a fourth major contribution, Jamison tracks mood disorder illnesses within the family lineages of famous creative writers and finds strong patterns of genetic transmission and co-occurrence. Her own data corroborates what Andreasen had already demonstrated.

David Nettle, both as a solo author and in collaborative research with Helen Clegg, has provided a continually refined presentation of hypotheses regarding the interplay of mental illness and creativity. His 2001 book, Strong Imagination, advances the notion that the general notion of "psychoticism" is actually a variable that is the cross-product of two orthogonally related variables. The first variable had already been proposed in the literature on personality type and mental illness. It is called "schizotopy," a term that denotes the ability to create novel associations by means of divergent thinking. Nettle himself coins a term for the other component, a variable having to do with the ease of shifting between mood extremes (the technical term is "lability"), and his word is "thymotypy," which means types of mood (Strong, 85). His 2001 book heavily cites Jamison and Andreasen (discussed above) and Ludwig (discussion to follow).

The puzzling fact that intrigues Nettle and which drives his inquiry is that anyone who is determined by general reputation to be a highly successful in creativity is much more likely than the general population to be prone to some psychosis, while, in contrast, any population of those with psychotic disorders is very unlikely to demonstrate members who are recognized for creative achievement. This conundrum is not unusual when basic statistics rules are reviewed and we recall that "the probability of A given B" is only the same as "the probability of B given A" when A and B each have a 50\% probability of 
existing. Such perfectly balanced phenomena are rare to find in nature. That said, the question of why they are not balanced in this case remains, and in his 2001 book, he hypothesized that, when psychotic-prone individuals do achieve great creativity, the success is due to superior intelligence (Strong Imagination, Chapter 6).

By referring back to the excursus on "pumps" and "dissipative structures," a very important parallel in method emerges. Nettle has two variables (two components), but that number would only allow for a "permeable membrane" model that should eventually show an equilibration of concentration across two unequal volumes as separated by the semi-permeable divider. He knows, however, that his evidence shows that the two related systems maintain a unequal concentrations, and such a system has to have a "pump." He searches for a third variable that will build a pump, and he latches onto the idea of "superior intelligence." The problem, however, is that "intelligence" -- besides being a complex variable in itself, and one that generates contention among researchers -is already confounded with creativity. It is not truly a separate variable. This recourse to "intelligence" is a noble, but failed, attempt to describe accurately an energy-harnessing system.

Nettle refined his approach to this problem in his solo journal article of 2006. Here he investigated a variable called "introvertive anhedonia," a trait of isolation and lack of pleasure. If we here remember what we have already read above, this is precisely that kind of problem Cszikzentmihalyi in 1990 had seen among people with schizophrenia, the problem which prevented them from experiencing flow. In this 2006 study, Nettle finds this variable to predict whether a person who scores high in the variable schizotopy is impaired or enhanced regarding creativity. Given subjects with an 
equally high score on schizotopy, a high score on introvertive anhedonia correlates with a higher disease state and lower creative product, while a low score on introvertive anhedonia correlates with lower disease state and higher creative product ("Schizotopy and mental health," 886). Nettle notes, "Bipolar patients not only have the divergent thinking of schizotopy, but at least some of the time they avoid the inhibiting negative symptoms of a potentially productive flight into activity." The parallels to Czikszentmilhalyi's components of flow are obvious: Another brilliant aspect of the Nettle 2006 article is his inclusion of measurements within a contrast-group of highachieving mathematicians. Those successful thinkers have low schizotopy scores (as predicted), and this result helps build the argument that the personality predictors of success in any field depend on the domain requirements of the field itself. That is to say, math is not poetry. Nettle's solo authored article, however, only investigates poets among the creative writers. He does not look at fiction writers.

Nettle had sought to position creative achievement as a result of evolutionary selection in his 2001 book. He had proposed there that mental illness was an evolutionary conserved trait because schizotopy, i.e. a propensity for divergent thinking, allows humans their own form of a "peacock feather performance" advantage in mating competition. He returns to this hypothesis in the collaborated 2006 article by Nettle and Clegg, and they refine it to show that it is the healthy presentation of schizotopy (i.e. novel problem solving without high levels of introvertive anhedonia) that enhances mate selection. The strength of that study lies in its use of human subjects rather than an animal model. The two researchers conclude that humans are sexually drawn to humans who both demonstrate novel ways of approaching the world and demonstrate positive 
affect in the course of dealing with the world. It is not a stretch to see that preferential mate selection is, in fact, taking us back into the domain of leadership. Leadership and creativity are both correlative and mutually enhancing.

Arnold Ludwig, in his 1995 book, turns to leaders - people who are vetted by rather strict measurements to be the best in their fields - and he reports the results from his study involving thousands of subjects who were ranked by strict and numeric criteria regarding achievement. Among these are leaders in the creative fields. Unlike Czikszentmihaly's book, Creativity, Ludwig's approach does not depend on subjects to “opt-in” the study, so Ludwig avoids self-selection bias. And unlike Czikszentmihaly, Ludwig employs statistical analyses of his results. His design is about as good as can be expected for a "file based," retrospective study. The only conceivable improvement would have been that another researcher might have selected the samples independently and then handed those samples to Ludwig would then have tested his own hypotheses, thereby minimizing possible selection-bias. Ludwig's work is particularly salient for this discussion because he specifically looked at the variables of drug use and alcoholism.

The data on alcoholism for poets and fiction writers is intriguing, especially when compared to comparisons of their mood disorders. As seen in the review of Jamison, Ludwig also finds poets much more likely to have both mania and depression than fiction writers. But poets are less likely (though not by a lot) to be alcoholic or drug addicted when compared to fiction writers. Lifetime prevalence for poet alcoholism is $34 \%$ while for fiction writers is $41 \%$. The prevalence of drug addiction for poets is $17 \%$ and for fiction writers $19 \%$ (Price 132-150). Ludwig has established by a chi-square analysis the distinction of his "high achievers" versus his control population and he has achieved a 
great contrast in that regard. But an analysis of these "within class" contrast differences of the groups, including for poets and fiction writers, would require an analysis of variance (essentially a statistical tool that runs several tests simultaneously) and he does not perform that test. In this case, however, an "eyeball" examination suggests that the means are not terribly different between poets and fiction writers for drug addiction or alcoholism, but that the means are different among the two types of word-smiths for bipolar illness. Although it would be considered "cheating" in statistics to pull out your pairs-of-interest too often and then to test them one pair at a time, a good statistician could probably take Ludwig's research files and devise a legitimate way to reanalyze the data as a way to test for differences in the expected means for the four variables of poets, fiction writers, drug addiction, and alcoholism. While we wait for such precision, I am comfortable with the estimation already offered.

Following the trend in the research to consider heredity, Ludwig also looks as family patterns of all the variables of interest and finds agreement with everyone from Goodwin and Andreasen forward: all the characteristics (alcoholism, drug addiction, depression and bipolar illness) track in families at rates much greater than chance.

With Faulkner, the inheritance pattern for alcoholism is clear running back three generations and laterally across his brothers. It is almost impossible to determine, however, whether he suffered from major depressive disorder because it is impossible to find a time in his life when the more probable explanation of depressive symptoms are not better accounted by alcohol and/ or barbiturates. I can find no convincing evidence, however, that Faulkner ever met full criteria for a manic episode. His biographers all agree that he was awkwardly shy and reticent in childhood and adolescent interactions 
with peers, though he would take a commanding and leading role in his play with his younger siblings.

We can now look at the question, "Does alcohol-use enhance creativity or impair creativity, and what is the action if it, indeed, has an effect in either direction?"

The witty and brilliant1996 Polish Nobel laureate poet (and completely normal drinker), Wisława Szymborska, opined to a reader who was planning on deriving inspiration from alcohol:

If a poet drinks, it's between one poem and the next. This is the stark reality. If alcohol promoted great poetry, then every third citizen of our nation would be a Horace at least. Thus we are forced to explode yet another legend. We hope that you will emerge unscathed from beneath the ruins. (Szymborska)

The quip is really quite funny, but there is a logical problem that is as glaringly serious as the one seen in Faulkner's quip about nutrition from an acre of corn: both jokes are selfcontradicted. Horace was, in fact, a poet who insisted that drink was required for the art of poetry. "No poems can please for long or live that are written by water-drinkers (Horace, quoted by Goodwin, Alcohol, 3).” Whether Horace was alcoholic or not, I do not know.

Some recovered alcoholics take Szymborska's view. Tom Dardis, the writer with many years of recovery before his death and whom we reviewed thoroughly in Chapter 2, writes:

What did Faulkner obtain from drink that he couldn't have found sober? We obviously don't know the answer, but one can guess that he found in alcohol what a number of other great talents have sought in drugs: an altered state of consciousness that permits the artists a freedom they don't believe they possess that permits the artists a freedom they don't believe they possess in sobriety. The fact that this freedom is illusory is beside the point; many artists have convinced themselves that they obtain it in no other way. The ability to create successfully when drinking is a rare one indeed. (Thirsty, 44) 
Dardis then turns for support of his own disbelief in the effective inspiration of alcohol to another recovered alcoholic of immense talent, "Raymond Carver commented that he, for one, was not helped by alcohol when he tried to mix it with writing. 'Nothing good came of it. I never wrote so much as a line that was worth a nickel when I was under the influence of alcohol' (Thirsty, 44)." Although I do not know if the price Faulkner paid for bottled inspiration was worth the creative product he engendered, I can actually believe Faulkner was inspired by alcohol even while Dardis doubts him. Dardis himself notes "When Faulkner remarked that 'civilization begins with distillation,' he was not joking but stating what he believed to be self-evident: a writer requires the liberating infusion of whiskey in order to reveal the nature of the world around him' (Thirsty, 7)."

What of normal drinkers who also say they find inspiration from the bottle?

Goodwin tells us:

[T.S.] Eliot may have been more of a drinker than many thought, according to a recent biography by Peter Ackroyd. "Throughout his life," Ackroyd reports, "he drank a good deal" and confessed that he "needed alcohol to get himself into the mood to write." In 14 B.C. Horace wrote, "No poems can please for long or live that are written by water-drinkers." Eliot's poems have lived long, and perhaps we now know the reason. He was not, however, alcoholic by anybody's definition. (Goodwin, Alcohol, 3)

These statements, with some reference also to Upton Sinclair from Chapter Two, now let us construct a $2 \times 3$ matrix of crossed variables of opinion and involvement. (see Table 2) 


\section{Creativity}

Alcohol Inspires Alcohol Does Not Inspire

Alcoholic Drinker

Normal Drinker

Non Drinker
Faulkner

T.S. Eliot

[?]
Dardis; Carver

Szymborska

Upton Sinclair

\section{Table 2}

I cannot think of an example of a primary-abstinent writer (as opposed to a recovereddrunk abstinent writer, whom I still classify as an alcoholic, though in remission) who confirms that alcohol inspires.

The reality is that some writers probably experience via intoxication a temporary schizotopy, a state that imbues them with divergent thinking and a novel way of linking things. This experience allows them to find their point of inspiration, but this experience is not burdened, at least early in the drinking game, with what Nettle terms introvertive anhedonia.

Richard Hugo left us with some remarkably clear and unpretentious reflections on the process of good, inspired writing; at least at it applies to poetry. He talks about finding a "triggering town" with some strong images of interesting subjects, but then learning to "write off the subject." These metaphors drive his collection of essays titled The Triggering Town (1979). Hugo insists that the poet has to have that spark to start, but that if the poet stays focused on that trigger, the poem will die before it is born. This powerful vision, after the initial contact, still has to be managed by the writer with the lightest of hand and with a slant vision. Too much attention kills it. This view from the poet has a resonance with Cszikszentmihalyi's observation quoted above: 
When a person becomes so dependent on the ability to control an enjoyable activity that he cannot pay attention to anything else, then he loses the ultimate control: the freedom to determine the content of consciousness. Thus enjoyable activities that produce flow have a potential negative aspect: while they are capable of improving the quality of existence by creating order in the mind, they can become addictive, at which point the self becomes captive of a certain kind of order, and then unwilling to cope with the ambiguities of life. (Flow, 62)

Some poets and fiction writers probably do not need a chemical to find the trigger, or to relinquish the anxieties that allow them to cope with the very ambiguities of the characters' lives and free direction of the plots that "want" to emerge. Their endogenous fount of schizotopy is sufficient, and the addition of alcohol does, indeed, put out the flame. Others, however, have to make a trip to Echo Springs, perhaps not for Brick's "click" but for Faulkner's sense of expansion and as a relief from the inhibition. The very areas of the brain that shows the deficiencies in dopamine metabolism for alcoholics -- a deficiency that a dose of alcohol relives in them at least for a little while so that they get some relief from being "restless, irritable and discontented" -- are the same areas of the brain that, for normal subjects, is associated with positive emotionality (Volkow et al. "Positive Emotionality," passim.) For the right person at the right time, alcohol intoxication can simultaneously quell anxiety and unleash creativity. This is true for the person who is predisposed to alcoholism as it is for normal drinkers like Eliot.

Normal drinkers can find strong imagination in strong drink. Even the book Alcoholics Anonymous has no problem at all in recognizing this fact, "For most normal folks, drinking means conviviality, companionship and colorful imagination (151)." It is not a stretch to consider Nettle's phrase, borrowed from the Bard, "strong imagination," and the A.A. term "colorful imagination," as essentially representing the same experience. Unlike the Temperance Movement, A.A. has never had a problem with 
normal drinkers who drink normally and who enjoy the normal responses that alcohol brings. The members have simply learned that they are not normal. They also do not say that "colorful imagination" comes to all normal folk who drink; only that most experience it. The first one hundred A.A. adherents are implicitly tolerant of the individual experiences expressed by Faulkner, Symborska, Eliot, Carver, and Dardis though wary of any attempt to prescriptively universalize anyone of them. Where they part company is, paradoxically, with their supporter, Upton Sinclair, who showed considerable "hatred of drinking as an institution." They may have concerns about other impending dangers for those in the Faulkner camp, but they know that early in the drinking game, even the alcoholics have both their imaginations sparked and their anxieties relieved. In fact, A.A. posits that both of those effects are even stronger for them as alcoholics because they are abnormally sensitive to the relief and the inspiration alcohol brings. What A.A. insists, however, is on the alcoholic's inability to maintain the lovely balance for the long-game. For them, alcohol will stop working.

In the above discussion of Goodwin's early insight that bipolar disorder and alcoholism appear to correlate, I cited O'Brienna et al.(2014) and the findings that there are three disease correlations loaded on one important gene. There are about as many coauthors on that article as narrators in As I Lay Dying, and the article title is about as long as any notorious Faulkner sentence, but the gist of the work is that they have isolated a variant that "[...] affects the risk of schizophrenia and alcohol dependence as well as bipolar disorder." We are near, then, to describing the pump mechanism that concentrates alcoholism among writers at a greater rate than the population at large: three things are correlate, two of which can increase creativity, and one which will inhibit 
creativity. The two traits that flow together drive the pump to keep mania and alcoholism more greatly concentrated among the people who are then able to harness the inspiration created, whether by endogenously available schizotopy (hypomania and mania) or by exogenously acquired schizotopy (acute intoxication). The people with both schizotopy and introvertive anhedonia (i.e. people with schizophrenia) either never get pumped into the mix of writers because they do not "catch" the energy (Czikszenmihalyi's notion that they cannot focus on goal oriented behavior), or they are "pumped out" when they fail to produce good work. We will have to return to this vexing and somber phenomenon in Chapter Five. When does the "system" pump out the writer who has lost his or her edge?

We also have seen another correlation that is discovered by the transitive property. If leadership (demonstrated by the vervets) is now seen to correlate with intoxication, and if schizotopy correlates with intoxication, then leadership correlates with schizotopy. It does not matter how schizotopy is generated. A vervet does not have to be a drunk to be a leader, but it does not hurt his tenure. Leadership, as demonstrated in mate-selection, also correlates inversely with introvertive anhedonia, which means it does correlate positively with the personality trait that might be called an élan vital or bonheur or joie de vivre. Creativity and good-natured extroversion bode well for a career in leadership. Having added "good natured" to the mix moves us beyond the monkeys. Like a sticky ball of wax, a character trait has attracted another character trait that has attracted another character trait, all combining (somewhat exponentially in power rather than merely additively and without dissolving completely one into the other) to create a new level of meaning for a social role. Just as recent research in the Swedish adoption records demonstrates that the ease of 1) self-restriction for eating, 2) thin body type, and 
3) the propensity to save money for the future and to self-inhibit spontaneous spending all correlate, we see that foundational physiological processes (metabolism) and foundational species behavior (eating) start to "clump" with social-constructs such as money and frugality (Cronqvist and Siegel 2015).

With the adumbrated social meaning comes both increased responsibilities and increased possibilities. Whereas the vervets only need a leader who serves rather simplistically as a sentinel for latent environmental benefits, humans are attracted to leaders who create novel solutions for many environmental and social dilemmas. Those dilemmas may be of the primary narrative type, or they may be of the secondary, complex narrative type generated by humans looking at themselves in the act of looking. If novel solutions and joie de vivre should arise from endogenous cellular processes, so be it, and crown the king. And if novel solutions should arise because someone tipples, or if an irritable, restless and discontented person suddenly should bloom into a "halefellow, well-met" after a few drinks, then again so be it and crown the king. The origin of the inspiration does not matter as long as it works.

But if the endogenous source sours (the plight of many people with bipolar disease, for example, as they age) or an exogenous substance either stops supplying that trait, or if the body's adaptation causes the substance to block a natural ability to generate those traits, then we end up with Waylon Jennings singing "Goodtime Charley's Got the Blues"

My old heart keeps telling me There ain't no kid at thirty-three Play around and lose your wife You play too long and lose your life I got my pills to ease the pain Can't find a thing to ease the rain 
Sometimes I'd like to try and settle down

But everybody's leavin' town

Some got to win, some got to lose

Good time Charlie's got the blues

But when do the others in a system decide to cut ties with the goodtimer who has turned into bad news? This is never an easy decision, and the case with Faulkner will be examined in more detail in Chapter Five.

One other nagging question from Chapter Two still remains unanswered: Why are American writers affected more than British and European by the alcoholism? I will venture a very tentative answer, and I know even as I articulate it, eyebrows will rise and frowns will form, for the proposed solution posits an acceleration of natural selection. That mechanism was once invoked in an attempt to explain the higher rates of African American hypertension compared both to European American rates and to continental African rates (Wilson and Grim 1991). The proposed solution depends of a theoretical application of what is called a "bottle neck" event in an acceleration of natural selection (Jackson I-131). The explanation posited that the harsh conditions of hugely heightened mortality on slave ships in the Middle Passage selected for survival at a great probability the individuals who retained salt (and therefore water) more effectively, leaving them as the ones to pass on that selected characteristic to their progeny in the Americas. The explanation has not held up well, however. From a perspective of "pure" science, it is argued first, that there simply was not enough time spent on board the slave ships to squeeze down the "bottleneck" sufficiently to effect such selection, and second, that there is no documentation of enough gastrointestinal water-loss illnesses on board the ships to account for enough deaths. From the perspective of social-justice theory, critics contend that the theory depends on a false racial essentialism (Armelagos 2005). 
Another example of conferred adaptive advantage based on polymorphic genetics, however, has held up superbly in the scientific literature. A trait (having only one allele) for some variant amino acid sequences in hemoglobin confers a resistance to malaria, although a disease state of sickle cell anemia is created when two alleles are present as a survival (Allison). The problem with extending this fact analogically to the selection of increased alcoholism is that the environmental pressure for sickle-cell trait-selection occurred over a long period of time in a broad swath of the Eastern Mediterranean world, extending into Africa and into India, and the pressure came from a non-human source (Plasmodium falciparum) and a non-human vector (the anopheles mosquito), with very little social mediation.

As an indulgence, however, I will sketch out the possibility (while repeating my hesitancy) that self-selection for immigrations under conditions of social and economic pressure might be considered. Rather than looking to the Middle Passage of Africans to the Americas, however, this proposal looks to the Northern Passage of Europeans to the Americas. I acknowledge that this explanation gives a woeful lack of attention to the issue of the Americans who were here when the Europeans arrived, but I will note that William White gives a good account of the way they were (and are) affected by alcoholism. They are underrepresented among our writer sample, however, and that population is the one of particular interest. African Americans, descendants of a forced diaspora, also have a different story of origin that needs better explication in terms of alcohol, creativity and the arts. But they too are underrepresented in all of the lists, whether short (five of seven Nobel winners in the late 1980's when the reviewers were writing) or long (Goodwin's off-the cuff catalog of some forty as noted in Chapter Two). 
Americans of European origin, in great measure self-selected, under certain social and economic pressures that had emerged in Europe, to leave one continent for others. This exodus required two cadres of folks to find each other before leaving: very strong leaders, and easily-attracted followers. Furthermore, there were several exoduses of this kind over more than a century. If leadership is correlated at a primate level with an attraction to alcohol consumption that supersedes even carbohydrate consumption, then each wave of immigration brought a concentration of genes dedicated to those correlated traits to these shores. Those leaders would be, by correlated characteristics, more prone to our bundled of traits. Those others who followed the hyper-leaders would then be hyper-followers who were, by definition, less inclined to be attracted to alcohol at all. In effect, American colonization patterns drew from both ends of the spectrum of the drinking graph to create the one Ingraham has given us. They then selected among themselves by assortative mating after arrival in the Americas. Although genetic drift and dilution of trait will occur over time, there really have not been very many generations separating the immigrant ancestors of our famous writers and the writers themselves.

Even today, the average Western European (including British) per-capita consumption of alcohol is far greater than the American per-capita consumption and the percentage of naturally abstinent Americans is greater than for Western European abstainers, but the rate of alcoholism in America is greater than in Western Europe (World Health Organization 2011). This fact does not make sense unless we assume that the Americans self-selected for traits that amplify drinking in the upper decile and that nearly squashed all drinking in the lower three deciles. The per capita consumption in 
Europe is greater because the general percentage of people who drink in Europe is greater. They have of course, their share of alcoholics in the upper decile and they have their share of denial that goes with it. Sartre, for example, was alcoholic but and underreported as such (Forseth 8). Roger Forseth reports the humorous interchange,

I asked Jean-Charles Sournia, vice-president of the French government's Commission on Alcohol and author of History of Alcoholism, why the French, as he had asserted, avoided the "alcoholic label. His answer: "Because we French don't think it a nice thing to do." (4).

The reply certainly belies Henry Higgins' assertion in My Fair Lady, "The French do not particularly care what you do as long as you pronounce it correctly." Still, a cultural sensitivity about social labeling cannot account for the measurable fact that alcoholism is more prevalent in the U.S. than in Europe even though the per capita consumption of alcohol in Western Europe and Britain is higher. Europeans also have some nondrinkers, but nowhere near the percentage found in the U.S. The extra European consumption seems to occur in the mid-range of the deciles.

In short, it is possible that the U.S.A. became the Alcoholic Republic because we self-selected to become such. Our creative folks are still sharing correlates of leadership, inspiration, and intoxication, each related to schizotopy, and that schizotopy can come from either bipolar illness or euphoric intoxication. These two sources converge in creative folks more than they converge in the population at large, and are also interactive variables. This may be why our percentage of drunk writers is so high. Other cultural factors certainly influence the picture, but those merely nudge the boundaries of differences here and there a bit.

Whether or not this tentative hypothesis of a "bottle neck" self-selection for genetic concentration can be sufficiently confirmed, it does evade at least three of the 
complaints brought against the bottle-neck selection theory for African American hypertension. First, the selection process for the immigrants occurred over a longer period of time and in several waves. Second, the hypothesized process does not require a third variable of adventitious infection such as with cholera or a gastrointestinal virus. Third, the theory does not depend on any particular notion or construct of race or difference between races.

Now, though we must face another reality about the relationship of alcohol to creativity. Just because it works for a while does not mean it will work forever. Furthermore, it does more than fail. It begins to inhibit. "The Lord gives and the Lord takes away" by testimony of the Judeo-Christian tradition, and Euripides presents Dionysius as equally capable of both actions in the The Bacchae. Members of A.A. have a rather dramatic sentence for this experience: "As we became subjects of King Alcohol, shivering denizens of his mad realm, the chilling vapor that is loneliness settled down (151).”

That matrix relationship of alcohol-to-inspiration is, after all, only a snapshot of one point in time. The longitudinal reality is that alcohol (actually, all drugs) do more than one thing to the brain, and these multiple actions are mediated by both direct effect and by indirect neuronal accommodation. Excess alcohol consumption for the person predisposed to alcoholism (whether that predisposition is caused by direct alcohol lineage or by a bipolar genetic propensity, or both if they are co-tracking) will eventually lead to an amplification of the introvertive anhedonia and a diminished schizotopy. At that point, creativity is no longer invoked; it becomes unhinged. As Nettle has shown in his 
solo 2006 article, increased introvertive anhedonia in the presence of schizotopy is the recipe for mental illness.

We must now consider again Brother Bill. After I have defended him against his detractors who deny his belief that alcohol helped him write, I will now show that alcohol also destroyed his ability. This revelation is not pleasant. Providing proof-texts to justify a gnawing disaffection with a favored writer is as problematic as showing a lover the exact point where the relationship went wrong. The finger-pointing at events often indicates the occasions more than the causes. An autopsy on dead love is an ugly act and the pathologist's report is depressing to read.

I insist, however, that Faulkner's powers for creative fiction were best expressed in the period demarcated by the publication of The Sound and the Fury and Go Down Moses and had declined by 1948. I choose that one point on the time line not because his loss of craft was precipitous in those months, but because the publication of Intruder in the Dust signaled that a decline had been in progress for some while. As I have looked more closely at the detail of Faulkner's life experience with alcohol, I am convinced that the progressive nature of the disease shows up on the pages as it was expressed in his brain and body.

I will sound here as if I am talking out of both sides of my mouth. Before starting with its faults, I am compelled to confess that I thoroughly enjoyed Intruder In the Dust. It was the first Faulkner novel I had read, and it came into hand by accident rather than plan. It made me want to read more of his work. As a Faulkner "starter" novel, I doubt I could have done better. The book confronted me, steeped as I was in the heritage os Tennessee and Mississippi, with the racial and social realities that had shaped and 
misshaped our region. More importantly, Faulkner succeeded in pulling me into his world by deftly depicted the relationships Chick Mallison forges with his side-kick, Alec Sanders, his idol, Uncle Gavin, his nemesis, Lucas Beauchamp, and his saint, Miss Habersham. Those relationships take fire and burn brightly as the narrator moves through the basics that every narrative plot requires: a character who is faced with a problem and embarks on acts that will leads to a win or a loss or a draw. I was taught that "foundation of fiction" almost forty years after I had read Intruder, but despite my ignorance of the principles, they worked on me through that book and kept me engaged as reader for my part of the bargain. The narrator took me through the plot without having to explain it to me. For the most part., that is. And the exception will reveal the problem. As a rule, however, the narration showed me that simple formula in a marvelous complex set of twists, turns and reversals as the novel moved me alongside the characters from point $\mathrm{A}$ to point $\mathrm{B}$.

I also distinctly remember realizing, when I was about three-quarters of the way through Intruder, that Faulkner had taken the elements of the Passion narrative (a three day time-line, an unjust arrest, filled tombs, empty tombs, faltering disciples, surprise endings, etc.), that he had fragmented them thoroughly, and that he had then spread them out again in what I can only call a "literary Cubism" on the canvas of that fictional town of Jefferson, making it new in a startling way. Before I had recognized what he was telling me, I had already been retold "The Old, Old Story," as the hymn lyric has it. Ezra Pound would have approved, though this was long before I knew that poet's dictum, "Make it new!" This act of a creative craft transforming old forms is not surprising in itself; I was later to discover when reading Auerbach's Mimesis that there really are only 
a handful of stories to be told, and that each success always depends on the way it is told. Whether or not Faulkner had any conscious notion of what he had done to "make it work and to make it new," I do not know. I suspect he had a hint, and I will explain that hunch as we look back to The Sound and the Fury and forward to A Fable. But it does not matter because his craft was rich enough - though beginning to show dissipation -- in Intruder in the Dust that the archetypes could grow naturally in his soil rather than be treated like hot-house plants to be forced into bloom.

So why praise this "first date" with Faulkner, only then to say it was not the pinnacle of our relationship? Because Intruder led me to The Snopes Trilogy (read in order of The Hamlet, The Town and The Mansion) which I again found to be fun and entrancing, even if uneven (I found The Town a bit lackluster). Next came Sanctuary, which brought all the guilty-pleasure of watching a train wreck from a safe distance: with a transfixed gaze on the horror and with a secret pleasure in my heart.

But when I came to As I lay Dying, Absalom, Absalom!, and The Sound and the Fury! Oh, my. Those last three works simply stunned me. The word "enjoyed" does not seem to encompass the experience. That emotion was part of the encounter, but I also simply knew that the fictive worlds involved (and each one achieved quite differently) were registering in me something more than entertainment and social challenge. The effect in me transcended the genre in front of me, and such a testimony is about as clear as I can offer toward explaining a sacrament.

Surprisingly, I had known very little of Faulkner other than that my parents (both native Mississippians, raised in the 1930's and 1940's about 70 miles south of Oxford, Mississippi) wanted nothing to do with him and "his dirty books," and that professor 
David Minter, our Master at Baker College, a residential community of Rice University where I was an undergraduate, was a Faulkner scholar. He and I had talked one day in the college commons about our experiences of squirrel hunting in the virgin timber of the South. I did not know until thirty years later that our conversation was mediated by all that Faulkner put into Big Woods and "The Bear." Although Oxford and Rowan Oak are only some eighty miles from my hometown, Memphis, I have never visited either place. There is no need. I have been in Yoknapatawpha and in Jefferson, I know exactly the land where the Gowrie's farmed, and I have seen Sutpen's mansion burn.

I was hooked (another form of addiction) and I went read Go Down, Moses and The Unvanquished. With interest piqued to pursue the more academic explorations of Faulkner, I added the other novels (Soldier's Pay remains only an obligation; Mosquitoes is irritating because the characters are irritating, but it is readable and entertaining in a Prufrock sort of way), the short stories, and the poems (let's just say I am very glad Faulkner discovered prose) to the "must read" list.

That comprehensive task included The Fable, which he published finally in 1954 after spending more than a dozen years re-torturing the Galilean. After I had made about four bad starts on that book, and after blaming myself for the first three aborted readings, I finally knew that something terrible had happened on the way to this Calvary. I would hesitate to pick-apart so forcefully one book as an example of the failure of poetic power, but choosing this book as the object lesson is frankly inescapable given its falsely high profile. It was given both the National Book Award and a Pulitzer, presumably because Committees -- embarrassed that they had missed their chance in the late 1920's and early 1930's -- were now in a full-tilt overcompensation run at an error in the mid 1950's. 
My opinion is not based merely on an author's uneven output across time. Not every song can be a hit, and the same goes for fiction. The Reivers: A Reminiscence, is the last novel. Though nostalgic and light in effect when compared even to the first Yoknapatawpha novel, Flags in the Dust (first published in a trimmed version as Sartoris), The Reivers is a superior novel to The Fable, though perhaps not considered as "important." Reivers is quite accurately labelled as "lightheated adventures," but at least it is true to itself in that regard (Weinstein 227). Frankly, I do find that the prose in $A$ Fable to be anymore syntactically challenging than that found in The Reivers. Faulkner's Fable is simply too "heavy laden" with the Passion narrative and this fact, ironically, bleeds the story of all its passion. In a perverse and reverse alchemy, A Fable turns gold into lead.

Before turning to the opinions of others regarding what Faulkner had hoped would be his magnum opus in A Fable, I will return to Intruder in the Dust to consider why I now find the cracks in creativity power emerging in 1948. The sections of Intruder that were onerously baffling occur when the story ends and the preaching begins. Faulkner lets Gavin Stevens absolutely violate narrative frame to ramble on for pages concerning the proper way to let the Southern folks deal with their Southern issues of race (Graham). Charles Glicksburg began his 1949 review:

If a newcomer to fiction had submitted the manuscript of this novel for consideration by a publisher, it would most likely have been rejected as promptly and decisively as Sanctuary was before Faulkner 'achieved recognition. It has all the glaring faults that would disqualify a beginner: a pretentious vocabulary, a baroque style, a thesis which, though skillfully integrated within the context of the story, is ridden hard for all it is worth. Even so, the most memorable feature of this novel is not the story but the 'moral' which stands out sharply and challengingly; the entire plot is so constructed as to elaborate and emphasize the author's central convictions about the Negro problem in the South. (Basset, Ed. Critical 343) 
In those sections, though the title is Intruder in the Dust, we are really confronted with the author, Faulkner, as the "intruder from the dust jacket." The content from the hijacked narrator is not particularly "bad" and, given Faulkner's social origins as a privileged white southerner, it is an extraordinarily progressive statement of racial and social politics. But it is not fiction. It contributes nothing to the development of plot to let us see if the challenged character(s) will succeed or fail. It is an excuse to pontificate, and there is a sense that Faulkner's soft, high voice -- amplified and spoken through the "Great and Wonderful Gavin" -- is nervously commanding the audience, "pay no attention to the man behind the curtain." Intruder is mostly a success as a Bildundgsroman in regard to Chick, but it is a failure in regard to a social-realism or social-advocacy medium. Edmund Wilson saw the problem in 1948 when he wrote in the New Yorker, "But Intruder in the Dust does not come to us merely as a novel: it also involves a tract." (In Basset, p. 335) Here is the problem. Even with his most experimental works, Faulkner had not really confused his genres prior to this book. He reports that he turned his hand to Intruder as a pot-boiler to make money, and that adopted the detective fiction genre because of its popularity. The book obviously exceeded both the motivation and the genre. Here Faulkner was showing his old spark; his ability to let a seed idea take root, but then to let the plant grow and go where it would, and it did well where Gavin did not crush the stalks with his soapbox.

In As I Lay Dying, the creative freedom is expressed in a very rapid writing, minimal re-writing, and (in Faulkner's words) a "tour de force" presentation. It is not over-thought, and he trusts his instinct to let fifteen characters alternate narration some sixty times. When he started the story that became The Sound and the Fury, he had let a 
single visual image - the imaginary sight of mud-soiled undergarments on an imaginary little girl -- grow into a novel which, in fact, does take us through the timeless Passion Week via time-travel across decades, and ends with the convincing testimony of Dilsey on Easter Sunday, "I have seen the First and the Last." For Absalom, Absalom!, Faulkner was able to start with a single vision about "two children in a dark house" and then let it grow into the quartet recitation of Sutpen and his Hundred; all built from the timber of Greek tragedy most recently stolen by O'Neil in Mourning Becomes Elektra and now transformed from the stage with a flawed Yankee General recast as the character-flawed Confederate General. Theft is no crime for a fiction writer, but squandering what you steal certainly is; and A Fable is a waste of a good story.

I suggest that those great novels of the great decade "worked" because this was a time when Faulkner was still able to ride the wild horse of intoxicated imagination with some degree of success. There is no doubt that his drinking was already frankly alcoholic even in the early 1920's and through the 1930's, but he was one of the writers who could actually use the chemical invocation of a mild type of "schizotopy" to find a "triggering" point and then to shepherd (but not quash) the sparked imagination into that which it knows it needs to become. This is what Richard Hugo tells about with his description of his creative process and the ability to be "writing off the subject." Once the image of inspiration has been found the poet or writer does well to move away from it so that it will lead to what it intends to become. The inspired image is courted but never captured.

Falkner had found his triggering town in Jefferson years earlier with Sartoris, posthumously republished in his intended form and his preferred title as Flags in the Dust. When Faulkner was still in New Orleans in the early 1920's, Sherwood Anderson 
had told him, "write what you know," and that is when Faulkner discovered his genius. As the cartoon caricature depictions by Spratling, one of Faulkner's colleagues in words and sprees, Faulkner was well into the juice at this time: one drawing shows the triple-x mark on a ironstone jug beneath Faulkner's chair (Spratling and Faulkner 1926). Faulkner showed promise in Soldier's Pay, and he demonstrated a developing craft of character depiction in Mosquitos. But he finally discovered voice, vison and soul in Yoknapatawpha, and the discovery was well after the onset of heavy drinking.

What, then happens after Go Down,Moses? More alcohol and more alcohol. No human brain can escape unscathed the quantity and frequency of the chemical. The brain eventually does not respond with the same augmentation of an otherwise defective dopamine neurotransmitter system so as to experience equivalent release from a foundational state of being "irritable, restless and discontented." As accommodation occurs, the former experiences of creative triggers do not emerge. As the exploration of the intersection of schizotypy, mental illness and substance use and addiction has shown dopamine function is crucial for the three processes.

So what is wrong with A Fable if both The Sound and the Fury and Intruder in the Dust each also share the Passion narrative? Those two earlier books ended up retelling the old story after Faulkner managed to "write off the subject," to borrow again from Hugo. Each story began with "a triggering town" that Faulkner knew. Absolutely nothing is similar with A Fable. The idea of an overt resetting of the Christ story into modern Europe was not his idea. Some other screen writer in Hollywood had suggested it to him in the early 1940's when Faulkner was working in misery as a script hack and drinking obsessively. Faulkner latched onto the subject and never let himself "write off 
the subject." He drove it, rather than grew it. Faulkner, despite all of his confabulations and his few months roaming Europe as a young Bohemian poet, had never seen combat duty. This was a violation of Anderson's dictum, "write what you know" and Hugo echoes a corollary in another essay on the process of writing: "Quest for a self is fundamental to poetry." (Hugo, "Stray Thoughts," 33) Faulkner's corporal in A Fable functions perfunctorily in a predictable land, but it is as if Faulkner has turned WWI Europe into a Hollywood sound-set. The setting is accurate, but it is ersatz.

Furthermore, it is forty years behind the times in which it appeared. So many choices were made so badly.

How does alcoholism explain these bad outcomes? The active disease will eventually impair judgment, hamper integration of new sensory experiences into the emotional fabric of the drinker, create immense internal insecurity, and promote episodes of excessive external bravado that alternate with periods of social isolation. A type of perseveration often appears, leading to the inability to leave a thought, feeling, or remembered historical event alone. These changes can occur simply from the impress of the chemical, but accidents and secondary illnesses may also contribute to brain dysfunction.

My misgivings about Faulkner's creative powers are generally echoed by those who have spent their lives with his works and his biography. Most tellingly (and this is a point nearly every biographer picks up) Faulkner himself felt by 1953 that he was "written out (Dardis 77)." David Minter notes his sense of the change in Faulkner's powers and offered demarcation after Go Down, Moses in 1942. Weinstein offers a similar mark: "I do not recant my conviction that Faulkner's contribution to the world of 
letters began in 1929 (The Sound and the Fury) and concluded in 1942 (Go Down, Moses). Apart from a small number of scholars who argue otherwise, this has long been the consensus about Faulkner's work (221)."

Daniel Singal (1997) also notes a major change in Faulkner as a person and as a writer. He turns to an episode from 1940 when Faulkner was off with fellow hunters in mid-winter at the hunting camp. As usual, Faulkner drank excessively and constantly. More disturbing this time, however, was that his companions found him nearly unresponsive and "ashen." By good fortune, a motor boat on the river neared them and they were able to get him to the hospital in Oxford many miles away. Faulkner had a gastric hemorrhage (a condition caused by chronic alcoholism) and had lost considerable blood through his bowel. He was severely anemic. Singal speculates that the anoxic injury left some cortical scar that accounts for other symptoms: amnesia, seizures, etc. Frankly, this interpretation of the etiology of the problems is an excess stretch of speculation. The problems are more efficiently accounted by simple recourse to what we know to be the chronic, progressive nature of unchecked alcoholism (Singal 259-260).

As Weinstein notes, some defenders of Faulkner's later work insisted during the 1950 's -- and persisted in the assertions even against the tide of contrary opinion -- that the master was still with his powers. Among American literary lions, Delmore Schwartz is most prominent, defending strongly the message and he merit of $A$ Fable. In Europe, $A$ Fable was much better received than in the North America. Heinreich Straumann's review is almost polemical in tone, chastising the Americans for not recognizing the greatness that is A Fable. In each case, however, the tone of defense is related to the message of novel and pays little attention to complaints about the craft of the work. This 
resistance to a critique of the art, in my opinion, signals what would be the strong shift from the Modernism's canon of art as a craft that reveals the human condition into a PostModern demand that art be applied to change social structures.

Other contemporary reviewers hated the book. Philip Blair Rice was one:

When Faulkner leaves the microcosm of Yoknapatawpha for the great world of. contemporary society, he maintains the same attitudes at whatever cost of oversimplification. The suffering servant is now the common soldier or the European peasant; the man of deathless folly is the army flyer, the stunt pilot or the professional military leader (Rice 381 ).

R.W. Flint in 1955 simply called the novel 'an embarrassingly literary experiment.' In his 1971 dissertation, published in 1983, Keen Butterworth argues that no one had given A Fable enough time to find its proper, high place of regard:

A number of critics who like and admire Faulkner's other work find A Fable a great disappointment; and a number of people have told me that for them the book is unreadable. Of course, being unreadable at this point in the novel's age has little to do with its quality. How many people found Moby Dick unreadable in 1875, or Ulysses in 1950? (Butterworth 12)

Unfortunately for Butterworth and his proposed test-of-time, the forty years since his dissertation defense have not recruited readers who will defend A Fable.

Although this negative obsession with A Fable has dominated the examples of my discontent with Faulkner's last period, other of his "last novels" have not escaped criticisms. "Buzz" Bezzerides was Faulkner's friend and colleague screen-writer in Hollywood. He provides a vignette about his first encounter with Faulkner's writing in 1931. It illustrates brilliantly the reality that readers will, in fact, read a difficult book (despite the difficulty) as long as the author has fulfilled his or her part of the bargain and has provided something that catches the reader's imagination: 
She gave me Faulkner's As I Lay Dying, and I remember that as I read it I had a totally new experience: the frustration of trying to read what he had written, trying to understand what he was saying; the anger of not being able to comprehend it; flinging the book across the room, then running to pick it up and going back to the beginning and trying to read it over again, desperate to understand it, and finding it difficult, cursing Faulkner for writing the way he did, but yet incapable of putting it down. The phenomenon of this man writing that book with its strange complexity, the inner feelings that it has, unstated statements that it makes, your having to read into it the things that he is saying-all of this was a remarkable experience for me, so I never forgot Faulkner. I read everything he wrote as the books came out. I tried, anyway, always with the same fury. (Brodsky 56)

This encounter contrasts with Bezzerides' experience of Faulkner's later writing:

Oh, the drinking for years had certainly dulled off his sharpness. When I read that he had had shock therapy applied to him by a psychologist who hadn't even asked for permission to do it, had done it without getting permission from the family, I asked a lot of questions about what shock therapy does to a person. One of several very bright doctors put -it this way: "It deletes memory, the memory of the past, the pain." Faulkner's great fiction had been written out of the memory of pain; this had been deleted. Suddenly I could understand how in The Town Flem Snopes had become a loveable character, not the monster he had been depicted as being in The Hamlet. Suddenly Bill was a man who had sweet memories of his past. Certainly Bill must have realized in some strange, profound way that he had lost something terribly important, and this loss drove him to his special kind of suicide. (Bodsky 78)

Here again, alcoholism, the elephant in the room, is acknowledged for a moment and then oddly treated like a house cat. Faulkner did have six bilateral shock treatments but there is no indication that this was the start or origin of his altered capacities. This odd recourse to denial is characteristic not only of the alcoholic, but of all those closely connected to the alcoholic. Faulkner's own pet theory for his neurological changes attributed the problems to a supposed head injury after a fall from a horse. The fact that he did not actually remember there having been a head injury and the fact that no medical evaluations could confirm such an etiology did not deter him from his hypothesis.

In contrast, Donald Newlove, understood exactly the effect of alcohol both on Faulkner's writing and on his own reading of Faulkner's writing. Newlove notes that 
when he himself was still drinking alcoholically, "I admired the liquid poetic effects of $A$ Fable, if not the tearful grandeur of its endings (35)." After Newlove quit drinking and embraced recovery, he had a wholly new view of Faulkner:

William Faulkner, our greatest Southerner, had a writing period that lasted for about eight year, during his thirties. Something disastrous happened when he turned forty; whatever grip he had had on his alcoholism faded, and so did the hot focus of his imagination. He wrote for twenty-two more years, but his brain was stunned - not that you could tell it by looking at him. What we get from his later decades in the famous mannered diction, senatorial tone, a hallucinated rhetoric of alcohol full of ravishing musings and empty glory. Dead junk beside the cloudburst pages of his thirties. (147)

I am assuaged, at least, to know that I am even a bit more gracious than Newlove.

If the report of a noted decline in the early 1950's from critics and friends were not enough, the "bottom line" began to have a say. Money talks, and magazine publishers do not readily turn down short story submissions from a Nobel laureate. Yet in 1953, this is exactly what happened, and it happened three times with a story that ironically demonstrates the intersection of Faulkner's alcoholism and creative decline. He offered to The New Yorker, Collier's and Esquire a story he called "Weekend Revisited." It was a fictionalized rendering of his recent inpatient detox treatment at Doctor's Hospital, the swank facility facing Central Park. They all three rejected it, and when three magazines of that caliber turn down a piece from a writer of Faulkner's prominence and drawing-power, you know the piece suffers from terrible faults. The story was eventually published posthumously in The Saturday Evening Post in 1965 as "Mr. Acarius." For that story, embalming fluid worked after alcohol failed. (Blotner Faulkner 2 vols., $1448-51$ and notes to those pages.)

The evocative title of Jay Parini's biography One Matchless Time: A Life of William Faulkner nostalgically recalls that for a while in this great writer's life, there 
truly was a period of creativity that could not have been predicted, and which was never replicated. It seems that for whatever the final cost on body a soul, a blend of the human spirt, distilled spirits, and a triggering town known as Jefferson, the "place" the writer really knew, erupted in a plan as audaciously terrifying and inspiring as Sutpen's Hundred. That planation is a creation-within-a-creation in Absalom, Absalom!, own thrown up as a mimic of Milton's Pandemonium, with Sutpen replacing Satan in dark splendor in the nadir of his pride. That novel towers in the "sweet spot" of Faulkner's career. By all reports from those that track his chronology, he wrote that novel over a period of some eighteen months when he was neither totally abstinent, but also never entirely given to oblivion. The "triggering town" and the open bottle cooperated for a little while. Tom Dardis quotes in English translation from Baudelaire, Enivrez-vous (1864),

"Always be drunk. That is all. It is the question. You want to stop Time crushing your shoulders, bending you double, so get drunk - militantly. How? Use wine, poetry, or virtue. Use your imagination, Just get drunk." (Thirsty, 46)

All these elements are there for the eight years Newlove mentioned. What Newlove seems to miss, however, is that even on occasions after 1942, Faulkner could still find some inspiration in his "triggering town," and still let the town dictate a few fairly good stories. Frankly, even that trigger fails to save the travesty that is the semi-play, Requiem for a Nun, and that failure will be considered more thoroughly in Chapter Four. By the time we get to The Town, the "triggering town" has begun to lose out to the bottle. When the town is ignored entirely, as in A Fable, there is nothing left but a "tale of sound and fury, signifying...." Well, signifying exactly too much and showing us much too little. 
Good fiction is not, in the end, stronger than chronic alcoholism. The parallel tracking of William Faulkner's oeuvre and his drinking patterns seems to bear out this truth. Alcohol will make a hollow man of the alcoholic.

This is the way the world ends. Not with a bang but a whimper.

T.S. Eliot, "The Hollow Men" 


\section{CHAPTER FOUR \\ OF DOUBLE VISION AND A DOUBLE LIFE: \\ ALCOHOL AND CHARACTER DOUBLING IN FAULKNER'S FICTIONS}

More than most people, the alcoholic leads a double life. He is very much the actor. To the outer world he presents his stage character. This is the one he likes his fellows to see. He wants to enjoy a certain reputation, but knows in his heart he doesn't deserve it.

Alcoholics Anonymous, 73.

Having established Faulkner as an alcoholic writer who both wins and loses creativity in the pursuit of a drink, we can address a set of three related questions. First, how does Faulkner work his own alcoholism into his characters? Second, are his characterizations convincing as fiction? Third, how do these characters "hold up" across the rise and fall of Faulkner's creative powers? Answering these questions will require examining who among the characters gets to drink like a gentleman, who gets to drink like a drunkard, who refuses to drink at all, and who is simply ignored in regard to drink.

Drinking characters appear across all of Faulkner's writing years, from the earliest prose fiction, the years when he is writing freelance in New Orleans at age twenty-seven, to The Reivers, the novel published only months before his death at age sixty-four. Across the body of work, varied plots present drinking characters with varied behavior qualities, and those drinking characters are accorded varied responses from other characters. Sometimes the drinkers appear simply as loners, sometimes they are in the context of the measured social-drinking that accompanies other social activities, and sometimes they are in social drinking settings where the main goal is drinking to get drunk. His treatment of drinking, therefore, is not uniform, and although he shades it with both the written and unwritten rules of white Southern society, there is no absolute 
universalism in his treatment. The lingering traces of this association in early twentieth century depictions certainly arise in Faulkner's depictions of drinking at Miss Reba's brothel in Memphis in both versions: the chillingly dark side found in Sanctuary and the warm nostalgia depicted in The Reivers.

Perhaps the closest approximation to a strong rule is that an adult male character who does not drink is somehow socially or sexually suspect, and he must suffer derogation unless some other actions or explanations justify his abstinence. Under Faulkner's pen, it is easier for a man to be excused for outrageous drunkenness than it is to earn a bye as a teetotaler. His famously asymmetric eyebrow, already cocked for a disapproving rise, springs to his hairline at the sight of a dry man. The dry man is guilty until proven innocent and the drinking man is innocent until proven guilty. Then there is the conundrum of how to evaluate a drinking woman, of whom there are but a few. The cult of masculine drinking as explored by John Crowley in The White Logic for the other writers is thoroughly applied to an understanding of Faulkner by Conor Picken in his 2013 unpublished doctoral dissertation. The eminent Southern U.S.A. history scholar, Bertram Wyatt-Brown also positions both the author, Faulkner, as a son of the South and Faulkner's characters as enactors of Southern mores of masculinity in similar manner ("William Faulkner: Art"). These insights will have some bearing on the discussions of particular characters that follow in this chapter.

The Faulkner fan will see where some of these plot and subplots emerge in his writings, and will also see where some of them never get a bit of ink. The despicable side of Snopesism, for example, is manifested in characters who are barnburners, ambushers, bloodless bankers, brass thieves, purveyors of porn, and blackmailers, but not a one of 
them is a good, honest heavy drinker. They are, by dint of caste, simply excluded from any hope of "learning to drink like a gentleman." Faulkner reserves drinking, whether aberrant or as a "gentleman," for the feudal cadres of Yoknapatawpha, though they be of the aristocrats like the Benbows of Warwick or the yeoman class such as Ben Hogganbeck. It is obvious that the Snopeses are barred from access to the gifts of the grape and the grain. Similarly, the bootlegger and murderer, Popeye, in Sanctuary is not a drinker. This fact is not so much a choice for him as it is a dictate of his physiology. As Robert Kirk and Marvin Klotz (1963) telegraphically summarize him, "Popeye, born of a syphilitic father. He is impotent and so weak of stomach that alcohol will kill him (62)." In Faulkner's mythic world, a fictional character has to start with some moral character before he or she can dissipate it in obsessive sex and aberrant drinking. The Popeyes and Snopeses of his world are really beyond redemption because, ironically, they are excluded from the only real sins that "count."

I focus in this portion of the project on Faulkner's frequent use of twinned or doubled characters. I find Faulkner uses the technique both as a literary craft deviceone very well represented in the plays of his favorite nemesis, Shakespeare, - and as a psychological defense employed unconsciously as a way to dissipate his ambivalence about his own relationship with alcohol. I distinguish between two approaches to doubling: first, the manner in which Faulkner's choice of plots drives his doubled drinking-or-abstinent characters through actions to arrive at a win, loss, or draw within the narrative, and second, the way that Faulkner's choices in crafting doubled characters drives plots. Both choices allow Faulkner simultaneously "to reveal and to conceal" his own equivocal relationship with alcohol, both to-and-from the reader and to-and-from 
himself. Doubling serves as a splendid way to run two conflicting narratives simultaneously, yet to arrive at two different conclusions. The device can work well in fiction. For real life, the probabilities of success are not as good in the long run. Faulkner was quite familiar with Joseph Conrad's novella, The Secret Sharer, as an example of doubling that allows two outcomes: one character escapes the rules of the ship while another character remains the guardian of the rules. The very melodramatic expression of doubling in Robert Louis Stevenson's Dr. Jekyll and Mr. Hyde is explicitly cited by Faulkner in Pylon, as will be discussed below. But with his use of doubling Faulkner bought himself some time to deal with himself as a winner even if the final outcome of his own narrative is, at best, a draw; more realistically, a loss.

I am, perhaps, engaging in the "biographical fallacy," but I will risk the accusation. I also overtly blur the line between the use of psychological theory to interrogate a text and the use of psychology to analyze the author. Faulkner himself found attempts of the first sort to be laughable and attempts of the second sort to be infuriating. I know exactly the terror, if not the error, of my ways, but Noel Polk had no problem putting Faulkner's texts on the couch, David Minter has always put both the author and the books into analysis, and Philip Weinstein seems to go directly for setting appointments with the man himself. A look at the "drinking characters" helps us look at the character of the drinker: the author. We will be able to see how the author fences with his or her own discomforts - i.e thrusts and parries with the Self --and then, perhaps, "fences them in" with psychological defenses. Though the poet Richard Hugo in his essay "Stray Thoughts on Roethke and Teaching" has noted that the discovery of self is the primary purpose of writing, another poet, T.S. Eliot has observed, "Humankind 
cannot bear very much reality." Like the collective, the individual human has his or her limits.

The Eliot quotation comes from the Four Quartets, and Faulkner's Requiem for a Nun (1951) is rife with its influence, as Noel Polk shows in his 1981 critical study. I would use the word "rich" rather than "rife" if Requiem were itself not such a tragically bad book. It may be "important," as Polk argues; but it is important only because Faulkner wrote it and not because it ever succeeded as fiction, whether read as a novel or enacted on stage. Due to the one quotation, "The past is never dead. It is not even past," it will always be as sturdy as a mule within the Complete Works; and as equally infertile. It is no accident that it began its existence as a really well-inspired idea for a true novel during Faulkner's prime years and then became the disappointment that it is in the early 1950's when Faulkner's drinking had not only failed to inspire, but had undermined his craft. The difficulties with Requiem are also not an accident when the doubled character of Gavin Stevens and Gowan Stevens, relatives who finally are allowed to meet face-toface in that work, are considered in their psychological function for Faulkner as well as their plot functions for his fictions.

Judith Bryant Wittenberg in her book, Faulkner: The Transfiguration of Biography (1979), builds her very convincing book on the thesis that Faulkner's own lives - his external life and his internal life -- show up strongly in his fiction, and she is able to cite the author, speaking as himself and in regard to his craft, to bolster this assertion:

Faulkner knew that his work was often directly autobiographical. He also conceded on one occasion that it was always indirectly psycho-biographical: "The writer unconsciously writes into every line and phrase his violent despairs and 
rages and frustrations or his violent prophesies [sic] of still more violent hopes." (5. Quoting Faulkner from Meriwether, Ed. Faulkner Miscellany, 158)

I will not take on the task of defending the universality of Faulkner's assertion as it regards all writers, but I will not disregard the permission he gives concerning his own work and process.

Marcy Lasota Bauman defends her similar biographical and psychological approach to Faulkner's work in her unpublished 1991 Ph.D. thesis, "The bottle in the sideboard: Alcoholism as a defining force in 'The Sound and the Fury,", with reference to both Judith Wittenberg and David Minter, another eminent Faulkner scholar and interpreter. Bauman states,

I will examine his writing to determine the possible influence of alcoholism on his work.

To date, there has been a great deal of resistance to thinking about Faulkner - or any other writer - as an alcoholic. (12)

When I consider, however, the juxtaposition of those two sentences, one a paragraph summary and one a paragraph topic, I discover, however, a logical non sequitur in her project. Although Bauman does a thorough job of tracing the dynamics of alcoholism within the Compson household, the characters she analyzes - especially three of the Compson children, Caddie, Quentin and Jason, Jr., as well as, to a lesser extent, their mother, Caroline - exhibit the thoughts, actions and feelings that are generated by their living with a chronic alcoholic, the father and husband, Jason Compson, Sr., rather than the characteristics of being themselves designated alcoholics. Bauman does not attempt, however, to correlate William Faulkner with Jason Compson, Sr. When we look for the correlate of an alcoholic like Mr. Compson within Faulkner's own life, the identification is easily found in Faulkner's father, Murry Falkner. He drank alcoholically most of his 
adult life, though he did manage to quit in his last few years, and Maud would bundle the boys up with her on her frequent missions to take Murry to the Keeley Institute on the outskirts of Memphis (Blotner, Faulkner 2 Vols., 98-100). Bauman, therefore, actually shows the influence of Murry Falkner's alcoholism as it relates to Faulkner's experience of being what is now called an ACOA ("adult child of an alcoholic"), and the character correlation to Faulkner himself would be the Compson children, especially Quentin. Her work, however, does not actually correlate Faulkner's own drinking with the way he writes his characters.

Gary Storhoff carries forward with a similar family-systems analysis of the characters in two articles, “Jason's Role Slippage: The Dynamics of Alcoholism in The Sound and the Fury (1996)" and "Caddy and the Infinite Loop: The Dynamics of Alcoholism in The Sound and the Fury (1997)." Again, however, the identified alcoholic is Mr. Compson, so once again any Faulkner biographical correlate to an aberrant drinker is in the author's father, Murry, and not in the author himself.

I have claimed the adjective "equivocal" in regard to Faulkner's relationship with his own use of alcohol and hope here to defend that attribute. The evidence for this claim is already strewn across the many pages of Blotner's 1974 two volume work, but Blotner mostly leaves the work of labelling this quality to the reader. Blotner shows it, but he does not tell it, and a deeper interpretation of his choices will be much the matter of Chapter Five. A hot focus on Faulkner's ambivalence about his aberrant drinking, and not simply on his aberrant drinking itself, does not burn a hole in a page or on the reader's retina, however, until Tom Dardis' book, The Thirsty Muse (1989). There Dardis collects the many famous statements like "Isn't any thin' Ah got whiskey won't 
cure (Blotner Faulkner 2 Vols., 1449)," his previously quoted defense to Lauren Bacall about an expansion of courage with every extra martini, and the disclaimer, "I consider drinking to be a normal instinct, not a hobby. A normal and healthy instinct" (Merriwether and Millgate Lion, 149 )." But then Dardis juxtaposes those claims against less-reported quotations, such as to the plaintive, questioning exclamation "God damn it! Why do I do it?" and the resigned admission, “'Never ask me why.[....] I don't know the answer. If I did I wouldn’t do it.' (Blotner, Faulkner 2 Vols., 1604).”

Despite his bravado about drinking, Faulkner's ambivalence toward his relationship with alcohol was about as real and as vexing as his ambivalence toward his relationship with his wife, Estelle. The extended interview with "Buzz" Bezzarides in Brodsky's 1990 edited book makes the equivocations of both of those fractious relationships painfully clear, with alcoholic drinking and domestic violence both present and a problem for both parties in the marriage. Alcoholics are indeed rather fickle toward each other regarding opinion of character and tolerance of behavior. In one moment they may be, in all seriousness, comparing the better ways to get at an episode of alcoholic oblivion, as Faulkner did with fellow veteran drinkers, or the alcoholic may turn to despise another of his or her kind as a lowly drunk. Faulkner disparaged alcoholism in others, and he especially hated Estelle's drinking. This distaste may have been learned the hard way, of course. On one occasion, he told David Hempstead that certain bruises on his head and face resulted from Estelle taking a croquet mallet to him as he was just simply sitting in a chair reading his Time magazine in their Hollywood apartment (Blotner, Faulkner 2 Vols., 944) . "Buzz" Bezzarides offers more details of an unsavory night he and his wife spent at Rowan Oak with the Faulkners when the evidence of 
domestic violence and sexual encounter were all too audible from the next room, and where Bezzarides bluntly acknowledges that Faulkner had slapped Estelle in the face (Brodsky 69). Long before the Brodsky interview with Bezzarides was published, Blotner had himself interviewed Bezzarides himself as he forged the first two-volume work. Although Blotner reports on Estelle's croquet-club violence toward her husband, and though knowledge of his violence against her apparently lurked in his sources, that direction of the violent transaction was not expressed directly in his 1974 biography. By 1984, even Blotner -- in the revised, one-volume biography -- was compelled to craft at least the rather genteel understatement, "[a]nd then there was the drinking. If his drinking sometimes made him sometimes an impossible husband, her drinking made her sometimes an unattractive wife (Faulkner, One Vol., 360)." These are not courtly love scenes from Camelot.

In the 1974 work however, Blotner not only reports on Faulkner's doublestandard in regard to drunkenness, but the biographer participates in it by his choices with the narration of an episode gleaned from David Yalden-Thompson who, on a visit from the University of Virginia, was dining with Faulkner in a restaurant in Oxford, Mississippi. An intoxicated local man interrupted their dinner and conversation, and after the interloper is rebuffed by Faulkner, Blotner closes the scene:

Baffled and disgruntled, the drunk returned to his table where he fell over his chair. Faulkner turned to David. "All of his family have been game hogs," he said. "He's a lying oaf who likes to pick fights, but he can't deal with a little mental quickness." It was revolting, he said, that you lost your privacy from drunks like that because you wrote books. (Blotner Faulkner 2 Vols., 1775)

From Faulkner's perspective, other people who drink too much are drunks of dissolute character. The significance of Blotner's willingness to use the term "drunk" in his own 
narrative voice about Faulkner's fellow townsman, but never about Faulkner himself, will be considered again in Chapter Five. It is pretty clear, though, that if you drink a lot and write famous books, you are a tortured soul seeking solace and inspiration in the noble quest of interpreting chaos through the mysterious gift of creativity. If you are an intoxicated local yokel who badgers a famous writer for an autographed copy of a book, you are a drunk. This is a clear example of the use of the psychological defenses of projection and displacement.

Alcoholics are also equivocal about their own ability to control their drinking, despite their many protests to the contrary. On the one hand, they claim the notion of control at any moment by choice. On the other hand, they construct elaborate plans ones that rarely work-- to prevent an embarrassing binge. This was Faulkner. At a lunch in Hollywood in the Spring of 1944, as Blotner notes, "He took steps to impose safeguards (Faulkner 2 Vols,, 1162).” Faulkner appeared at the Roosevelt Hotel with a stranger in tow -- not a participant in the conversation -- and a man simply introduced to Ed Kohn, a studio executive, as a "Mr. Nielsen." Blotner relates:

When they had finished, Kohn suggested a visit to the Chapeau Rouge on Highland Avenue. They left the Roosevelt, Mr. Nielsen two or three feet behind them. Faulkner put his arm around Kohn, and as they strolled down the street he recited "The Phoenix and the Turtle" -- loving the language, Kohn remembered, speaking the words as though he had written them himself. When they were seated at the Chapeau Rouge, Faulkner turned to Nielsen.

"Give me the bottle," he said.

Nielsen was reluctant.

"Now, don't be a sissy," Faulkner said.

Nielsen drew a bottle of bourbon from the black bag and handed it over. Faulkner poured the drinks and then excused himself. When he had left, Nielsen turned to Kohn. "You must be wondering who I am," he said. "I'm a nurse. Mr. Faulkner hired me to see that he got to work on Monday." (Faulkner 2 Vols., 1162) 
As noted in the Chapter One, Faulkner's recitation of that Shakespeare poem was always the harbinger of a binge. Blotner assesses Faulkner's dilemma here, "But here there was acute conflict in the escape from the conflict (1162)."

With Faulkner's equivocal relationship to alcohol clearly established as a fact in his life, we can now look at the ways that similar equivocation is written into his fictions.

Faulkner's published collection of poems, The Marble Faun, preceded his prose fiction by two years. The work was bull-dozed into print by his mentor Phil Stone, and it attracted some minor attention. By its virtue, Faulkner arrived in New Orleans for a sixmonth stint in 1925 as a self-professed poet. His published work while living there, however, was in prose. He wrote some descriptions of New Orleans life that the Double Dealer, a literary magazine published. The Sunday supplement of the Times-Picayune newspaper published some short stories, all collected in William Faulkner: New Orleans Sketches (1958).

One story, "Yo Ho and Two Bottles of Rum," depicts a tramp steamer somewhere in near-equatorial Pacific. It is a lolling tub with a deck-crew of Chinese sailors and, in the narrator's words, "officered by the scum of the riff-raff of the United Kingdom, a scum which even the catholic stomach of the dominions beyond the seas refuses at intervals, vomiting it over the face of the globe [...] (New Orleans Sketches, 121-122)." If that description of arrogant white male character is bad at the start, their ensuing actions only paint them as even more morally corrupt. They drink incessantly and could tolerate each other only "as long as the liquor held out." One white officer, when quite drunk, kills the Chinese cabin boy Yo Ho "by accident." Mr. Ayers, the officer, was really trying to knock the Chinese Bosun in the head with a club and, as the narrator 
reports, he shrugs off the error: "Mr. Ayers filled his glass again viciously. 'Plenty more of the fellers; one Chinee like another. [....] 'Dammit, sir,' Mr. Ayers said with justifiable exasperation, 'ain't I a white man? Can't I kill a native if I want to?' (Sketches, 124)." The Chinese crew refuses to allow their murdered friend to be buried at sea and demand interment on land. This action forces an unplanned trip ashore. During the funeral trek inland, the white officers tire of walking, pile themselves on the funeral cart and proceed to rob the basket containing the burial gifts of the two bottles of rum which had been intended to go in the grave as a ritual offering. That travesty of all social boundaries is evidently not enough for the white officers, for after they drain those bottles, they then decide, in a drunken moment of White Logic, that they can get more liquor by killing others of the Chinese crew. They leap from the cart with this purpose, but the sober Chinese crewmen simply evade the drunken whites by blending into the woods where they wait out the binge. The story ends with the Chinese crew patiently crouching at the harbor and anticipating the arrival of the sobered-up white men so that all can re-board the ship to deliver the cargo.

That story obviously serves to level a scathing critique of drunken, white masculinity that was exhibited at its worst and at most racist, and projected onto the British. Yet Faulkner was writing the story in the very same months he himself was participating in the "softer" behaviors of drunken white masculinity, side-by-side with William Spratling. They would regularly get drunk and shoot the butts of white matrons and black nuns with a BB air rifle from the window of their Bohemian attic apartment on St. Peter Street (Blotner, Faulkner 2 Vols., 524). Tagging a black nun garnered more points in this game. 
In the beginning of 1935 William Faulkner could write with some authority about the devastating effect on the central nervous system of a night of heavy drinking. He begins "The Golden Land," the only story he wrote based on his Hollywood years, by describing the main character's attempt to begin his working day. Dardis quotes a paragraph from the story and then correlates the fiction to Faulkner's life:

"If he had been thirty, he would not have needed the two aspirin tablets and the half glass of raw gin before he could bear the shower's needling on his body and steady his hands to shave .... Now it was his trembling and jerking hands that he watched as he shook the two tablets onto the glass shelf and set the tumbler into the rack and unstoppered the gin bottle and braced his knuckles against the wall in order to pour into the tumbler."

At the age of thirty-seven, Faulkner had become knowledgeable about the terrible need for the morning, or "restorative," drink, the drink that makes it possible to start the new day, to start thinking about living again. (Dardis, Thiristy, 25. Quotation from "The Golden Land." )

These were the years when Faulkner was infamous on the studio lots and in the executives' offices as a drinker, one who closely matched his fictional character.

As mentioned in Chapter Three, in 1953 Faulkner unsuccessfully shopped-around a short story he called "Weekend Revisited." He had based it on his recent hospitalization for treatment from a terrific alcoholic binge, and he had modeled it on Charles Jackson's The Lost Weekend, a novel about an alcoholism and one which Faulkner had recently read. No one bought the story, and the rejection letters came despite his recent rise in social prestige with the 1949 Nobel award. The story was finally published posthumously as "Mr Acarius," and that publication probably reflects more interest in the dead author than the anemic story. Blotner takes a passage from this story for the epigraph to Chapter 63 in his 1974 two volume work:

--the surrender, the relinquishment to and into the opium of escaping, knowing in advance the inevitable tomorrow's inevitable physical agony; to have lost nothing 
of anguish but instead only to have gained it; to have merely compounded yesterday's spirit and soul's laceration with tomorrow's hangover--

(Faulkner 2 Vols., 1447)

Opium here is the metaphor of alcohol, and Faulkner's narrator is explicit in the interpretation of the equivocal plight of the character at whom the narrator is casting a gaze. The character name, "Acarius," is evocative in its own right. It rhymes with "precarious" and it is an anagram of "A Icarus." He has been flying too close to the sun, though in the story the character comes down to earth before plummeting into the sea. He does not "drown," and he quits drinking. In his own life, however, Faulkner does not invoke the fantasy solution of pouring out the liquor and launching into a life of permanent sobriety. He keeps on soaring high as he tries to escape the metaphorical island of imprisonment which was his self.

Blotner's choice of this passage from "Mr. Acarius" to head a chapter in Faulkner's actual life shows, but does not tell, that he, the biographer, is gazing at the equivocal plight of his character of interest. Blotner's focus, Faulkner, however, had been on this earth in flesh and blood; not merely as an imagined man of ink on paper. This richly fascinating layering of narratives -- a story told about a dead man (Faulkner) using a dead-story, "Weekend Revisited," that would not stay dead but finally emerges in print as "Mr. Acarius," -- strikes me as generating the kind of complexities already explored in Chapter Three with Antigone. We are starting to hear narratives about narratives about narratives; conversations that agonize over how to treat a dead man.

As noted above in the mention of Bauman's dissertation and Storhoff's articles, alcoholism obviously plays a strong role in The Sound and the Fury, but the role is not with a character looking squarely at his own relationship with alcohol, and the plot- 
development does not cultivate outrageous drunk-scenes. Although we can perhaps, as readers, infer that the father, Jason Compson, eventually dies secondary to alcoholism, the plot-development of the book itself does not depend on narrated drinking scenes or on direct claims of alcoholic mortality. Alcohol is simply present like the air; it does not surge like a wave to flood a previously dry landscape. We can riff on the joke of the otter and the fish mentioned in Chapter Three. If you ask a Compson, "What's it like to live in a household that is always under the control of aberrant drinking," the baffled responders would answer with the question, "What is aberrant drinking?"

In fact, when The Sound and the Fury, As I Lay Dying, Absalom, Absalom!, and Light In August -- the indisputably best novels of Faulkner's major-period -- are considered carefully, no exposition in any of them really devotes much time to descriptions of drunken episodes, and none of the plots are really driven by drinking. There is drinking, of course, and there is some drunkenness, but Faulkner does not spend page-on-page detailing every vertiginous detail of an episode, nor does he show the characters turning gaze on themselves in an attempt to interpret their drunkenness. In those truly great novels, he does not depict characters driven to nearly insane lengths to lay hands on alcohol, he does not show characters passing out from a spree, and he does not explicitly set up disasters that some drunk has directly engendered. I contend that when Faulkner was both at his creative strength and while still armored sufficiently with the psychological defense of denial, his own overt drunkenness did not erupt into his creative focus to distract him from his larger vision. The drinking is there, but only as an element of the culture in his fictional county, a county that mirrored his actual region. It 
is part of the scene painting and not the action that treads the boards, nor the monologues that fill the theater air.

Two of the lesser novels from this same great creative period, Sanctuary and Pylon, however, present sordid, sotted details. I do not consider either book to fail as a novel, but neither one rises to the heights of the other four. A full review of such opinion falls outside of this particular project, but every critical biography of Faulkner consulted (Blotner, Minter, Grey, Parini, Karl and Weinstein) point to the same division.

Three of the four great novels - The Sound and the Fury, As I Lay Dying, and Absalom, Absalom! - are examples of a modernist mythopoeic genre, while Sanctuary and Pylon exemplify a modernist realism. Light in August straddles the genres, and actually straddles the division between "the better" and the "the lesser." Claims for distinction in quality engage controversies, but I will stick with the division. Before expounding on difference in quality, an explication of the two genres is in order.

The term mythopoeic (or mythopoetic, which is the same) is often associated with the later nineteenth and early twentieth century British writers who included strong fantasy elements in the plot, often with characters modeled on obvious archetypes. The names George MacDonald with his Phantastes and Lilith, Charles Williams with The Place of the Lion and The Greater Trumps, C.S. Lewis with the children's series, The Chronicles of Nania, and the adult fiction, Space Trilogy, and, of course, J.R.R. Tolkien with The Hobbit and The Lord of The Rings trilogy. Those examples certainly represent mythopoeic fiction, but have no discernible tangents with modernism. I turn to Gilmore's operative definition of modernism to show the contrasts: "[...] two of the leading characteristics of modernism are a radical dissatisfaction with commonplace 
reality and a consequent attempt to undermine conventional reality by greatly altering traditional states of consciousness, [...] (170)" as cited in Chapter Two. For all of their efforts, those British authors actually tame the unruly aspects of myth because their narrative style follows the linear, predictable flow of causality as found in the nineteenth century Romantic and Realistic novels. It is one thing to create Orcs who resemble humans; the real mythic terror, however, comes when a modernist can create humans who behave like Orcs.

Creating myth - and recreating old myths -- within a modernist aesthetic is, indeed, a challenge, because the entire tenor of modernism focuses on the human spirit in a struggle to cope with an indifferent universe. Faulkner, however, when working at the height of his powers and in a modernist mind, is able to generate the myth of Yoknapatawpha by dint of his own imagination and by the interweaving of old world mythic plots and tropes. Some prominent characteristics of this style is framing the broad scope of time across generations, and fracturing the flow of time within a generations, and splintering narration among narrators and characters. The Sound and the Fury appropriates the Passion Week myth but shatters the four days across three decades in its Passion play, from the child Caddie's witness of Damuddy's funeral wake to her adult daughter's escape in the pre-dawn of Easter. Faulkner suffuses the plot and characters so foundationally in his story with That Story that the myth is constantly resounding but never overtly proclaimed. Benjy, the idiot, sees not like an idiot but like a prophet, and smells the world like a savant. In place of old myths' talismans such as rings and chalices, Faulkner gives Quentin Compson (the first-born Son of the Father) the burden of the father's pocket watch to carry through life, and coat-pockets full of cast iron to 
carry him into death. After dying, he is resurrected as Quentin (his niece) who tricks Satan, the Adversary, (her uncle Jason) on Saturday (the day of the Harrowing of Hell) and leaves the empty tomb (her locked room) to run off in the pre-dawn with Jason's stolen hoard. Dilsey testifies that she has seen the first and the last, the glory of the resurrection, which reveals in code her witness to the fact that Jason has finally gotten what he deserves through the proclamation of her own true and transcendent faith.

As I Lay Dying gives us wild floods, rivers to cross, and a promised land in way that inverts nearly every original mythic origin into a perverse myth of contorted visons. Darl is insane but prescient; Vardaman is emotionally maimed and gnomic, speaking the infamous five-word, one-sentence chapter, "My mother is a fish." There is a near immolation of the corpse in the barn, so that the story literally shows trial by fire and by flood. The printed text incorporates, and as not simply as an illustration, a rune that really is a ruin: a line drawing of the hexagonal coffin is inserted into the line of the text to be read as if it were a word.

Absalom, Absalom! is a covert retelling of Aeschylus' Oerestia, probably a riff on Eugene O'Neill, Mourning Becomes Elektra. As myth, it is half-Greek and halfMiltonic, with Sutpen falling to earth in Yoknapatawpha to raise up his Pandemonium, Sutpen's Hundred. The book uses tall-tales to set the atmosphere, exemplified in the hilarious story of the captive architect who almost manages to escape Sutpen's grasp (and note how close Sutpen's name is to Satan's) by taking his flight into trees, bending one to another, to leave the hounds stymied where his scent fails them on the ground. Sutpen communicates with his black slaves in a dark tongue (a creole French) obscure to the locals, and the slaves themselves are reported to sleep naked in the mud of the fields, and 
to rise up at the master's call for his bidding, an obvious reemployment of the sowing of the dragon's teeth which sprouted the mighty Spartoi, the myth of Thebes' founding.

These examples do not indicate mere inter-textualities; they demonstrate intermythologies.

Faulkner's modernist realism differs from the modern social realism (or naturalism) his contemporaries John Steinbeck and Richard Wright championed, and Faulkner's realism can also be contrasted with his own mythopoeic work. The distinction with his peer writers appears in the differing loci of "the problem." Social realism reports moment-by-moment, sequential interactions of the hero with other people to reveal the flaws in society's structures while modernist realism uses the hero's sequential encounters with society's structures to reveal flawed human character. Both forms tend to follow a rather predictable sequence of chronological time and even when the plot is not accomplished within an Aristotelian poetics of a single day, it proceeds without ruptures of decades and years. The narration tends to be third person, limited, with most characters and actions closely followed; but there is freedom to pull back for wide-angle, panoramic views, and there is some ability to observe two or more loci simultaneously. The characters tend to assert themselves as failing characters against a rejecting society or in struggle with passionate love relationships. The distinction of what I term "modernist realism" compared to "social realism" is that the modernist vision simply precludes the notion that society will change for the better, or even that it can be changed for the better. The encounter with the human tragedy, instead, changes the human individual, often ambivalently. 
In this regard, Light in August draws from both genres, with the near-mythic and very-pregnant Lena Burch wandering dusty roads from Alabama into Mississippi, like a lone Madonna, in search for the true father while an ersatz Saint Joseph fruitless follows her with his unrequited spiritual passion. Yet the horrific murder and lynching that transpire are carried out in just a few days, though those travesties are placed against a complex background: flashbacks regarding the mysterious mixed race origins of Joe Christmas, the retrograde socio-religious ramblings of the disgraced Reverend Hightower that are mired in the endless loop of a failed mythology born in a failed South, the insane military vigilantism that has emerged in its place, and the failed Reconstructionist mission that brings it own death.

Neither Sanctuary or Pylon are as deeply immersed in myth nor set against such complex a background as is the case for Light in August. They each have the reader experience horrific encounters with incompressible faults in humanity and the cold indifference of the universe, but the encounters are basically sequential; even predictable. They tend to follow the Chekov adage, "If you say in the first chapter that there is a rifle hanging on the wall, in the second or third chapter it absolutely must go off." In Sanctuary, once we see a drunk man driving a car while looking for more booze, we can be fairly certain that not much good will come from the efforts, and the amplifying disaster unfolds sequentially. In Pylon, the mention of a dangerous prototype airplane fills-in the blanks in the reader's mind before the pen-on-page completes the picture. Faulkner keeps the reader appropriately satisfied with predicted disasters, and salaciously appalled by plot twists such as the corncob rape in Sanctuary and an aerial copulation in Pylon. Faulkner himself always considered Sanctuary to be a more "commercial" work 
and less important, and he never really tried to defend Pylon as being much more than diversion from the intensity of writing Absalom, Absalom!. Scholars in Faulkner critical studies -- writers such as Minter, Grey, Karl, and Weinstein -- also tend to winnow the novels of his eight- year period of undisputed mastery similarly. Go Down, Moses will be considered in its own right in discussion below regarding doubling. It is indeed strong, but much of its success in its 1942 collected version depends heavily of the work that went into its component stories from his earlier mythically-rich and creative years.

In summary, realistic fictions, whether social of modernist, tend to adhere to Occam's Razor which holds that "less is more." Mythopoeic fictions, whether British Christian of American Modernist, breath dark vapors in the Delphic cave and find a need to tell a "more" that can never be made "less."

If Faulkner's choices for the four great novels indicate a rather effective use of denial as a defense mechanism, two other amplified defense mechanisms are employed in his lesser works: projection and displacement. The defense of projection is summarized by the phrase what I do not like in myself I will see in you and defense of displacement works in the manner, when I am prevented from aggressing against a strong opponent I will aggress against a weaker target.

Those motives would be entirely unconscious to the analysand according to strict psychodynamic theory, but when we are faced with a skilled writer, the line between conscious and unconscious processes can blur precisely because every convincing character has to spring from the unconscious fount of imagination as it coalesces around the writer's conscious experience. Furthermore, the good writer has almost always been an even better reader of others' works, so the good writer arrives at that liminal junction 
of imagination and experience with a set of tools or a bag of trick either collected in journeyman-fashion or abstracted by intentional analyses of favorite authors' techniques. I suggest that those extremely creative eight years were a time when Faulkner could successfully deflect himself creatively so as to "write off the subject," referring back to Richard Hugo as discussed in Chapter Three. He could thereby split his experience (probably with no conscious plan) across a pair of characters so as to manage his own developing internal ambivalence regarding his use of alcohol. This action allows him to discover himself in acceptable doses, even if it does not yield fictional products that equal the efforts derived from the "inspired denial" that produced his best work.

Faulkner was quite conversant with doubling as a craft technique and I will show below several examples where he applies the tool to characters in regard to alcohol: in on case where two characters are comparable in drinking habits, but who find different ends in the plot, or cases where members of a pair are contrasted in drinking affinity and achieve different ends. Before I pursue the examples of doubling in narratives where aberrant drinking is the obvious focus and somewhat enmeshed with Faulkner's own aberrant drinking, it is instructional first to look at two examples of doubling that are relatively free of drink as a problem and which show his technical proficiency with this tool of his craft.

The most astounding and audacious example of doubling appears in a lesserknown experiment that was published under the title, The Wild Palms (1939). Faulkner did not want that title. He submitted the work under the proposed title, If I Forget Thee, O Jerusalem. This historical fact of "author-versus-editor" is important because the book doubles two stories of two men, each in the company of a woman, and with the stories 
separated by ten years. Faulkner called one of the narratives "The Wild Palms" and the other "The Old Man." Not only are two sets of characters doubled, but two plots are doubled. He never intended for the title of either narrative to dominate the whole project, and each chapter alternates to the two narratives. I highlight this example because it demonstrates a case where the plots require (or at least exploit) the two different outcomes that can be achieved with doubled characters and doubled plots. Is it two stories? Yes. Is it one story? Yes. This conundrum is not a contradiction; it is a complexity. It is a complexity where similarity parries contrast while the contrasts pair with the similarities.

“The Old Man” takes place at sea level (or below) with swamps and floods dominating the context of dangers. "The Wild Palms," alternates between sea level (New Orleans), mountains (in Utah mining regions) and sea level (the Mississippi Gulf Coast. The dangers are mostly the dangers of human impulsivity, cowardice, greed, and dishonesty. "The Old Man" has the Tall Convict, on a work-crew fighting a flood, thrown into the role of rescuing a pregnant woman from a tree limb and into his johnboat. He shepherds her like Joseph through the immense difficulties of the 1937 Mississippi River Valley flood, a setting which drives them in reverse through mythic time. They regress through the archetype of the Noahic Flood to arrive in the snake-infested swamp of an anti-Eden. The hero (perhaps anti-hero better applies) in the "The Wild Palms" is a lackluster medical intern who meets a disaffected wife of a socially prominent lawyer. She impetuously abandons her children and husband to follow her passions, some of which is for the intern, but most of which is simply for a different vision of life. The narrative is set mostly in the context of mineral mining, with foreign-born laborers of 
immense strength and wild temperaments toiling in dark adits like denizens of Dante's Inferno but who threaten violent labor strikes that recall the clash of Pinkertons. The hero in "The Old Man" successfully helps, like Joseph, the woman deliver herself of her baby and then to deliver them both back safely to her home. In "The Wild Palms," the anti-hero, now the mining company "physician" - despite having abandoned his internship and rendering himself a not-such-Great Physician (pun intended) -- succumbs to his lover's request to end her pregnancy of his own making an elective abortion for which he knows he has little training and no legal right. She dies by sepsis after they return to the Mississippi Gulf Coast. The hero in "The Old Man" makes his way back in prison with an extra ten years added to his sentence for the ridiculous charge of attempted escape (he had desperately been trying to return to the safety of the Parchman Penal Farm during the entire ordeal), while the hero in "The Wild Palms" ends up in prison as a result of his crime, a fate he accepts to remember his guilt and his love, yielding the famous aphorism, "between grief and nothing, I'll take grief." The genre of "The Old Man" is modernist mythopoeic while "The Wild Palms" is modernist realism.

There are some autobiographical hints in both narratives. Wittenberg cites Faulkner's early flame, Helen Baird, as the model for the physician's lover, and she also mentions that Estelle actually had attempted suicide by drowning when on their Gulf Coast honeymoon. There seems to be conflation of the two women into the one female character - but the alcohol binges are not driven by the plots, nor do they drive either plot. The doubling of plots and the doubling of characters do not so much set up a comparisons of this man is better than that man or that action is better than this action as it allows both stories to be told as being simultaneously true. This drive towards 
iterations of two maximally-different stories is a rather interesting (and, I feel, successful) variant of the quartet of minimally-different narratives that compose Absalom, Absalom!. The Wild Palms is a project that has been underestimated in the Faulkner oeuvre.

I turn to "Was" of Go Down, Moses, and to the McCaslin twins, as another example of how Faulkner first chooses a plot and then doubles characters to arrive at different ends within the plot. In this case, however, the characters are specifically contrasted in regards to alcohol, though once again, blatant, drunken binges are not part of the story. The two are Amodeus and Theophilus McCaslin, also known as Uncle Buddy and Uncle Buck, respectively. If we read "Amodeus" as an orthographic variant of "Amadeus," then it is exactly the Latin version of the Greek Theophilus, and both would mean "beloved of God." If we read "Amodeus" as a corrupt spelling of "Asmodeus," then the name means "divine demon" and contrasts with Theophilus. Whichever the case, Faulkner did not determine the spellings; he only confirmed them. He had collected both the given-names and the nick-names from his own life, for they are exactly the names of two great uncles of his older friend and early-career mentor, Phil Stone (Kerr, 80). Faulkner translated the names from Lafayette County, Mississippi into Yoknapatawpha, Mississippi.

Uncle Buddy abstains from both alcohol and women, but he is the best poker player of the region. As the story in Go Down, Moses unfolds, we learn that Buddy's choice is conscious in regard to celibacy. He has adopted that strategy to stop the spread of McCaslins on the earth, a mission he accepts because he had become aware that his father, unrestrained by moral decency, had created an untenable tragedy. The father had bought a slave woman, had impregnated her, and then later had impregnated his own 
daughter born from the slave, thereby fathering the slave that the McCaslin twins now own and are chasing down. The elder McCaslin's acts of arrogant indifference and betrayal had led not only to the distraught mother drowning herself on Christmas Day, but had saddled the twin white brothers with owning their own one-quarter black brother. If Cain's evasive question, “Am I my brother's keeper?” is asked here, the answer comes back in horror and irony as "Yes!" because their motive in returning Tommy's Turl (the slave who is their brother) to their own land was not so much because he was their property but because he was their kin. They planned to free upon their deaths and they wanted to protect hum from falling into the hands of any other slave owner. Whether Buddy's refusal of alcohol is culturally concomitant with his celibacy (he is not whitemasculine performative), or whether it is his conscious way, by maintaining sober vigilance, of not losing control of his sexual drive, is not clear. But he is not a drinker. Buck, however, is a normal drinker and, evidently, normally prone to sexual desire. He is adamantly wary, however, of getting trapped in marriage. This seems for him not an aversion to procreation as much as it is an aversion to a loss of masculine freedom. The comedy in "Was" turns entirely on the way Faulkner starts with comic scenes of his fox hounds chasing a fox through the house (with the fox entirely in charge of the action during the whole romp), then pairs fox-hunting with chasing of a slave who keeps running off to another farm to see his lover, and then segues to the comedy of the white owner of the other plantation who has a single, eligible, but aging daughter, Sophonsiba who lies in wait to be "caught." She ostensibly ends up as the "trapped fox" when Buck's mistakenly enters the wrong bedroom and its bed in the dark. The plot turn is a bed-trick lifted straight from Shakespeare. Obviously she has lain in wait for Buck 
throughout the entire plot because she had actually taken charge of the runaway slave situation from the start to make sure that Buck would have to stay overnight at the house. This story is a Shakespearean comedy classics that ends with two marriages - one between the two slaves, even though they cannot legally marry, and the one between Buck and Sophonsiba, though that union with its progeny is not revealed fully until a later chapter and though Buck, technically, was relieved of obligation to marry by the outcome of Buddy's poker playing. The story is hilarious and involves one of the most complex games of poker ever described. Even here, the male slave, Tommy's Turl, has stacked the deck to get the game to end in the way that puts him and his sweetheart under the same ownership. He wins, and he was not even playing.

As for the issue of drink, the story follows the rules of the region. Buddy is a sexual suspect because he does not drink, but Faulkner exonerates his abstinence(s) because of his noble motive to stop sin in its tracks. All the drinking that is depicted occurs under the norms of the South: Sophonisba flirts via alcohol (she "sweetens" Buck's toddy by stirring it with her finger) but she does not transgress the rules by drinking with the men, nor is there indication that she drinks alone. She leaves the toddies with her father and Buck who both drink with strength and restraint, the very models of the way to drink like a real man.

With the character-doubling in "Was," Faulkner has achieved a level of sheer genius. He ends up with a story where "one" character (because the character is doubled in two twins) has all three outcomes: a win, a loss, and a draw. Buddy's plot line does not achieve his final goal (i.e. to stop McCaslin men from procreating), but he himself is able to avoid such a fate. His story comes to a draw; very much like the poker game 
itself. Buck "loses" his narrative "game" by losing his masculine freedom in a marriage in the first round of poker he tries to play on his own, but then his brother Buddy ends up "winning” Buck's freedom from a forced marriage. In the end, however, Buck simply concedes to his fate, and loses his freedom in a free-choice of marriage to Sophonsiba, but he ends up winning a son, a masculine asset. Yet now Buddy has a "loss" because another male McCaslins has been birthed. Though Faulkner does not invoke the fratricide of the story of Cain and Abel (as analyzed in Chapter Three), the brother who offers the pure sacrifice has his story end. The one who is tainted and marked has a continuing narrative.

The novel Pylon (1935) was loosely based on Faulkner's life experience of being in New Orleans for the air show festivities that were planned for the grand opening of the modern wonder the New Orleans airport. The book is bleak and grey in almost all respects, with the only colors ever noted being the garish purple and yellow as the signature of the New Valois city streets strewn with Mardi Gras trash and confetti. The novel presents two especially hard-drinking characters whom the narrator watches closely as they binge-drink their way into, and past, disasters. They are not a natural pair (as in the case of brothers) or even a social pair (as in cases of shared career or origins). They are, however, paired in regard to alcohol, and thrown together by fate. One of the characters never has a name; only a job. He is simply The Reporter. The other has a name, Jiggs, and he is the airplane mechanic whose job it is to keep the crafts flying. His name also reflects his vocation, as a little reflection on our words "whirly-gigs" and "thingamajigs" reveals. 
Alcoholism impairs the ability for both to function in their jobs. The Reporter is off-and-on fired by his editor for chronic failure to fulfill functions, though it appears that the editor also tends to hire him back. He cannot resist the temptation to start drinking early even when he knows he has a city-desk deadline to meet, and he cannot pace his drinking once he has started. He is in denial about the role the drink plays, however, and blames his problems on a editor who wants him to get at "facts" of a news story rather than at the meaning of the lives of the people he covers. He has become enthralled with the rag-tag group of barnstorming aeronauts who have come for the New Valois air show and air race. He is enthralled both with the flight jockeying itself and with rampant sexuality that the group exhibits. His gaze is fixed on their sexual excess which revolves around two men who share one woman (or one woman who enjoys two men, depending on perspective of gender power), a ménage that procreates in a son of undetermined paternity. These "sexual exceeders" in the novel is the inverse of the "sexual suspects" associated with alcohol abstinence. Although all the characters drink, the two outrageous drinkers, The Reporter and Jiggs, do not share in sex-relations with anyone. They gaze at the luridness but run a parallel only with an orgy of the bottle.

The sexual outrageousness of the woman and two of the men reaches both a new height and a new climax (the pun here is not avoidable) when Laverne, on a parachute exhibition flight at jump altitude, strips off her jumpsuit in the plane, arouses the male pilot partner, mounts him for full vaginal intercourse to the point of orgasm for both, and then skydives to land in the mud to find herself nearly attacked by the sexually frenzied crowd. As typical for Faulkner, sex and alcohol go together, but not neatly. 
When Faulkner catalogs the drinking excess, the narrator closely follows The Reporter who, in turn, closely follows the aeronauts. The binge he enters with them, and with Jiggs in particular, extends for pages and pages. It involves car trips, bar trips, and drunken hospitality where The Reporter invites the gypsy-like flyers to flop at his apartment. The chaos of the drunkenness involves mooching drinks, stealing bottles, the tremors of detoxification, and the ineluctable drive to get drunk again. When the Reporter finally passes out in his building doorway, his happy-time (but very depressed) guests take money from his pockets and leave him asleep, having locked his key to his own apartment inside it. The actions are not consciously malevolent; they are all just driven by a grim combination of White Logic and desperation.

In the midst of all this drunken chaos, however, it becomes clear that there is a terrible price to pay for the drinking. Jiggs, who drinks like The Reporter, can never stay sober long enough to do his mechanic's job well. The team waits in vain for him to adjust the valves on the engine of the one plane which they brought with them to New Valois. It is a, aircraft which, if the engine were well-tuned, could have a good chance at placing well-enough in the race to get part of the prize. Jiggs' irresponsibility, however, leads to a non-fatal crash that takes it out of commission. This act amplifies their financial quandary: they now must win first prize to garner enough cash both for living expenses and for repair expenses, and the dilemma leads to a finagled, forged acquisition of a very fast, but very flawed, prototype aircraft owned by a New Valois local man. The lead pilot risks the danger of racing it. He dies. Just as the plane escapes his control at the pylon (a phallic structure not to be ignored), he is able to aim for Lake Pontchartrain 
so as to avoid the crowd. Here another Icarus attempts too great a flight and he is smashed and drowned.

Neither the narrator nor any other character in the novel points an accusatory finger at Jiggs. The tragedy and grief are merely shouldered and shrugged in resignation to their fates. Jiggs leaves the group, changes his career to parachute jumper, and joins up with another pilot's aeronautic act. He moves on.

The Reporter, however, goes back to his dual vocations: drinking and writing. He returns to his bars, his typewriter and his bottle. The narrator reports on him in a bar early in the day, not yet open to the public:

The porter let him in and poured him a drink in the empty bar while starting the cork in another bottle. "Yair," the reporter said. "I was on the wagon for an entire day. Would you believe that?"

"Not about you," the porter said.

"Neither would I. It surprised me." (299)

Please no not miss this irony: as in Macbeth, we hear a porter in a conversation about drinking. I will repeat what I offered in Chapter One: Brother Bill seems always to have kept the bottle and the Bard near each other in his head and on his desk.

This drink begins yet another binge, with the porter soon physically holding The Reporter up and urging him to quit. The Reporter says in drunken speech that he has quit, yet he immediately asks for another shot. The porter pours it, the Reporter drinks it, and then he stumbles out of the bar and into his inner reflection:

He had himself in hand fine now; he did not feel at all; just the liquor flowing slowly down him, fiery, dead, and cold. Soon he would even quit shaking, soon he did quit; walking now with the bright unsoiled morning falling upon him he did not have anything to shake with. "So I feel better," he said. Then he began to say it fast: "Oh God, I feel better! I feel better! I feel! I feel!" until he quit that too and said quietly, with tragic and passive clairvoyance, looking at the familiar twin door through which he was about to pass: "Something is going to 
happen to me. I have got myself stretched out too far and too thin and something is going to bust." (300)

He enters the building and goes to the newspaper city-desk office. As he drank more from his own bottle, the liquor now

[...] tasted, felt like so much dead icy water, cold and heavy and lifeless in his stomach; when he moved he could both hear and feel it sluggish and dead within him as he removed his coat and hung it on the chairback and sat down and racked a sheet of yellow paper into the machine. He could not feel his fingers on the keys either: he just watched the letters materialize out of thin air, black sharp and fast, along the creeping yellow. (301-302)

This scene is the last one where we "see" The Reporter in the novel, but it is not the last scene where we "hear" from him. That evening, the copyboy and the editor each find two versions of The Reporter's story of the pilot's death. The account thrown into the trash and recovered by the copy boy is a modernist composition that sets the tragedy of competition against the greatest competitor, Death. The report submitted to the city desk editor for publication reads in staid and measured lines of decorum, giving just the facts. The Reporter had appended "savagely in pencil" at the typed ending a note to the city editor,

I guess this is what you want you bastard and now I am going down to Amboise st. and get drunk a while and if you don't know where Amboise st. is ask your son to tell you and if you don't know what drunk is come down there and look at me and when you come bring some jack because I am on credit. (315. Italics and orthography in original.)

There are echoes of William Carlos Williams’ poem, “Asphodel, That Greeny Flower," in the contrast of the two stories: the rejected visionary version that wrestles with Death, and the perfunctory journalism that is demanded:

It is difficult

to get the news from poems

yet men die miserably every day for lack 
of what is found there.

This diatribe ends the novel. The writer of the doubled-pair has the last word, and that word flows from a drunken rage. The mechanic has a new life and has vanished.

Faulkner's biography is littered with the wreckage of crashed airplanes of varied sorts: some were flimsy, some were faked, and one was in the family.

When Faulkner was just a boy with his younger brothers, they (and William in particular) had been obsessed with air flight. They stole their mothers tomato stakes from the shed, then tacked and lashed them together into a glider frame large enough to seat one. After pasting newspaper over it -- in the same way they made "doped" kites with flour-paste sizing -- they dragged it to the edge of a ten-foot bluff, Bill climbed it in it, and, at his request, the adult black worker pushed him over the edge. Faulkner plummeted to the sand below, ego bruised but uninjured in body (John Faulkner, My Brother Bill, 77-78).

Some years later, when he was in air flight training in Canada, we know definitively that he copied the mechanical drawing designs of the aircraft for which they were being trained to pilot (Blotner, Faulkner 2 Vols. 217). Concerning the cadet training flights, he tells us anecdotally:

War came. Liked British uniform. Got commission R.F.C., pilot. Crashed. Cost British gov't 2000 pounds. Was still pilot. Crashed. Cost British gov't 2000 pounds. Quit. Cost British gov't \$84.30. King said, "Well done." (Blotner, Faulkner 2 Vols., 225-226)

Blotner dismisses the veracity of those reports due to lack of any corroboration from military records or from Faulkner's peers, and he states “[t]he creative imagination had apparently made up the deficiencies of reality. It seems clear, then, that Cadet Faulkner 
did not crash. Did he ever fly (Faulkner 2 Vols., 226)?” Probably not in those years, but he did fly later.

His interest engendered a greater passion (and skill) for flying in his youngest brother, Dean. Faulkner blamed himself for his brother Dean's death in a plane he helped him buy, and though that accident occurred after the crash scenes in Sartoris and Pylon were already in print, Faulkner felt that his writing had somehow jinxed their lives.

There is a lot of Jiggs in Faulkner, and there is a lot of Faulkner in Jiggs.

It is, however, The Reporter, drunk at his typewriter, who leaves the last word in the book. That word is about drinking. He free-lances for a newspaper in New Valois, an ersatz New Orleans, in which city a hard-drinking Faulkner had freelanced for ten years earlier. At that time, though the drinking shenanigans were of the obnoxious fraternityparty type (BB guns pointed at nuns' butts, etc.) and Faulkner had not advanced to the point of having "the morning shakes." As Dardis has noted in the reference to "Golden Land," such physiologic consequences were emerging during the months he was writing Pylon. There is a lot of Faulkner in The Reporter and a lot of The Reporter in Faulkner. Faulkner was also quite conscious of the notion of doubling as he wrote Pylon. The passage quoted above notes the reporter attending, even when drunk, to "the familiar twin door through which he was about to pass." This reference to "twin" is more than accident, a claim bolstered with a conversation that The Reporter has just overheard a few hours earlier at the airport. On this morning after the pilot's death, gossipers are commenting on the uncertain paternity of Laverne's boy:

[...] they don't even know who the kid belongs to,"

"Maybe both," the fourth said. "A dual personality: the flying Jekyll and Hyde brother, who flies the ship and makes the parachute jump all at once." (290) 
There is no clearer example from Faulkner's own pen (or his typewriter tapping on yellow sheets of paper) that articulates bluntly the way a doubled character allows for two different, but simultaneous, endings.

Jay Parini, in One Matchless Time (2004), notes that nearly all the characters in Pylon are beset with alcohol in some way, and he raises a question parenthetically, "One has to wonder if Pylon was, in part, a form of self-interrogation, as Faulkner moved deeper into his own involvement with alcohol, often disastrously (190)." I feel confident that this review has responded well to the question Parini raises, and that this answer shows that Faulkner self-interrogates his aberrant drinking by doubling, a device which allows him to admit his disasters on one hand while holding out for a fiction of personal change with the other.

As shown by the reference to Sartoris (1929), Pylon is not the first Faulkner plot to use an air crash. Even the plot of his first novel, Soldier's Pay (1926), is driven by the actions that surround a head-injured pilot who had been downed in aerial combat. He returns home to South Carolina where he will die. Sartoris, however, was the first work that allowed Faulkner to find his "triggering town" (the metaphor Richard Hugo uses to describe the first images for a writer's inspiration) of Jefferson in Yoknapatawpha. He neither liked the editor's huge cuts made to his manuscript, nor the title Sartoris. He wanted it published in full and with his title choice, Flags in the Dust. His got his wish only after his death. In both versions, we meet the twins, Bayard and John Sartoris. We never actually meet John except in the memories of his survivors, and we really do not know much about what his drinking habits had been like. John had been shot down in air combat at the end of World War I just before the novel begins with Bayard's return 
home, but just after the two brothers had argued violently about John's decision to go up for another combat flight. The rest of the novel is concerned with Bayard's raging grief, much of which is treated with outrageous alcohol abuse.

The depictions of Bayard Sartoris' drinking episodes show an interesting dissolution of the southern white rule that prohibited drinking in the company of blacks. His evening serenade of college coeds, which includes hired black musicians to help the effort, turns into an all-night binge. As intoxication increases, rules go by the way. Not only do they end up drunk together, they end up drinking from the same jar of corn liquor, an enormous violation of the racial division standards. Where Faulkner has used doubling in some fiction to allow twinned characters to achieve different ends, in this novel Bayard's death is as close to his brother John's as peace-time would allow: Bayard crashes a faulty airplane in a test flight. That scenario, of course, is found again with only slight variance in Pylon, published some six years later. But finally, we have arrived in Yoknapatawpha in terms of Faulkner's chronological years. Though The McCaslin twins precede the Sartoris twins by about 60 years in the mythic, narrative time, the Sartoris boys, Bayard and John, are the first twinned characters to emerge in Yoknapatawpha when measured by Faulkner's publication timeline.

More doubling follows. Within another five years of his own writing life, it is in this "postage stamp" fictional realm that Faulkner creates the most complex doubling of two characters, a pair which is entangled in the problem of alcohol. The doubles do not even arise in one work, and they span works published from 1931 with Sanctuary through The Mansion in 1959. In Faulkner's developing myth of Yoknapatawpha, we will meet Gowan Stevens and Gavin Stevens. 
Their double relationship is so ambiguous that Faulkner even changes their kinship as he writes their actions. Robert Kirk and Marvin Klotz (1963) list Gowan Stevens among "Characters Handled Inconsistently," stating, "He is called Gavin Steven's nephew in The Town. In Requiem for a Nun, he is Gavin's nephew (313).” Within the timeline of Faulkner's publishing history in Requiem for a Nun (1951), Gowan Stevens, of some age around late twenties or early thirties, is Gavin Steven's nephew. When The Town (1957) appears, Gowan Stevens is seventeen years old, and is forced constantly to correct V.K Ratliff who continues to refer to Gavin Stevens as Gowan Steven's uncle: “'He's my cousin, I tell you,' Gowan said (The Town, 107).” In that novel, Gavin Stevens is evidently at least in his late twenties or early thirties and serving as the YMCA director in France as part of the war-effort at the time of the conversations. That kinship is confirmed in The Town by Chick Mallison, a cousin to Gowan Stevens (presumably a second cousin, though this can never be exactly ascertained) and the nephew to Gavin Stevens by dint of being born to Maggie Stevens Mallison, Gavin Stevens' twin sister. (And if anyone is counting just the cases mentioned in this project alone, Faulkner has peppered his Yoknapatawpha fiction with three sets of twins, a number that would make any obstetrician incredulous.)

Gowan Stevens is consistently depicted as significantly younger than Gavin Stevens; nearing, but not quite reaching, a generation's gap. Chick Mallison is younger than Gowan Stevens, and Gowan Stevens functions in The Town only to relay to Chick the information about Gavin Stevens as R.K. Ratliff gives it to Gowan. Ratliff's "error" in attributing kinship status to Gowan Stevens imposes a social relationship based on age, a rank that trumps whatever the exact biological relationship might be. Gowan Stevens , 
at age seventeen, resists the subordination to his "elder and better," Gavin Stevens in The Town. It is not an accident that he resists the term, "uncle": that's the cry of the defeated guy in any wrestling match.

Within the narrative time Faulkner builds for his Yoknapatawpha myth in The Town, the author and the reader is "not allowed" to know what will happen with Gowan in just a few narrative years in Sanctuary -- and then eight narrative years beyond that novel's actions in Requiem for a Nun -- but any faithful Faulkner reader already "knows" those developments and cannot help but "cheat" in the interpretations of Gowan's character and his actions. The reader already knows that Gowan has cried "Uncle" in Requiem. Similarly, the events in The Town, viewed through Chick's child-like relationship with his uncle Gavin, preceed the narrative time of Intruder in the Dust by at least four years. Again, the reader of The Town is "not allowed" to let the change in Chick's relationship to his uncle that "will” transpire in Intruder, affect attitudes toward Chick and Gavin in the novel in hand, but such a feat is impossible because the change has already transpired in the reader's experience. It may be possible to exercise a willful suspension of disbelief as we enter a fictional world from our "real world," but it is seemingly impossible to exercise willful amnesia once we have entered a fictional arena. This application of "reader response" theory, by reflection, invokes the exact same quandaries for what I call the "writer-response" relationship. At some level, Faulkner is participating in the psychological defense of undoing as his doubled characters Gowan Stevens and Gavin Stevens emerge and change. He gets to have it both ways: "you cannot know" and "you already know," and is essentially saying to himself, "I cannot know" and "I already know." 
Gowan Stevens may be younger than Gavin Stevens in mythic years, but Gowan Stevens lands on the published earth several years ahead of Gavin Stevens. Gowan is the minor character who triggers major consequences in Sanctuary (1931). In manuscript form, however, Gavin Sevens appears first as a two-dimensional functionary (the county attorney) with only a handful of words in a short story, "Hair," submitted to, and rejected by, The American Mercury in March 1930. He crops up again in unpublished drafts from around 1933 of what was Faulkner's first conception of Requiem for a Nun when it was in pure novel genre with no admixture of stage writing. Faulkner envisioned that project to be "esoteric" in the vein of As I Lay Dying, and the manuscript suggests that the character Gavin was emerging as the narrator who would unfold the history of the Yoknapatawpha court house and jail. Gowan might have had a few years (maybe only a few months) head-start on Gavin in an inked life, and although the blood relationship of the two is not yet made clear enough to be subsequently muddled, it seems that the pair are nearly coeval in creation, but separated at birth. They are twins of sorts, who will vie with one another like Jacob and Esau.

Until the time Conor Picken presented his 2013 dissertation, Gowan Stevens received faint attention among Faulkner scholars; especially when compared to Gavin Stevens. Picken provides an excellent summary of Gowan Stevens' inability to “drink like a gentleman," and he rightfully notes, when looking at Sancutary, that

[d]iscussion of alcohol as it relates to a tenuous southern culture in the novel must begin with the most egregious problem drinker, Gowan Stevens. Gowan is a minor character; his presence accounts for barely one quarter of the text, and, on the surface, he is merely the catalyst responsible for Temple's encounter with Popeye. (Picken 41)

I would argue, too, that discussion of how Faulkner writes his own aberrant drinking and not just the region's cultural quandary - also begins with Gowan Stevens. 
Wittenberg finds several projections of Faulkner's self at work in Sanctuary, most notably as Horace Benbow, who fails miserably as a defense lawyer, and as Popeye, the mafia sociopath: "Popeye has a curiously striking physical resemblance to Faulkner. He is short, carries his body stiffly, has dark eyes, "little doll-like hands," a nose that is "aquiline," and almost "no chin at all" -- terms that would all be used to describe the author. (99) Popeye is impotent, and Wittenberg notes that Faulkner had struggled with erectile dysfunction when writing The Sound and the Fury (90). She ignores, however, Faulkner's autobiographical parallels that are evident in Gowan Stevens. In fact, she never reviews Gowan Stevens' drunk-driving, booze-seeking behavior that lands Temple Drake in danger. She mentions him only as the recipient of Goodwin's fist-to-the-face in the encounter soon after the car wreck (96). Picken is quick to see what that striking fist meant for Gowan:

Finally, this episode further undercuts his masculinity, since his flight from the Old Frenchman Place seems spurred as much by physically confronting the men as it does facing Temple. Reduced to bloody clothes and desperation, his "disreputable" self becomes defined by this act, and, as Gowan sees flight as the only option, he abandons Temple. Gowan becomes the dangerous fusion of the alcoholic drinker and the "inverted white knight," a woozy, caricatured identity long ceasing to be a bastion of stability and chivalry in the South. (51)

Picken's perceptive phrase, the "inverted white knight," is keenly accurate, and though Picken does not hunt for Faulkner's attempt to offer us an "upright white knight," we will find him in Gavin Stevens, though not in the novel Sanctuary. He comes to fore in the collection of stories, Knight's Gambit (1949).

Picken's notion of a "dangerous fusion of the alcoholic drinker" with the knight is also perceptive, but again he does not note Faulkner's subsequent attempt to separate, by the nib of his pen, the dangerous drunk from the crusading cavalier, Gavin Stevens. Cleanth Brooks in 1978 had noted the connection of Gavin Stevens and knights in his 
essay, "Gavin Stevens and the Chivalric Tradition.” Rather than endangering women, Gavin Stevens spends much-too-much time and effort trying to save women in peril. The efforts directed toward his "damsels in distress" range from his winning, at last, his childhood sweetheart from the dark threat of an Argentinian suitor ("Knight's Gambit"), to his failed attempt to protect a Eula Varner from creeping Snopesism and a creepy Snopes (The Town (1957)), and, finally, to his odd platonic affair with the adult Linda, Eula's daughter by a previous relationship, that is transpiring even as he is obsessed with another Lolita-like nymph at the soda fountain.

As Wittenberg notes, by the time we arrive at The Mansion (1959) "Gavin Stevens begins courting fourteen-year-olds. (228)" Only the few pages of poetry he teaches her in the public soda fountain function to keep his lust sublimated. Yet readers know that Faulkner had already put a stop to Gavin's own "creep toward creepiness" because, in "Knight's Gambit," he marries his adolescent sweetheart, even though that event comes after the events narrated in the Snopes Trilogy. In our reader's timeline, we are assured, therefore, that though Gavin courts unwisely, he will still emerge in his quest as a righteous knight; flawed, but saved. We can, therefore, give him permission to court disaster in so many different ways. The narrative timelines in The Town and The Mansion do not afford such information, however, to the characters, such as Chick, who have their gaze fixed on Uncle Gavin. Wittenberg perceptively gleans Chick's observations in The Mansion - observations from an adult Chick who is the seasoned air combat veteran and prisoner of war released after the end of WWII, and not the starryeyed adolescent who both worshipped and challenged his uncle in Intruder in the Dust :

Chick notes his uncle's tendency to "[pick] out children, or maybe he was just vulnerable to female children and they chose him" (194), and goes on 
cynically to assert, "The only moment of motion which caught his attention, his eye, was that one at which they entered puberty." (233. Wittenberg's page citation in the quotation refers to The Mansion.)

Wittenberg correlates precisely the extramarital affairs in Faulkner's life that concord with everything but Gavin's restraint: Meta Carpenter as the correlate of Eula, Joan Williams as the correlate of Linda, and Jean Stein as the correlate of the fourteen-year old soda-shop protégé. The fictional characterizations are all amplified in some regard, including the last temptation to engage an underage girl for sex, but even then, as Wittenberg points out, "Jean Stein was almost forty years the writer's junior [...] (228)."

When we turn attention to the spelling of the names, it does not take much scratching with a pen to transform "Gowan" into "Gavin." Gowan and Gavin not only share family blood by some close tracing, as well as the paternal name "Stevens," but their given names are a splitting and redistribution of "Gawain," the heroic knight of chivalric lore. Gowan gets the "w" and Gavin gets the "a." It is no accident that the first extensive introduction to Gavin Stevens, the country cavalier lawyer, is in the collection named for the novella, Knights Gambit. Even when Gavin shows himself as a rhetorical blowhard, he remains the respected -- though eccentric -- model citizen.

The similarity of the author's self-presentation to Gavin Stevens' depiction was not lost on Joseph Blotner. In a very interesting example of a narrative about a narrative, Joseph Blotner record his first sighting of Faulkner when the author was brought to the University of Virginia as writer in residence.

In January, I had glimpsed him for a moment from the other end of the long, dimly lit corridor when he had made a brief visit to the firth floor of New Cabell Hall. A small man, severely erect, he had moved slowly, turning into Fred Gwynn's office and out of my sight. He had shown what he had described in Knight's Gambit: "an erect and dignified carriage which the Negroes called 'rearbackted."' (Faulkner 2 Vols, 1637. Aberrant spelling is from Faulkner.) 
Commentators have long suggested a strong identity of Gavin with Faulkner, but the identification leads to consternation because, although Faulkner does seem to funnel his voice quite directly through Gavin Stevens at times, it is also apparent that Faulkner also finds Gavin Stevens' words to be too preachy. There is, for example, the long-winded, sermonic monologue about the proper way to let the South deal with its race problem, found in Intruder in the Dust, where Gavin Stevens ruptures the narrative frame of the fiction, but which concurs quite closely with Faulkner's views. And yet Chick chides his uncle Gavin for not seeing the reality of the shame in the county folk as they flee the freedom Lucas Beauchamp has arranged for himself. Critics are never sure when Faulkner is affirming Gavin and when Faulkner is criticizing Gavin, but they also assume that if Faulkner pours himself into Gavin, that means univocal approval. Noel Polk asserts, “[p]erhaps no character in Faulkner's fiction has caused more trouble for critics that Gavin Stevens. Most of the trouble has stemmed [...] from the fact that Stevens has been traditionally accepted as Faulkner's "spokesman" in the late novels; too many people believe that everything that Stevens says carries the weight of Faulkner's own convictions. (55)"

I suggest that it is as if Faulkner attempts to achieve within Gavin the reversal of his own reputation, but that even Faulkner himself can never quite trust this trick. Faulkner knew he was always considered odd, and that he received little respect. Rather than being revered as some sort of knight in his community, he was called the "Count No Count" by his Oxford, Mississippi neighbors, and much of this reputation was due to his drinking. His attempt, then, to transmute "the Count No Count" into the knight --flawed 
but cogent -- can only meet with partial success, whether considered as a literary character or a literature creator.

In some respects, Gavin's role to represent Faulkner is more successful in the fiction than was the Gavin-like role Faulkner adopted in his own life. In the fiction, Gavin Stevens is the master of language and languages, yet while being Harvardeducated, speaking fluent German, holding a University of Heidelberg Ph.D., solving crimes, and translating intermittently the entire Bible into classical Greek, he also squats on country-store porches to speak with his Mississippi neighbors in their vernacular and on their level. Faulkner's adopted "Gavinesque" demeanor does not afford such flexibility. Blotner gives us a clue as to how this "actor" persona of Faulkner fails. Having just compared Faulkner to Gavin Stevens, Blotner continues his recollections of Faulkner's first times in the University of Virginia classrooms:

Though he looked attentively at questioners, I had the sense of a distance which he imposed between himself and the rest of us, one far greater than that normally imposed by the teacher's desk. When I stopped for a moment on the way out to thank him, he answered with polite remoteness. (Faulkner 2 Vols., 1637)

With Gavin Sevens, Faulkner can achieve, by fictional projection, a communal integration he never could achieve in his own life.

I suggest that this problem is because Faulkner cannot show his Gowan Stevens to his flesh-and-blood world while simultaneously parading his Gavin Stevens alter-ego. In fact, Gowan Stevens cannot show himself to his ink-and-paper counterpart, Gavin Stevens, within the fictional narratives and have the narratives survive with any kind of cogent force, as will become apparent when we reach Requiem for a Nun.

Where Gavin Stevens differs from both Gowan Stevens and from William Faulkner is in the respective relationships with alcohol. Gavin does drink some, and 
despite his position as county attorney, he is not too much the legalist to keep from drinking at a bootlegger's tavern in one of the detective stories bundled in Knight's Gambit. But Gavin is never drunk in any presentation in any story of novel, much less does he cause havoc with alcohol. Gavin is perhaps tempted to sexual excess, but the temptation never cracks his resolve. The only indulgence that does "take him out" is his habit to "binge" when he turns his hand and brain to the ridiculous translation project: that idea of rendering the Bible into Attic Greek, starting with the English translation. Chick and others know to leave Uncle Gavin alone when he is in one of those spells, just as Jill Faulkner and others knew to leave Brother Bill alone when he was launching into recitation of Shakespeare poems just prior to an episode of alcoholic oblivion. What better sublimation of the morally-suspect behaviors of drunken excess can anyone imagine, yet a transmutation that retains the notion of pointlessness, than fiddling with dead languages and holy scripture, and trying to make Hebrews speak Greek?

Jay Watson, in Forensic Fictions: The Lawyer Figure in Faulkner (1995), argues that Gavin Stevens becomes a replacement for the failed Horace Benbow as the leading lawyer figure in the developing Yoknapatawpha myth. Watson also takes a moment in an important footnote to reflect on the connections of Gowan and Gavin:

Nor perhaps is Gavin meant to replace Benbow alone. Consider the rather obvious homonymy between Gavin and his nephew Gowan, another of Sanctuary's notable moral failures who disappears from the Faulkner canon until the publication of Requiem for a Nun in 1951: Is Gavin, at least in this earliest appearances, the heroic-chivalric Gawain figure his nephew cannot be? (241)

This insight deserves attention, and some scrutiny. As I will show in the discussion of Gavin's and Gowan's only encounter with each other in all of the Faulkner fiction, I am not as comfortable with the word "replace" as I am with the word "complement." But the 
"complement" is no "compliment." They function like matter and anti-matter, and when brought together, the two identities annihilate each other.

Gavin may be generally quixotic, but Gowan is dangerous; at least until we look at Requiem where the roles are somewhat reversed. Having considered Faulkner's connection of Gavin as the knight who parallels, and corrects, the "Count No Count" image, we must consider the anti-knight (or in Picken's term, the "inverted white knight") who first endangers women in the narratives and where seeds might have grown from Faulkner's life..

In the extensive 1974 biography, Joseph Blotner recounts a vignette from Faulkner's life in 1921. Faulkner had an evening date with Dorothy Conkling (at that time still Dorothy Wilcox) that ended up at three a.m. with his car off the road and stuck in a muddy pasture:

At times, however, he would surprise her. One day he telephoned. "Put on your best bib and tucker," he said. "I'm going to take you up to the Moon Lake Club. We'll crash the party." She was ready when he arrived that evening, waiting for him in a white evening dress beaded with gold, wearing her gold evening slippers. They had no trouble getting into the party, and they had a good time, though Faulkner was quiet as usual and danced little. It was nearly three o'clock in the morning by the time they left. Their return along the dark roads was uneventful until suddenly one of the wheels spun off the axle. The car swerved but Faulkner fought it to a stop in a cotton patch. He descended and walked through the mud to the nearest cabin. There he roused a Negro who fetched his team and dragged the car through the mud of the cotton patch and back onto the road. They put the wheel back on and finally Faulkner delivered Dot to the door of her home, safe but wearing golden slippers covered with mud. (Blotner Faulkner 2 Vols., 292)

Some details in this story do not add up well. I will steal Shreve's phrase, "Let me play a while," as I will play amateur detective to examine crucial aspects of this story, just as Shreve played the interloper detective for the Sutpen saga. 
Blotner gathered that story from Conkling herself in an interview in 1965, but some of the details do not make sense. First, when a wheel comes off an axle, cars do not swerve; they stop with a jolting, grinding abruptness. Second, a car with a wheel missing and stuck in a muddy cotton patch is not likely -- mules or no mules -- to be dragged back onto a road prior to the wheel being replaced: the frame, axle and fender at the lost-wheel location are simply going to plow into the mud. Finally, the notion of replacing a wheel securely at roadside in the predawn or early morning hours without recourse to good tools seems implausible. I am skeptical, and I strongly suspect that Dorothy Conkling was not willing to expose the role of drinking in the event. I do not doubt that Faulkner put a car in the mud at three a.m. and that his date had her shoes and gown spoiled, but I suspect that the problem was behind the steering wheel and not with wheel coming off an axle.

I am even more suspicious because the paragraph in Blotner's account immediately before the Curious Incident of the Car in the Cotton Field states:

If people like the campus wits saw Faulkner as an object of satire, some of his friends had feelings of concern. Dot Wilcox would see him with mismatched shoes, with the elbows out of his coat. Sometimes, she thought, he looked pathetic --- trampy and raggedy-looking. (Katrina Carter saw him waiting to change trains at Holly Springs barefooted-the same young man Myrtle Ramey had seen strolling down to the Square adorned with pocket handkerchief, cane, and spats.) And he drank a good deal. He carried his whiskey well, so one could hardly tell that he was feeling it except that he would get just a little thick-tongued.

'Bill," Dot would say, "why do you want to go around looking like that? Don't you want to make something out of yourself?"

"All I want to do is write," he would reply quietly. He was amused at her concern about his appearance. "Who knows, someday you may see a headline in the newspapers, 'Tramp Becomes Famous.'"(292)

Almost immediately after the tale of the Cotton Field Fiasco, Blotner states, "There was no question about Bill Faulkner's fondness for liquor. He could not afford the brand he 
found in the Colonel's stock when he worked in the bank, so now he took what he could get, including the powerful "white mule" made by county moon shiners (293)."

These coincidences of narrative, the inconsistencies in probabilities, and the bracketing with concerns about Faulkner's social functioning and his ability to be nearly undetected in his aberrant drinking point me to equate Faulkner's car wreck and Gowan Stevens's car wreck. I would prefer to defend the whole scenario as I have reconstructed it, but even a prima facie acceptance of the Dot Conkling interview gives us the biographical correlate of Faulkner's accident on a date to Gowan Stevens' accident on a date.

Blotner tips his hand to his readers as to his own recognition of Faulkner's affinity with Gowan Stevens. His “Chapter 70, February-May, 1957,” the chapter which takes the reader into Faulkner's writer-in-residence years at the University of Virginia and where he recounts his association of the first sighting of Faulkner with the character Gavin Stevens (quoted above), is headed with several epigraphs. One short quotation is from Gowan Stevens' direct speech, from page 32 of Sanctuary: “'I went to school at Virginia. Teach you how to drink, there' (Faulkner 2 Vols., 1635)." When Blotner pairs the Gavin-like Faulkner with a quote from Gowan Stevens in the context of the University of Virginia, we are no longer dealing with subtleties. Gowan is the man who had gone off to the University of Virginia to learn to "drink like a gentleman," and that was at least one course he failed miserably. Faulkner, though never a student at "Mr. Jefferson's University," obviously had failed in the course of drinking like a gentleman, and here he is now at the University of Virginia. Gavin, in contrast, always drinks exactly like a gentleman. 
In short, Gavin Stevens and Gowan Sevens cannot be understood apart from each other, but they also cannot stand too near each other. When we hear them in stereo, and at a distance, however, we are hearing Faulkner's desperate attempts to control his inability to control himself. As long as they do not meet up, things go fairly well. When they are in the same room, there is not much to see but meanness, misery, and a collapse of the double life that this chapter's epigraph from Alcoholics Anonymous reports, a report that comes from the members' own experiences of dealing with themselves in their cumbersome bifurcations.

Gowan Stevens and Gavin Stevens are placed in the same room in Requiem for a Nun, and what a wretched room that turns out to be. That book is such a wrongly executed project on so many different levels that it is hard to choose a floor on which to stop the elevator. I will try some charity and start with the ground floor. I admit an absolute, entranced admiration for the rich prose sections that build the jail as Faulkner builds "The Jail." That inspired "trigger," apparently touched on as far back as 1933, had immense promise, and from it he fires off some pages of great writing that make for good reading. It is as good as any of Faulkner's modernist mythopoeic descriptions, and it obviously had its origins in the days of his strength. For example, the trope of a Cecilia Farmer's name etched by a diamond ring into the old flow-glass window pane in the jail, is so richly evocative of time, time passing, hope and imprisonment, that it alone probably saves the book from oblivion. I agree heartily with Noel Polk in Faulkner's Requiem for a Nun: A Critical Study (1981) where he states, "The passages treating Cecilia Farmer in Requiem are among the most eloquent in all of Faulkner [...] (12).” 
The one too-often quoted statement about the Past, however, about the Past is as dense as it is memorable. As Noel Polk says, the statement was probably meant to be evocative, but it is frankly indecipherable in its setting. It is more Delphic than aphoristic. Perhaps the best dramatic line to come out of the dramatized portions is a toss-away given to Nancy when Gavin Stevens superciliously questions her as to how she could not be certain of the paternity of her own child. She slices him down with the slam, "If you backed your behind into a buzz-saw, could you tell which tooth hit you first? (Requiem, 220)" That quip is a spark of the old genius not yet dead, and I suspect it had survived from the early 1930's.

The problem with Requiem is not that Faulkner was trying to be experimental. He had been experimental (or "esoteric" as he dubbed it) with great critical success in the Benjy section of The Sound and the Fury, in all of As I Lay Dying, with the quadruple telling of Absalom, Absalom! and with considerable success in the interspersed doubledfictions of The Wild Palms. The problem with Requiem is that he was not writing for his own need to write. Not only had he himself not spawned the stage project, he somewhat disingenuously had palmed the project onto his new young romance, Joan Williams as an enticement to keep her in his orbit. He tried to generate her interest in a project that was probably not her chosen genre either, and which was obviously triangulated with secondary gains. But the notion of a play was never his own, and the problem here is similar to the origins of $A$ Fable, which was also not born of his own inspiration. Ruth Ford, a distinguished stage actor, wanted him to write a play. The last play Faulkner had written was The Marionettes, for a college production. It is found in the same period of his poems. We can only hope it will stay there. The theater was not his home, and he 
tended to fall asleep when attending performances. Noel Polk stretches the evidence when he defends Requiem by saying, "There is also, not incidentally, considerable evidence that he had been interested in drama since the earliest years in his career $[\ldots]$ (237)" for his footnote to the claim is exactly the reference to the college play and the fact that he was borrowing from playwrights (fn. 5 268). Faulkner had also been interested in poetry from his earliest years and he admitted that he failed miserably as a poet. This observation is not to point a moral fault, but just a career fact. There are probably similar reasons why we do not have novels by Eugene O’Neill.

Noel Polk argues with Cleanth Brooks over the proper interpretation of Gavin Stevens in Requiem. Polk argues intensely with the interpreters who find decide that Nancy is somewhat justified in killing the child and that Temple, though never fully exonerated from her sordid past, is redeemed by Nancy's "substitutionary atonement." Polk states of them all (including Stevens, who is always Gavin Stevens, despite the fact that there are three adults, one surviving child and one dead infant all with that name in the book):

The reading advance in this study is quite the opposite of what I have just described. I shall argue that Nancy's murder of Temple's baby is the most savage and reprehensible act of violence in all of William Faulkner's fiction; that it is totally without justification; that it is the act of a mad woman and not a saint; that Nancy's and Stevens' stated motives are not necessarily their real ones; that Stevens is not out to "save" Temple but rather to crucify her; and that Temple rather than Nancy is at the moral center of the novel. I shall not outrage Faulknerians by arguing the Requiem is a major work in the Faulkner canon [though I believe it is], but I do hope to persuade them that, read correctly, it is a powerful and complex novel, perhaps the darkest and least hopeful of all of Faulkner's work. At the very least, I would like to convince readers that Requiem for a Nun, like all of the late Faulkner, is very much worth taking seriously. (xiii, Brackets in original.) 
.I do not fault every specific item in Polk's interpretations. For example, I agree that Gavin is simply cruel in his haughtiness. My major problem, however, is with Polk's premise that, as a work of fiction, the book is even interpretable. The work is more like a Rohrschach inkblot test. Our responses to the random shapes, shades and colors on the cards are interpretable (that's the point of the psychological test), but the shapes, shades and colors on the cards have no meaning in themselves. Faulkner, however, had probably had not intended to make the bunch of inkblots that emerged in Requiem. I would agree that it should be taken seriously, but as a warning to any writer as to what can happen if writing goes wrong.

Every lost cause deserves a patron saint, and Noel Polk has been such an advocate for Requiem, from the days of his $1970 \mathrm{Ph} . \mathrm{D}$. dissertation until his last hours of scholarship, but his interpretative review fails to convince me that this work is complex in the way that I can affirm for a work such as Wild Palms. Requiem is simply a muddled, mean-spirited mélange. There is no way to come to a meaningful conclusion about the characters in the dramatic portions of the book, and those sections detract from the prose-poetry sections that build the early years of Yoknapatawpha. The characters on stage are never developed well-enough by their actions and interactions to allow interpretation. Their lack of development on stage cannot be compensated by the paragraph-length depictions of the characters that Faulkner gives as stage directions. The only clear sentiments they reveal in the dialogue are resentment, cruelty, remorse and frustrated hope, but those emotions do not point any direction with sufficient clarity and force to drive characters to seek transformations, or to demonstrate why the characters cannot be transformed. I learned from a good fiction writer and creative writing 
instructor that there is nothing easier for the writer to accomplish than to confuse the reader. Whether Faulkner sought such confusion as a cheap trick, or fell into it by his loss of creative control, can be argued. I opt for the latter. He drove this vehicle drunk into a muddy field.

Once again, I will turn to the harsh marketplace for a defense. Just as three magazines would not buy "Weekend Revisited" from a man who had just accepted the Nobel prize in literature two years earlier, the 1951 play-novel was not staged in New York until 1959 when Ruth Ford finally forced it on the boards; and it barely survived one performance. Broadway has seen infamous "turkey productions" -- the seasonal pieces that were specifically meant to run only from the turkey of thanksgiving until the turkey of Christmas -- last longer. When Broadway producers refuse to pick up a Nobel laureate's piece in such fashion, there is a problem, and it is not with the controversial content. It is with "box office" and the fear that Variety, after opening night, will read something like KNICKS NIX HICK'S TRICKS. Camus's translation and praise be what they may, Requiem fails as American theater. The better reviews and receptions in Europe seemed to accompany the State Department sponsored visits that Faulkner made, and they seemed to be generated more by interest in him as a writer and the controversial nature of the play's topic than by any notion of the dramatic quality. Even when touted as philosophy in the footlights, this is neither Waiting for Godot nor No Exit.

I find that Conor Picken is closer to an accurate reading of Requiem when he attempts to place the work in the context of the cultural and regional meanings of recovery, pathological states, and social progress. He writes

With the damaging effects of alcoholism (and their subsequent treatment) having become so personal, Faulkner could be excused for an unusual preoccupation with 
drinking in his work at this time. Such preoccupation is evident in Sanctuary's sequel, Requiem for a Nun. Like its predecessor, the dramatic action in Requiem for a Nun is soaked in alcohol. There is, however, one major exception this time around: neither Temple nor Gowan ingest a single drop. Although alcohol and drinking are spoken of constantly, they are conceived of in explicitly pathologized terms indicative of the Sobriety Movement. Faulkner's resurrection of Temple Drake and Gowan Stevens as the main characters proves no accident and suggests that his literary treatment of drinking requires a second look, one focusing on how the disease of alcoholism threatens domesticity and, subsequently, socialeconomic standing in Jefferson's post-war middle-class. (63-64)

I particularly agree with placing the onus of the problem on alcoholic impairment.

Faulkner's alcoholism was entering its fourth decade. The biographical review at the beginning of the chapter indicates the extent of the medical and physical symptoms of the problem.

At the risk of violating prohibitions against attempts to divine "authorial intent," I am less inclined, however, to find with Picken that Faulkner in Requiem has much interest in addressing the problems of the disease of alcoholism. I find, instead, that the disease of alcoholism at work in the author simply makes it impossible for him "to get to work on time." The bottle which used to inspire him has not only abandoned him; it has handicapped him. His early wisdom about protecting his craft from the undue influence of others has dissipated, and I attribute that fault to the advancing disease process. I also find that Gavin Stevens in Requiem is an all-too-true representation of Faulkner's anger at women by this point in his alcohol-soaked life; women who could not prop up a sense of self that was eroded by amplified discontentment as alcohol failed to satisfy him. "Buzz" Bezzarides had noted that he saw clearly that Faulkner had been using Meta Carpenter fifteen years before; in fact, Bezzarides was open about the fact that Faulkner was quite willing to use most anyone in rather presumptuous manners, but always couched in the demeanor of the Southern gentleman (Brodsky 62). As Alcoholic 
Anonymous members summarize the persona of the actor who manipulates those around to achieve selfish ends,

He may be kind, considerate, patient, generous; even modest and self-sacrificing. On the other hand, he may be mean, egotistical, selfish and dishonest. But, as with most humans, he is more likely to have varied traits. What usually happens? The show doesn't come off very well. (61)

Requiem for a Nun, whether set on a stage or pulled from a shelf, does not come off very well.

As long as Faulkner was able to keep his "varied traits" distributed across Gowan and Gavin, and then, in turn, to keep them away from each other, those two characters cannot pick at each other. He lets them go on-stage together to talk, however. The outcome is not good. Gavin is self-righteous and imperious, and Gowan is selfdenigrating both in his immediate misery and in his review of an eight-year long resentment against not drinking. Picken selects well Gowan's words and places them in context:

He was "trained at Virginia to drink like a gentleman, [then] gets drunk as ten gentlemen, takes a country college girl ... cross country ... gets drunker than twenty gentlemen, gets lost, gets still drunker than forty gentlemen, wrecks the car, passes eighty gentlemen now..." (62). In reconstructing these events, Gowan implicates the "Virginia gentleman," assigning personal culpability to the identity he once thought so important. As the severity of his transgressions increase, so too do the number of gentlemen complicit in them until, finally, he commits the gravest crime of all, admitting that "Marrying her was purest Old Virginia. That was indeed the hundred and sixty gentlemen" (63. Page numbers in the quoted text refer to Requiem.)

Gavin is mean and Gowan is miserable. Faulkner's twins, separated at birth, are now united on a badly-set stage to hate their Creator in unison. The epigraph of this chapter notes the double-life of the alcoholic. The paragraph immediately after it in Alcoholics Anonymous states, 
The inconsistency is made worse by the things he does on his sprees. Coming to his senses, he is revolted at certain episodes he vaguely remembers. These memories are a nightmare. He trembles to think someone might have observed him. As fast as he can, he pushes these memories far inside himself. He is under constant fear and tension - that makes for more drinking. (73)

If, then, we want the key to unlock the riddle of Requiem, this is it: "The past is never dead. It is not even past." In contrast, the members of Alcoholics Anonymous who have learned a way to work through their past, and thereby to find themselves no longer faced with more drinking, promise each other, "We will not regret the past nor wish to shut the door on it (83)." There is a lot of regret in Requiem. Despite a white-knuckled adherence to abstinence, there is no recovery.

I asked three questions at the beginning of this chapter. First, how does Faulkner work his own alcoholism into his characters? The answer is by incorporating biographical aspects of his own life into his characters and their actions, particularly as doubled or twinned characters. Second, are his characterizations convincing as fiction? The answer, is, they are convincing when he is at the height of his creative powers (some of which power may be attributed to the benefits of alcohol) but before his advanced alcoholism eroded both his creativity and his psychological defense of denial. These two features, creative power and healthy denial, are probably synergetic for the production of good fiction. Third, how do these characters "hold up" across the rise and fall of Faulkner's creative powers? The answer is, the most apparent pair, Gavin Stevens and Gowan Stevens, disintegrate when placed too close to each other, but Gavin makes the full arc - remaining fairly intact and interesting even when he is irritating - by his last appearance in The Mansion. That being said, even though Gavin survives as one of Faulkner's most memorable characters, Gavin never thrives in any of Faulkner's best 
works. The Gavin sections of Requiem are tediously irritating. Intruder in the Dust (1948), Knight's Gambit (1949), The Town (1957) and The Mansion (1959) are each entertaining as story collections or novels, but none compare well with the high period. This indicates Faulkner's increased need to dissipate with projection, displacement, and undoing the very character flaws that alcoholism was revealing strongly even to himself. This advanced disease sapped his ability to use healthy denial when he entered into his mythic, fictive worlds. Rather than discovering self, he could not get away from self, and his thrashing about hurts the quality of his work. Requiem for a Nun becomes, quite apart from any comparison of the dramatic worth of the two plays, Faulkner's version of $N o$ Exit. Gavin Stevens and Gowan Stevens are in Huit Clos (closed court) together, 


\section{CHAPTER FIVE \\ “THE LION IN THE GARDEN," THE ELEPHANT IN THE ROOM AND "IN TIME, THAT MADE A MONEY OF US ALL"}

The performance began. The entire Gallimard family clan descended upon him with one smile and a half dozen tentacles. The society women trooped in. The hunt was on. After an hour of it, Faulkner had retreated as far as he could go. He was standing at the far edge of the garden, beneath the tree with the heaviest foliage, backed up against the wroughtiron barrier.

-- Madeleine Chapsall, "The Lion in the Garden," The Reporter, November 3, 1955. In Meriwether and Millgate, The Lion in the Garden: Interviews with William Faulkner, 229-230.

The epigraph cites one of our most famous metaphors for Faulkner, "the lion in the garden," a phrase coined by a French journalist who cast her gaze on the honored guest at a cocktail party held in the walled-garden of a powerful publishing family in Paris. Meriwether and Millgate elevated the image to prominence in the title of their 1968 catalog of Faulkner interviews, conversations executed sometimes in the service of high literature, sometimes in the service of U.S. State Department cultural missions, and sometimes as a mix of both.

But there are other metaphors that come to mind, and we must ask which one better reveals the real Faulkner. Is he the "Lion in the Garden," i.e. the king-of-the-beasts now become hunted prey or safely trapped by civilizing conventions; a literary trophy, now made the play-thing of the powerful arbiters and owners of a literary landscape which is really nothing more than a zoo? Or is he the "elephant in the room," and we, who host him, are the ones trapped, caged by our social conventions which forbid recognition of an immensely embarrassing problem with alcohol? For even Chapsal notes immediately before the words quoted as epigraph, "[a]lso he had his bourbon. He is very 
fond of bourbon." Or is the correct metaphor, "In time, which made a monkey of us all," the riff on evolution Grace Paley gives us? That is to ask, are Faulkner's "matters of concern" and our "matters of concern" (with the possessive pronoun "our" meaning "all who have encountered him with interest, whether inside or outside his fiction," and with a strong emphasis on our demand to possess), considerably illuminated (though not "explained away") as a richly adumbrated heritage we share with the vervets?

I argue that the answer to each is "Yes." I argue that the answer to each can be "No." Each metaphor is true when considered in the context of the other two. None of the metaphors remains true when taken alone.

Concerning the Lion metaphor, this chapter addresses the view that Faulkner, the man, (and not just Faulkner's works) has been a type of inventory; a product to be traded. The book-length study by Lawrence H. Schwartz, Creating Faulkner's Reputation: The Politics of Modern Literary Criticism (1988), focuses this discussion about the "caged lion," and, Schwartz' Marxist-tinged analysis succeeds in illuminating two major realities that are consonant with the equivocal "yes and no" I offer. As for the "yes," Schwartz demonstrates convincingly both that publishing is an industry that markets its products and that ideologists (whether intellectual or governmental) will use any means necessary to dominate other ideologies, even if those actions mean propping up a stumbling-drunk genius. As I read Schwartz' accounts of the manner in which Faulkner, during his years of decline, was coopted by others for their own interests, I am reminded that Samson, shorn of his glory and sapped of strength, was put to work grinding grain. The "no" I offer Schwartz regards the Marxist naiveté noted in the review of myths of alienation in Chapter One. If the myth of a purely "objective science paradigm" has a blind spot 
concerning the claim to objectivity, that normal vision problem is no more obvious than deluded simplicities of rational economics that scientific dialectical materialism invokes to explain human behavior and human longing for meaning. Our interests and our values as a species have transcended the rudiments of materialism, a conclusion that even the bête terrible of postmodern Marxist thought, Slavoj Žižek, reaches in his works, The Parallax View and Less than Nothing: Hegel and the Shadow of Dialectical Materialism. I still hold that it takes as much faith to expect "the withering away of the State" as it does to preach the bodily resurrection of the dead, and that each belief claims some necromancy over molecules. The Marxist myth cannot demonstrate that science defends its tenets or that the humanities require them. Furthermore, believing that economies and ideologies affect the human condition is a far cry from proving that they determine it.

An open-minded reading of Schwartz in the context of the "capture lion" metaphor, however, will highlight a crucial matter of concern that unfolds in each of the other two animal metaphors: Each of us takes interest (pun intended) in the writer, though the specifics of that interest vary from person to person. Consequently, the way we value the writer (again, pun intended) varies amongst ourselves, and the degree of value can vary within one person across time. I have learned from Schwartz, but do not affirm his creed, however. The genie of the human spirit will not be tricked back into a brittle bottle of molecules, even if Marx turns Hegel on his head and shoves on his legs with all his might.

The image of stuffing large bodies into small spaces, however, brings us to the Elephant metaphor. This chapter looks very carefully at the way Faulkner's biographers have changed the way they gaze at (or avert gaze from) his drinking by our gazing at 
publications from 1963 to 2004. This look advances through four decades: from Michael Millgate (1963), to Joseph Blotner (1974), to David Minter (1980,) to Joseph Blotner again (1984), to Stephen Oates (1986), Frederick Karls (1989), to Joel Williamson (1993), to Richard Gray (1994), to Jay Parini (2004) and to Philip Weinstein (2010). Blotner receives "the lion's share" of the review for two reasons. First, his chronology provides the scaffolding on which each of the others, except Millgate, depends and builds. Second, Blotner's interpretative gaze on Faulkner as a drinker shifts significantly from 1974 to 1984.

The works of Donald Goodwin (1988) and Tom Dardis (1989) - the reviews of Faulkner as a drinker -- are noted not to have been as much the causes for the shift as examples of the shift. Blotner, for example, shows his significant change in gaze prior to their works. In fact, analysis of intertextuality among the biographies shows that it is more probable that David Minter's biography, William Faulkner: His Life and Work (1980), triggers via his application of a psychological model of alcoholism the reevaluation of the role of drink in Faulkner's life and his ink. Once Minter acknowledges the "elephant" to be in the room, a certain permission is granted to all others who gaze to explain how the big beast got there. Blotner, in 1984, consolidated his 1974 biography by half while more than doubling his willingness to label Faulkner, via the medical model of alcoholism, an alcoholic. Goodwin in 1988 reinforces this medical model as bolstered by heredity, and Dardis in 1989 offers the binocular gaze of Alcoholics Anonymous that had synthesized medical models and moral psychology models. By the time of Parini's 2004 biography, no one doubts those changed views, until Weinstein, in 2004, offers what appears to be another run with Minter's 
psychological model. Gray is absent from the issue by silence, and he seems not to find the issue of alcohol at any point, good or bad, relevant to construction of a biography that is approached exclusively from the writer revealed in the inner world of his fiction.

The only truly novel addition I offer in this project comes in the third animal metaphor of monkey, the riff on evolution that I steal from Grace Paley. I believe it offers the key to understanding the metaphors of both Lion and Elephant, but that even it is not entirely complete without reference to those two predecessors. Having established in Chapter Three the reasonable view that there is a evolutionarily-selected propensity for a few people to bundle traits of aberrant drinking, schizotypy, leadership, and creativity, we must now consider the inescapable corollary: there is a an adaptive propensity for the remainder of our human primate troop to be attracted to those few people who express those bundled characteristics. We become easily addicted to drunks, to leaders, and to creative people, and sometimes that inclination means we are addicted to one person who has all three attributes in play. The two propensities (to express the bundled attributes and to be attracted to the person who expresses them) exist symbiotically when the mutual benefits of survival are in balance, but they can also exist parasitically when one feeds off the other without adequate reciprocation of benefits.

Though the alcoholic often rightly earns the bad reputation of being "the mooch" in the social relationship, a certain self-service can also be seen regarding those on the other side of the transaction. When we, therefore, enter into the metaphor of Monkey, we are no longer simply gazing at people who gaze at Faulkner while he is gazing at his creation. We now must look at ourselves, and we become the focus of our gaze. In Hans Christian Andersen's comic tale of the "Emperor's New Clothes," the Emperor, as a 
character, is really only the foil for the plot, and at this point in the project, Faulkner really is only a similar foil. The Andersen narrative truly focuses on everyone else by dint of the way each one responds to the folly of the leader as each plays "follow the leader." From the genre of tragedy, as mentioned in Chapter Three, Sophocles' Antigone arises. Like Polynices, Faulkner is already dead when we get to the biographies. What follows are arguments about what can-and-cannot, or what should-and-should-not, be done with the corpse and (by extension) the corpus of his writing. This leads us to create narratives about narratives about narratives, a response that is never as much to protect the corpse and corpus as to protect ourselves against the repercussions of our positions regarding both. As the Pogo cartoon on Earth Day 1974 stated, "We have met the enemy and he is Us."

\section{To His Credit, or On Borrowed Time?}

Faulkner achieved the apogee of his fame during the nadir of his creativity, and this is a puzzling fact. Chapters Three and Four show that Faulkner's best powers in fiction had fallen considerably before he was awarded the Nobel Prize in 1949, and that works appearing in the next dozen years continue to trace the declining arc with Requiem For a Nun (1951) and A Fable (1955) as prime examples of failure. As a toss-off response, I suggest in Chapter Three that the committees responsible for the Pulitzer Prize and the National Book Award, each award given for A Fable, had embarrassed themselves by overlooking Faulkner's great works in his great period and chose to credit a book with the honor that really should have gone to some other work. But even that supposed answer only describes the situation rather than explains it. Human factors deeper than chagrin are at work. 
The situation concerning the Nobel Prize in Literature is actually interpretable with little effort. That prize honors the writer - or at least the span of a writer's work - as well as a single title. The process is intended to allow or an extended period of adjudication well before a nomination. Delays of a decade between creative apogee and recognition are not so unusual.

We also saw in Chapter Three, however, that even at the height of fame following the Faulkner's Nobel, the years when his scribbled grocery lists should have become instantly a hot item in the literary market, he could not find buyers for a simple short story. We saw that in the America, A Fable found very few strong champions despite receiving the Pulitzer Prize and the National Book Award. In Chapter Four, we found that it took eight years to get Requiem for a Nun mounted on a U.S. stage. Subsequent decades have not helped the artistic reputations of those two works. Kenneth Butterworth expressed confidence in both the unpublished 1971 dissertation and the 1983 book based on it that time would redeem the book, but four decades have failed to prove him true. Noel Polk, even after immense efforts to clarify Requiem for a Nun as an interpretable work, finds himself in his major commentary retreating for the cover of an excuse that asserts the work's "importance" rather that its quality. Again, extra decades have not generated extra appreciation.

During the same years, however, the U.S. State department sends Faulkner to Japan, Greece, the Philippines and Brazil on cultural missions. Delmore Schwarz and Albert Camus both express high praise for A Fable. The august - even stodgyUniversity of Virginia brings him as guest of the faculty for several terms, yet the same institution turns down the opportunity to keep him ensconced in a permanent position. 
The data then, for the relationship between fame and success, are not simply uneven; they graph in a wildly jagged pattern. What accounts for such variance in opinions and treatments, and what accounts for stubborn attachment to a hope that a piece of fiction from a great author is actually better than it is, and what can reverse the polarity of the magnetic attraction for such a famous man so that unseen forces create repulsion?

Lawrence Schwartz turns his attention to a variant of this question. Schwartz wants to discover what forces lead Faulkner, a commercially unproductive author before World War II, suddenly to become a commercially successful literary figure after that war. Schwartz fully recognizes that Faulkner had, in fact, in the late 1920's and early 1930's attracted some strong reviews and an attendant following among a few cognoscenti within one faction of literary critics, and he acknowledges that Sanctuary did earn a few dollars in its publication day, but the reality was that, with the exception of Sanctuary, all the other novels were out of print. In fact, the original copper plates for all the books had been melted in the War Effort. Yet there also is no overlooking the fact that Faulkner's portrait was featured on the cover of Time magazine January 23, 1939 with the caption "To make men stand on their legs and cast a shadow."

It is obvious then, that Faulkner had already been casting his own shadow on the literary landscape, but Schwartz is correct to note that the post-war years aimed a spotlight at the man and his works. Schwartz locates the impetuses for the change in the interaction of three variables, two of which he finds to have been consciously manipulated. The first variable, however, seems to arise sui generis.

As both popular and high-brow taste for American social realist novels dwindled in the second world war, people desired some art that embodied the human spirit as 
individually doomed but corporately intact, a hope that was real but not naïve and which did not place faith in the grand transformations of economies and character. Schwartz finds the change due both to the dilemma American readers faced with the untenable realities of Europe's competing totalitarianisms (Germany's recent Nazi demise and Stalin's continuing reign of terror), an experience that was coupled with the disarray and dismay in which Western Europeans' found themselves facing living after the war. All eyes turned to the U.S. not only a military liberator but also as a cultural savior.

I must emphasize how important it is to note that Schwartz simply is forced to acknowledge that the shift simply occurred, and that there was no conspiracy to cause the shift. People across the world simply felt that they needed to find a creative voice that championed the individualism of the American spirit even as that spirit struggled to negotiate the harsh injustices exposed by the human condition. Schwartz does not invoke the shopworn word, Zeitgeist, but it hovers above the argument. Yet there also hovers a certain resentiment in the way Schwartz is forced to acknowledge this shift. He is a bit bitter that the agendas of social realism had failed to create the great goal of a greater good: the social and economic transformation of the U.S. Schwartz vaguely complains:

There was no conspiracy to launch the novelist, but in the context of the postwar era, critics came to value his values. For example, the key work of several critics, [Malcolm] Cowley, Mark Schorer, and Irving Howe, representing different communities within the literary elite, adopted common assumptions about the significance of literary formalism and modernism, and the limitations of naturalism. Had the aesthetic values of the 1930s persisted or had antiCommunism not become prevalent, Faulkner could not have achieved renown. (5)

There is in his argument a bit too much of the Mother Goose rhyme: "If ifs and ands were pots and pans, there'd be no work for tinkers." The problem with this sort of argument is 
that it is a complaint against history, which then turns around next to say that history is in charge. Schwartz has already noted the goal of his project:

This analysis looks at the way in which aesthetic criteria changed, how the critics interpreted literary consequence in the 1940s, and what that meant for Faulkner. Literary reputations rise and fall dramatically because the critics reflect not universal, but relative, literary values, which are, in large measure, historically determined. (2-3)

Whether or not The Anxiety of Influence by Harold Bloom, when compared to Schwartz' project, is better prepared to explain shifts in aesthetics is certainly debatable, but at least Bloom offers, with his psychodynamic model for "strong" versus "weak" responses to the parent generation of poetics and poets. His is a dynamic explanation of aesthetic vacillation that allows for a concentration gradient difference between the "strong" misprisions that fuel strong poets and the "weak" correctives that lesser poets and critics offer in response. Schwartz simply invokes historical determinism, which implies the old faith in a materialistic dialectic and that the theses and antitheses are simply always there and vying one with the other. This faith in "history" may be as valid as Bloom's faith in Freudian Oedipal struggles, but what Schwarz fails to do is to show why the critics like Cowley et alia were somehow missing the mark to correct their own aesthetics (Cowley, for example, had not liked Faulkner in the 1930's) and to find a renewed need to be nurtured by "literary formalism and modernism." I would suggest that after Arthur Koestler's Darkness at Noon (1940), it is quite easy to see why the disaffection of the farleft, which had begun in the 1930's when Malcom Cowley made his shift from communist-left to liberal-left, was quite complete by the end of World War II. Schwartz's stated motivations for his project are fairly clear and are not unwarranted. He attempts to keep alive the message that soon after the U.S. intellectual 
avant garde first distanced itself from Stalinism it also lost hope in some purportedly pure Marxism. Simultaneously he holds that the intellectuals played themselves into the hands of U.S. State Department realpolitik and they crawled in bed with the remnant of the southern aristocratic academics, formerly known as The Agrarians, now touted as the New Critics. Cleanth Brooks out of Vanderbilt in Nashville had become the leading critical voice for interpreting Faulkner, while Malcom Cowley from a desk in New York was the leading editor cum publicist when he created The Portable Faulkner. A pulpfiction market from the East coast and a celluloid industry from the West coast, powers greater than any individual critics, met in middle to acquaint America with the Southern farmer who had gone to Stockholm. The U.S. State Department, the most powerful force of all as America settles into a new role of global hegemony, sent Faulkner -- always under the careful watch of some "keeper" who was to monitor their national treasure when he was near a bottle -- around the world.

With literary naturalism (also known as social realism) out of fashion, and with Communism denigrated, holes in thought and culture had appeared. Where nature "abhors a vacuum," the market loves a niche. To fill the space both on the book shelf market and in the global cultural market with Faulkner, Schwartz finds that two coordinated movements arose. Although, as noted above, he explicitly denies any sort of “conspiracy," his denial often seems a bit weak. He targets a certain cadre of New Yorkbased intellectuals, especially those, such as Delmore Schwartz, who had aligned with The Partisan Review as left-liberals but not communist after that magazine had severed ties with the American Communist Party, as being the spiritual leaders of Faulkner's renovation. The U.S. State Department, with its several cultural missions for which it 
hired Faulkner, was the temporal leader of his reinvented reputation. In the midst of these orchestrations, two market-place industries contributed changes: the rise of pulp fiction publishing which enable cheap editions of Faulkner's works to be reprinted, and the movie industry which, after paying Faulkner a pittance salary in his 1940's stint as a screen writer, now paid him some fifty thousand dollars for the rights to Intruder in the Dust (1948), a deal made before the book appeared in print. Not only was that a princely sum in those years, Metro Goldwyn Mayer studios actually made the script into a movie that premiered only months after the book's publication, unlike the fate of The Unvanquished which Faulkner had sold some years earlier for about twenty-five thousand dollars. It never saw camera lens and so it had never contributed to any popular dissemination of Faulkner's name movie goers.

In Schwartz' defense, his scholarly attention to both the published and unpublished sources is impeccable, a fact he is not shy about telling the reader (6). He looks at all the relevant sources, and digs deep into the behinds-the-scenes information available in the archives. Though I disagree with the interpretative lens he chooses, I am astounded by how some images he builds are quite poignant in regard to the "Lion in the garden" metaphor. For example, his description of the way Faulkner became his publishers' "pet project" (pun intended) after they sprang him from the Warner Brothers contract in 1946 so he could complete A Fable deserves quoting:

Haas and Ober were enthusiastic about the new novel, a World War I fable, believing it to be the best way to end the writer's "schizophrenic" existence, which had perpetuated and deepened his emotional despair and stifled his creativity. They were convinced that the novel could only be written in Oxford with Faulkner free from the nagging worries about money and his Hollywood contract. Their new strategy was to keep Faulkner at home and at work on his novel, hoping that, protected and isolated, he would quickly produce a new and important book. In this way Ober and Haas felt that Faulkner could contribute to 
the modest but tangible revival of interest in his work, prompted by Cowley, as we have seen, while also rebuilding seriously diminished self-confidence.

(Schwartz 45)

This passage reads like plans to breed a rare animal successfully in captivity. It also totally ignores at every turn the problem of alcohol.

As I will make clear when we look last at the "monkey metaphor," I completely agree with Schwartz's depictions of the way that, suddenly after World War II, everyone around Faulkner suddenly was wanting "a piece of Faulkner," and that each player was devising his or her own strategy regarding his management. I argue, however, that the origin of this drive to attach to the coattails, while simultaneously trying to groom his coat, predates human economies and national politics. Our genes pull us to the genius and try to pull as much out of the trapped power as we can manage. Just as those in A.A. had discovered that "[...] liquor was but a symptom" of their foundational problem, economics, whether Marxist of Capitalist, and politics, whether liberal or authoritarian, are but a symptom of deeper drives. And just as the alcoholic is ever-deluded into thinking he can devise a way to drink successfully, those who wrangle alcoholics are just as delusional about their abilities to fix, manage or control them with success.

The Elephant in the Room, Alcohol in the Biographies and Harold Bloom on Misreading

Harold Bloom offers the paired terms clinamen (the falling away from) and misprision (misreading) in The Anxiety of Influence: A Theory of Poetry, second Edition (1997). I offer an all-too brief summary of the concepts, noting that were it not for a necessary "swerve" of two forces, causing one to intersect the other, all thought would simply run in perfect parallels and would never generate new creation. This is a variant of the argument offered in Chapter Three with the distinction between pure adoration (a 
sterile endeavor) and rich narrative (a messy matter). I argue that the concepts are at play in the way the gaze on Faulkner's drinking has shifted across time, and that Bloom's model is helpful because he locates the collision of misprisions in the psychic struggle of the ephebe with the sponsor or the child with the parent.

I affirm the notions of both the sense of falling (and failing) and the recognition of misreading because I found myself guilty of both in the course of this project. With an autobiographical narrative of that experience, then, I begin the process of distancing myself from the discomfort (the chagrin) of that experience by telling a tale about the way I watched others tell a tale about Faulkner.

This project was spawned originally by an initial discovery of Tom Dardis' The Thirsty Muse and Donald Goodwin, M.D.'s Alcohol and the Writer. The books comprised my love of Faulkner's fiction, an interest in alcoholism and recovery, and mental health treatment as I learned them in my medical education and my practice of psychology. An opportunity to pursue graduate studies in the humanities concurrently with my professional mental health practice led to a curriculum encounter with scholarship on "Creativity and Madness." I began to note in reading that material that, time-after-time, substance addictions had been relegated to a derivative, or secondary, status for writers who were declared to exhibit other illnesses such as major depression, bipolar disorder or schizophrenia. Dual-diagnosis of substance addiction and another mental illness is quite frequent, but epidemiological studies demonstrate definitively that, in the population at large, primary addiction disease is much more prevalent that the affective or thought disorders. I found the biographers to be misreading the writers. I was gazing at misprision. 
In my first reading (and I will call it a subtle misreading) of the materials, I felt that the literary interpreters had consistently placed the cart before the horse. I adhered to the philosophical dictum that, in careful thought, whether that thought be exercised in mental health fields or in the humanities, Occam's Razor still applies. The simplest explanation of a problem remains the preferred explanation of the problem until mounting evidence contradicts simplicity and requires complication. For this reason, I was adamant that a primary affective disorder or thought disorder should never to be entered as a definitive diagnosis when the affective disturbance or thought disturbance occurs in the presence of substance abuse and/ or addiction. I felt that this hierarchy should apply to all cases, whether those cases present in clinics or in biographies. As a corollary, I felt that attempts to consider the relationship of "Creativity" to "Madness," will fail unless 1) the relationship of "Creativity and Addiction" is not addressed and 2) if the Addiction category of mental illness is not excluded in individual cases before the relationship of endogenous mental illness and creativity is considered. Basically, I was intent on showing that Addiction is the new Madness more times than not, and that this fact was definitively true in Faulkner's case.

Those opinions and facts occupied my mind from the inception of this project, but the investigation took a sharp turn at its midpoint; a direction that has required much additional work. I had first intended to offer a rather sermonic exposition of Faulkner's alcohol dependence to contrast with his biographers' impaired abilities to recognize and name this great writer's great problem. I was forced to abandon such a simplistic dichotomy. To refer back to Chapter Three, I was not dealing with a simple tragedy of Cain and Abel, the kind of narrative that lends itself to sermons. 
The project became more nuanced after I paid adequate attention to an inescapably trenchant observation an advisor made about my preliminary bibliography: "I notice that you have not included more recent representatives from Faulkner studies." My first response to that criticism was to assume that no real changes had occurred in Faulkner studies since the early 1980's, whether regarding the creative arc of Faulkner's life or the relative emphases his biographers have given his alcoholism. But I quickly realized that this assumption was lazy thinking and an impediment to scholarly accuracy. It was the tendency to exercise "contempt prior to investigation," a character flaw warned against in fellowships of addiction recovery. I reopened the investigation.

I changed tactics in two ways. First, I spent the necessary time reading in John Bassett's four annotated bibliographies (1972, 1983, 1991 and 2009), checklists that provide the most extensive catalog of all works on Faulkner from the earliest interview in 1926 through articles and books appearing in 2007. Those printed sources were a needed correction of a growing tendency to place too great a confidence in electronic data-base searches to reveal items of interest because digital search-engines depend heavily on convergent processes and they sometimes miss materials detected by divergently related sources, though such electronic searches had to supply the years between 2007 and the present. Second, in four standard, but shorter, biographies (Minter (1980), Oates (1987), Gray (1994), and Parini (2004), I marked and read every page indexed under the subjects "drinking" and/ or "alcohol(ism)" in an effort to determine which author, if any, showed any tendency to ignore the brute facts of Faulkner's alcoholism. 
With each one leaning on Blotner as a source (perhaps like the mysterious "Q" document proposed to support the New Testament synoptic gospels) we see emerge four biographers who might be termed "Faulkner's Four Evangelists." They are the "Three Synoptics and the one Mystic," with Gray holding the parallel to John the Evangelist. Three of the four biographers --Minter, Oates and Parini -- replicate the basics of Blotner's chronology concerning salient events regarding alcohol. Gray differs significantly by remaining rather indifferent to drink as a matter of concern.

Gray's difference has not deterred him, however, from earning highest praise for the work as a "critical-intellectual biography," (Basset 2009, 59) nor from his scholarship earning an impressive thirty-two listings for an eighteen year period in the 2009 Basset bibliography (564), the most citations of all the scholars for that period. Beyond simply omitting, however, pertinent reports on Faulkner's alcohol-driven events, Gray tends to mitigate the meaning and importance of the reported events where alcohol erupted into Faulkner's public life, such as after the Herald-Tribune interview when Faulkner, obviously drunk and in a black out, spoke of a willingness to shoot Negroes in the street. Gray's biography serves as a chronological, sequential, and critical interpretation of Faulkner's works and evades psychosocial interpretations of Faulkner's life.

A rough way to estimate the four specified biographers' attention to the role of alcohol in Faulkner's life is to turn to the subject index in each book, to count the places listed under the salient words of "drinking" and/ or "alcohol(ism)," and then to calculate the ratio of mentions compared to numbers of pages of text as a whole. When viewed in order of publication year, the results are as follows: Minter has 32 in a 250 page text (average of one every 8 pages), Oates has 31 in 321 page text (average of one every 10 
pages), Gray has 8 in a 372 page text (average of one every 46 pages), and Parini has 48 in a 433 page text (average of one every 9 pages). Parini tops the list in sheer quantity, though only barely offers more than Minter on average, a quantitative difference that is not significant. Excepting Gray (once again) the three biographies that demonstrate sufficient attention also concentrate that attention on the last third of Faulkner's life: on average two-thirds of all the references fall in the narratives that cover the years 19391962, and they increase in frequency and intensity in the decade of the 1950's. This uneven distribution of the data in the last third of his life most probably indicates that the advancing progressive nature of the illness was increasing the number of problems to be reported, but I must take care here. I cannot be entirely sure that the increase is not due to a general increase in gazes cast on Faulkner after he received the Nobel prize. Greater public scrutiny may simply have generated a greater detection-rate for behaviors that had been occurring at a steady rate -- but with less frequent notice -- because of a lower public profile.

The statistics, however, challenged a much fuzzier impression that I had developed in what I consider a misreading. That misprision led to the feeling that the earlier the biography publication date, the less mention of alcohol is observed. Since the numbers do not lie, the question arose as to why I perceived differing valences. The review given above clearly shows that both Minter and Oates had included adequate reports on alcohol related incidents. They weave the theme into their stories as a bold thread that runs like a basting stitch through the torn fabric of Faulkner's life. Minter not only has no need to hide Faulkner's problem, but his project should be the one that amplifies attention. He states, "My claim to the reader's attention is specific, then; and it 
stems from the story I tell - of deep reciprocities, of relations and revisions, between Faulkner's flawed life and his great art." (Preface. ix) Oates' biography also indicates that he clearly saw alcohol persistently flooding Faulkner's life. Yet his pages still show that he interprets the alcohol events as "caused by" the many accidents of life: bad marriage, shy nature, and so forth.

Parini's book is the one most clearly focused when alcohol emerges in a Faulkner episode. In fact, Basset characterizes Parini's work specifically in this light (and with some degree of disparagement):

A very readable biography by a poet-critic, this brings narrative coherence to the period of Faulkner's maturing, to his Hollywood sojourns and to his final years with due attention to his financial worries and his alcohol problem. It portrays well the broad range of persons with whom Faulkner interacted but does not shed much new light on the novels themselves or address questions raised by recent critics. (Basset, 2009 43)

The average number of citations does not significantly distinguish Parini from Minter, who preceded him by nearly a quarter of a century. Why, then, did I perceive Parini as more focused on the problem than Minter? I hypothesized that the change had occurred with a change in the rhetoric of valence, and that the developments in medical and social understandings of alcoholism during the intervening twenty-five years led to the shift that had been both detected and predicted by Thomas Gilmore (1987): i.e., that postmodern readers were increasingly impatient with discussions that mollified or glorified alcoholic behavior. Yet even this hypothesis failed to sustain me after another iteration of gaze. I went back to Blotner, the patriarch of all full Faulkner biographers. I first only retuned to Joseph Blotner's 1974 exhaustive, two-volume biography. I assumed that it remained the source, or fount, for all subsequent Faulkner studies, including Blotner's shorter 1984 work. In great measure, this was not a wildly incorrect assumption. His 
work is the gold-mine and the gold-standard for digging and evaluating material in any Faulkner chronology.

I discovered that in the 1974 work, Blotner includes nearly every possible reference to any events in Faulkner's life when alcohol-use rose to significance, but the reader will not find them cataloged under the word "alcohol" or "alcoholism." Blotner, instead, indexed the word "drinking," and comparing the page citations in the index against thorough reading of all his pages shows very many relevant passages that the index ignores. The Appendix of this project reproduces, within the narrative contexts, every relevant passage from the 1974 two volume biography that relates to Faulkner's drinking, and the introduction to that appendix addresses the issue of the lacunae.

Beyond the flaws in the index, the careful reading of Blotner's 1974 work revealed a stylistic and rhetorical tendency to buff away the sharp, jagged edges from many harsh realities about Faulkner's character and behavior. Blotner achieves this polish by preferring narrative-framing over the use of narrator commentary. Even when the narrator does offer direct comment, he opts for euphemisms about Faulkner's alcoholic penchant and episodes, with the descriptive phrases reporting the bald, bad events caused by alcohol addiction simply as "bouts of heavy drinking." I recall here the vignette explored in Chapter Four where Blotner frames the car-in-the-cotton-field event with references to Faulkner's drinking. The event was bracketed beforehand with the indirect speech report, “And he drank a good deal. He carried his whiskey well, so one could hardly tell that he was feeling it except that he would get just a little thicktongued," and afterward with the sentence, "There was no question about Bill Faulkner's fondness for liquor (Faulkner 2 Vols.282 - 293).” Even when Blotner admits the phrase, 
"He drank a good deal," he immediately mollifies it with "He carried his liquor well." The word "fondness" ratchets down the severity of the problem to the level of a hobby. And yet, the evidence is still all there. How could I have initially misread Blotner so thoroughly?

It suddenly became very clear to me that Joseph Blotner, in the years between 1963 and 1974, was intent on writing a very modernist biography about a high modernist author, but his project was conceived and finished in the pivotal time when highmodernism was on the wane and on the way out. In that vein, and in those years, Blotner was simply not going to tell the reader about the "elephant in the room." He was more than willing to show the reader all the contours and the shadows of the elephant, but he was restrained, at least by style, from telling the reader the obvious. Such direct writing would have been in "poor form," and modernism was quite concerned with form

I also realized that there was also more than mere stylistic preference at work in Blotner's choices for the 1974 work. The expression "poor form" also refers to the way we conduct ourselves in regard to social convention, and it is "poor form" in certain cultures to express the obvious facts of unpleasantries, as noted of Forseth's answer from the French expert on alcoholism, reported in Chapter Three, “Because we French don't think it a nice thing to do." (Forseth 4). Besides the conventions of Southern culture, Blotner was also constrained from bearing "too much reality" (Eliot's famous phrase) by his dual roles, both as close companion and academic interpreter. This creates a double gaze that he was forced to resolve stylistically and within the context of narrative

First, Blotner was not simply writing about some mere mortal; he was writing about his literary idol. In Chapter Four I quoted Blotner's accounts of his first encounters 
with Faulkner on the University of Virginia campus. The vignettes express his initial anxiety at Faulkner's distant, cold reserve (Faulkner 2 Vols, 1637). But the relationship between the distant admirer and the detached celebrity transformed rapidly, and Blotner was allowed into Faulkner's inner life as much as any male on record except for, perhaps, Faulkner's nephew. Joseph Blotner, though always a normal drinker, became a drinking buddy:

When we started driving again we looked for a likely place to have dinner, but the proprietor of the first one we tried regretfully told us that we could not bring with us Mr. Faulkner's bottle of Jack Daniel's. But he was glad to supply the ice, water, and paper cups I then asked for, and we drove only a little way before we found a pleasant meadow. I pulled over and switched off the engine. It was good to sit there as the sun began to set, talking at random and ingesting the mellow sour-mash bourbon that neither Fred nor I could ordinarily afford. We had a second drink. When that was finished, Mr. Faulkner said, "Let's have another one."

"Why don't we go on," Fred countered, "and find a restaurant where we can have one while we're waiting for dinner."

"I don't see why we can't finish the bottle here," said Mr. Faulkner, with what sounded to me like the slightest edge to his voice.

Fred and I exchanged fleeting wary glances. We were both bourbon fanciers but only amateur drinkers, and I think Fred must have had the sudden vision I did of darkness falling on the meadow with him and me both tight and none of the three of us fit to drive my car. "Let's have one more here and then go," I suggested, and the others agreed. (Blotner Faulkner 2 Vols, 1660-1661)

Blotner's anxiety is redirected from concerns about mastering rejection to managing the master.

This is a messy arrangement for an apprentice to keep tidy. It becomes more complicated when the master adopts the apprentice as the son. It is hard to keep an objective gaze on a powerful man, noted for creative genius, when he pulls the biographer into the close orbit of a filial role. Faulkner did just this thing. Blotner reports, using the first-person, on one of Faulkner's hospital stays in Charlottesville, Virginia, when Faulkner was questioned just before discharge: 
The cleaning woman reappeared. Indicating me, she asked, "Is he your son?" Besides the exhaustion, he was still suffering from a medication hangover, and it was a long moment before he answered. When he did, his voice was slow and tired. "He is more or less my son," he told her. "He's my spiritual son. He loves me better than he does his father." We both knew I could not be to him what Jimmy or Malcolm or Paul could, but I was grateful for the polite answer he had given the sympathetic woman tidying up his room. (Faulkner 2 Vols, 1809)

Note that Faulkner does not say that he loves Blotner like a son. His phrase places Blotner in obligation to love Faulkner as a father, and more than his own father. This sort of relationship is filial in name only and smacks of the friezes of the Ara Pacis that show Caesar Augustus leading the pignori, children taken from the vassal states, into Rome to be raised in Roman culture so as to spread the glory of Rome. It was played out in Faulkner's relationship with both Joseph Blotner and Fred Gwynn when Faulkner would lead them in a rather bizarre game of military charades where the two faculty members would respond to the writer's command to march before him, stand at attention, and salute. Of course this was all gest, but play always symbolizes other unspoken realities at work, and those realities were casting Blotner in a subservient role to the man who soon was to take up the task of interpreting the father to the world. When real matters of Blotner's real work as junior faculty arose, Faulkner also offered himself on several occasions as a bargaining chip when Blotner entered final consideration for tenure at the University of Virginia. Blotner records:

Now I was feeling some anxiety and reading the situation somewhat pessimistically. I began talking about it one day over drinks. During the past year one of my departmental colleagues had been elected president of the university, and now Mr. Faulkner mentioned his name. "Why don't you tell him, 'If Blotner goes, maybe Faulkner will go.' "He thought for a moment and then added, "I've got only two friends in Charlottesville, Blotner and Vandevender, and if Blotner goes Faulkner will spend all his time out at Farmington." I knew, of course, that he had a number of friends in the town and the county, but it warmed my heart to hear those words, a testimonial of friendship that would have meant much at any time but was even more welcome now. He did not know, of course, exactly how 
such decisions were reached, and I had no intention of telling him how ineffectual the course he had proposed would be. But when he urged it a third time, I said I would do it, even though I knew I would not. Then he smiled. "Yes, try it," he said. He reached for a new tin of his Dunhill blend which had just come in from New York. "Here, take some of this tobacco," he said. (Faulkner 2 Vols.1751)

Faulkner was by now perceiving himself to be a commodity, and he thought he knew how to trade himself on the market. In reality, Faulkner was overestimating his worth as inventory, as even Blotner knew at the time. "Mr. Jefferson's University” would eventually demonstrate the same assessment by their choice not to keep Faulkner. Blotner, however, received tenure, probably no small part due to his role in co-editing with Fred Gwynn Faulkner in the University (1959).

I introduced this section of the chapter with reference to Harold Bloom and his notion of weak poets; the poets who lack audacity to challenge their anxiety in the face of predecessors in the manner of Milton's Satan rising up against God (Anxiety, 19 - 45). I hold that Blotner is, at least through 1974, such a weak voice. There is no way he could challenge with a sufficiently-direct diction Faulkner's persistent myth that his drinking was a "normal instinct." But Blotner was also no fool, and could see certain realities when he gazed at them. Between his relationship with Faulkner as a captured son who is watching Faulkner become a captured lion, and his later dependence on Jill Faulkner - an ersatz sister -- as the executrix of the estate's holdings manuscripts, letters, and other ephemera, Blotner must move sensitive narratives by methods of indirection.

I was therefore very puzzled when I read Conor Picken's blunt appraisal of Blotner:

Joseph Blotner's biography of William Faulkner is soaked with references to the author's notorious drinking, underscoring not only the prevalence of alcoholic consumption in Faulkner's life but the disastrous effect that it had on his relationships and, in the end, his health. The emphasis on Faulkner's drinking 
simultaneously casts the author as the celebrated stereotypical figure of the white southern artist - replete with bourbon drunk neat, pipe in hand, tattered tweed jacket representing the travails of a struggling writer - and, more seriously, a person who struggled with alcoholism from an early age. (Picken 36)

Why had Picken seen so clearly in Blotner's biography a life-size, three-dimensional presentation of the elephant in the room where I could only find weak feints and faint shadows?

I looked at Picken's bibliography and discovered that he had been reading a different biography. He leans totally on the 1984 revision. I had unwarrantedly assumed that the 1984 work was simply a contraction, and not a revision of gaze, when compared to the 1974 work. I was wrong. Blotner had developed a strong voice in a matter of a decade.

Some aspects of Blotner's new-found strength may be attributed to his access to new sources that had appeared in print after his 1974 work. As noted in Chapter One, Blotner relates in the introduction to the 1984 revision that Meta Carpenter had refused to be interviewed for his preparation toward the 1974 work, and her 1976 autobiographical report of Faulkner's episode of delirium tremens in the 1930's helps date the early damages of his disease. Blotner included much of her saga in his 1984 revision, including that report.

This hypothesis of "new material arising," however, does not explain why Blotner had suppressed clear data he already held in hand as he prepared the 1974 work. An example of his choice to withhold evidence appears in the way he rewrites a 1953 episode, an event when Faulkner was at the Gartley-Ramsey psychiatric hospital in Memphis. In the 1974 version, Blotner describes the event, "He began to grow impatient, as he usually did after forty-eight hours of treatment that would cut off the acute phase 
and begin recuperation: The staff tried to reason with him, to no avail. They called to enlist the family's help, but by that time the patient had already left (Faulkner 2 Vols, 1466)." The incident in 1984 reads, "As usual, forty-eight hours into recuperation after the acute phase had passed, he grew impatient. The staff tried to reason within and telephoned to enlist the family's help, but by that time he had already left. His file now bore the notation: 'An acute and chronic alcoholic.' (561)" How do I know that Blotner had that phrase, "An acute and chronic alcoholic"” at hand, but locked in a file, prior to 1974? I must now turn "amateur detective" again.

At the time Lisa Hickman in 1993 interviewed both the treating psychiatrist and internal medicine physician who had treated Faulkner, D.C. McCool, M.D., the internal medicine doctor, told her, " 'There are no existing records,' he says. 'The hospital closed in 1972 or 1973 and as astounding as it may seem, within weeks or months after that all records were destroyed' ("William Faulkner: Dealing with his Demons," 116)." I have found no other source anywhere that Blotner could have used as access to that medical record. Blotner, furthermore, does not offer an endnote citation for that final sentence in his 1984 work. The footnote to the 1974 passage notes, however, "Courtesy GartleyRamsay Hospital." He had to have seen the records during his research in the 1960's but then to have chosen not to include it in the 1974 book. By the 1984 revision, however, he had found a motivation to reveal the medical-model diagnosis of alcoholism.

Before possibile explanations of that change in those years can be established, however, it will be helpful to look at the source common to all who comment on Faulkner's drinking. In July, 1963, decorously writing the one-year anniversary of Faulkner's death, Robert N. Linscott published a short piece for Esquire, "Faulkner 
without Fanfare." That memoir reports on some of his conversations with Faulkner about drinking. Rumors, of course, about notorious drinking had circulated for decades, and there was, as mentioned in the Introduction to this project, that perplexing 1953 Life magazine article in which the reporter, Robert Coughlan, goes out of his way to declare of Faulkner, "“not an alcoholic but perhaps more accurately an alcoholic refugee, selfpursued' (quoted in Blotner, Faulkner 2 vols.,1467)." But Linscott was the first to publish words over the corpse, i.e., Faulkner after his death, concerning alcohol. Since everyone who writes about Faulkner and alcohol must return to Linscott, and since the take-away message varies with the pen of each writer who looks at the way Linscott looks at the dead man's drinking, it is important to read exactly what Linscott wrote. And it is not extensive:

He sat swishing the bourbon and listening to the tinkling ice, and that set him off on the subject of liquor. His grandfather used to give him heeltaps (the last drops left in the glass), he said. The later he drank a lot to ease the pain when he was in an airplane crack-up. But mostly, he thought, his drinking was a matter of chemistry. He'd go along for weeks or months at a normal gait - two bourbons at luncheon, two more after five, a martini before dinner, and half a bottle of wine with it, and maybe another bourbon or two to nurse along during the evening. And then the craving would come. Most often he'd fight it off. But once in a while something would happen that would "get me all of a turmoil inside," and liquor seemed the only escape. It was only when he was caught in a situation he couldn't easily cope with that he'd give in to what he called the chemistry of craving and go overboard. You would be aware of the symptoms of increasing tension drumming fingers, evasive looks, monosyllabic replies to questions - then he'd disappear, and, when you next heard of him, he'd be out cold. (Linscott in Inge, Ed. 96-97).

In the structure of that paragraph, there is no way to distinguish which person - Faulkner or Linscott - thinks that that this catalog of a day's consumption of alcohol is a "normal gait." There are at least twelve one-drink equivalents mentioned. Even at a "normal gait" Faulkner is well over seventy two drinks per week, or in the top tenth decile of the 
Ingraham (2014) graph. When the periods of "overboard" are factored in, it is easy to see that Faulkner's position is plastered to the right wall of the picture. Yet though we hear the elephant trumpeting in the room, we are baffled by an odd invisibility.

Michael Millgate's brief review of Faulkner's drinking quotes the Linscott article, but Millgate also turns to the memoir by John Faulkner, My Brother Bill, and parries Linscott's reports with, “[a]bove all, when Faulkner was writing he drank only very occasionally, or not at all, and there is much shrewdness in John Faulkner's remark that 'no man could turn out the amount of work Bill did and drink as much as people claim he did' (Millgate 31)." Blotner quotes Linscott as a source for the report that Faulkner gave about his childhood introduction to drinking the "heeltaps," but Blotner does not expound more on the Linscott material in the 1974 book.

David Minter also resorts to Linscott, dutifully sending the reader to that source via a footnote on page 133. What is so importantly different with Minter's treatment, however, is the entire tenor of Minter's page. Without malice, Minter is blunt. Unlike the indirect, narrative-framing style found in Blotner, Minter begins the paragraph that addresses Faulkner's appearance at a literary conference in1931 at the University of Virginia, with this topic-sentence "[t]he chief accomplishment of the conference in Charlottesville was to establish Faulkner's public reputation as a drinker (133)." Minter then quotes Sherwood Anderson's first-hand report of that drunken debacle in the next few sentences. Yet Minter also tries, in that same paragraph, to understand Faulkner's recourse to drink. He notes the writer's insecurities about lack of education and the value of his work compared to the assembly of august writers and scholars. Minter interprets a phrase from Linscott material ("the chemistry of craving") within the conference setting: 
"As a result, old anxieties about his life and his career tended to surface when he was around other writers. [...], he would yield to what he called 'the chemistry of craving' (133)." Minter refers the reader to the Linscott article at the end of the sentence.

Minter, on that same page, also refers to Blotner's 1974 work for another incident related to drinking at that conference. The contrast, however, between the manner in which Minter, in 1980, retells this tale from the 1974 book reveals the difference in gaze between Blotner and Minter. Blotner's report of an incident (another day at the 1931 literary conference) states, "[...] on the second morning of the conference Faulkner had entered the Farmington Country Club only to become violently ill, to the consternation of admirers who had approached to greet the literary celebrity (Faulkner 2 Vols, 714)." From Minter's page, this tale turns into, “[...] once he entered the rotunda of Farmington Country Club only to begin vomiting as people came forward to greet him." Any reader can, of course, imagine the scene from Blotner's phrase "violently ill" and “consternation," but with Minter's version, no imagination is required. Minter's participle "vomiting" invokes unpleasant sounds and unpleasant smells. Word choice matters when expressing a matter of concern, and even biographies are shaped by poetics.

Minter's strong struggle to understand Faulkner's alcoholism in terms of the psychological paradigms that were current in the 1970's, rather than by hereditary and neurochemistry models, is not surprising because those other models were not well developed when he was researching his book. Donald Goodwin's work on heredity and alcoholism were only beginning to appear in articles in the Journal of the American Medical Association, his layperson-oriented book on hereditary influence did not appear until 1976, and techniques for neuroimaging that launched the "Decade of the Brain" in 
the 1990's had not yet arrived. Minter grasps the only interpretative tools he had at hand. He also has in hand the 1976 Meta Carpenter memoir, a work which had heightened every scholar's attention to the realities of Faulkner's trouble with drink. As he wrestles with the meaning of drinking for Faulkner and for the fiction, his gaze is direct: he tells us directly that there is an elephant in the room. His unswerving gaze, however, has swerved from the parallel to Blotner's approach and the two ways of viewing the elephant have collided. I had misread Minter, however, when I first read him, and that misprision was because I was unwarrantedly expecting the elephant to be explained in the terms I carried to the book; i.e., the models of neuroimaging and Alcoholics Anonymous. This misprision spawned my own attempt to mount a strong response.

I strongly suspect, however, that in 1980 Blotner had not misread Minter, and that he recognized in him a challenger. Minter's new way of gazing directly at Faulkner's alcohol problem appears to be the only substantial change in gaze that occurs within Faulkner scholarship in the late 1970's and early 1980's. Blotner's shift occurs before the spate of late 1980's books on drinking writers by Gilmore, Goodwin and Dardis, but it follows Minter's 1980 biography. Even though Minter never sharpens the gaze into a medical-model of alcoholism, Minter's work is forthright, though not disparaging, about the blunt fact that Faulkner undeniably had a drinking problem all of his adult life, beginning in late adolescence. Blotner, the elder Faulknerian, had been challenged by Minter, one of the rising generation of scholars. I suggest that this challenge moved Blotner to the 1984 revision which distinctly amplifies his strength to tell about -- not just gesture at - the elephant in the room. As we move away from showing to telling, we are 
moving away from the preferred style of high Modernism. We are moving into the postmodern impatience that Robert Lowell expresses in "Epilogue,"

Yet why not say what happened?

Pray for the grace of accuracy

Vermeer gave to the sun's illumination

stealing like the tide across a map

to his girl solid with yearning.

We are poor passing facts, warned by that to give each figure in the photograph

his living name.

Every biographer's work after the Blotner 1984 revision are seen seeing that the old guard had responded to the Young Turk, and they continued the movement toward frank recognition and medical assessment. I doubt that even Donald Goodwin and Tom Dardis could have stepped up to their tasks of describing Faulkner's disease as they did had not Blotner revised his gaze in response to Minter's gaze.

The overview offered in the first of this chapter takes us from 1963 to 2010, so there some other works to be considered. The Oates biography (1987) shows the movement to label the beast as an elephant, but Oates still clings closely to Minter's psychological analysis as to how the creature had insinuated itself. The 1989 interpretative biography by Frederick Karl was not cited above because I did not know it early in this project's development. His is an encyclopedic view of Faulkner's life as approached through the scaffolding of Faulkner's works, and is much to be commended for interpretative insight he brings to the fiction. The book, in terms of ease of use for biographical scholarship, however, provides too few hints as to where Karl learned his material. Concerning Faulkner and alcohol, Karl is, however, bluntly aware of the 
elephant in the room, and addresses the fact in his overview where he tells the reader his interpretation of the relationship of the alcohol to the art.

Faulkner's drinking bouts - each one a prolonged gesture of suicide were further linked aspects of his creative imagination. What went into the writing was also part of what went into his desire for oblivion. The drinking was ordinarily not for fun or entertainment, but to intensify the quiet and silence which were already there. (13)

The problem with Karl's work, however, appears as we try to learn how he had learned about Faulkner's alcohol. He notes a 1985 journal article that gives the interview with "Buzz" Bezzarides that Brodsky placed in his 1990 book, and Bezzarides was forthright in his recognition of Faulkner's alcoholism. Karl also cites Blotner, but only for the 1974 work. He does not tip his hand concerning the 1984 work; nor does he tell of any knowledge of Minter, an absence which is hardly credible given the field's recognition of Minter's contribution to exactly the kind of project Karl presents. It is theoretically possible he had read neither Minter's 1980 biography nor Blotner's 1984 revision, but this notion is doubtful. Karl also presents a two page review of the many different drinking American writers and theories of why they drink so much - lists and discussions very much like those in Goodwin's 1988 book - but Karl gives no hint as to the background reading that leads him to his statements (130-131). I cannot forgo the suspicion, however, that Karl has failed to alert the readers of his important sources, and that we have already reviewed the main ones in this project that are quietly supporting his text.

With Joel Williamson, William Faulkner and Southern History (1993), the intrusive presence of alcohol is so obvious as to be prosaic. Where Blotner in his 1974 work relates long reports of the delicate and failed negotiations in 1959 to obtain for 
Faulkner a permanent chair at the University of Virginia, a failure attributed to the administration's reticence to set a precedence of turning guest artists into tenured faculty, Williamson simply states,

Soon, higher administration in the university decided not to bring Faulkner back as writer in residence for the spring semester, and they did not accede to a suggestion from Faulkner that they give him a permanent appointment. There was some concern that his drinking might embarrass Mr. Jefferson's University. (323)

By the 1990's writers begin not only to see the problem; they see the consequences of the problem and interpret events in the light of the illness. It is an ironic collision of the metaphor of Lion and Elephant: In very same months that Faulkner proposed, on the strength of his self-perceived market-value, to leverage tenure for his friend Blotner, the University was assessing Faulkner as a liability, rather than as an asset, to their mission.

The Richard Gray biography, The Life of William Faulkner (1994) simply does not care much about the elephant; and frankly, not much about the lion either. It is as if Gray were sayiing, "I am here to look at literature and I really do not care much as to how it got here. These other facts of addictions and economies are not matters of my concern; they are relative indifferences."

For those for whom Faulkner's relationship to alcohol is a matter of concern, the paradigm shift is complete by the time Jay Parini gives us One Matchless Time: A life of William Faulkner (2004). Faulkner is an alcoholic, the facts are obvious in the book, and the fact that Parini wants to underscore the reality is obvious (as noted above) to John Bassett as he annotates the Parini book in his checklist, tinging the gloss with a tone of impatience at Parini's repetition of the obvious.

It is not surprising, then, that a new rumbling arises to challenge the codified and simplified medical understanding of drunk writers. Philip Weinstein, in Becoming 
Faulkner: The Art and Life of William Faulkner (2010), knows better than to deny the presence of the elephant, but, as noted in Chapter Two, he is not happy with Tom Dardis' tautological conclusion that "alcoholic writers drink because they are alcoholic." Weinstein pushes back and asserts, 'No single cause emerges as the key to Faulkner's abuse of alcohol. A chorus of contributing motives - all of them dimensions of his encounter with the world - cooperate, increasing his susceptibility to this disease (178)." Weinstein wants to revisit the meaning of alcohol for Faulkner and in Faulkner's work. In a way, Weinstein is urging a return to the spirit and method of David Minter's work.

I doubt that Weinstein can undo what the medical model of the primary disease of alcoholism has accomplished, but I am intrigued at the possibility of retaining it while still considering psychological and sociological interpretations. This move is a swerve for me; a clinamen where I know I am falling into a new place from which to gaze; a fall that comes after having acknowledged my several misprisions along the way. Without denying the elephant in the room, I would love to find a way to see the humanity in our midst.

\section{The Primacy of Primates in the Human Condition}

There is not much more to be added to the metaphor of monkey as previewed at the beginning of this chapter. Just as the propensity to seek alcohol is evolutionarily selected, so, too, is the propensity to attach ourselves to those who drink. If we fail to follow the drunk-monkey leader, the selection-drive sets up the anxiety that we may miss a supply of carbohydrates, and this fear of missing the leader's gesture towards something more persists even if the contingencies in the environment are hugely different from those of a pre-agrarian culture. Those drives are not the rational products of the 
neocortex of the brain; they are the function of the limbic system. With increasing complexities of social structures and advances in our technologies, we have attached other adaptive traits to leadership, one of which is schizotypy, or the ability to use divergent mental process to create new solutions to problems that emerge in the environment. We also become anxious to miss the something more that the creative person brings to life.

On the other hand, we also have added an attraction for another set of people who are relatively low in schizotypy; those who demonstrate highly convergent thinking. We are torn between two leader-types because we are governed by two brains, each with a very different agenda, and each leader type might be the better choice at any time as the contingencies of the environment change.

The products created by convergent thinking are easily judged by the rational processes that our cerebral cortex sponsors. This means that for the general population we have a low tolerance for a bad interstate bridge constructed by a formerly-respected engineering, but we will tolerate a bad novel from a good author (or we will repeatedly attempt to read a bad novel from such an author). Similarly, we will tolerate a drunk writer for a lot longer than we will tolerate a drunk driver. Although authors in certain settings get arrested for political violations or moral violations found in their works, no one gets arrested for a "bad" novel (though I am still hoping for justice to be served in response to The Bridges of Madison County). When an author fails, the readers are not as prone to see the failure because they are still sustained by the positive feelings that the author's previously successful creations generated. We can store goodwill for favored authors, but we spend it down at rates that vary within our population. 
Within the world of high literature, four different sets of people attend to a writer: scholars, critics, general readers, and publishers. Each role has a different tolerance point for failure before the person in the social-role reverses opinion about the author. A scholar, for example, who has already staked a career on interpreting an author will be strongly inclined to maintain a long-view of the relationship because his or her reputation is already founded on what that writer can do for his or her career. Critics are similar, and they often overlap in role with academy scholar, but they may abandon (or turn to) an author more easily because many critics work in the popular media that attends to trends, fads, and fashions in culture. They will shape their assessments of authors - even wellestablished writers -- in accord with those vagaries, because, once again, reputations are built on what they can gain by following authors, and if one author begins to misdirect readers to sources that lack creative nurture, the critic will find another author to consider. General readers often do not know precisely why they have a particular appetite for a particular kind creative product, but they do follow their appetites; and they will follow trends. They are likely to stick with a favored writer, at least for a while, even if the writer is not supplying what they previously had tasted. Their reputations are not at stake, but a sense of satisfaction or dissatisfaction is at play, and this is a very visceral aspect of human experience. Publishing house and magazine editors simultaneously monitor fads, fashions, trends, writers' talents, and marketplace realities. Of all those who have a relationship with a writer, they are the ones who have to monitor their own limbic systems and the cerebral cortices in a single moment. For example, in the late 1980's in the U.S. an upsurge in demand for the memoir genre and its small-press cousin, creative nonfiction, led to an exponential difference in prices paid for manuscripts 
marketed as nonfiction. Some writers took liberties with designations (sometimes prodded by literary agents) and this nexus of appetite-cum- economy created the perfect storm for the fraud later exposed in James Frey's A Million Little Pieces (2003), a work that coincidentally centers on addiction and recovery.

In Faulkner's case, for example, Random House, a publishing firm that should have had a great ear and eye for quality, still put both Requiem for a Nun and A Fable into print. As noted above, the company had been supporting Faulkner's writing after buying out his movie studio contract, and they wanted his novels to be a critical success for his own psychological good and a commercial success for their benefit. The firm's attachment was based on a complex relationship with the "leader" who should be the one solving their problems; instead, the publishing house was now trying to recoup their investment and to save face. The commercial magazines of the same years - the ones that turned down "Weekend Revisited" - had nothing, however, invested in Faulkner and, therefore, no need to hope for a payoff from an obviously bad product. They realized that Faulkner, who by then had found way too much fermented fruit, was actually gesturing them toward a pile of cellulose, the chemical first-cousin to dietary carbohydrates, but a molecule entirely useless for either nutrition or recreation unless you are a termite. The magazine editors were pretty sure their readers were not termites. The same can be said for the Broadway play producers when they read Requiem.

A critic like Malcom Cowley, who had consciously promoted Faulkner's reputation since the mid 1940 's, was placed in a difficult spot with the publication of $A$ Fable (1955). As Blotner reports, “A Fable was a noble failure. It was Malcom Cowley who said it kindly in the New York Herald Tribune on Sunday, August 1 (Faulkner 2 
Vols., 1502)." The adjective, “noble," protects Faulkner, to whom Cowley was quite addicted, while Cowley's admitted recognition of the book as a "failure" protects his own reputation as a critic. As noted above, Blotner had his own addiction to Faulkner; perhaps the most primal: Faulkner was the father figure; the one who is to provide identity for the son. The University of Virginia was not so emotionally attached, however, and assessed Faulkner the way they would an architect submitting design a building for the campus: does this addition enhance or diminish the institution's reputation? The school extracted some value from their relationship with Faulkner, but they were conservative investors who would not risk being ruined by buying stock in a mismanaged enterprise. Vervets may not fire their leaders, but vervets also do not have corporate stockholders or university trustees to satisfy.

For many readers, however, it is inconceivable that a famous writer could write bad books just as the adults in the "The Emperor's New Clothes" could not imagine that the supreme ruler could be convinced to parade nude in public. A person who is codependent in a relationship with a person who is substance dependent will often blame himself or herself for not seeing the world the way the addict does, and for not appreciating what the addict really offers. It is their own version of the "peculiar mental twist" that members of Alcoholics Anonymous recognize in their own relationship with alcohol (33). Similarly, the fans and critics who approach the famous writer's shortcomings will often convince themselves that, somehow, it is their own fault that they cannot see the genius in the newest work. We are wired this way, some of us more than others, and different people require different levels of disappointment before they find 
motivation to look at their situation from a new perspective that can free them from distorted responses.

Richard Dawkins made his name in genetic theory with his explanation of the concept of "the selfish gene" in the book by that name. His work makes it clear that genes only have an "interest" in being reproduced, and a gene does not care which particular organism passes it on to progeny or what particular actions are needed to promote greater probability of reproduction. If hitching its wagon to a star facilitates reproduction, it does not care much about the ethics of the situation. Our propensity to be addicted to an addict is driven by "selfish gene" motives as much as is the alcoholic's propensity to be driven to drink. This similarity also means that our decisions to cut ties with an addict will also be driven by selfish-gene mechanisms. Humans have exceeded the other primates in this level of developed selfishness, for the monkeys do not cut the ties with their drunken leaders. For some people, severing ties is an easy task. A mere bit of rational thought applied to a risk-benefit analysis tells them whether to stay or to go. But just as individuals are variable prone to become addicted to a substance, other individuals are differentially prone to stay attached to person whose creativity has been compromised.

But when it comes to the source for a good story, what could be better than these complexities? And this is why we argue over how to deal with Faulkner's corpse and corpus. Since the template for every story requires at least one character who faces a problem and then embarks on a series of actions that lead to a "win," a "draw" or a "loss;" some type of flaw must drive every narrative to this end. But not all narratives are of the same genre. If the flaw is in the character, the narrative tends to generate a drama. 
If the flaw is external to the character, the narrative generates an epic. If flaws are found within and without, the narrative generates richly complex blends of genre. Once a primate society, such as humans, creates conditions that designate aberrant drinking as a problem, and since evolutionary selection has already "cast" a certain number of the population in the role of aberrant drinkers, the stage is set for many potentially fascinating stories concerning drinkers.

At the same time, once a primate society retains drinkers as esteemed leaders who find creative inspiration in alcohol, the stage is set for conversations that ignore the problem while the followers wrestle with the symptoms. Anyone, then, with a feel for a good story can immediately see why the alcoholic, whether perceived as heroic, immoral, or ill, will automatically generate - at least for a while - some compelling narratives by the others who talk about the alcoholic. Even readers who do not have much of a taste for alcohol seem to have an appetite for pulp-fiction, and stories with alcoholics can prove to be entertaining if told well, and if not told for too long. It might be the story of the outrageous drunk who "shows them all" exactly where the frowning critics can stuff their criticism, or shows how pitiful the timid, sober folk are as the inspired hero boisterously grabs and holds the victor's wreath in life and then carries it courageously to the grave. It might be the story of the brilliant hero irrevocably waylaid by the bottle and who dies degenerate, with subplots of social pity or social derision generated by observers in the story. It may be the story of the "ne'er do well" drunkard who, being "doomed from the womb," holds no prospects for success but who then, somehow, embraces sobriety. At that point the subplot variant may show either a meteoric rise in esteem and leadership, or it may depict the hero's dismissal from prominence as the 
result of her diminished character, handicapped now by restraint rather than excess. We use alcoholics for our own entertainment, and the more creative the alcoholic is, the more entertained we are. Faulkner was quite creative and quite the alcoholic. He used us and we use him. 


\section{EPILOGUE}

"We were prepared to look at it from an entirely different angle."

Alcoholics Anonymous, 66.

Are we as humans, then, "more" sophisticated, but less "ethical" than monkeys? Answering yes would be unavoidable if we adhere only to the materialist, evolutionary model. I argue above, however, that none of the animal metaphors will be true if not taken with the others. In order to defend this notion of a non-integrated, simultaneity of multiple gazes, I now add to the animal metaphors: I must eat crow.

In the Introduction, I grudgingly admitted a few of the Critical Theory figures into the conversation while snidely implying that we could have gotten on very well and merrily well without them at this party if they had not forced themselves onto the social registry in the middle of the last century. That is, I treated them rudely as invited but unwanted guests, and placed their friend, Bruno Latour, in charge of them so that they would not spoil the fun for those of us who wanted free reign to talk about good books. One guest who has crashed the party now at the twelfth hour will not be so easily diverted. Whether we like him or abhor him, none of us can ignore him. He behaves as unrulily in thought and in academic society as Beethoven did in music and in the salon. But even I have to admit he is of similar genius. Welcome, then, Slavoj Žižek.

I cite above Žižek as a contemporary critic who proposes that, at some level and in some way, humanity incurred a split from our purely material origins and that this split has allowed for an authentic experience of mind or spirit. This split, however, does not 
eradicate the materialism which remains both obvious and incontrovertible in our nature.

This fact - or these facts -- for him demand(s) that we see both conditions simultaneously and without any illusion of a synthesis.

He offers a solution - one that is itself not a synthesis -- as he invokes a model that is based in optical physics: the parallax view. This phenomenon describes the experience that an object appears to move in relation to its background as it is viewed from two different perspectives. Parallax has great implications for calculating interstellar positions and distances for astronomers, but it is easily observed for any person with intact, binocular vision by extending an arm at its full length, holding up one finger, looking at the digit, and then rapidly opening and closing of each eye in alternation. The finger appears to move, and objects behind the finger are alternately obscured and revealed. If the experimenter asks himself or herself, "Is the finger here or is it there?" the answer comes back as both and neither. Frederic Jameson, in his review of Zizek's The Parallax View, offers to translate for us:

A parallax, Webster's says, is 'the apparent displacement of an observed object due to a change in the position of the observer'; but it is best to put the emphasis not on the change or shift, so much as on the multiplicity of observational sites, for in my opinion it is the absolute incommensurability of the resultant descriptions or theories of the object that Žižek is after, rather than some mere symptomal displacement. [....] In parallax thinking, however, the object can certainly be determined, but only indirectly, by way of a triangulation based on the incommensurability of the observations.

Armed with this model of parallax, Žižek gives a strong rereading (I will call it a strong misreading) of Hegel, claiming that Hegel never claimed that the agon of Thesis and Antithesis results in Synthesis, but that the Synthesis is only the apparent result of shifting perspectives. Žižek then undertakes the ultimate heresy in Marxist historical dialectic: he marches Marx's materialism back into the realm of the Spirit. 
I find that Jameson and Zizek offer us much as they break our certainties, but they

limit themselves as they indulge their own faiths. Jameson, reviewing of The Parallax

View, speaks their creed on behalf of both:

The reader will judge from the case-studies in this volume whether parallax theory has been fruitful. In particular, the chapter on the dilemmas of cognitive science - the material brain and the data of consciousness - is a superb achievement which transcends Spinozan parallelism towards the ultimate Hegelian paradox: 'Spirit is a bone.' As far as politics is concerned, it seems to me that Žižek's lesson is as indispensable as it is energising. He believes (as I do) that Marxism is an economic rather than a political doctrine, which must tirelessly insist on the primacy of the economic system and on capitalism itself as the ultimate horizon of the political situation (as well as of all the other ones - social, cultural, psychic and so forth). (Jameson, "First Impressions." No pagination.)

We are back to stubborn faiths in myths of alienation. My chosen myth differs, but that choice is as equally irrelevant as is theirs. Yet the fact that Zizek has included in his book a "chapter on the dilemmas of cognitive science - the material brain and the data of consciousness" obviously shows that this small project on Faulkner and alcoholism shares some matters of concerns with Žižek's larger theory.

Of course, being a big theory is precisely a problem. The Theorists, following Jean-François Lyotard, are to eschew the grand narratives in favor of the petits récits. Jameson voices a concern that points as much to his own work as it does to Žižek's, for both are a bit grand in their scope of things:

Yet theory was always itself 'grounded' on a fundamental (and insoluble) dilemma: namely, that the provisional terms in which it does its work inevitably over time get 'thematised' (to use Paul de Man's expression); they get reified (and even commodified, if I may say so), and eventually turn into systems in their own right. The self-consuming movement of the theoretical process gets slowed down and arrested, its provisional words turn into names and thence into concepts, the anti-philosophy becomes a philosophy in its own right. My occasional fear is, then, that by theorising and conceptualising the impossibilities designated by the parallax view, Žižek may turn out to have produced a new concept and a new theory after all, simply by naming what it is probably better not to call the unnameable. (Jameson, "First Impressions.” No pagination.) 
Those very folk who have resisted the grand narrative find themselves making them. Not only are the origins founded on an insoluble dilemma, the outcomes will be unavoidably grandiloquent.

I defend Žižek’s misreading of Hegel, however, precisely on the basis of the grandness of it, and by recourse to Harold Bloom: "[...] perhaps there are only more or less creative or interesting misreadings, for is not every reading necessarily a clinamen. [...] The stronger the man, the larger his resentments, and the more brazen his clinamen (Anxiety 43)." If this sort of thinking sounds speciously modern, it is entirely reminiscent of the rebellious monk, Martin Luther, who wrote to his own protégé Philip Melanchthon, "Be a sinner, and let your sins be strong ( $\sin$ boldly), but let your trust in Christ be stronger, and rejoice in Christ who is the victor over sin, death, and the world." The paradox of strength and weakness seems to arise in all ages.

Before Jameson leaves Žižek, he thinks one step beyond him: "I would only want to wonder whether there are not more complex forms of the parallax situation which posit more than two alternatives (on the order of subject and object), but which rather confront us with multiple, yet equally indispensable codes (Jameson. No pagination)." I hope that this small project, where we have gazed at the "matter of concern" -- alcoholism in general and William Faulkner's alcoholism in particular -- from many perspectives, answers Jameson affirmatively. As complex, or as impossible, as the assignment may appear to be, when we gaze from many perspectives -- the materialist, the psychological, the medical, the artistic, the moral, the spiritual, the religious, and the philosophical -- our apprehension of the object will be improved. Although Bill Wilson declared the program of recovery offered in Alcoholics Anonymous to be "synthetic" of those domains, the 
program is probably better understood as offering multiple perspectives, all employed simultaneously, and quite in accord with Jameson's hope for an adumbrated parallax view. It is a veritable riot of recovery.

I hope this project has also demonstrated that the multiple-perspective model is a proper exercise in the humanities. I noted in Chapter Five, "Without denying the elephant in the room, I would love to find a way to see the humanity in our midst." I expand that also to say that without denying the monkey in our mix, I would still love to find a way to see the humanity in our midst. I offer that wish both in response to the unlovable ways Faulkner treated those around him and the way we have treated Faulkner as a caged lion to be used for our own benefits; angry at his inability to give us more so that we can do less; angry that he retained, not simply as scars but often as points of pride, aspects of white privilege, male privilege, heterosexual privilege, and American colonialism. I find some hope for fulfilling this wish with yet another perspective, one borrowed from the members of Alcoholics Anonymous. I offer it with the advance reminder that they tell us, "When therefore we speak to you of God, we mean your own conception of God (47)": This is the entirely different angle that the epigraph proposes:

This was our course. We realized that the people who wronged us were perhaps spiritually sick. Though we did not like their symptoms and the way these disturbed us, they, like ourselves, were sick too. We asked God to help us show them the same tolerance, pity, and patience that we would cheerfully grant a sick friend. When a person offended we said to ourselves, "This is a sick man. How can I be helpful to him? God save me from being angry. Thy will be done."

We avoid retaliation or argument. We wouldn't treat sick people that way. If we do, we destroy our chance of being helpful. We cannot be helpful to all people, but at least God will show us how to take a kindly and tolerant view of each and every one." (Alcoholics Anonymous 67)

In our humanness, we swerve between the poles of adoration and condemnation; praising Caesar and burying him. The tendency applies to considerations of William Faulkner or 
alcoholism; or William Faulkner and alcoholism; or Faulkner's fictions about alcoholism; or Faulkner's fictions about his own alcoholism; or our fictions about his fictions; or our fictions about his alcoholism. We swerve between the poles of adoration and condemnation. Robert Lowell asks in his "Epilogue," "Why not say what happened?" We can say what happened, but we cannot say it in only one way. There are so many ways to say what happened, and if we restrict to one, we are prone "to carry blame or praise too far." Robert Frost suggests we "choose something like a star" for our bearings.

But to locate a star, we will have to consider more parallax and less synthesis.

"Choose Something Like a Star"

O Star (the fairest one in sight), We grant your loftiness the right To some obscurity of cloudIt will not do to say of night, Since dark is what brings out your light. Some mystery becomes the proud. But to be wholly taciturn In your reserve is not allowed. Say something to us we can learn By heart and when alone repeat. Say something! And it says, 'I burn.' But say with what degree of heat. Talk Fahrenheit, talk Centigrade. Use language we can comprehend. Tell us what elements you blend. It gives us strangely little aid, But does tell something in the end. And steadfast as Keats' Eremite, Not even stooping from its sphere, It asks a little of us here. It asks of us a certain height, So when at times the mob is swayed To carry praise or blame too far, We may choose something like a star To stay our minds on and be staid. 


\section{REFERENCES}

Adams, Ben. "Heavy Drinking and the AA Model." Chapter 5 in Lilienfeld, Jan and Jeffrey Oxford. Eds. The Languages of Addiction. New York: St. Martin's Press. 1999. Print.

Alcoholics Anonymous: The Story of How Many Thousands of Men and Women Have Recovered from Alcoholism. Fourth Edition. New York: Alcoholics Anonymous World Services. 1939, 1955, 1976, 2001. Print.

Allison, A.C. "Protection afforded by Sickle-Cell Trait Against Subtertian Malarial Infection.” British Medial Journal. February 6, 1954. 290-294. Print.

American Society of Addiction Medicine. "Definition of Addiction." Adopted by the ASAM Board of Directors April 19, 2011. Web. Accessed November 02, 2012. http://www.asam.org/for-the-public/definition-of-addiction .

Andreasen, Nancy C. "Creativity and mental illness: prevalence rates in writers and their first-degree relatives." American Journal of Psychiatry. 144:1288-92. 1987.

Armelagos, George J. "The Slavery Hypertension Hypothesis -- Natural Selection and Scientific Investigation: A Commentary.” Transforming Anthropology. 13:2. 2005.119 124. Print.

BBC Worldwide, BBC Animals. “Alcoholic Vervet Monkeys!” Video. Web. Accessed December 03, 2014. https://www.youtube.com/watch?v=pSm7BcQHWXk.

Bassett, John E. Faulkner: An Annotated Checklist of Recent Criticism. Kent State University Press. 1983

. Faulkner in the Eighties: An Annotated Critical Bibliography. Meutchen, N.J.: Scarecrow Press. 1991. Print.

. William Faulkner : An Annotated Bibliography Of Criticism Since 1988. Lanham, Md.: Scarecrow Press, 2009. Print.

. William Faulkner: An Annotated Checklist of Criticism. New York: David Lewis. 1972.

. Editor. William Faulkner: The Critical Heritage. London: Routledge \& Kegan Paul.1975. Print. 
Bauman, Marcy Lassota. "The Bottle in the Sideboard: Alcoholism as a Defining Force in The Sound and the Fury." Unpublished Dissertation. Michigan State University. 1991. Dissertation Abstracts International 53 (5): 1746A. Print.

Bloom, Harold. The Anxiety of Influence: A Theory of Poetry. Second Edition. New York: Oxford University Press. 1997. Print.

. Shakespeare: The Invention of the Human. New York: Riverhead Books. 1998. Print.

Blotner, Joseph. Faulkner: A Biography (Vols 1 and 2). New York: Random House. 1974. Print.

.. Faulkner: A Biography (One Volume). New York: Random House.

1984. Print.

Ed. Selected Letters of William Faulkner. New York: Random House.

1977. Print

Booth, Wayne C. The Rhetoric of Fiction. Chicago: University of Chicago Press. 1961.

Brodsky, Louis Daniel. William Faulkner, Life Glimpses. Austin: University of Texas Press. 1990. Print.

Brooks, Cleanth. "Gavin Stevens and the Chivalric Tradition." In On the Prejudices, Predilections, and Firm Beliefs of William Faulkner: Essays by Cleanth Brooks. Ed. Louis D. Rubin. Southern Literary Studies. Baton Rouge, LA; Louisiana State University Press. 1987. 92-106. Print.

Butler, Judith. Antigone's Claim: Kinship between Life and Death. New York: Columbia University Press. 2000.

Butterworth, Keen. A Critical and Textual Study of Faulkner's A Fable. Ann Arbor: UMI Research Press. 1983.Print.

Dardis, Tom. "Harrison Smith: The Man Who Took a Chance on The Sound and the Fury." In Faulkner and Popular Culture: Faulkner and Yoknapatawpha, 1988. Jackson, MS: University Press of Mississippi. 1990. 163-178. Print.

Carson, Higgins, Peterson, "Decreased latent Inhibition Is Associated With Increased Creative Achievement in High-Functioning Individuals," Journal of Personality and Social Psychology, 85:3. 2003. 499-506. Print.

Carver, Raymond. “Gravy.” All of Us: The Collected Poems. New York: Knopf. 1998. Print.

Coindeau, M. F. “The Faulkner I Knew.” Shenandoah. 16:29. 1965.Print. 
Cromie, William. "Creativity Linked to Mental Illness." Harvard University Gazette. October 23, 2003. Web. Accessed January 05, 2015. http://news.harvard.edu/gazette/legacy-gazette/\# .

Cronqvist, Henrik and Stephan Siegel. "The Origins of Savings Behavior." Journal of Political Economy. 123:1. 123-169. 2015. Web. Accessed February 28, 2015. http://www.jstor.org/stable/10.1086/679284.

Crowley, John. W. The White Logic: Alcoholism and Gender in American Modernist Fiction. Amherst, MA: University of Massachusetts Press. 1994. Print. . Ed. Drunkard's Progress: Narratives of Addiction, Despair, and Recovery. Baltimore: The Johns Hopkins University Press. 1999. Print.

Czikszentmihalyi, Mihaly. Creativity: Flow and the Psychology of Discovery and Invention. New York : Harper Collins. 1996. Print.

Dardis, Tom. “'Oh, Those Awful Pressures': Faulkner's 'Controlled' Drinking.” In Beyond the Pleasure Dome: Writing and Addiction From the Romantics. Eds. Sue Vice, Matthew Campbell, and Tim Armstrong. Sheffield, England: Sheffield Academic Press, 1994. 192-99. Print.

. The Thirsty Muse: Alcohol and the American Writer. New York: Ticknor and Fields. 1989. Print.

Davies, Luke. [And if every step taken is a step well-lived]. From Totem Poems. London: Allen \& Unwin. 2004. Print. Web. Accessed February 25, 2015. http://www.poetryfoundation.org/poem/243068

Dawkins, Richard. The Selfish Gene. Revised Edition.New York: Oxford University Press. 1989.

Dennett, Daniel C. Darwin's Dangerous Idea: Evolution and the Meanings of Life. New York: Simon and Schuster. 1995.

"Donald J. Goodwin: Obituary." Journal Of the American Medical Association. Vol 282. n 17.1999.Web. Accessed November 02, 2014. http://www.trussel.com/maig/goodwin2.htm .

Dudley, Robert. "Fermenting Fruit and the Historical Ecology of Ethanol Ingestion: Is Alcoholism in Modern Humans an Evolutionary Hangover?" Addiction. 97. 2002. 381-388. Print.

Ervin, Frank R. Roberta M. Palmour, Simon N. Young, Carlos Guzman-Flores, and Jorge Juarez." Voluntary Consumption of Beverage Alcohol by Vervet Monkeys: Population Screening, Descriptive Behavior and Biochemical Measures." Pharmacology Biochemistry \& Behavior. 36. 367-373.1990. Print. 
Faulkner, William. Absalom, Absalom! New York, Random House. 1936. Print.

. As I Lay Dying. New York: Random House. 1930. Print.

. A Fable. London: Chatham and Windus. 1955. Print.

. Essays, Speeches and Public Lectures: Updated, with Material Never Before

Collected in One Volume. Ed. James B. Meriwether. New York: The Modern Library. 2004.

Print.

.'Golden Land." Collected Stories of William Faulkner. New York. Vintage. 1995. 701 - 726. Print.

. "Go Down, Moses" and Other Stories. New York: Random House. 1942. Print.

. The Hamlet. New York: Random House. 1931. Print.

Intruder in the Dust. New York: Random House. 1948. Print.

. Light in August. New York: Random House. 1935. Print.

. The Mansion. New York: Random House. 1955. Print.

. "Mr. Acarius." Uncollected Stories of William Faulkner. Ed. Joseph Blotner.

New York: Random House. 1979. 435 - 438. Print.

. Pylon. New York: Random House. 1935. Print.

. The Sound and the Fury. New York: Random House. 1929. Print.

. The Town. New York: Random House. 1957. Print.

. William Faulkner: New Orleans Sketches. Ed. Carvel Collins. New York:

Random House. 1958. 121-131. Print.

Fisk-Green, R., Byrne, J., Crider, K.S., Gallagher, M. Koontz, D. Berry, R.J. "FolateRelated gene variants in Irish families affected by neural tube defects." Frontiers in Genetics. Article 223. 4. November. 2013. Web. Accessed February 21, 2015. http://www.ncbi.nlm.nih.gov/pmc/articles/PMC3818582/pdf/fgene-04-00223.pdf

Flanders, Michael and Donald Swann. The best of Flanders and Swann: A Transport of Delight. London: EMI. 1994. Audio CD. Excerpt on Web. Accessed March 14, 2015. https://www.youtube.com/watch? $\mathrm{v}=\mathrm{VnbiVw}$ _1FNs

Flint, R. W. "What Price Glory?" The Hudson Review. 7. Winter, 1955.602-606. Print.

Forseth, Roger. "The Alcoholic Writer by Any Other Name."

Frost, Robert. "Chose Something Like a Star." Come In and Other Poems. New York: Henry Holt. 1943. Print. 
Goldstein, Rita Z and Nora D. Volkow. "Dysfunction of the Prefrontal Cortex in Addiction: Neuroimaging Findings and Clinical Implications." Nature. 12. November 2011. 652- 669. Print.

Gilmore, Thomas B. Equivocal Spirits: Alcohol and Drinking in TwentiethCentury Literature. Chapel Hill: University of North Carolina Press. 1987. Print.

Goodwin, Donald W. Alcohol and the Writer. New York: Andrew McMeel. 1988. Print. Is Alcoholism Hereditary? New York : Oxford University Press, 1976. Print.

Graham, Jean E. "Gavin Stevens in Faulkner's "Intruder in the Dust": Only Too Rhetorical Rhetoric?" The Southern Literary Journal. 22:2. 1990. 78-89. Print.

Gray, Richard. The Life of William Faulkner: A Critical Biography. Cambridge, MA: Blackwell. 1994. Print.

Guze, Samuel B., M.D. “Obituary: Donald W. Goodwin, M.D.” Journal of the American Medical Association. 282:17. Print. Also on Web. Accessed February 16, 2015 http://www.trussel.com/maig/goodwin2.htm

Gwynn, Frederick L. and Joseph L. Blotner. Eds. Faulkner In the University: Class Conferences at the University Of Virginia 1957-1958. Charlottesville, VA: The University of Virginia Press. 1959. Print.

Hickman, Lisa C. "Lonesome Spirits: William Faulkner and Joan Williams." Unpublished Dissertation. The University of Mississippi, 2003. ProQuest, UMI Dissertations Publishing, 2003. 3089838. Web. Accessed January 05, 2015. http://search.proquest.com.echo.louisville.edu/pqdtglobal/docview/305322230/fulltextPD F/D744D9DA656D40DCPQ/1?accountid=14665.

. "William Faulkner: Dealing With His Demons." Memphis. September. 1993. Print.

. William Faulkner and Joan Williams: The Romance of Two Writers. Jefferson, NC: McFarland Publishers. 2006. Print.

Frost, Robert. "Choose Something Like a Star." Come In and Other Poems. New York: Henry Holt. 1943.

Hoffman, Michael. "The Woman who Quit." Poetry. Chicago: Poetry Foundation. February, 2015. Print. Web. Accessed March 29, 2015. http://www.poetryfoundation.org/poetrymagazine/toc/2470

Hugo, Richard. "Stray Thoughts On Roethke and Teaching." In The Triggering Town: Lectures and Essays On Poetry and Writing. New York: Norton. 1979. 27-36. Print. . "Writing Off the Subject." In The Triggering Town : Lectures and Essays On Poetry and Writing. New York: Norton. 1979. 3-10. Print. 
Ingraham, Christopher. "Think you drink a lot? This chart will tell you.” Wonkblog. The Washington Post. September 25, 2014. Web. Accessed January 25, 2015. http://www.washingtonpost.com/blogs/wonkblog/wp/2014/09/25/think-you-drink-a-lotthis-chart-will-tell-you/

Jackson, Fatimah Linda Collier. "An Evolutionary Perspective on Salt, Hypertension, and Human Genetic Variability.” Hypertension. 17. Supplement I. I-129 - I-132. 1991. Print.

Jameson, Frederic. "First Impressions." Book Review. The Parallax View by Slavoj Žižek. London Review of Books. 17:17. September 7, 2006. Web. Accessed March 25, 2015. http://www.lrb.co.uk/v28/n17/fredric-jameson/first-impressions

Jamison, Kay Redfield. Touched With Fire: Manic-Depressive Illness and the Artistic Temperament. Macmillan, 1993. Print.

Jellinek, E. M. The Disease Concept of Alcoholism. New Haven: Hillhouse.1960. Print.

Karls, Federick R. William Faulkner: American Writer. New York: Weidenfeld and Nicholson. 1989. Print.

Kerr, Elizabeth Margaret. William Faulkner's Yoknapatawpha: “A Keystone in The Universe.” New York: Fordham University Press. 1983. Print.

Khantzian, Edward J. "Self-Regulation and Self-Medication Factors In Alcoholism and the Addictions." Chapter 4 in Lilienfeld, Jan and Jeffrey Oxford. Eds. The Languages of Addiction. New York: St. Martin's Press. 1999. Print.

Kirk, Robert W. and Marvin Klotz. Faulkner's People: A Complete Guide and Index to the Characters In the Fiction of William Faulkner. Berkeley: University of California Press. 1963. Print.

Kurtz, Ernest. Not God: A History of Alcoholics Anonymous. Center City, MN: Hazelden Educational Services.1979.

Laing, Olivia. "'Every Hour a Glass of Wine': The Female Writers Who Drank.." Books. The Guardian. Friday, June 14, 2014. Web. Accessed February 05, 2015. http://www.theguardian.com/books/2014/jun/13/alcoholic-female-women-writersmarguerite-duras-jean-rhys The Trip to Echo Spring: On Writers and Drinking. New York: Picador. 2013.

Latour, Bruno. "Why Has Critique Has Run Out of Steam? From Matters of Fact to Matters of Concern." Critical Inquiry. 30:2. 2004. 225-248. Print. 
LaVallee, Robin A. and Hsiao-ye Yi. "Apparent Per Capita Alcohol Consumption: National State and Regional Trends, 1977-2009.” Surveillance Report \#92.

Washington,D.C.: National Institute on Alcohol Abuse and Alcoholism. August 2011. Web. Accessed January 31, 2015 http://pubs.niaaa.nih.gov/publications/Surveillance92/CONS09.pdf .

Levey, Douglas J. "The Evolutionary Ecology of Ethanol Production and Alcoholism." Integrative Comparative Biology. 44. 2004. 284-289. Print.

Liem, Edwin B, Chun-Ming Lin, Mohammad-Irfan Suleman, Anthony G. Doufas, Ronald G. Gregg, Jacqueline M. Veauthier, Gary Loyd, and Daniel I. Sessler." Anesthetic Requirement is Increased in Redheads." Anesthesiology. 101:2. 2004.279-283. Print.

Lilienfeld, Jan and Jeffrey Oxford. Eds. The Languages of Addiction. New York: St. Martin's Press. 1999.

London, John. John Barleycorn.. New York: Century Press. 1913. Print. Also available Web. Accessed November 02. 2014. http://www.gutenberg.org/files/318/318-h/318-h.htm .

Lowell, Robert. "Epilogue.” Day by Day. New York: Farrar, Straus \& Giroux. 1977. 127. Print. Also available Web. (Accessed March 25, 2105) http://www.poetryfoundation.org/poem/177164

Ludwig, Arnold M.. "Mental Illness and Creative Activity in Female Writers." American Journal of Psychiatry 151:11, November 1994.

.The Price of Greatness: Resolving the Creativity and Madness Controversy. Guildford Press, 1995.

.Understanding the Alcoholic's Mind: The Nature of Craving and How to Control It. New York: Oxford University Press. 1988.

Luther, Martin. "Let Your Sins Be Strong: A Letter From Luther to Melanchthon." Letter no. 99. August 1, 1521. From the Wartburg. Trans.Erika Bullmann Flores. Dr. Martin Luther's Saemmtliche Schriften. Dr. Johannes Georg Walch. Ed. St. Louis: Concordia Publishing House, N.D. 15. Cols. 25852590. Print. Web. Accessed March 25, 2105.

http://www.iclnet.org/pub/resources/text/wittenberg/luther/letsinsbe.txt

Mash, Deborah C., Julie K. Staley, Francis M. Doepel, Simon N. Young, Frank Ervin and Roberta M. Palmour. "Altered Dopamine Transporter Densities in Alcohol-preferring Vervet Monkeys.” NeuroReport. 7. 457-462. 1996. Print.

Merriwether, James B. Ed. A Faulkner Miscellany. Jackson, MS: University Press of Mississippi. 1974. Print. 
Meriwether, James B. and Michael Millgate. Eds. Lion in the Garden: Interviews With William Faulkner, 1926-1962. New York: Random House. 1968. Print.

Millgate, Michael. The Achievement of William Faulkner. Athens, GA: University of Georgia Press. 1963. Print.

Minter, David. William Faulkner: His Life and Work. Baltimore, MD: The Johns Hopkins University Press. 1980. Print.

"Monday Meetings." Alcoholics Anonymous. Syracuse, New York. Web. Accessed February 06, 2015.

http://www.aasyracuse.org/sched_02_mon.htm

Nettle, Daniel. "Schizotypy and Mental Health Amongst Poets, Visual Artists, and Mathematicians." Journal of Research in Personality. 40. 2006. 876-890. Print. . Strong Imagination. Oxford, 2001.

Nettle, David and Helen Clegg. "Schizotypy, Creativity and Mating Success in Humans." Proceedings of the Royal Society. 273. 2006. 611-615. Print.

Newlove, Donald. Those Drinking Days: Myself and Other Writers. New York: Horizon Press. 1981.

Oates, Stephen B. William Faulkner: The Man and the Artist, A Biography. New York: Harper and Row. 1987. Print.

O’Briena, Niamh L. Michael J. Waya, Radhika Kandaswamya, Alessia Fiorentinoa, Sally I. Sharpa, Giorgia Quadria, Jarram Alexa,Adebayo Anjorina, David Ballc, Raquin Cheriand, Karim Dard, Aynur Gormeze,Irene Guerrinic, Mathis Heydtmanng, Audrey Hillmanh, Sudheer Lankappaj,Greg Lydalla, Aideen O'Kanek, Shamir Pateld, Digby Questede, Iain Smithi,Allan D. Thomsona, Nicholas J. Bassa, Marsha Y. Morganb, David Curtisa and Andrew McQuillina. "The functional GRM3 Kozak sequence variant rs148754219 affects the risk of schizophrenia and alcohol dependence as well as bipolar disorder." Psychiatric Genetics.24. 2014. 277-278. Print.

Pace, Ed. "Tom Dardis, 78, Literary Biographer Fascinated By Film." Arts Section. The New York Times. November 11, 2001. Web. Accessed May 19, 2014. http://www.nytimes.com/2001/11/14/arts/tom-dardis-78-literary-biographerfascinated-by-film.html .

Paley, Grace. "In Time Which Made a Monkey of Us All." The Collected Stories. New York: The Noonday Press, Farrar, Straus and Giroux. 1994. Print. 
Parini, Jay. One Matchless Time: A Life of William Faulkner. New York: HarperCollins. 2004. Print.

Pace, Ed. "Tom Dardis, 78, Literary Biographer ascinaed By Film.” Arts Section. The New York Times. November 11, 2001. Web. Accessed November 02, 2014. http://www.nytimes.com/2001/11/14/arts/tom-dardis-78-literary-biographer-fascinatedby-film.html .

Peele,Stanton. "Exploring Psychological Benefits Associated with Moderate Alcohol Use: A Necessary Corrective to Assessments of Drinking Outcomes?" Drug and Alcohol Dependence,60. 2000. 221-247. Print. Available by Web. http://www.peele.net/lib/exploring.html Accessed February 03,2015

. "Why We Need to Stop Nora Volkow From Taking Over the World." Substance.com: The Stuff That Hooks Us. ”January 15, 2015. Web. Accessed February 02, 2015. http://www.substance.com/stop-nora-volkow-late/2720/

Pickens, Conor Adam. "Friends of Bill F.: Alcohol, Recovery, and Social Progress in Southern Fiction. Unpublished Dissertation.” Louisiana State University .2013. Web. Accessed January 05, 2015. http://etd.lsu.edu/docs/available/etd-04092013-103115/unrestricted/Picken.diss.pdf .

Polk, Noel. Faulkner's “Requiem for a Nun”: A Critical Study. Bloomington, IN: Indiana University Press. 1981. Print.

Projet MATCH Research Group, "MatchingAlcoholism Treatments to Client Heterogeneity: Project MATCH Postreatment Drinking Outcomes." Journal of Studies on Alcohol. 58. 1997. 7-29.

Rice, Philip Blair. "Faulkner's Crucifixion.” Kenyon Review, 16. Autumn, 1954. 661670. In Frederick J. Hoffman and Olga W. Vickery. Eds. William Faulkner: Three Decades of Criticism. Michigan State University Press. 1960. 373-381. Print.

Rilke, Maria Rainer. "Archaïscher Torso Apollos." "Torso of an Archaic Apollo.” Trans. C.F. MacIntyre. In Rilke: Selected Poems . Berkeley: University of California Press.1957. Web. Accessed March 30, 2015. http://homepages.wmich.edu/ cooneys/poems/gr/Rilke.html

Roizen, Ron. 'How Does the Nation's 'Alcohol Problem' Change from Era to Era? Stalking the Social Logic of Problem-Definition Transformation since Repeal." Altering American Consciousness: The History of Alcohol and Drug Abuse in the United States, 1800-2000. Ed. By Sarah W. Tracy and Caroline Jean Acker. Amherst, MA: University of Massachusetts Press, 2004. 267-297. 61-86.

Saha, T.D., S.P. Chou and B.F. Grant. "Toward an alcohol use disorder continuum using Item response theory: Results from the National Epidemiologic Survey on Alcohol and Related Conditions." Psychological Medicine. 36:7. 2006. 931-941. Print.

Schwartz, Delmore. "William Faulkner's 'A Fable,"' Perspectives U.S.A. 10 .Winter, 1955. 126-136. Print. 
Schwartz, Lawrence H. Creating Faulkner's Reputation: The Politics of Modern Literary Criticism. Knoxville, TN: University of Tennessee Press. 1988. Print.

Sensibar, Judith L. Faulkner and Love: The Women Who Shaped His Art. New Haven, CT: Yale University Press. 2009. Print.

Silkworth, William D. “The Doctor's Opinion.” In Alcoholics Anonymous: The Story of How Many Thousands of Men and Women Have Recovered from Alcoholism. Fourth Edition. New York: Alcoholics Anonymous World Services. 1939, 1955, 1976, 2001. xxv- xxxii. Print.

Sinclair, Upton. The Cup of Fury. Great Neck, NY: Channel Press. 1956. Print.

Singal, Daniel J. William Faulkner: The Making of a Modernist. Chapel Hill: The University of North Carolina Press. 1997. Print.

Spratling, William and William Faulkner. Sherwood Anderson and Other Famous Creoles. Facsimile of the 1926 original. Austin, TX; Universitiy of Austin Press. 1966.

Storhoff, Gary. "Caddy and the Infinite Loop: The Dynamics of Alcoholism in The Sound and the Fury." Faulkner Journal 12:2. 1997. 3-22. Print. . "Jason's Role Slippage: The Dynamics of Alcoholism in The Sound and the Fury." Mississippi Quarterly 49, iii (Summer 1996): 519-35. Print.

Straumann, Heinrich. "An American Interpretation of Existence: Faulkner's A Fable." (Trans. Of "Eine amerikanische Seinsdeutung, Faulkners Roman 'A Fable," Anglia. 73:4. 1956. 484-515.) In Frederick J. Hoffman and Olga W. Vickery. Eds. William Faulkner: Three Decades of Criticism. Michigan State University Press. 1960. 349-372. Print.

Szymborska, "How To (and How Not To) Write Poetry: Advice For Blocked Writers and Aspiring Poets From a Nobel Prize Winner's Newspaper Column.” From Literary Life. Trans. Clare Cavanaugh. Poetry Foundation. Originally published August 29, 2006. Web. Accessed December 01, 2012. http://www.poetryfoundation.org/article/178592

Three Talks to Medical Societies by Bill W., Co-Founder of AA. New York: Alcoholics Anonymous World Services, Inc. No date. Print. Web. Accessed February 17.2015. http://www.aa.org/assets/en_US/p-6_threetalkstomed.pdf

"Tom Dardis, 78; Wrote About Greats of Film, Literature." Obituaries. Passings. Los Angeles Times. November 16, 2001. Web. Accessed February 16, 2015. http://articles.latimes.com/2001/nov/16/local/me-4895

Valliant, George E. The Natural History of Alcoholism Revisited. Cambridge, MA: Harvard University Press. 1995. Print. 
Volkow, Nora D., Dardo Tomasi, Gene-Jack Wang, Joanna S. Fowler, Frank Telan, Rita Z. Goldstein, Nelly Alia-Klein, Patricia Woicik, Christopher Wong, Jean Logan, Jayne Millard, and David Alexoff. "Positive Emotionality is Associated with Baseline Metabolism in Orbitofrontal Cortex and in Regions of the Default Network." Molecular Psychiatry. 16:8. 2011. 818-825. Web. Accessed February 28, 2015. http://www.nature.com/mp/journal/v16/n8/full/mp201130a.html

Watson, Jay. Forensic Fictions: The Lawyer Figure in Faulkner. Athens, GA: The University of Georgia Press. 1995. Print.

Weinstein, Philip. Becoming Faulkner: The Art and Life of William Faulkner. New York: Oxford University Press. 2010. Print.

White, William L. Slaying the Dragon: The History of Addiction Treatment and Recovery in America. Second Edition. Bloomington, IL: A Chestnut Health Systems Publication. 2014. Print. (Endnotes only by electronic source Web. Accessed January 31, 2015.) http://www.williamwhitepapers.com/pr/ books/misc/Slaying\%20the\%20Dragon \%202014\%20References.pdf.

Wilde, Meta Carpenter and Orin Borstein. A Loving Gentleman: The Love Story of William Faulkner and Meta Carpenter. New York: Simon and Schuster. 1976. Print.

Williamson, Joel. William Faulkner and Southern History. New York: Oxford University Press. 1993. Print.

Wilson T.W. and Grim C.E. "Biohistory of slavery and blood pressure differences in Blacks today: A hypothesis." Hypertension. 17. Supplement I. 1991. I-122-I-128. Print.

Wittenberg, Judith Bryant. Faulkner: The Transfiguration of Biography. Lincoln, NB: University of Nebraska Press. 1979.

World Health Organization. Global Statue Report on Alcohol and Health. WHO Press. Geneva. 2011. Web. Accessed February 28, 2015. http://www.who.int/substance abuse/publications/global alcohol report/msbgsruprofiles .pdf

Wyatt-Brown, Bertram. "William Faulkner: Art, Alienation, and Alcohol." In Bridging Southern Cultures: An Interdisciplinary Approach. Ed. John Lowe. Baton Rouge, LA: Louisiana State University Press. 2005. 77-98. Print.

."William Faulkner: Creativity and the Ravages of Alcoholism." In Thirteenth International Conference on Literature and Psychoanalysis. Ed. Frederico Pereira. Lisbon: Instituto Superior de Psicologia Aplicada. 1997. 13743. Print. 
Zieger, Susan. Inventing the Addict: Drugs, Race and Sexuality in NineteenthCentury British and American Literature. Amherst, MA: University of Massachusetts Press. 2008.

Žižek, Slavoj. Less than Nothing: Hegel and the Shadow of Dialectical Materialism. New York: Verso. 2012.

. The Parallax View. Cambridge, MA: MIT Press. 2006.

Zolfagharifard, Ellie. "We've Been Drinking Alcohol for Ten Million Years:

Gene Mutation Reveals Our Primate Ancestor Enjoyed Fermented Fruit." The Daily Mail. December 1, 2014. Web. Accessed December 3, 2014.

http://www.dailymail.co.uk/sciencetech/article-2856241/We-ve-drinking-alcoholTEN-MILLION-years-study-finds.html . 


\section{APPENDIX \\ BLOTNER DISTILLED}

This appendix is offered as a tool both for ready-reference assistance for the discussions above as well as for the benefit of anyone who wishes to read as an abstracted chronicle the way alcohol played a role in Faulkner's life and the Falkner/ Faulkner family. The material is taken from Joseph Blotner, Faulkner: A Biography, Vols 1 and 2, New York: Random House, 1974. The bold-face type numerals indicate the pages from that work. The dates by month and year are taken from Blotner's dating of the chapters in which the pages appear.

In this appendix, page number designations given without brackets are the page numbers listed in the index under the topic "drinking," on pp. 237-8 of the index. Blotner's index does not use the topic heading of "alcohol" or "alcoholism." (The pagination of the "Notes" section for the two volumes is continuous in italic font across both volumes, with pp. 1-127 in the Vol. 1 and pp. 128-217 in Vol. 2. The "Chronology," "Genealogy," “Acknowledgement" and "Index" sections are found only in Vol. 2, with the "Index" contained in pp. 228-269. )

Page number designations enclosed in brackets are deemed by the dissertation author to be extremely relevant to "drinking" but which - for reasons not clear - are not listed in the index pp. 237-8 under the topic "drinking." Perhaps the omissions from the index are oversights or simple mistakes. This hypothesis is particularly likely for a large sequence of pages found to be relevant between the last listing on p. 237 of the index that referred to pp.1172-4 of the text and the first listing on p. 238 of the index that referred to 
p. 1296. Given the pre-digital (or at least crudely-digital) years when the massive Blotner biography was being subjected to typesetting and page layout, it seems entirely plausible that a line of numerals in sequence was simply ignored. Indices of those years were also prepared by human readers without powerful digital tools to search for specific vocabulary in a text.

Some omissions, however, reflect a distinct editorial stance. When Blotner uses the term "drinking" in the index, he obviously means "excessive drinking." Numerous pages that document situations of casual and moderate alcohol consumption do not appear in the index. They are included here to lend perspective. Blotner also indulges some euphemisms which can obscure the act of drinking alcohol or the states of intoxication.

Some bracketed-numeral pages merely reflect the inclusion of material that allows for cogent reading of the periscopes. That is to say, those passages introduce a situation that becomes overtly related to alcohol use, or they round-out an episode or story with a sense of symmetry.

The format for reproducing the Blotner text in this appendix offers his main text in 11-point font with the citations that support that text following immediately in 10-point font. If the citation is copied directly from the page-and-line notes, the abbreviation "Fn" for "footnote" precedes the citation as an added effort to distinguish clearly where the text ends and the supporting citations begin. This convention is provided so as to allow the reader immediate access to Blotner's sources. Those citations reproduce as exactly as is possible Blotner's own notation conventions. The first numeral indicates the page number and a second numeral, separated from the page number by a space, indicates the 
line number in Blotner's typeset text. Though the line numbers in this appendix do not match Blotner's line numbers, there arises, at most, minimal problems in associating the citation with the relevant sentences in the cited biography text. Blotner's work is exquisitely well documented by sources, although many of those sources are derived from his own interviews with Faulkner's associates as conducted in the mid-1960's and are not readily available in published form for comparison If Blotner does not provided a specific citation in the notes, the text itself usually makes it crystal clear that Blotner was the eyewitness source.

Blotner's key (pp. 1-3 in Vol. 1 and also pp. 128-130 in Vol. 2) to his notes is reproduced here to assist in the easy decoding of his system:

All materials below are quoted verbatim for educational purposes only. They constitute less than ten percent of the original publication. The dissertation author does not claim to usurp the copywrite for those quoted passages.

The numbers at each left-hand margin indicate the pages and lines to which the citations following apply. Abbreviations for Faulkner works and the editions employed (those currently most reliable) are as follows:

AA Absalom, Absalom!. New York, Random House, 1936; New York, Modem Library, J 1951.

AGB A Green Bough. New York, Harrison Smith and Robert Haas, 1933.

The Marble Faun and A Green Bough. New York, Random House, 1965.

BW Big Woods. New York, Random House, 1955.

CS Collected Stories of William Faulkner. New York, Random House, 1950.

DRM Doctor Martino and Other Stories. New York, Harrison Smith and Robert Haas, 1934.

EPP William Faulkner: Early Prose and Poetry, ed. Carvel Collins. Boston, Little, Brown, 1962.

ESP Essays, Speeches \& Public Letters by William Faulkner, ed. James B. Meriwether. New York, Random House, 1965.

$F A B \quad$ A Fable. New York, Random House, 1954 (fourth printing).

FIU Faulkner in the University, eds. Frederick L. Gwynn and Joseph L. Blotner.

Charlottesville, University of Virginia Press, 1959; New York, Vintage, 1965.

FR The Faulkner Reader. New York, Random House, 1954; New York, Modem Library, 1959 . 
FWP Faulkner at West Point, eds. Joseph L. Fant, III, and Robert Ashley. New York, Random House, 1964.

GDM Go Down, Moses and Other Stories. New York, Random House,1942. Go Down, Moses. New York, Modem Library, 1955.

HAM The Hamlet. New York, Random House, 1964 (third edition).

IID Intruder in the Dust. New York, Random House, 1948; New York, Modern Library,

1955.

KG Knight's Gambit. New York, Random House, 1949.

LIA Light in August. New York, Harrison Smith and Robert Haas, 1932; New York, Random House, 1967.

MAN The Mansion. New York. Random House. 1959; New York. Vintage. 1965.

MOS Mosquitoes. New York, Boni \& Liveright, 1927; New York, Liveright, 1955.

NOS William Faulkner: New Orleans Sketches, ed. Carvel Collins. New York, Random House, 1968.

PF The Portable Faulkner, ed. Malcolm Cowley. New York, Viking, 1946. .

PYL Pylon. New York, Harrison Smith and Robert Haas, 1935; New York, Random" . House, 1965.

REQ Requiem for a Nun. New York, Random House, 1951 (third printing).

REV The Reivers. New York, Random House, 1962; New York, Vintage, 1966.

SAN Sanctuary. New York. Random House. 1958; New York. Modern Library. 1958.

SAR Sartoris. New York, Harcourt, Brace, 1929; New York, Random House, 1956.

$S \& F \quad$ The Sound and the Fury. New York, Jonathan Cape and Harrison Smith, 1929; New

York, Random House, 1966; New York, Modern Library, 1966.

SP Soldiers' Pay. New York, Boni \& Liveright, 1926; New York, Liveright, 1954.

TMF The Marble Faun. Boston, Four Seas, 1924.

The Marble Faun and A Green Bough. New York, Random House, 1965

$T_{13}$ These 13. New York, Jonathan Cape and Harrison Smith, 1931.

TWN The Town. New York, Vintage, 1961.

UNV The Unvanquished. New York, Random House, 1938 or 1965.

WP The Wild Palms. New York, Random House, 1939; New York, Vintage, 1964.

WT The Wishing Tree. New York, Random House, 1964.

Abbreviations for other frequently cited works:

FCF The Faulkner-Cowley File: Letters and Memories.1944-1962, Malcolm Cowley. New

York, Viking, 1966.

FOM The Falkners of Mississippi: A Memoir, Murry C. Falkner. Baton Rouge, Louisiana State University Press, 1967.

LIG Lion in the Garden: Interviews with William Faulkner, 1926-1962, eds. James B.

Meriwether and Michael Millgate. New York, Random House, 1968.

MBB My Brother Bill: An Affectionate Reminiscence, John Faulkner. New York, Trident,

1963 .

MW "Man Working," 1919-1962: William Faulkner, A Catalogue of the William Faulkner

Collections at the University of Virginia, comp. Linton R. Massey. Charlottesville,

Bibliographical Society of University of Virginia, 1968.

OTF Old Times in the Faulkner Country, John B. Cullen, with Floyd C. Watkins. Chapel Hill, University of North Carolina Press, 1961.

of North Carolina Press, 1961. I889, Donald Philip Duclos. Ann Arbor, Mich., University Microfilms, 1962.

WFL William Faulkner's Library: A Catalogue, comp. Joseph Blotner. Charlottesville, University Press of Virginia, 1964. 
WFO William Faulkner of Oxford, eds. James W. Webb and A. Wigfall Green. Baton Rouge, Louisiana State University Press, 1965.

Abbreviations for frequently cited newspapers:

MCA Memphis Commercial Appeal.

MPS Memphis Press-Scimitar.

NOTP New Orleans Times-Picayune.

NYHT New York Herald Tribune.

NYT New York Times.

OXE Oxford Eagle.

$R A \quad$ Ripley Advertiser.

\begin{tabular}{lllll}
\multicolumn{2}{l}{ Abbreviations for persons: } & & \\
WF & William Faulkner & & JB & Joseph Blotner \\
EF & Estelle Faulkner & BC & \multicolumn{2}{l}{ Bennett Cerf } \\
JFS & Jill Faulkner Summers & SC & \multicolumn{2}{l}{ Saxe Commins } \\
JMP & James M. Faulkner & & MC & Malcolm Cowley \\
MCF & Murry C. Falkner (Jr.) & & AE & Albert Erskine \\
SMW & Sallie Murry Williams & & MG & Morton Goldman \\
RKH & Robert K. Haas & HS & Harrison Smith \\
EJ & Else Jonsson & & BW & Ben Wasson \\
DSK & Donald S. Kloppfer & & JW & Joan Williams \\
HO & Harold Ober & & &
\end{tabular}

Abbreviations for repositories:

ACLT Academic Center Library, University of Texas at Austin.

FCVA William Faulkner Collections, University of Virginia Library. Unless otherwise noted, letters from Faulkner to Anne Louise Davis, Morton Goldman, William Herndon, Horace

Liveright, Harold Ober, Dorothy Olding, Harrison Smith, Ivan von Auw, Jr., Ben Wasson, and Joan Williams are in these collections, as well as letters from any of the above to Faulkner and to others. The collections also include all unpublished class conferences at the University of Virginia.

JFSA Jill Faulkner Summers Private Archive. This includes the Faulkner materials discovered at Rowan Oak in 1971 by Prof. James W. Webb; also Faulkner's report cards, pilot's log (all information on his flying in private aircraft comes from this source unless otherwise noted), passports, various letters, drawings, and the like, and the Greenfield Farm commissary ledger and studbook.

MCL Materials of the late Mrs. WaIter B. McLean, courtesy Mrs. Norman N. Thompson.

MCUM Mississippi Collection, University of Mississippi.

NYPL New York Public Library, Astor, Lenox, and Tilden Foundations.

PUL Princeton University Library.

RH Random House. Unless otherwise noted, letters from Faulkner to Bennett Cerf, Saxe Commins, Albert Erskine, Robert Haas, Donald Klopfer, and Robert Linscott are from this source; also letters from any of the above to Faulkner and to others.

YUL Yale University Library.

Each citation of these sources in the Notes is made with the grateful thanks of the author to these people and institutions. Where no repository is listed for Faulkner's letters to persons not mentioned above, the recipients themselves are the sources, and their help is again acknowledged with grateful thanks. 
Other abbreviations:

comp. compiled.

I interview, followed by the name of the person interviewed and the date. E.g., I: BC, 7

Oct. 1965.

recd. received.

repr.. reprinted.

Most chapter epigraphs are from novels and are so identified. Chapter epigraphs from short stories reprinted in Collected Stories are not identified in the Notes. All epigraphs drawn from other sources are footnoted herein.

Faulkner's abbreviations, conventions of punctuation and capitalization, spellings, and misspellings are reprinted without change. Thus [sic] is not used except where confusion might otherwise arise.

All quotations from Faulkner's published and unpublished writings are made through the kind and gracious permission of Jill Faulkner Summers.

Each note refers to the sentence in the text ending on the line specified in the column at left. When two sentences end on the same line, the note will be introduced by the quotation of the last word from the relevant sentence. On pages bearing epigraphs, the line count will begin with the last line of the epigraph.

\section{MAY, 1865 - DECEMBER, 1885}

\section{4}

With his family settled in a temporary home, Colonel William C. Falkner turned to public benefaction. He deeded a block of land to the Ripley Female Academy-one of the casualties of General A. J. Smith's visit-and probably contributed to the fund which permitted it to reopen in 1867 as Stonewall College. To celebrate the occasion he set to work on a play. According to one source, he usually did his writing at night in his Office, "with his faithful body servant Nathan to whisk the flies and supply him with the bourbon whisky which he consumed in large amounts." Sometimes he would work until past midnight, "and then, to relax his mind and body for sleep, frequently bowled for half an hour or so on the alley he had set up in his front yard, with Nathan as pin boy."

Fn 3313 Coughlin p. 36.

\section{FEBRUARY. 1890 - EARLY 1897}

\section{$[55]$ and 56-7}

But Falkner had time in his life for more than business, and the whole family was active. There was an intensive round of church activities in this Methodist household, varied in summer at the Oxford Camp Ground, a few miles out of town, where religion and vacation were combined. On platforms built a few feet above the ground to discourage snakes and other unwelcome visitors, the families would erect their tents. In some cases these were more like cottages. As chairman of the committee for beautifying the Camp Ground, J. W. T. Falkner took his responsibilities seriously, exhorting others to help with the work and trying to set an example himself.

When the Camp Meeting season was over, the men would take to the woods again, as when the Eagle noted that J. W. T. Falkner, his son Murry, three companions, and a cook "left 
yesterday morning for the mouth of Tippah to give the squirrels, turkeys and fish trouble." On other occasions the men would go west to the Delta for an extended stay to hunt deer, bear, and other game. Besides the game there was the fellowship of the camp and hunt, enhanced by good whiskey. Although Oxford was not as much of a temperance town as Ripley, there was no social drinking in mixed company, and any drinking a husband did with his cronies would have to be tempered in the light of its reception at home, particularly if his spouse were an ardent temperance worker like Sallie Murry Falkner. There were times when the Young Colonel's drinking became more than social and required extreme measures.

Sallie Murry Falkner may have read Dr. Leslie E. Keeley's major work, The NonHeredity of Inebriety, published in 1896, which held that drinking was a disease rather than a vice. Whether she did or not, it seems likely that she was the main force behind J. W. T. Falkner's trips to the Keeley Institute located in Memphis when he went on one of his periodic, nearlegendary drinking bouts. The sufferer would be injected with the solution of double chloride of gold which, according to Dr. Keeley, produced "the sudden disrelish of the patient for his whisky." Skeptics asserted that relapses were frequent, though Dr. Keeley claimed that the rate was only about five percent. It was an indisputable fact that J. W. T. Falkner was among that five (or more) percent. But that did not deter his wife (or later his daughter-in-law) from seeing to it that he returned to the institute whenever he had fallen again.

Fn 536 OXE, 16 Aug. 1894. S6 2 OXE, 11 Oct. 1894. 56, 14 "In 1891, Keeley had organized a company to administer this cure to sufferers in various parts of the country. By 1895, there were 359 chapters of the Keeley League claiming 30,000 members; “all of the men members were cured patients but in the women's auxiliary leagues many of the members were temperance workers. Dictionary of American Biography, X, p. 280.” p. 30 of V. 1.

\section{SEPTEMBER, 1902-AUGUST, 1905}

\section{9}

Murry Falkner was settling down to his new life and career slowly and with difficulty. Like his father, he appreciated the solace of good whiskey, and he availed himself of it in this period following his uprooting from Ripley and the railroad. Sometimes he would not be able to contain himself. He would think about the beckoning West, about prairies and cattle, and he would storm and shout.

Fn 79, FOM, pp. 9-10.

90

In spite of his temper, Murry Falkner tended to be an easy-going man most of the time. When he drank, of course, it was a different matter. In her anxiety about her husband, Maud sometimes overdid it. She seemed uneasy about what he might do when she was not at his side. This was one reason why she went to the Club House on occasions when Murry Falkner could have gone there with his boys, an outing for males only. What a shame, Faulkner would later say, that Mr. Murry and the boys couldn't have gone there to hunt by themselves.

Fn 9030 I: EF, 12 Feb. 1965.

\section{SEPTEMBER, 1905 - SEPTEMBER, 1908}

\section{8-100}

It was not surprising that from time to time Grandfather should take solace from the whiskey he kept in the barn. The trouble was, of course, that often he could not content himself with a few stiff drinks or even a twenty-four-hour release. Instead, the drinking might go on for 
three or four days. He was by no means alone in this behavior pattern, for "liquor was an accepted way of life as far as many of the menfolk were concerned. Few women would touch it on pain of certain and universal condemnation by the community. This did not mean that men were taught to indulge in it, any more than they were instructed to rise when a lady entered a room, to lie only when it would be of great value to another, or to take pride in their family and their country. These things-the drinking, the code of personal conduct and philosophy of life-were simply passed on from generation to generation by manners and deportment, no succeeding one having sought or found B more agreeable way to live with his fellows."

This transmission had clearly taken place in the case of Murry Falkner, and quite early. During his relatively brief tenure as a university student he had been known for sprees in which he would gallop a fast horse around the campus. Now he continued to drink-and sometimes to ride off the after-effects-but without the dash of his student days. Sometimes normal withdrawal would not work, and he would have to follow in J. W. T. Falkner's footsteps in another way. He would be taken to the Keeley Institute, fifteen miles from Memphis, for the salubrious effects of the Cure. The fastest route Was via the Illinois Central Railroad-for which J. W. T. Falkner and G. D. Shands were local attorneys. Although J. W. T. Falkner would not take the train-he would have his bags packed and Ned Barnett would drive him in the carriage-this was the conveyance that Murry Falkner would use.

Maud Falkner detested whiskey. She could not understand what made her husband drink it to excess, and she was terrified of the results. But it was she who had to see that her husband got to the institute when he reached that certain state, and it was she who had to stay-or felt she had to stay-outside Memphis until he was ready to return to Oxford, debilitated, yet dried out and sober. In spite of having Mammy Callie at home, Maud Butler felt better having her children along with her. So, on more than one occasion, Billy, Jack, and Johncy Falkner went along with their diminutive mother when Father was transported to Memphis. Perhaps she hoped that this would be an object lesson for them. Actually, they were much more impressed by the facilities for fun during their stay at the institute. They were allowed to ride by themselves, so long as they promised not to get off, on the four-wheeled, open-vestibule streetcar that traveled from the Cure to Memphis and back. For the first thirty minutes they would travel through the changing rural countryside, but soon, moving along at the rate of eight or nine miles per hour, they would reach "the immense and wonderful city itself ... Large, imposing residences lined each street. ... "But there was even more, for "John it was who, one never-to-be-forgotten day, happened to glance across the aisle and happily announce a sight that held us spellbound. It was a fleeting glimpse of the Mississippi River. We all stood up to get a better view and what we saw almost stunned us with' excitement. ·. It was the first time we had ever seen a boat, or water deep enough to support one." Finally, the course of treatment would come to an end and the Falkner family would board the train for Holly Springs, Oxford, and home, leaving the wonders of Memphis behind.

Disrupting though it was, Murry Falkner's fondness for whiskey gave him an insight denied the other members of his immediate family. He displayed it on the occasion of the visit of Aunt Willie Medora from Ripley. She had come by train, shipping her luggage in the coach and carrying only her handbag. When she was in the buggy on her way to the Falkner home, she found that her grips had by mistake gone on to Water Valley. Murry Falkner immediately called the station to wire ahead and have them taken off the train and shipped back to Oxford. She said she didn't mind the inconvenience. The only thing was, she did have her medicine in her luggage and she was supposed to take it faithfully. It was Peruna, she confided to Maud Falkner, a preparation for female ills. When Murry Falkner came home from work that evening, he found that the luggage had not yet arrived and that Aunt Willie was nervous, irritable, and displayed a slight but noticeable tremor. Murry Falkner called his wife into the next room. "For God's sake, Maud," he said in a gruff whisper, "take Aunt Willie upstairs and give her a couple of shots of my whiskey!" Dedicated opponent of the Demon Rum though she was, Maud Falkner took the 
sufferer upstairs and did as her husband suggested. The symptoms disappeared, and later that evening the luggage arrived.

Fn 996 FOM, p. 47. 9910 Ibid., P.48. 9916 OXE, 15 Mar. 1905. 100, 4 FOM, pp. 46-7. 100, 25 WF to JB.

\section{OCTOBER, 1908 - DECEMBER, 1910}

\section{4}

[J.W.T.] Falkner seems always to have considered it his bank and no one else's. On one occasion, returning late with several cronies from Jackson, he descended from the train and ushered his guests into the car. All were by now both high-spirited and tipsy. Falkner ordered Chess not to drive to the respective homes but to circle the dark and deserted Square for a while. As they approached the bank on one of their circuits, the Colonel ordered Chess to stop and fetch him the brick he saw lying by the board walk. That done, he ordered Chess to drive slowly by the bank. Steadying himself, he faced the shiny plate-glass window of the First National Bank of Oxford. To the encouragement of his fellow revelers, he drew back his arm, took deliberate aim, and let fly with the brick. The car passed, and there was the resounding smash as the big pane was shivered into splinters. Later that night one of his friends asked him why he had done it. Buoyed up by still more bourbon he replied, "It was my Buick, my brick, and my bank."

Fn 13415 FOM, pp. 67-8.

\section{SUMMER, 1914 - APRIL, 1918}

\section{9-80}

Later he recalled that job in a jocose way. "Quit school and went to work in Grandfather's bank," he said. "Learned the medicinal value of his liquor. Grandfather thought it was the janitor. Hard on the janitor." He had known the taste of liquor since the time when Grandfather had let him drink the "heeltaps" in his glass that remained of his toddies. Now on the hunts the boy sometimes drank the powerful corn potion made by stills concealed in the hills and pine barrens. With Grandfather's private store he had a chance to drink very good whiskey indeed. And he drank it for more than just the taste and feeling of well-being. He found himself in a situation he detested yet from which he could not escape. Liquor apparently made it easier to bear. He did not confine himself to secretive nips at the bank, however.

At eighteen, Bill Falkner began to be seen with well-known drinking companions. One was "the town drunk," a harmless, amiable man named Charlie Crouch. The association gave rise to situations that amused Jack and Johncy Falkner, though they could scarcely have given any pleasure to Maud Falkner or her husband. On one occasion Bill had met Charlie and begun to drink with him. They warmed up to the task, and Bill did not come home that night. "The next morning when Jack and I were on our way to school," wrote Johncy, "we met him coming home. He was in a foul humor and had on Charlie's hat. They had swapped during the night." Bill's hat was narrow-brimmed, selected especially to go with a highly prized suit of the latest mode.

"Charlie always wore a sort of a cowboy hat, a black one with the crown creased fore and aft and a big wide brim. Bill sure looked funny in that suit and Charlie's cowboy hat. Jack and I stepped off the walk and bowed as he passed. Without looking at us he said, 'God damn it!'”

Fn 17930 Marshall J. Smith, "Faulkner of Mississippi," The Bookman, 74 (Dec. 1931), p. 416.18014 $M B B$, pp. 132-3.

\section{APRIL - DECEMBER, 1918}


Hinchley [a colleague cadet in the Canadian RAF training - Author] remembered Faulkner as having "a wealth of unprintable Limericks which he recited frequently in his delightful Southern accent." He also liked to drink, and the noise which came from Faulkner's room on some occasions when Hinchley wanted to sleep did not seem to him so amusing.

Despite the uncertain mustache, Cadet Faulkner of Wycliffe College was still recognizable as William Falkner of Oxford. At the same time, however, he gave signs of constructing a persona that apparently pleased him a good deal better than his own identity five months before. "1 always had the idea that he had been a student at Yale," Hinchley recalled, though he was not sure how or when he had received that impression. The amiable Monson [another cadet in training] felt sometimes that Faulkner might be assuming an air of confidence he did not actually feel, that he might be overcompensating for his ' shortness or his generally unimpressive appearance. On one occasion, after using his monthly check from home to provide drinks for himself and his roommates, he was seen out on Hoskin Avenue, conducting a one-man drill on the sidewalk, calling out commands loudly and then executing them smartly. He seemed to be in the process of building a new exterior for himself. There were few clues beyond the occasional letters home to what was going on in the interior.

Fn 215, 11 Millgate, “Faulkner in Toronto," pp. 198-9 215, 29 ibid.

\section{4-5 and [226]}

"The war quit on us before we could do anything about it," he told Jack the following spring. "The same day they lined up the whole class, thanked us warmly for whatever it was they figured we had done to deserve it, and announced that we would be discharged the next day, which meant that we had the afternoon to celebrate the armistice and some airplanes to use in doing it. I took up a rotary-motored Spad with a crock of bourbon in the cockpit, gave diligent attention to both, and executed some reasonably adroit chandelles, an Immelman or two, and part of what could easily have turned out to be a nearly perfect loop."

"What do you mean --- part of a loop?" his brother asked.

Bill laughed. "That's what it was; a hangar got in the way and I flew through the roof and ended up hanging on the rafters." He had to climb down on one of the hangar support poles, he said.

John Falkner's recollection was that his brother "had flown his Camel halfway through the top of a hangar. The tail of his ship was still outside and they got Bill down from inside the hangar with a ladder." When he got home to Oxford, John recalled, he still had a limp as a souvenir of the accident. A long time later Bill Faulkner would tell his stepson, Malcolm Franklin, that he got his broken nose "honestly by landing upside down .... "To Phil Stone he gave a happier version. He had taken a companion up with him, and after the crash they felt well enough to apply themselves to the bottle again. "Funniest thing you ever saw," a bystander was reported to have said, "the two of them hanging there trying to drink from a bottle upside down." Nearly a dozen years after the event, Faulkner would produce a written and amplified account:

War came. Liked British uniform. Got commission R.F.C., pilot.

Crashed. Cost British gov't 2000 pounds. Was still pilot.

Crashed. Cost British gov't 2000 pounds.

Quit. Cost British gov't \$84.30. King said, "Well done."

These stories of a gradually mushrooming catastrophe call into question the credibility of some of the accounts Cadet Faulkner had written home to his loving mother. One was the possibility that he could be graduated from ground school two days after such a spectacular disaster. Another was that he should ever be allowed near another military aircraft in the wake of such damage to government equipment, installations, and personnel. Another unlikelihood was 
that it should have escaped the notice of his fellow cadets, the inscribers of official records, and the newspapers. There was never any awareness of such an event in any of these quarters. The crash Faulkner described would have been a dramatic though ludicrous close to a brief and finally disappointing military career. The creative imagination had apparently made up the deficiencies of reality. It seems clear, then, that Cadet Faulkner did not crash. Did he ever fly?

Fn FOM, pp. 90-1. 2258 MBB, pp. 138-9. 22510 I: Malcolm Franklin, 26 Sept. 1966. 22514 Phil Stone to Robert Coughlan, 1953; I: Coughlan, 17 Nov. 1965. 2264 See contributors' column, Forum, LXXXIII (Apr. 1930), p. lvi. 22613 Millgate, "William Faulkner, Cadet," p. 125; "Faulkner inToronto," p. 198.

\section{DECEMBER, 1918 - SEPTEMBER, 1919}

\section{[236] and 237-8}

Sometimes Faulkner would drift over to Clarksdale by himself. Once he arrived when Dot and Reno, Willie Mays and his wife, and a group of other friends were going to New Orleans. They asked him if he wanted to go along.

"Yes," he said, "but I've only got fifty cents in my pocket."

"That's all right," Reno said. "Come on along. I'll take care of it." The party went by train, drinking and enjoying themselves on the way. They would stay at the Roosevelt in New Orleans, Reno decided, and have dinner in the hotel's stylish Blue Room.

After they checked in, Faulkner said he was going to see a friend. It had begun to rain, and when he returned, some time later, what had been an unprepossessing set of garments now appeared completely disreputable. Reno looked at him.

"Come on with me," he said. "You can't go to the Blue Room looking like that." When they returned to the hotel a little later, the old clothes were ina box under Faulkner's arm. Reno had bought him a new outfit. Faulkner opened the box to hang up his traveling ensemble, but Dot intervened before he could begin.

"Here," she said, "you don't want those old clothes any more." With that she threw them out one of the windows. Still in high spirits, they were preparing to go down to dinner when they were stopped by a knock at the door. Two policemen had come to investigate the shower of old clothes onto Baronne Street.

Reno, .who was an expert at mollifying policemen, tried to explain that it was just a harmless joke. As he talked, the officers began to check the room, opening drawers and closets. One of the party was an agreeable and sizable young man from Pocahontas, Mississippi, named Walter Lee Bates. He was still legally a member of the United States Army and had ridden the train in his private's uniform. He felt, however, that he could not lower the tone of the group during the evening and had brought along a tuxedo, which he now wore. One of the policemen found in the closet the drab khaki tunic, breeches, and puttees which Walter Lee should have been wearing. He turned to the merrymakers.

"Who owns this uniform?" he asked.

For the moment Reno found himself without an answer. Walter Lee stood there, immobile in his satin-lapeled [sic] dinner jacket. Bill Faulkner spoke.

"I do," he told the policemen. Neither Reno nor Dot was prepared for this sudden volunteering of information. Faulkner's afternoon had been a convivial one. His own momentum matched that of the party, and now he had apparently decided in a spirit of camaraderie to offer himself as some sort of sacrifice for his friend. The police could arrest him for giving them misinformation, but at least Walter Lee would have a chance of avoiding trouble with the M.P.'s and the army. But there was one immediate problem. Walter Lee weighed a good 170 pounds, and notorious though army quartermasters were, one could not conceivably have issued a uniform of this size to the slight man who had just claimed ownership of it. There were more annoyed questions from the police followed by a good deal of conversation. Reno recovered his aplomb, 
and after more protestations of innocence and good will, he persuaded the police to join him and the others in a drink and forget the whole business. When they had finished their drink they were seen to the elevator, in courtly fashion, by William Faulkner. There was now no impediment to the celebration in the Blue Room and the rest of their brief stay in New Orleans.

Walter Lee Bates remembered Bill Faulkner's effort to help him. Not long afterwards he was discharged from the army, and they would see each other from time to time in Clarksdale, sometimes at Dot's home. He was now making a comfortable living transporting and supplying liquor without benefit of the blessing of state and federal agencies. (He would make an even better living a year hence when national prohibition went into effect.) He was a lively companion but not, his friends insisted, ever rowdy. Occasionally, he liked to try his hand at the manufacture, as well as the transportation and sale, of hard liquor. Dot Wilcox's backyard, enclosed by a sevenfoot board fence, struck him as a perfect place to carry out one of these efforts. He found a ready assistant in Bill Faulkner. Together they suspended a five-gallon jug up in a tree. It was full of spirits which needed further processing. Through a hole in the stoppered neck of the jug, they ran a strand of wool yarn down to a five-gallon crock on a platform close to the ground. In the crock was a quantity of charcoal which was meant to purify the liquor after it had made its way out of the jug and down the yam. Walter Lee and Bill kept checking frequently to see how the run was coming, dipping samples out of the crock to test the quality. From time to time Dot would come out with snacks. Deviled eggs were one of Bill's favorites. On one of her trips out to check on her two guests he said to her, "Put some devil in those eggs, Dot." Eventually, she found Bill Faulkner asleep on the floor of her quiet, latticed back porch, a pillow under his head.

It was a foot-loose life-Charleston, Clarksdale, New Orleans, Memphis-with the only limits imposed by what he could afford. He did not want for much. The trench coat he had brought home from Canada was more than enough protection against Mississippi weather, and the pockets were capacious enough for a bottle of whiskey, a book or two, and whatever other items he wanted to carry.

Fn 23728 I: Dorothy Conkling, 16 Mar. 1965. 23813 Ibid.

\section{MAY, 1920-NOVEMBER, 1920}

\section{5}

By the fall of 1920 Lee Russell was ready to carry out his plan. Every month, he would visit each of the institutions in his capacity as president of the university board of trustees. The faculty was divided. Russell had told the student body at Ole Miss that it was too high-toned to engage in conduct that would bring discredit upon the school. And now, zealous as a Roundhead stamping out Cavalier excesses, he meant to see that this was true. The Puritanical aura was conspicuous already in some state schools. In January the faculty of Mississippi State College had banned smoking by the student body anywhere except in private, but there were other things going on at Ole Miss besides tobacco smoking. There were dances and parties and long weekends which saw drinking and a lot more.

Fn 28513 Betts, p. 9. 28517 The Mississippian, 14 Jan. 1920.

\section{AUTUMN, 1920 - AUTUMN, 1921}

\section{$[292]$}

If people like the campus wits saw Faulkner as an object of satire, some of his friends had feelings of concern. Dot Wilcox would see him with mismatched shoes, with the elbows out of his coat. Sometimes, she thought, he looked pathetic --- trampy and raggedy-looking. (Katrina Carter saw him waiting to change trains at Holly Springs barefooted-the same young man Myrtle 
Ramey had seen strolling down to the Square adorned with pocket handkerchief, cane, and spats.) And he drank a good deal. He carried his whiskey well, so one could hardly tell that he was feeling it except that he would get just a little thick-tongued.

'Bill," Dot would say, "why do you want to go around looking like that? Don't you want to make something out of yourself?"

"All I want to do is write," he would reply quietly. He was amused at her concern about his appearance. "Who knows, someday you may see a headline in the newspapers, 'Tramp Becomes Famous."'

At times, however, he would surprise her. One day he telephoned. "Put on your best bib and tucker," he said. "I'm going to take you up to the Moon Lake Club. We'll crash the party." She was ready when he arrived (that evening, waiting for him in a white evening dress beaded with gold, wearing her gold evening slippers. They had no trouble getting into the party, and they had a good time, though Faulkner was quiet as usual and danced little. It was nearly three o'clock in the morning by the time they left. Their return along the dark roads was uneventful until suddenly one of the wheels spun off the axle. The car swerved but Faulkner fought it to a stop in a cotton patch. He descended and walked through the mud to the nearest cabin. There he roused a Negro who fetched his team and dragged the car through the mud of the cotton patch and back onto the road. They put the wheel back on and finally Faulkner delivered Dot to the door of her home, safe but wearing golden slippers covered with mud.

Fn 2935 I: Dorothy Conkling, 16 Mar. 1965.

\section{3-4}

There was no question about Bill Faulkner's fondness for liquor. He could not afford the brand he found in the Colonel's stock when he worked in the bank, so now he took what he could get, including the powerful "white mule" made by county moon shiners. When he couldn't afford that, there were other Sources. An enterprising young man from the county named Edison Avent, another kinsman of T. W. Avent, had moved into town to improve his position in the world. He was a quiet youth with large eyes, a wide, thin mouth, and a nose that looked like the beak of some predatory bird. "He started out with nothing," one observer remarked, "and got rich by being the sharpest horse trader for miles around." At this time he was working as a pharmacist in Dr. Bramlett's drugstore. "He tried to promote some dances to make him some money," Faulkner recalled later. "He asked me to help him .... So I'd go by the drugstore in the afternoon and drink Edison's or Dr. Bramlett's prescription alcohol, and talk about the dance. After a week or so of that, then I wouldn't help Edison with his dance." He had of course come by his taste and his capacity naturally. But there were obviously other factors at work besides heredity and conditioning. In his verse he had often imitated Verlaine and Swinburne, neither noted for abstemiousness. And Swinburne-like Verlaine and Rimbaud-had been influenced by the gifted and rather sinister Charles Baudelaire, the poet whose work, in books such as Les Fleurs du Mal, had created what Victor Hugo called "a new shudder." Baudelaire courted the muse in any way he could. Toward the end of his life his addiction to both liquor and drugs was notorious. Faulkner was playing the bohemian poet as he experimented with verse forms and images. It is not unlikely that he was Interested in experimenting with the preverbal portion of the creative process, too. And for a man who liked liquor anyway, it would provide a pleasant form of experimentation.

Murry Falkner could certainly understand a man's drinking, and probably the impulse toward vagabondage and the avoidance of work, too. But when you put it all together-the drinking, the roaming, the often seedy appearance, plus the assertion that he was going to be a poet-it didn't add up to much for a man already twenty-three years old. Murry Falkner was working hard at his job, and he expected his sons to do the same. And it. was difficult for him to credit some of the things Billy's friend Phil Stone was difficult for him. 
see one."

"Mr. Murry," he said, "I'm not a writer, I never will be a writer, but I know one when I

Fn 29413 Phillip E. Mullen, Osceola (Ark.) Times, 22 Dec. 1966. 29435 I: Emily Stone, 27 Mar. 1965. 29439 I: Robert Coughlan, 24 Feb. 1967.

\section{4-5}

Faulkner apparently enjoyed these trips and this brief immersion in such an alien atmosphere. For one so much a spectator and increasingly fascinated by human behavior, it was an admirable opportunity to watch, and to speculate. He had always been interested in strange, out-of-the-ordinary people, and there were plenty of them here. For another thing, there was a greater variety of whiskey in Memphis. So it was a pleasant change for him to visit one of the brownstones on Mulberry or Gayoso with his friend, whether he went upstairs or Just sat downstairs in the parlor, listening quietly and putting in an amiable word now and then.

Faulkner rarely gambled, but he was not impervious to temptation. Onone occasion, he seems to have embraced it almost fatalistically. He returned one noontime to the room he and Jack were sharing at the Peabody and asked Jack if he had any money left. Jack knew that when his brother had gone out earlier he had close to one hundred dollars with him. He also knew that since then Bill had been drinking. Jack told him he had about twenty dollars. Bill said he would like to borrow it. When Jack gave it to him, he walked to the door and then stopped and turned. As though he felt Jack was entitled to some sort of explanation, he told him he had lost his money in a crap game-in about fifteen minutes, as a matter of fact. When he admitted that he was going back to the same game, Jack asked him if he thought this twenty would go the way of the others.

"It probably will," he said. "But I've got to go back."

To Jack's surprise, Bill asked him if he wanted to go along. As they walked under the hot midday sun, Jack tried to point out the folly of throwing good money after bad. Bill paid no attention as they made their way up North Main Street. Finally he climbed the steps of a shabby, rundown brownstone and knocked on the door.

The door was opened by a "seedy looking character" who silently admitted them. Closing the door, he picked up a jug of clear com liquor, lifted it, and drank. Jack watched him, shuddering inwardly. Then the manwiped his forehead, staring straight ahead at the cracking plaster of the wall. "Aah-aah," he said. "Eeyie!"

Bill took the jug from the man's seemingly nerveless grasp and passed it to Jack. Lifting it, Jack wondered "as I always did how a man could bring himself to partake of something so murderous to the taste and so repellent to the smell." Next Bill helped himself. Then he looked at the owner of the jug, who simply pointed to the room above. "Follow me, Bill said, and preceded Jack up two rickety flights of stairs. They entered a large, bare room in which only one window was raised against the oppressive heat. The silent players stood about a large table covered with a white sheet. As one grasped the dice, Bill stepped into the circle.

Fn 30524 FOM, pp. 107-11; I: MCF, 31Mar. 1965.

\section{DECEMBER, 1921 - SEPTEMBER, 1924}

One Saturday afternoon during that winter of 1921, James K. Feibleman, a seventeenyear-old would-be poet, decided the time had come. He dressed carefully and then, his poems under his arm, set out for the offices of The Double Dealer. These were located in an old, nearly deserted building owned by Julius Friend's uncle, Sam Weis, in New Orleans' business district but near to the French Quarter. Feibleman climbed the three flights of stairs leading to the rent-free loft which sheltered the editors and their stream of guests. He was admitted to the large room and 
sat down quietly to listen. About fifteen men-mostly writers, he thought-were drinking whiskey and talking. He noticed another man as quiet as himself, who was sitting on the floor in one comer in spite of an empty chair quite near him. He was "a little man with a well-shaped head, a small moustache and a slightly receding chin." He had a bottle of whiskey, "which he held near his head and tipped into his mouth from time to time." Watching this process, Feibleman "had the impression more of nursing than of drinking." Finally the conversation turned to Shakespeare and to Hamlet. It was only then that the little man in the comer spoke.

"I could write a play like Hamlet if I wanted to," he said, and then lapsed back into silence. Later Feibleman found out his name from one of the others. Mulling the experience over, Feibleman decided that though he could not tell which of the aspirants would become a great writer, he could be sure which one wouldn't. Without question it was William Faulkner, the small, silent man who sat drinking whiskey in the corner of the large, bare room.

Fn 3028 James K. Feibleman, "Literary New Orleans Between World Wars," The Southern Review, I, N.S. (July 1965), pp. 705-6.

\section{7-8}

"Wait for me," he told them, "I have to go in the house for a minute." He emerged soon, his shirt front bulging, and got into the back seat of Farley's car. As they drove away Faulkner produced from under his shirt a bottle of "white lightning" and a single glass. This came as no surprise to Farley. If Faulkner didn't enter into conversations at the post office, said a friend, he didn't miss a word-or a drink. "There is no such thing as bad whiskey," Faulkner declared, "some are just better than others." So now, as Murry Falkner began to drink less-substituting pleasures such as racing one of the daily trains to the bridge in his red Buick-his son began to drink more.

It was a hot July day. Faulkner, Farley, and Wills began to drink, turn and turn about, working their way through the bottle of corn liquor which "burnt going down and kicked like a mule." The tenor of the conversation changed and deepened as Faulkner began to discuss philosophies of religion. Asked about his beliefs, Wills said he was not much of a Christian.

"If you could be anything you want to," he asked Faulkner, "what would you rather be?"

"A lay reader in the Episcopal Church," Faulkner answered.

"Oh," Wills said. "You're a real Christian. You want to go to heaven."

"Certainly," Faulkner said solemnly.

"You want to be an angel. What would you do until you got to be a full-fledged angel?"

"I'd manicure the wings of the other angels, do what I could."

"That's no goal!" Wills said derisively.

Faulkner clapped him on the back. "My boy," he told him, "you don't have the true Rotary spirit."

As the afternoon drifted away they began to feel dehydrated. Farley drove to the golf course, where they went to the stand Ned Beanland kept. Nearby stood Oliver Abbott Shaw, dean of the school of education, ready to tee off. Suddenly Wills ran out, seized the driver from the astonished ball, and returned to hand both the ball and club to Shaw. Farley just stood there. Shaw's partner, Judge Thomas Charles Kimbrough, dean of the law school came Over. "Who is that fellow?" he asked Farley. "I don't know, Judge," the young lawyer about to go into practice answered, "just some fellow who came over here with Bill Faulkner." When they managed to return to the car, Farley declared he had had enough. He wanted to go home, but Faulkner and Wills demurred. They wanted to finish the bottle. Finally Farley let them out at the Colonial Hotel, where Wills was staying. Wills would be stuck with Faulkner all night, he thought to himself. This was usually what happened now that the drinking had become such a serious pastime with Faulkner. Farley drove home. The next morning Wills returned to Memphis and Faulkner reported for another day at the post office. 
Fn 3579 I: Robert Farley, 3 Apr. 1965. 357 II I: Branham Hume, 23 Nov.1965. 57 14 I: A. P. Hudson, 4 Apr. 1965. 35717 T. Ashby Woodson, M.D., to : JB, 17 Mar. 1966. 35810 I: Robert Farley, 3 Apr. 1965. As far as Rotary in Oxford 3 was concerned, WF was anticipating a bit. The club would be organized in November. I: William Reed, 14Nov. 1966.

\section{JANUARY - JUNE,1925}

\section{7-8}

Faulkner enjoyed giving the impression that his experience with bootleggers was considerable evidence of the brisk liquor trade abounded in the Quarter, in spite of prohibition. Joe Cassio's grocery store, at the comer of St. Peter and Royal streets, rang up many of its sales on Scotch, bourbon, and gin. The same was true in the grocery of Manuel and Teresa, directly across the street. The customer could not always be sure, however, that the bottles' contents corresponded exactly with the labels. It was commonly supposed that Cuban alcohol served as a base; it was readily available. "You would go fishing and come back with a five-gallon can," Keith Temple remembered. "A speedboat would have brought the alcohol to the marshes, and all you would have to do would be to rent a skiff from a fisherman to get to the marshes. You would pay him for the skiff and the alcohol." Then it would be processed, with the addition of iodine for bourbon, creosote for Scotch, and juniper-berry juice for gin. Faulkner doubtless knew as much as his friends did about this traffic, and it appealed to his imagination. Soon he began to use it as an adjunct to an early' persona-that of the writer who had bummed around doing a little of everything, partly because he needed, to earn a little money and partly because he enjoyed seeing the variety of life. Until the end of his life he would talk about rumrunning with considerable amusement. "I ran a launch," he would say, "from New Orleans across Pontchartrain down the Industrial Canal out into the Gulf where the schooner from Cuba would bring the raw alcohol and bury it on a sand-spit and we'd dig it up and bring it back to the bootlegger and his mother -- she was an Italian, she was a nice little old lady, and she was the expert, she would tum it into Scotch with a little creosote, and bourbon. We had the labels, the bottles, everything - it was quite a business."

Twenty years later Faulkner would talk of being hijacked, of seeing a crewman murdered. One of his friends would hear that he had also flown whiskey into the United States from Canada. Faulkner told his brother Jack that he had made one trip with some bootleggers who went from New Orleans to a place on the Mississippi coast to pick up a shipment. Bill Spratling said his friend had no more run alcohol for bootleggers than he had delivered liquor to a writer who gave him one-dollar tips, as he had once declared.

Fn 42713 I: Mrs. Louis Andrews Fischer, 2 Feb. 1965; Flo Field, 3 Feb. 1965; Hermann Deutsch, 2 Feb. 1965. Deutsch, 2 Feb. 1965. 42734 FIU, p. 21. For a semifictional account, see EPP, pp. 28-9. 42736 I: Robert Coughlan, 24 Feb. 1967. Cf. Once Aboard the Lugger, below. 42737 I: George Healy, Jr., 4 Feb. 1965. 428 1 I: MCF, 31 Mar. 1965. 4284 I: William Spratling, 28 Jan. 1965.

\section{JUNE, 1926 - JUNE, 1927}

\section{4-5}

He moved back into the attic apartment with Bill Spratling. Little had changed apart from the fact that Sherwood Anderson-now at his farm in Virginia and soon to leave for Europe-no longer occupied the same place in their lives. The Quarter was as lively as ever, with parties four or five nights a week, often at Spratling's or Lyle Saxon's, with everyone talking, smoking, and dipping drinks out of whatever liquid filled the big bowl on the table. A Swiss living in the Quarter made pernod. He would bottle it, affix his own labels, and then sell it for six dollars. They would pour it into a pitcher of crushed ice and add a little water. For other parties Spratling 
and Faulkner would make their own gin, using gallon cans of alcohol. They would put it in a barrel and, to aerate it, would roll it across the floor until the tenants below complained. On Sundays they might enjoy the hospitality of a well-known figure of the Quarter, a man called Baron Hanno von Schucking, who had enjoyed a romantic relationship, it was said, with a wealthy and generous woman. They would go to the Baron's apartment for Sunday breakfast preparatory to setting out for a picnic. After breakfast they would have a drink and drift into lunch. Then, after another drink, they would forget about the picnic.

For rainy days there was a diversion which did not even require leaving the attic apartment. They would take down a Daisy air rifle from the wall and open one of the windows that overlooked St. Peter Street. Unseen, they would aim at passers-by, the buttocks their usual target. A point list on the wall was graded for various targets. An ordinary citizen counted for little, but a nun from the nearby convent was worth several points, and a Negro nun several more. There were other prime targets. An ordinary citizen counted for little, but a nun from the nearby convent was worth several points, and a Negro nun several more. There were other prime targets. One day as a wealthy, Spratling pulled the trigger. Years later he remembered with pleasure the look of incredulous outrage on the dowager's face.

Faulkner still rose early each morning and often went to a coffee stand in the French Market down near the river. It was fashionable to end a night's gaiety with the strong black coffee, and mornings after gala Mardi gras balls men and women in evening dress would sit before the high mirrors drinking the steaming, chicory-flavored brew. It was said that duelists met there, which gave rise to the saying "pistols for two, coffee for one." Flo Field remembered Faulkner's coming back with three doughnuts powdered with sugar. He consumed them, she said, with a tumbler of whiskey.

Fn 52438 I: William Spratling, 29 Jan. 1965. 5256 I: Mr. and Mrs. Marc Antony, I Feb. 1965. 52616 Spratling, "Chronicle of a Friendship," p. 36; I: 30 Jan. 1965. 52525 I: Flo Field, 5 Feb. 1965.

\section{JUNE, 1927 - SEPTEMBER, 1928}

\section{$552-3$}

Liveright wrote back on July 23 asking him to let them know in advance next time. Faulkner offered an explanation with his letter of thanks. "Its quite a yarn," he said. "I had just purchased twenty-five gallons of whisky, brought it home and buried it in the garden. Two days later I went to Memphis, lost over three hundred dollars on a wheel, and gave a check for it. I had about one-fifty in bank, and I knew I could dispose of my whisky and raise the balance with only the minor risk of being had by the law for peddling it. So I came home in about three days, found that one of our niggers had smelled the whisky out, dug it up, sold a little and had been caught and told where the rest of it was. So I lost all of it. He would not have turned to Liveright, he added, but for the fact that "what with the flood last spring, southern people have no cash money for gambling debts."

If Faulkner had lost money on a roulette wheel, it had probably been in a club such as the one Reno DeVaux ran. It is not unlikely that he also visited some other familiar places in Memphis, for it appears to have been during these years of the late 1920'S that he knew a businesswoman in Memphis named Bella Rivers or Mary Ware. She had come from Alabama as a girl to work in the Memphis Tenderloin, but she had felt herself superior to the other girls for she had pretty much stuck to one man on her own time. Now she ran her own house, which she tried to make a model- of decorum. Out of Faulkner's observation of it probably came the offer of a job he described: "to become a landlord in a brothel. In my opinion it's the perfect milieu for an artist to work in. It gives him perfect economic freedom; he's free of fear and hunger; he has a roof over his head and nothing whatever to do except keep a few simple accounts and to go once every month and payoff the local police. The place is quiet during the morning hours which is the 
best time of the day to work. There's enough social life in the evening, if he wishes to participate, to keep him from being bored; it gives him a certain standing in his society; he has nothing to do because the madam keeps the books; all the inmates of the house are females and would defer to him and call him 'Sir.' All the bootleggers in the neighborhood would call him 'Sir.' And he could call the police by their first names." This account was probably no more true, literally, than that of the silver plate in his skull. But just as that tale was related to a reality out of which came such figures as Donald Mahon and Bayard Sartoris, so this description bespoke another kind of acquaintance which would be just as rich for the purposes of fiction. Faulkner did nothing to counteract the impression that he was well-acquainted with the Memphis demimonde. One story, which sounded as though it might bear the mark of the author himself, suggested the way he used this milieu for purposes of humor as well as squalor. According to this account, Faulkner was approached, as he sat quietly enjoying the sociability of the parlor, by one of the inmates of the house. She asked if he wouldn't like to go upstairs with her, only to be, stopped by his reply. "Please leave me alone," he said. "Can't you understand I'm on vacation?"

Fn 55214 Both WF letters are undated. Liveright's reply to the first one is dated 23 July 1927, to the second, 1 Aug. 1927. 55235 Jean Stein in LIG, p. 239. 539 Louis Cochran in WFO, p. 224.

\section{SEPTEMBER - DECEMBER, 1928}

\section{[590] and 591-2}

One Saturday night - it may well have been about this time, after Faulkner had given the book [The Sound and the Fury] to Wasson, who would in turn pass it on to Harcourt -- Jim Devine and Leon Scales decided to make the subway trip from 111th Street down to the Village to see Faulkner. "It was fairly late and we were uninvited, but this was the way that New York City dwellers lived in those days. Saturday night was always the night to prowl around looking for a drink perhaps, or just a visit with someone you happened to know." They knocked and turned the front doorknob to go in but found the door locked. They waited, but there was no sound. This seemed strange because they could see that the lights were on inside. When Scales lifted Devine up to the transom, he saw Faulkner stretched out on the floor, near him some of the familiar square bottles, empty. Devine thought they ought to see if he was all right, so they forced the door. When they roused him they found that he had not eaten for a couple of days. He needed nourishment and nursing, and the only place they could think of to take him was their apartment. He was too debilitated to be of much help as they slipped an overcoat around his shoulders, but with Devine on one side and Scales on the other, they got him out of the apartment. It was about midnight as they made their way slowly to the 14th Street subway entrance. There they paused to rest before descending. Faulkner sat on the curb, his head in his hands. He was ill and he looked, thought Scales, very sad. But he roused himself for a moment.

"Don't make me go up to your place," he said, "I have never been upstate on the subway."

Devine and Scales couldn't help laughing. Carefully negotiating the grimy steps they made their way down, passed the turnstiles, and caught the next uptown express.

If this sequence of events did in fact occur after Faulkner gave the book to Wasson, it foreshadowed many repetitions. Ernest Hemingway would later speak of the irresponsibility that comes after the awful responsibility of writing. There were the other after-effects: a feeling of exhaustion, of being spent, and an accompanying depression and lassitude. Liquor was an anodyne that would drown it all out. It was one to which Faulkner would, resort with some frequency, and almost always he would seek it when he had finished the creative labor of a book.

He enjoyed himself upstate at 111th Street. Breakfasts were particularly pleasant. With Devine and Scales he would go to some small restaurant on Broadway or Amsterdam Avenue, where he would order toast and coffee. When breakfast arrived he would" draw from one of the tweed overcoat's capacious pockets a large crockery jar of Crosse \& Blackwell's marmalade. He 
would apply the marmalade to the toast and then, at the end of the meal, he would carefully wipe off the jar, snap the metal retainer in place on the $d$, and return it to his overcoat pocket. He soon felt well enough to work again, and during the day, while Devine, Scales, and Bob Walton were out, he could write. They thought he was working on a book, but they did not ask him.

There were modest parties during his few weeks' stay in the apartment. They were informal, and after the few pieces of furniture were occupied, newcomers would sit on the floor. That was the place Faulkner seemed to prefer. He would drink with the rest, returning to moderation--for him -- after his period of concentrated drinking. He would take off his shoes and begin to tell stories which would make him the center of attention. The stories purported to be autobiographical-about his youth in Mississippi or his service in Canada where, he said, he cracked up two airplanes before they discovered he didn't know how to fly and washed him out. He told about the woman in New Orleans and the two children she had had by him. Someday, he said, he was going to go back and marry her. Scales had the impression that Faulkner was making up the stories as he went along and that he could go on as long as he chose. Later, when Scales read some of his fiction, he had the feeling that he had heard the story before.

Fn 59117 Leon Scales to JB, 23 June1965. 59212 Ibid.

He would open one of the small notebooks, Crump said, which he bought at a nearby Woolworth's five-and-ten on Eighth Street. (When he laid in a supply he would also buy a big ten-cent bag of tasty and filling roasted peanuts.) Faulkner would number a notebook and then start writing. When he reached the back he would write his way through to the front on the backs of the pages. Then he would drop the notebook into something on the floor that looked like a doctor's valise. Also there by the bed would be a bottle of gin procured from the neighborhood bootlegger on the fourth floor of a tenement just a block away in an Italian district. Occasionally Faulkner would sip at the gin as he wrote. When enough of the small notebooks had accumulated in the valise, he would take them up to Ben Wasson's office, where one of the secretaries would type them.

Fn 59521 I: Owen Crump, 9 June 1966.

\section{DECEMBER, 1928 - JUNE, 1929}

\section{8-9}

Each spring the Ole Miss baseball team would play its arch-rival. Mississippi A\&M, at Starkville, seventy-five miles to the southeast. The rivalry was intense, and the fans who made the trip to see the game expected a wild time. Because the roads were still so bad, Ole Miss students and alumni would charter a train, where many of the spectators would take an anticipatory drink or two. There would be plenty more when they got to Starkville, where, despite prohibition, demijohns of corn whiskey would circulate in the crowd. This did nothing to reduce the number of fights. The whole weekend would be festive as well as raucous, with a dance on the night of the game. Sometimes the injuries would be more than superficial bruises and cuts. People in Oxford talked covertly about one of these more serious incidents at Starkville. Whatever it was, it happened to an Ole Miss co-ed, an extremely popular girl who somehow left the train and suffered some sort of sexual molestation. She had lived on University Avenue across from the Kirkwood house, just two blocks north of where the Falkners had lived as boys. If William Faulkner needed a bridge between Popeye's alleged Memphis outrage and the milieu of Yoknapatawpha and the university, this would have provided it.

Fn 60912 W. H. Hutchinson to JB, 1 Nov. 1965. 


\section{JUNE, 1929 - MARCH, 1930}

\section{1}

Occasionally Estelle would join her husband in one of his visits to her new mother-inlaw, sometimes bringing a small gift. She noticed, though, that Miss Maud would shortly fall silent. She felt sure that this did not happen when Billy went by himself. The truth was that Miss Maud was not reconciled to her son's marriage. Instead, she had nagging worries about it. One was very specific. Far from being an implacable enemy of alcohol like herself, Estelle drank. When Billy drank too much, Miss Maud was likely to feel not only that Estelle didn't try to put a check on him but also that she encouraged him-if he needed any encouragement-by her example. Over the long run, Estelle would see more of Maud Falkner than her other three daughters-in-law. But it would be no easy relationship at best.

Fn 63130 I: EF, 7 Aug. 1963, 29 Apr. 1968.

\section{OCTOBER - DECEMBER, 1931}

\section{7-24}

Why did he drink? There were at least half a dozen situations that would produce drinking. And there were different patterns of drinking. There was, as a matter of fact, abstinence, too. Before he was much older he would abstain completely for a year. Most of the time, however, he did drink. For long periods his intake would be moderate, or considerable, but controlled. It would have had to be so, for him to accomplish all the work he had done. At times, as with Charlie Crouch or Rusty Patterson, he spent an evening in heavy drinking, from which it would take a day or so to recover. There were also extended bouts which would end when he finally stopped drinking and recovered from the after-effects. The family could handle some of these; on other occasions hospitalization would be necessary.

There was certainly a predisposition to drinking, in his culture and in his family. As Jack Falkner would later recall, there was no such thing, when Bill Faulkner was growing up, as social drinking in the modem sense, and nothing like the integration of wine and spirits into family life that some Europeans knew. Drinking was for men-or so it was made to appear-and it was not a drawing-room occupation. In "wet" areas a man could drink in a bar or hotel. In dry areas such as Lafayette County, liquor was bought from bootleggers and consumed sub rosa. As a result, the drinking tended to be hard and often to end in drunkenness. In William Faulkner's family drinking was a tradition. His great-grandfather was said to have been a heavy drinker. (One of the reports, it is true, came from an enemy.) His grandfather and father were both habitual drinkers whose bouts might end in hospitalization. Both" had been forced to undergo the Keeley Cure without long-term success. The Colonel had continued to drink heavily until his death. Murry Falkner had begun to cut down only recently at about the time he had begun to suffer from stomach trouble.

Miss Maud met this behavior in her son just as she had met it in his father: with determined but largely undiscriminating resistance. She would pour his whiskey down the sink, and in these early years of his marriage she was convinced that Estelle encouraged his drinking. The example of abstemious Grandfather Murry had not been very persuasive. All of Murry Falkner's sons drank, and to excess. Of the four of them, only Jack finally became an abstainer. Excessive drinking can often be a familial condition. It is not transmitted biologically; it is "passed on in the same way that money is inherited, not in the way that, say, eye colour is." In this case the means of transmission was only a technical matter. The inheritance was conveyed. And he was constantly with fellow inheritors, whether in Oxford or in the Vieux Carré, where 
one, looking back later on the old days, would not recall him as a particularly heavy drinker. "We all drank hard," she said.

Like most people who drink, William Faulkner drank because of the way liquor tasted and the way it made him feel. He had liked the flavor from the time when he was allowed to drink the "heeltaps" that remained in his grandfather's toddy glass. He greatly enjoyed the taste of good bourbon, and by the time he reached mature years he was a wine drinker of knowledge and discrimination. He enjoyed drinking for these "positive" reasons. He enjoyed it because it made him feel good-as he relaxed after work or eased the strain from a variety of causes.

He also drank, in a connected yet separate way, out of avoidance as well as out of gustatory and psychological pleasure. He was a shy man who would wryly say he got "claustrophobia" in crowds. He was a private man who generally disliked questions about himself or his work. For many shy people, liquor is an agent which eases the apprehension that may accompany a crowd situation. It probably acted this way for him. He tended to distrust physicians generally. ("He had a curious way of treating a doctor," one said, "courteous, but you had the feeling that he wasn't paying any attention to you and would go on doing what he wanted to.") Liquor was for him an analgesic, an anodyne, an anesthetic, and he would dose himself with whiskey in treating a sore throat or a bad back. When the ailment persisted he would increase the dosage. He would use liquor to ease worry as well as pain -- worry over finances, for instance. If he felt deeply unhappy or depressed, he would tum to liquor. Faced with a situation (sometimes of his own making) which presented equally unacceptable alternatives, he would avoid the decision by removing himself from the whole situation through excessive drinking. When faced with an unavoidable obligation suddenly come due, he might make himself incapable of fulfilling it. Unhappily, however, one of the characteristics of alcohol taken in this way is that it tends in the long run to intensify the thing it is meant to treat. The drinker is less able to deal with his depression, for instance. The alcohol reduces his intellectual control over the response he is using the alcohol to inhibit.

Sometimes these drinking bouts were predictable. They would usually come in the reaction that followed the completion of a book. Each novel but The Sound and the Fury, he said, was written with an "accompanying feeling of drive or effort," and a "following feeling of exhaustion or relief or distaste." As Sherwood Anderson expressed it, "then the reaction comes. There has been this intense concentration and now you are striving to come out of it. You go to walk. Sometimes I have found that drink helps at such times. You have been in one world and you are trying to return to another. Your nerves are jumpy." These periods of excessive drinking would usually follow a rhythm. In November came the trip to hunting camp. Here there was a complete change of atmosphere, of scene, of company. There was also the release of intensive drinking, which might ease off or go on, finally terminating the hunt for him. These bouts might occur from two to four times a year. They might last for a week, ten days, or a month and a half.

The bouts were usually deliberate. Faulkner would ensure a sufficient supply of liquor. He would plan when he would start, and he would often plan when he would stop. John Falkner thought these sessions were merely faked drunkenness-when Bill was bored, when he wanted to avoid work or to be waited on. On many occasions, however, they were not fakes but rather serious, prolonged, and debilitating illnesses.

The onset might come at any time. "He'd go along for weeks or months at a normal gait," R. N. Linscott, later Faulkner's editor, would write, and "then the craving would come. Most often he'd fight it off. But once in a while something would happen that would 'get me all of a turmoil inside,' and liquor seemed the only escape. It was only when he was caught in a situation he couldn't cope with that he'd give in to what he called the chemistry of craving and go overboard. You would be aware of the symptoms of increasing tension--drumming fingers, evasive looks, monosyllabic replies to questions-then he'd disappear..." To another Faulkner once said, "I feel as though all my nerve ends were exposed...." 
The progress and effects of his drinking bouts were very similar to the average ones of the periodic heavy drinker. Shortly after the cycle began, he would lose interest in food. When his own supply of liquor, sometimes I ingeniously cached, would run out, he would become dependent on others. Then he might use food to bargain with those who were nursing him. When he was not yet ready to stop or to taper off, he might accept an eggnog in exchange for another drink.

He would retire to his bed, sometimes dispensing with his pajama top, or bottoms, or both. He might leave his room without donning a robe, to the discomfiture -- if he happened to be in a hotel -- of guests and staff. One thing which had always struck some of his friends as extraordinary was his ability to recall later the conversation during a period of intensive drinking. He retained this faculty together with what seemed an acute awareness of what was happening to him. Sometimes this could produce a somewhat poignant effect, as when a friend nursing him realized that Faulkner knew the effect that seeing him this way might have. But this was a minor consideration. The bout would go on until he was ready to taper off, or until he was hospitalized.

The reactions following prolonged intensive drinking are far more severe than just headache, nausea, and sensitivity to sound. They constitute withdrawal symptoms very like those caused by other addictive agents. Some of the symptoms are caused by the sudden lessening of alcohol concentration in the blood. Others result from retention of body fluids with accompanying cerebral edema. First to appear is usually acute tremulousness and nervousness which may persist for days or even weeks. There will often be insomnia. There may follow hallucinations as the sufferer sees and hears things which are not there. There is also likely to be an accompanying distortion of the time sense. Even worse, of course, is delirium tremens: disordered mental activity, hypersensitivity to random stimuli, and a pervasive terror produced by the flickering yet absolutely convincing hallucinations. There may he instances of alcoholic epilepsy, after the irritation of neuronal tissue from overfluidation, in which the brain produces a discharge of electricity which disorganizes the body's circuitry and muscular control. The victim may fall into convulsive spasms marked by labored breathing, blueness of the skin from lack of oxygen, and involuntary voiding. At one time or another, William Faulkner suffered all of these effects.

Severe and protracted drinking brings in its wake other ills: gastritis, memory blackouts, cirrhosis of the liver. Faulkner was fortunate. Appetite and digestion never failed him upon his return to health. He remained a gourmet. The few blackouts that he would suffer much later in life came from other causes, and there is no indication that he ever developed the liver ailment. $\mathrm{He}$ had a strong constitution and he was spared the extremities to which other writers among his contemporaries were reduced. But the drinking did produce the equivalent of one or two serious illnesses a year for thirty years. His own euphemism for such an illness was "a collapse." In a way, it was just that.

The treatment of such illnesses could extend from home remedies to the ministrations of a specialized hospital. And even in hospitals, the regimen and medication would differ from one to another according to philosophy, theory, and practice. The physician may have to treat several complaints at the same time. The patient on arrival is likely to show malnutrition as well as intoxication. He may be suffering from a cold or an infection contracted during the course of the bout. The physician may administer glucose, vitamins, and antibiotics. With the onset of violent withdrawal symptoms, which may come as late as six days after the patient has stopped drinking, the physician will have to increase or change some of the medication. Whereas he may have administered a mild sedative when the patient was admitted, he may now switch to something stronger. In the1930's and 1940's it would have been paraldehyde. An alcohol substitute, it was a powerful and addictive drug which could be administered in several forms, some of them characterized by an odor many patients found nearly unbearable. But it acted as a deep sedative for the victim suffering from acute tremulousness and nervousness. (In recent years, of course, tranquilizers and other drugs have been substituted increasingly for the older ones.), Gradually the body's balance is restored. Abstaining now, the patient begins to eat normally. In due course 
the medication is reduced. The patient may remain in the hospital until he has returned completely to normal. Often he may choose to go home sooner-still a bit shaky and debilitated, with the tag end of a cold, and with a bottle of large vitamin capsules in his overnight bag. Faulkner knew this cycle, too.

Now, riding northward toward New York on the two-lane roads of 1931, he was in no such protective environment. He was with one old friend, and two new ones who admired him and would do what they could -- 1ike others in New York. For a period of nearly seven weeks Faulkner would be away from home -- still grieving for his baby, concerned over his wife's health, worried about money, and engulfed periodically in situations involving tension and crowds. He would not drink heavily all of this time, but he would during much of it. And it would be periodically harrowing for him and for others.

He was still apparently enjoying the trip. He recited Joyce, and then reaching into the canvas bag, extracted the manuscript of Light in August and read some of it aloud. He asked Green to stop so he could replenish his supply of liquor. Green did. By the time they reached Washington, Green had to stop again because of trouble with the old Buick. As he pulled into a service station, Green told Faulkner to be sure to keep the liquor hidden. They had been able to drink all they wanted in Charlottesville, but this was Washington, and Green did not know what view the capital's law enforcement officers took of the Volstead Act. As the mechanic peered at the engine, a policeman strolled by and Faulkner genially offered him a drink. The officer smiled, declined with thanks, and walked on. Green, - Smith, and Abernethy looked at each other. Smith did not complete the trip to New York with the rest. It may have been at this point that he took a train instead. It would do a publisher no particular good to be jailed in Washington for violating the liquor laws, particularly when he ought to be in New York trying to start a new business.

It must have been Monday, October 26, when they arrived in New York. Green dropped Faulkner and Abernethy off at their hotel, arranging to meet them that evening for dinner. By the time he returned, Faulkner's telephone had been ringing. Alfred A. Knopf was interested in him, as was Harold Guinzburg. Six years earlier Guinzburg had founded The Viking Press with George Oppenheimer. From the start they had aimed for a small list of quality books and had done well. Now they had expanded their activities to include Canada, and they were ready to add more authors to their list. Four months after Guinzburg and Oppenheimer had organized The Viking Press, Bennett Cerf and Donald Klopfer had purchased The Modem Library from the foundering firm of Boni \& Liveright. Five years later they had bought The Sun Dial Press, and now, as Random House, their - company was working vigorously to stay solvent in the teeth of the Depression. Cerf had been selling books in the Centaur Book Shop in Philadelphia that February when the manager gave him a new book to read. It was Sanctuary. "I read it," Cerf said much later, "and flipped." Like his competitors, he was determined to sign up this thirty-four-year-old author if he could. On that same Monday, he pressed his suit in person. As a token of esteem he presented a copy of the handsome Modem Library edition of one of the two books Faulkner had called his favorites: Moby Dick. It was inscribed for "Bill Faulkner from-----Random House \& The Modern Library." The recipient also inscribed his name and the date in the book.

Cerf had a concrete plan in mind. He wanted to publish Sanctuary (which had gone into its sixth printing in July) in The Modem Library. And there was another possible deal. Faulkner had sent "Idyll in the Desert" to Ben Wasson on June 5, but Ben had not placed it. During the time Faulkner was in New York, Wasson would offer it to Cerf as a possible special Random House publication. Faulkner now responded to the stepped-up tempo of activity by drinking harder. Abernethy got in touch with Smith, who had struck him as a rather dynamic man who would know what to do, and told him what was happening.

It was in these years that a certain kind of motion picture enjoyed a special vogue. It mixed romance, music, and athletics. There were co-eds who sang. Cheerleaders in short skirts and white bell-bottomed trousers danced. One of the female cheerleaders usually fell in love with the college's football star. Often, for a climax, the football star would be kidnapped by gamblers 
or other foresighted or disgruntled persons. This would happen on the eve of The Big Game. At the last possible moment, the star would escape from his captors and swiftly make his way to the stadium to score the winning touchdown just before the final gun sounded. The fade-out would combine the sweetness of lovers reunited with the triumphal frenzy of the victorious football fans. Hal Smith, beleaguered as he felt by Alfred Knopf (about whom he was particularly worried), The Viking Press, and Random House, may have thought of such a strategem [sic] at this precarious moment to protect his literary property. He gave Milton Abernethy money for two tickets on a ship plying the waters between New York City and Jacksonville, Florida. He asked him to get William Faulkner aboard it as soon as he could and to keep him in Jacksonville, or some place other than New York, until the pursuit cooled off. Abernethy said he would do it. Faulkner, if he was consulted, made no objection.

The Clyde-Mallory lines advertised service in big, modern liners sailing between New York and Jacksonville and calling at Charleston. Two vessels made the run regularly: the Henry $R$. Mallory and the Algonquin. Abernethy was impressed by the size of the Mallory as they boarded it at dinner time on Tuesday, the twenty-seventh. Clad in brown tweeds and smoking his pipe, Faulkner had little in the way of baggage. Not until the ship had nosed its way out of the harbor on its southerly course did they learn that there was no liquor aboard. Faulkner's solution was to procure some German beer from the steward together with sugar and yeast. He then "needled" the beer to increase its potency.

The next morning, Abernethy recalled, they arrived in Norfolk. That day's journey was uneventful, but during the night after both men had retired the wind rose and the ship began taking rough waves. The beer bottles rattled and one popped with a report like a pistol shot that brought Faulkner jumping out of his bunk. The rest remained intact, however. By the time they reached Jacksonville, they were all empty. But now there was a new difficulty: Faulkner had an acute case of hiccups.

They checked into a hotel, where Abernethy tried to help his friend. He suggested the usual folk remedies: drinking water, breathing in a paper bag, holding his breath. Faulkner had suffered this complaint before and knew that none of these would work. There was only one thing to do.

"What is it?" Abernethy asked.

"I have to fly in an airplane, upside down," Faulkner said.

Abernethy thought that if that was the only way to stop the hiccups, Faulkner had better do it. He would wait for him at the hotel.

"No," Faulkner said, "I have to do it with someone."

The two took a taxi out to the airport where Faulkner hired a pilot and gravely gave him instructions. They took off, reached a safe altitude, and then, as Abernethy recalled it, flew upside down over the Jacksonville marshes, returned to the field, and landed. Faulkner no longer complained of the hiccups.

Fn 71734 I: EF, 17 Oct. 1967. 7183 Neil Kessel and Henry Walton, Alcoholism (Baltimore, 1965), p. 71. 7188 I: Louis Andrews Fischer, 3 Feb. 1965. More than one observer noted, however, that WF could consume quantities of alcohol out of all proportion to his size. A better understanding of conditions like his will doubtless come with increased knowledge of the biochemical processes involved. 7195 Meriwether, "Faulkner, Lost and Found," p. 7. 7199 Sherwood Anderson, Memoirs, p. 353. 71919 MBB, pp. 148-9. 719 29 See Robert N. Linscott, "Faulkner Without Fanfare," Esquire, LX (July 1963), pp. 36, 38. 71930 I: Peter De Vries, 16 Oct. 1970. 72027 See Kessel and Walton, pp. 33-9. 72124 Ibid. A further word on after-effects: pneumonia is a common aftermath of drinking bouts. Delirium tremens, which usually occurs within seventy-two hours of the cessation of drinking, can be produced by trauma, surgery, or sleep deprivation. The mortality rate is as high as 15 percent. Insomnia is characteristic of alcoholics. Some get very little sleep and become progressively more jittery as a result. 72133 A working definition of an alcoholic is that he is one who has lost control of the drinking pattern to the extent that it interferes with his interpersonal relationships, family, or socioeconomic situation, or involves him with the law. (I: Harry 
Hyer, M.D., 13 Aug. 1968.) If WF can be said to have suffered from alcoholism, it was a kind of periodic and volitional alcoholism. As he aged, the incidence of extended drinking bouts decreased. 72213 I: Paul Green, II July 1968. The memories of Messrs. Green and Abernethy are understandably imprecise on some of the dates, times, and other elements in what was to prove a particularly hectic series of events. Part of the following account is therefore constructed by inference. 72235 WFL, P.43. 72237 I: BC, 20 Sept. 1967. 723 I FCVA. 7236 I: Paul Green, 11 July 1968; Milton Abernethy, 23 Apr. 1965. 723 24 I: Milton Abernethy, 23 Apr. 1965. Harry Hansen's New York World-Telegram column for 5 Nov. 1931, "Book Marks for Today," gives the Union Square Hotel as the place where WF stopped at this time. Abernethy's recollection is that it was the Hotel Algonquin, where WF definitely did stay later in his visit. Anthony Buttitta records the Algonquin as the hotel at which WF stayed on this first arrival in New York in 1931. Buttitta, "William Faulkner: That Writin' Man of Oxford," The Saturday Review of Literature, XVIII 7: (May 21, 1938), p. 7.

\section{OCTOBER, 1932 - AUGUST, 1933}

\section{5}

It may have been with something of this feeling of well-being that, though rarely a joiner, he put his name down on a membership list. It was a new organization called the Crusaders, and when it was chartered in Jackson that year Faulkner was listed as one of the executive directors. The object of the crusade was to legalize liquor and beer in Mississippi. The Twenty-first Amendment, repealing prohibition, was now being ratified by the states. But even if the amendment were ratified, the state law would remain on the books unless the pro-repeal forces were mobilized to defeat what some called an alliance between the Baptists, the bootleggers, and the county sheriffs. Looking back much later, Faulkner said he had joined the organization "one hot summer night over a bottle of gin." But he was disappointed and angry at the outcome, and he would continue to espouse the Crusaders' objectives in skirmishes to come.

Fn 80525 Tom S. Hines, Jr., in WFO, p. 114.

\section{JUNE, 1933 - FEBRUARY, 1934}

\section{8}

Before the month was out they were able to discuss future plans when Smith came down for Jill's christening. Reverend McCready performed the ritual in St. Peter's Episcopal Church, with Jack Falkner and Sallie Murry Williams standing as the baby's godparents. There was a champagne supper party afterwards at Rowan Oak, with the guests from Memphis and New Orleans. Faulkner had gone to Memphis to buy the champagne as well as some things Mrs. Oldham wanted for a dinner party she gave in Hal Smith's honor. Smith stayed on for over a week and then departed for a short visit to New Orleans. The tentative plan was for him to come back to Rowan Oak for some hunting. When he returned, however, Faulkner was drinking, and after a few days Smith went on to New York.

Fn 81839 EF to JB, 17 Sept. 1968.

\section{$[820]$ and 821-2}

Bennett Cerf wanted to talk to Faulkner about the limited edition of The Sound and the Fury. He had already asked Ed Grabhorn for specimen pages and a suggested binding, and now he wanted to go over some of the details. Gregarious and outgoing, Cerf gave a cocktail party at his apartment for Faulkner. Dorothy Parker, Frank Sullivan, Harold and Alice Guinzburg, and a number of Faulkner's other New York friends were there. But the guest of honor was not. When he did arrive, much later, it was immediately clear that he was in no other way behind the rest of the guests. Cerf was serving powerful martinis. As they drank them, Sullivan recalled, Faulkner 
(never one to allow veracity to stand in the way of a good story or a friendly gesture) "announced he was commandeering" Mrs. Parker and me to come to Oxford and stand godparents to a new Faulkner just arrived." The party continued on that happy note for a while, but as it wore on Faulkner's powers of resistance waned, and before long he was gone.

It was Vernon Omlie who flew the Waco out of New York on November II and set the course for Washington and then home. Apparently the better part of a month passed before Cerf heard anything from his guest. When he did, it was in the form of an apology. "I'm mighty sorry I made more or less of a fiasco of my part of the afternoon at your place. I was sick. It had started coming on soon after I got to New York, and I made the mistake of trying to carry on on liquor until I could get back home. That was the reason I was so near blotto, though it is no excuse. Anyway, that's why I was late and why I left soon."

Fn 82117 WF to Be, undated. BC's reply dated 12 Dec. 1933.

\section{SEPTEMBER, 1934 - MARCH, 1935}

\section{1-2}

This year he was going to hunting camp-away from family, children, and his workroom, in the company, for a short time, of adult males only. Near the end of the third week of November he set out with the others for General Stone's lodge, below Batesville in the Tallahatchie bottom land thirty miles west of Oxford. At the Batesville train station the wagons were waiting to carry them and their gear to the lodge, where old Ad, the cook, and his helper, Curtis, had been established for nearly a week. There Faulkner was not to find the relaxation he sought. He was susceptible to sudden and prolonged bouts of hiccups which seemed to strike unpredictably and bore no relation whatever to sobriety. They would go on uninterrupted until he could neither eat, drink, nor sleep. Suggestions of folk remedies would come in to Rowan Oak -- drinking water, breathing in a paper bag, standing on his head. He would always try them all. He might also resort to whiskey. Finally, after three or four days, they would disappear, leaving him totally exhausted and in an execrable humor. Now, in the midst of a comradely hunt, the hiccups struck. With the involuntary spasms regularly racking him, he could not go out for deer, and the rough accommodations of the lodge did little to make the affliction more bearable. Finally the others became concerned and took him into the town of Batesville, where the hiccups finally stopped. The hunt by now had been spoiled for him, but it would not be a total loss.

Back home at Rowan Oak he sat down at his desk in the west wing and began to write. "I am now working at a story which the POST [i.e. The Saturday Evening Post] should like," he told Morty Goldman in an undated letter. "I am sorry I didnt see you again. I got into my usual drinking gang and drank pretty hard for a time after reaching home, was taken sick, quit drinking, had hiccoughs for forty-eight hours, and as a result I am expecting to be notified that I have permanently ruined my stomach and must live from now on upon bread and milk. I hope not, but I still feel pretty bad, though I am working all right."

His uncomfortable experience had supplied him with material for the story and so had the members of the party, especially Uncle Ad, who had cooked for many Oxonians on hunts in the Delta. Suratt told the story. Lucius Provine tried to cure his hiccups-brought on with too much bear meat and whiskey in Major de Spain's hunting camp-by holding his breath, swallowing a buckshot, and drinking water while standing upright and hanging from a tree limb by his knees. An annoyance to the whole camp, he finally followed Suratt's suggestion that he go to John Basket, a whiskey-making Indian, for a remedy unknown to white men.

Fn 8226 MBB. pp. 156-8. 822 19 I: EF, 17 Feb. 1967; JFS, 12 Aug. 1968.

\section{7}


On top of the problems of tradesmen's bills and insurance premiums, there were taxes due. He hoped for some kind of deferred payment, but the Bureau of Internal Revenue pressed him. He had tried to earn the money by writing short stories but he had not earned enough. He did not want to take out second mortgages, and if he went to Hollywood it would mean putting off Absalom, Absalom! yet another time. There was only one strategy of evasion open to him. He began drinking. Miss Maud reacted with more than her usual concern-he had been so good for so long. Her method of pouring the whiskey down the sink worked no better than it had before. She finally called Champ and asked him to come and see if he could do anything.

Champ sat down at his bedside. "You know, Bill," he said, "you can't drink if you want to fly."

Faulkner looked up at him, his face drawn and his eyes deeply circled. "If you say quit, I'll quit," he said.

He began to taper off, and the bout was aborted. Before long, he would be flying with Champion again, displaying the qualities the younger man admired: intense powers of concentration and quiet courage.

His recovery coincided with one event and made possible another: the appearance of the initial reviews of Pylon and the beginning of the final manuscript of Absalom, Absalom!.

Fn 88734 I: E. O. Champion, 23 Mar. 1965.

\section{NOVEMBER, 1935 - OCTOBER, 1936}

Sayre and Faulkner went out to celebrate. They had agreed to meet a group of friends at the Brown Derby restaurant on New Year's Day to board a chartered bus for the Rose Bowl game in nearby Pasadena. When they appeared, it was obvious to Nunnally Johnson that they had not interrupted their celebration for sleep. On the bus Faulkner dozed, his head on the shoulder of his seatmate, the first Mrs. James Thurber. In spite o fa traffic jam at Eagle Rock the bus arrived on time. Faulkner enjoyed himself at the game, where writer Gene Fowler joined them. There was only one awkwardness before they returned to Beverly Hills: when Faulkner boarded the bus for the return trip he was barefoot. Having taken his shoes off in the stadium, he was unable to find them when the crowd began milling toward the exits.

He recovered from the celebration sufficiently to report for work after the holiday and to continue with the last of his manuscript. The final chapter was the shortest, as Faulkner picked up the second time-level of his story in the night visit of Quentin and Miss Rosa to Sutpen's Hundred. In the preceding chapter Faulkner had called Quentin "the morose and delicate offspring of rain and steamy heat." (346) Now, even in bed, he trembled and jerked violently, but from more than just the cold. Once again Faulkner was emphasizing the symbolic nature of Sutpen's story for Quentin. Once again Shreve was the not quite obtuse questioner, whose jibes Quentin answered with two short phrases that emphasized his own fatal isolation: "You cant understand it. You would have to be born there." (36I)

Fn 92616 I: Nunnally Johnson, 23 Apr. 1965.

\section{7-8}

Finishing the final draft of this novel he had worked at so long, Faulkner felt a brief euphoria. During the first week in January he called David Hempstead into his office. Like Sayre, Hempstead admired Faulkner's work and enjoyed his Snopes stories. "In the normal flow of conversation," Hempstead remembered, "Faulkner would refer to the Snopeses as though they were real people who were just down the hall." In spite of this storytelling, Hempstead also saw Faulkner as a man who was shy and self-effacing. The conversation in Faulkner's office came as 
something of a surprise. Now that the long pull was over, he had begun to drink, as Hempstead could see. Faulkner handed him a thick batch of pages covered with the handwriting that Hempstead called "Carlovingian minuscule."

"I want you to read this," he said.

"What is it?" Hempstead asked.

"I think it's the best novel yet written by an American," Faulkner answered. "I want you to read it tonight." To Hempstead's dismay, Faulkner confirmed the fact that it was his only copy.

"Suppose the house should burn down," he protested.

"Take it," Faulkner said, refusing to hear any demurrer.

Hempstead took it home and read what he could of it that night. The next morning he returned the manuscript of Absalom, Absalom! to its author with relief.

As Faulkner continued drinking and stopped eating, his friends' concern increased. "Bill," said Hempstead, "how can you keep this up?"

Faulkner looked at him unalarmed. "Dave," he said, "there's a lot of nourishment in an acre of com."

When he had finished his part of the shooting script of Wooden Crosses, he went to Hawks, who had protected him. As Hawks had interceded for him with Louis B. Mayer, so he had spoken for him to Zanuck. "Don't close him out," he had said to Zanuck, and Faulkner had stayed on the payroll.

"Am I through?" Faulkner asked. To Hawks he seemed in a terribly nervous state.

"Yes, Bill, you are," answered his friend.

Most of what Faulkner had done would not appear in the final script, which was chiefly the work of Nunnally Johnson. What was needed here was what Johnson called "the telegraphic style." But he had worked conscientiously, trying to supply what Zanuck, Johnson, and Hawks wanted. His payroll card would show a brief notation for Tuesday, January 7: "Taken off temporarily due to illness."

He was suffering not only from nervous exhaustion but also from the unassuaged anguish over Dean's death. He submerged himself now, reacting against his grief and the dual works he had completed, one of them more complex than any other work he would ever write. Hawks saw his friend through his illness, and ten days later Faulkner was able to leave for Mississippi. At home he continued to labor over the manuscript, probably reading through it again and making further marginal additions and occasional deletions. He made three sets of notations at the bottom of the last page:

Mississippi, 1935

Absalom, Absalom!

California, 1936

Rowanoak.

31 Jany 1936

William Faulkner

Mississippi, 1936

The completion of the typing with its accompanying revisions lay ahead of him. So did a return to Hollywood. He could see that after he had paid off his outstanding obligations he would soon be back where he had been unless there was more money coming in. He was loath to stop work again on Absalom, Absalom!, now that the end was in sight, to write stories for the Post. He began to drink again. Malcolm sat up with him, spelling his mother for a while, but they soon saw that they could not cope with the problem this time. There was a small private sanitarium at Byhalia, fifty miles to the north beyond Holly Springs, and they took him there. When he came home several days later, he continued the regimen of rest and nourishment begun at the hospital and returned to Absalom, Absalom!.

Fn 92726 I: David Hempstead, 6 and 10 June, 1965. WF had told Hempstead too about the Snopeses who were mailed to each other. 92731 I: David Hempstead, as above. 92738 I: Howard Hawks, 3 June1965. 
9284 I: Joel Sayre, 9 Nov. 1964; David Hempstead, 6 June1966; Robert Buckner, 10June 1966. 9286 Courtesy Twentieth Century- Fox. 92820 ACLT. He may also have been making other changes as he put the pages in their final manuscript order. When he had finished, the page numbers ran to 172 , but there were actually 205 sheets in all. The difference was accounted for by additions such as pp. 150A and 150B, though most such additional pages came in the first quarter of the manuscript. 92828 I: Malcolm Franklin, 26 Sept. 1966. 92832 I: EF, 29 Apr. 1968.

\section{9}

Faulkner resumed his practice of walking Over to see Miss Maud each morning. Louise was still there, her baby due in less than two months, and he was tender and solicitous with her always. It was clear that he still suffered from guilt feelings over Dean's death, and it was not just the business of the airplane and the lessons. It was as though he felt he had forecast his brother's death in Sartoris. In a three-page typed letter he told Ben Wasson that he had been drinking heavily because of guilt over the accident. He asked Ben to destroy the letter.

Fn 92924 I: BW, 28 Mar. 1965.

\section{NOVEMBER, 1935 - OCTOBER, 1936}

\section{3}

This kind of feeling made the emotional climate-already oppressive--even worse. Faulkner would come home from the studio fuming. As Estelle had feared, she liked California little more than her husband did. Her health had never been robust and she had never completely recovered 'from her illness following Alabama's birth. She suffered not only from anemia but periodically from nervousness and the old depression. Hollywood increased all the stresses in spite of the added income it brought. Faulkner had been hard-pressed since early adulthood and now he was looking after his mother, Louise, and little Dean, as well as his wife and children. There were less justifiable expenses. His drinking was a trial to everyone, himself included, and the family problem had of course become complicated by the fact that Estelle now suffered from alcoholism too. It would be a long time before she would finally conquer it. But they were together, and he had a chance now to put them on a sound financial basis until, hopefully, his books could do this under the Random House imprint.

[JB offers no citation for this passage - Author]

\section{[944-5]}

They did a little entertaining from time to time. Clark Gable would drop in for a drink now and again. He didn't have much to say, but he and Faulkner got along well and still hunted together. Joel Sayre remembered sitting in the large candle-lit living room, having a drink with his host while Estelle sat at the piano in a long-sleeved gown. Sometimes Sayre would bring his wife, or the Ronald Colmans, Estelle's favorites, would come for dinner. Their nearest neighbors were the Val Lewtons. A Russian like his actress aunt, Alla Nazimova, Lewton was a charming man who made his living as a screenwriter. Estelle would see Mrs. Lewton when she brought Nina to play with Jill, but it was a quiet life for the most part. Faulkner dug in, determined to stay for a while this time.

Sometimes, however, the quiet was apparently broken in disastrous ways. Departing from his custom of avoiding parties, Faulkner agreed to go with Estelle to a cocktail party at Joel Sayre's house. After they had been there for a time, Joel and his wife helped Estelle upstairs, where Mrs. Sayre took her into a quiet room so she could lie down. Joel went back down and drew Bill aside.

"Do you want to take Estelle home and then come back?"

"No." 
"Why don't you go ahead, and then you can come back and relax."

Faulkner finally did as Sayre suggested. When at last he returned, Sayre saw scratches on his face.

"See?" Faulkner said.

One morning when he arrived at the studio, Dave Hempstead noticed a mark in the middle of his forehead. Joel thought he saw lumps on his face.

"Bill," he said, "what happened?"

"I was just sitting there, reading Time magazine," Faulkner told him, "when Estelle came at me with a croquet mallet."

Fn 94417 I: Joel Sayre, 9 Nov. 1964. 94422 I: EF, 4 Aug. 1963, 12 Dec. 1964. 94435 I: Joel Sayre, 9 Nov. 1964. 5 2 I: David Hempstead, 12 June1965; Nunnally Johnson, 23 Apr. 1965.

\section{7}

Random House had planned a first printing of 6,000 copies for October 6 plus a limited edition of 300 signed copies. It would be a handsome book with a black cloth binding traversed by five thin scarlet lines with the author's signature on the front cover in gold. The pages for his signature probably arrived in Santa Monica in late September, but they were not returned to New York and there was no word from Faulkner. Random House wired him. He was drinking again, and Smith may have feared that he was in the Cedars of Lebanon Hospital. On October 8 Faulkner replied: HAVE FLU STOP WILL SIGN PAGES QUICKLY AS POSSIBLE.

Fn 9475 Knox, p. 12. [Joseph Blotner does not clearly indicate that this citation supports the statement that William Faulkner was drinking again. - Author]

\section{OCTOBER, 1936 - AUGUST, 1937}

\section{5-6}

In the studio bungalow Faulkner had completed descriptions of the locales and times for the six major sequences into which he had divided the action of Drums Along the Mohawk. Julie Davies was watching her boss as well as her shorthand pad. On the first day of the assignment Bill Hawks had come in to talk to her in confidence. There was a clause that voided Faulkner's contract if he did any drinking on the lot. If she ever noticed anything she was to call him immediately and he would come and get Faulkner off the lot. One day she had found an unopened bottle of Courvoisier cognac in the lower left-hand drawer of his desk. Each morning after that she would check the level when she arrived for work. It remained unchanged as several weeks passed, and now it was mid-April.

She returned from lunch one afternoon and sat down at her desk to resume work. The door between the two offices was open as Faulkner usually left it. As she prepared to type she heard a drawer open. Then there was the unmistakable pop of a cork. Five minutes later she heard the same sound again. She immediately slipped out to the next bungalow, where she called Bill Hawks. Forty-five minutes later he arrived and closed Faulkner's door after him. Twenty minutes later the buzzer sounded. When she answered Faulkner said, "Miss Davies, bring in your book." She was not prepared for what she saw. William Faulkner, always so formal, was leaning back in his swivel chair with his feet propped on the desk. Bill Hawks gazed silently from the couch. Julie sat down in the armchair, opened her book, and held her pencil poised. For ten minutes there was nothing but silence in the room. Finally Faulkner spoke. "Hostile," he said. Then he added, "That is all, Miss Davies."

She went back to her office and five minutes later Faulkner and Hawks made a careful exit from the bungalow and the lot. She thought over the one-word dictation she had taken. Her boss apparently surmised that it was she who had called Hawks, and the result might be a week or 
two of the hospitalization which he detested. A pink interoffice slip dated April 14 went to the records section bearing the notation "One week off for illness."

Bill Spratling had appeared unexpectedly for a visit and Estelle had invited him to dinner.

They had a few drinks but then Faulkner passed out. Spratling could see that they were miserable, and later Estelle showed him bruises on her arms. They could not take care of him properly at home, and she was afraid he would have to go into the hospital again. The next day, when Spratling visited him at the Good Samaritan, he seemed to be somewhat better. His family and friends could see these bouts coming on, but there was little anyone could do to head them off. Joel Sayre had urged him to see a psychiatrist, but Faulkner distrusted them even more than other doctors and would have none of it. Added to his general misery at such a time was the knowledge of what it was costing him -- the room rate, the drugs, the doctors' fees, and the nursing. And besides his own medical expenses, Narcissus had fallen ill, which had meant an unexpected bill for $\$ 400$.

He was finally able to return to work on April 29, after what the studio recorded as two weeks' sick leave. He was not paid for the two weeks, but neither was the contract voided; instead its term was extended for fifteen days, so that it would now expire on August 15. That Thursday morning when he entered the bungalow once again, he said, "Good morning, Miss Davies," and put a book on her desk as he walked into his office. It was a copy of the newly published English edition of Absalom, Absalom!. On the flyleaf he had written, "To Miss Davies, With my deepest appreciation. William Faulkner."

Later when he met Dave Hempstead, Dave complimented him. "That's a handsome tweed you're wearing," he said.

"Dave, I'm 'fraid to put this on," Faulkner replied. "Every time I put it on I wake up in one of those ovens." It was the last suit he had worn before he had entered the Good Samaritan Hospital.

Fn 953 I9 Courtesy Twentieth Century-Fox. 95337 Ibid. 954 II MBB, pp. 173-4. 95417 Courtesy Twentieth Century-Fox. 9551 W. C. Bryant to WF, 5 and 14 Mar., 10 Apr., and I June, 1937. JFSA. 9557 J. R. Hildebrand, "Machines Come to Mississippi," The National Geographic Magazine, LXXII (Sept. 1937), p. 293·293·Fox. 956 I I: Julie D. Anderson, 15 June1965, II June 1966. 9569 I: William Spratling, 18 Jan. 1965. 15610 I: Dorothy Parker, 17 Apr. 1965.956 16 Robert Cantwell, "The Faulkners: Recollections of a Gifted Family," repro in Frederick J. Hoffman and Olga Vickery, eds., William Faulkner: Three Decades of Criticism (New York, 1960), p.60. 95620 Courtesy Twentieth Century-Fox. 95625 I: Julie D. Anderson, II June 1966. 95630 I: David Hempstead, 12 June 1965.

\section{4}

The studio did not take up the option. It may have been about this time that Jack Falkner received a telephone call in El Paso. His brother had not been to the office for several days. Friends such as Hempstead and Hawks would try to check on him, but they were understandably not prepared to see him through a prolonged bout. One of them must have feared such a problem now. And even though his present contract was ending, it would be a mistake to jeopardize his chances of another at some future time. The caller told Jack that his brother "had evidenced no desire or inclination to return, and it was hoped that some member of the family might prevail upon him to do so. I knew what to expect and, based on past experience, had precious little hope that I would be able to do anything." Arriving in Hollywood, Jack found his expectations confirmed: "All I could do was to lend Bill a friendly ear until he himself decided that he had drunk enough for the time being. With his houseboy at the wheel, we roamed the countryside. I'm sure that the endless miles of stucco homes and concrete streets appalled him and he supported the sight of them only with a faint hope that sooner or later we would find ourselves on a dusty country road that would remind him of Mississippi." He was not looking for the beauties of the 
landscape. "Nobody would live in Hollywood," he told Jack, "except to get what money they could out of it."

Fn 96429 I: MCF, 31 Mar. 1965. POM, pp. 195-7; these pages apparently combine elements from more than one of WF's sojourns in Hollywood.

\section{AUGUST, 1937 - FEBRUARY, 1938}

\section{[971]}

There were other familiar pursuits. He read mystery stories and went camping near Sardis Reservoir with Dr. Bell, C. D. Bennett, Dink Kelly, and Tad Smith. They would fish and then sit and sip the first drink of the day while Ed Means from the university dining hall would clean and fry their catch. Later, when Tad was in his tent under the mosquito bar, he would hear Faulkner and four or five others - all night it seemed - drinking corn whiskey and playing poker for matches, betting one or two million. He would hear Faulkner say in his soft high voice, "I call." As he had always done, Faulkner enjoyed camp without actually participating much. "Bill would just walk off by himself," Smith remembered. "He never did talk too much. He'd always just stand around in the shadows and watch."

Fn 97I: 30 C. M. Smith in WFO, pp. 66-7.

\section{4-6}

Now Faulkner's visit lengthened into November and Estelle began to worry. When she telephoned the Algonquin, his room did not answer, and there was no response to the messages she left. She wrote to Morty Goldman, but Goldman had no more luck than she had. When Faulkner failed to appear for interviews which had been scheduled, Jim Devine decided something must be wrong. He knew Faulkner had begun drinking heavily and he had not seen him for the last few days. When he gained entry into Faulkner's room he found him unconscious, face down on the floor, clad only in his shorts with the cold November wind sweeping in through the open window. In the small of his back, on the left side in the area of the kidney, was a thirddegree bum the size of the palm of a hand. It had come from a steam pipe leading to an overhead radiator in the narrow bathroom, Devine later learned. He lifted Faulkner into bed and telephoned Hal Smith's friend Edith Haggard, who sent for a doctor. With Faulkner now conscious, the doctor treated the burn and prescribed paraldehyde to carry him through the alcohol withdrawal. Then he grasped the opportunity to moralize over his famous patient, now debilitated by the drinking and wincing from the severe bum.

"Why do you do this?" he asked him.

Faulkner looked up at him from under the hooded eyes, his jaw outthrust. "Because I like to," he said with a grimace.

When the doctor left, Faulkner took the evil-smelling paraldehyde in exchange for a drink. Then he slept for fourteen hours. When he awoke the next morning he seemed to be feeling fine except for the bum. In fact, he felt well enough to quote Thomas Campion. When Devine asked him where he'd come across Campion, Faulkner told him that Canadian troops had been billeted at Oxford and were welcome to attend lectures. He had heard one on Elizabethan literature and made the acquaintance of the sixteenth century English poet. During the day Devine went over to Sixth Avenue and brought back a thick milkshake with two eggs beaten up in it. Faulkner took it in exchange for another drink. Later Devine had room service sendup a full meal, and once again Faulkner consented to the same exchange. He was still suffering from nerves as well as a cold and general debility, however, and Devine wanted to keep him from working himself into another state.

"Who would you like to see?" he asked. 
"Joel Sayre or Sherwood Anderson," Faulkner answered.

Devine could not find Sayre but reached Anderson, who soon appeared. Sitting down at

Faulkner's bedside, he began to talk in his easy way. To Devine he seemed quiet and soft, almost saint like. What the doctor had not been able to understand presented no problem whatever to this other storyteller. Anderson was warm and solicitous, but he made no mention of his one-time protégé's illness; he was just visiting.

In a few days Faulkner was on the mend. When it was time for him to leave, he was looking fine, Cerf thought, marveling at his recuperative powers. But, like the doctor, he could not resist an admonition.

"Bill," he said, "here you come to New York and spend your time under a doctor's care. What kind of a vacation is that?"

"Bennett," Faulkner replied quietly, "it was my vacation."

Bob Haas asked Jim if he would help Faulkner with the return trip, and so the two men boarded the train south. Estelle met them in Memphis and drove them to Oxford. On Wednesday, November 10, Devine wrote to Haas. "Bill and I had a fairly pleasant trip down -- no sedatives nor liquor were needed and the back apparently didn't bother too much. But the doctor here, who is also a surgeon, has been cutting off the dead tissue and later intends to graft on some skin. As a result, Bill has been in a very nervous state, but I don't think it will last long." He [i.e. Devine; not Faulkner] would return to New York, he said, early the following week.

Fn 97434 I: EF, 18 Feb. 1965; MG, 23 Apr. 1965. 97535 I: Eric J. Devine, 15 Aug. 1965. 9763 I: BC, 20 Sept. 1967. 76 I: EF, 18 Feb. 1965. 976 29 I: Eric J. Devine, IS Aug. 1965.

\section{7}

When he wrote to Bob Haas two days later, he did not mention the novel but he did bring up the contracts and the check for his advance. He wondered if his royalty couldn't be increased to fifteen percent on the first printing, twenty percent on the second, and twenty-five percent thereafter. As to the check, "now that I have got myself mentally together, I would like to do this. I wish to keep a balance with the firm without any skulduggery to show on the books." He would send the advance back to them to be credited to his account, and they could send the first of the six cashier's checks. It was to go to his cousin John, who was apparently going to help him to stay solvent. As to his general health, "I am feeling a little better, though it will take my back some time to heal, and it is still damned painful. However that is that, and curse my own folly."

Fn 97732 WF to RKH, 19 Nov. 1937.

\section{MARCH, 1940 - JANUARY, 1941 .}

\section{3-4}

At the end of the day's hunt they would sit around the campfire, drinking bourbon and waiting for supper. After the plain, hearty fare the appointed ones would help with clean-up chores and then sit again for the rambling talk, the storytelling, and sometimes the nickel poker games that whiled away the short evenings. Faulkner seemed to enjoy it all, hardly distinguishable from the others in his stained hunting clothes and worn slouch hat. He did tell some of the memorable tales, though, and there were a few other things that made him different. Often he would sit reading a book. Occasionally someone might see him scribble a note or two and pocket it. And whenever anyone began a dirty story, he would unobtrusively make his way off by himself.

He would drink moderately with the others until the middle of the week. Then his tempo would increase. It may have been on this hunt that he frightened his companions. When Uncle Bud came in one morning, Ad Bush called to him. He said he ought to go and take a look at Mr. 
Bill. Miller found him unconscious and ashen. The others came in and gradually their alarm mounted. They knew he had been drinking, but now, they thought, he had suffered a kidney seizure of some sort. The problem was transportation: there was eight miles of river to traverse before he could even begin the trip to Oxford and the hospital. As they tried to plan the quickest course, the sound of a motorboat reached them-"the sweetest motor I ever heard in my life," Red Brite called it. They rushed him to the hospital in Oxford, and there, Red heard, Dr. John Culley told them a few hours more would have been too late. He had been hemorrhaging. Alcohol, together with the weeks and months of irritation and worry, had done its work. Brite did not know if it was a perforated ulcer the doctor had feared. Whatever the danger was, it had been a close call.

Fn ,64 5 Coughlan, pp. 77-8. 106421 OTE, p. 16; Jerrold Brite in VFO, p. 157. Brite dates this episode "probably in the early forties."

\section{JANUARY, 1941 - JANUARY, 1942}

\section{9}

It was the depth of the winter now, with the fields out on the farm showing only the bare bushes and stalks of last year's cotton and corn. In the town the principal activity was one Johncy described for the Oxford Eagle: the historic old Cumberland Presbyterian church on South Street was being demolished to make way for a Kroger supermarket. In the country at large, war preparations went forward, but there was still no indication of a satisfactory job [i.e. a military assistance job - Author] Faulkner could do. It was at bleak times like this that he was apt to retire to his room with a supply of Old Crow or whatever else was available to accomplish his flight from the outside world and assuage his inner turmoil. He might escape for a week or two weeks, or even three.

Fn [JB does not indicate for these lines a specific source to support this assertion.- Author]

\section{AUTUMN, 1941 - JULY, 1942}

\section{[1008] - 1109}

Of the seven stories Faulkner had done thus far in 1942, "Shingles for the Lord" was perhaps the best, but if he was aware of its echoes of As I Lay Dying, and if he compared it with the dynamic power and terrible beauty of that work of a decade earlier, he might have reflected even more bitterly on the costs to his spirit and his art of the need to make money. He might well have said, like Herman Melville, "Dollars damn me." That he did feel this- rage and despondency was indicated by one fact. At a certain point during the desk and work, and had been forced to dictate part of the story to Bill Fielden. But he was well enough to do the twenty-one-page typescript, on the back of still another typed version, in time to get it to Harold Ober's office on Friday, July 17.

On July 11 Ober had wired Faulkner that there was something pretty definite in the works in Hollywood. He did not say what it was but he told Faulkner to wire Swanson authority to go ahead. Faulkner complied, but neither he nor Ober nor Swanson had reckoned with one factor: the claims of William Herndon.

Despite Herndon's silence, he had been working in a complicated and ambitious way. An agent like Swanson had many prominent clients to serve; Herndon was in his twenties and had scarcely any clients at all. And the11, thin, crew-cut agent with the badly discolored teeth admired William Faulkner and persistently worked on people such as James J. Geller, the head of Warner Brothers' story department, on Faulkner's behalf. A onetime New York newspaperman, plump and bald, Geller was a literate person who also admired Faulkner's work. He helped Herndon get 
Jack Warner's ear for a special project Herndon was promoting -- a picture about a man who had caught the imagination of many: the Free French leader, General Charles de Gaulle. Herndon not only had the story idea, he had the scriptwriter: William Faulkner. But here he was up against a double problem. It was almost axiomatic in Hollywood that the bigger the novelist, the worse he was as a screenwriter. Hugh Walpole, Sinclair Lewis, Arnold Bennett, Aldous Huxley, and Scott Fitzgerald had all been disappointments. Screen credits were the only solid assurance a studio could trust, and Faulkner had only the credits for Today We Live, The Road to Glory, and Slave Ship. Moreover, if the rumors were true, executives like Zanuck had been sufficiently outraged by his drinking to make another studio head wary. But Herndon showed "Turn About" to Jack Warner and what Faulkner had done with it in Today We Live. "Say, this is good," Warner said. "Why wasn't this brought to my attention?"

Fn 110924 I: Stephen Longstreet, 12 June 1966. [Without access to the interview transcript the reference to "if rumors were true" is difficult to substantiate from this citation alone.- Author]

\section{JULY, 1942 - AUGUST, 1943}

\section{3-4}

One day Buckner went to lunch with them at the Musso \& Frank Grill, a restaurant more popular with the writers than such widely known places as the Brown Derby. Buckner's two companions were oddly paired: Faulkner small and gray in his light seersucker suit, Faust well over six feet three inches tall and strikingly handsome. Faust was also a phenomenal drinker. As Frank Gruber recalled, "He [Faust; not Faulkner - Author] came to work in the morning carrying a quart thermos bottle full of whiskey. By noon this was gone. His lunch consisted of twelve to fifteen drinks. During the afternoon he dashed out through the back gate about once an hour and had three quick rum drinks in a handy bar. When he went home at five-thirty he had a light supper and then settled down to his serious drinking." Faust ordered Myer's dark rum and Faulkner asked for Old Grand-Dad. They began to discuss the best vehicle for a good, solid, two days' oblivion, Faust extolling rum and Faulkner holding out for bourbon. Buckner listened silently. It was like hearing two masters discussing stocks and bonds, he thought, or stamps, and it seemed to him that in a way liquor nourished both their talents. For Buckner it was a comic luncheon.

Fn 112333 I: Frank Gruber, 12 June1965. 11242 I: Robert Buckner, 9 June1965.

\section{[1125]-1126}

The two men spent some time together off the set that fall. Faulkner went along when Hawks took his son and daughter on a fishing expedition to Big Bear Lake in the mountains of southeast California. The fifth member of the party was Hawks's beautiful wife, called "Slim" by her friends, who had set a new style among high-fashion models. They would troll for fish in a small boat during the late afternoon and then Slim would begin preparations for dinner. "The way she cleans a fish," Faulkner would later say, "it's beautiful. "He was on the wagon then, Slim remembered, but not the next time they went on an expedition. They drove to Calexico, a hot dusty town on the Mexican border, for some bird-shooting. This time the children did not accompany them. Instead, Hawks's good friend Clark Gable made a fourth. Only a fair shot, Slim winged a bird and had to search through the brush of the sandy riverbed. She stooped to find the bloody bird looking up at her. "I couldn't bring myself to pick it up and wring its lovely pearlgray feathered neck. It was really a sort of staring contest. When Bill found us looking intently into each other's eyes, he very kindly did the nasty deed for me with a swift sharp gesture. And he never told anyone what a coward I had been." They covered the 200-mile trip back to Los Angeles in the dark with Faulkner and Gable in the back seat sharing a bottle of bourbon-very 
jolly and then very sleepy, she remembered. Though it was early morning when they dropped Faukner [sic] off, he showed up the next afternoon looking for a pipe he had forgotten. He had apparently continued from where he had left off in the back seat, and it was some days later before he passed through his saturation point-with some medical assistance. On occasions such as this his admirer in the main building, James J. Geller, would report him sick.

Hawks had always seemed to move in exclusive circles, and now, in wartime, this was especially true. One night he took Faulkner and Gable to a dinner party in Sullivan Canyon above Beverly Hills. Among the guests were more than thirty Army Air Corps officers including General "Hap" were more than thirty Army Air Corps officers including General "Hap" Arnold, who had provided Jack Warner's colonelcy. Civilian authority was and who was now Assistant Secretary of War for Air. Faulkner mentioned the hunting trip to Calexico and then began to talk about airplanes. He wanted to get into the war, he said. Lovett did not take the bait, and Faulkner did not pursue the subject. A few days later, however, he let Lovett know that he hoped he could obtain a pilot's commission. Lovett tried to discourage him: his age and his habits were against him. Besides, he couldn't pass the physical. But Faulkner persisted, trying another approach which finally arrived at Lovett's desk anyway. There it stopped. "I will not approve making a Public Relations Officer out of William Faulkner," he said.

Fn 1 I26 17 Mrs. Howard Hawks, now Mrs. Kenneth Keith, to JB, 10 Mar. and 15 Apr., 1966. 112619 I: Stephen Longstreet, 12 June 1966. 112635 I: Robert Lovett, 16 Aug. 1965.

\section{[1127]}

His weekends were uncertain. Then under contract to Warner Brothers was actress Ruth Ford, the former Ole Miss coed who had dated his brother Dean. Faulkner would visit her and play with her small daughter, Shelley. Sometimes the Buckners would entertain him at their home in Encino. Faulkner would swim with their six-year-old daughter and four-year-old son. He would sit and talk with them as adults, never down to them as children, and they loved it. He would compliment Bob Buckner on his juleps, and his wife-whom he called "Miss Mary"--on the dinner. They "They have to be pinched," he had told her.

Fn .128 10 I: Robert Buckner, 9 June1965, 8 June 1966.

\section{9}

The script moved along. Writing Victoria, who had joined her husband in Wilson, North Carolina, Faulkner told her, "I feel pretty well, sober, am writing to the satisfaction of the studio. The script I did now has the official O.K. of De Gaulle's agent and of the Dept. of State, so nothing to do but write in the dialogue." He was done with the dialogue in November, and by the sixteenth the mimeograph department had the 153-page screenplay ready for distribution. But all the difficulties were not resolved. When Buckner read the screenplay through, it did not allay his misgivings: "It was a curious ms and perhaps 20 years ahead of its time in technique, more by accident I suspect than prescient genius .... His natural circumlocutious style and endless sentences were diametrically opposed to the stringent, telegraphic needs of pictures. But in the DeGaulle script he hit on an odd offbeat note, almost 'nouvelle vague' a la Fellini and Bergman. It intrigued me, but worried me, and even baffled Bill in places." Faulkner was frank about his deficiencies as a screenwriter, Buckner remembered. Sometimes unsure of terminology, he might use "Dissolve" for "Fade" or "Cut" for "Dissolve." He employed these terms with more facility than accuracy, like a cook who felt additional seasoning was needed. Along with this approach went a kind of equanimity, it seemed. He took things at face value, never adopting the attitude of superiority to Hollywood often assumed by Eastern writers. 
Fn 112.9 16 Courtesy Warner Bros. Sept. 1942. Courtesy Mrs. Fielden. 112923 Courtesy Warner Bros. 112936 Robert Buckner to JB, 30Mar. 1966. I: 9 June 1965. WF continued to see Buckner from time to time, occasionally talking literature. One book in particular he recommended: The Triumph of the Egg by Sherwood Anderson.

\section{8}

His letters were not all reassuring, of course, and occasionally there was discord in their correspondence, some of it arising from financial matters and some from other causes. Estelle would write that she needed extra money, and he would supply it together with urgings that she be careful. One of her own anxieties would become persistent. Her reply, written on August 4, must have seemed to him perverse: "Your letter sounded so cheerful that it made us all feel good. I've a notion that Mr. Hawks must have his old secretary back and that once again you're finding California worth while -- Don't misunderstand this, and write back that I begrudge you pleasure -I truly do not. . . . Suppose I've lived so long now with the knowledge that it has become a familiar and doesn't frighten me as it did."

It was said that Hawks had it written into his [Hawks'] contract that he did not have to talk about his productions to Jack Warner and that studio officials were not to come on the set without his approval. These cool relations with the executive wing worsened as costs continued to mount. People on the picture heard rumors of a face-to-face argument. Faulkner and Fisher continued to work at the script, until one morning Fisher picked up a trade paper to read that Hawks had walked off the lot. Whether the picture was closed down or not, Hawks was apparently through with it; if he was, the chances were that his writers were, too. Soon the word came through: Battle Cry was off. That day, Fisher remembered, Faulkner walked across the street into a bar.

Fn 114812 JFSA. 114815 I: A. I. Bezzerides, 7 June 1966. 114823 I: Steve Fisher, 13 June 1966.

\section{AUGUST, 1943 - DECEMBER, 1944}

\section{[1155]-1156}

Bezzerides was soon aware of difficulties at Warners'. Faulkner wanted to get back to the Hawks picture, but Wallis was interested in Faulkner's redoing God Is My Co-Pilot. Wallis called him in.

"Do you want to do it?" he asked.

"No," Faulkner answered.

"Have you read the book?"

"No."

"Do you want to read it?"

"No."

"What do you want to do?" Wallis asked in exasperation.

"Go home to Mississippi," Faulkner told him.

Wallis exploded. "You're under contract and you'll work here," he said. The "Can I work at home?" business was one Hollywood legend that would not be reenacted, and particularly not at his expense.

Faulkner reacted characteristically. He began to drink -- one week after he had reported for work. Bezzerides got him home and during the weekend managed somehow to abort the drinking bout. What probably saved the situation was an administrative decision to take Faulkner off the Wallis picture and send him back to Hawks. It may have been Geller's good offices. Whatever the source, it was a providential intervention, and he went back on Monday to one of the few Hollywood working relationships that he found tolerable. After that, people at the studio 
assumed that they could do things with Faulkner through Bezzerides, and there would be other occasions when they would try.

Fn 11563 I: Steve Fisher, 13 June 1966. 115614 I: A. I. Bezzerides, 14 June1965.

\section{9-60}

He found her an appealing companion. Before she had gone to New Orleans to work as a waitress, Betty Francis had grown up in the country. She and Faulkner were both amused by the "Southern gravy" served with the broiled pork chops at Musso Frank's, for neither of them had ever tasted anything like it in the South. Though they liked the chops, they both hated the vegetables, which seemed tasteless. Before dinner there would be appetizers-two or three Old Fashioneds, delicious drinks in big glasses. Occasionally strangers would recognize Faulkner. A few would even come to the table and ask him about his work. After one such occasion, Faulkner asked Betty to do something for him. She agreed, and thereafter she would say to any questioner, "Mr. Faulkner doesn't care to speak of his work, but we would be glad for you to join us in a cocktail." It usually worked.

On occasion, though, there was literary talk at their table. Owen had been a close friend of Thomas Wolfe, whom Faulkner seemed anxious to learn about. It was apparent that Jo Pagano adored Faulkner's work, and sometimes, when they continued with the Old Fashioneds after dinner, Jo might say just how much he cared about it and how good he thought it was. "Bill would usually just sit there quietly puffing on his pipe," Betty remembered, "his piercing soft black eyes looking off into space, like maybe back to Mississippi. You ... had the feeling with Bill that when anything got uncomfortable, he sort of transported himself back to a more comfortable time and place."

But "many a night, Bill did all the talking... about down home, the people and things, and hunting trips." Betty remembered best his "grand repertoire of little creature stories which gave us a breath of fresh air in Hollywood. Precious and funny stories about little wood animals in their holes and turtles here and there ... which were wonderful in the real sense of the word." Then, before the journey back to the bedroom-sitting room on the side of the mountain, he would finish his last Old Fashioned. He drank the cocktails rather than straight whiskey because, he said, he had to be able to "punch the clock" in the morning.

Weekends were a different matter; then he would ask the bartender for bourbon and branch water. As the evening wore on he might order double shots, straight. Often Owen and Jo Pagano would match him drink for drink. After a particularly strenuous evening the Francises or the Paganos would drive him home. One evening at the bar Jo introduced him to a short, plump man In a sergeant's uniform. After a childhood in the tenement sections of Philadelphia and Brooklyn, Edmund Kohn had used his talent as an artist on several New York newspapers before moving to the West Coast during the Depression. The army had found a use for his skills and quartered him in a hotel off Hollywood Boulevard. The Saturday afternoon after they met, Kohn returned to Musso's carrying a copy of The Hamlet. Joining Owen, Betty, and Faulkner in a booth, he told Betty that she was missing something great. She should start reading Faulkner's books right away. Faulkner interrupted.

"I think it would be a good idea if you didn't read any of my stuff just now," he said to Betty.

"All right, Billy," she told him, "I won't until I leave Hollywood."

"That's good," he said.

Later he would tell her more than once how good it was to have a friend who hadn't read his work and had no notion or opinion of it.

Fn 116013 Betty Francis Cooper to Elisabeth Linscott. Courtesy Mr. Arthur Cooper and Mrs. Linscott. 


\section{2}

At times like this--confronted by a problem, he could not solve, trapped in a situation that presented no escape-he would turn to the anodyne. But here there was acute conflict in the escape from conflict. Both for past favors and for future possibilities, he could not let Hawks down. And if he did abrogate control, there would be a limit to the extent Geller could protect him.

He took steps to impose safeguards. One Sunday afternoon Ed Kohn waited for him at the Roosevelt Hotel at 5:30. When Faulkner appeared a few moments later, neatly turned out and carrying a cane, Kohn could see that he had been drinking heavily. Walking behind him was a man in his fifties, dressed in a dark suit and carrying a small black bag. Faulkner introduced him as Mr. Nielsen, and they had a quiet dinner. Faulkner spoke little, and what talking he did was somber. He brought up the subject of Hollywood. "They worship death here," he said. "They don't worship money, they worship death."

When they had finished, Kohn suggested a visit to the Chapeau Rouge on Highland Avenue. They left the Roosevelt, Mr. Nielsen two or three feet behind them. Faulkner put his arm around Kohn, and as they strolled down the street he recited "The Phoenix and the Turtle" -loving the language, Kohn remembered, speaking the words as though he had written them himself. When they were seated at the Chapeau Rouge, Faulkner turned to Nielsen.

"Give me the bottle," he said.

Nielsen was reluctant.

"Now, don't be a sissy," Faulkner said.

Nielsen drew a bottle of bourbon from the black bag and handed it over. Faulkner poured the drinks and then excused himself. When he had left, Nielsen turned to Kohn. "You must be wondering who I am," he said. "I'm a nurse. Mr. Faulkner hired me to see that he got to work on Monday."

Fn 116235 I: Edmund Kohn, 11 June 1966.

\section{[1165]-1166}

Wald was assigned to another picture and he took Faulkner with him. The Adventures of Don Juan had already been done in two scenarios, both unacceptable. On June 12 Faulkner began revising the second. It seems to have been a particularly inept script in which the Don was a kind of reluctant Lothario forced into his amorous career by a combination of circumstances and women. Full of cliché in both form and language, it must have been one of the more excruciating jobs Faulkner undertook, no I matter how hard he steeled himself to regard scriptwriting as a job with no real relation to his true vocation. It seems likely that it was also during this period that the studio decided they could not use Faulkner's amalgam of The Damned Don't Cry and "The Brooch." And it may have been now that another episode occurred that Ed Kohn recalled later: managing to get a case of bourbon, Faulkner checked into a hotel and stayed there the better part of a week, until the supply was gone.

Fn 116526 Courtesy Warner Bros. 116537 Ibid. Apparently WF had been given the file on The Adventures of Don Juan in mid-May, for it was on May 13 that the studio research department recorded WF's only call on their services. He wanted to know the date of the battle of Cartagena and the name of the British admiral. The date was 1740; the admiral, Edward Vernon. 11662 I: Edmund Kohn, 11 June 1966.

\section{0}

But there would still be days when he would come home from the studio in a black humor - furious or depressed, or both. It grew worse in August when he was put back on God Is My Co-Pilot. For a time Bob Buckner had taken the picture over, but now apparently Hal Wallis had reassumed personal charge. He had not forgotten his earlier interview with this recalcitrant 
writer, and he was keeping a close check on him. He scheduled a conference which Faulkner awaited with dread.

Known to his secretary of three months to be morose and uncommunicative, but sober, Faulkner had a reputation for being independent for not taking anything from anyone. "All the writers were in awe of him, "she remembered (though her own reaction was one of annoyance, for she was an outgoing person). The day of the conference arrived, and a call came summoning him to Wallis' office. When his secretary got no answer from him, she went into his office.

Horrified to see that he was drunk, she tried to help him collect himself. Meanwhile Buzz appeared. After a half-hour Faulkner declared he was ready. "Bud," he said, "take me over there and push me in." This would have been too obvious, so Bezzerides got him started in the right direction and stood ready to leap out and help him if he faltered. Peeking through the blinds, Buzz and the secretary watched with the others who had gathered as Faulkner slowly and woodenly negotiated a painfully straight line toward Wallis' office. They waited. A half hour passed before the door reopened and Faulkner made his way back his posture, gait, and appearance unchanged. Once back in his office, he collapsed.

None of them ever learned what had transpired, but apparently his responses had been affirmative and they had been accepted by Wallis. "If you said no," Bezzerides remembered, "they would cut your throat." Bezzerides got him home and saw him through the weekend, and he was able to report back to work on Monday. It was an exceedingly grim time in the small apartment, a time of depression that affected Estelle as deeply-and sometimes almost as disastrously-as it did her husband. For Jill, fortunately, there was Lady Go-lightly and House's Glendale stables.

Fn 117019 I: Sylvia Rosenthal, 12 June1966. 117033 I: A. 1. Bezzerides. 14 June1965.1170 33 I: A. I. Bezzerides, 14 June1965. 117035 I: EF 27 Oct. 1965.

\section{1}

[There does not seem to be an overt or covert reference to "drinking" on this page despite the listing under that topic in Blotner's index.- Author]

\section{2-4}

[This passage is better designated as "1173-74" since no drinking appears on 1172. - Author]

By November 18, the end of his first week on Mildred Pierce, Faulkner had reworked much of the original script. Wald asked him to come to a story conference. When he arrived, he found the director already present. Mike Curtiz was a man known to some as a "butcher." While he talked at length, discussing what they already had and suggesting possible changes, Faulkner sat silent, puffing on his pipe. Finally Curtiz turned on him. "Why don't you say something?" he asked. Faulkner rose and left the room without answering. Back in his office, he began drinking. Later Jo Pagano discovered what had happened, and he and Tom Reed, another writer, managed to walk him off the lot without detection.

Something like this would set him off for an unpredictable time. On such another occasion Bezzerides had watched Faulkner sitting there in his living room, the bottle of Old Grand-Dad on the table, a Filipino knife in his hand. "I'm gonna cut Herndon up," he said. It was the same persona he had adopted a dozen years earlier when he told about shooting the doctor. He felt the same fury toward Curtiz. When Bezzerides saw something like this coming, he would put the liquor away.

"Bud," Faulkner would say, "give me a drink." .

"No. I know what will happen."

"You're a self-righteous, stiff-necked bastard."

After one such exchange, Bezzerides left the room. When he returned, his Faulkner novels were piled on the coffee table. Faulkner had autographed all of them. "Now will you give 
me a drink?" he asked. When he was refused once more, he got to his feet. "All right," he said, "I'll go up to Gene's. He'll give me a drink." And he went up the hill to the home of Bezzerides' neighbor, writer Gene Fowler, who was also supposed to remain on the wagon. They made an evening of it together.

Bezzerides would try every strategy he could think of. Dynamic, explosive, emotional, he would try to reach Faulkner somehow. A doctor had told Bezzerides after one of these bouts that if Faulkner did not have heart trouble, this kind of habitual excess could certainly bring it on. Now Bezzerides appealed to him. "Don't go that way, Bill. You're too precious." It seemed to make no impression, and Buzz walked away. When he returned Faulkner was not there.

Wondering where he had gotten to, Buzz noticed that two bookshelves were bare. He looked in the other rooms and then went outside on the porch. From there he caught sight of his friend straining to carry two sacks -- lumpy with the books -- up the hill.

"Bill, what are you doing?" he called out.

Faulkner answered through gritted teeth. "I want to see if I've got a bad heart or not."

When he reached this stage, Buzz knew he could no longer deal with the situation. Big and muscled like a wrestler, he picked the other up bodily to take him out to the car and thence to a private hospital in the Valley. As he moved toward the door Faulkner twisted, screwing up his arms in Bezzerides' enveloping grasp.

"Bill, what are you trying to do?"

"Ah'm tryin' to get down," Faulkner said.

Buzz stood there and began to laugh. Then Faulkner was laughing, too. Bezzerides took him on out to the car.

On two such occasions Jo Pagano helped. When they first arrived at the sanitarium, Faulkner demanded his promise that he would come and get him the next morning. But when Pagano returned, he found his friend so debilitated that he could not consider taking him out. On the next admission, Faulkner turned to Tom Reed for the promise of release. To Pagano he said only, "You broke your word to me."

But they were friends who understood, friends for whom the friendship was more than worth these obligations. And what they would remember most vividly would be the good times and the storytelling. Pagano remembered the story others had taken seriously. His grandmother had upbraided his grandfather, Faulkner said: "Don't you ever let me catch you giving that child whiskey again-without sugar." They remembered his talk about home and what he would do when he finished in Hollywood. "I'm gonna grow me a goatee and a big mustache and be a real Southern Gentleman and retire," he told Bezzerides. To Pagano he seemed like the Little Colonel in The Birth of a Nation.

Fn 117311 I: Constance Prinzmetal, 15 June 1965. 1173 13 I: Jo Pagano, 9 June 1966. 117317 I: Edmund Kohn, 11 June1966. 1174 15 I: A. I. Bezzerides, 14 June1965·1965. 117421 I: Jo Pagano, 5 June 1966. A. I: Bezzerides, 14 June 1965.

\section{[1175]}

Departure time came Soon. The following Wednesday he went out to the stables to say goodbye and to ask Jack House to be sure to keep Lady until Jill came back in June. He had not been able to finish all the changes in The Big Sleep, so when he boarded the train on the morning of December12 he took a copy of the script with him. He had not bothered to clean out his desk. Looking through it, Jerry Wald found a number of bottles in the deep drawer on the lower lefthand side.

Fn [For 117539 see 11763 I: Budd Schulberg, 15 June1965.- Author]

\section{DECEMBER, 1944 - SEPTEMBER, 1945}


He was concerned about something else as well. "What I'm getting at is, this is going to take longer than I thought .... I left Warners Dec $15^{\text {th }}$ for 6 months. As usual, I may run out of money before the six months are up .. If I do, I'll either have to pot boil, or go back to the salt mine; in either case, I'll have to put this aside." There may have been something else worrying him, too. On one occasion, walking with Bezzerides after a drinking bout, he had suddenly burst out, "God damn! Why do I do it?" And Buzz had said, "The only one who can tell is you." Now, with the old creative discontent nagging him once more, with a new manuscript on his worktable, he must have looked with dread and horror not just at the prospect of putting it off as he had put off The Hamlet for so long, but at the destructive collapses to come-at more lost days and nights in the hushed rooms and twilit corridors of hospitals in the Valley. He needed time. "Can I send you in some of this," he asked Cerf and Haas, "and take an advance to keep working on it with until my leave is up? That is, can I count on say 2 or 3 thousand if I need it, about March'?"

[For the citation of this letter to Bennet Cerf and Howard Haas dated January 1, 1945, see 117829 WFL, pp. 19, 32. - Author] 117929 I: A. I. Bezzerides, 14 June 1965.

\section{[1180-1181]}

Suddenly in April there was another possibility. The Personnel Narratives Office of the Army Air Corps wanted him to go into one of the combat theaters for about forty-five days to gather material for a book on Air Force operations overseas. He confirmed his interest and was to meet with Major Bernard A. Bergman between flights at the Memphis airport on April 20. Bergman wrote Ober (who had set things in motion) to say he was very pleased. One day after the meeting Faulkner wired Ober what had happened: INCONCLUSIVE BECAUSE I WAS TIGHT WRITING DETAILS CAN ANYTHING BE DONE AS I WANT THE JOB. Nothing, it turned out, could be done.

Fn 118038 Maj. Bernard Bergman to WF, 11 Apr. 1945. FCVA. 11815 WF to HO, 21 Apr. 1945.

\section{[1192-1193]}

His things at the Bezzerideses required little more packing than had those at the studio. There was more to do out at the stable. He had known, really, since the previous year, that he was going to take Lady home with him. He had known it ever since that day the summer before when Jill had looked up at him and said, "Pappy, I've got to have that horse. It hurts my heart." But he had not made it definite; the unexpected could still bring disappointment. Lady had not been inexpensive-he would later say that she had cost him $\$ 125$ and that he had paid $\$ 70$ more to cure the distemper-and there had also been stud fees, for they had tried to breed her. It was impossible to tell if they had been successful, but now she had a heavy look about her. For \$125 he bought a small, black, two-wheeled horse trailer just big enough for Lady. For \$350 Newt House, Jack's oldest son, agreed to haul it to Mississippi behind his Cadillac. Faulkner was just about ready. Then, the night before departure, he did an uncharacteristic thing: he agreed to go to a party.

Christopher Isherwood had proved as adept a screenwriter as a poet, novelist, and dramatist. A tactful man, he chatted politely with Faulkner in the din of the party. People had told him, "It's hopeless to talk to Faulkner about books, just hunting dogs." But Faulkner seemed to him very much the gentleman. He even asked a literary question, inquiring about Auden and Spender, about their work, with a distant politeness in what sounded like a very British accent. Faulkner (who, when he replied to Cowley's letter mentioning his fame in France, wrote, "Yes, I had become aware of Faulkner's European reputation") recalled the brief conversation differently. He had gone to the party under pressure and determined to get through the ordeal as best he could. "I was sitting on a sofa with a drink, suddenly realised I was being pretty intently listened 
to by three men whom I then realised were squatting on their heels and knees in a kind of circle in front of me. They were Isherwood, the English poet, and ; a French surrealist, Helion; the other one's name I forget. I'l1.have to admit though that I felt more like a decrepit gaffer telling stories than like an old master producing jewels for three junior co-laborers." But he had tried to rise to the occasion, whereas a few years before he would simply have glowered in silence or departed. It could not be said that he was mellowing, but as the weight of his reputation fell more heavily upon him he was changing. He was still relieved, however, when he could decently leave the. party.

Fn 119219 WF to JB. 119226 The New Yorker, XXIX (Feb. 28, 1953), p. 20, in LIG, : pp. 74-6; I: JFS, 18 Nov. 1966. I192 28 WF to MC, 5 Oct. 1945, in FCF, pp. 34-5. 119235 I: Christopher Isherwood, 6 June 1965. $11937 \mathrm{WF}$ to MC, 5 Oct. 1945 , in $F C F$, p. 35.

\section{SEPTEMBER, 1945 - APRIL, 1947}

\section{[1196]}

Each week more familiar faces appeared on the streets of the town and in the pages of the Eagle as more servicemen returned home. But nearly half a hundred who had left Lafayette County for the war would never return. ,

Lifting a glass to those who were gone involved some inconvenience, for beer and wine had been added to the list of beverages not legally available in the county. A special referendum on the question held in 1944 had not included absentee ballots, and the bootleggers' monopoly was now achieved. But the town was prospering. T. Edison Avent would soon open a milkprocessing plant. At the same time he was busy planning a subdivision, with lumber for the houses supplied from his own sawmill. A new kind of progress was looming up ahead for Oxford and Lafayette County.

Fn 19622 OXE, 20 and 27 Sept., 29 Nov. 1945.

\section{[1204]}

Every day seemed to bring some new harassment. Even the National City Bank of New York sought him out, sending to the Bank of Oxford a check that should have gone to Harold Ober. He wrote them an irate letter. "If you had given me any information about this matter, I could have saved you having your books out of balance, as well as wear and tear on your fountain pen and perforating machine, by telling you at once where to send this money in place of this epistolary button button whos got it. No wonder you make only 5 or 6 percent on your money." He seemed barely able to contain himself as he concluded:

Thanking you, I remain, and that this sort of hairbrained recklessness with information will not some day bring you to grief, is the sincere hope and prayer of Yours truly,

William Faulkner.

Not long after this, Harold Ober wrote to an Italian waiting for a reply about a translation he had proposed. "Mr. Faulkner has not been very well lately, and has not been able to do much writing," he told the man. Faulkner had been undergoing the accumulation of problems, frustrations, and anxieties that had sent him into collapses in Hollywood. Sometimes Jill could see one coming when, a few days before the onset, he would begin to recite "The Phoenix and the Turtle" or that other harbinger, "When daisies pied and violets blue." She pleaded with him to hold on, to resist. "Think of me," she appealed. But it was already too late, and he answered her with a phrase she never forgot. "Nobody remembers Shakespeare's children," he said. 
Jill dreaded what would follow. When the household was thrown into this kind of chaotic situation, all the Negro help would leave. And there was no point in appealing to relatives; it was better to see it through without their knowing. Sometimes Jill would have to help her father get back into bed. On one occasion, perhaps this time, no one was near as he made his way out of his bedroom to the landing and then toppled all the way down the staircase to the hall floor below. He was lucky the fall didn't kill him. When such severe collapses occurred the doctor would be summoned, and watch things run their course without needing the hospital.

Fn 1204 17. WF to National City Bank of New York, 5 Feb. 19 1946. FCVA. 120420 HO, carbon to WF, 8 Feb. 1946. 110427 I: JFS, 25 July and 11 Aug., 1968. "When daisies pied" is found in Love's Labors Lost, V, ii, p. 902.

\section{FEBRUARY - DECEMBER, 1948}

\section{[1254]}

In Oxford Faulkner was preparing for a debut of another kind. At the end of the war, Hugh Evans and his wife Mary had come back to settle in Oxford. After commanding the Ole Miss army R.O.T.C., Evans had been given his own infantry regiment. He had served with distinction and retired as a full colonel. Three years older than Faulkner and a little taller and heavier, the white-haired colonel was much like him in other ways. The two men had found each other congenial from the time of Evans' R.O.T.C. assignment, when he and Ross Brown and Faulkner would sometimes go flying together. Vigorous and active, Evans planned no sedentary retirement. With Brown and Dr. Ashford Little he had developed a project the previous fall: pooling material, money, and labor, they would build a houseboat. Bill Faulkner was in on it, too. Like Dr. Little, he was limited in the amount of time he could give; nevertheless, he threw himself into the spirit of it, with Brown as the architect and Evans the engineer and construction supervisor. As Faulkner would later inscribe it on the vessel's impressive letters of marque, "Out of Confusion by Boundless Hope: Conceived in a Canadian Club bottle She was born A.D. 15th August 1947 by uproarious Caesarian Section in prone position with her bottom upward upward in Evans's back yard eleven miles from the nearest water deeper than a half inch kitchen tap \& waxed \& grew daily there beneath the whole town's enrapt cynosure."

Fn 5430 I: Robert Farley, 3 Apr. 1965; Dr. and Mrs. Ashford Little, 21 Jan. 1967; Mr. and Mrs. Ross Brown, 20 Nov. 1966. 125436 JFSA; in WFO, pp. 232-4.

\section{$[1265-1268]$}

That night there was the dinner party at the Haases' Fifth Avenue apartment, where the guests included Malcolm and Muriel Cowley, who now met Faulkner for the first time. Among the other guests were Don and Pat Klopfer, Bennett and Phyllis Cerf, Hal Smith, and Jim Devine. Observing the two butlers, Cowley felt it was "one of those dinners in style (though nobody dressed) where the ladies withdraw as they did fifty years ago and leave the gentlemen discoursing over cigars and cognac. There was a good deal of cognac." Faulkner even talked a little literary talk the party. Hemingway had no courage to experiment, he told Cowley. His own method was different. "You have to take chances and put it down good or bad," he said. It was as though the twin apologies may have rankled. He would not impugn Hemingway's physical courage in any way, but since it had been brought out into the open he stuck to what he said about his great contemporary's aesthetics. Later, after Malcolm and · Muriel left at two o'clock, Faulkner and Devine continued the party at Hal Smith's place.

Faulkner had engagements the next day. Don Klopfer took him to "21" for lunch, and afterwards he did one job for the firm. Louise Bonino was working in publicity now, and in previous years her old" friend had been a source of frustration with his reluctance to grant 
interviews that would help promote his books. But now he gave one to Ralph Thompson of The New York Times. He was reluctant, as usual, and a little edgy. Critic Richard Chase had just published an essay which treated Faulkner's imagery primarily in terms of curves and lines. When Thompson asked him about this, it appeared at first that he was not going to answer. Then he said, "Look, I'm just a writer. Not a literary man." He shifted uncomfortably but then began to try to explain, saying some things in his anxiety to get the interview over with-that he probably would have denied vehemently under other circumstances. "I write about the people around Oxford. I know them, and they know me. They don't much care what I write." But when these same people saw that he'd published another book, it was different: "they come around and try to borrow money, figuring I've made a million dollars. Or else they look twice and figure I couldn't make a thousand." In some ways he was better off before he had ever published a novel. "In those days I was a free man. Had one pair of pants, one pair of shoes, and an old trench coat with a pocket big enough for a whiskey bottle. Now I get stacks of letters asking what I eat for breakfast and what about curves and linear discreteness."

On Wednesday Ruth phoned him at the Algonquin and invited him to go to a party with her. When he declined she thought his voice sounded strange. She called him the next day and again he wouldn't go out, and his voice sounded even stranger. There was no answer at all when she rang his room on Friday. Harvey Breit had been spending some time with Faulkner, so Ruth called Harvey, but he had neither seen him nor talked to him. Bennett Cerf had not only not seen him but told her that he had missed several appointments. The day before, Cowley had telephoned to confirm a luncheon engagement, and Jim Devine had told him Faulkner probably would not be able to make it, although he might check the next day. When Cowley knocked on the door of Room 307 at the Algonquin at noon on Friday, October 22, there was no response. He knocked again and this time heard a voice mutter, "Come in." Entering the darkened room, he walked over to the bed where Faulkner lay. There was no conversation. He gave him a drink, sat by him for a long while, and then left. When he returned at four, things were happening.

Ruth and Harvey had gone to the hotel and heard no answer when they knocked. They got the manager to let them in and found Faulkner semiconscious. He had apparently been drinking for three days, and he had not eaten. When Cowley returned he found Bob Haas there, too, with Ward Moorehouse, the theater critic of the New York Sun. They made a series of phone calls which ended with arrangements to take Faulkner to the Fieldstone Sanitarium at 250th Street. Cowley got him into his clothes and then watched as, leaning on Harvey, he made his way downstairs, out the hotel's service entrance, and into the waiting ambulance. Ruth, Jim Devine, and Harvey got in, too, and then the attendant closed the doors and they drove away. They saw him through the hospital admissions procedure and waited while he was installed in a room. As they were about to leave, Harvey stopped to talk to the doctor in charge.

"Please take good care of him," he said, "he's a genius."

"Don't worry," the doctor replied, "I've had experience in this line. I used to take care of Tom Wolfe."

- When Ruth and Harvey returned the next morning, the doctor said he wanted to keep the patient four or five days. When they went to Faulkner's room, they found him in a very different state from when they had last seen him. He was highly agitated and he would not hear of staying. "You gotta get me out of here," he said. "You gotta get me out of here." The usual reaction had set in, and with it his abhorrence of confinement. During the two hours they stayed with him, he remained agitated. He suggested to Harvey nothing so much as a fox one might see behind bars, padding from one side of his cage to another and back in desperation. The doctor was adamant that Faulkner needed further time and care for recuperation. They didn't know what to do. Finally, they hit on a compromise. They called Malcolm at his home in Sherman, Connecticut. Yes, he and Muriel could put Faulkner up for a few days while he got back on his feet. 
Cowley drove down, and it was late that night when they got him discharged from the hospital and began the drive out of the city, across the bridges and onto the parkways leading north. They passed the ranges of apartment buildings and finally the houses began to thin out. Now, at every crossroads where there was a tavern, Faulkner would suggest they stop and have a drink. Harvey began to feel terrible. Here was a man he admired, even venerated. He wanted to agree to everything Faulkner asked, but he knew he had to say no. Finally they reached a junction point where Cowley stopped so Harvey and Ruth could take the train back to New York. Then he drove on to Sherman and with Muriel's help got their guest settled in his room.

On Sunday he felt weak but enjoyed some leek and potato soup Muriel made for him. The Cowleys had seen friends go through this before, and now they helped him. With the pangs of withdrawal. During the day he would ask for a drink, and from time to time they gave him a weak one, spacing the intervals as widely as they could. By Monday he was up, determined now to recover as soon as possible. Cowley would remember him that day: "he showed extreme selfcontrol, pacing up and down the living room with beads of cold sweat on $~$ his forehead and not asking for a drink except at long intervals of perhaps three hours, and then only politely: 'Do you think I could have a beer, ma'am?' "With his short steps and small features, he gave Cowley an impression of delicacy and fastidiousness. At fifty-one, and weighing 148 pounds, he could still wear a pair of young Robbie Cowley's pants with their 30-inch waist. "A small head, very dark brown eyes," Cowley remembered later. "One eyebrow goes up, the other down, and perhaps that is what gives him the resemblance to Poe. Hair lies close to his head and is ringleted like a Roman gentleman's. Very small hands and feet "

Fn 126611 FCF, pp. 103-4. 126613 I: DSK, 16 Aug. 1965. 126633 NYT, 7 Nov. 1948, in LIG, pp. 61-2. Richard Chase's article, "The Stone and the Crucifixion: Faulkner's Light in August, " was published in The Kenyon Review, X (Aug. 1948), pp. 539-51. 12671 I: Ruth Ford, 16 July 1964; Harvey Breit, 12 Nov. 1964. $126813 \mathrm{Ibid}$. [For 126830 see 126938 I: Mr. and Mrs. Malcolm Cowley, 14 Nov. 1964.- Author]

Cowley had telephoned Ruth Ford that the train would arrive at three o'clock. She was planning a small dinner for Faulkner, and the preparations would keep her busy until the scheduled time of seven. Afraid of what might happen in the meantime, she telephoned Harvey and asked him to meet the train. "Why don't you do something that will keep him busy?" she suggested. "Why don't you take him to the planetarium?" Harvey was waiting at the platform at Grand Central when the train pulled in. As they walked slowly to the upper level, Harvey carefully framed his question.

"Bill," he said, "I've always wanted to go to the planetarium. How about it? Would you like to go along with me?"

"Fine," Faulkner said, and they spent the whole afternoon there. To Harvey, Faulkner seemed to be interested in everything they saw, especially the instruments on display because of his experience at aerial navigation.

At seven o'clock they arrived at Ruth's apartment. Harvey's dinner partner was a very attractive woman, and to Ruth's relief the whole thing went off beautifully. Faulkner enjoyed the cocktails before dinner, the wine with it, and the cognac after it. None of them set him off again,

Fn 127017 I: Harvey Breit, 12 Nov. 1964.

\section{DECEMBER, 1948 - JANUARY, 1950}

[1275-1276] 
That January of 1949 he finally brought himself to the point of writing Cowley about something that had been nagging at him. He didn't want him to do the piece for Life. He had talked Life out of doing one ten years ago, he said, and two years ago it had taken him six months to convince Vogue that he was against their doing such a study. The only thing he could accept would be a plan giving him final editing rights: "Which means I will want to blue pencil everything which even intimates that something breathing and: moving sat behind the typewriter which produced the books." He was still trying to think of some plan so that Cowley might do the piece and collect, but obviously he couldn't and he felt bad about it. "This is a damned bastardly clumsy letter. I'm trying to say No, but in a ten-page polysyllable since conscience, heart, liking and what dregs of gratitude I might possess, forbid that simple rapid word. Write me again, lets see if we cant work out something Life will take." Cowley did, sending an honest and persuasive letter which Faulkner brooded over. He had seen the piece which Cowley had done for Life on, Hemingway but this had convinced him that such was not for him. "I will protest to the last: no photographs, no recorded documents. It is my ambition to be, as a private individual, abolished and voided from history, leaving it markless, no refuse save the printed books; I wish I had had enough sense to see ahead thirty years ago and, like some of the Elizabethans, not signed them., It is my aim, and every effort bent, that the sum and history of my life, which in the same sentence is my obit and, epitaph too, shall be them both: He made the books and he died." He had not, however, forgotten the debt of gratitude. "But I still owe you a drunk. I will hold it on demand at sight draft, not transferable of course since you and Muriel will have to be present. But I will furnish someone to do the actual drinking; not myself this time."

Fn 127624 WF to MC, 5 Jan. and 11 Feb., 1949, in FCF, pp. 121-6.

\section{$[1279-1280]$}

He would sometimes retreat to the water. Jim Devine had sent presents: for Malcolm, Donald Culross Peattie's An Almanac for Moderns (which Faulkner was now reading), and for himself a big leather box. Faulkner told Jim: he was using it "mainly for my 'navigator's' kit on our home-made steamboat, the flat-bottomed houseboat I told you about that my ex-colonel hunting mate built in his back yard." During the filming to come, Faulkner would often head for the Minmagary, where he was out of reach of Clarence Brown's assistants. In mid-February, however, the Minmagary provided anything but a quiet retreat. "Last Sunday we took 42 people aboard, one sheep and one shoat, two cases of whiskey, hung up two lanterns on cypress snags for markers and sailed into a cove across the lake and had a barbecue. Good fun, poker and crap game, one fight. Evans and I are by now probably the best fiat-bottom boat sailors in the world." Ross Brown would vividly remember that barbecue. The weather had been so cold that the guests had been advised to wear long underwear and some had almost decided not to go. But by the time they embarked it had turned fair. "Don't let the weather bluff you," Faulkner said, "bluff the weather." They barbecued and sat up half the night drinking about the fire -- Faulkner, Brown, Evans, Ashford Little, and the others. Faulkner wore what they called his Admiral's hat and sang "Water Boy." They had a good time.

[For the citation of this portion of the letter see $12793 \mathrm{WF}$ to Eric J. Devine, 23 Feb. 1949. Courtesy Mr. Devine. And specific for this section as 127916 Ibid. - Author] 12806 I: Mr. and Mrs. Ross Brown, 20 Nov. 1966.

\section{[1291]}

At home the house was quiet-too quiet to be interesting to teenagers, Bill Fielden feared. There were television sets in town now, but there was none at Rowan Oak, and not even a phonograph or a radio. Jill would listen to the radio only at Miss Maud's house or the homes of her friends. "Pappy," Bill said one day, "if you don't let Jill have her fun at home, she'll go outside 
her home for it." Bill wanted to give her a phonograph, and this time Faulkner consented. The problem extended, of course, to a deeper level than that of entertainment. The drinking was embarrassing, horribly so when Jill happened to bring friends home on the wrong day. She had visited in Memphis and made some friends there, and they were to visit her at Rowan Oak. When the time came and they arrived, her father and mother were drinking. There was nothing she could do but just sit there, seething. Often, sometimes twice a month, she would have the same dream: in twenty-four hours her legs were going to give out, or be cut off. She would never walk again, and she had to decide how she would spend those hours, with her father or with her mother. They both stood looking down at her, and she realized, as she tried to decide, that neither of them really cared. That spring she had gone to New Orleans as a friend's house guest at Mardi gras. And now she would go to Memphis from time to time. Like most children she looked forward to growing independence, but sometimes she felt a longing which few of her friends would understand.

Fn 129117 I: William Fielden, 13 Oct 1964. 129122 I: JFS, 6 Aug. 1968. 129127 I: JFS, 20 Aug. 1968.

\section{6}

He stood patiently and answered the questions, telling some of the old stories about how he got to be a writer. After each response he would fall silent and moodily swirl the ice in his glass, waiting for the next question. One guest noted that this celebrated bourbon-drinker was sipping club soda. How about a real drink? "No whiskey, thank you," he replied. "Not till November. I go on the wagon every now and then. It's not good for a man to let habits get too much hold on him. I've quit smoking for a while too." In November he would go to deer camp again, and there would be plenty of opportunity to make up for the abstinence. He was temporarily off writing too, it developed. "But I might start one about November, when the weather gets too bad to get out."

Fn 129622 Edwin Howard, "A Surprise -- Faulkner Meets the Press," MCA, 12 Oct. 1949. I: JMF, 21 Mar. 1965.

\section{JANUARY - NOVEMBER, 1950}

\section{9-31}

His own concerns during late August were strictly local and highly particular. There was going to be a beer election to determine the legal status of that beverage for the next five years at least. It had been voted out during the war, and now loon Mullen and others on his Jaycee Committee were determined to bring it back. Confederated against them were all of the town's clergymen except the Catholic and Anglican priests. The clerical anti-beer committee printed an ad in: the Eagle proclaiming the evils of drinking and the potency of four-percent beer-one bottle of which, they declared, contained twice as much alcohol as a jigger of whiskey. Faulkner sided with Mullen on practical as well as ideological grounds. Before the previous election Dot Oldham had run a profitable beer wholesaling business at a cafe she called the Green Fern. She had felt compelled to carry a pistol in her purse to safeguard her receipts, but she didn't mind that. Faulkner had shared her indignation when the wartime election deprived her of this livelihood.

Following the appearance of the preachers' ad, Faulkner walked into the office of the Eagle and left a letter to the editor with Phil Mullen. It was a four-point refutation combining chemistry, satire, and polemic. In the first place, he wrote, beer was voted out not because of its "obnoxiousness" but because "too many voters who drank beer or didn't object to other people drinking it, were absent in Europe and Asia defending Oxford where voters who preferred home to war could vote on beer in 1944." A bottle of four-percent beer contained not twice as much alcohol as a jigger of whiskey but somewhat less. As for the argument that beer money would be 
better spent for essentials, maybe they should decide on the legality of radios, pleasure cars, and picture shows, too. As for following the moral example of Starkville and Water Valley, it was true that Mississippi State had beaten Ole Miss at football, "But why must we imitate Water Valley? Our high school team beat theirs didn't it?" He concluded in a sterner tone, signing himself "Yours for a freer Oxford, where publicans can be law abiding publicans six days a week, and Ministers of God can be Ministers of God all seven days in the week, as the Founder of their Ministry commanded them to when He ordered them to keep out of temporal politics in His own words: 'Render unto Caesar the things that are Caesar's and to God the things that are God's.' " When the newspaper appeared on Thursday, August 31, without the letter, Faulkner walked into Mullen's office.

"Was there something unethical about my statement?" he asked.

Mullen had felt it would do their cause no good, so he had obtained the concurrence of the paper's new owner, Colonel Eldon J. Hoar, and left it out. "No," he told Faulkner, "we just didn't want the Eagle to help you in jumping all over the preachers."

Faulkner looked at him in silence. "Strike me some circulars," he said. To help distribute the broadside, entitled "To the Voters of Oxford," he mobilized Johncy, Malcolm and his bride Gloria, Dean, Vicki, and Broadus Lyles. The three men used cars and the children went on bicycles and on foot. When Dr. Frank Moody Purser, the Baptist minister, came to his front door in answer to Dean's knock, he let them know he was scandalized that their uncle and step-grandfather should be using children on such an errand. They gave him a broadside, anyway'. When Johncy reported back he told his brother that he had distributed some of the circulars at the Baptist church.

"What did you do that for?" Bill asked him.

"It's all right," Johncy said, "I handed them out at the back door."

The chairman of the anti-beer committee, Methodist minister Ellis Finger, was less exercised than Reverend Purser. He read Point Two of the broadside and laughed. "Well," he admitted, "Bill Faulkner would know more about both beer and whiskey than we do." He may have laughed from, confidence as much as amusement; when the vote was tabulated a week later, beer was banned for five more years by a vote of 480 to 313- In the follow-up in the Eagle, Faulkner was listed as one of the proponents of legal beer. The next day he wrote another letter, full of irony and acerbity, and this time it was printed. He resented that listing: "I am every inch as much an enemy of liberty and enlightenment and progress as any voting or drinking dry either in Oxford." He named the disadvantages that could accrue from the revenue of county-operated beer and liquor stores-recreation facilities and public libraries, for instance. It was better to stick to the old bootleg usages, "better than to break up the long and happy marriage between dry voters and illicit sellers, for which our fair state supplies one of the last sanctuaries and strongholds." Actually, he wrote, his major objection in issuing the broadside was "to a priest so insulting the intelligence of his hearers as to assume that he can make any statement, regardless of its falsity, and because of respect for his cloth, not one of them will try or dare to check up on it." But most of all, and he hoped their superiors would consider this, "I object to ministers of God violating the canons and ethics of their sacred and holy avocation by using, either openly or underhand, the weight and power of their office to try to influence a civil election."

The last public mention of the controversy came not from Oxford but from New York. Two months later The New Yorker's "Talk of the Town" section began, "We take pleasure in reprinting, in its entirety, what is probably the clearest and most concise prose ever written by the moody master of Yoknapatawpha County." There followed the beer broadside, sent to the editor by an Oxford reader.

Fn 1330 . 5 I: Dorothy Oldham, 17 Nov. 1967. 13307 Phillip E. Mullen, Osceola . (Ark.) Times, 22 Dec. 1966. 133025 ESP, p. 207. 133033 Phillip E. Mullen, as above. 13312 I: Dean Mallard and Victoria 
Black, 18 Mar. 1965. 13316 I: JMF, 17 Mar. 1965. 133110 Phillip E. Mullen, as above. 133114 OXE, 14 Sept. 1950. 133130 ESP, p. 208. 133136 The New Yorker, XXVI (Nov. 25, 1950), p. 29.

\section{[1335]-1316}

In Intruder in the Dust Lucas Beauchamp had received justice only because of the efforts of two boys and one old woman. Nancy Mannigoe [from Requiem For a Nun] would receive justice but no mercy. And now--not in the world of his imagination but in the world of fact which he was so often accused of distorting-a white man might go free in fifteen years after murdering three Negro children [An actual trial of Leon Turner in Mississippi]. Faulkner would speak out increasingly on the subject of justice to Negroes with the result that his native state would become a more and more uncomfortable place for him to live. This kind of emotional upheaval usually cost him dearly, and often, when it was severe enough, he would turn to liquor.

He was able to enjoy Jill's performance as Cornelia Otis Skinner when the junior class presented Our Hearts Were Young and Gay on April 6, but twelve days later when he wrote Ben Wasson a note his handwriting was woozy. He apologized for the delay in sending the horse race piece for the Levee Press; "am busy farming now," he wrote, "also writing a play at odd times, and just forgot it." He had enough on his mind to make him forget, even if he didn't want to repress something that might drag with it the perennial problems of the unfinished fable.

Fn 13168 JPSA. 131610 Jack Ryan, "The Lady of the Dakota," The Delta Review, J2. (July-Aug. 1965), p. 45. 131617 I: JW, 20 Apr. 1965.

\section{NOVEMBER - DECEMBER, 1950}

\section{5}

At just about this time Faulkner's paperback publisher, Victor Weybright of New American Library, paid him a visit. Faulkner appeared to him "a small and rather courtly gentleman, unmistakably southern and tome somehow reminiscent of Puss-in-Boots." In their brief meeting, he told him some rather curious things. One was an account of how "he had trained a mule to jump barbed-wire fences in the moonlight." This may have been another version of the midnight equestrian ism Faulkner had given Captain Gualdres in "Knight's Gambit." It may also have been an indication that he was beginning to react in a familiar way to a situation that was closing in around him.

Further evidence came in a one-page letter he wrote on that same November 16. It was to Sven Åhman, and it was marred by a dozen typographical errors. Faulkner was never a meticulous typist, but this was considerably worse than usual, and it may have been due to something other than stress. He told Åhman that in his reply to the formal notification of the secretary of the Swedish Academy he had said that he would be unable to be present at Stockholm.

Fn 134520 Victor Weybright, The Making of a Publisher: A Life in the 20th Century Book Revolution (New York, 1967), p. 216. 134612 Courtesy Sven Åhman. JPS was quoted as saying her father had left on this day for deer camp. UP dispatch, 21 Nov. 1950, in MCA, 22 Nov. 1950.

\section{[1347]}

They [i.e.- Faulkner's hunting companions at Cypress Lake -Author] sat around the fire afterwards and talked. Jimmy Harkins was an Air Force reservist, and he offered to try to get permission to fly Faulkner to Sweden. Faulkner laughed and went along with the idea. He gave Renzi the key to his whiskey box, and the hunters enjoyed a nightcap or two of Old Crow. Faulkner never slept in the tent in fair weather, so he took his sleeping bag and bedded down nearby. At three o'clock, when they retired, Renzi was still solicitously passing from one cot to 
another offering additional nightcaps. The next morning brought snow and sleet, but the hunters were unperturbed; they had not come to the big woods for an effete vacation. As for Faulkner, the isolation felt good. His detachment was not shared in Stockholm, Washington, and Oxford.

Fn 134726 OTF, pp. 18-20; Coughlan, pp. 133-4; Jerrold Brite in WFO, p.160

\section{8-52}

Meanwhile, the situation on Cypress Lake was sliding into a familiar pattern of deterioration. Renzi was ordered to keep the whiskey box unlocked and to dispense its contents at regular intervals. Faulkner was expected back from the hunt on Saturday, November 25, but he did not appear then or the next day. The truth was, he was in no condition to travel. Uncle Ike had been trying to get him to take some nourishment along with the bourbon, bartering drinks of a diluted Whiskey punch for his accepting soft-boiled eggs and black coffee. In spite of this, he was not coming out of the bout, and the depletion of resources was taking its toll. He had come down with a heavy cold. Finally the men broke camp, and by the early hours of Monday, November 27, he was in bed at Rowan Oak, threatened with pneumonia.

Fn 13493 Coughlan, p. 134. 13495 MCA, 27 Nov. 1950; OXE, 30 Nov. 1950.

$\cdots$

Now further subterfuge was added to persuasion as time seemed to speed up and tensions heightened. Faulkner had agreed to make the trip, but he had not agreed to stop drinking. The quickly made travel plans called for them to fly to New York on Wednesday, December 6. "I'll take my last drink at six o'clock Monday night," he said. "Then I'll be ready to go to Memphis on Tuesday and on Wednesday we'll fly to New York." He and Jill both needed passport photos. Phil Mullen said, "I'll do the photos if Jill does some stories for the Eagle from Sweden." The editor of the the [sic] Optic agreed, accepting the offer of seventy-five dollars, and Mullen drove out to Rowan Oak. They helped Faulkner to the front parlor. He wore a tweed coat, the collar of his colored shirt open at the throat, showing his strong corded neck. His face was bristly from several day's stubble, and beneath his eyes were the lines and pouches of sleeplessness and fatigue. The eyes themselves were still the same intense black-brown, however, and the dominant expression was one not of debilitation but of absolute irascibility.

But as soon as the picture-taking was over, he retired to his room and his bourbon, varying the latter only occasionally with small portions of chicken soup fed to him by one of the family or a friend such as Uncle Ike. Finally someone hit on the ruse of setting the calendar ahead, for there was no telling how long or severe the withdrawal process might be. Jimmy Faulkner was there when they told him it was Monday and he had to start sobering up. Reluctantly, he began spacing the drinks farther apart. That afternoon, taking more interest in things around him, he asked where Malcolm was. "He's at the high school football game," someone said without thinking. Faulkner was silent, motionless for a moment. Then he raised himself on an elbow and glowered. "Somebody's been deceivin' me!" he said. "They don't play football games on Monday." He lay back. "I've got three more days to drink."

Fn I350 20 I: JMF, 21 Mar. 1965; Robert Coughlan, 24 Feb. 1967. Coughlan, 24 Feb. 1967. (Ark.) Times, 22 Dec. 1966.

What he described as the "hurrah and uproar here" continued-not just reporters asking for interviews, but the telephone ringing, telegrams arriving, and relatives and friends felicitating him on the prize he wasn't overjoyed to get and the trip he didn't want to take. He was still plagued with the usual sleeplessness, nerves, and irritability of withdrawal, which made the whole business even more excruciating. Glad of a chance to slip out of the house on Tuesday evening, 
he went over with Estelle to see Ross and Maggie Brown. They played pool in the basement, and it was three o'clock before they left. He dozed lightly for a few hours at home and then drank some coffee as Estelle waked Jill, who arose sleepily in the December darkness. Early as it was, there were friends there to see them off after the hurried breakfast. Phil Stone shook his hand. "Now, Bill, you do right," he said.

Faulkner glared at him. "I'm so damn sick and tired of hearin' that," he shot back.

"Everybody from the Swedish ambassador to my damn nigger houseboy has been tellin' me to do right!"

Fn 135224 Maggie Brown in WFO, p. 122. 135226 JFS's account of the Nobel Prize trip, MCA, 7 Jan. 1951. 135233 Coughlan. p. 135. I: EF. 11 June 1969.

\section{4}

To Jill, white-haired, thin-faced Robert D. Haas looked like a Florentine nobleman, or the way she imagined one would look. To trim and attractive Merle Haas, William Faulkner looked like a sick man. When they had gotten him and Jill settled at the Algonquin, Merle told him so. He admitted that he didn't feel so well. "Do you have any antibiotics?" he asked. She had some Aureomycin, but she called her doctor before she gave it to him. Yes, Mr. Faulkner could have one now and one in four hours, but he was to consume no alcohol while he was taking the drug. That evening at their party Merle saw that he was following one half of the advice but not the other. He was drinking Jack Daniel's and water before dinner and continuing afterwards.

Fn I: Mrs. Robert Haas, 29 Dec. 1964.

\section{[1355]-1356}

There was no rest for him that evening, either. He had gone to the Haases' party, and he felt he should go to the one at the Cerfs'. Harvey Breit, Anthony West, and John O'Hara were there with their wives. Carol Brandt was there, too. It was she who had moved quickly, two years before, to buy the rights to Intruder in the Dust for MGM. Now when she finally talked with Faulkner it was about horses. Then, as she watched him, she couldn't help noticing the gentle solicitude he showed toward Jill, amid this group of highly sophisticated adults. As at the Haas party, some of the guests felt moved to offer testimonials before they left the table. O'Hara rose, a portly, red-faced man eight years Faulkner's junior. Several years before, Breit remembered, O'Hara had called Scott Fitzgerald the greatest American writer. In early September of 1950, O'Hara had concluded his review of Across the River and into the Trees by acclaiming Ernest Hemingway "the most important, the outstanding author out of the millions of writers who have lived since 1616." Now he launched into a long speech in which he finally adjudged William Faulkner "our only living genius." He began to name some of Faulkner's works. "We were running neck and neck until you pulled away and left me behind," he said. He paused, as though waiting for Faulkner to say, "No, no." But Faulkner just sat there quietly-perhaps feeling the effects of the medicine and the bourbon, the grippe and the speech. Then he spoke in the quiet way he would when he was agreeing with someone, saying something because a remark was expected, though his mind was actually miles away. "Yes, that's right," he murmured.

Fn 135625 I: Harvey Breit, 16 Apr. 1965; Anthony West, 24, Feb. 1967; DSK, 21 Sept. 1967. NYT Book Review, 10 Sept. 1950.

\section{JANUARY - SEPTEMBER, 1951}

\section{6}


There was little that he cared to do other than work. If he completed the script in four weeks, he would get a bonus. This he was now trying to accomplish, for he preferred less money and a shorter stay to more money for a two months' assignment. He also had part of Requiem for a Nun with him, sections he had asked Joan Williams to return to him, and from time to time he would work on that. By mid-February the strain was beginning to show in a familiar way. He wrote Estelle about household affairs, and on the same sheet he asked Jill about the animals at Rowan Oak. The notes were just barely legible. Irwin Shaw was in Hollywood working on a script and staying at the Beverly-Carlton. "I remember coming down at 9 o'clock in the morning to the lobby to pick up my mail and finding him sitting there, upright in a chair, very neat and unHollywood like, looking a little lost. He said to me that he had six bottles of beer in his room and asked me to join him to knock them off. Unfortunately, I had to leave immediately and could not accept his invitation. He sat down again, waiting patiently for somebody else to help him with the beer."

But he did not let himself go over the brink; instead, he reasserted the self-discipline he could sometimes muster and got a good deal of work done. On Sunday, March 4, he earned the bonus by finishing his script for The Left Hand of God with one day to spare.

Fn 1376 ,9 WF to JW, 4 Mar. 1951. 137612 WF to EF and to JPS, 18 Feb. 1951. JFSA. 137619 Irwin Shaw to JB, 26 Oct. 1965. 137628 WF to JW, 4 Mar. 1951.

\section{SEPTEMBER, 1951 - MAY, 1952}

\section{[1400]-1401}

It was to be a wild comic extravaganza, Marre gathered, like a Jacobean comedy. "The idea of doing it amuses me," Faulkner told him. But it palled as he tried to get into the second act, and soon the feeling of wasted time returned.

The result was predictable. Jill came from Wellesley to spend the weekend with him, and his spirits picked up briefly. But soon she was gone back to school, and Marre observed that Faulkner had begun to drink at what was to him a spectacular level. At 7:30 A.M. he would be drinking beer, and before lunch he would already have switched to bourbon. He was always coherent, but he would be "rigid and swacked by early afternoon."

Fn [1399-1402] 139930 I: Albert Marre, 22 Sept. 1967. 140012 Ibid. 14025 Ibid.

\section{[1402]-1403}

He crammed a good deal of activity into the last half of October. After stopping for a few days at home and checking on the farm, he went on to New Orleans for a brief holiday before the award ceremony. Miss Maud apparently had misgivings about his mood when she saw him, and these were in no way lightened when he drove south alone. Leaving his car north of the city, he boarded a train and watched the boats on Lake Pontchartrain as they approached New Orleans. He began his holiday with Helen and Guy Lyman, but soon he had outdistanced them. Finally Lyman had to telephone George Healy. "Your friend's here and he's getting so I can't handle him," he said. Healy got John McClure, who called a doctor friend. The doctor said he would make arrangements at the Baptist Hospital and told them to meet him there. They went to the Lymans' and over Faulkner's protests managed to get him to the hospital. A few days later Healy attended to the discharge and put his friend on a northbound train, one bottle of ale to see him on his way.

Fn 14039 I: George Healy, Jr., 3 Feb. 1965.

\section{5}


There was some reward for the drudgery when Jill came from Wellesley again to spend the weekend with him, but he was glad when it was time to go back south. Albie [i.e. Albert Marre - Author] drove him down to New York so that he could fly home to join the others in deer camp on the seventeenth. On the four-and-a half-hour trip to the city it seemed to Albie that Bill consumed most of a fifth of Old Grand-Dad.

Fn I I: Albert Marre, 22 Sept. 1967.

\section{MAY, 1952 - JANUARY, 1953}

\section{1-3}

There was, of course, some formal entertaining [i.e. - in Paris - Author]. On one occasion it came from the Gallimards. Present was one of the Gallimard wives, a striking young woman who seemed spoiled to some. Faulkner handled her beautifully, Else thought, politely but wittily, to the delight of others who were less courageous or who couldn't think of the right words. He was in good form.

But soon things changed. He would later tell a physician that he had in the Bois de Boulogne, or perhaps he was romanticizing the fall two months earlier on the Old Taylor Road. Whichever it was, the pain in his back was real enough. To ease it he began to drink, and. just then his obligations came due. He was summoned by the secretary of the Writers' Congress, a woman, who had already managed to offend most of the writers she had met. When he failed to respond, she went to his hotel herself to ensure his appearance. The story that novelist Glenway Wescott heard was that she unceremoniously opened the door and began her harangue, whereupon Faulkner raised himself high enough in bed to fling a bottle which drove her precipitately down the stairs-thus earning the further appreciation of some of his fellow writers.

In spite of the success of his appearance, his condition by May 27 was worsening. To assuage the pain in his back he had resorted to his favorite anesthetic: liquor. But he had told Monique to put him in the hospital if, he ever needed it. What she did was to get him to the Clinique Remy de Gourmont, where he was examined by Dr. Leibovici. He was then referred to Dr. Weil, a radiologist on the Rue du Moulin-Vert, who took four large x-rays and five smaller ones.

The patient had a broken back. There were compression fractures of the twelfth dorsal vertebra and the first lumbar vertebra, both located just above elbow height in the small of the back. It was an injury which could be very painful, with rough edges of bone either irritating the sinu-vertebral nerves in the disc or causing muscle spasms. But they were old fractures, and because they had occurred at a place where the back is very strong, there had been a natural splinting of the breaks. The x-rays also showed clear arthritic involvement which was adding to the pain. There was no telling just how old the fractures were or what had caused them. The injury was common to horsemen, often sustained in the violent impact after the rider left his seat on the horse and struck the ground in the same position. It could have happened on one of the hunting trips. It could also have happened six years before when he had taken the bad fall all the way down the stairs at Rowan Oak. But the problem now was the treatment, not the cause.

Fn 142126 I: EJ, 8 May 1964. 142128 I: Marcus Stewart, M.D., 14 Nov. 1966. 14222 Glenway Wescott, in P.E.N. News, IX (Nov. 1962). I: George Garrett, 7 Nov. 1964.

\section{[1424]}

Faulkner slowly began to resume his interest in the life around him, noticing details with that bright hooded glance as he ate on the sunlit hotel terrace set among the peaks with the Oslo harbor barely visible in the far blue distance. As in Stockholm, the language interested him, and 
he enjoyed blue distance. As in Stockholm, the language interested him, and he enjoyed word bilgummi for a friend, split the first and second syllables by a line, and say, "See? Automobile rubber tires." There were other words and phrases he would remember, such as $\phi l$ m $\phi r c k$ for the rich, dark export grade beer.

Fn 142424 WF to JB. 142433 Ibid.

\section{0}

[Though listed in the index under "drinking" there appears to be no pertinent information of such activity on this page. - Author]

\section{3-4}

In mid-September, after Jill returned to school, the process accelerated and the collapse came. He had been trying to control the pain with beer and Seconal, but it gradually grew worse. Then, on September 18, he suffered a convulsive seizure. They took him to Memphis, to the Gartley-Ramsay Hospital, a fifty-bed psychiatric hospital where Dr. Dick C. McCool, an Ole Miss graduate ten years Faulkner's junior, examined him. Faulkner was able to give a coherent history of his trouble, though he said it had begun with the wartime plane crash which had left him with multiple injuries of the face, limbs, and back. He had paid no attention to his spine at the time, he said, but the fall from the horse in Paris had aggravated the injury. Now he was suffering from the spasms of the deep spinal muscles all the way from his humped upper back on down. The neurological examination was essentially negative, but his range of spinal movement was only seventy percent normal. The x-rays that were taken showed no new fractures, but on this reading other old ones were discovered. In addition to the pronounced fractures of LI and DI2, he had also suffered mild compression fractures of dorsal vertebrae 8, 9, and 10 . For some years now he had been walking around with five broken vertebrae in various stages of natural splinting. The lesions had finally healed, but there had been bone-lipping and spur formation. In addition, he had developed moderately severe hypertrophic arthritis of the dorsal and lumbar spine. In other words, all of the spine below the cervical and above the sacral vertebrae was involved. A fall, probably the one in March, had apparently stirred everything up, and the blow from The Ring Dove's keel may have done the rest.

They began treatment immediately, withdrawing him from alcohol and administering Seconal in proper dosage to give him relief from the terrible nights he had been having. On his back they used hot packs, massage, and Pantopon for the pain. By September 24 he was able to say he was feeling better. The next morning was also a good one, but that afternoon he suffered another convulsive seizure. The next day his physicians suggested a spinal fluid test to help in the diagnosis. The effect was simply to frighten him, and he began to insist on leaving in spite of the fact that he was still nervous and on edge. They advised against it, but he persisted. When they released him on the twenty-sixth, it was with the advice that he stay in bed for a week or ten days, sleeping on a firm bed and applying heat to his back. If he was not considerably improved within two weeks, he should return to be fitted with a long Taylor spinal brace and possibly undergo some physical therapy.

Fn 143414 I: Marcus Stewart, M.D., 14 Nov. 1966. 143430 Ibid.

\section{5}

The improvement he had predicted to Ober failed to appear. Jimmy Faulkner would see him sitting on the fender before the hearth in the library, his bare back to the open fire so the heat, he said, could take the sting out of it. The cycle resumed as he returned to the beer and Seconal regimen to counter the pain and the sleepless nights. Then he fell. He fell, again, all the way down 
the stairs. Estelle called Saxe Commins in Princeton, and Saxe responded quickly, arriving in Oxford on October 7. The next day he took his ailing author back to the hospital in Memphis.

The routine began again. Although the pain was worse than last time with his movement now morbidly restricted, the new x-rays showed no new injury or change in the old. But he was ravaged from the effects of nights with only a few hours' sleep, from self-administered treatments, and from general debilitation. The patient was sedated. Paraldehyde was administered as he was taken off alcohol. Again there were the hot packs, the Pantopon, and the Seconal. It was several days before the combined treatments began to produce significant improvement, but gradually the convalescence progressed. He began to sleep and eat better and occasionally to go for a solitary stroll, a small slow-moving figure in pajamas and bathrobe on the hospital grounds. He was fitted for the back brace, which would give some relief, but apparently he would have to get used to the idea of living with some degree of pain so long as he refused to undergo surgery. On October 21 he came home again to Rowan Oak.

Fn 1435 19 I: JMF, 14 Nov. 1966. 143522 I: Dorothy Commins, 20 Aug. 1965. 143523 WF to JW, "Thursday," 23 Oct. 1952. 143537 Courtesy Gartley-Ramsay Hospital. HO to WF, 24 Oct. 1952; WF to JW, 2 Nov. and "Thursday," 23 Oct., 1952.

\section{MAY, 1952 - JANUARY, 1953}

\section{2}

Closer to him and more dependent, Joan accepted him once more on his terms. But very soon he began to drink heavily, suffering another collapse, and the last days of November were lost in treatment at a sanitarium not very different from the one in Memphis.

He was admitted to the Westhill Sanitarium, a private hospital located on a well-eared-for estate at Riverdale in the Bronx. At this point a doctor whom Joan had seen briefly offered to go out to the hospital to visit him. Eric P. Mosse was a European-trained psychoanalyst who had written plays and novels and specialized in the treatment of artists. He was particularly anxious to attend this man whose work he admired. Diagnosing the illness as the result of combined drinking and depression, he prescribed a treatment the patient had never undergone before: electroshock. In this procedure electrodes were fastened to the patient's temples and a hard rubber bit inserted between his teeth. Then his whole body would jump in a convulsive start as he was jolted into unconsciousness by a current of electricity. The intent was that, having undergone a kind of electrochemical catharsis, his mental processes could gradually reorganize themselves, free of the repetitive patterns that had produced the depression. Dr. Mosse administered a series of these treatments-perhaps six in all. He was impressed at Faulkner's behavior on coming out of them. Unlike many patients, he was neither hostile nor disoriented. Instead, he was gentle; he put his arms around the doctor. He was a man, thought the doctor, with a great need for affection, and he put his own arms around the patient to return the warmth. The doctor would go from his office in the city up to the sanitarium at noon, when he would not normally make such a trip. While his wife sat in the car, he would talk with Faulkner. At one such lunchtime he asked, "Will you eat if I feed you?" The patient said he would, and he did.

It must have been late in November by the time he was released from the hospital. When the doctor's bill arrived it amounted to several hundred dollars. Both Faulkner and Commins were furious. Dr. Mosse wrote Commins that each trip to Riverdale took him two hours, but he was sorry that they were shocked at the bill, and he would accept whatever they thought was fair. This did not expunge Faulkner's feelings of outrage. And no one would ever get near him with a pair of electrodes again.

Fn 14427 I: JW, 15 Nov. 1964, 22 Aug. 1965; Dorothy Commins, 20Aug. 1965. 144230 I: Mrs. Eric Mosse, 21 Jan. 1966. The electroshock treatment was meant to cut short the depressive cycle by its final 
third. Six such treatments would have been a small number -- not enough to cause significant permanent changes in brain waves, personality and character patterns, or the like. I: Lever Stewart, M.D., 25 Feb. 1966.

\section{JANUARY - NOVEMBER, 1953}

\section{[1447]-1448}

--the surrender, the relinquishment to and into the opium of escaping, knowing in advance the inevitable tomorrow's inevitable physical agony; to have lost nothing of anguish but instead only to have gained it; to have merely compounded yesterday's spirit and soul's laceration with tomorrow's hangover--

--"Mr. Acarius"

[Epigraph to Chapter 63 - January-November, 1953 - Author]

Very quickly the situation changed. The back pain and sleeplessness 'grew worse, and the antidote he found in Smith's sideboard was a bottle of what Smith later said was forty-year-old applejack. Joan and Bob Linscott discovered that he was in trouble and sent for Ben Gilbert. Ben examined him, prescribed, and arranged for a nurse. By the time Smith returned home, Faulkner was better, and by February 7 he was well enough to accompany Smith and Commins to the National Book Awards at the Hotel Commodore. With 500 other writers, critics, publishers, and agents, he heard Ralph Ellison, Bernard DeVoto, and Archibald MacLeish receive their awards. After a talk by Supreme Court Justice William O. Douglas, the chairs were removed and a crowded, milling, noisy cocktail party began. The New Yorker's man Stanley reported later that "the lion of the afternoon was, we would say, William Faulkner, who, very small and very handsome, with a voice that never rose above a whisper, stood with his back to the wall and gamely took on all comers." He took them on chiefly with yeses and noes, but still, reported another observer, "it was hard to get a word with him, so closely packed around him were his admirers. His famed reticence and dislike of publicity were much in evidence, as were his dignity, poise, and shy friendliness." All he would say about the writing he was doing at Random House was that it was his "magnum opus" and that it would probably keep him there until spring. He stood for a photograph with Commins and Douglas and for another by himself. The second photograph clearly showed not only the ensemble-tweed suit, with pocket handkerchief, yellow tattersall vest, and shining striped tie-but also a surprisingly broad, genuine, spontaneous, smallboy grin. The questions had constituted an ordeal, as usual, but at this point in his life there were obviously sometimes when he did not mind being a literary lion. Finally, having had enough, he turned to an attractive young woman covering the affair for one of the New York magazines. "You know," he said, "you look like a girl who would know something about sour mash whiskey." With that she joined him in escaping from the crush to the comparative peace of the hotel bar for the tonic effect of Jack Daniel's.

Fn 14477 The Saturday Evening Post, 238 (Oct. 9, 1965), p. 27. 1447 15 I: JFS, 6 Aug. 1968. 144719 I: JW, 20 Apr. and 22 Aug., 1965. 144722 I: Mrs. Sewell Haggard, 17Apr. 1965. 144724 I: JW, 20 Apr. 1965. 14489 The New Yorker, XXVIII (Feb. 7, 1953), pp. 21-2. 144819 Ralph Morrissey, "When Authors Get Together," Nashville Tennessean, 15 Feb. 1953. 144826 NYT Book Review, 8 Feb. 1953.

\section{[1448 - 1449]}

No sooner had he returned to Smith's place than the pendulum swung back again. He had continued drinking after the reception, and though there was no sign that his tolerance for alcohol had decreased any, there was a symptom that frightened him: what he would later call "spells of complete forgetting." When Joan and Linscott checked on him the next day, he was worse. With 
Smith they decided it was time for professional treatment. Ben Gilbert made the arrangements, and they took him to the Charles B. Townes private hospital on Central Park West.

Sick as he was and despite the periodic amnesia, he displayed again that quality that had surprised his friends: the ability to remember what had happened during times when he had been drinking heavily. Later he would describe the hospital: "an address in an expensive section facing the Park, itself outwardly resembling just another expensive apartment house .... A switchboard In a small foyer enclosed by the glass-panel walls of what were obviously offices." He would recall sensory detail: "hearing the slow accumulation of the cloistral evening," and seeing in the corridor "men in pajamas and dressing gowns .... " He had not descended as deeply this time as in the previous hospitalization in Memphis, and he began to recover more quickly, taking his medication, reluctantly eating a little more, and observing the other patients. There was one old man in particular who would drift in and out of his room, sometimes during the night, singing to himself the same refrain: "Did you ever see a dream walking? Well, I did." In another day Faulkner was able to smile to himself at the man's alcoholic nonchalance. Telephoning Commins to arrange for his discharge, he was out of the hospital in less than a week. When he returned to the apartment, Smith slipped a note under the door of his room. It said he had behaved so badly that he would have to go elsewhere.

He stayed with the Haases for a few days, plunging into several projects and penitently writing Malcolm Franklin and his wife Gloria to assuage family worries about him. He was continuing to develop his theory about his illness. "I know that I have not been quite myself since last spring," he wrote, "I mean, these spells of complete forgetting. I have had three of them, one in Paris for two days last spring, two here. The idea has occurred to me that maybe, when Tempy snatched me off Sunny last March, that when I hit the ground so hard on my back, that I might have struck my head too." Bob Haas had made a doctor's appointment for him and he would find out if he was right. "Meanwhile, dont tell Mamma, to alarm her, just tell her that I am well now .... since I have an idea what the trouble might be, I will take better care of myself." He tried to conclude on are assuring note: "I am earning money again, first time in two years almost now, and have every reason to keep on at a gait which wont give anyone reason to worry." But his conclusion was ominous. He was glad they had called Saxe, who was taking good care of him. "Remember, he will not lie to you about me. When anything serious happens, he will tell you."

Fn 144910 I: JW, 20 Apr. and 22 Aug., 1965. "Mr. Acarius," pp. 27, 29 [The Saturday Evening Post, 238 (Oct. 9, 1965) - Author]. 144913 WF to Malcolm Franklin, "Monday," 16 Feb. 1953. Courtesy Mr. Franklin. SC to HS, 10 Feb. 1953. 144932 WF to Malcolm Franklin, "Monday," 16 Feb. 1953. Courtesy Mr. Franklin. 144935 JFS to WF, 20 Feb. 1953. JFSA.

\section{[1449-1451]}

Though he had sounded bad to Jill when she called him at the Haases', Saxe felt that he was now at work in earnest and nearly back in his normal stride again. Sitting in Commins' fifthfloor office, making notes for a brief New Yorker piece, Lillian Ross watched him work. "He was hunched over a typewriter on a stand and was a study in gray, brown, and blue: neatly parted gray hair, brown-rimmed glasses, a shirt with blue stripes, a blue tie, gray suspenders, gray tweed trousers', - and brown shoes." He typed very slowly and with extraordinary concentration, seemingly oblivious to phone calls and Commins' visitors. When he coughed, Commins glanced at him anxiously.

"Got a cold, Bill?"

Faulkner shook his head.

"Think you ought to take some medicine?"

"Isn't any thin' Ah got whiskey won't cure," he said. He got up and stretched, his back aching. "Ah think Ah'm goin' to invent somethin' like an ironin' board, so Ah can lie flat on mah back while Ah type." 
Commins showed Miss Ross a picture of Faulkner taking a horse over a four-foot jump. The subject explained that it was his daughter's mare, Lady, and went on to describe his tribulations with her. Miss Ross watched him as he turned again to his typewriter and lit a cigarette.

"Ah have a feelin' of doom hangin' over me today," he said. He finished the page, crossed out a paragraph with a red pencil, and put the sheet on top of a stack. "Damn it! Ah wish mah doom would lift or come on. Ah got work to do." Commins looked at him questioningly. "Somethin' is happenin'. Ah can feel it." Commins wondered if he felt this way often. "Not very often, but when Ah feels it, somethin' happens."

"You don't look worried. Suppose it's something awful?"

"Ah can bear any thin'," Faulkner said.

A little later he rose, put on his jacket, coat, and green Tyrolean hat and set out for Madison Avenue and lunch.

Recuperating well, he had moved from the Haases' to the Algonquin. He was really working quite hard. He would even come into the office on Saturday mornings, when Saxe was not there. Passing Jean Ennis' office in the publicity department, he asked her to go to lunch with him, but she was wearing a skirt and sweater and fiat shoes. Moreover, she thought to herself, what if they went to lunch and he didn't say anything? he declined with thanks. Later, recalling how lonely he had looked, she regretted not going with him. On Sunday he wrote letters, in one telling Monique Salomon that he missed Paris and explaining his head injury theory. He was able to tick off a series of projects to Else Jonsson: "a piece last week for a magazine, have just finished a foreword for, Sherwood Anderson's Published correspondence, will make a television play of one of my stories this week, then a piece on Mississippi for another magazine." But this letter -- like the one to Malcolm and Gloria -- ended on an ominous note: "I still have back trouble. Am seeing another doctor this week. Because something is wrong with me; as you saw last spring, my nature has changed. I think now that when I fell off the horse last March, I may have struck my head too. I will know this week."

The feeling of doom was obviously real enough, but in spite of it, as he had told Miss Ross, "The work is gettin' itself done here. Ah don't want to disturb it." The story he had mentioned to Else was entitled "Weekend Revisited," and it was based upon his recent hospitalization on Central Park West. When he had left Malcolm Cowley's Connecticut home after a similar hospitalization four years before, he had carried away with him Charles Jackson's novel The Lost Weekend. Now he had apparently decided to try to give the sense of such a descent as Jackson had described. To it, however, he attempted to add both comic and metaphysical elements. His protagonist, Mr. Acarius, was a prosperous man, beset with a sense of both an undistinguished life and impending nuclear doom. Unlike Faulkner, he made the hospital arrangements first and then deliberately drank himself into it in a kind of Dostoevskian quest to give his life meaning through suffering. Through debauchery he hoped to link himself with other suffering men and come to terms at the same time with the intolerable human condition. Instead, once in the hospital he met both farce and despair. Hired women smuggled in whiskey to the patients. Most traumatic, however, was the sight of another patient: "That terrible, terrible old man, who should have been at home telling bedtime stories to his grandchildren." The piece ended with Mr. Acarius at home destroying his liquor supply. Even though the story may have indicated something like self-loathing as well as macabre amusement, Faulkner was still in no mood to destroy whatever supply he might have laid in at his room at the Algonquin.

Delivered to Ober by February 19, the story would go to The New Yorker, which would reject it as would two other magazines.

Fn 145024 The New Yorker, XXVIII (Feb. 28, 1953), p. 20, repro in LIG, pp. 74-6. See also Linscott, pp. 78,80. Harold Raymond thanked WF for his copy of the "equestrian portrait" SC had shown Miss Ross. Raymond to WF, 31 July 1952. Courtesy Chatto \& Windus. 145032 I: Jean Ennis, 12 Nov. 1964. 145033 
WF to Monique Salomon, 22 Feb. 1953. Courtesy Mme. Lange. 14514 WF to EJ, 22 Feb. 1953. 14517 The New Yorker, as above, p. 21. 145124 "Mr. Acarius," p. 31. A long time admirer of Conrad Aiken's poetry, WF may also have known his "Mr. Arcularis," a short-story dream vision of impending death. 1451 29 "Weekend Revisited" would also be rejected by Collier's and Esquire.

\section{2-4}

By that time he had made the first of two visits to the office of Dr. Robert Hastings Melchionna -- with results that were reassuring yet disturbing. On February 25 and March 2 Dr. Melchionna performed a complete medical examination which proved essentially normal. It was good to know he seemed organically sound, but if there was no medical reason for the forgetting and the personality change he thought he detected, what was the cause of it? He had described the three episodes of blackout after heavy drinking which had been accompanied by retrograde amnesia -- a loss of memory, occurring with or without loss of consciousness, of what transpired for a period immediately prior to an injury. Dr. Melchionna thought it would be a good idea to have skull x-rays, an electroencephalogram, and other tests.

As things turned out, he needed other treatment during the month of March. When he did not appear at Random House, they discovered that he was prescribing for himself again in his room at the Algonquin. Finally Saxe telephoned Dorothy in Princeton. "Do'," he said, "I'm bringing Bill Faulkner home." It was about 6 P.M. of a blustery March evening when she met them at the door. Her guest stood there, his hat in his hand, a handkerchief to his running nose. "Dorothy," he said, "I've misbehaved again." She took his things while Saxe got him to bed and gave him an alcohol rubdown. Then she put a jug of lemonade by his bed and made him take aspirin every four hours. Finally, as he slept, the Comminses sat together in the living room, talking quietly. This was the same thing Saxe had done with Lewis and O'Neill. "These are their sick periods," he would say to Dorothy. "We must see them through it." The next morning Faulkner was much better. Settled in his favorite corner of the living room sofa, he talked about his childhood, about his grandpappy, his uncle, and his teachers. The next day he was able to go back to New York. Later he sent a dozen red roses.

As usual, he had left too soon. Dr. Melchionna had him admitted to Doctors Hospital for the better part of a week. While he was there, on March II, Melchionna asked a colleague to see him. He was Dr. S. Bernard Wortis, professor and chairman of the department of psychiatry and neurology of the New York University medical school. Estelle had sent the Paris x-rays to Saxe, and the doctors studied them. Then Dr. Wortis ar ranged for the tests Dt. Melchionna had suggested. On March 24 they would do the skull x-rays and the electroencephalogram. A few days after that there would be a complete spinal x-ray and liver function tests. They would see if there was any evidence for Faulkner's trauma theory. They might also discover what, if anything, this periodic punishment over a span of years had done to his body.

The X-rays of the skull were normal and there was nothing new in the spine. The liver function tests were normal, too. The spiky lines of the electroencephalogram showed some hypersensitivity in the brain waves, but there was no organic illness. He still had the vertebral problem and the arthritis, but apart from that the extensive testing indicated that he was neurologically and physiologically all right. Dr. Wortis felt that it was now time to shift from the physical to the psychological in this sequence which would extend to nine visits before it was completed.

On March 31 Dr. Wortis saw him again in his office. A tall, balding, imposing man with the authority of his profession and experience, he re viewed the medical findings and then began trying to draw his patient out. - It seemed to him that Faulkner talked easily-so long as he was handled as an artist rather than the way the average technician would treat the ordinary case of malaise and depression. But Faulkner still retained the distrust of psychiatry that he had expressed in "Books and Things" over thirty years earlier. Wortis felt that Faulkner might not have received enough love from his mother, but when he tried to touch on this area the patient refused to talk 
about it. Wortis felt, however, that he had learned a good deal about him. Faulkner had an intense emotional responsiveness which was different from that of ordinary people. He had such receptiveness for others that their problems hurt him. On another level, he suffered with problems of the South which were somehow related to his own tensions. He was so sensitive, reflected Wortis, that life must have been very painful for him. Obviously, his alcoholism was a narcotizing device to make it almost bearable for him, but there was not the aggressiveness in. his drinking found in so many others. One curious thing was the way his intense responsiveness never seemed to overflow into facial expression-at least in this consulting room situation. It was as though he always exercised conscious control. He may have begun the mustache out of admiration for the British and because he thought it made him better looking, but one thing it seemed to do now was to help him conceal emotion, to help provide, in effect, a poker face. He was a man with a strong need for affection, it appeared, one looking forward to some sort of emotional equilibrium but very uncertain of finding it. He was a man built to suffer, thought Wortis, to be unhappy and to make his contribution partly because of this.

As it came time to go, Faulkner volunteered a bit of information. The next cycle of drinking would come in May, he said.

"Well, see me or someone like me," Wortis told him.

"I'll call you for an appointment myself," Faulkner said.

Later that day Faulkner set down some of his own recollections of the visit in a letter to Else Jonsson. "I have had a great deal of doctor, medical expense. I had two more spells like that in Paris, in which I would not know what happened until I would wake up in a hospital, and have just finished a series of examinations for a possible skull injury when I fell off the horse. There is no skull injury. According to the doctor, the tests show that a lobe or part of my brain is hypersensitive to intoxication. I said, 'Alcohol?' He said, 'Alcohol is one of them.' The others are worry, unhappiness, any form of mental unease, which produces less resistance to the alcohol. $\mathrm{He}$ did not tell me to stop drinking completely, though he said that if the report had been on him, he would stop for 3 or 4 months and then have another test. He said that my brain is still normal, but it is near the border line of abnormality. Which I knew myself; this behavior is lot like me."

Fn 45224 Robert Melchionna, M.D., to JB, 11 Aug. 1965. 145232 I: S. Bernard Wortis, M.D., 7 Aug. 1965; Lever Stewart, M.D., 25 Feb. 1966. 5235 I: AE, 13 Nov. 1964. 45310 I: Dorothy Commins, 20 lug.1965. 15436 WF to EJ, 31 Mar. 1953. Dr. Wortis generously supplied me with a copy of a portion of the electroencephalogram. Though it did not represent a sufficient sample for diagnostic medical interpretation, Dr. Stewart kindly offered a few observations which could be made from the sample of eight lines of tracings: "Patients who are tense or anxious or who are chronic alcoholics generally have low amplitude, fast tracings, amplitude, fast tracings, · ... This EEG shows a very well developed, well regulated, and symmetrical alpha rhythm of normal frequency." Dr. Stewart added, .. Patients with pronounced visual imagery-that is, those individuals who can close their eyes and visualize their surroundings in detail, as well as the visual circumstances surrounding their experience in the past-do not have pronounced alpha rhythms and may, indeed, not have any alpha at all." Dr. Stewart to Thomas Hunter, M.D., 27 Jan. 1966. Courtesy Drs. Stewart and Hunter.

\section{[1454-1455]}

Faulkner's feelings about his medical treatment would undergo an alteration when the bill arrived. "Stay away from Wortis," he advised Joan. "I thought I had warned you. His bill was four hundred and fifty dollars. I asked how come, he said he charges 50 dollars a visit, made me 9 visits. I remember only 3, two of which I called at his office by his request, not mine. He is a psychiatrist; in my experience, psychiatrists will do anything. Stay with Melchionna, who is a simple doctor. He gave me a complete physical overhaul, charged $\$ 85$ against Wortis's $\$ 450$, out of which I got one bottle of seconal capsules."

Fn 14557 WF to JW, 24 Apr. 1953. 


\section{6-7}

[Though listed in the index under "drinking" there appears to be no pertinent information of such activity on these pages. - Author]

\section{6}

Ben could see that their host was not yet back to normal, so before they, left he got in touch with Malcolm and Gloria. It was a wise precaution, for Faulkner was now apparently suffering pain as well as depression, and he had put himself back on the ill-fated alcohol and Seconal regimen. By September 8 it was clear that he needed medical help. With the aid of September 8 it was clear that he needed medical help. With the aid of Jimmy, just back from flying Corsairs in Korea, they took him back to the Gartley-Ramsay Hospital in Memphis.

He was not quite as ill as he had been on his previous admissions. Moreover, his appetite was good and he asked for paraldehyde, not only for his nerves but for help in taking himself off the alcohol. At Cowley's home five years before, he could taper off on beer and will power, but this would no longer work -- not, at least, when he had to fight vertebral pain, too. The next day he developed a symptom that may have concerned him: vague abdominal distress. There was tenderness in the area of the liver, but beyond that few other definite signs. He began to grow impatient, as he usually did after the forty-eight hours of treatment that would cut off the acute phase and begin the recuperation. The staff tried to reason with him, to no avail. They called to enlist the family's help, but by that time the patient had already left.

Fn 14667 I: BW, 28 Mar. 1965. 146624 Courtesy Gartley-Ramsay Hospital.

\section{[1467]}

Articles about Faulkner at home had been appearing for over twenty years, but after this one his world would never again be so private as it had been. It began with a catalog of the major novels which emphasized the violence and abnormality in them and commented that it could be said "with relief" that Jefferson and Yoknapatawpha were "the literary invention of William Faulkner." He had been "an elusive personality," but the books had become a part of the American literary scene like Poe's and Melville's. This led to one of the premises of the article: "Because he has created them, he does not belong entirely to himself." It was a premise Faulkner would always abhor, yet there appeared little he could do to combat it. Coughlan went on to describe his family and certain aspects of his life, such as his "legendary" drinking-observing that he was "not an alcoholic but perhaps more accurately an alcoholic refugee, self-pursued."

Fn 146725 Robert Coughlan, "The Private World of William Faulkner," Life, XXXV (Sept. 28, 1953), pp. 118-36, in Coughlan, p. 25.

\section{8-9}

Few members of the Faulkner clan would have appreciated the article's virtues, and almost all would have recognized most of the errors of fact (which were numerous, though it was the most careful biographical article that had been done about anyone in the family since A. L. Bondurant's monograph on the Old Colonel). Some might have agreed, however, that it contained perhaps the best description of the man himself ever written: "William Faulkner is a small, wiry man with closely cropped iron-gray hair; an upswept mustache of a darker color; a thin, highbridged aquiline nose; heavy lidded and deeply set brown eyes in which melancholy, calculation and humor variously are reflected; and a face tanned and webbed, especially near the eyes, with the creases and lines and tiny tracings of advancing middle age and the erosion of many days spent in the open in all weathers. He is entirely self-possessed, with a manner easy, courteous, speculative, and deadly. He is a quiet man; yet when he is at ease, with his short legs outstretched 
and a blackened pipe in his thin lips, and perhaps a drink at his elbow, he is like a somnolent cat who still in the wink of an eye could kill a mouse. Faulkner does not look or act like what he is. He acts like a farmer who had studied Plato and looks like a river gambler. In the way he looks there is something old-fashioned, even archaic." In the concluding part of his essay, Coughlan would try to explain how he got that way.

"The Man Behind the Faulkner Myth" appeared on October 5. It traced Faulkner's career from the time of his friendship with Stone to the present. Again, in spite of occasional inaccuracies and invasions of the subject's privacy, it was the most comprehensive and interesting thing of its kind to have appeared. After a reference to the new novel ("recently finished"), Coughlan ended with the Nobel Prize occasion and Faulkner's return, when Bill Griffin suggested that there was, after all, a difference between an institution and a man, thus forestalling the painting of his name on the town water tower. With its vast readership, Life had helped make any such gesture superfluous.

Though Faulkner read neither article, he continued to react to them. Shortly after the first one appeared he was in Wright's Sanitarium, a small private hospital at Byhalia, fifty miles to the north of Oxford on the way to Memphis. He was in the same cycle that had begun in Greenville, and the knowledge that millions of people were intruding upon his cherished privacy can have done little to help such a private man bring the cycle to an end. When Phil Mullen read Life, he was so appalled at the personal material that he dashed off a note telling Faulkner he had not told Coughlan "all those things about the Faulkner family." On October 5 Faulkner wrote Mullen that he had not seen the piece yet, "but if you had anything to do with it, I know it is alright and I hope you make a nickle [sic] out of it."

Fn 146825 Coughlan, p. 21. 146835 Robert Coughlan, "The Man Behind the Faulkner Myth," Life, XXXV (Oct. 5, 1953), pp. 55-68, tl Coughlan, p.138.

\section{DECEMBER, 1953-APRIL, 1954}

\section{[1481-1482]}

It began disastrously. Hawks was at Orly on December 1 as planned, waiting with Harry Kurnitz, whom he had hired as a kind of backup scriptwriter, and Kurnitz's friend, photographer Robert Capa. One New York plane arrived, but Faulkner was not on it. Then there was another. When he did not emerge from that one either, the three returned to the city to wait, but there was no word that night or the next morning. Actually, Faulkner had arrived on December 1 -- at Cointrin Airport in Geneva. Though he may have made a mistake about the plane, he was under no misapprehension about his destination. He cleared customs and then set out, presumably by train, for Paris, 350 miles away. Meanwhile, his luggage unaccountably went on to Zurich.

At his Paris hotel Hawks waited impatiently. Faulkner's absence was holding up the whole production, for they had to have a script before they began casting. It had been more than twenty-four hours and still Hawks had heard nothing. Finally, there was a knock at the door. $\mathrm{He}$ opened it to find i two gendarmes, supporting his scenarist between them: in his tweed suit, the rosette in his lapel and a gash in his scalp. One of the two had found him in Montmartre. About to send him where any bibulous Parisian would have been housed to await the judge, the policeman noticed the emblem of the Legion of Honor in the buttonhole. He and his colleague checked for identification. When they read his passport, they took him to a cafe and provided hot coffee. After a bit he spoke to them. "Hawks-Plaza," he said, and they brought him there. Hawks thanked the policemen fervently and helped Faulkner into bed.

Hawks began to plan. They ought to go someplace where Faulkner could work in isolation, and he knew just the spot. The next day they drove south, and on Friday, December 4, the party crossed into Switzerland at Vallorbe, just north of Lausanne, and continued eastward through the day, ascending gradually until the great Alpine peaks began to loom in the distance 
against the cold sky. They swung south, threading their way through the windy Simplon Pass, down toward the Italian lakes. Passing through customs at Domodossola, they continued through the Val di Ossola until the long blue outline of Lake Maggiore came into view above the plains of Lombardy. They stopped at Stresa, where they settled in for a two-week stay in a villa overlooking the lake, lent to Hawks by one of his friends.

As Faulkner gradually pulled himself together, a three-way collaboration began.

Fn 148120 I: Howard Hawks, 3 June 1965; Harry Kurnitz 8 Jan. 1964- Many of WF's movements related here are inferred from stamps in his passport.

\section{4}

As they entered Christmas week he tried to make the best of things. One of his first acts, Kurnitz remembered, was to commandeer a whole bin of thirty-six bottles of Montrachet in the Suvretta House cellar. Each day at lunch with Kurnitz he would drink half a bottle, having begun the meal with an appetizer of two martinis. Warner Brothers had provided Hawks with a liberal budget, and apparently Faulkner had decided this was no time to be thrifty. He did not go near a ski, skate, or alpenstock, however, but left the winter sport to Hawks and his glamorous wife Slim. He still remembered their excursion into Baja California a decade earlier. "You ought to see her clean a fish," he told Kurnitz. "It's beautiful." He looked ahead to his departure to Stockholm on Christmas day and a full week's holiday with the friends he had made there before returning to St. Moritz.

Fn 48436 I: Harry Kurnitz, 8 Jan. 1964.

\section{7}

As on his return to St. Moritz, he attended to a little business and then · turned to the pleasures of the city. He and Kurnitz went out together, stopping at the Excelsior to pick up Humphrey Bogart. As they sat sipping drinks, they 'discussed the report that Ernest Hemingway had been forced down in a light plane in Africa and was feared dead. Later the three joined some of the others. Lauren Bacall was there, and Faulkner seemed glad to see her.

"When you finish this picture, what do you want to do?" she asked him.

"I think 1 would like to drive through the Loire Valley," he answered slowly, "tasting the wine of the country."

Sometimes she would see him sitting alone at a table in the bar at George's, around the corner from the Excelsior. She would leave him to his privacy, but one night, at Passetto, she said, "Bill, why do you drink?"

Liking this slim, green-eyed girl, he answered. "When I have one martini," he said, "I feel bigger, wiser, taller. When I have a second, I feel superlative. When I have more, there's no holding me."

Fn 148730 I: Harry Kurnitz, 8 Jan. 1964; Lauren Bacall, 22 Feb. 1967. Miss Bacall asked him if she could have a copy of his Nobel Prize speech. So must have others as well, for on February 6, after asking SC to send tax information to his attorney in Oxford, WF asked for five or six copies of the speech. In due course Miss Bacall received hers, inscribed. WF to SC, 6 Feb. 1954.

\section{9-91}

Kurnitz arrived in Cairo on Friday, the twelfth. Like most of Hawks company, he settled in at the Mena House, a tourist hotel near the pyramids. Work would begin in earnest on Monday. Faulkner was due at 2 A.M. Monday morning, and Kurnitz went to the airport with Hawks to meet him, each silently remembering the fruitless wait at Orly almost exactly eleven weeks before. Hawks was now decidedly apprehensive, for he had had word from Paris that his 
scriptwriter was not being particularly abstemious. The plane came in on schedule, and soon they could hear the distant drone of its motors in the night sky as they waited in front of the brightly lit terminal. Just then, an ambulance pulled up at the landing strip and stopped at the gate where the plane was to taxi in. Kurnitz thought that, under the bright lights he saw Hawks suddenly blanch. After the other passengers deplaned, the two men found that the ambulance stretcher was indeed for their compatriot. He had presented himself at Orly on time and boarded the right plane, but in the depths of his moroseness at leaving Paris for Cairo he had managed to dispose of a bottle and a half of brandy. They escorted him as he registered not at the Mena House but at Cairo's AngloAmerican Hospital.

- Now they waited for the illness to run its course, but it proved to be a stubborn siege. As Soon as they could, they transferred him from the hospital to the hotel. This was welcome to Faulkner-always restive under hospital but particularly now because of one of the nurses at the hospital who refused to believe that he was William Faulkner. At the Mena House he struggled with himself, and he had a difficult time of it. Debilitated and shaky, he was striving gradually to take himself off the alcohol. Before long, he had substituted beer for bourbon, but he was also plagued with another habitual aftermath. Hawks walked into his room, sat by his bed, and asked how he was. "Howard," he answered huskily, "I just can't seem to shake this cold." Gradually, however, he made a little progress and began to turn outward. One morning at six o'clock Kurnitz checked on him. Faulkner invited him in to share a liter of beer that stood on his table. "It's good for my cold," he said.

No matter how he felt, he was determined to see this thing through. .By February 17 the second draft of the script had been completed, chiefly by Kurnitz, but Faulkner intended to do his share of the rewriting as they worked toward Hawks's shooting script. "Feeling pretty wellworking," Faulkner told Commins in a shaky note in late February, adding, "Don't think much of Egypt." He was also unimpressed with the hotel. Kurnitz, a one-time violinist, had noted a rarity, however: a left-handed violinist playing with the dinner ensemble. When he mentioned it, Faulkner said he would like to hear the musician play "Summertime." (A short time before he had told one Roman interviewer, "Music makes me nervous. I don't listen to it at all.") Now, however, his eagerness to hear "Summertime" was undiminished by the fact that the Egyptian violinist did not know this Gershwin composition. Kurnitz cut the meal short and averted an incident.

In his room, Faulkner continued to work each day. It was perfectly obvious that he would much rather be in either Paris or Oxford, but he felt obliged to continue with the script. He may, of course, have been thinking too of his promised percentage of this picture and the two others which he thought would finally make him rich. So each day he would pass out to Kurnitz sheets of manuscript written on lined yellow legal-size pages. From what he could read, Kurnitz knew that his collaborator was still far from top form. This became quite clear, he thought, in one scene where tension began to build between Pharaoh and Hamar, the Priest. Finally the angry Hamar dared to touch Pharaoh's sacred person. It was at that point that Pharaoh, drawing himself up to his full height, commanded imperially, "Leave go of my arm." Kurnitz did not pass these pages on to Hawks.

Fn 148937 I: Harry Kurnitz, 8 Jan. 1964; Howard Hawks, 3 June 1965. 49013 Ibid. 149017 Courtesy Warner Bros. 149019 When WF's Oxford tax attorney wrote him on February 18 asking for information. WF supplied it on his letter together with the note to SC written in late February. Two of the 1953 deductible expenditures RH had listed for him were $\$ 195.10$ for doctors and $\$ 882.25$ for a hospital. 1490 26 I: Harry Kurnitz, 8 Jan. 1964.

[1492-1493] 
He was now more trouble than he was worth. Hawks agreed to his departure, and he took the night flight from Cairo on March 29, putting down once more at Orly on March 30. At least he would get one wish: to be in France in April again.

Two days after his arrival in Paris, the appearance of The Faulkner Reader was noted in American book columns. He was, of course, by now an international literary celebrity, almost a literary institution. Charles Poore noted in The New York Times that more than 600,000 of his books had been sold in Random House and Modem Library editions, while the New American Library reported nearly five million paperback sales. It would seem he had all the acceptance a writer could have desired. In spite of this, and though he was back in Paris in the spring, he was obviously still unhappy. He was also ill. Monique Salomon remembered his request to her: to put him in the hospital if he needed it. On April 5 she and Else Jonsson took him to Neuilly-surSeine, where he was admitted at the American Hospital of Paris.

It was a disturbing experience for both women. When they returned the next day he looked at them- reproachfully. "Monique," he said, "you put me in jail." He had told Else something about his drinking before, that he sometimes drank out of fear. At home, in a situation like the present one, he would have someone drive him out into the country, and he would be sober by the time he walked home. But now his hospital claustrophobia was at its height. He told Monique and Else he would jump out the window if they didn't get him out of there. They capitulated. As they were preparing to leave, his doctor said to them, "Do you know what kind of responsibility you're taking on yourselves?"

In Cairo, Faulkner's prodigious capacity had been a source of wonder to Kurnitz; now he began to call again on his unusual recuperative powers. At home he would have begun to take a concoction of raw eggs and Tabasco sauce, and these were presumably available to him at the Hotel Beaujolais. Whatever regimen he employed, he felt well enough a week later to be thinking about revisions of A Fable and plans for returning home. On April12, he sent a cable to Commins: FORGOT JUDAS MISERY DESIRE REWRITE ONE SECTION PLAN ARRIVE 20 APRIL OR WILL CABLE TO SEND SECTION HERE. The book was much on his mind. In its last scene, as the funeral cortege of the supreme commander, the marshal, made its way to the Arc de Triomphe, the horribly disfigured form of the runner -- a disciple of the dead corporal -stepped out of the dense ranks of spectators to repudiate the Generalissimo and all he stood for. Flinging his battle decoration at the coffin, he was mobbed and then dragged bleeding to lie "in the gutter of a small cul-de-sac side street...." (436) Twice Faulkner wandered near the Arc searching for the exact location he had in mind when he wrote the passage. The second time, as Jean Stein watched him, he photographed from several angles a portion of the Rue Tilsitt, next to the A venue de la Grande Armée. A few days later, as though paying a final homage, he went once more to Verdun with Monique and Jean-Jacques.

Fn 149219 I: Howard Hawks, 3 June 1965. 149226 "Books of the Times," NYT, 1 Apr. 1954. 149232 I: Monique Lange, 9 Jan. 1964. 14934 Ibid.; FJ, 27 Mar. 1964. 14936 I: Harry Kurnitz, 8 Jan. 1964. 14938 I: JMP, 21 Mar. 1965. 1493 13. WF to SC, 12 Apr. 1954. Courtesy Mrs. Commins. 149324 Jean Stein to JB, 8 Feb. 1969. It seemed to Jean that WF was even going through some sort of identification with the runner. "In World War I," he told her, "I enlisted as an RAF pilot, and when I wasn't flying I drank almost all the time to forget what we were up against." later he added. up against." Later he added, "One day the plane crashed. I was pulled out of the wreck, declared dead. I knew I wasn't dead. They couldn't kill me." WF's Words reminded her of those of the fallen runner: "I'm not going to die. Never." In the interview in La Fiera Letteraria, WF quoted the runner's speech from memory. Later, asked why he wrote, he answered, "Writers have private illusions [about] the origin of their books. I intend my writing as the phrase which appeared all over on the wall during the last war [in America] 'Kilroy was here!' Kilroy has been here. I write to say No to death." One borrowing for the last passage involved earlier work and earlier memories of France. This last segment of $F A B$ began, "It was a gray day though not a gray year." P. 433. Cf. Temple Drake in the Luxembourg Gardens at the end of SAN. 


\section{5}

Though this feeling was now intense, it had been there all along. He had explained the meaning of the plot to other screenwriters in Musso Frank's in 1943. Later when Dot Oldham sat by his bedside at Rowan Oak as he recovered from a collapse, he had told her the story of $A$ Fable, gripping her hand so tightly she felt he was crushing it. It was the one book he would explain in detail to Estelle and Jill. As the pages accumulated, Estelle read a portion and told him she didn't understand it. He defined the military terms for her and explained how blanks had been substituted for the live ammunition. Thereafter he would read the novel piecemeal to her and Jill. Now, as the book's publication approached, he must have been 'seized with this same anxiety to make people understand. At some point the preface (which Commins also considered for the dust jacket) was mimeographed for distribution. Ultimately, however, the craftsman won out over the moralist, and the preface went into Commins' files. The novel would stand on its own, with no glosses from the author.

There were a few more things to do before he turned southward. When he wrote Jean Stein on April 22, he told her, "I wrote this on the typewriter because I have just finished signing my name 1100 times on autograph sheets for the book. By now, I not only cant hold the pen anymore, I hate Wmfaulkner almost as much as mccarthy." The next day he checked in at Harold Ober's office, where he talked with Ober and Anne Louise Davis, who later reported to Holiday magazine. Holiday editor Ted Patrick had told Ober they hoped Faulkner would find other ideas he might do for them. "Mr. Faulkner says he has no ideas at all as the outcome of his trip," she told Patrick, "and he asked us to tell you this." He would, however, like to do another article for them on the South. He thought he could do that quite well, he said.

Fn 14957 I: Dorothy Oldham, 21 Mar. 1965. 49522 WF to Jean Stein, 22 Apr. 1954. 49529 Anne Louise Davis to Ted Patrick, 23 Apr. 1954.

\section{MAY, 1954 - JANUARY, 1955}

\section{5}

This was for Faulkner a fast pace, and though things seemed to be going better and better, danger signals appeared. That afternoon there was "a modest cocktail party" of about forty people hand-picked for their interest in Faulkner, with an interpreter to help them ask questions. It seemed to Driver more like a Chautauqua conference than a cocktail party, with a semicircle of questioners seated around Faulkner, who reached fora fresh drink every time a tray passed nearby. "Bombarded" with questions for a solid hour, he later said courteously that he had enjoyed it. It was nine o'clock at night before they took him out to dinner. By now he $\cdot$ was talking "incessantly" about Machu Picchu, the abandoned citadel hidden on an Andean mountaintop where the Incas made their last stand. He wanted to return to Peru soon, he said, and his hosts asked about his coming for a year or so for an assignment to Lima with road trips to other countries. The next morning after very little sleep he caught the 8:IO plane, taking with him, remembered Driver, "two bottles of the finest Pisco I could find for him and for which he developed a deep appreciation." A product of the Ica Valley180 miles to the south, pisco is a brandy distilled from freshly fermented muscat wines, with a pronounced fragrance and flavor of the muscat grape. Bottled at the age of two years or more, it is also eighty proof.

He was into the cycle now, and its course was unpredictable. As he got off the plane in Sao Paulo at 7 P.M., the effects of the Peruvian brandy were obvious to critic Morton Dauwen Zabel, who had gone to meet him at the airport with the embassy people. At that point two Brazilian officials hospitably presented him with two beautiful decanters of Brazilian brandy. They all went to his hotel and then out to dine at a Russian restaurant. He was silent, eating nothing but drinking vodka. By the time they left, late that night, he needed help. Forty-eight hours and one physician later, he was ready to resume the grind. 
Fn 15052 Thomas Driver to Muna Lee, 9 Aug. 1954. Courtesy Dept. of State. i505 18 Ibid. 150525 I: Leon Edel, 30 Mar. 1966.

\section{[1508-1509]}

The wedding was as beautiful, and as taxing, as big weddings can be. Guests streamed into town as presents kept arriving and flowers were delivered to both church and home. Sallie Murry and Kate Baker, Estelle's neighbor, pitched in to help as the tempo increased. Bridesmaids checked each other's hems while groomsmen wrestled with ties. Ben Wasson helped his friend of thirty-five years dress for the wedding. Faulkner put on the dark striped trousers and the white shirt with its wing collar, and Ben lent a hand with the studs and links, the shining cravat and stickpin. He slipped into the gray double-breasted waistcoat and went down to the front hall to watch as Jill descended the stairs in her figured white satin gown and train, lace at her wrists, pearls at her throat, and the sheer white veil floating behind her from the satin cap that halfcovered her blond hair. With Estelle, petite in a blue taffeta gown from New York, they gathered for a moment in the parlor. They must drink a glass of champagne before they left for the church, Faulkner said. Estelle was wary of the wine and hesitant, but he insisted. Standing, glass in hand, he smiled down at his daughter, seated near the hearth, her yards of shining white spread out around her. The toast drunk, he put on his dark morning coat and turned to one of the red-coated waiters hired from the Peabody in Memphis. "Charles," he said, "be sure the wine is properly chilled." .Then, her hand on his arm, he escorted Jill out the door and down the steps of Rowan Oak into the waiting limousine.

Fn D8 8 I: SMW, 19 Mar. 1965. 1509 9 I: BW, 28 Mar. 1965.

\section{0-11}

Reaction and letdown came quickly after the newlyweds departed for Mexico. He had seen the tossed bouquet and the shower of rice, and then they were gone. He too would be freer now, but suddenly he wanted people with him. He asked Arthur Halle and Don Lake and their wives to stay fora small family dinner afterwards, but they had to get back to Memphis. Ben Wasson, who had sat with the family at the church, stayed for a while, as did Saxe and Dorothy Commins. After supper Faulkner switched from champagne to whiskey. He and Estelle were both drinking heavily now.

The next day another female reporter arrived. "What can you say about the wedding, Mr. Faulkner?" she asked.

He looked up from the table where the bottle stood. "I remember the lady with the cockatoo on her hat," he said. "Do you remember what color it was?' she asked.

"It was a mustard-colored straw hat," Dorothy Commins said, and Faulkner turned on his silence.

Later he took Saxe Commins to see the bed in which Maggie Brown's great-grandmother had been shot by a Union soldier. He pointed to the bullet hole in the headboard. "This is why the war will never die for these people in the South," he said. "This happened to this girl's family." By the next day he was in bed himself. As the Comminses left he tried to ease Dorothy's concern. "Don't worry," he told her. "I'll see you in two weeks."

Fn 15116 Maggie Brown in WFO, pp. 122-3.1511 8 I: Dorothy Commins, 20 Aug. 1965.

\section{JANUARY - JULY, 1955}




\section{$1541-[1542]$}

At some point during or after the trip, what he had done apparently came home to him: his patriotic impulses, his wish to speak out on current issues, and his desire to get back to Europe had led him into the kind of situation that unnerved him. It would be worse than the trip to Stockholm. Now confronted with the imminence of the ordeal, with another one of his promissory notes come due, he could not meet it. He employed the predictable strategy and began to drink. It was clear to Dr. McLarty what had happened: Mr. Faulkner didn't like these things but he felt an obligation to accept them. Once again he was the subject of intensive care.

He was able to board American Airlines flight 207 at 3:25 P.M. on Friday, July 29-just barely. By dinner time he would be in Fort Worth, and then he would fly to Los Angeles. There he would board Pan American Flight 825, which would deposit him in Tokyo twenty-four hours later on the first leg of a trip that would take him around the world before he saw Rowan Oak again.

Fn 154137 I: Chester McLarty, M.D., 21Mar. 1965. 15426 Courtesy Dept. of State.

\section{JULY - OCTOBER, 1955}

\section{[1544] - 1545-6}

In the year 1955 little had yet been written about the time the human body required in adjusting to flights from one side of the world to the other and Faulkner's carefully planned schedule had been set to begin almost immediately. After lunch he was taken to the Kabuki-za Theater to see a Japanese-American cast rehearse The Teahouse of the August Moon and to talk with the producers. At four-thirty there was a press conference-cocktail party at the Foreign Correspondents' Club, where he appeared in suspenders, shirt sleeves rolled against the heat, to answer the questions of thirty newsmen about his opinions of Japan, Ernest Hemingway, the racial situation at home, and comparative civilization. The French had a culture of rationality, he said; the British, a culture of insularity; the Italians, a culture of the five senses; and the Japanese, a culture of the intellect. He had "a vast respect" for Japanese culture, he continued, but added, "I'm afraid a Westerner is going to be pretty gauche and look pretty stupid to the Japanese." Afterwards there was a long radio and television interview conducted by a professor and a social critic. That evening there was a party, on the town. Faulkner did not want to go but finally gave in. Not eating, he sat there drinking with the rest and appeared determined to make a night of it. It was São Paulo all over again.

The next morning Dr. Leon Picon, the officer in charge of the embassy's book program, appeared at Faulkner's room and took over. Faulkner was well into the cycle, but after he had showered and breakfasted Picon broached the subject of the lunch scheduled in his honor for 170 guests. "Leon," Faulkner replied, "I won't face those people." His back was hurting, he said, and he asked Picon to jump on it while he stretched out on the floor. Picon was horrified: he had no intention of jumping on the back of the United States Information Service's celebrated visitor, particularly when it already hurt. Finally, Picon left for the club to try to salvage what he could from the deteriorating situation. There he rose and announced that the guest of honor was unable to attend due to an indisposition caused by the heat. "What kind?" interrupted one of the newspapermen. "Canned or bottled?" Short, stocky, bespectacled Picon did his best to salve the general disappointment with a talk about the absent guest and then returned to- International House as soon as he could get away.

The crisis for the whole mission would come that afternoon at a residence reception to which Ambassador and Mrs. John M. Allison had already formally invited many prominent Japanese and members of the foreign community. Faulkner arrived with Picon at five-thirty and stood in the reception line, glass in hand. Then he stationed himself against a wall and silently stood his ground until the appointed end of the function at seven. One photograph showed the 
ambassador looking at his guest very closely. Seeing it later, Faulkner would say, "You can just see him drafting the memo." The memo was addressed to Lew Schmidt. Written and delivered after the reception, it read, in effect, "Get him on the next plane out of here or show me reasons why you shouldn't." The missed luncheon was a popular topic of conversation, and the reception had done little to retrieve it. There was a meeting scheduled for the next afternoon with six top ranking members of Japan's P.E.N. Club, and to the ambassador it seemed that he had to do what he could to avert complete disaster.

Faulkner had come to Japan at the right moment, Leon Picon later realized. Though it was summer and they were understaffed, the visit was being handled by the best USIS unit picon had ever observed. He, Lew Schmidt, and Don Ranard were all three holding down more than one job, but they were all young and their morale was high. Schmidt read the: ambassador's memo and then sat down at his desk. He typed out a short statement and handed it to Leon. "Sign this," he said. Leon read it. "Our resignations will be on your desk tomorrow morning," Schmidt had written. "If we don't pull this off, you can make them effective." Though he did not want to resign, Leon signed it and so did Ranard.

That day there was a very real chance that the resignations would wind up on the ambassador's desk, for by now Faulkner's collapse was complete, and he had been bundled out of his room for emergency medical treatment to pull him out of this depth of the cycle and get him functioning again if possible. The next morning when Leon arrived, Faulkner looked at him carefully. "Yesterday you were smiling," he said. "Today you're not. Why?" Leon told" him about the ambassador's ultimatum and their reply. Faulkner looked at the younger man again. "Leon, I'll keep faith with you," be said. "I won't let you down. The U.S. Government commissioned me to do a job and I'll do it."

When he met the six Japanese authors from the P.E.N. Club that afternoon at two o'clock, he was sipping what one of them took to be a glass of gin (another said beer), but he was determined that it would be an interview which would vindicate Schmidt and his colleagues.

Fn 15458 Asahi, 2 Aug. 1955; Japan News, 2 Aug. 1955; Mainichi, I2. Aug. 1955. Gay Wilson Allen, p. 567. 154514 LIG, p. 92.154517 I: Leon Picon, 28 Dec. 1965. 154532 Mainichi, 3 Aug. 1955. I: Leon Picon, 28 Dec. 1965. Picon to JB, 22 July 1966. 154536 Mainichi, 3 Aug. 1955. 154610 I: Leon Picon, 28 Dec. 1965. .546 20 Ibid.; 24 Apr. 1967. 154625 I: Marvin Felheim, 2.6 Mar 1971, 154720 Mainichi, 4 Aug. 1955; Asahi, 5 Aug. 1955; Shimbun. 5 Aug. 1955.

\section{5}

The pace would have worn down a younger man in better health, and Leon had to try to help him cope with it. On some days, when his spirits flagged, Faulkner might say, "I don't want to go today. Let's have a drink first." Sometimes Leon would simply reply, "You're under contract to the U.S. government." At other times he would go to the improvised bar in his room and mix a weak gin and tonic, and Faulkner, having sustained himself, would muster his forces and go on to the scheduled meetings. By now the younger teachers were questioning him without hesitancy. Leon had noticed something else which he used to sustain Faulkner's interest and keep the tone of the sessions from sagging. It seemed to him that Faulkner always did better when there was a pretty girl in the audience. Now he always saw to it that Kyoko Sakairi was there, or a slim, boyish-looking little student named Midori Sasaki, a twenty-four-year-old teaching assistant at the Hiroshima Women's College. Faulkner was fond of Kyoko Sakairi and somehow touched by Midori Sasaki, and he always seemed to be more on his mettle when they were there.

Fn 155530 I: Leon Picon, 28 Dec. 1965. 


\section{6}

As usual, the questions eventually veered off to his books and his habits. He gave a short verbal essay on the composition of The Sound and the Fury. He said his hobbies were horses, hunting, and sailing. "How about drinking?" asked one teacher. "Well, drinking," he said with a smile, "I consider drinking a normal instinct, not a hobby. A normal and healthy instinct."

Fn $155433 L I G$, pp. 135-41.

\section{[1561]}

What had been accomplished had of course been the result of a joint effort, but much of the impetus and labor had come from Picon, in relation to whom Faulkner had developed a special dependency and intimacy. Though his attitude was warm and often genial, Faulkner would nevertheless sometimes seem to resent him, as he did the obvious concern of others about his drinking. Technically, Leon was his "escort officer," but in more than one situation Faulkner had said to him, "Are you acting as the control officer now?" And once, when a Japanese came to the door and asked for five minutes with him, Faulkner had said brusquely, "See my control officer." At other times he would call him his wet nurse. Four days before the end of the seminar, Leon had wanted to get away to celebrate his birthday with his wife. Early in the mission Faulkner had seemed suspicious and fearful of others. As these feelings waned he had placed greater reliance on Leon, and now he did not want him to leave. "Aw," he said, "baby doesn't want to miss his birthday party." Leon stayed at Nagano.

Fn 156137 I: Leon Picon, 24 Apr. 1967.

\section{6}

A.s for his impact upon the Japanese, one of them again paying him the ultimate compliment: "Every Japanese-without any exception-was so attracted to him because of his Oriental, likeable, and sincere personality." Nearly ten years later an American traveling in Japan would note that whereas some Americans still talked about his drinking, "Japanese who were there spend all their time talking about what a great person. he was. The Japanese who met him still light up when one mentions his name and they talk in awed tones about it-meeting him was obviously one of the great events of their lives. This holds true not only of the literary folk who met him, but the common folk-the people at his inn in Nagano, for example-as well." On one point the traveler agreed with the Department of State: that the mission had done more to better Japanese-American cultural relations than any other single act of the department.

Fn 15673 Walter Harding to JB, 23 Feb. 1965.

\section{[1574]}

He had planned on two weeks in one of the cities he enjoyed. But he had told USIS that they could have half of this time and suggested they prepare a tentative schedule for activities in Paris only. He said he would hold press or radio-television conferences and perhaps participate in discussion groups with university students or young people. He would continue to assist in the USIS program whether or not they went on paying him per diem. Somewhat alarmed by the Tokyo directive on how to handle their eminent visitor, the US IS people in Paris went ahead with the preparation of a light schedule. Following one of the directive's admonitions, they assigned to him an officer who would be on call constantly and whom, it was hoped, he would rely on and trust. A young man named Richard Grenier drew the assignment. As in Rome, however, the anxieties were soon dispelled -- so much so that the USIS hospitality extended to Faulkner included a few bottles of bourbon, which he used and dispensed with pleasure and discretion. 
Fn 157423 G. S. Hooker to USIS, Rome and USIS, Paris, 9 Sept. 1955. 157427 William E. Weld, Jr., to JB, 28 Apr. 1969. 157431 I: George Plimpton, 22 Feb. 1967.

[1577]

Mondadori, the house of Gallimard was anxious to entertain one of its principal foreign writers. They asked USIS to help with the guest list, and they in turn consulted Faulkner, who suggested Madeleine Carroll, Francoise Sagan, and André Malraux's daughter. Promptly at six o'clock he entered the elegantly styled eighteenth-century building on the Rue de l'Université. Only a few other guests had arrived of the 400 who would jam the Gallimard precincts before the cocktail party was over. Sizing up the terrain, Bill Weld ushered Faulkner through the building to the large formal garden in the back, "'one of the most famous secret gardens of Paris." Leading him to one of the corners beyond the three trees which would shade the guests from the late afternoon sun, Weld handed him a glass of bourbon and water and told him he would bring on, one at a time, people he would presumably want to see.

Fn 157710 I: Howard P. Vincent, 27Dec. 1968. 157719 William Weld, Jr., to JB, 28Apr. 1969.

\section{[1579] - 1580}

There were other reasons, too, why he was thinking of Mississippi now. It had been a bad summer for Estelle, who had never been strong and whose vitality had been sapped by sickness. But now as she convalesced, working back toward physical health, she moved courageously in another direction and joined Alcoholics Anonymous. Jill, who had visited Rowan Oak that summer, had written her father that she had gone there for a rest but had also been glad to be there, to give her mother what she needed from both of them: their love and understanding and encouragement. The rest had been important for Jill; she was ill herself and only a few months into a precarious pregnancy that might not go to term. Malcolm, who might otherwise have helped, had been seriously ill during the summer. And then, on October 23, there was a telephone call from Oxford. Miss Maud had been rushed to the hospital suffering from a cerebral hemorrhage. Now approaching her eighty-fifth birthday, she might not survive. Her son boarded a plane for Memphis.

Fn 15806 JFS to WF, 29 Aug. and 7 Sept., 1955. 158013 Anne Louise Davis to RO, Anne Louise Davis to HO, Geller, I Nov. 1955; Harold Howland to WF, 24 Oct. 1955. Courtesy Dept. of State.

\section{OCTOBER, 1955 - JULY, 1956}

\section{0-1 - [1592]}

He was almost frantic at what he saw as the approach of a momentous crisis. For almost exactly a year now he had been urging his countrymen in letters and speeches to accept integration. It was no longer simply an issue that loomed menacingly; it now had a deadline attached. The Ober office had given a copy of the Life letter to news commentator Edward. R. Murrow and was awaiting word from him. With the rising tension, Faulkner began to drink, but he continued to cast about for a more direct means of heading off the disaster he foresaw. Jean" Ennis, in the Random House publicity department, was ready to help him where she could. She knew he had told Harold Ober he needed a forum, but there was not much she could do to provide one. Jean Stein was caught up in his concern and trying to help. Her cousin had told one of the staff of the Tex and Jinx radio show, and the principals of this conversation-and-interview program - Tex McCrary and his wife, former tennis star Jinx Falkenberg -- were anxious to have Faulkner appear. The show was carried only in the East, but the NBC newsroom would give nation-wide coverage and the wire services would presumably pick it up from there. It was arranged that he would meet with one of the staff on Friday, February 24. 
Meanwhile something else was developing. When the word went out that Faulkner was anxious to speak on this explosive subject, many were eager to offer him the chance. Philip Horton, of The Reporter, had been too late to buy "On Fear" and had lost out on "A Letter to the North" because his circulation was only 120,000 . Now he requested an interview with his circulation was only 120,000. Now he requested an interview with Faulkner by Russell Warren Howe, a correspondent for the London Sunday Times, at Random House on February 21. Faulkner, who probably did not know that it would not appear in the Times until March 4 or in The Reporter until March 22, granted the interview. When he gave it, with Saxe there in the small office, too, he had been drinking steadily but not enough to prevent his making comments more desperate and provocative than any he had thus far uttered.

His answers to the questions closely followed what he lad said in the essays for both Harper's and Life. They also revealed further why he feared the oncoming crisis so keenly. After the Supreme Court decision of May17, 1954, he told Howe, "you couldn't get as much as a few rounds for a deer rifle in Mississippi. The gunsmiths were sold out." Furthermore, he said, "I know people who've never fired a gun in their lives but who've bought rifles and ammunition." For the past year and a half it had been dangerous for him and others like him to speak out. People would phone him at three and four in the morning and threaten his life, he said, but they were drunk by then, and he did not carry a pistol even though his friends had told him he should. "But the other liberals in my part of the country carry guns all the time." The danger to them was totally overshadowed by the danger now to the nation at large. As for Autherine Lucy, he repeated no less than four times In the short interview his conviction that she would be killed if she appeared to register. "If that girl goes back to Tuscaloosa she will die," he said grimly. "Then the top will blow off. The government will send its troops and we'll be back at 1860 . They must stop pushing these people. The trouble is the North doesn't know that country. They don't know the South will go to war." The North was moving implacably toward disaster and silencing the voices of moderation whose counsel alone provided a viable alternative. His sense of desperation -- the sense, probably, of being pushed too far -- showed in one comment as transcribed by Howe. "As long as fighting I'd fight for Mississippi against the United States even if it meant going out into the street and shooting Negroes." He kept repeating to make himself clear. "I will go on saying that the Southerners are wrong and that their position is untenable, but if I have to make the same choice Robert E. Lee made then I'll make it."

The next day he had a luncheon appointment with Joan Bowen, but he canceled it abruptly. Almost a year later she would receive a letter of explanation: "At that time, the Lucy girl had been expelled from the University of Alabama. The next step would be for the NAACP to return herby compulsion, force. If they did that, I believed she would be killed. I had been rushing here and there, trying to get air time before they sent her back. I dont know why I thought then that drinking could help, but that's what I was doing, a lot of it. I woke up that morning in an apartment not mine with just sense enough to tell you I couldn't make the luncheon, collapsed. Came to Friday and friends resuscitated me just in time to make a presentable appearance on the Tex Something, Tex and somebody like a Frankie and Johnny team on the air from the Waldorf and make my plea."

Before air time, however, Greg Dawson, of the staff of the Tex and Jinx program, had come up to Harold Ober's office to meet with Faulkner. Once he had gotten an idea of Faulkner's views, he would pass his notes on to Tex McCrary, who would then conduct the interview live or on tape. Harold Ober was careful to have one of his people make notes of the conversation. Again Faulkner made points he had made earlier, but again there was the sense that the mounting pressure was pushing him farther to the right than he liked. Now he seemed to be advocating separate schools for black and white students. If Negroes could receive a good education in their own schools, the immediate problem would be solved in five years. Then, in a hundred years complete integration could be achieved, and in three hundred the black race would be assimilated into the white. Talking about the turmoil in his homeland he recalled a remark in the longstanding 
dispute with his brother on this subject. Johncy had said that if a Negro went to school with even one of his descendants he would be out on the front gallery shooting. This was the attitude Faulkner once bitterly disputed, but somehow it had apparently slipped perversely into his own speech in the interview with Howe three days earlier. The New York Times had carried the notice that Faulkner would appear that night on the Tex and Jinx show, but there was no mention from the wire services the next day. He would have to rely on Life for the dissemination of his viewsand The Reporter.

Fn 159013 Anne Louise Davis to HO, 20 Feb. 1956. 159022 I: Jean Stein, 10 Nov. 1964. 159025 I: Jean Ennis, 12 Nov. 1964. 159034 Anne Louise Davis to HO, 2 Mar. 1956. Charles D. Peavy, "Faulkner and the Howe Interview," CLA Journal (Dec. 1967), pp. 117-23. 159037 I: Jean Stein, 10 Nov. 1964. Now as always it was hard to keep him from drinking when he wanted to. Realizing that Jean had thrown out some the liquor in a bottle, he read her a lecture. "Deprivation never makes a saint; it only makes a minister," he told her. "Think of all the work that went into that bottle of liquor. When man discovered the distillation of liquor, he raised the civilization of man above animals. Until then man had only made a few scratches on walls. Pouring out liquor is like burning books." Miss Stein to JB, 24 Sept. 1969. 159127 The Reporter, 14 (Mar. 22, 1956), pp. 18-20, in LIG, pp. 257-64. See Peavy for a detailed discussion of the controversy which arose over WF's repudiation of the last quoted part of the interview. Howe wrote Peavy that the time [sic] correspondent in Memphis passed on to him a remark WF supposedly made there in March: "I'd been drinking so much that week I might have said anything, and so much since I don't remember what I said." (Peavy, p. 121.) In this interview, WF again emphasized the justice of equal rights for the Negro and reasserted his theory of the economic basis of discrimination. He also suggested that in 300 years the Negro would be assimilated into the formerly white race. 1592 I WF to JW, "Tuesday 12th," Jan. 1957.15927 FCVA.

\section{[1594-1595]}

The result was the most compendious, the best single Faulkner interview ever published. There were Polished anecdotes: the offer of the job as "landlord in a brothel," meeting Sherwood Anderson in New Orleans, and the Louisiana Lou fiasco. There were new glimpses of his life: saying grace at breakfast in childhood under the gentle but searching eyes of Great-grandfather Murry. He told in what seemed to be careful detail about the writing of The Sound and the Fury, As I Lay Dying, and The Wild Palms. And there were comments that rang like epigrams: "If a writer has to rob his mother, he will not hesitate; the Ode on a Grecian Urn is worth any number of old ladies." At some points he was tart and acid; at others he spoke in the tones of a man taking a long melancholy look back at life: "One of the saddest things is that the only thing a man can do for eight hours a day, day after day, is work. You can't eat eight hours a day nor drink for eight hours a day nor make love for eight hours-all you can do for eight hours is work. Which is the reason why man makes himself and everybody else so miserable and unhappy." At other times there was a kind of humor not too far from that of As I Lay Dying and Sanctuary. As for reincarnation, "I'd want to come back a buzzard. Nothing hates him or envies him or wants him or needs him. He is never bothered or in danger, and he can eat anything. "

Jean ultimately ended the interview with a question of fundamental importance. "What happened to you between Soldiers' Pay and Sartoris," she asked, "that is, what caused you to begin the Yoknapatawpha saga?" Well, he said, he wrote the first two novels because they were fun. But then, "Beginning with Sartoris I discovered that my own little postage stamp of native soil was worth writing about and that I would never live long enough to exhaust it, and by sublimating the actual into apocryphal I would have complete liberty to use whatever talent I might have to its absolute top." As time went on he built his own cosmos peopled by characters he could use and reuse at will, as he was now doing with the second novel of the Snopes trilogy. Then, in the last words of the interview, he spoke again in that reflective tone: "I like to think of the world I created as being a kind of keystone in the Universe; that, as small as that keystone is, if it were ever taken away, the universe itself would collapse. My last book will be the Doomsday 
Book, the Golden Book, of Yoknapatawpha County. Then I shall break the pencil and I'll have to stop."

Fn 159520 Jean Stein in LIG, pp. 237-55.

\section{8-9}

On Sunday, March 18, the effects of the accumulated anger, fear, frustration, injury, sickness, and drinking suddenly caught up with him. He began to vomit blood and collapsed into unconsciousness. He was taken immediately to the Baptist Hospital in Memphis, where they placed him in an oxygen tent and later started a blood transfusion and intravenous feeding. Though Miss Maud had made a surprising recovery, she was not well enough to go to Memphis and so called Jack. When Jack was admitted to his brother's room, he found him still in the oxygen tent, a tube inserted in one nostril. Bill was conscious but he did not speak. The doctor had told Jack what he thought: the immediate cause was an ulcer, but if Faulkner didn't stop drinking it would eventually kill him. "Mr. Falkner," he said, "you should try to persuade him to give it up." Jack said he would try, though he had scant hope of success. He had given up liquor himself, because, as he later said, "I couldn't excuse in a grown man what I could in a boy." But his brother was like the Young Colonel. Bill had suffered a hemorrhage before, Sallie Murry thought, and when she had told him to stop he had said to her, "If I can't lead a normal life I'd just as soon be dead." Now, sitting there on the uncomfortable hospital chair by the shining canopy that enclosed his brother, Jack told him what the doctor had said. Bill just smiled. Jack knew he would never give it up.

Again his strong constitution helped him to rally. Four days after he was admitted, he felt well enough to send a telegram of reassurance to Jean. The next day he was taken to x-ray, where the plates they took showed no ulcer. The tests of his stomach went on through the following Monday, and they proved inconclusive. The doctors still thought there might be an ulcer, Faulkner reported to Jean, though by now it might have closed up with stomach shrinkage. "Anyway," he wrote her, "I am going to act for the next 3 months as though I did have one: cut out alcohol and coffee, etc., live on baby food. I hope that I will be discharged in such good ulcer shape Monday that we can leave for C-ville about Wed. [or] Thursday." He still felt "pretty weak and rotten," but he and Estelle wanted to go up to Charlottesville where Jill was awaiting the imminent birth of her baby; if they did make the trip, he would be in New York by April 1 or 2.

Fn 159836 I: MCF, 31 Mar. 1965. 1599 I I: JMF, 15 Nov. 1966; Robert Coughlan, 24 Feb. 1967.159916 WF to Jean Stein, 25 Mar. 1965.

[1599]-1601 [Page 1600 is a photographic plate - a three quarter head-shot of William Faulkner - with the caption "Convalescing."- Author]

Before he was out of the hospital, however, he was writing about the civil-rights crisis again. On March 23 the wire services carried a report that he was "convalescing satisfactorily" from an unnamed ailment and that "attendants" said his condition was not serious. The hospital switchboard began to receive calls from reporters who wanted to get his views on the considerable response to the Life article and the strong reaction to The Reporter's interview. Finally he wrote out a statement in longhand for release to the press. As for fighting for Mississippi even if it meant going out into the streets and shooting Negroes, that was "more a misconstruction than a misquotation." The quoted statement was both "foolish and dangerous." He also repudiated the idea that the South was armed to resist.

By Tuesday, March 27, he was up and dressed and feeling well enough to sit for a series of portraits by Richard B. Crowder, one of his doctors who was an amateur photographer. Years before, Faulkner had written of Ratliff, recuperating from a gall bladder operation, "he had been sick and he showed it"; but now, like Ratliff, he was mending, "the smooth brown of his face not 
pallid but merely a few shades lighter, cleaner-looking; emanating in fact a sort of delicate robustness like some hardy odorless infrequent- woodland plant .looming into the actual heel of winter's snow..." He was ready to return home.

Back at Rowan Oak he decided that the hospital statement would have to be amplified lest The Reporter's interview produce the reverse effect of what he hoped and seem incendiary. He wrote the editor of The Reporter that from letters he had received and excerpts he had read in Time and Newsweek, he thought parts of the interview were not correct. If he had seen it before it had gone to print, those statements could never have been imputed to him. Then he repeated the denials in the press release: "They are statements which no sober man would make, nor, it seems to me, any sane man believe." Though he did not explain, he had been pushed too far by a combination of factors and pressures. But there now in that carefully written sentence was the final equilibrium he wanted to establish. When The Reporter carried the statement on April 19, it would also print a short and convincing rejoinder from Russell Howe: "All the statements attributed to Mr. Faulkner were transcribed by me from verbatim shorthand notes of the interview. If the more Dixiecrat remarks misconstrue his thoughts, I, as an admirer of Mr. Faulkner's, am glad to know it. But what I set down is what he said." Half a dozen years later, in an effort to correct another description of the incident in The New York Times, Jean Stein would review the interview, denial, and rejoinder and then sum up justly: "given the circumstances of the review and Mr. Faulkner's subsequent statement, I believe that History should accept the latter."

Fn : 59927 By AP, as publ. in Jackson Daily News, 26 Mar. 1956. It seems that at least one reporter managed to question him, for the last paragraph of the story ran, "Faulkner said he is at work on another book, taking it easy and writing when he feels like it, as he no longer has to write to earn a living." 159935 HAM, pp. 77-8. 160115 The Reporter, 14 (Apr. 19, I956), p. 7, in LIG, pp. 265-6. 60119 NYT, 16 Oct. 1962; see Peavy for additional material. WF sent a similar letter to Time (67 [Apr. 23, 19S6], p. 12, in ESP, p. 226.) Before the appearance of the Time story, writer Judson and his researcher had consulted AE. When it came out, AE felt that they may have garbled something he had said to them: WF had told him Johncy had said that if the day came when they tried to get a colored child into a white school in Oxford, he would bar the way with a gun. WF had said he started thinking, If it came to shooting, and my family were involved in it, where would I stand then? And he became so upset he started drinking. I: AE, 23 July 1965.

\section{[1603-1604]}

He went to see Dr. Ben Gilbert about his stomach, and sometimes he would have dinner with him and Anne. He was fascinated with the breadth of experience the stocky, vital, jovial doctor had known. He would ask about the odd cases, and Ben would tell him something of what a doctor with his broad practice would meet: the influential men who died in the embrace of call girls, the priests who came to New York in ordinary clothing to drink and get away from it all, one of them a prison chaplain. Ben had witnessed two executions at Sing Sing, and Faulkner was interested in his account of them -- how the authorities put barbiturates in the food as the time approached, how one man carefully pulled his trousers up so as not to mar the creases when he sat down in the electric chair. "How did you feel,?" he asked Ben. He was interested in the reactions of the relatives of the condemned, the relief of one father that now it was all over.

His relationship with the Gilberts had grown close during the four years that they had known each other. "You know," he would say to Ben, "you're the only fellow who doesn't ask me about my work."

"That's because I can't understand what the hell it's about," Ben would tell him, laughing.

Gilbert had treated him for drinking as well as for other ailments, and he could see he was probably straying now from the strict diet that Dr. Crowder had enjoined for three months. But Ben had enjoyed no more success than any of Faulkner's other doctors. And he resented questions about his drinking. "Never ask me why," he had once told him. "I don't know the answer. If I did I wouldn't do it." 
Fn 16043 I: Benjamin Gilbert, M.D., 20 Jan. 1966.

\section{[1604-1605]}

They had a short, pleasant noontime conference on a grassy slope by he house at Fox Haven Farm. Accompanying Gwynn was Floyd Stovall, the chairman of the English department. Faulkner offered them coffee, and as they sat there stirring it Stovall came right to the point.

"Mr. Faulkner," he said, "I'm embarrassed. We don't have much money. I doubt if we could raise $\$ 2,000 . "$

"Don't worry about money," Faulkner replied. "Don't pay me anything. It would only confuse my tax situation, and besides I don't know whether I'll be any good at this or not. All I need is enough to buy a little whiskey and tobacco. Let me work at it awhile and we'll see how it goes."

By the time they left he had agreed to come in the late winter and early spring of 1957 for a period of eight to ten weeks. He would meet classes and individual students on a mutually acceptable schedule. Beyond that, there would be no duties.

Stovall, a distinguished scholar in American literature, prepared to take his next step, a meeting with the president of the university. Stovall's main interests were Poe and Whitman, but the short, amiable, silver-haired Texan was almost as pleased as Fred Gwynn with the report he was about to give to President Colgate W. Darden. The tall, spare aristocrat was a direct and often brusque executive, a former governor of the state and a member of the DuPont family by marriage. Seated in Darden's office in a Pavilion on the Lawn, Stovall enumerated some of Faulkner's distinctions and urged the appointment.

"It would add prestige to the university," he said in summing up.

"The University of Virginia," said Darden, stiff-necked, "has sufficient prestige without William Faulkner." He had obviously been told about Faulkner's last appearance at the university. "I feel sure nothing like that will happen again," Stovall said reassuringly.

President Darden agreed to recommend the appointment for confirmation to the Board of Visitors.

Fn 160436 I: Floyd Stovall, 8 Jan. 1965. 160529 Ibid.

\section{JULY, 1956 - FEBRUARY, 1957}

\section{4}

Independence was of course only one of the constellation of values -- like privacy and individual freedom -- that particularly concerned him now. When he saw any of them threatened he reacted quickly, as when he wrote the Batesville Chamber of Commerce to accuse the local sheriff of having an informer who had provided a tip leading to the arrest of a woman who had legally purchased a bottle of whiskey in Memphis and illegally carried it home into Mississippi. "Only a decade ago," he wrote, "we emerged from a terrible war in which our nation gave blood and money that the world might be freed of a tyranny founded on and supported by secret police and informers." Though he was too late to join the admirable citizens who had contributed to pay her $\$ 125$ fine, he hoped it was not too late for the dollar he was sending toward "the tar and feathers fund for the brave, honorable and nameless patriot who informed on the lady."

Fn 161417 MCA, 11 Aug. 1956. Courtesy Prof. James B. Meriwether.

\section{[1622]- 1623}

It proved to be a strange, confused, and inconclusive meeting. Faulkner had come to Harvey's attractive, book- and picture-filled little English house on East 64th Street after having 
arrived in New York at six o'clock that morning. Besides himself and the host, there were present two men from the State Department, three of Faulkner's colleagues from Random House, and fourteen writers. To poet Donald Hall it seemed a curious gathering. Faulkner was seated near the door, "looking just like his pictures, very stony-faced as he was throughout the day, no expressions of feeling in his facial expression at all and very little in the inflections of his voice. He was holding a gigantic Old Fashioned glass ... and it was full of a dark brown liquid which I later found out to be Jack Daniel's and a little bit of ice and nothing else. He drank at this regularly and it was refilled. He Was, extremely calm and quiet and his voice was not slurred .... "

Fn 162325 Donald Hall to JB, 2 Jan. 1968.

\section{5}

'Then it was cocktail time, and the discussion continued while drinks were passed around. As the talk turned again to the problem of presenting America as it really was, John Steinbeck made another suggestion. "I once thought the best propaganda would be a mail order catalog," he said. "You can describe America to another country by a Sears \& Roebuck catalog how we live and how we pay for it." By now Harvey was trying to derive what consensus he could from the discussion. "I think everybody got pretty sloshed by the end of it," recalled Hall Mr. Faulkner's part was to assent mildly to most of the propositions about Hungarians, about the dissemination of cheap books, about the freeing of Ezra Pound, and to offer his own contribution of fellowships to the automobile plants. This, I think, was his only major contribution." A committee was formed comprising Faulkner, Steinbeck, and Hall to distribute a record of the discussion together with a draft of the proposals. As Hall left Harvey's house one image remained clearly in his mind from the hours of talk: "William Faulkner himself, a small, tidy, delicate, aloof, stern, rigid, stony figure-delicate and stony at the same time... that small aloof figure sitting in his chair rather away from the rest of the people, holding that enormous glass from which he frequently took a long sip, and that quiet, mellow, bourbony voice coming out with its absurd proposals."

Fn 16266 Donald Hall to JB, 2 Jan. 1968.

\section{[1628] - 1629-31}

He did not arrive in New York in time to arrange a briefing. Late Sunday afternoon, however, Harvey's phone rang, and it was Faulkner. He Sunday afternoon, however, Harvey's phone rang, and it was Faulkner. He sounded depressed, so Harvey asked him to come over and have dinner with him and his wife Pat. Faulkner said he would like that. It was a generous thought typical of the good-natured Breit, especially so in view of the fact that once when he had needed consolation he had gotten little from Faulkner. Breit had sat in his friend's room in the Hotel Madison and described the marital problems he was encountering. Faulkner had sat there silent, impassively sipping his drink. By the time Harvey had finished his recital, his melancholy had been superseded by annoyance. He thought to himself, "He's a country boy and I'm a city boy and he thinks I just have to talk. Well, I'll show him." He said nothing, and a half-hour of silence followed. At the end Faulkner rose, wandered over to the window, and stood looking out. Finally he spoke. "Harvey, come on over here and look down," he said. "Don't all them people look like bugs'?" Breit's annoyance turned to amusement, and he smiled in spite of himself as he thought how that same comment must have been made countless times before by nameless hotel guests not literary at all.

When Faulkner arrived, Harvey saw that he had not misread. his tone of voice. He mixed him a drink, and as Faulkner sipped it the trouble came out. He was supposed to have met Jean Stein, but she had telephoned to say she could not keep the date. Bennett Cerf and Donald Klopfer had noticed that he seemed to be out of spirits when they had last seen him, and Don remembered a thank-you note Faulkner had sent Pat Klopfer after they had entertained him and 
Jean. "To Pat," he had written, "who is always good to me whether I've been thrown over by a horse or a dame."

Dinner changed the atmosphere. Pat Breit had prepared Cornish game hens, which were just becoming known in America, and the small birds had been baked to a savory brown when she set them steaming on the table. Her guest ate two of them. Later he said, "Tell you what, Harvey. Some week you get in the car, load it up with those game hens, and come down to Mississippi." But when they returned to the living room, his black mood descended again. He began to attack women in general, talking about how they belonged in the kitchen. Pat, who came from a diplomatic family and had been in many situations demanding tact, found that even her poise faltered at this. After the liqueurs they switched back to whiskey as the desultory conversation veered to the next morning's meeting. Harvey remembered an early talk about the project. "Bill," he had said, "what did you get into this for?" Faulkner had sat silently, and then, looking at ,nothing in particular, he had quietly answered. "When your president asks you to do something," he had said, "you do it." It sounded now, though, as if Faulkner regretted his patriotic impulses. Harvey's uneasiness soon turned to alarm.

"What are you going to say at the meeting, Bill? About what the writers approved."

"I don't go along with that stuff," Faulkner replied. "We don't need any foreign writers here, and our writers don't have to go anywhere. Writers all over the world understand each other. What we need is an exchange of plumbers and carpenters and businessmen." '

"But it's not that simple. Take someone like Sartre. People like Sartre and ourselves don't see eye to eye. We need a ground for common understanding."

"No," Faulkner insisted, "here's what I think: we should have no censorship. Here's what we should do. We should get two stamps, and we take every book that goes out of this country and we stamp it 'True' or 'Not True.' "

"Bill, we can't do that. Besides, the writers' meeting approved some conclusions, something different from that."

"That don't make no difference. We stamp it 'True' or 'Not True.' "

"But who's to say what's true and not true?"

"We'll get a committee of writers, and they'll know what's true and what's not."

Making further inroads on Harvey's Jack Daniel's, they talked sporadically until Faulkner took his leave at about one o'clock. Fifteen minutes later Harvey's doorbell rang. It was Faulkner. bottle?"

"Harvey, everything is closed," he said, "but I need something to drink. Have you got a

Harvey gave him one, and Faulkner left. Then, thinking about the coming meeting, Harvey retired for a sleepless night.

The next morning offered no promise of a solution. When Harvey phoned the Algonquin at 8 A.M., Faulkner didn't sound very good. When he went by the hotel at 8:3o, Faulkner looked terrible, seemingly having cut himself in half a dozen places shaving. Harvey tried as tactfully as he could to get some idea of Faulkner's plans. It seemed that he was prepared to stick to the "True-Not True" scheme, and by now Harvey was horrified at the thought of the impression this would make. Faulkner's perverseness was obviously due in part to the mood of black depression which had settled over him, which might have made all the deliberations seem trivial if not even futile, as some had said at the outset. One reaction would be to deny the whole thing with such a perverse proposal. But there was doubtless something else. He was a writer who abhorred not only committees but confederations of any kind. The talk of committees -- literary and otherwise -- tended to fill him with revulsion. Now, on this dull February morning, he faced another group where the situation he detested would be raised a power. Beyond this, there may also have been operating a particularly Faulknerian sort of black humor. Sometimes there would flicker out from him a kind of mordant and sardonic wit or invention, particularly when he was depressed at what he saw around him. And it did not seem to matter that Harvey, as co-chairman, would also bear 
the brunt of the reaction. .. Inwardly writhing, desperate for some way out of the dilemma, Harvey made a desperate stab.

"Bill," he said, "I don't feel very well. I don't think I can take this meeting. Let's not go."

Faulkner considered this in silence. "Well," he said slowly, "let's just 'look in." With that he began to put on his coat. Following suit, Harvey left with him, hoping he could somehow avert disaster when they got there. They went through the heavy doors of the Metropolitan Club and deposited their hats and coats in the cloakroom. Following the others to the members had already assembled. Faulkner and Harvey took seats near the back. They listened as Charles Wilson proceeded to the business of the meeting. Harvey searched his mind again for ways to keep the chairman of the writers' group from making his disastrous pronouncement. Then Faulkner leaned toward him. "Let's get out of here," he said. With enormous relief, Harvey followed him from the meeting room to the cloakroom and out into the wintry morning. William Faulkner had participated for the last time in a formal function of the People-to-People Program.

Harold Ober's office was keeping track of his comings and goings as usual. In late January Ober had performed the pleasant task of telling him he had sold the last chapter of the Snopes book, now called The Town, to 'the Post. It would appear there on May 4 under the title "The Waifs," at a profit to the author of $\$ 3,000$. There was less pleasant news to pass on to Geller, however, a few weeks later. He was afraid it would be a month before their author would be able to sign the contracts for the purchase of The Sound and the Fury. He would be in the hospital, thought Ober, for some time. The cycle Harvey had seen beginning had gone into the next phase. Ober was aware that Faulkner was due shortly to take up his duties as writer-illresidence at the University of Virginia. On the basis of what he knew, the alternatives were either cancellation or a fiasco.

Ober was reckoning without the combined forces of Benjamin A. Ober was reckoning without the combined forces of Benjamin A. Gilbert, M.D., Stanley W. Mackenzie, R.N., and the recuperative powers of Bill Faulkner. On Saturday morning, February 9, Mackenzie had taken his patient to Ben Gilbert's office and from there to Penn Station. At 12:50 P.M. Faulkner was sitting in a roomette, pale and weary-looking but self-possessed, as the train pulled out on the first leg of the trip to Charlottesville. There, one week later, in the heart of rolling Albemarle County in the shadow of the Blue Ridge Mountains, he would embark on a new phase of his life.

Fn [628 32 I: Harvey Breit, 12 Nov. 1964. 16292 I: Be and DSK, 22 Sept. 1967. 16316 I: Harvey Breit, 12 Nov. 1964. Breit to JB, 27 Oct. 1967. Thereafter WF delegated to Jean Ennis such duties as were involved in the Writers' Group of the People-to-People Program. . 163112 HO to WF, 22 Jan. 1957. 163116 HO to James Geller, II Feb. 1957. 163126 Stanley W. Mackenzie to SC, 14 Feb. 1957. 163128 On January 20, 1957, Prof. Frederick L. Gwynn had received a telegram at the University English department: . WHEN DO I REPORT FORWORK? PLEASE WIRE REPLY. WILLIAM FAULKNER. Courtesy U. of Va.

\section{FEBRUARY - MAY, 1957}

\section{[1635]}

"I went to school at Virginia. Teach you how to drink, there." --Sanctuary (32)

[Epigraph to Chapter 70, February-May, 1957. This is a portion of direct speech attributed to the Sanctuary character, Gowan Stevens. - Author]

\section{5}

The State Department's International Educational Exchange Service had made its usual careful plans. Hal Howland and James C. Nelson were there at Washington National Airport to brief Faulkner while he waited for the plane to New York. In Athens the tentative schedule was set, and Cultural Affairs Officer Duncan Emrich had duly received a copy of the department's 
advice on handling William Faulkner. As an undergraduate at Brown in 1932, Emrich had won a $\$ 300$ prize with a study of Faulkner's early works. Now a veteran Foreign Service officer with a distinguished background in ballad and folklore studies, Emrich reacted to the document as did Second Secretary Stephen Gebelt: they thought it was ridiculous. They were almost incensed at the idea of taking such elaborate precautions with such a distinguished guest. Duncan and Sally Emrich were congenial, outgoing people, and when they and the Gebelts met Faulkner at the Athens airport after his 11 P.M. arrival, their first thought was to take him to the bar of the Grande Bretagne as soon as he had registered. The bar and dining room formed a kind of cultural center in Athens, and they saw no reason why Faulkner should not begin to enjoy his visit in one of the liveliest and pleasantest places in the city. They did not know, of course, how they would pay later for disregarding Leon Picon's carefully written suggestions.

Fn 164512 Dept. of State Memorandum. 16 Mar. 1957. 164526 I: Dr. and Mrs. Duncan Emrich, 24 Apr. 1967. Dr. Emrich to Dept. of State, 13 May 1957. Courtesy Dept. of State.

\section{[1646]}

Though Emrich and Gebelt had discounted the stories about Faulkner, Ambassador George V. Allen had not. He waited until Emrich informed him that he had left Faulkner in good shape before he went ahead with plans for a formal dinner. The evening went well despite a slight contretemps. Heading the guest list was to be Acting Foreign Minister Tsatsos. The last guests to arrive for the dinner were named Tsatsos, but they were the wrong ones. Allen's secretary had invited cement manufacturer Alexander Tsatsos instead of politician Constantine Tsatsos. As it turned out" however, the Tsatsoses -- friends of the AlIens -- had done their homework more conscientiously than anyone else and seemed able to comment intelligently not only on Requiem for a Nun but on any work of Faulkner's that arose inthe conversation. The next morning when Allen passed by his secretary's desk she was gazing "with quizzical astonishment" at the huge box of chocolates accompanied by Alexander Tsatsos' card bearing the message "Requiem for a Secretary!"

March 19 brought a visit to Dimitri Myrat at the Kotopouli Theater followed by a dinner given in Faulkner's honor by painter Nikolas Radzikyriakos-Chikas, and then the heavy part of his schedule began. Accompanied by Emrich and Gebelt, Faulkner called the next morning on Panagiotis Poulitsas and Athanasiades Novas, presiding officers in the Athens Academy. It was more than a formal visit. Emrich had hoped the academy would award one of its annual medals to Faulkner, and the forty members had determined that the year's Gold Medal would go to the embattled people of Cyprus, the Silver Medal to William Faulkner. After arrangements were made for the presentation on March 28, the three Americans departed for a buffet luncheon given for other guests by the general secretary of the Merchant Marine. These were activities of a kind likely to lower Faulkner's resistance, and this is apparently what they were doing. Then came an unscheduled appearance at an - unofficial reception given by the Association of Traffic Police of Athens. Later that evening there was a visit backstage during a special performance of Requiem at the Kotopouli and then a curtain speech to the audience composed of 1,200 members of the Workers Clubs of Athens. [...]

Fn 164610 Duncan Emrich to Dept. of State, 13 May 1957. Courtesy Dept.of State. 164621 Hon. George V. Allen, : courtesy James A. Donovan, Jr., 27 Sept. 1967. 16475 Duncan Emrich to Dept. of State, 13 May 1957. Courtesy Dept. of State.

\section{$1647-[\mathbf{1 6 4 8}]$}

The next day it was announced that Faulkner had left on a two-daytrip to Delphi with Stephen Gebelt. It was a welcome relief from the round of official functions, unbroken by the meetings with young people which Faulkner felt provided the best chance for him to do any real 
good. He and Gebelt kept a leisurely pace. He napped in the car, and whenever they stopped there was always plenty of ouzo, the potent, licorice-flavored liqueur of Greece. He enjoyed the countryside as they traveled westward, a fabled mountain rising before them to the north and ahead of them the site of the shrine of the great oracle. "There's no end to what you can see," he would say later, "and then sure enough you see something which is exactly like what you imagined. There will be a plain and across it suddenly there is Parnassus with snow on it, and the old ruins, they look ancient but there's a sense as though it happened only yesterday."

Now came the interlude he had hoped for. Duncan Emrich had asked industrialist

Bodosakis Athanasiades if he planned to use his yacht, the Jeannetta, between the twenty-third and the twenty-seventh.

'You can take it for as long as you want it," the munitions and pottery magnate replied.

"Can we put supplies aboard?"

"No, everything goes with it."

Everything included champagne and caviar, Scotch and smoked salmon. The chef would see to it that they bought fresh fish in the islands. The master and four other crew members would see to everything else.

Fn1648 10 FlU, p. 130. 164820 I: Dr. and Mrs. Duncan Emrich, 24 Apr. 1967.

\section{0-1}

"He was delighted that it was finished," Emrich recalled later, "and went back to join the others in the semi-enclosed deck at the stem-ouzo and snacks. This was probably mid-morning. I went up on the small bridge with the captain. The sea was rough even in the lee of the island, and the captain was muttering about turning back. It was mal teme, said one of the crew, 1 bad time, a bad sea. I said, No, this was bracing, or some such nonsense, but the captain knew his ship. We rounded the point and were really hit, heading into a very rough sea with strong winds. The captain immediately decided to return to Siros, saying the boat couldn't take it and that the motors would tear the bottom out of the boat in a sea like this. I went back to join the others. They were seated at a table, half of them on a banquette with their backs to the starboard side, the others including Faulkner in chairs facing them. I told them the captain's decision. The captain in the meantime, gauging the sea and waiting for the best moment, gave the wheel a full turn and the boat was immediately broadside to the sea. She heeled over dangerously in the trough and was hit hard by a wave, and it seemed touch and go whether she would come back. I had read of people's faces going white with fear but had never seen it. I saw it then on Metcalf who was one of those sitting on the banquette. He had reason. The Jeannetta was topheavy and one more wave probably would have finished her. In any event she made the full turn, and with that sea behind us we returned to Siros."

they had put into Siros in storm and rain that showed no sign of abating. It could blow this way for two or three days, or more, and the meeting of the Athens Academy was less than two days away. Looking about the storm-swept harbor, they could see they had little choice: the only vessel going to Piraeus that night was a miserable island-hopping steamer, a dirty red-gray hulk that heaved even though she was berthed at the dock. They would have to board her. The captain paid their fares since they had no money, and they stepped gingerly onto the filthy, vomitstained decks. It was a ghastly ship, thought Emrich, the only concession to comfort being the two cramped cabins. Duncan and Sally Emrich and Susie took one, and Faulkner and Lee Metcalf took the other. They got under way in the teeming darkness, slogging out of the harbor and into the open sea while the wind screamed. Emrich tried to sleep, but the ship shuddered with the impact of the head-on waves. Then, in the middle of the night, came a knock on his door. It was Faulkner, appareled in his shorts. Raising his voice over the roar of the wind, he shouted, "They've got a little ouzo in the bar." They managed to get him to bed. As the remainder of the sleepless night passed, they made their way back to Piraeus. The next morning the Emrichs 
gathered their belongings and left their cabin. "There was William Faulkner on deck," remembered Emrich, "fresh as a daisy."

Fn 165034 Emrich to JB, 11 May 1967. 165034 Ibid. 165116 Ibid.

\section{3-5}

Afterwards, he and Duncan and Sally Emrich went out on the town. Faulkner liked the Greeks. He saw poverty but no squalor, and he admired their toughness and pride. Many of them had the gaiety he had seen among Mediterranean people such as the Italians. Also with their party was an Egyptian Greek whom he particularly liked named George Hadjistavrou, a dark-haired Levantine who was going gray at the temples. Making his- living at the Phaleron race track, he was a handicapper of horses. There Faulkner had met "George the Horse" and had taken to him immediately. (When Bill had sent Estelle a cable giving the amount of drachmas he had won at the track, she knew he must have been tight.) Now the four were off to a tavern George knew, singing as the taxi threaded its way through the Old Quarter. George enjoyed making money, but this he preferred: being with friends, enjoying food and music. He liked books too, and had actually read some of Faulkner's. Tonight he insisted that he and the Emrichs should be his guests for a late supper. Before they left the tavern he 'gave Faulkner a going-away present: a silver coin in a small gift box. he gave Faulkner a going-away present: a silver coin' in a small gift box. Touched, Faulkner pocketed it, and soon afterwards the evening was at an end.

His other things were packed by the next morning at ten o'clock, including a souvenir from the Association of Traffic Police of Athens: a shining stainless-steel adaptation of the ancient Greek warrior's helmet. He would let his houseboy, Broadus, wear it, he confided to Emrich, and when he did Broadus would be the most distinguished figure in his circle. It seemed to Emrich that everyone had shown up at the hotel suite. George- the Horse was there, helping himself and the others to the bottle of Ballantine's on the table. The connecting doors were thrown open, and from the living room it seemed that the bathroom was a profusion of flowers. So many had come that finally the bidet had been employed as an enormous vase. "Miss Sally," Faulkner said, "I didn't get much sleep last night. There was an awful noise and water all over. And I have to apologize about the carnations. When the bidet blew up there wasn't much I could do about the carnations.

The Emrichs and the Gebelts took him to the airport. When he kissed Sally Emrich goodbye, she asked, "A bottle of ouzo?" He shook his head. "I think I can get a little bourbon on the airplane," he said. When it took off, a half-hour after noon, they waved, in tears to see him go.

.Like the visit to Japan, it had been the best stroke that Americans could remember in their time there. After the tour many Greek homes displayed autographed pictures of the Mississippi author beside those of the 'displayed autographed pictures of the king and queen. Press and radio comments continued for several weeks. One of his own came from an interview in Eikones: "I have learned to say: good morning and thank you, the words ouzo and retsina, but I shall never learn the Greek word for goodbye because I shall be back."

In early April he was in Charlottesville, apparently suffering no ill effects from the air travel, ouzo, or the Jeannetta. He was taciturn about the cruise ship: "too much top works, not enough bottom," he told Atch Hench. He did not hold back about the host country, however. "To give two weeks to Greece is an insult to the country," he said. Not long after; wards he would try to sum up for a group of students what he had felt in the time he had spent there. "It was a strange experience," he said, "in that the time he had spent there. "It was a strange experience," he said, "in that that was the only country that looked exactly like we had -- I mean, the background, the educational background of the Anglo-Saxon had taught him to expect it to look. And sure enough there was the Hellenic light that I had heard of, had read about. And I saw Homer's wine-dark sea too. And there was a-the only place I was in where there was a sense of a very distant past but there was nothing inimical in it. In the other parts of the Old World there is a sense of the past but 
there is something Gothic and in a sense a little terrifying." This was not true, however, in the isles of . Greece: "The people seem to function against that past. ..."

This time he had apparently not left behind him a trail of cuff links, shirts, and waistcoats. But it was not a perfect record. "Shortly after 1reached home here," he wrote Emrich from Charlottesville, "the medal and scroll given me by the Greek Academy disappeared. I recovered them two days later, the scroll intact in its velvet case, and the silver medal, but the velvet case for it was gone and I have given up hoping to recover it." He wanted it for a May exhibition of his manuscripts and medals being planned at Princeton University. Could the original jeweler supply another box so that the Greek mementos would appear exactly as he had received them? Emrich saw to it.

Suddenly, he was out of circulation. The cycle begun in Greece had gone on to run its course in Virginia, and he landed in the hospital on April7. To add to Estelle's troubles, Malcolm, who had come up from Mississippi, was sick, too. But Faulkner demonstrated his recuperative powers once more, and inside a few days he was home again, helping to care for his stepson.

He was dealing once more with a busy professional, business, and social life. He signed a contract with Jerry Wald and Columbia for an option of $\$ 3,500$ against a $\$ 35,000$ purchase price for The Hamlet. He read from his work for the Raven Society and for John Coleman's class in advanced composition. He and Estelle came to a party given by Fred and Anne Gwynn, and as he stood with novelist Nancy Hale in their pleasant living room sampling the punch, someone wondered what the base for it was.

"'I think it's a rum base," said Miss Hale.

"I believe it's gin," said Faulkner.

"I'll bet you a dollar," said Miss Hale.

Faulkner's face broke into what was for him a broad grin, and then he began to laugh. "I didn't think anybody who knew anything about me would bet with me on a subject like that," he said.

Fn 165330 I: EF, 26 Apr. 1967. 165338 I: Dr. and Mrs. Duncan Emrich, 24 Apr. 1967. 165418 Ibid. 1654. 25 Duncan Emrich to Dept. of State, 13 May 1957, Courtesy Dept. of State. 165430 I: WF by Atcheson Hench, 11 pr. 1957. Courtesy Prof. Hench. 16553 FlU, p. 129. 165512 WF to Duncan Emrich, undated and "Monday 13th," prob. 13 May 1957. FCVA 165522 Jerry Wald project book for The Long Hot Summer. Courtesy Mrs. Myron Prinzmetal. [For 1655 32, see 16562 I: Mrs. John Weston, 6 May1969. - Author]

\section{[1657]}

His back did not keep him from one social event that week of a kind: he would ordinarily have shunned. On Friday, April 12, John Dos Passos came to the university to address the law school and the Jefferson Society. He filled the good-sized auditorium and later went to a reception at the Thomas Jefferson Inn. Smiling and diffident, he talked with the undergraduates clustered around hill). Then the circle broke as some of the boys made way for another guest come to congratulate the speaker. It was Faulkner, and at his approach those nearby fell silent amid the cocktail din to hear if possible every word uttered by these two novelists, who-according to. Faulkner at least-were among the five best contemporaries in their craft. Faulkner extended his hand, and Dos Passos, a good head and a half taller, reached out and grasped it.

"Hello, Dos," said Faulkner.

"Hello, Bill," said Dos Passos.

They exchanged a few casual pleasantries as the circle reformed at a respectful distance and a photographer recorded the meeting. They sipped at their drinks in the frequent silences between them. Even if they had been bursting with things to say to each other, the crowded main lounge of the inn would hardly have been the place for conversation. After a short but polite interval, Faulkner offered his hand again. 
The ring closed around Dos Passos once more, and Faulkner returned home.

[Blotner does not cite a source for this interaction nor for the immediately preceding conversation between Faulkner and Fred Gwynn, one of Blotner's faculty colleagues. It appears that Blotner was present at the interchanges during those University of Virginia events and offers here eye witness accounts.- Author]

\section{$1660-[1661]$}

We had nothing summoning us back to Charlottesville immediately, so we were free to take our time. We stopped by the brick-walled cemetery where Confederate soldiers lay and made our way through the grass under the newly fledged trees. Looking down at the dark weathered stones, unprepossessing with their fading letters, we read the names and regiments of the young whose bones had been laid under these mounds almost a century before. Faulkner was silent, hands clasped behind him as he slowly made his way between the graves, stopping now and again to read a name before moving on.

When we started driving again we looked for a likely place to have dinner, but the proprietor of the first one we tried regretfully told us that we could not bring with us Mr. Faulkner's bottle of Jack Daniel's. But he was glad to supply the ice, water, and paper cups I then asked for, and we drove only a little way before we found a pleasant meadow. I pulled over and switched off the engine. It was good to sit there as the sun began to set, talking at random and ingesting the mellow sour-mash bourbon that neither Fred nor I could ordinarily afford. We had a second drink. When that was finished, Mr. Faulkner said, "Let's have another one."

"Why don't we go on," Fred countered, "and find a restaurant where we can have one while we're waiting for dinner."

"1 don't see why we can't finish the bottle here," said Mr. Faulkner, with what sounded to me like the slightest edge to his voice.

Fred and I exchanged fleeting wary glances. We were both bourbon fanciers but only amateur drinkers, and I think Fred must have had the sudden vision I did of darkness falling on the meadow with him and me both tight and none of the three of us fit to drive my car. "Let's have one more here and then go," I suggested, and the others agreed.

The Jack Daniel's was tasting even better now, but we went on to find a restaurant that served moderately good steaks. We arrived home at a reasonable hour, and the next day in Cabell Hall we commented on what a good time we had had. But after that I had some sense of the kind of nervousness Ben Wasson, Jim Devine, and others must have felt with this fine companion who had, nevertheless, a propensity for disaster.

[Blotner offers no citation and the passage indicates his eyewitness account and his own opinion. - Author]

\section{[1665-1666]}

The next day turned out to be the ordeal he had been afraid was in store. This "joint ceremonial" of the academy and the institute was usually the occasion Cowley thought of as "a combined prize day, spring festival, of the arts, and tribal corroboree." As Dos Passos would later put it, "Neither Faulkner nor I were very happy in these stuffed shirt surroundings." There were tributes to departed members and other formalities before the cocktail hour that preceded luncheon at the big round tables. "At lunch Faulkner sat next to my wife," Dos Passos recalled, "and she earned what seemed to be his undying gratitude by giving him her wine. The waiter must have thought she had great capacity because her glass was always empty." Halfway through the luncheon Cowley, Faulkner, and Dos Passos were called into an adjoining room to rehearse the presentation of the medal. Erect and abstracted, Faulkner held out the medal stiffly while Dos Passos reached for it with a large brown hand and beamed through his shiny spectacles. Just then the notes of an organ began to rumble in from the auditorium, and they were summoned to the Green Room without a chance to finish lunch. 
Fn 166615 John Dos Passos to JB, 7 Oct. 1969.

\section{[1666-1667]}

The past appeared in some of the people he saw that day, as in the person of Hamilton Basso, now a vice-president of the institute. One meeting was a melancholy one. When Dashiell Hammett had been jailed for refusal to testify before the House Un-American Activities

Committee, Lillian Hellman had written to Faulkner, hoping he would say something publicly in defense of Hammett and condemnation of the procedure. He had. never answered the letter, and she had been deeply offended. This day, - however, she joined him in a drink for old times' sake.

"How's Hammett?" Faulkner asked her.

"He's a very sick man."

"He drank too much," said Faulkner.

Taken aback by the abrupt comment, Miss Hellman felt that Faulkner didn't care that Hammett was sick, and that those evenings spent together years before should have left a warmer residue of feeling and concern than this. She walked away and did not go near Faulkner again.

A cocktail party of his own awaited him shortly after his return to Charlottesville. On. Monday, May 27, he and Estelle entertained the whole English department together with other university friends and a few from the county. Pollard, the Faulkners' courtly butler, presided over a bar in the dining room, while his wife, Elizabeth, moved in and out from the kitchen replenishing the trays of hors d'oeuvre. The French doors were thrown open, and arriving guests stepped from the living room onto the- spacious flagstone terrace behind the house. There in the warm spring sunlight the host greeted them and mixed drinks from a second bar. The familiar reserve and apparent shyness seemed to have vanished. Once he became the host, thought Nancy Hale, he couldn't have been more social-minded or more agreeable. Talking of the party afterwards, another guest recalled Mr. Faulkner's deliberate conversational gambits. "That's right," agreed Miss Hale, "to terrible old ladies! All the reserve gone. That was very nice, a social obligation and he felt it. But he felt no obligation as a guest at all." We knew how people derived this last impression, for we had seen him close his eyes and doze in a living room after dinner. But he could also be an animated conversationalist. It all depended on how he felt, and on this fragrant May afternoon, his tree-secluded terrace filled with guests, he wanted to repay his social obligations, and he did it with style.

Fn 16674 I: Lillian Hellman, 17 Jan. 1966. 166720 I: Nancy Hale, 28 Sept. 1966.

\section{$[1670]$}

[.... After the games we would go back to his house or our house for a drink. From our terrace we could see the distant mountains in the blue haze of late afternoon. Looking at the fading gold of the sun on the new leaves, he would call it the best time of day. As my wife led us out onto the terrace one afternoon, she indicated a large wet spot on the flagstones.

"I have to apologize, Mr. Faulkner," Yvonne said, "Nancy had a little accident here." Our one-and-a-half-year-old daughter stood there silently listening. "I mean," Yvonne continued hastily, "she spilled her juice." bourbon."

Mr. Faulkner smiled. "Oh," he said. "That's good. For a minute I was afraid it was

[Blotner provides no citation and the event appears to be reported from his eyewitness. - Author]

[1671]

[.... That evening, after our trip to the Civil War battlefields, the Faulkners gave a Squadron dinner out on the terrace at Rugby Road. Besides Fred and me and our wives, Jill and 
Paul were there, and Malcolm. We drank gin and tonic as the sun set. (I had taken care to mix mine and Yvonne's. One day Pollard had made one for me, saying, "I made it just like I make them for Mr. Bill," and when I had thirstily drunk deep, it had nearly taken the top of my head off.) Estelle had by now recovered from a nagging kidney ailment, and she had prepared one of her celebrated curry dishes, using giant shrimp. We ate quail eggs with it and drank champagne, and dessert was served with coffee and brandy. By now it was dark under the huge elm tree just come into leaf, and we sat talking in contentment amid the candle flames. Then, in one of the momentary pauses that will fall on such conversations, the Chief spoke suddenly in a clipped, abrupt voice. "Lieutenants Gwynn and Blotner, front and center."

Fred and I rose and came to attention. He stood at attention before us and made a short speech about our work. Then he stopped as abruptly as he had begun. "Thank you, sir," we said, saluted, did an uncoordinated about-face and resumed our seats. Fred was then forty-one, six years my senior, but I think he glowed a little as I did. It had been a kind of play acting that would have seemed silly to some, but to us it was a moment to cherish. As we drove home that night I reflected that Mr. Faulkner ad had spent a total of fifteen hours in each other's company that day between dawn and darkness, and neither of us seemed the worse for it.

The next week there were more Little League games and drinks on the terraces -- the Faulkners' and ours -- but departure time was approaching. On June 20 he wrote out a carefully composed, three-paragraph recommendation for Elizabeth and Paul Pollard in which he said that he had Pollard's promise of first claim on his services when he and Estelle were next in Virginia. A few days later they were packed. On June 25, Yvonne and I made our farewells, and the next morning he and Estelle pulled slowly out of the narrow driveway in the station wagon for the two-day drive back to Oxford.

[Blotner provides no citation and the event appears to be reported from his eyewitness. - Author]

\section{JUNE, 1957 - NOVEMBER, 1958}

\section{[1678] - 1679}

The color was being done that day by Virginia's only real football "immortal," "Bullet Bill" Dudley. When Charlie had gone up to the booth earlier, he had given the news to Dudley with some excitement.

"I've got William Faulkner to go on with you at half time," he said.

"Who?" said Bullet Bill.

Charlie explained and quickly wrote out a few lines for him to use in his introduction. Now Faulkner moved into the tiny booth, still wearing his brown Tyrolean velour hat and his trench coat, which in the confines of the booth was nearly overpowering. The two men made a sharp contrast: Faulkner, looking like an old-nobleman who had just stepped out of a duck blind, and Dudley, now an insurance man, his bluff, amiable, honest features battered so they still showed the marks of his former calling.

As Faulkner took his seat, Dudley made the introduction. "And so," he concluded, "it's a real pleasure to have with us today Mr. William Faulkner, winner of the Mobile Prize for Literature." Faulkner's own amiable expression did not alter, and for the space of perhaps four minutes the listeners to a regional football network were treated to the experience of hearing Bullet Bill Dudley talk literature and William Faulkner talk football.

The next Saturday found his situation considerably changed. During : the week he had begun to suffer from a sore throat and, as usual, had refused to go to the doctor. Used to asking Jill to swab his throat with silver nitrate for such complaints, he now insisted that Estelle get some Argyrol and pain this throat with it. The condition did not respond to this treatment, which was not surprising in view of the fact that he was suffering from a strep- throat. Besides bringing on fever, this kind of pernicious infection is characterized by a sharp, biting pain that afflicts the 
sufferer not only when he attempts to swallow but sometimes even when his throat is absolutely still. As it grew worse Faulkner applied his old remedy, and before long he was in a private hospital in Richmond being treated for the effects of both complaint and treatment.

A. few days later, on Thankgiving [sic] Day, a traditional event took place for the thirtieth time in the life of the Keswick Hunt, with guests from-Farmington and others from as far away as Richmond. Congregated on the lawn before the Grace Episcopal Church in nearby Cismont, the front door of the church adorned on either side with shocks of corn, the huntsmen and hounds of the Keswick Hunt Club waited for the "Blessing of the Hounds" by the Reverend F. L. Robinson, who stood there in vestments to perform the office. Following this the hunt would assemble on the rolling grounds of Kinloch, the handsome and imposing residence of Linton and Mary Massey, by now good friends of the Faulkners and the Summerses. The hunt would begin as the massed riders urged their mounts over a series of five or six fences and then headed into the pines on the slopes of Broadhead Mountain, hoping to start a fox as the hounds gave tongue. Faulkner was out of the hospital but he would not be riding with Keswick or Farmington-not this fall. He and Estelle had left for home as soon as he was able to travel. Antibiotics had taken care of the streptococcus, but he was no better now than he ever had been at following medical advice, and it was a while before he felt really well again.

[For 1679 6, Blotner offers no citation and the event is apparently reported from his eyewitness.- Author] 679 II I: JFS, 25 Aug. 1969. 167931 I: Mary Massey, 26 July 1972. [For 1679 36, Blotner offers no citation and the event is apparently reported from his eyewitness.- Author]

\section{$[1702]$}

At last, after Dean and Jon escaped by the route he had devised and the guests departed, they could relax. "No more cheap champagne," he said. He got out a good bottle of red wine to go with a few of the hors d'oeuvre that were left. He poured some whiskey on the rocks (Bourbon De Luxe for Louise and Jane Coers, Jack Daniel's for himself) and then took them downtown to Aubrey Seay's Mansion restaurant for a late steak dinner.

[For the citation to support 1702 30, see Fn 7034 I: Louise Meadow, 26 Nov. 1965.- Author]

\section{[1706-1707]}

Now he began to put down more roots in Albemarle County, an area of 729 square miles. According to residents one of the four richest counties in America, it boasted not only numerous First Families of Virginia but some of each riding with both hunts, but it was a conglomerate society in which the backgrounds were likely to be as disparate as the accents. The Keswick Hunt Club was the oldest in this part of Virginia, dating from well before the turn of the century. It had always included members in the tradition of the legendary John Peel -- in the saddle at daybreak and after the fox in all weathers while the light lasted. Not much for show, it was the hunt that the old-timers in Albemarle County knew best. The Farmington Hunt Club had come along later, membership initially more cosmopolitan and its pleasures more social, with elaborate breakfasts and generous stirrup cups when the hunt ended at some reasonable hour. By this time, however, the old differences were fading, and the two hunts were more alike than dissimilar. They included gentleman farmers originally from New York and hard-working horsemen like Grover, English physicians and American professors, the wives of young instructors and matrons who loved horses more than they did their husbands. In this diversity Faulkner would find himself talking one day with a retired diplomat and on another with likable young ne'er-do-well who occasionally trafficked in moonshine whiskey. A few of the women bore titled names and a few others bore scandalous associations which would have been a distinct handicap in any Albemarle set other than this hard-riding, hard-drinking heterogeneous group. 
But both Farmington and Keswick hunters were generally congenial, enjoying the hearty hunt breakfasts and the noisy, roistering parties. [....]

Fn - 17075 See Shelby Coffey, III, "Meet Albermarle's Landed Gentry," Potomac (Washington Post magazine section), 23Apr. 1967, pp. 21-9. 1707 17 I: JFS, 13 Aug. 1968.

\section{NOVEMBER, 1958-JUNE, 1959}

\section{[1708-1709]}

Sometimes it seemed that this was an element he had been seeking all his life, or at least one that he was completely ready for now. The Master of the Hunt, English-born Dr. E. D. Vere Nicoll, knew that he was not a particularly good horseman but said he "had the courage of a lion and adored the hunt." He showed a formal yet unobtrusive courtesy. He would come up, doff his hat, and say, "Good morning, Master." It was an Old World manner, thought Nicoll, watching Faulkner follow custom easily yet punctiliously. The other members showed him courtesy, too. They all knew what he did, though not many had read him, and most knew in some general way at least the nature of his achievements, but they never asked about his work. He would be there to drink the early morning coffee before the fire even when the hunt had been called off, and on days when no hunt was scheduled, he would come and sit on the rail by the mounting block and observe everything that went on. It gave Jill pleasure just to watch him riding in an old tweed jacket-or dressed up sometimes, when the others wore their pink coats: his boots shined, his white stock neatly pinned, his black derby firmly settled on his head. Somewhere in the coat would be two other indispensables, a tobacco pouch and a brandy flask. It was only now, Jill sometimes thought, in the last few years, that she really got to know him and he got to know her. He had mellowed.

Fn 170834 I: E. D. Vere Nicoll, M.D., 28 Feb. 1966. 17098 I: JFS, 25 July and 13 Aug., 1968.

[1710]

He remained unpredictable as ever in conversation as in social situations. The Stovalls had invited a few friends in for drinks one evening and then dinner at the Old Ivy Inn. Estelle was unable to join them but Faulkner agreed to go. Leaving for the inn, John Coleman said he had room for Faulkner in his car with Professor and Mrs. James Southall Wilson. As they approached one tum, Faulkner spoke to Coleman from the back seat where he sat beside Mrs. Wilson. "I wish you'd do me a favor," he said.

"I'll be delighted, Mr. Faulkner, ' said Coleman, looking at him in the rear-view mirror

"Stop at my house. I've got to get my false teeth."

"Why, Mr. Faulkner," said Julia Wilson, "I didn't know you had false teeth." Roebuck."

"Yes, ma'am," he said, "these are my talking teeth. My eating teeth are made by Sears,

John Coleman pulled up in front of the house to let him out. He returned in a few moments, now presumably wearing the small partial plate he called his "Sears-Roebuckers."

Fn 71014 I: Julia Wilson, 9 Mar. 1965.

\section{[1725] - 1726-9}

It was a brisk March day when the Farmington Hunter Trials were held on Saturday, the fourteenth. The oval course was studded with jumps of various sizes and shapes to simulate the obstacles a hunter would meet in the field, and it was long enough to provide a fairly good run. The footing was rather wet and uncertain but not enough to warrant a postponement. When his turn was called, Faulkner walked Powerhouse through the gate, urged him onto the course, and 
put him into his regular jumping gait. The big hooves threw up clods of wet earth as they moved swiftly around the curve toward the first barrier. When Faulkner turned him hard for a straight run at it, Powerhouse lost his footing on the treacherous ground. As Faulkner twisted free, his momentum carried him out of the saddle. He did not land on his back, but his right shoulder took the full force of the heavy fall. He was shaken and he rose slowly, but the shoulder did not seem to bother him too much. Grover talked with him and did not think he had broken anything, but Doug Nicoll decided he had better be looked at because he just might have suffered a broken collarbone. He phoned the resident on duty at the university hospital and sent him in.

Faulkner grumbled at the trip, but it was a good thing he had been forced to make it. The $\mathrm{x}$-ray showed not just a break but a shattering of the clavicle. He was determined, however, that this was not going to spoil his day. As soon as the resident had applied a figure-of-eight bandage and plaster and put his right arm in a sling, he slung his coat over his shoulder and returned to Farmington to watch the remaining trials. "Virginians are fast people," he told reporters, "and if you want to keep up with them you have to get on a horse to do it." Before the afternoon was over he was actually back in the saddle again. "I don't intend to miss the last hunt of the season on Tuesday," he said. The cast wouldn't bother him and neither would any pain. After all, he added with bravado, "a fractured collarbone is no worse than a hangnail." He was more grateful than usual, nonetheless, for the Jack Daniel's at cocktail time.

Later he would reassure friends with his own version of what had happened. "I dont think you need worry about the riding," he wrote Albert Erskine. "'Falling off the horse' is a customary modest hunting field euphemism. What happened was, I was going too fast in wet ground and turned the horse too quick to face a fence and threw him down myself. I broke my collar bone twisting out from under him when he fell. I wont turn one that fast in treacherous ground anymore."

He missed the hunt on Tuesday, March 17, but when the cast and bandage came off on Wednesday, the x-ray showed everything in excellent position. With only a sling for protection he was able three days later to watch an event he had hoped to be in: the Virginia Field Hunter Championship Trials at Tall Oaks in Keswick. He had enjoyed riding Alexander Rives's champion, Wedgwood, and he was determined to ride one of his own. On the sidelines now, he looked forward to the next year.

He was determined despite the injury to go ahead with the work on the book. On March 18 Doug Nicoll had given him a prescription for APC tablets, but Faulkner had apparently not troubled to have it filled. The x-ray was encouraging, and he said he was more comfortable than he had been, but the injury began to bother him. He was unable to go up to New York with Linton Massey on March 22 as he had planned. Meriwether had flown in from Texas, and by Thursday, the twenty-sixth, he and Erskine had gone through The Mansion together. It was clear that there was much adjusting of discrepancies to be done. When Erskine telephoned Charlottesville, Faulkner suggested that they both come down that weekend; when Albert went back, Meriwether could stay on as late as Tuesday to finish up the list if he could get someone to take his Tuesday class in Austin.

By now, however, there were complications. Besides the pain from the collarbone, Faulkner had developed a respiratory infection. After Albert's second call, Estelle telephoned Dr. Leo Falk, who had treated Malcolm two years before. The doctor found it a seemingly uncomplicated complaint, but the editorial trip to Charlottesville was called off.

By now Faulkner had resorted to a remedy he trusted more than APC pills, and, as in other cases, it may have helped to weaken his resistance to the cold. He was not up to the kind of work required in repairing the discrepancies in the Snopes saga, as a note he sent to Ober seemed to indicate. Ober had sent him a check for something over $\$ 14,000$, the first installment on his share of the film rights to Requiem for a Nun, asking him to endorse it and send it back so that he could pay Random House their share. A few days later Faulkner returned the letter after 
scribbling a brief query on the bottom: "Dear Harold," he wrote, "I seem to have mislaid this check. Will you see if your bank cleared it?" The bank had not.

He needed further medical attention. Leo Falk was away and James B. Twyman saw the patient in his stead, both at home and at the office. Besides the effects of the liquor and the cold, Faulkner was still suffering pain from the collarbone. There was considerable swelling there, but no sign of real trouble. Dr. Twyman thought it would be a good idea to check his general condition. He found that another problem had developed since Dr. Falk had seen him: a urinary tract infection, but one which would respond to sulfa. As he checked him over, he noted a few other things. There was a prostate enlargement, but this was not unusual in a man of his age. When he thumped him on the chest, however, the sound was one sometimes heard in cases of enlarged heart. The liver seemed enlarged, too, but the x-ray showed no enlargement; moreover, if cirrhosis were the cause, it was at most an early stage of the disease-the fatty stage which is reversible by abstinence. Apart from the sulfa, the prescription and directions Faulkner received were the same as those given him so many times before: abstinence, nourishment, and rest. As usual, he would follow the directions at his own pace.

A few days later he knew that his plans for the trip to New York would have to be postponed indefinitely, and he wrote to tell Joan Bowen. "A horse fell with me 2 weeks ago. I have a broken collar bone which is giving me more trouble than I thought. It's my age I suppose. I have a driver and am leaving for Miss. tomorrow and wont come to New York now. I will be back here in June, and want to see you then." Meanwhile, he would write again when he returned to Oxford.

He and Estelle left with the driver the next day, April 6, and he seemed to feel better as soon as he was back at Rowan Oak. "I am at home again," he wrote Erskine, "still sore but sober and think I can ride again soon." He agreed that Albert probably had the manuscript in good enough shape so he could do without him until June. He did have one item to pass on, however: the dedication. It would be simply "To Phil Stone." This was "for consistency" with the other volumes of the trilogy, he said.

In Charlottesville, he and Dr. Nicoll had gone over a list of orthopedists who could check on his progress and had settled on a Memphis specialist. On the day he arrived home, however, he wrote Nicoll with a new idea. His childhood friend Felix Linder, now a widower, had returned to Oxford after many years' practice as an orthopedist in Memphis and he was living with his brother, Dewey, just a short distance away on the Old Taylor Road. Faulkner asked Nicoll to write him "so he will take me seriously when I go to him, as he has retired and he and his unmarried brother spend all their time fishing and shooting and he wont take me seriously since most of our contacts have been to help me out of hangovers." His recuperative powers were showing themselves again. "I feel pretty good," he wrote, "still stiff and sore from bruises mostly; I think I did most of the damage twisting free when the horse went down, or maybe he just shot me off pretty hard when I threw him. But strength coming back. I am anxious to work my two here, having no groom or jockey who will set them at a jump. The accident happened I think March 14th. How much longer before I can risk riding again? I dont want to break myself up for good at a mere 61."

Nicoll did as he was asked, but he was not nearly as sanguine as his patient. Faulkner should not ride until both examination and $\mathrm{x}$-ray showed good union of the break. The time this took varied, but, since he had suffered shattering rather than one clear break, Nicoll thought it would take about two months. Faulkner should not count on riding until June, anyway.

He could tum to reading and writing as he had done in recent years when the weather was too bad to be outdoors. If he wished, he could read another local author. On March 27 an inscribed copy of a new book entitled No Place to Run had been left for him by the author: eighteen-year-old Harvard freshman Philip Alston Stone. The novel he had completed as a senior at Hotchkiss had as its protagonist a Mississippi gubernatorial candidate of the same stripe as Theodore G. Bilbo. The protégé in Phil Stone's own family had treated the kind of people that 
Phil Stone and his earlier protégé had been laughing about for thirty years. It was not unexpected that some reviewers should see a Faulknerian influence; what was extraordinary was the technical dexterity. Glendy Culligan's commentary in the Washington Post and Times Herald was entitled "Out-Faulknered by a Stripling." The copy of the book was inscribed "To Mr. Bill and Mrs. Bill from Philip."

As the countryside began to shade into the pale pastels of late April, Faulkner found that he was not as well as he had thought at the time he wrote Nicoll. When he had finally gone to see Felix Linder, he had literally wept with the pain, the doctor recalled. Felix strapped him, and that gave him some relief, but he refused to accept a prescription for the pain. "I am still having trouble with my arm," he wrote Joan; "evidently at my age you should stop breaking bones. Something is pressing, against a nerve somewhere. If it dont get better, I will go to Memphis for a day or two and find out what is wrong." He wondered what she was doing. He had not gotten much done himself, but he was beginning to turn things over in his mind. "I still have one more book I want to write. Now that I cant waste time with horses, I should get at it. Though I hope every day I can ride again." He was also planning ahead now to a New York trip and then Virginia again in June. And in September he would attend a UNESCO conference in Denver. But he still had a considerable way to go before he was back to normal health, as the shaky handwriting of the letter showed.

Fn 17257 I: Grover Vandevender and Ethel Moore, 19 July 1965. 172524 Ibid.; JFS, 19 Dec. 1969. WF to AE, undated. Washington Post and Times Herald, 17 Mar. 1959. 172530 Nicoll's notes recorded the xray results: "a fracture at the junction of the middle and outer third of the right clavicle with a slightly displaced central fragment and some displacement between the central and the distal fragment." Courtesy Dr. Nicoll. 172536 Washington Post and Times Herald, 17 Mar. 1959. 17266 WF to AE, undated, in reply to AE to WF, 8 Apr. 1959. 172611 Courtesy Dr. Nicoll. 172613 Charlottesville Daily Progress, 22 Mar. 1959. 172618 Courtesy Dr. Nicoll. 172625 Anne Louise Davis to HO, 26 Mar. 1959; AE to WF, 8 Apr. 1959. 172627 Courtesy Dr. Nicoll. 172629 I: Leo Falk, M.D., 9 Mar. 1966. Dr. Falk saw WF 26 Mar. 1959. 172630 I: JFS, 19 Dec. 1969. 172638 HO to VF, 27 Mar. 1959. 17272 The returned letter with WF's note recd. in New York 3 Apr. 1959. 3 Apr. 1959. 172719 Courtesy Dr. Falk; Dr. Twyman treated WF on Apr. 3, 1959. 172726 WF to JW, "Sunday," 5 Apr. 1959. His mood was not improved by receipt of a letter asking for the return of the key to his library study at the end of the semester. "'Stelle, what did I do with that key?" he growled. "They want that office back." No one had taken the trouble to tell him that the letter was routine: the keys were called in but the studies were reassigned for the fall. I: LRM, 19 Dec. 1969. 172733 WF to AE, 7 Apr. 1959. 172812 WF to E. D. Vere Nicoll, M.D., 7 Apr. 1959. Courtesy Dr. Nicoll. 172817 E. D. Vere Nicoll, M.D., toWF, 14 Apr. 1959. Courtesy Dr. Nicoll. 172829 Washington Post and Times Herald, 19 Apr. 1959. 172830 WFL, p. 53. 172835 Felix Linder, M.D., in WFO, p.173. 17298 WF to JW, "Sunday," 25 Apr. 1959.

\section{JUNE, 1959 - OCTOBER, 1960}

\section{$[1733]$}

And you, the old man, standing there while there rises to you, about you, suffocating you, the spring dark peopled and myriad ... the cup, the bowl proffered once to the lips in youth and then no more; proffered to quench or sip or drain that lone one time and even that sometimes premature, too soon. Because the tragedy of life is, it must be premature, inconclusive and inconcludable, in order to be life; it must be before itself, in advance of itself, to have been at all. - The Town (317-318)

[Blotner's epigraph to Chapter 73, June 1959-October, 1960. - Author]

\section{$1739-[1740]$}

It would be months yet before The Mansion royalties, and Faulkner in the University, which would be out before that, would not bring in much. Fred and I had transcribed and edited 
his sessions at the University of Virginia, but then Saxe Commins had argued against publication. "Saxe was defending my dignity or something by some obscure reasoning," Faulkner wrote Erskine when Ober asked if he could offer some of the material to magazines. "He did not want the stuff printed at all, saying it would inevitably be taken as Faulkner's definitive opinion on Faulkner. I didn't quite see this, or didn't think it mattered, and was ready to agree to the publishing of it, but submitted to Saxe since he was my literary wetnurse, etc. He finally agreed that the Univ of Va could print it in their own organ, but if it were ever printed commercially, Random House should do it." That was how it stood, but perhaps Erskine had better check the material, too. "I didn't think it was all that important, myself," the letter continued. "It was done impromptu, off the cuff, ad lib, no rehearsal; I just answered what sounded right and interesting, to the best of my recollection after elapsed years, at the moment." Erskine had by this time seen the material and liked it, and so plans went forward. The sales would be good for a university press publication but never enough to help appreciably with the upcoming real-estate transaction. The royalties were to be split evenly among the three of us. Besides, we made a joint resolve about what we would do with them: they would always go for Jack Daniel's.

A few weeks after this Faulkner reacted very differently to another title bearing his name. Professor Floyd Watkins, of Emory University, wrote Erskine that he had completed the editing of a manuscript by one of Faulkner's hunting friends. Without naming him, Watkins asked if Erskine thought Random House would be interested in such a manuscript, which was in the main favorable though it did describe one drinking bout and discussed the reasons why some of Faulkner's neighbors disliked him. Erskine sent the letter to Faulkner, who promptly suggested the reply that "Faulkner himself has already milked his private life of any or all interesting literary matter so anything in this mss. that is true will be dull and what; not dull probably wont be true, and therefore the mss. will belong to the scavenger school of literature, and Random House doesn't want it. Though the scavenger school of writing seems to have a following, so he should not have too much trouble placing it, and we hope he enjoys the profits."

Fn 173920 WF to AE, "Friday," 24 July1959. 173932 AE to WF, 4 Aug. 1959. 17401 WF to AE, 6 Aug. 1959.

\section{[1744-1745]}

None of this was lost on Miss Lee [i.e. Muna Lee - Author]. She invited Abram Minell to lunch and asked his help; if Faulkner had one friend there at the conference from the department - one man who might serve in the way Leon Picon had done in Japan -- he might not give way to feelings of claustrophobia or boredom. A navy veteran and seasoned Foreign Service officer, Minell said he would be glad to take on the three-day assignment.

The cultivated, soft-spoken Minell got on well with Faulkner from the first. Minell spotted him on the opening day in the lobby of the Brown Palace Hotel. It was astonishing: there was William Faulkner in a pepper-and-salt tweed suit, dignified, alone, and ignored. When Minell introduced himself, it seemed to him that Faulkner greeted him like a long-lost brother. Minell was in charge of the program and so had things to do, but Faulkner was reluctant to let him go.

"What is my duty?" he asked.

"Just your presence," said Minell.

He suggested that if Faulkner wished, he could address a meeting or simply attend one. Faulkner seemed ready to discuss the idea, but Minell had to excuse himself. He had a meeting that would probably run from eight o'clock that evening until eleven. When Faulkner asked him to come by and see him later that night, Minell said he was afraid it would be too late when he was free. No, Faulkner told him, he should come ahead.

At eleven-thirty Minell went up to the sixteenth floor and tapped lightly on Faulkner's door. Faulkner opened it immediately and invited him in. He uncorked a bottle of Cutty Sark and they began to talk. Minell soon found himself reminiscing about his time on an LST on the China 
coast and about the traveling he had done after the war from Shanghai to the Great Wall. Soon Faulkner was talking about working as a sailor in his youth. The conversation drifted on, enhanced by the smooth Scotch. They spoke of life at sea, of Japan and South America. After an hour or so Minell repeated his earlier suggestion about a talk.

"Good," said Faulkner, "let's you and I write a talk together."

"Fine," said Minell, "but why don't you begin."

Faulkner took a sheet of hotel stationery from the desk and began to write. When he had covered most of a page, he asked Minell for corrections and changes. Minell suggested one or two and Faulkner made them. By the time Minell left, it was close to two-thirty.

Though Faulkner was not on the program, Minell arranged for him to speak at the plenary session on Friday, October 2. He sat there at the speakers' table and listened to what seemed an endless talk by one of the principal dignitaries. When he was introduced he walked slowly to the podium, carrying the single sheet he had typed out. It bore another celebration of individuality and freedom: "we have gathered here from our arduous distances because we believe that 'I, $\mathrm{Me}^{\prime}$ is more important than any government or language. We are descendants of people who in the old hemisphere believed that to be possible, and burst the old bonds into a new hemisphere where that belief could be tested. There are times, too many times, when we have failed in that dream. But out of every failure there arises always a new handful who decline to be convinced by failure, who believe still that the human problems can be solved."

He did not believe that failures would stop man, and he ended on a note from the Nobel Prize speech. Russia's Chairman Khrushchev had recently told the West, "We will bury you." Faulkner thought Khrushchev knew that was nonsense. "But if he means that Communism will bury capitalism, he is correct. That funeral will occur about ten minutes after the police bury gambling," he said. "Because simple man, the human race, will bury both of them. That will be when we have expended the last grain, dram, and iota of our natural resources. But man himself will not be in that grave. The last sound on the worthless earth will be two human beings trying to launch a homemade space ship and already quarreling about where they are going next."

With his rapid delivery it had taken him less than two minutes to deliver the speech, and when he stopped the audience did not realize that he had finished. Then suddenly they burst into applause. When the session was concluded, it seemed to Minell that everyone was talking about it. Most had found it profoundly moving. It was more important than all the others together, thought Minell. Whereas Faulkner had at first been ignored, now he was sought out, but having performed his duty he was ready to leave.

At the end of the conference Minell congratulated him again on the speech. "Do you want it?" asked Faulkner. Then he inscribed it and handed it over. "Written by William Faulkner and Abram Minell," it read, "with the help of a bottle of Cutty Sark." Minell saw him off for home.

Fn 17446 I: Abram Minell, 18 Jan. 1967. 174436 Ibid. 174522 ESP, pp. 166-7. 174533 I: Abram Minell, 18 Jan. 1967.

\section{[1746]}

Two days after his return to Charlottesville, we went to the Virginia-Vanderbilt football game. This time I had gotten us seats in the press box, a spartan structure providing shelter and a ledge for typewriters. His serviceable trench coat had lost none of its pungency. Afterwards we had drinks at his house, and the next night the Faulkners and Summerses came to dinner at ours. It was another of the easy, pleasant evenings that showed the gift for friendship the Faulkners had.

$1749-[1950]$

Evalyn Galban noticed some of the same things. She hated to jump, and the one horse she felt safe with had finally worn out after twenty years. Besides, she now had to wear a brace when 
she rode to protect a cracked vertebra. Faulkner would stay with her, opening and closing the gates. This usually left them behind the hunt, but once, when they were no more than two feet apart, the fox ran right between them and they both nearly shouted their lungs out crying "Tallyho!" until the rest of the hunt finally came up. Like most of the others, she carried a flask in the saddlebag for the nippy end of the afternoon. When she would offer him a swig, he would almost always say, "No, thank you. I don't drink until after sundown." But this did not mean he was cool. "How long," he asked her one day, "do you have to live around here before people call you by your first name?" She felt timid to live around here before people call you by your first name?" She felt timid about this but he insisted, and before long she was used to it.

Harry Hyer was one of the others on a first-name basis with Faulkner. A West Virginian in his late thirties, Hyer had come to Virginia in the early1940'S to attend medical school and had stayed on at the hospital, where he was now medical director of the Division of Alcoholic Studies and Rehabilitation. Neither he nor Faulkner had any interest in talking about their professional specialties, and their conversation usually radiated out from the subject of the hunt. They had first met when they lived on Minor Road, where sometimes Harry would pick Faulkner up at about six in the morning and they would go out to hunt together. His assessment of his friend's horsemanship was exactly the same as David Yalden-Thomson's, but he did witness one mishap more serious than the spill in the ditch. Faulkner was riding Quilter, a roan jumper of Grover Vandevender's, and all was going well until they came to a split-rail fence and Quilter refused. Faulkner was thrown off and onto the rails. Hyer saw that he had taken the impact on his ribs, lower back, and kidney area. His face had gone white, and as he collected himself Harry offered to help.

"I'll jump your horse over," he said. Immediately he saw that his words had started the adrenalin flowing.

"I'll jump my own horse over," Faulkner said with hauteur.

Later he told Hyer that this fall, like others, would shake his vertebrae back in place. Hyer didn't think he meant it for a moment, and as he looked at Will it seemed to him that he had all the symptoms of a broken rib.

Fn 174926 I: Evalyn Galban, 13 June 1967. [For citation to support 175010 see 175028 I: Harry Hyer, M.D., 7 Aug. 1968.]

\section{[1750-1751]}

He continued to reveal aspects of himself, as one night at Rugby Road when he rose at dinner to say a simple grace: "0 Lord, for what we are about to receive, we give Thee thanks." It was in this period I began to understand what Phil Stone had meant when he had written, nine years before, about the way Faulkner would try to help his friends. Like most assistant professors, I had to think from time to time about my prospects, specifically about my chances of advancement to tenure rank at Virginia. If they seemed moderately favorable, we liked it well enough to stay; if not, we had better think about moving. Department interviews for prospective additions to the staff during the previous year had made me wonder, and when I had talked with the chairman after our return from Denmark, he offered o raise the question with the senior staff. Now I was feeling some anxiety and reading the situation somewhat pessimistically. I began talking about it one day over drinks. During the past year one of my departmental colleagues had been elected president of the university, and now Mr. Faulkner mentioned his name. "Why don't you tell him, 'If Blotner goes, maybe Faulkner will go.' "He thought for a moment and then added, "I've got only two friends in Charlottesville, Blotner and Vandevender, and if Blotner goes Faulkner will spend all his time out at Farmington." I knew, of course, that he had a number of friends in the town and the county, but it warmed my heart to hear those words, a testimonial of friendship that would have meant much at any time but was even more welcome now. He did not know, of course, exactly how such decisions were reached, and I had no 
intention of telling him how ineffectual the course he had proposed would be. But when he urged it a third time, I said I would do it, even though I knew I would not. Then he smiled. "Yes, try it," he said. He reached for a new tin of his Dunhill blend which had just come in from New York. "Here, take some of this tobacco," he said.

[Blotner offers no citation for this event and it appears to be based on his eyewitness and memory. Author]

\section{[1752-1753]}

As the holiday season came in that year Faulkner seemed to be enjoying himself. Dot Oldham came up from Mississippi for a visit, and at dinner one night he was in good form, telling stories and imitating the roundabout way Chrissie would answer telephone callers at Rowan Oak. He was looking ahead, too. As soon as there was snow on the ground, he said, we would get some tap sticks and a .22 rifle and go on a rabbit hunt. He even went so far the next day as to go to an enormous cocktail party where literally hundreds of guests milled from room to room. We were standing in the hall, our coats just hung up and drinks in our hands, when he put his glass down abruptly. "I got to get out of here," he said, "my claustrophobia's closing in on me." He walked outside, and, as soon as it was polite, Estelle, Jill and in on me." He walked outside, and, as soon as it was polite, Estelle, Jill and offend the host, and the next day he asked him to come for a proper drink at Rugby Road.

He continued to hunt in all weathers, out with the first riders and in with the Master and the hounds whether it was fair or drizzling. On one of these hunts it was cold enough by afternoon for him to break his rule and accept a draught from the flask Ev Galban offered him. By the end of the first week in December he was coughing and running a temperature. He thought he had pleurisy, but Leo Falk diagnosed it as pneumonia and began a course of antibiotics. Before Falk left he advised his patient to come in for a complete checkup, because he hadn't had one in some time. When he came in a week later in mid-December, the x-ray showed that the medicine had knocked out the pneumonia. Faulkner did not bother with the physical.

He bounced back quickly. We had been there for drinks a few days before, when he had given us our copy of The Mansion, and he had looked and sounded like himself. He had sent copies of the book as Christmas gifts to Jimmy Faulkner and others in his family and had succeeded in obtaining enough of the McAlpine plaid to make kilts for Tad and Will and a smoking jacket for himself. The Faulkners had guests in as a part of Connie Massey's prewedding ceremonies, and then at the rehearsal dinner Faulkner even made a short speech. He felt well enough for a traditional Christmas ritual-having friends in for sangaree. When we arrived at about ten-thirty that morning, he met us at the door. Before we could give him and Estelle the plum pudding we had brought, he said, "Here's your Santy Claus," and held out a package that proved to contain Jack Daniel's. Inside, we went up to the table where the silver bowl stood with apple slices floating on the shimmering surface of the sangaree. He kept filling the silver cups for the dozen or so guests from the hunt, the county, the city, and the university-the good host and the good friend.

Fn 175230 I: Leo Falk, M.D., 9 Mar. 1966. 175234 I: Evalyn Galban, 13 June 1967. 7532 I: Leo Falk, M.D., 9 Mar. 1966. [753 10 LRM to JB, 27 Oct. 1969. 75314 There was one gift WF was not enthusiastic about. On December 9, AE had written that a friend of one of the RH editors was going to Russia. The granddaughter of Leonid Andreyev, she was going principally to interview Boris Pasternak for The Paris Review. She thought it would be nice if she could take with her an inscribed copy of MAN because Pasternak was an admirer of WF's work. A copy of the book was in the mail to him in case he was willing to autograph it. Instead, he scribbled a note at the bottom of the letter and returned it to AE. "Nonsense," he wrote. "Pasternak is a good writer, of the 1st class, and no first-rate writer wants strangers scribbling and scrawling on his books. I wouldn't want Pasternak or Shakespeare either writing on mine, and I believe he feels the same way." 
1754-6 - [1757]

Apart from seeing to his mother's care, he had no obligations there at home. He drove out into the country for bird-shooting, and usually Jimmy Faulkner went with him. Jimmy noticed how well turned out he was -- wearing the best hunting clothes, some of them from the L. L. Bean catalog. He carried his Browning 12-gauge over-and-under shotgun with its engraved breech, specially cut stock, and butt bearing a silver disc with his initials on it. He was certainly equipped for the sport, but Jimmy noticed that his shooting was off. "I better get some hunting glasses," said his uncle.

When they came back from the fields in the dusk they would often have a drink at Jimmy's house, built about the same time as Rowan Oak and looking much like it. Jimmy's children would be there, and Brother Will enjoyed them as he did Jill's. Jimmy would see him watching them as he sat on the couch beside the fireplace. One afternoon, looking at Jimmy's oldest, he shook his head. "People are my business," he told his nephew. "Usually I can see behind their eyes and see what they're thinking, but I can't with Buddy."

He was not home two weeks before he was sick again, either from a recurrence of the infection that had plagued him in Charlottesville or a new bug picked up while hunting. When his temperature shot up to 103 he concluded that his pleurisy had returned. Dot called Felix Linder, who gave him penicillin and told Dot and Jimmy to get someone to stay with him, partly because he had already started his own course of bourbon therapy. Two days later, on a Wednesday morning, the situation began to go out of control. When something like this had happened eight years before, he had ultimately used it in the story "Weekend Revisited." These events now transpiring would amuse him even more, so much so that one of his first acts upon his recovery was to write them all out in a long letter to Estelle in Charlottesville, with directions to her to read it or not, at her own discretion, to Linton Massey and me, for he was sure we would enjoy the tale as much as he had.

It covered the six-day span from the time he left Rowan Oak on Monday morning until he returned on Sunday. He didn't remember any of the first part of it, he wrote, because of the combination of fever, delirium, penicillin, and whiskey, but he had reconstructed the events. "John drove into the yard in an ambulance, came up to my bedside and said, 'I'm going to save you. The ambulance is waiting.' I probably said, 'Fine, I'd like a nice ride this morning.' Christine of course had gone to work, and Andrew was probably squatting over the fire in the cabin as he always is when something happens on the place that he should stop or at least know about."

That noon Jim Silver went over to Dot's table in the university cafeteria. "I hear Bill's home," he said.

"He's doing more than that," Jim said. A friend of his had seen an ambulance driving up South Lamar that morning and had looked in and thought she had seen Bill in it, but she couldn't be sure because there were two people inside, and like many others she had trouble telling the Faulkner brothers apart.

All Bill knew was that he woke up Friday night in Wright's Sanitarium in Byhalia. "Now this, Wednesday," he told Estelle, "is built up from evidence not mine. When we got there, John demanded a single room with two beds in it, and wanted a rate. They told him they had the two beds but there couldn't be any rate. So he gave them his check for one. I evidently knew where I was; I just didn't remember until sometime Thursday, because I asked for a drink at once. They brought it to me. John, in the other bed, said he would have one too. They told him he had only paid for me and they couldn't give him one. He said, By God, he would go back to Oxford then. They said, 'But the ambulance has already gone, Mr. Faulkner.' 'Then call me a cab,' John says. So they did, and he left. The first thing he did was to stop in Holly Springs and buy two cases of beer."

Back in Oxford, Dot and Louise decided that with the whole town discussing these events, they had better go to the hospital and tell Miss Maud about it gently before someone else 
blurted it out to her. When Louise told her, she surprised them all. "If John had dropped Billy off at a hospital," she said, "he's probably somewhere still riding around in the ambulance."

"Louise then went to Lucille, I imagine out of simple kindness. And of course, Lucille being his wife, was the only person in town who hadn't heard anything yet. Lucille says, 'Where is John? Not that I care,' something like that. Louise said, 'We don't know. The ambulance came back without him, so evidently [he] stayed with Bill. But he'll certainly be home by night'-at which moment John himself walked in the door behind her carrying his beer. Louise said she could have gone through the floor but chose the door instead; nobody asked her to stop around."

Finding himself already in Byhalia and free of fever, having absorbed more medicine "and ajug of that stuff they hang on a thing like a hatrack," Bill stayed there Friday and Saturday recovering. Saturday night he called Jim to come and get him the next morning. Later he regretted this. "If I had stayed the full week, I would have got all John's money back, since in a poker game Saturday night another patient and I won thirty-five dollars from the young doctor on duty; maybe that's why he discharged me so readily Sunday."

The aftermath was calm. When he returned home he went to see Miss Maud. "I crossed Lucille at the hospital, she never said beans; just beamed at me, a really good beam of four or five seconds -- you know, like a tiger." Now he was staying in for a few days, but he was feeling pretty fair. "Keep this letter," he told his wife; "it's one of the funniest tales of good intent and human foolishness I know"

As the January days slowly lengthened, however, there must have been little to provide amusement. For one thing, he had asked David Yalden-Thomson down for some shooting, but because of Miss Maud's condition and his own recuperation he had been forced to postpone the invitation. And if the knowledge that he had required intravenous nourishment had not given him pause, there was another memento mori on his desk in early February. Albert Camus had died in an automobile accident, and one of the people at Gallimard had asked him to contribute to a special number of La Nouvelle Revue Francaise to be called "Hommage à Albert Camus." He had obliged with a short tribute and now they had sent him the galley. He had written that in spite of being convinced of the absurd in human life and denying God, Camus had spent his life "searching himself and demanding of himself answers which only God could know .... " He was still doing that, Faulkner believed, at the moment he hit the fatal tree. "People will say He was too young; he did not have time to finish, Faulkner concluded. "But it is not How long, it is not How much; it is simply What. When the door shut for him, he had already written on this side of it that which every artist who also carries through life with him that one same foreknowledge and hatred of death, is hoping to do: I was here. He was doing that, and perhaps in that bright second he even knew he had succeeded. What more could he want?"

Fn 175425 I: JMF, 21 Mar. 1965, 14 Nov. 1967. 175622 WF to EF, undated, prob. 18 or 19 Jan., 1960. 17575 ESP, pp. II3-14. See WFL, p. 120.

\section{$[1757-1758]$}

He was glad when the six weeks in Oxford began to draw to a close. He would make the trip to Charlottesville with Neil Thornton, of the University of Virginia Library, who was driving to Oxford to return the portrait, medals, and manuscripts borrowed for the Faulkner exhibit. Faulkner insisted that Thornton stay at Rowan Oak. As they had a before dinner drink, Faulkner listened sympathetically to Thornton's description of his trip through the northern Alabama countryside. "Yes," he agreed, "the only thing that's memorable about it is the signs, 'Jesus Saves' and 'Seven Killed Here.' " That night when they talked about the Civil War, Faulkner gave him what amounted to a lecture about the battle of Shiloh, and they resolved to stop there on their way north.

When they arose on the morning of February 12, there was two inches of snow on the ground and it was still falling. But when Faulkner called the police they told him that the roads 
were better in Tennessee, so they made plans to leave after lunch. It was the beginning of a rather hectic forty-eight hours. As they drove toward the Tennessee line, the snow fell so heavily that soon Thornton could make out the road only by the tire tracks. "To make matters worse," he remembered, "I had neither chains nor snow tires on the car. Mr. F. and I took the whole matter with a frightening (now) degree of nonchalance and even stopped by Shiloh battlefield where Mr. F. treated me to a running account of what we could see through the snow." By evening of the following day Faulkner had grown silent, however, and Thornton noticed that he had a cold which seemed to be getting worse. Then, about half an hour before sunset, they reached the Cumberland Gap. Tires were whining as cars slipped and slid on snow rapidly being packed into ice. Thornton got out and helped some of the others to push the cars ahead. When that was done, he found there was no one left to help them. Instructing Faulkner about his push-button transmission, he got out and pushed until the car began to move in the darkness. He raced after it and jumped in, and they continued down the mountain, proud of themselves and doubly ready for cocktails when they found a motel for the night. They reached Charlottesville at dusk on St.

Valentine's Day. In spite of the vicissitudes, it had been a memorable trip for Thornton, who had found Faulkner a fine companion. "He reminded me of my grandfather," he said.

Fn 17588 Neil Thornton to JB, 7 Mar. 1966.

[1760]

By now he approached these occasions with assurance if not pleasure. After he and Fred and I had gone to Mary Washington that day three years before, he had talked about other trips. "We're gonna get some trained dogs," he said, "and take the show on the road." As these occasions grew fewer he made an even handsomer appearance, wearing one of his best suits, his mustache full, and his hair a silvery white. Afterwards, when we were having a nightcap at his house, one of the family had mentioned his appearance.

"I'll bet I know how the Chief gets his hair so white," I said. "I'll bet he shampoos it before he appears."

At the sideboard, mixing a drink, he looked up at me. "Now you're catching on," he said with a smile.

[Blotner offers no citation for this event and it appears to be based on his eyewitness and memory. Author]

\section{OCTOBER, 1960 - OCTOBER, 1961}

\section{[1767-1768]}

He was often with children now. He did pictures for his grandchildren, pen-and-ink drawings with wash coloring. One showed Pappy jumping a horse. Another showed a cow and a horse, with a four-line verse between the two. Some afternoons when I would stop in at Rugby Road for a drink after I left the university, Jill would be there with Tad and Will. Often Tad would be using his junior in a brotherly fashion, practicing flying tackles on him, rolling over him, $\mathrm{n}$ the immemorial fashion of older brothers. When Will would finally give way to tears, his grandfather would look down, smile, and shake his head. "If he sees two he'll see sixty," he would say. One thing that Will would do pleased him especially.

"Listen to this," he said to me. He looked down at the boy, who looked so much like a miniature of his grandfather that it made you smile. "What's your name, boy?" he asked.

Legs firmly planted, hands in his pockets, Will looked up. "Will Faulkner," he said.

[Blotner offers no citation for this event and it appears to be based on his eyewitness and memory. Author] 


\section{[1768-1769]}

Some of the adults would ride together every morning. Faulkner was usually among them and so was surgeon Euclid M. Hanbury, Jr. A daring horseman and robust companion, Red Hanbury loved to ride among these men who called themselves a "band of brothers." Riding with them in the mornings, with others in the afternoons, hunting when the hunt went out, Faulkner put in full days. One afternoon when I stopped in, he poured the first drink of the day with special pleasure. He had spent five hours on Powerhouse, he told me, and he really needed it. He took the first swallow with satisfaction. "It's a good thing that in a changing world there are some unchanging things you can count on," he said, "like the quality of Jack Daniel's."

From time to time he would give some small indication of his thoughts about the changing world. On another afternoon in early November our conversation had been very ordinary, pleasant and easy, quite casual. Later that evening, as I sat alone in our living room, there was a knock at the door. I opened it to find him standing there. He did not usually drink whiskey after dinner now, so I offered him some port. As we sat there sipping it, he took a copy of the Manchester Guardian from his pocket and read me an took a copy of the Manchester Guardian from his pocket and read me an account of the tributes paid in Parliament to Ernest Bevin, one of them from Winston Churchill. Then he mused on Churchill's greatness. "I wrote him once during the war," he told me. "I said that his speeches would be studied by schoolboys when Hitler was forgotten." Then he turned to another page and pointed to a photograph showing a party scene, with two women in the foreground. One was Eleanor Roosevelt, smiling and talking politely to the other, Marilyn Monroe. "She's something of the new age," said the Chief, "wiggling even while she's 'standing still."

[Blotner offers no citation for this event and it appears to be based on his eyewitness and memory. Author]

\section{$[1772-1773]$}

Late December brought both holiday ritual and business. The Sunday before Christmas, he met us at his door with the familiar "Here's your Santy Claus!" And then on Christmas morning we gathered again before the brimming silver bowl. He was in fine form. Instead of sangaree, he was serving a mellow yet potent mixture of his own. When I wondered about the recipe, he named the principal components: a light wine, brandy, applejack, and the like. It was a familiar recipe, he said, but he had added one secret ingredient: Seven-Up. The innocuous soft drink had been most successfully turned to festive purposes. Later the Faulkners had Christmas dinner with the Summerses, the Fieldens, and the Masseys. Three days later he signed a codicil to the new will he had executed in Charlottesville six months before. It read, "I give and bequeath to the William Faulkner... Foundation, Charlottesville, all of my manuscripts and other tangible personal property deposited at the Alderman Library." On the last day of the year the account appeared in the newspapers of the issuance of a state charter to the William Faulkner Foundation. He had given cash as well as manuscripts, and the foundation would welcome gifts from those who subscribed to its aims. These aims were broadly philanthropic but were centered on scholarships and grants, especially for worthy Mississippi Negroes, and for the encouragement of American literature, especially the novel. The directors included the founder, his daughter and son-in-law, Mac Reed, Linton Massey, and John Wyllie. At one time Faulkner had held on to the major manuscripts because they might be all he would have to give to Jill. Now he could provide for her in his estate in more conventional ways. And, of course, the gift of the manuscripts to the foundation (which would make them available to scholars) would provide a welcome income tax advantage.

[Blotner offers no citation for this event and it appears to be based on his eyewitness and memory. Author] 
One evening Jimmy and his wife, Nan, invited them to dinner at the country club. Before they met there, Faulkner told David about Jim. "He got two DFC's, five Air Medals, and three court martials," he said. "He's a good boy." They both laughed, but suddenly Faulkner's mood changed and he made the saddest remark David had ever heard from him. "I think that Jim is the only person who likes me for what I am," he said. When Jimmy and Nan took them into the dining room, they ordered and then sipped while they waited. At that point a man rose from a nearby table and lurched over to them. If Faulkner would autograph a book fora friend, he said, he would let him shoot a deer on his place with a bow and arrow.

"Maybe I couldn't hit the deer," said Faulkner. ,

"I'll put some com on the ground to make it stand still," replied the drunk.

"Perhaps it wouldn't like corn."

"I'll tie it up for you."

"Shooting it would be great fun," said Faulkner with a freezing look as he turned away.

Baffled and disgruntled, the drunk returned to his table where he fell over his chair.

Faulkner turned to David. "All of his family have been game hogs," he said. "He's a lying oaf who likes to pick fights, but he can't deal with a little mental quickness." It was revolting, he said, that you lost your privacy from drunks like that because you wrote books.

[Blotner does not provide a clearly attributed citation for this event involving David Yalden-Thomsen during that Virginian's visit to Oxford. It would appear the Blotner is reporting from a conversation he himself had had with Yalden-Thomsen.]

\section{[1782]}

That night the N.A.A. gave a cocktail party for him at the luxurious country club. Large numbers of Americans and Venezuelans were introduced to him, and for the first time he began to resemble the harried lion in the Gallimards' Parisian garden. He had not come to Venezuela to endure the buzz and rumble of the big cocktail parties he detested. If he could do any good, he was much more likely to do it in smaller groups, and among Venezuelans.

Moreover, there was other cause for uneasiness which also validated the excuses he had made to President Betancourt. When he had telephoned Jimmy to find out how Estelle was, he had learned that she had been moved to the University of Mississippi Medical Center in Jackson. Her condition had worsened, and on April 4 they would operate to remove the infected kidney. Fortunately for the Faulkners, Arthur Guyton was now head of the physiology department there, and he had been able to suggest a urologist. Faulkner would later call Arthur to check on his wife's condition.

He carried on with his heavy schedule for the rest of that week. He carried on with his heavy schedule for the' rest of that week. Assessing the early reports on April 4, Harner noted that he had been nice to the Americans as well, making a call on Ambassador Edward Sparks and called him "el hombre simpatico." Working at his Spanish, he said, he wanted "saborear el vino del pais." Soon there was another appellation for "el Senor William Faulkner, Premio Nobel de Literatura"; some began calling him simply "El Premio. " Harner told Muna Lee that he was "standing up to the grind beautifully, says he is tough and wants to do everything he can. And he is."

Fn 178210 Jencks, p. 3 and Attachment A p. 1. 178216 I: JMF, 15 Nov. 1966. 178219 Arthur Guyton, M.D., to JB, 5 Oct. 1967; LRM to JB. 27 Oct. 1969. 178229 Charles Hamer to Muna Lee, 4 Apr. 1961. Courtesy Dept. of State. 


\section{[1785-1786]}

The next day, Friday, April 14, the formal program of the Venezuelan visit came to an end. After more school and university visits, he and Jencks took the noon plane back to Caracas, and that night the American embassy wound things up with a cocktail party at the Ateneo de Caracas. Faulkner decided he was not through, however. After a weekend of rest and relaxation with the Fieldens, he autographed books he wanted to go to Venezuelans he had come to know and wrote out a statement in answer to a list of questions from a university magazine. That night he stood at the door as host at the Fieldens', welcoming to his cocktail party all of those who had worked on the arrangements. One of them was his friend General Linares, who had come with an aide directly from a cabinet meeting so as not to miss the party.

After his plane lifted off the runway at Maiquetia on Monday morning and left the Cordillera behind, the assessment of the results began. John Vebber wrote Muna Lee that Faulkner had been "lionized here and in Maracay, Valencia, and Maracaibo. Everyone was enchanted by him and youngsters and oldsters vied with each other in trying to touch the hem of his garment." Looking back, Charles Harner told Washington that Faulkner "did not spare himself in the grinding schedule of the job he came to do." One embassy officer thought he knew why: "Mr. Faulkner is patriotic," he observed, "in the old-fashioned, untarnished sense of that adjective." Harner thought the visit had been "an enormous personal success." Faulkner had "rendered a high service to the United States," and both the embassy and his countrymen would be able to draw for a long time on the fund of good will the visit had engendered.

His cynical misgivings before the visit seemed to have been thoroughly quieted, so much so that he took it upon himself to write follow-up letters and to make plans for the future. One of his letters was written mostly in Spanish. He was glad that "el mission Venezuelano no fue fiasco, per un poco de succes," and he would not forget "la buen comida, el puncho con ron agrariano, la conversacione, la cultura ...." He and Mrs. Faulkner 'would be leaving soon for Virginia, "where I know a Cuban professor whom I hope will take me on in Spanish. I intend to know the language next time."

Fn 178610 John Vebber to Muna Lee, 16May 1961. Courtesy Miss Lee. 178617 Hamer, as above, p. 7. [Refers to 178229 Charles Harner to Muna Lee, 4 Apr. 1961. Courtesy Dept. of State.- Author] 178625 WF to unnamed recipient, 2May 1961. Courtesy Dept. of State.

\section{OCTOBER, 1961 - MAY, 1962}

\section{[1805]}

There was time now to see friends such as Ben and Anne Gilbert. Her telephoned and asked them to have lunch with him at the Algonquin. As usual, he was fascinated with the stories Ben told out of his long and varied experience: how he had worked his way through medical school playing the trumpet in Jimmy Durante's band at the Parody Club, how he was the bestdressed man in anatomy class, walking in without time to change from his tuxedo after his night's work. Faulkner was interested in the breadth of Ben's experience: performing insurance examinations and reassuring the dubious Negro performer who was afraid that a white doctor would put him out of the show; treating male ballet dancers for splinters in their buttocks. nd there were other cases that made good listening. The star of Fanny had fallen ill, but the understudy disliked him so much that he didn't even want to help him by going on in his place and got drunk instead. Ben had worked on him and got him to the point where he could go onstage. But then, near the end, the actor who played the deathbed scene with him came off terrified: the understudy had fallen asleep. They hurriedly dressed Ben in Italian costume to go onstage and covertly work on him, but Ben had an inspiration. "Pinch him," he said to the other actor, and when he did, the understudy roused enough to finish the scene. Columnists had been after Ben to let them write up his life, but he always refused. Bill made Ben and Anne promise 
that they'd let no one but him do it, and they solemnly agreed. Ben told about the time when the income tax examiner had made him spread all his records out over the office table and Jimmy Durante had come in while he was poring over them. "What's dis?" asked Durante, and when Ben told him, he had shouted, "You can't check on my doctor dis way!" and started throwing the papers around until the examiner gave up and left. Before the Gilberts went home, Bill asked them to please invite him the next time they had dinner with Jimmy. Fine, Ben said. Jimmy would be playing soon at the Copa. Faulkner had mentioned this before, and when Ben had told Jimmy, the little man had said, Oh, if I could only meet that fella. I'd like to meet him so much that I'd even get drunker than him, even though I don't drink!" He had even called once or twice from Hollywood though I don't drink!" He had even called once or twice from Hollywood Charlottesville, Ben and Anne said they would see to it that the two men got together.

Fn 180535 I: Dr. and Mrs. Benjamin Gilbert, 20 Jan. 1966, 23 Feb. 1967.

\section{6-9 - [1810]}

She returned home somewhat better after a week's stay, but less than a week after that it was her husband's turn to fall ill. On December 14 he had felt well enough to go into Charlottesville to read "Christmas Night in the Quarters" for a special holiday program being taped at radio station WELK. Mississippi-born Irwin Russell had been one of the first Southern writers to appreciate the possibilities of Negro characters in serious literature, and he was fascinated with the problems of rendering Negro dialect. Faulkner read the long poem with skill and satisfaction, but it could have done his tender and susceptible throat no good. And he was apparently already harboring cold germs of some kind, though it was his back that was bothering him most.

Doug Nicoll went out to see him but left with little conviction that his directions would be followed. By Monday, December 18, the back was worse and the cold had developed into an acute respiratory infection. On top of that, he had begun his usual course of bourbon therapy. Leo Falk gave him an injection of gamma globulin to protect him from the hepatitis Jill had contracted and put him in the University of Virginia Hospital.

Once again he seemed to rally and make rapid progress. By Tuesday morning he was well enough to eat a good breakfast though the backache was compounded by soreness of the chest and pelvis. Spinal x-rays showed no new injuries, and by dinner time that night he was feeling very much better. In two days he was extremely restive, and Leo, though he would have preferred that he stay, finally agreed to discharge him. If Faulkner took things easily, he might be able to enjoy Christmas with the family.

That morning Jill telephoned to ask if I had time to go to the hospital and be with him until Estelle came to pick him up. I went right over, and it was about ten-thirty when I arrived at his room in the Barringer Wing. He sat there in the quiet of exhaustion. On the table his standard hospital reading lay untouched: the Bible, Taylor's Holy Living and Holy Dying, and Boccaccio's Decameron. I tried to get some coffee while we waited, without success. A cleaning woman came in and he mistook her for an attendant. "I'm sorry I gave you so much trouble last night," he said. Estelle arrived and we helped him put on a few clothes over his pajamas. Then Estelle left to pull the car around to the entrance, and while we waited again we collected his vitamin pills and other medication. The cleaning woman reappeared. Indicating me, she asked, "Is he your son?" Besides the exhaustion, he was still suffering from a medication hangover, and it was a long moment before he answered. When he did, his voice was slow and tired. "He is more or less my son," he told her. "He's my spiritual son. He loves me better than he does his father." We both knew I could not be to him what Jimmy or Malcolm or Paul could, but I was grateful for the polite answer he had given the sympathetic woman tidying up his room.

When Estelle returned I held the bulky trench coat while he slipped into it, and with the two of us on either side of him we made our way down the hall to the elevator and out to the car 
at the curb. We got him into the front seat, and after I had closed Estelle's door I stood there while she put the car in gear. He looked out of the open window, weary and wan, and spoke in that soft voice. "Come out soon, Joe," he said, "I need you." Then they pulled away. I knew that he would be very well taken care of, and it was the busy Christmas season, so I did not go out to Knole during the days that immediately followed. Later I would think of Ivan Albright's painting That Which I Should Have Done I Did Not Do.

The premature departure from the hospital brought predictable results. Seventy-two hours later he had relapsed. Just after breakfast on the morning of Christmas Eve, Jill called. Leo Falk and Doug Nicoll both thought he should go to the Tucker Neurological and Psychiatric Hospital in Richmond. I was ready two hours later when Paul drove up in front of our house in the Rambler. I tried to be casual as I got into the front seat, but I was disturbed to see how extremely debilitated the Chief looked, with his eyes sunken and darkened by deep circles. I sat halfway turned and talked with him as Paul drove. He mustered his spirits and picked up the conversation, speaking coherently but very slowly. We talked about the men and planes of the First World War, and gradually the hour passed until we drove up to the big stone gate of the hospital in Richmond. Weak as he was, we took it very slowly in getting him to his first-floor room just beyond the lobby and admitting office. He sat there in his trench coat in an overstuffed chair, looking very small and wan while a nurse and an attendant bustled energetically about. Paul and I stood there, uncertain what to do.

"Well, I guess we can go now," Paul said.

I leaned over the chair to say goodbye to the Chief. "We'll see you soon," I said. _ . "Will they give me a drink now?" he asked.

I said that I thought so, not knowing that Tucker excluded both- alcohol and paraldehyde. Then we left.

James Asa Shield, one of the hospital's four doctors, took charge. Master of Fox Hounds with the Deep Run Hunt, Shield had met Faulkner a year before at Keswick and had hunted with him several times there and at Farmington. A tall and somewhat portly man with neatly combed white-gray hair and close-clipped mustache, he radiated competence and authority. He took a history and began the examination. All the vital signs were good: blood pressure I26/70 -extremely good for a man his age; lungs clear, and heart normal; abdomen negative, no enlarged liver, and no hernia. Dr. Shield found him an excellent patient who would tell you about his pain if you asked but did not complain or ask for a lot of medicine. The pain he reported was in his lower back, and Dr. Shield found it when he pressed the area of lumbar vertebrae 1, 2, and 3. The cause was probably strains and stresses from the fall. There was also some gastrointestinal discomfort which would be treated with ordinary remedies. They would follow the other obvious indications: rest, some heat perhaps, mild sedation, treatment for the cold, and nourishment to build up his resistance.

Linton and Mary Massey went out to Knole Farm to have Christmas dinner with the Faulkners and Summerses as usual. I checked with them later in the day. Putting the phone down I told Yvonne that the hospital had reported he was resting comfortably. "Oh," she said, "he missed his Christmas."

He was back at the cottage at Knole for the tag end of the year. Released on December 29 , he insisted that he did not want anyone to come for him and so left the hospital in the later afternoon in time to catch the 5:45 bus to Charlottesville. When Linton visited him, he felt well enough to talk about the library he intended to build up there in the cottage, not only for himself but for Tad, Will, and "Bok" Summers-the books he wanted to have around them as they grew up. He had already asked Tommy Tullos to get him the twenty-volume Doubleday Malay edition of the works of Conrad. He had signed a blank check which Tommy had carried nervously in his wallet until his ad was answered. Now Faulkner made up a list of nine more titles and then dictated seven more which Linton wrote down -- his usual favorites plus a few new ones: 
Browning, Treasure Island, and The Good Soldier Schweik. Linton promised that he would get them.

By New Year's Day, 1962, he thought he was practically well and once again overestimated himself. He wrote Ivan von Auw that he would do the "induction paragraphs" that Stuart Rose wanted for the "Hell Creek Crossing" excerpt in the Post. Two days after that, he was out riding again. There as a layer of snow, a thin one, but just enough to conceal the groundhog hole into which Fenceman stepped. The horse tumbled down and flung him to the ground. Later he could not remember what had happened, but by the time he got home his left eye had begun to swell and a bruise had appeared on his forehead. The next day Leo Falk sent out some Demerol. for the back pain and once more laid down a regimen of rest, moderation, and temporary cessation of riding. But he was not very optimistic. Like Doug Nicoll, he always received the greatest courtesy from his patient, but he had the feeling that Faulkner wasn't really paying any attention and would go on doing what he wanted to. Two nights later the patient was suffering from coughing spells and chest pain. The Demerol had not relieved the back pain and he was drinking again. That evening when I brought out an autographed copy of Faulkner in the University Estelle wanted for Jim Silver, Paul said that we had better be prepared for a trip to Tucker the next day, which was Sunday. In the morning, however, Jill called to say that he had tapered off, then decided to stop, and so the trip was off.

This time his family had overestimated him, and on January 8 he was readmitted to the Tucker Hospital. Once again Dr. Shield got the details from the patient and examined him. His left eye was black and draining, probably from an injury to the mucosa, and there was a large plum-colored bruise on his left forehead. The amnesia concerning the fall suggested that there had been some cerebral concussion as well as bruising. But it appeared that the measures applied before would control the problems again. By January 10, however, he was running a fever and complaining of pain in his chest. At that Dr. Shield called in Dr. Paul Camp, a cardiologist who was one of Dr. Paul Dudley White's most distinguished students. Dr. Camp found that the cold had gone into pleurisy, or pneumonitis, and that this was probably the source of the pain rather than anything cardiovascular. Putting his stethoscope to the chest, he heard rales in the left lung. There was probably some fibrosis of that lung mid-laterally, with the possibility of fairly acute pneumonia. When he listened to the heart he detected a slight sinus tachycardia -- that is, it was a little fast and one area was louder than another -- but what he heard was well within the normal range, and there were no murmurs or anything abnormal to be detected. The heart was not enlarged, and an electrocardiogram showed a steady rhythm. As a matter of fact, it was a very good tracing for a man of sixty-four. The examinations had detected the ribs on the left side broken about five years before, but that was about all. Dr. Camp put him on Combiotic-penicillin and streptomycin-every eight hours.

The therapy began to take hold, and in a few days he was free of fever. He was still weak, but he was feeling a little more like himself. Before he left the hospital with Linton Massey on January 15, Dr. Shield came in to see him. Faulkner told the doctor he had made a new resolve. "I'm going to stop being a damn fool and acting like a forty-five-year-old and start living as a sixty-five-year-old and perhaps live to be an eighty-five-year-old." side, and he was counting on the Butler longevity. Leo Falk had seen something of this: Faulkner seemed to have a feeling that nothing would happen to him.

Fn [For 180612 Blotner 1806 Il I: E. D. Vere Nicoll, M.D., 28 1Feb. 1966. 1806 19 I: Leo Falk, M.D., 9 Mar. 1966. 180626 Ibid. [From 180613 to 1807 38, Blotner offers no citation for these events and the accounts appear to be based on his eyewitness and memory.- Author] 180816 I: J. Asa Shield, M.D., 21 July 1966. 180818 LRM to JB, 27 Oct. 1969. 180834 Ibid.; WFL, Plate I. (The dating of the list in Plate I is erroneous.) . 180838 WF to Ivan von Auw, Jr., "Monday," 1 Jan. 1962. - "Monday," 1 Jan. 1962. 1966. 18102 I: J. Asa Shield, M.D., 21 July 1966. 18106 LRM to JB, 27 Oct. 1969. 18108 I: James Shield, M.D., 21 July 1966. 181012 I: Leo Falk, M.D., 9 Mar. 1966. 
The Gold Medal Award was no less a trial for him than such affairs usually were, but he manfully presented himself for it, checking into the usually were, but he manfully presented himself for it, checking into the Muriel Cowley went over to him and soon brought Conrad Aiken into their Muriel Cowley went over to him and soon brought Conrad Aiken into their South Carolinian's early poems. "Bread we broke was more than bread," he recited, and went on for a few lines more as if he could have repeated the whole of it. Muriel sat on his right at lunch, with critic Kenneth Burke on his left. He declined the small talk until someone led him onto the Virginia countryside, his riding, and his grandchildren. Three little boys were enough, he said. Now he wanted a granddaughter. "Little girls are born civilized," he told Muriel. "That day he had a country look," Malcolm recalled later, "his face bronzed under the white hair and apparently glow ing with health."

Near the end of the luncheon he spotted Lillian Hellman and went over to her table to greet her warmly. He sat down and they had coffee together. They exchanged information about what they were doing and then he began to talk about the past, about the good times they had enjoyed with Dash Hammett. "I think they were the best days of my life," he said. He remembered how she would sit curled up on the sofa and she remembered the way they had talked until all hours, and the evenings when they had gotten drunk together. "I often think about those days," he told her. "I'm going to the Klopfers' for dinner. Where will you be?" They talked about meeting again, but they couldn't work anything out.

Fn 182312 Aiken wrote that this, their only conversation, continued as follows:

Aiken: No, Mr. Faulkner, I've changed the second line-it's bed I broke with you was more than bed.

Faulkner: Bread I broke with you was more than bread.

Aiken: Bed I broke with you was more than bed.

Faulkner: Bread I broke with you was more than bread.

Aiken: Bed I broke with you was more than bed.

Faulkner: Bread ...

And looking each other steadily in the eye, we tacitly decided it was a dead heat, and broke it off. [Aiken to JB, 16 May 1964] (Blotner's brackets - Author). 182318 FCF, pp. 147-8. 182328 I: Lillian Hellman, 17 Jan. 1966.

\section{[1824-1825]}

We saw him only briefly as May drew to a close. He and Estelle still did not have as much of a library to draw from as they wanted, so I brought out a few paperbacks. There on the coffee table was the book he had been reading: Herodotus' The Persian Wars. The next afternoon he stopped at our house for a drink, bringing our inscribed copy of The Reivers with him. , We sat out on the terrace enjoying the fragrance of the new buds and leaves. Yvonne excused herself to go in and start dinner, and he and I sat silently in the twilight for a while before he slowly rose, straightened his back, and said he had better be getting along. We had to go through the kitchen to reach the front door, and he paused for a moment where Yvonne stood at the sink to say goodbye to her. Then she and I walked down the front path with him. There he halted and bent down to talk to our Nancy. "I had a little girl like you once," he said in his soft voice, "but she grew up on me." We saw him on his way and went back inside.

"Did you hear what Mr. Faulkner said to me in the kitchen?" Yvonne asked.

"No."

"He said, 'Come and see me in Mississippi, Miss Yvonne.' "

"That was nice," I said.

"Were you looking at him when he said it?"

"No."

"There were tears in his eyes," she said. 
[For 182519 Blotner offers no citation for this event and it appears to be based on his eyewitness and memory. - Author]

\section{MAY - JULY, 1962}

\section{[1834] - 1835-6}

Outwardly, Tuesday, July 3, began as a normal day. In the morning he walked down to the Square. He checked the mail and then went over to the drugstore to see Mac Reed. He had Else Jonsson's copy of The Reivers with him. "I come off and forgot my glasses this morning," he told Mac. "Would you address this for me?" He already had the required foreign postal forms, but he was apologetic about asking Mac to do the extra work. "I ... my back was hurting me so I just couldn't think of anything much this morning," he said. Mac knew he still had to use the back brace for riding that he had worn off and on since the fall. Bill picked up his reserved copy of the Commercial Appeal and a package of tobacco and left.

About that same time in another part of Oxford, two of his old hunting companions were talking about him.. "I haven't seen Old Bill in a long time," said Uncle Bud Miller. "Wish he'd come to see me." Charlie Hathorn said he'd tell him the next time he saw him. The old hunter needed a cane now and got about less and less. Later Charlie decided he would drop by that day. Faulkner asked him in and they talked casually. When Charlie asked how he was, Faulkner told him his back was bothering him, but he felt well enough to take him outside and show him his horse and his dog.

"Listen, Charlie," he said as they stood there at the paddock. "Is it all right with you if I hunt your land?"

"Sure, Bill, but you're too old for that kind of thing." It was a 6oo-acre tract of pretty rough country, but Faulkner thought it would be just right for bird-shooting.

Charlie told him about Uncle Bud. "By George," said Faulkner, "one of these days I'll pick up a bottle and go out and see Uncle Bud." Soon Charley left.

That night the Faulkners appeared at the Mansion at their regular time. Tonight there was nothing funny about eating -- or pleasurable, for that matter. He ordered filet mignon as usual, but things hadn't been tasting right. "The meat and the bread taste alike," he said. Even so, he looked fine to Aubrey, in spite of his complaints.

Later that night Jimmy stopped by to see how he was. Leslie Oliver was there. Faulkner had begun drinking a little.

The Fourth of July dawned inauspiciously at Rowan Oak. When Jimmy telephoned at breakfast time, Mr. Leslie told him that his uncle was still in bed. He was still drinking and had been dosing himself with some of the prescription painkillers on the bedside table. Jimmy drove in and sat on his bed and talked with him for a while. At this stage, there was nothing much to be done. When he left, Aunt Estelle talked with him in the hall. "What shall we do?" she asked. He was no more sure of that than she, so they decided to wait and see how he was the next day. Chester McLarty confirmed their judgment when he made a routine call that night. Mr. Faulkner's blood pressure was all right and there were no extraordinary or alarming symptoms. But they did talk about sending him to the hospital.

The next day things were worse. He was suffering the kind of pain not easily imagined by one who has not known that injury. David Yalden-Thomson had sympathized with him, for he had broken his back three years before and would not forget the pain that radiated out from the spine right around to the front of the rib cage and even down toward the legs. David would take all he drugs he was allowed and still have to drink half a bottle of whiskey to get a few hours' sleep. After months of that one would reach the end of one's tether. The pain simply became too acute to go on. Faulkner was now apparently close to that state. When Jimmy telephoned, Estelle spoke with him. "Maybe it's time to go to Byhalia," she said. Such illnesses could reach a 
frightening stage where the family could no longer cope with them even with house calls from the physician, and this was now the case. The pain was too severe and the drinking was getting out of hand. Besides, there was the problem of controlling the medication --Seconal, the Demerol, the tranquilizers, and whatever else was there.

After lunch Jimmy drove in and they began making plans for the trip. He sat down on the bed again to broach the idea to his uncle and found to his surprise that he was ready to go. $\mathrm{He}$ could not have consumed more than a fifth and a half, Jimmy thought, and this was relatively early in the cycle for him to agree to go, but Jimmy decided that his uncle did not want to mess with this one. He began to talk to Jimmy in earnest, obviously intent on what he was saying, but Jimmy could not make it out. They packed his bag and helped him to dress.

There was something paradoxical about the way this was happening. There had been other times when he needed to go to Byhalia. This time he could walk and he was going earlier in the cycle, but his behavior had not been the same. Dot Oldham thought he had been worried. J. R. Cofield said he had been so much nicer to people than ever before. Chrissie Price just thought he had been acting differently of late. When they were taking him out to the car, they stopped for a moment at the kitchen door and Chrissie spoke to him.

"Mr. Bill," she said in her plaintive voice, "do you want to go to the hospital?"

"I want to go home, Chrissie," he said.

Chrissie thought she had a good idea of what he knew and what he meant.

It had been a sweltering day with the temperature driving on up to ninety-five as the high afternoon sun beat down. It seemed no cooler now, though it was nearing five o'clock as they drove out the gates of Rowan Oak, through town, and onto the Holly Springs road to the north. When they I reached Holly Springs, they took Route 78 to the northwest, and in an hour they had covered the forty-nine miles to Olive Branch. They followed the road to the west, and there at Byhalia, about a mile from town on a gentle hill to the right, was Wright's Sanitarium. They drove up the long drive to the main house and the two smaller ones at the summit of the slope, all white clapboard with green-trimmed shutters. They parked off to the right where the bushes bordered the parking area. Estelle and Jimmy helped him out of the car. They went in the main entry at the rear of the main building and slowly made their way down the dark corridor to the foyer. There behind the Dutch door to the left was the downstairs station, with desk, telephone, lab equipment in cupboards and some dispensing containers. Not far away were a few patients, sitting in robes, smoking and talking quietly, who fell silent as they watched. Estelle and Jimmy left him in a comfort able chair while they gave the information at the desk. He was admitted at 6 P.M., July 5, 1962.

They began to look to him immediately. A nurse in starched white prepared him for Dr. Wright's examination. Then the doctor appeared and greeted Estelle and Jimmy. Leonard Wright was just under medium height, a pleasant-looking man with a snub nose, bright blue eyes, and a ruddy complexion, his short brown hair flecked with gray. A no-nonsense physician, he was the son of a Tennessee country doctor and himself father of two Tennessee physicians. While Estelle and Jimmy watched, he performed the examination. Faulkner's blood pressure and heart were normal. So was his chest, but now he complained of pain there as well as in. his back. This could have been heart pain, but there was no direct indication that it was. He was able to give Dr. Wright his own medical history. He was jumping, he said, and his horse threw him on his back. Dr. Wright finished and put him in a first-floor room across from the station. The soft-spoken doctor noted that he was a quiet and tractable patient, humble even, who joked as they took care of him. He knew the attendant who was now helping him and spoke to him. "Shorty," he said, "I need a pair of carpet slippers."

The nurse was to be with him for the rest of his time there. There was nothing more Estelle and Jimmy could do, so they made ready to leave. After Estelle kissed him, Jimmy went to his bedside. 
"Brother Will," he said. Faulkner's eyes lit up. "When you're ready to come home, let me know and I'll come for you."

Earlier his uncle's speech had been confused, and he had talked of sergeants and captains. Now he spoke quite clearly. "Yes, Jim, I will."

With that Estelle and Jimmy left.

The ordinary routine of the first floor commenced again. Dr. Wright started treatment with vitamins, Benadryl, and the other standard preparations indicated. He felt there was no need for pain medicine. From across the hall drifted the meaningless sounds of a television set in a small lounge where a few patients watched. To the right was a simply furnished dining room where a sideboard held hot coffee. A few more patients sat there, drinking it, smoking, talking about the illnesses that had brought them there and about when they could go home again. By now Dr. Wright had gone to his quarters behind the main building, and the quiet of the evening shift began.

The big clock ticked past midnight and July 6 came in -- the old Colonel's birthday -with no promise of a letup in the heat of the previous day. Insects thumped against the screens while electric fans hummed here and there in the building. Faulkner had been resting quietly. A few minutes after half past one, he stirred and then sat up on the side of his bed. Before the nurse could reach him he groaned and fell over. Within five minutes Dr. Wright was there, but he could detect no pulse or heartbeat. He applied external heart massage for forty-five minutes without results. He tried mouth-to-mouth resuscitation, again with no results. It had been a coronary occlusion. There was nothing more he could do. William Faulkner was gone.

Fn 183421 W. M. Reed in WFO, p. 188. 183437 I: C. C. Hathorn, 18 Nov. 1967. 18354 Aubrey Seay in WFO, p. 195. I: 11 Sept. 1964, by James Webb. Courtesy Prof. Webb. 18356 I: JMF, 17 Mar. 1965. 1835 17 Ibid.; Chester McLarty, M.D., 21 Mar. 1965. 183525 I: David Yalden-Thomson, 16 July 1963.18362 I: JMF, 17 Mar. 1965, 16 Nov. 18 1966; EF, 3 Sept. 1966. 1966; 183615 I: Chester McLarty, M.D., 21 Mar. 1965; Christine Price, 8 July 1962. 183634 I: Dr. Leonard Wright, Sr., 17 Nov. 1966. 183720 Ibid.; JMF. 16 Nov. 1966. 27 Nov. 1965. 183730 I: Dr. Leonard D. Wright, Sr., 17 Nov. 1966. 18383 Ibid.; Chester McLarty, M.D., 21 Mar. 1965. 


\section{CURRICULUM VITAE}

NAME:

ADRESS:

DOB:

EDUCATION

\& TRAINING
Quiintin Thomas Chipley

516 West Ormsby Ave

Louisville, Kentucky 40203

Memphis, Tennessee - August 25, 1956

B.A., History and Russian Language

William Marsh Rice University

1974-1978

M.Div., Church History and Biblical Langauges

Southeastern Baptist Theological Seminary

1981-1984

M.A. - Clinical Psychology

Universtiy of Louisville

1988-1992

M.D.

Universtiy of Lousiville

1996-2000

\section{PUBLICATIONS:}

Academic

Chipley, Quinn T. "Hypnosis and the Habit Disorders." Chapter 9 in Robert G. Meyer, Practical Clinical Hypnosis. New York: Lexington Books. 1992. 157-177. Print.

Murrell, Stanley A., Fran H. Norris and Quinn T. Chipley. "Functional Versus Structural Social Support, Desirable Events, and Positive Affect in Older Adults."

Psychology and Aging. 1992. 7:4. 562-570. Print.

Poetry

Chipley, Quinn T. "Eve, Remembering Mississippi.” Sawmill. Vol. 03. Louisville, KY. Typcast Publications. July, 2011. 7-9. Web. http://www.typecastpublishing.com/sawmill03/ 
Chipley, Quinn T. "Natural Transfomations." Sawmill. Vol. 03. Louisville, KY.

Typcast Publications. July, 2011. 13-14. Web.

http://www.typecastpublishing.com/sawmillo3/

\section{NATIONAL MEETING PRESENTATIONS:}

"Conducting an Outpatient Assessment for Substance Abuse/ Dependence." The $15^{\text {th }}$ Annual Conference on the Clinical Applications of the Principles in Treatment of Addictions and Substance Abuse. Lexington, Kentucky. January 30, 2015.

"Chronic Psychiatric Conditions Secondary to Cannabis." The $14^{\text {th }}$ Annual Conference on the Clinical Applications of the Principles in Treatment of Addictions and Substance Abuse. Lexington, Kentucky. January 24, 2014.

"Adult ADHD: The Problems, the Tests, the Treatments, the Challenges." The $13^{\text {th }}$ Annual Conference on the Clinical Applications of the Principles in Treatment of Addictions and Substance Abuse. Lexington, Kentucky. January 26, 2013.

"Chronic Psychiatric and Neurological conditions Secondary to Ssubstance Abuse and Addiction." The $11^{\text {th }}$ Annual Conference on the Clinical Applications of the Principles in Treatment of Addictions and Substance Abuse. Lexington, Kentucky. January 28, 2011.

"'Here's How It Works': 12-Step Recovery Viewed through the Lens of Psychology." The $9^{\text {th }}$ Annual Conference on the Clinical Applications of the Principles in Treatment of Addictions and Substance Abuse. Lexington, Kentucky. January 24, 2009. 